\title{
IntechOpen
}

\section{International Perspectives of Distance Learning in Higher Education}

Edited by Joi L. Moore and Angela D. Benson

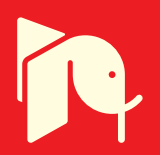





\section{INTERNATIONAL \\ PERSPECTIVES OF \\ DISTANCE LEARNING IN HIGHER EDUCATION}

Edited by Joi L. Moore and Angela D. Benson 
International Perspectives of Distance Learning in Higher Education

http://dx.doi.org/10.5772/2404

Edited by Joi L. Moore and Angela D. Benson

\section{Contributors}

Paul Birevu Muyinda, Gordon Naidoo, Charles Potter, M Mahruf C Shohel, Clarence Ng, Olabisi Kuboni, Maureen Snow Andrade, Jon Robert Hufford, Belén Muñoz-Abella, Lourdes Rubio, John Wall, Olga Zhuravleva, Boris Kruk, Kester Osegha Ojokheta, Ingrid Helleve, Nahid Zarifsanaiey, Mehran Farajollahi, Henriette Bier, Angela Benson, Carolyn Starkey, Nicole Norfles, Joi L. Moore

\section{(c) The Editor(s) and the Author(s) 2012}

The moral rights of the and the author(s) have been asserted.

All rights to the book as a whole are reserved by INTECH. The book as a whole (compilation) cannot be reproduced, distributed or used for commercial or non-commercial purposes without INTECH's written permission.

Enquiries concerning the use of the book should be directed to INTECH rights and permissions department (permissions@intechopen.com).

Violations are liable to prosecution under the governing Copyright Law.

\section{(cc) BY}

Individual chapters of this publication are distributed under the terms of the Creative Commons Attribution 3.0 Unported License which permits commercial use, distribution and reproduction of the individual chapters, provided the original author(s) and source publication are appropriately acknowledged. If so indicated, certain images may not be included under the Creative Commons license. In such cases users will need to obtain permission from the license holder to reproduce the material. More details and guidelines concerning content reuse and adaptation can be foundat http://www.intechopen.com/copyright-policy.html.

\section{Notice}

Statements and opinions expressed in the chapters are these of the individual contributors and not necessarily those of the editors or publisher. No responsibility is accepted for the accuracy of information contained in the published chapters. The publisher assumes no responsibility for any damage or injury to persons or property arising out of the use of any materials, instructions, methods or ideas contained in the book.

First published in Croatia, 2012 by INTECH d.o.o.

eBook (PDF) Published by IN TECH d.o.o.

Place and year of publication of eBook (PDF): Rijeka, 2019.

IntechOpen is the global imprint of IN TECH d.o.o.

Printed in Croatia

Legal deposit, Croatia: National and University Library in Zagreb

Additional hard and PDF copies can be obtained from orders@intechopen.com

International Perspectives of Distance Learning in Higher Education

Edited by Joi L. Moore and Angela D. Benson

p. cm.

ISBN 978-953-51-0330-1

eBook (PDF) ISBN 978-953-51-5125-8 


\section{We are IntechOpen, \\ the world's leading publisher of Open Access books}

\section{Built by scientists, for scientists}

\section{$3,700+$}

Open access books available

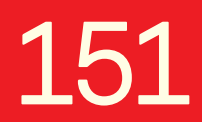

Countries delivered to

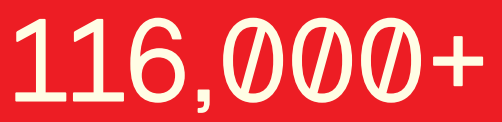

International authors and editors

Our authors are among the

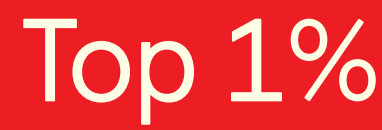

most cited scientists

Contributors from top 500 universities

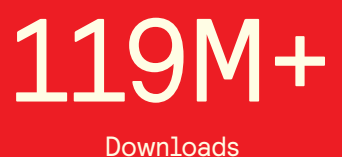

$12.2 \%$

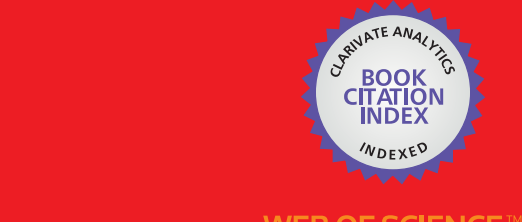

Selection of our books indexed in the Book Citation Index in Web of Science ${ }^{\mathrm{TM}}$ Core Collection (BKCI)

\section{Interested in publishing with us? \\ Contact book.department@intechopen.com}





\section{Meet the editors}

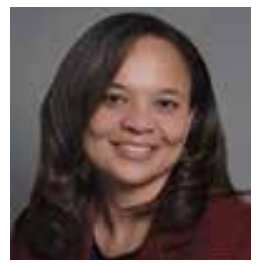

Dr Joi L. Moore received her B.S. degree in Computer Science and M.S. degree in Management from North Carolina State University, both focusing on a minor in Management Information Systems.

Her professional experience includes consulting with technology companies in Research Triangle Park, North Carolina, and teaching in the Department of Computer Information Systems at Shaw University. Dr. Moore earned her Ph.D. in Instructional Technology from the University of Georgia - with a cognate area of Management Information Systems. Her current research agenda is the application of appropriate design principles for technology environments that support learning and/or effectively improve a desired performance. Additional areas of research include: analyzing information architecture and evaluating performance in distance learning environments; designing performance-centered applications; and Human Computer Interaction.

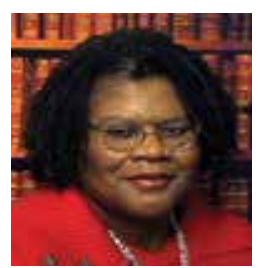

Dr Angela D. Benson is an Associate Professor of Instructional Technology at The University of Alabama. Her research addresses the influence of educational technology on higher education organizations and underserved populations. She has given more than 50 conference presentations and published more than 50 academic articles related to distance and online learning. In addition, Dr. Benson has designed and taught a variety of traditional and distance courses. Her professional experience includes thirteen years as a systems engineer in the telecommunications industry. She holds undergraduate degrees in Mathematics (Spelman College) and Industrial Engineering (Georgia Institute of Technology), master's degrees in Operations Research (Georgia Institute of Technology) and Human Resource Development (Georgia State University), and a doctorate in Instructional Technology (University of Georgia). 



\section{Contents}

Preface $\mathbf{X I}$

Part 1 Distance Education Management 1

Chapter 1 Re-Engineering Open and Distance Learning Institutional Development for Knowledge Society in Africa 3

K. O. Ojokheta

Chapter 2 Distance Teaching and Learning in Higher Education:

A Conceptual Model 13

Mehran Farajollahi and Nahid Zarifsanaee

Chapter 3 Open and Distance Learning in Dual Mode Universities:

A Treasure Unexploited 33

Paul Birevu Muyinda

Part 2 Distance Education and Teacher Development 51

Chapter 4 Teacher Development Through Distance Education:

Contrasting Visions of Radio Learning

in South African Primary Schools $\mathbf{5 3}$

Charles Potter and Gordon Naidoo

Chapter 5 Open and Distance Learning for Teachers'

Professional Development: The English in Action (EIA) Model for the Global South 93

M. Mahruf C. Shohel

Part 3 Distance Learning Pedagogy 109

Chapter 6 Self-Regulated Learning Activities:

Supporting Success in Online Courses 111

Maureen Snow Andrade

Chapter 7 Strategically Integrating Blended Learning to Deliver Lifelong Learning 133 John Wall 
Chapter 8 Distance Learning:

Modern Approaches to Engineering Education 149

Boris Kruk and Olga Zhuravleva

Chapter 9 Assessment Methods of Student Learning in Web-Based Distance Courses: A Case Study 185 Jon R. Hufford

Part 4 Distance Learning Students 209

Chapter 10 An Analysis of the Search Skills of Online Graduate Students as the Basis for the Development of Appropriate Instructional Strategies 211 Olabisi Kuboni

Chapter 11 The Role of Self-Efficacy, Control Beliefs and Achievement Goals on Learning Among Distance Learners 233

Clarence $\mathrm{Ng}$

Chapter 12 Differences and Similarities in Approach Between Classroom and Distance Learning 253 Ingrid Helleve

Chapter 13 Distance Learning and the Low-Income Student 273 Angela Benson, Joi L. Moore, Nicole Norfles and Carolyn Starkey

Part 5 Distance Learning Educational Tools 297

Chapter 14 Web-Application for Engineering Graphics An Example of a Distance Learning Tool 299 Lourdes Rubio and Belén Muñoz-Abella

Chapter 15 Internet-Supported Multi-User Virtual and Physical Prototypes for Architectural Academic Education and Research 317 Henriette $\mathrm{H}$. Bier 


\section{Preface}

The term distance learning has different meanings to different people and populations. By presenting international perspectives of distance learning, this book embraces all those meanings and populations without giving preference to any. In today's global world where distance providers can address local learning needs, it is important for distance learning practitioners and researchers as well as higher education administrators and faculty to have a broad view of how distance learning is conceptualized, planned and delivered.

Almost two centuries ago, a form of distance education emerged in which learning activities were sent through postal mail (Spector, Merrill, Merrienboer, \& Driscoll, 2008). While this early method of distance learning is still used in many international communities, today's distance learning environments also embrace a variety of traditional and emerging technologies, including websites, ebooks, content managements systems (CMS), podcasts, social networks, mobile devices, and more. As distance learning in higher education evolves to embrace new technologies, it is also evolving to accommodate the changing nature of higher education students. Distance learning solutions are now being provided to traditional on-campus students with needs for courses offered at flexible times as well as to the growing numbers of nontraditional students, those working adults who are going back to college while balancing family and work responsibilities.

This book embodies the variety of distance learning formats addressed in Moore, Dickson-Deane, and Galyen's (2011) investigation of the terminology of distance learning. Terms such as correspondence education or study, open, online or distance learning, and elearning are often used synonymously to describe a learning environment where the student and instructor are separated in time and/or space. Some term differences emerge from the type of organization, for example higher education and business use distance learning and e-learning, respectively. Other terms emerge from the types of technologies and learning activities used, or the modes and frequencies of interactions between students and the instructor. Term differences are also noted between countries, such as Europe preferring open learning to describe a form of distance education whereas distance, online, and elearning learning are often used in the Americas. This book does not propose a common definition of the terms. Rather, it presents the different international perspectives of what is deemed as distance learning. 
This book is comprised of 15 chapters, written by authors representing 12 countries, and addresses issues of significance to distance learning practitioners, researchers, and higher education faculty and administrators. The chapters are organized into five sections. Four chapters comprise Section 1, Distance Education Management. The chapters address topics related to the planning, administration and management of distance learning programs in higher education. In Chapter 1, Ojokheta (Nigeria) argues that the administrative and academic processes that govern open and distance learning programs in Nigeria must be re-engineered if Nigeria is to reach $21^{\text {st }}$ century goals for development of a knowledge society. In Chapter 2, Farajollahi and Zarifsanaee (Iran) present a data-based model of effective distance teaching and learning in higher education that responds to the need of countries to develop educational capacity to meet the demand for higher education. In Chapter 4, Muyinda (Uganda) explores the challenges and benefits of managing and administering Open and Distance learning programmes in dual mode universities, using Makerere University as an example.

The two chapters in Section 2, Distance Education and Teacher Development, present approaches to teacher professional development delivered via distance learning technologies. In Chapter 5, Potter and Naidoo (South Africa) describe the 17-year evolution of the South African Radio Learning Programme. The program was designed to improve the quality of teaching in primary schools by targeting the development of English language competencies in the junior primary phase, through the medium of interactive radio. In Chapter 6, Scohel (United Kingdom) presents a proposal to use open and distance learning to provide teacher professional development to meet the crisis of an inadequately qualified teacher pool in the Global South region.

The four chapters that comprise Section 3, Distance Learning Pedagogy, present effective teaching and learning approaches in a distance environment. In Chapter 7, Andrade (United States) shows how a distance course design and teaching framework based on self-regulated learning can be used to promote learner success in online distance English language courses. In Chapter 8, Wall (United States?) presents strategies and processes for employing blended learning environments to deliver lifelong learning. In Chapter 9, Kruk and Zhuravleva (Russia) describe learning models that promote self-directed, personal-oriented and student-centered teaching, specifically in online engineering education. In Chapter 10, Hufford (United States) examines student assessment methods suitable for Web-based courses.

Each of the four chapters in Section 4, Distance Learning Students, describe the results of research studies that addressed factors and issues related to the student experience in distance learning courses and programs. In Chapter 11, Olabisi (West Indies) analyze the efforts of students enrolled in a Graduation Orientation course at using online resources to construct an annotated bibliography. The goal was the generation of instructional strategies to assist students in developing more effective skills for identifying, gathering and using information from online sources. In Chapter $12, \mathrm{Ng}$ 
(Australia) investigates the motivational and learning processes of Chinese distance learning students. Chapter 13, Helleve (Norway) explore the similarities and differences in classroom and distance learning by comparing the experiences of learners enrolled in classroom, hybrid and distance environments. In Chapter 14, Benson, Moore, Norfles and Starkey (United States) present an exploratory study of the lived experiences of low-income and working students enrolled in postsecondary distance learning.

The two chapters in Section 5, Distance Learning Educational Tools, describe distance learning development projects that support the learning of science and engineering topics. In Chapter 15, Rubio and Muno-Abella (Spain) describe the development and use of $2 \mathrm{D}$ and $3 \mathrm{D}$ animation rich web-based tutorials in the study of Descriptive Geometry. In Chapter 16, Bier (The Netherlands) implement Internet-supported applications that utilize interactive 3D game technology in an Internet-based postgraduate architecture program.

Because the book includes practical case studies, empirical research studies and theoretical/conceptual frameworks for distance learning, it can meet the needs of multiple audiences. Specifically, this book can easily be used as a textbook for distance learning or higher education courses, a reference book for international distance learning researchers and practitioners, or an introductory handbook for higher education administrators and faculty who are new to distance learning.

Joi L. Moore

University of Missouri

USA

Angela D. Benson

University of Alabama

USA

\section{References}

Moore, J. L., Dickson-Deane, C. \& Galyen, K. (2011) E-Learning, Online Learning, and Distance Learning Environments: Are They the Same? The Internet and Higher Education, 14, 129-135.

Spector, J. M., Merrill, M. D., Merrienboer, J. V., \& Driscoll, M. P. (2008). Handbook of research on educational communications and technology (3rd ed.). New York, London: Lawrence Erlbaum Associates. 



\section{Part 1}

\section{Distance Education Management}





\title{
Re-Engineering Open and Distance Learning Institutional Development for Knowledge Society in Africa
}

\author{
K. O. Ojokheta \\ Department of Adult Education, University of Ibadan, \\ Nigeria
}

\section{Introduction}

In the contemporary world, the major task of all countries is to raise higher-level employment skills so as to sustain a globally competitive research base and to improve knowledge dissemination to the benefit of society. This was long observed by Drucker (1994) that "the knowledge society will inevitably become far more competitive than any society we have yet known for the simple reason that with knowledge being universally accessible, there are no excuses for non-performance. There will be no poor countries. There will only be ignorant countries". Therefore, if countries are to raise higher-level employment skills, it simply signifies that there is the need for substantial reforms in tertiary education policy since tertiary education is the major driver of economic competitiveness in an increasingly knowledgedriven global economy. These reforms in tertiary education policy must essentially concentrate on the production of more educated persons which, obviously, the conventional tertiary institutions, cannot achieved single-handed. Besides, an educated person, according to Drucker (1994) is "one who has learned to learn and will continue to learn throughout his or her life, especially in and out of the formal education system. This is continuing education. This is lifelong Learning". The implication of this is that a truly educated person is produced through a lifelong learning process and not through the formal education process. This is where open and distance learning becomes imperative. Drucker further observed:

... in the knowledge society, clearly more and more of knowledge, and especially of advanced knowledge, will be acquired well past the age of formal schooling, and increasingly, perhaps, in and through educational processes which do not centre on the traditional school, e.g., systematic continuing education offered at the place of employment.

Drucker's argument is simply that learning all the knowledge available to us today will not take place in the confines of the classrooms alone. This is why open and distance learning (ODL) continues to receive wider and greater recognition and acceptability as an important and standard component of educational delivery. In essence, if ODL is to play an important role in this ever increasing knowledge-driven global economy, its scope and importance have to change significantly. This paper is, therefore, written, as an awakening call for open and distance learning policy makers and practitioners in Africa to begin the re-engineering 
process of open and distance learning institutional development to meet the challenges of the $21^{\text {st }}$ century knowledge driven society.

\section{Defining the knowledge society}

Knowledge has been widely recognised by the economists as the most important factor of production in a "new economy". The production and utilisation of knowledge is, therefore, essential for development. In other words, knowledge is the most important factor of production and its growth is essential to propel a country into self-sustained growth. The information society as well as the knowledge society is seen as the successor to the industrial society. The term, information society was introduced in the early 1970s by Yojeni Masuda in a book: The information society as post-industrial society. In this book, he referred to information society as the highest stage of societal evolution, seen in analogy to biological evolution. However, similar concepts had already been discussed in the 1950s and 1960s. For example, Daniel Bell was the first person to put forward the concept of a "postindustrial society" in 1959. In 1979, Bell renamed the post-industrial society as information society. Similarly, behind Bell's contribution was the discovery that between 1909 and 1949, in growth rates among the non-agricultural sector, skills contributed $87.5 \%$ towards growth, while labour and capital contributed a mere $12.5 \%$.

In the early 1990s, the Institute of Information Studies made up of the Aspen Institute and other agencies in the United States published an almanac in 1993-1994. Its main title was the Knowledge-based economy: the nature of the information age in the 21st century. The United Nation endorsed the term immediately afterwards, and gave it a clearer definition in 1996. It defined a knowledge-based economy as an economy whose most important elements are the possession, control, production, and utility of knowledge and intellectual resources. The knowledge society produces commodities of high knowledge value. Similarly, the term "knowledge-value society" was introduced by Taichi Sakaiya $(1991,2001)$. The term was defined as "a society where the value of knowledge is the primary source of economic growth and corporate profits". Ever since then, most countries, especially in the developing countries, where knowledge gap (K-Gap) tremendously exists, have been striving not only to reduce this gap but also embarking on an ambitious plan to use knowledge as a base for economic development. World Bank (1999) observed that education, especially tertiary education, remains one of the crucial variables for achieving a knowledge society. This is because tertiary education contributes to social and economic development through four major missions:

- The formation of human capital (primarily through teaching),

- The building of knowledge bases (primarily thro ugh research and knowledge development),

- The dissemination and use of knowledge (primarily through interactions with knowledge users), and

- The maintenance of knowledge (inter-generational storage and transmission of knowledge).

Tertiary education, these days, is much more diversified than in the time past when it was more commonly referred to as higher education symbolised by the universities. Today, tertiary education encompasses new types of institutions such as polytechnics, university colleges, technological institutes, and more recently, open and distance learning. Suffice it to 
say that open and distance learning, as a component of tertiary education, is much more crucial to the realization of knowledge society. If this is to be accomplished, it simply connotes that open and distance learning must be re-engineered, in its institutional development, to meet the challenges of the $21^{\text {st }}$ century. This paper thoroughly discusses the major characteristics that a $21^{\text {st }}$-century distance and open learning institutions are expected to possess in a knowledge-based society.

\section{The growing focus of open and distance learning}

Sparked by new technologies, particularly the internet, distance educational delivery is undergoing a radical transformation that is nothing less than a new educational revolution. This revolution is undoubtedly taken distance education delivery to higher height that was previously unimagined. The $21^{\text {st }}$-century distance and open learning institution that should emerge will in many ways be the polar opposite of the institutions that emerged in the $20^{\text {th }}$ century.

It is well established that many factors are driving change; however, none of these is more important than the rise of internet technologies. The Net has already become advanced with revolutionary consequences, most of which are now begun to be felt. The Net instantaneously gives everyone the opportunity and ability to access a mind-boggling array of information from anywhere. Instead of seeping out, over months or years, ideas can be got around the world in the blink of an eye. This simply means that the $21^{\text {st }}$-century distance and open learning institution must adapt itself to management via the web. This must be predicated on constant change, not stability; organized around networks, not rigid hierarchies; built on shifting partnerships and alliances, not self-sufficiency; and constructed on technological advantages, not bricks and mortars. In other words, the $21^{\text {st-century distance and open }}$ learning institution is far more likely to look like a web: a flat, intricately woven form that links students, tutors, employees, policy makers, practitioners, managers, partners of distance and open learning in various collaborations. They will grow more and more interdependent and managing this intricate network will be as important as managing internal operations.

\section{The need for reengineering distance and open learning institutions for knowledge society}

More recently, most organizations have moved beyond total quality management (TQM) programmes to a more comprehensive approach to redesigning organizational processes called re-engineering. According to Hammer and Champy (1993), "re-engineering is the fundamental rethinking and radical redesign of business processes to achieve dramatic improvements in cost, quality, and speed". Therefore, if distance and open learning institutions in Africa must achieve dramatic improvements in cost, quality, and speed in their administrative and academic processes, they must embark on radical redesign of these processes. In the administrative processes, open and distance learning institutions in Africa must begin to re-align with the dictates and expectations of $21^{\text {st }}$ century organization. Similarly, in the academic processes, open and distance learning institutions must begin to have new perception of learning in line with the constructivist perspective rather the objectivist perspective where learners are not involved in the real act of learning but are given ready view of social reality by the tutors. 


\section{Reengineering in the administrative processes of ODL}

As canvasses above, reengineering in the administrative processes of ODL involves moving the operations of ODL institutions from the dictates of $20^{\text {th }}$ century organization to the $21^{\text {st }}$ century organization. The detailed examination of characteristics of $20^{\text {th }}$ and 21th century's Distance Education Institutions in Africa becomes imperative here.

Distance education emerged in Nigeria, and most parts of Africa, as an educational opportunity embraced by knowledge-driven few who were driven by necessity. The history of distance education, especially in Nigeria dates back to the practice of correspondence education as a means of preparing candidates for the General Certificate in Education (GCE), a prerequisite for the London Matriculation Examination. This practice was described by Bell and Tight (1999) and Alan Tait (2003) thus:

...the University of London has been termed the first "Open University" because of this move, students all the world, but principally within the British Empire and its dominions, were soon looking for tutorial support to supplement the bare syllabus they received on registration wherever they lived.

The characteristics of distance education institutions at emergence in Arica in the 20th century are described in Table 1 :

$\begin{array}{ll}\text { Organization } & \text { Pyramid } \\ \text { Focus } & \text { Internal } \\ \text { Style } & \text { Structured } \\ \text { Source of strength } & \text { Stability } \\ \text { Structure } & \text { Self-sufficiency } \\ \text { Resources } & \text { Atoms-physical assets } \\ \text { Operations } & \text { Vertical integration } \\ \text { Product } & \text { Mass production } \\ \text { Reach } & \text { Domestic } \\ \text { Financials } & \text { Quarterly } \\ \text { Inventories } & \text { Months } \\ \text { Strategy } & \text { Top down } \\ \text { Leadership } & \text { Dogmatic } \\ \text { Workers } & \text { Employees } \\ \text { Job Expectations } & \text { Security } \\ \text { Motivation } & \text { To compete } \\ \text { Improvements } & \text { Incremental } \\ \text { Quality } & \text { Affordable best }\end{array}$

Table 1. Characteristics of the 20th Century Distance and Open Learning Institution in Africa.

This table provides 18 parameter descriptions of the characteristics of distance and opens learning institutions in Africa at emergence. The organization of distance and open learning

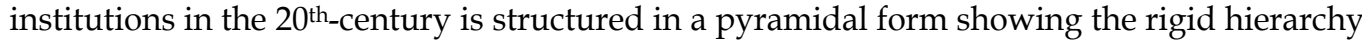
of authority and responsibility which promotes dependency phenomenon. At the apex of the pyramid is the management team comprising policy planners and makers. This is 
followed by the course designers, developers, and instructors. At the bottom of the pyramid are the distance learners who are completely or partially separated from the institution and the tutors. The learners, to a greater extent, depend on the institution and the tutors to achieve success in their learning. Thus, the focus of these institutions is largely internal. This is because the sophisticated multimedia technologies, which could have extended the focus, were practically minimal and largely limited to correspondence.

The $21^{\text {st }}$ century open and distance learning institutions in Africa are expected to possess the characteristics of a knowledge driven economy. These characteristics are itemized and thoroughly discussed below:

$\begin{array}{ll}\text { Organization } & \text { Web/Network } \\ \text { Focus } & \text { External } \\ \text { Style } & \text { Flexible } \\ \text { Source of strength } & \text { Change } \\ \text { Structure } & \text { Interdependencies } \\ \text { Resources } & \text { Bits-information } \\ \text { Operations } & \text { Virtual integration } \\ \text { Product } & \text { Mass customization } \\ \text { Reach } & \text { Global } \\ \text { Financials } & \text { Real time } \\ \text { Inventories } & \text { Hours } \\ \text { Strategy } & \text { Bottom up } \\ \text { Leadership } & \text { Inspirational } \\ \text { Workers } & \text { Employees \& free agents } \\ \text { Job Expectations } & \text { Personal growth } \\ \text { Motivation } & \text { To build } \\ \text { Improvements } & \text { Revolutionary } \\ \text { Quality } & \text { No compromise }\end{array}$

Table 2. Expected Characteristics of the $21^{\text {th }}$ Century Distance and Open Learning Institutions.

Table 2 equally provides 18 parameter descriptions of the expected characteristics of the 21st century open and distance learning institutions in Africa. The organization of distance and open learning institutions in the 21-century must be structured in a web or network which gives everyone in the institution, the ability to access a mind-boggling array of information instantaneously from anywhere. Therefore, the focus of $21^{\text {st }}$ century ODL institution will no longer be internal but external. Similarly, the style of administration will no longer be structured but flexible with change as the source of strength of the institutions. The $21^{\text {st }}$ century ODL institutions are expected to display interdependencies in their structure rather than that of self-sufficiency. The institutions resources will no longer be physical assets but information assets with virtual integration rather than vertical integration in their operations. The products of these institutions will no longer be mass production but mass customization while the institutional reach will be transformed from domestic to global. The financial structure of the institutions will no longer be quarterly but in real time. The monthly inventory has to change for the hour inventory. The strategy of such institutions 
will have to change from top down to bottom-up; so also, the leadership pattern which must also change from dogmatic pattern to inspirational pattern. The job expectation of workers of the $21^{\text {st }}$ century ODL institutions will have to change from that of security to personal growth; so also the philosophy of motivation of such institutions which should now be: to build rather than to compete. ODL institutions in a knowledge-based society must aim at revolutionary improvements rather than incremental improvements. Lastly, the philosophy of quality of ODL institutions of this age must be- no compromise and not affordable best has championed by the $20^{\text {th }}$ century ODL institutions.

\section{Reengineering in the academic processes of ODL}

The operational modalities of the $20^{\text {th }}$ century of open and distance learning institutions in Africa are, to large extent, based on the specifications of the traditional Objective-Rational approach to instructional design where knowledge and truth are perceived to exist outside the mind of the individual and, therefore, objective. In other word, learners are told the world and are expected to replicate its content and structure in their thinking. Knowledge, in line with this approach, is taught to the learners as finished product of other people's experience as they are not allowed to realize that they too can produce knowledge from processing their own experience. Thus, knowledge is perceived as a possession of other people's ideas without taken into consideration the experiences of the learners. Hence, it is the experiences of others that matter and not the experiences of the learners who are supposed to be at the centre of the teaching and learning activities.

However, recent events in the contemporary globalized world (especially in the massive revolution of information and communication technology, which has accelerated the internationalization of open and distance learning practice, and the systematic movement of this mode of learning from industrialized model to post-industrialized) has necessitated the infusion of the principles of constructivism in instructional design in open and distance learning. Constructivism is a fundamental departure in thought, from that of the traditional objective-rational approach, about the nature of knowing, learning, and teaching. In terms of learning, the constructivist perspective describes learning as a change in meaning constructed from experience (Newby, Stepich, Lehman, and Russell (1996). The constructivists believe that knowledge and truth are constructed by people and do not exist outside the human mind (Duffy and Jonassen,1991). Thus, the constructivists' view of learning differs radically from that of the objectivists in the sense that they perceive learning to be personal and not purely objective (Bonder, 1986). Von Glaserfeld (1984) submitted that through constructivism, learners construct understanding. They do not simply mirror and reflect what they are told or what they read. Learners look for meaning and will try to find regularity and order in the events of the world, even in the absence of full or complete information. In essence, the construction of knowledge is the major emphasis of constructivism.

In terms of learning process, the central tenet of constructivism is that learning is an active process. Information may be imposed, but not understanding because it must come from within. Woolfolk (1993:485) described the constructivist view of the learning process as follows:

---the key idea is that students actively construct their own knowledge: the mind of the student mediates input from the outside world to determine what the student will learn. Learning is active mental work, not passive reception of teaching. 
Jonassen, (1991) submitted that during the process of learning in constructivist approach, learners may conceive of the external reality somewhat differently, based on their unique set of experiences with the world and their beliefs about them. However, learners may discuss their understandings with others and thus develop shared understandings (Cognition and Technology Group, 1991). While different learners may arrive at different answers, it is not a matter of 'anything goes' (Spiro, R.J., Coulson, R.L., Feltovich, P.J. and Anderson, D. K. (1988); Spiro, R.J., Feltovich, P.J., Jacobson, M.J. and Coulson, R.L. (1991). Learners must be able to justify their position to establish its validity (Cognition and Technology Group, 1991). Even though the learners are central to the learning process, as emphasized by the Piagetian individualistic approach to constructivism, it is collaboration among learners that makes constructivism unique because it encourages the construction of a social context in which collaboration creates a sense of community, and that teachers and students are active participants in the learning process.

In terms of goal or stimulus for learning, it is the problematic situation (Dewey, 1938) or learners 'puzzlement' (Savery and Duffy, 1995) that serves as stimulus and organizer for learning. Hence, according to the constructivist perspective, learning is determined by the complex interplay among learners' existing knowledge, the social context, and the problem to be solved. Instruction, in the constructivist view, should be designed to provide learners with a collaborative situation in which they have both the means and the opportunity to construct 'new and situationally-specific understandings by assembling prior knowledge from diverse sources' (Ertmer and Newby, 1993:63).

The two major characteristics central to constructivist descriptions of the learning process, according to Brooks and Brooks, 1993; Cognition and Technology Group, 1993; Brown and Holum, 1991; Honebein, Duffy, and Fishman, 1993, were:

- Good Problems - Constructivist instruction asks learners to use their knowledge to solve problems that are meaningful and realistically complex. The problems provide the context for the learners to apply their knowledge and to take ownership of their learning. Good problems are required to stimulate the exploration and reflection necessary for knowledge construction. According to Brooks and Brooks (1993), a good problem is one that:

- Requires students to make and test a prediction.

- Can be solved with inexpensive equipment.

- Is realistically complex.

- Benefits from group effort.

- Is seen as relevant and interesting by students.

- Collaboration - The constructivist approach supports that learners learn through interaction with others. Learners work together as peers, applying their combined knowledge to the solution of the problem. The dialogue that results from this combined effort provides learners with the opportunity to test and refine their understanding in an ongoing process.

The role of the teacher during instruction, in constructivist view, is that instructional intervention should not only match, but also accelerate students' cognitive development. According to Copley (1972), constructivism requires a teacher who acts as a facilitator 'whose main function is to help students become active participants in their learning and make meaningful connections between prior knowledge, and the processes involved in learning'. 
Chung (1991) has described the type and characteristics of the learning environment favoured by the constructivists as follows:

- Shared knowledge among teachers and students;

- Shared authority and responsibility among teachers and students;

- The teacher's new role as guide in instruction;

- Heterogeneous and small groupings of students.

In line with Chung's description, the teacher is thus seen as a guide instead of an expert. Collins, Brown, and Holum (1991) and Rogoff (1990) have likened constructivism instruction to an apprenticeship in which teachers participate with students in the solution of meaningful and realistic problems. Thus, the teacher serves as models and guides showing students how to reflect on their evolving knowledge and providing direction when the students are having difficulty. Learning is shared, and responsibility for the instruction is equally shared. Newby et.al. (1996) submitted that the amount of guidance provided by the teacher will depend on the knowledge level and experience of the students.

From the description of the ideas of constructivism, Brooks and Brooks (1993) have summarized the characteristics of a constructivist teacher as someone who will:

- Encourage and accept student autonomy and initiative.

- Use a wide variety of materials, including raw data, primary sources, and interactive materials and encourage students to use them.

- Inquire about students' understandings of concepts before sharing his/her own understanding of those concepts.

- Encourage students to engage in dialogue with the teachers and with one another.

- Encourage students, inquiry by asking thoughtful, open-ended questions and encourage students to ask questions from each other and seek elaboration of students' initial responses.

- Engage students in experiences that show contradictions to initial understandings and then encourage discussion.

- Provide time for students to construct relationships and create metaphors.

- Assess students' understanding through application and performance of openstructured tasks.

Thus, from the constructivist perspective, the primary responsibility of the teacher is to create and maintain a collaborative problem-solving environment, where students are allowed to construct their own knowledge, and the teacher acts as a facilitator and guide. The pedagogical effectiveness of constructivism in instructional design made Reigeluth (1989) to argue for a 'new mindset, in the translation of the philosophy of constructivism into actual practice.

One of the most appropriate strategy for building constructivist learning environment is to create a collaborative learning environment which does not just entail sharing a workload or coming to a consensus. Rather, it is to allow learners to develop, compare, and understand multiple perspectives on an issue. According to Bednar, Cunningham, Duffy, and Perry J.D. (1992), 'it is the rigorous process of developing and evaluating the arguments that is the goal in collaborative learning". Hence, knowledge, in the constructivists view, is the construction of the learners and the construction of other people's view for the learners. 


\section{Recommendations}

The following recommendations are suggested if open and distance learning institutions in Africa are to be properly re-engineered for knowledge society:

1. Open and distance learning institutions must be revolutionized in line with the 18 parameters description of the characteristics of the $21^{\text {st }}$ century organizations.

2. Instructional dissemination in open and distance learning programmes must be designed in line with the principles of constructivism.

3. Tutors in open and distance learning programme must be re-oriented to become constructivist tutors rather than objectivist tutors.

4. Open and distance learning institutions must expand their scope of academic activities in order to reduce the knowledge gap (K-Gap) which exists in Africa.

5. Open and distance learning institutions must design strategies and create avenues through which distance learning students can make use of knowledge acquired as the base for self-sustained growth.

\section{Conclusion}

This paper has established the fact that Open and distance learning remains an important avenue for raising the higher-level employment skills of African countries in order to sustain a competitive research base and improve knowledge dissemination to the benefit of African societies. However, if ODL is to continue to be one of the major drivers of economic competitiveness in an increasingly knowledge-driven global economy, then there is the need for substantial reforms or re-engineering of its institutional development along the lines of administrative and academic processes. This is what this paper has been able to achieve.

\section{References}

Bednar, A.K., Cunningham, D., Duffy, T.M.\& Perry J.D. (1992). Theory into practice: How do we link? In T.M. Duffy and D.H. Jonassen (Eds.) Constructivism and the technology of instruction: a conversation, Hillsdale, HJ: Lawrence Erlbaum Associates, 17-35.

Bell,D. (1976). The coming of the post-industrialized society: A venture in social forecasting. Basic Books.

Bonder, G.M. (1986). Constructivism: A Theory of Knowledge, Journal of Chemical Education, $63,873-878$.

Brooks, J.G. and Brooks, M.G. (1993). In search of understanding: the case for constructivist classrooms, Alexandria, VA: American Society for Curriculum Development.

Brown, J.S., Collins, A. And Duguid P. (1989). Situated Cognition and the culture of learning. Educational Researcher, 18 (1), 32-41.

Cascio, W. F. (2003). Managing Human Resources: Productivity, Quality of Work Life, Profits. New York: McGraw-Hill Higher Education.

Chung J. (1991). Collaborative learning strategies: the design of instructional environments for the emerging new school. Educational Technology, 31 (6), 15-22.

Cognition and Technology Group at Vanderblit (1991). Some thoughts about constructivism and instructional design. In T.M. Duffy and D.H. Jonassen (Eds.) Constructivism and the technology of instruction: a conversation. Hillsdale, NJ: Lawrence Erlbaum Associates, 115-119. 
Cognition and Technology Group at Vanderbilt (1993). Designing learning environments that support thinking: the Jasper series as a case-study. In T.M. Duffy, J. Lowyeh, and D.H. Jonassen (Eds.) Designing environments for constructive learning, Berlin: Springer-Verlag, 9-36.

Collins, A., Brown, J.S. and Holum, A. (1991). Cognitive apprenticeship: making thinking visible. American Educator, 15 (3), 6-11, 38-46.

Copley, J. (1992). The integration of teacher education and technology: a constructivist model. In D. Carey, R. Carey, D. Willis, and J. Willis (Eds.), Technology and Teacher Education, Charlottesville, VA: AACE, 681.

Dewey, J. (1938). Logic: the theory of inquiry, New York: Holt and Co.

Drucker, P.F. (1994). Knowledge, work and society: The social transformation of this century. The Edwin L. Goldkin Lecture, Harvard University's John F. Kennedy School of Government,

http://www.ksg.harvard.edu/ifactory/ksgpress/www/ksgnews/transcripts/dru cklec.html. 3/25/2005.

Duffy, T.M. and Jonassen, D.H. (1991). New implications for instructional technology? Educational Technology, 31 (3), 7-12.

Ertmer, P.A. and Newby, T.J. (1993). Behaviorism, cognitivism, constructivism: comparing critical features from an instructional design perspective. Performance Improvement Quaterly, 6 (4), 50-72.

Hammer, M., \& Champy, J. (1993). Reengineering the corporation. New York: Harper Business.

Honebein, P. C., Duffy, T.M. and Fishman, B.J. (1993). Constuctivism and the design of learning environments: context and authentic activities for learning. In T. M. Duffy, J. Jonassen, D.H. (1991). Objectivism versus constructivism: do we need a new philosophical paradigm? Journal of Educational Research, 39 (3), 5-14.

Masuda, Y. (1980). The information society as post-industrial society. Institute for the Information Society. Tokyo.

Newby, T.J., Stepich, D.A., Lehman, J.D. and Russell, J.D. (1996). Instructional technology for teaching and learning: designing instruction, integrating computers, and using media, NJ: Prentice Hall.

Reigeluth, C.M. (1989). Educational technology at the crossroads: new mindsets and new directions. Educational Technology Research and development, 37 (1), 1042-1629.

Rogoff, B. (1990). Apprenticeship in thinking: cognitive development in social context, New York: Oxford University Press.

Sakaiya, T. (1991). The knowledge-value revolution or a history of the future. New York.

Sakaiya, T. (2000). The knowledge-value revolution and the internet fair 2001 Japan. Speech at OECD Forum, 27 June.

Savery, J.R. and T.M. Duffy (1995). Problem based learning: an instructional model and its constructivist framework. Educational Technology, 35 (5), 31-38.

Spiro, R.J., Coulson, R.L., Feltovich, P.J. and Anderson, D. K. (1988). Cognitive flexibility theory: advanced knowledge acquisition in ill-structured domains (Technical Report no.441), Champaign, IL: University of Illinois, Center for the Study of Reading.

Spiro, R.J., Feltovich, P.J., Jacobson, M.J. and Coulson, R.L. (1991). Knowledge representation, content specification, and the development of skill in situationspecific knowledge assembly: some constructivist issues as they relate to cognitive flexibility theory and hypertext. Educational Technology, 31 (5), 22-25.

Von Glaserfeld, E. (1984). Radical constructivism. In P. Watzlawick (Ed.) The invented reality, Cambridge, MA: Harvard University Press, 17-40.

Woolfolk, A.E. (1993). Educational psychology. Bosten: Allyn and Bacon. 


\title{
Distance Teaching and Learning in Higher Education: A Conceptual Model
}

\author{
Mehran Farajollahi ${ }^{1}$ and Nahid Zarifsanaee ${ }^{2}$ \\ 1Department of Education, Payame Noor University, Tehran \\ ${ }^{2}$ Center of Excellence for E Learning, Shiraz University of Medical Sciences, Shiraz
}

Iran

\section{Introduction}

Learning is the beginning of a need for perfection. It is evident that the more science and knowledge is developed; the more need for change in learning and its mechanisms are required. Distance learning is one of the alternative approaches which can be replaced with face to face or traditional learning and is one of the key factors in the development of higher education (Taylor, 2001). One of the pioneer scholars, Holmberg (1983, p. 25), defines distance education, as a non contiguous communication. It means that, with respect to the time and place, the learner and instructor are separate from each other. Keegan (1993, p. 75) consider the separation of the instructor and learner at the learning time as a main feature of distance education. From his point of view, distance learning refers to:"A programmed educational system for establishing the teaching-learning procedure by the use of an organization and not a teacher whose object is to select and apply proper techniques for using new technologies in education, facilitating the mutual relationship between the learner and instructor, providing independent learning situations and evaluating the learning outcomes by the learners themselves".

Garrison (2003) also stated three characteristics for defining distance learning as the followings:

1. Distance education implies that the majority of educational communication between a teacher and his/her student(s) occur non-contiguously.

2. Distance education must involve two-way communication between (among) teacher and his/her student(s) for the purpose of facilitating and supporting the educational process.

3. Distance education uses technology to mediate the required two-way communication.

Distance learning provides a far better situation for the students rather than the traditional learning because the learning can occur everywhere at anytime outside the university. Distance learning prepares the way for that most of educational goals like independent learning, self-directed learning, learning in every place and not dependent to a specific time, participation learning and education, self-assessment and fast presenting of the feedback from previous studies manifested to be more ascertainable. 
Regarding that the process of higher education is highly significant in any society, Nowadays universities have come across a main transformation. Lack of budget, an increase in the number of university students, a change in the student population, up-to-date and various educational needs of each society require fundamental changes that are coordinated with recent needs. Through distance learning, the feasibility of "learning with no time limitation" proportionate to the students' requirements has been brought about. In comparison to the traditional learning that disregards the students' requirements and addresses a group of students at a specific time and place, this method is a basic strategies.

UNESCO (2001) reports that an application for expansion the variety of higher education will be increased during the two next decades and universities compete closely with each other for attracting the students, break national borders, moving toward globalization and cooperating throughout the world (Cerf \& Schutz, 2002, p.3) Rapid economical, social and technological changes have affected the nature of life and the individuals' occupations. Individuals should continuously learn and educate for dealing with such changes and these features in the present decade have caused a constant increase in the number of candidates for entering to the higher education (Groff \& Mouza, 2008). In most countries, numbers of candidates for entering to the universities are more than their capacity. Therefore, in most countries electronic universities have been developed to respond the educational needs (Buford \& Harper, 2005, p. 3).

Under these circumstances, the view of educational experts and politicians toward the distance learning subject has changed a little. For example, public report of Norway higher education specifies that distance learning, based on new communications technology, will be an important factor in future higher education strategies. Europe Union Research \& Industrial Development Commission describes in its report that Europe needs an extensive and flexible structure for electronic learning (Mendenhall, 2001, p. 37). Although globalization, development of information technology and other above mentioned factors have led to rapid changes in higher education. Permanent and consistent matters also exist in such a matter. One of these subject matters in the area of distance education is the presence of patterns or models proportionate to this type of education. Success and progress of distance education is possible just by the development of appropriate educational models, realistic strategies and proper pedagogy approaches of the twenty first century.

With regarding the fact that distance education is growing rapidly in higher education, clarifying learning strategies which can assist the university students to be successful in this ground is more needed. Researches have shown that there is a separation between the knowledge related to learning theories, distance education concepts and the application of this knowledge for using in distance education and higher education. Therefore, there is a need of providing theoretical basics which can reinforce effectively the development and presentation of distance education. This chapter represents our most recent research into an effective distance learning model in higher education.

\section{Background}

Many studies have been performed in relation to the effective distance education plans. These researches have shown that distance education can have either positive or negative effects on proficiency and attainment to the goals. Consequently, making an assurance for 
planning effective learning patterns is necessary. Matrink (2002) performed a study to examine the values and effectiveness of distance education. He evaluated the characteristics of an effective professor, a successful student and effective learning strategies in his study. The findings of this research showed that the success of professor and student in the online course is only possible if they are ready. Facilitating is an appropriate learning strategy for distance education and the more motivated the student is, the more successful they will be in distance education courses. Lastly, this research emphasizes that the communication between instructor, student and peer groups plays an important role on being successful in distance education courses.

In distance education, motivation plays an important role especially for adult learners. One of the main shortcomings of distance education is the lack of relationship between the professor, student and peer groups. A key factor for overcoming such problem is to have a chance for regular self-assessment, online and offline communication. Brawn et al (2005) study aimed to evaluate the elements of planning an effective electronic learning. From their view point, providing communicative learning activities, making motivation and interest in the learner, providing the right technologies for presenting, the learners' educating in the social and individual ground were as the required principles in an effective planning.

Mendenhall (2003) made a research which aimed to plan an effective distance education model based on the internet in Brigham Yang University. The fundamental principles of this model are to emphasize individual learning, active learning approaches, and a communication associated with the flexibility of time and place and making the learning societies.

Researches show that there is an interest in using the constructive learning theory for planning learning environment (Morphew 2000; Naidu 2003). Gillani (2000) presented a social research educational model. His online learning environment was based on the cognitive theory of Vigotsky, based on the learner and according to the learners' needs. He introduced three main shortcomings for the online learning environment: overloading data, the variety of the learners and the presence of web as a media for presenting the education. For solving this problem, he suggested an individualized curriculum as the pupils' needs. Therefore, he considered the social features of the students, the way of communicating, cognitive ability and their academic matters (p.162).

Garrison (2003) evaluated in his study the theoretical shortcomings of distance education in the $21^{\text {st }}$ century in his study. These shortcomings are an understanding of educational opportunities, limitations and learning with different developing approaches and technologies. He planned a concept model entitled "the model of learning society". According to this model, every effective educational experience is the result of distance education and needs the presence of three evident factors: social, cognitive and educational presence.

- $\quad$ Social presence: The teacher should make the educational environment in such a way in which the students can easily complete assurance communicate with each other. He must activate in the students the grounds of associating the viewpoints, searching the differences, similarities and a confidence feeling towards the peers and instructor. 
- Cognitive presence: For making effective learning, the teacher should provide a situation which could develop the main skills of concept and thought in the learner. He can provide the cognitive by presenting content and activities that reinforce the critical thought, problem solution and high level of concept in the students.

- Educational presence: It makes all the social research elements practical and keeps them in balance to become proportionate to all needs and capabilities. Educational presence should be powerful in effective planning of learning environment based on the technology (p.49).

Evaluation of the performed studies in distance education suggests that in recent decades, the attention toward distance education has increased in most universities. It caused that new models on the ground of distance education are used. Improving the quality of the curriculum of distance universities depends on the combination of the right facilities and capabilities associated with the related learning theories. These theories should encourage active learning-teaching strategies, cooperation, and flexibility and based on the learner in distance education, have the ability to admit new methods and technologies and form future functions.

\section{The characteristics and features of effective distance teaching and learning}

For determining effective distance teaching- learning features, effectiveness should be defined at first. Effectiveness is defined differently; Sasson (1987) refers to it as "the right actions", Patsula (2001) defines it as the degree to which a project attains the predicted objectives got by the organization duty, qualitative standards or other matters.

Effectiveness can be regarded as the viewpoint of learning and the learner's satisfaction, the profits of educational organization and attaining to the organizational goals or the satisfaction of faculty members. Certainly, the learner and learning are the bases of Distance Education institutions; effective educating and learning is a continuous procedure and does not happen at once. Boettcher (2007) says that planning an effective learning environment needs a conception and understanding of mental procedures, knowledge and pedagogic principles and basic learning theories that define the effectiveness and its value.

Learning-teaching is a process that has passed a developed and complicated history and change. Basic cases of this process are the teacher and learner. These two make an active relationship by using educational intermediates such as oral discourse and speech, written and printed texts and today distance education wares to transfer the main contents of teaching that is knowledge, skill and advantage from one to the other or exchange during a communication procedure (Ebrahimzadeh, 2009). For specifying the features of effective distance learning-teaching, its capabilities should be recognized thoroughly corresponding and a learning theory should be applied. Therefore, distance education theoretical basics, information communication(ICT) based education, learning theories, higher education mission, and researches related to the advantages and shortcomings of distance education have been evaluated; also through case-study, the features of effective distance education presented by valid institutions have been classified and analyzed that we describe them briefly as the followings. 


\subsection{The theoretical bases of distance learning}

Distance learning is a complicated global phenomenon that is associated with various terms, meanings, theoretical concepts and models. With studying the distance learning theories, the independence theory of Moore \& Wedemeyer and the interaction and communication theory of Moore \& Garrison are more relevant to the present theories.

- Independence and autonomy: Moore \& Wedemeyer refer to the independent study as an individual activity and say that learning does not happen until the learner involves himself in study and learning activities. From their point of view, the learners are free to choose the time, place and quickness of their study.

- Interaction and communication theory: one of the sub branches concepts of this research is communication. It is a complex concept in all types of the educational approaches. Learning should be communicative to improve to a higher level and be helpful in the construction of individual concept. According to Heinze et al. (2006), learning is the production of knowledge, skill and new attitudes which are obtained by the communication of the learners in the academic milieu and with data. Communication is essential for making a feeling of being in the society and the transformation of learning in learners.

Learners get the learning content through technology and process them, then personalize the data and use them in any grounds they wish. In this process, the learners communicate with the content, professors and other learners to test and approve their ideas and use what they have learned. Distance education theory makers (Grison \& Anderson, 1991, 2000; Holmburg, 2003; Moor \& Kearsley, 1996; Gamson \& Chickering, 2003) called the communication as an important criterion of the quality.

Therefore, the learner should take the responsibility of learning and regulate his learning activities for attaining to the goals at the right time and place, and also have communicate and react with the elements of academic milieu to improve learning and help create a the personalized concept.

\subsection{ICT based education concepts}

Using information and communication technology is a symbol of a new period for distance teaching (Peters, 2002). The reports of the eighteenth, nineteenth and twentieth Global Commission of International Distance education Society and most of the written articles by the pioneer researchers like Michael Moore (2003), Holmberg (1995, 2001, 2003), Garrison \& Anderson $(2000,2003)$ and Peters $(2000,2002,2003)$ show that the development and an interest in distance education is increasing. All of these pioneers emphasized that using information and communication technology transforms distance education.

Traditionally, distance learning was provided for those who were not able to register in normal classes, but through progresses in information and communication technology everyone can be a distance learner. The progressive technology is learning and its facilities should be adapted to the nature of learning in human beings (Keppell, 2003, p.634). Education which is based on information and communication technology contains the six following features: telepresence, flexibility, communication, active learning, Collaboration and motivation. Thus, using information and communication technology transforms and changes mental models of distance education, enriches the present educational models more than before and 
makes new models. Consequently, new models with different pedagogies and features are presenting. These models share the features of an education based on technology and suggest modern educational and learning approaches in which the learner plays an important role and emphasize on self-directed, independent, flexible and communicative learning.

\subsection{Learning theories}

Regardless of whether learners learn individually or in groups, distance or with presenting, it is widely known that individuals learn differently. Individual learners think and perceive differently. Therefore, knowing learning theories for getting a better understanding of distance learning is necessary. Through studying various schools of thought, the cognitive constructivist theory and social constructivist theory can be regarded as the foundation of effective learning.

Constructivist theory recognizes the learners as an active individual. The learner is central to learning and the instructor has the role of a facilitator and counselor. The learner should be open to form knowledge himself rather than acquire it through education. Constructivism teachers believe in an educational programming that is based on cooperative and group learning and reinforces active learning in the learner. Active learning, cooperation and working in the group are also important features of learning through technology. As a result, combining these features in distance learning determines an effective learning environment mentioned in this study.

\subsection{Mission of higher education}

The most important mission of higher education from the beginning has been to give information, knowledge and skills to the students (Morss \& Murray, 2005, p.5). But higher education is at the beginning of a revolution regarding information and communication power. Nowadays, the universities should educate those who have the ability for grouping, analyzing and combining information, problem solving \& communicative skills, discussions, talks, technological and management skills instead of preserving and saving data, to be able to adjust themselves to rapid social and industrial changes (Miguel \& Mc Pherson, 2004, p.78). Also, the results of the previous studies (Wegerif, 1998; Vonderwell, 2003) on distance learning environment emphasize that a distance university contributes more than the learning environment with the students' presence to raising objectives such as getting problem- solving skills, critical thinking, and management and make a decision in difficult situations, lifetime learning, and discussion and make the social communications.

Therefore, universities should currently emphasize on the importance of the promotion of learning and the learner, try to provide an environment which is learner- based and increase the feeling of the learner's responsibility toward learning. Moreover, they should reinforce learning at high cognitive levels in the learners and prepare an active learning environment. Finally, universities should undertake the learner's success.

\subsection{Advantages and disadvantages of distance learning}

For determining the features of effective Distance learning, its advantages should be raised and there should be an attempt to eliminate its disadvantages. Distance learning provides access to a learning independent from time and place and it has the potential to provide an 
educational environment which is based on the learner and individual and personal communication (Institute for Higher Education Policy, 20007). On the other hand in traditional distance education, since the students act independently and learning is individual, they hardly understand learning activities and follow a special time table. Although it reduces the anxiety and stress in the students, it decreases their challenge and effort (cho, 2002). One of the other shortcomings of distance education is that there is not enough class discussion. In education that students must participate and their presence in class is obligatory, to show the importance of learning activities, a model of social expectations is presented which determines the significance and quickness of learning activities. These expectations are mostly disregarded in distance education which decreases the price of completing the course compared to normal traditional education (American Federation of Teachers, 2000). As a result, in desired distance education, the objectives should be clarified, the quickness of learning should be suitable and group activities should be provided. By using high capabilities and right planning for the course, most of the traditional distance education shortcomings will be removed.

\subsection{Case studies}

Many organizations have distributed guidance for effective distance learning. These are a reflection of various viewpoints in diagnosing effective factors and better distance education performance. In table 1, the features of effective distance education and their theorists makers of them have been presented.

\begin{tabular}{|l|l|}
\hline theorists & \multicolumn{1}{|c|}{ Effective Distance Education Principles } \\
\hline $\begin{array}{l}\text { Chickering and Gamson } \\
\text { (1996) }\end{array}$ & $\begin{array}{l}\text { Student-faculty interaction, Collaboration, Active learning, } \\
\text { Prompt feedback, Time on task, High expectations, Diverse } \\
\text { talents and ways of learning }\end{array}$ \\
\hline $\begin{array}{l}\text { The Sloan-C Framework } \\
\text { (2003) }\end{array}$ & $\begin{array}{l}\text { Interaction, Communication and community building, } \\
\text { appropriate media, Learner-centered, feedback, flexibility }\end{array}$ \\
\hline $\begin{array}{l}\text { The Institute for Higher } \\
\text { Education Policy (2000) }\end{array}$ & $\begin{array}{l}\text { Student-faculty interaction, Student-student interaction, } \\
\text { feedback, proper methods of instruction, valid evaluation and } \\
\text { assessment, student support, proper technology }\end{array}$ \\
\hline $\begin{array}{l}\text { The Quality Assurance } \\
\text { Agency for Higher } \\
\text { Education(1999) }\end{array}$ & $\begin{array}{l}\text { System design, Program design, Program presentation, student } \\
\text { development and support, Student communication and } \\
\text { presentation, student assessment }\end{array}$ \\
\hline $\begin{array}{l}\text { University of } \\
\text { Massachusetts-Lowell } \\
\text { (2003) }\end{array}$ & $\begin{array}{l}\text { selection of course and programs; faculty development, support } \\
\text { and incentives; technology and infrastructure; redesign of } \\
\text { student services; program and course evaluation }\end{array}$ \\
\hline Boettcher (2007). & $\begin{array}{l}\text { Interaction, learner-centered, collaboration, active learning, } \\
\text { learner preparation, time on task, considering the learners' } \\
\text { individual differences }\end{array}$ \\
\hline Nikolz (2002) & $\begin{array}{l}\text { Interaction, student assessment, communication, quality } \\
\text { information, Individualization, flexibility, clear feedback }\end{array}$ \\
\hline Bransford (2002) & $\begin{array}{l}\text { learner-centered, assessment-centered; knowledge-centered; } \\
\text { and community-centered }\end{array}$ \\
\hline
\end{tabular}

Table 1. The features of effective distance education and their theorists. 
With respect to the common elements in effective distance education guidelines and principles, and fundamental learning theories and for removing present barriers and lacks of current distance education, the following features of distance education should be considered in order to improve the learning:

1. Learner- centered: The learner should be at the center of the learning environment.

2. Interaction: The key of learning is the exchange of information between the students, professors and students, students and content and participation in learning. For learning effectively, by evaluating the types of interaction and regarding their fundamental schools of thought, eight types of interaction in educational environment planning were considered in this study:

- Learner- content: Communication of the learner, content is as a cognition interaction which is associated with the content that leads to the learner and learning constructive-cognitive changes (Moor, 2003, P.20).

- Teacher-learner: Communication of the learner and teacher is an important factor in preserving interest and motivating the learner (Moor, 2003, P.22).

- Learner-learner: This type of interaction is a new dimension in Distance education and points out the learner centric in learning. The learners' interaction is necessary for making deep learning and constructing knowledge. The relation and sharing the opinions and ideas with other students increase the learners' motivation and interest (Brown \& Dugu, 2000; Anderson, 2003).

- Content-content: In this type of interaction, the content updates automatically through different entrances of receiving data and learning sources constantly develop through the learner's communication with intelligence factors (Moore \& Anderson, 2003).

- Learner-content: Content development and planning is one of the important roles of the instructor. Educational planning process has a significant role in the communication of the learner and content. This procedure should continue duration the course and the instructor should be able to communicate content regularly based on the learners' need or updating of the subjects (Tuovinen, 2000).

- Instructor-instructor: This type of communication and interaction form the learning societies of the instructors. Moore and Anderson (2003) recognize the close instructor coworkers and not the experts as the first and most important source of information and are helpful for encountering technical and pedagogical problems. These problems occur much more when the instructors do not communicate with each other. As a result, there must be a group of instructors who can support other instructors.

- $\quad$ Learner-technical supporter: Technical supporter has a significant role in ICT based education; it supports learners during the learning procedures and solves their technological difficulties.

- Instructor-technical supporter: The supporter assists the learner in planning and production of electronic courses and removes his technical difficulties during the instruction.

3. Paying attention to individual differences of the learners: If we generally define education as providing an area for development in various dimensions for learners, this 
is not possible without regarding individual differences and not considering them in education will lead to the traditional model of learning. In planning learning activities, the learners' educating style should be notified and various learning activities and communicative learning sources should be programmed by a multiple presentation to adapt with various learning methods.

4. Flexibility: In planning a desired learning environment, you should select an environment independent from time and place and assist the learner to acquire the learning sources as soon as he can (Aggarwal and Bento, 2000).

5. Encouraging active learning: Distance education should support an active learning environment and allow the learners to share their ideas actively. Consequently, the learner becomes acquainted with the others opinions and ideas and learning from each other encourages (Devoy, 2006, p.80, Farajollahi et al, 2009). For making a successful learning, there should be the right pedagogy and an educational plan coordinated with the learning method. Hitlz (2004) states that instead of representing all the answers and solutions to the students, we should plan an environment for asking the student, motivating him for finding and sharing the answer to the others and the role of a professor should be to facilitate learning. Another important element in planning educational materials for encouraging active learning is an environment that asks the student to relate the concepts with real situations and experiences. The activities of the course should be planned in such a way that they can reinforce the active role of the learner. In an active process, the learners need more to do something rather than to read something. They need to write, discuss, solve the problem and get involved in the high level of cognitive abilities such as analyzing, combing and evaluating. Active learning should also encourage learning in a learner. In this level, the learner is aware of his learning process, understands educational goals, knows his capabilities and weaknesses in attaining to the learning objects and is able to control the progress toward the objectives. Bransford (2002) suggested that the activities of learning along with selfassessment and feedback encourage the learner in educating and learning and the learners can actively get involved in learning activities.

6. Using capabilities of information and communication technology: ICT based education is divided into online and offline communication. Online communication of the student with the instructor, other students and through other learning materials, reinforce a spirit of belonging to a group, use exact and early feedbacks of the classmates and progress in coordination with others in the curriculum ((Mendenhall, 2003). On the other hand, an offline electronic communication also helps students access to the curriculum any time in proportionate to their family or occupational situation. By using these facilities, the students have much more time to participate in discussions, raising questions, answering and doing the homework's and thinks about them and they can use what they have learned in real situations.

7. Evaluation: Evaluation provides relevant information for further developments and expansions of any program. For any project, or initiative, evaluation provides useful data and information on the degree to which the initiative/project is meeting the objectives. Evaluation, therefore, is conducted to "examine and report on the strengths and weaknesses of programs, policies, personnel processes, products/outcomes, and 
organizations to improve their effectiveness" (Thompson \& Irele, 2003). The evaluation of the qualifications of distance education is not different with the evaluation of a class. The evaluation of an electronic learner can be divided into three parts:

- Beginning evaluation (assessment of learning acquirements): Learning should be connected to a more extensive social area including home, at work and social learner. In this approach, the professor evaluates the knowledge, skills, attitude and cultural areas of the learner and establishes his learning experiences on it and communicates with the student. The most effective education will be obtained only when it is coordinated and related with the developed learning requirements. The beginning evaluation must primarily regulate the learning environment based on the learners' features.

- Formative evaluation and immediate feedback: Formative evaluation refers to an ongoing process, which can be conducted at any stage. The purpose of formative evaluation is to assess and monitor progress with intentions to make adjustments and improvements to the project (Nguyen \& Kira, 2000). It aims to review, correct learning splits and understanding the learner's mistake. The professor is able to use the formative evaluation results for adjusting content and learning activities, regulating and setting the stages of learning process in a balance with the real requirements of learners and answering the learning needs of students in the best way.

- Summative evaluation: Final evaluation is equal to the total evaluation of effective education that provides a feedback for the whole system. Summative evaluation, on the other hand, focuses on the end results of a project in terms of its success or failure (Thompson \& Irele, 2003).

Therefore, from the view points of the researchers, effective leaning environment briefly should contain the following features: to be learner centric, to be interactive, proportionate to the individual differences of the learners, to be flexible, to encourage active learning, to use the capabilities of the information and communication technology, to evaluate all the learning stages(Table 2).

\author{
to be learner centric \\ to be interactive \\ proportionate to the individual differences of the learners \\ to be flexible \\ to encourage active learning \\ to use the capabilities of the information and communication technology, \\ To evaluate all the learning stages.
}

Table 2. Principles for Effective distance learning.

\title{
4. An effective distance education model
}

The proposed model has been formulated on the basis of studies conducted on different issues related to distance learning and the above- mentioned characteristics. The model has been made in accordance with the systemic theory of distance (Figure: 1). by definition, a system is a set of connected components which are aimed at achieving a specific goal. The basic components should interact with the peripheral environment such that inputs result in 
the expected output subsequent to entering the teaching- learning environment and going through the process of appropriate transform.

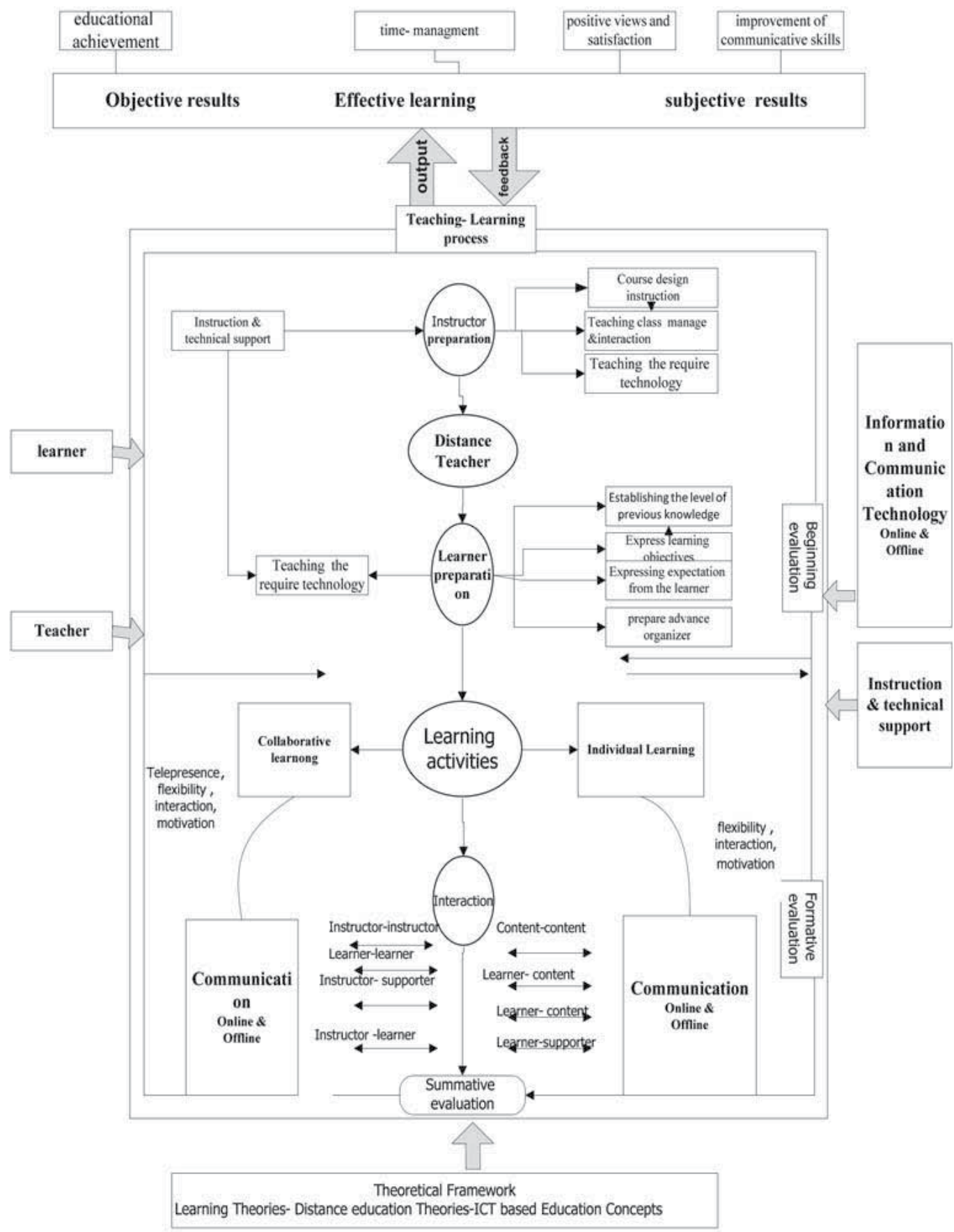

Fig. 1. The effective distance learning model. 
The components of this model are as follows:

\subsection{Input}

- The educational framework for the proposed model: The educational framework enters the system as input and influences the educational process. The basis for the proposed model rests on the following:

- cognitive and social Constructivism theory and metacognition

- Independence theory of Moore \& Wedemeyer and the interaction and communication theory of Moore \& Garrison

- $\quad$ ICT based Education Concepts

- The Learner:

The model lays emphasis on the learner and fulfillment of his/her requirements. It situates the learner at the center of the learning environment. The model rests on the assumption that there is more variety among learners as compared with their traditional counterparts. To be successful, the learner should be capable of establishing communications and interactions with the teacher, other students and content via technology, flexible learning and access to the learning environment in any place and any time.

The learner should follow the learning activities in accordance with the course structure and goals. He / she should believe in learning on every occasion and every where. Likewise, she/ he should be willing to and able to learn deeply and participate actively in learning activities taking charge of her / his own learning. The learner's motivation and views are also of paramount importance in her/ his success (Colakoglu \& Akdemir, 2010; Watson, 2010; Cutshall, 2002). In this regard, the ideal learner should, in this model, possess a positive view of distance education and learning. She/He should have the motivation for learning and be willing to and able to perform group tasks. The Desirable characteristics of distance learner are summarized in (Table 3).

In this regard, upon entering the learning environment, students have to be ready for the learning environment. Learner readiness consists of the following; the first four being performed by the instructor and the teaching of the required technologies are performed by the technical assistant:

1. Establishing the level of previous knowledge

2. Express learning objectives

3. Expressing expectations from the learner

4. Presenting the advanced organizer to activate the cognitive structure

5. Teaching the required technologies

- $\quad$ The instructor:

The success of the distance learning courses depends to a large degree on the instructor. Instructors involved in distance learning face specific challenges. The change of direction from traditional course to online ones cannot be easily performed a part from clear changes. One of which is technology, education takes new dimensions. In this model the instructor should be actively and tangibly present in the virtual learning environment. For this purpose, she/he should possess the capability and the tendency to establish 


\begin{tabular}{|c|c|}
\hline characteristic & Variables \\
\hline $\begin{array}{l}\text { Establishing relations } \\
\text { and interactions }\end{array}$ & $\begin{array}{ll}\text { - } & \text { Willingness to establish relations with the instructor } \\
\text { - } & \text { Willingness to establish online and offline relations with } \\
\text { other students } \\
\text { - } & \text { Ability to express opinions and raise questions. } \\
\text { - } & \text { Ability to express views in writing } \\
\text { - } & \text { Ability to work with online and offline learning } \\
\text { - } & \text { technologies. } \\
\text { - } & \text { Abillingness to interact with content } \\
& \text { Ability to interact with content }\end{array}$ \\
\hline $\begin{array}{l}\text { Ability to undertake } \\
\text { flexible learning }\end{array}$ & $\begin{array}{l}\text { - } \\
\text { Ability to have access to the learning environment on } \\
\text { any occasion, any where } \\
\text { - } \quad \text { Ability to follow learning activates at appropriate time } \\
\text { - } \quad \text { Belief in learning on any occasion anywhere. } \\
\text { - } \quad \text { Ability to use educational material and autonomous } \\
\text { learning. }\end{array}$ \\
\hline $\begin{array}{l}\text { Responsiveness and } \\
\text { active participation }\end{array}$ & $\begin{array}{ll} & \text { Willingness to get involved in deep learning } \\
\text { - } & \text { Willingness to actively participate in learning activities. } \\
\text { - } & \text { Ability to participate in active learning } \\
\text { - } & \text { Accepting responsibility for his/her own learning. } \\
\text { - } & \text { The problem solving skill. }\end{array}$ \\
\hline Motivation \& Feedback & $\begin{array}{ll}\text { - } & \text { Positive view about education and distance learning } \\
\text { - } & \text { High Motivation for learning } \\
\text { - } & \text { Achievement of educational goals } \\
\text { - } & \text { Feeling at ease to ask questions } \\
\text { - } & \text { Consulting the instructor } \\
\text { - } & \text { Consulting the classmates } \\
\text { - } & \text { Ability to accept the instructor as facilitator }\end{array}$ \\
\hline Group Activity & $\begin{array}{ll}\text { - } & \text { Tendency to undertake group or team work } \\
\text { - } & \text { Ability to perform group work virtually }\end{array}$ \\
\hline
\end{tabular}

Table 3. Desirable characteristics of distance learner.

communications with students via technology. S/H should provide a supporting, warm, welcoming and unofficial atmosphere. The instructor should clearly express learning expectations and goals for students. The instructor should also design and encourage group and individual active learning, with respect to various talents and methods of learning. She/He should provide learning activities at higher cognitive levels and encourage students to undertake research.

She/He should be willing to make innovations in etching (McLaughlin, 2002; Gilbert, 2002; White, 2000). One of the assumptions of the present model is to design an active learning environment for students. Supporting students to take an active part in learning requires the instructors who facilitate learning. The instructor should encourage the learner such that she/he understands and accepts her/his responsibility for learning and informational search. Desirable characteristics of distance teacher are summarized in (Table 4) 


\begin{tabular}{|c|c|}
\hline $\begin{array}{l}\text { Instructor } \\
\text { characteristic }\end{array}$ & Variables \\
\hline \multirow{2}{*}{$\begin{array}{l}\text { Establishing } \\
\text { relations and } \\
\text { interactions } \\
\text { with students }\end{array}$} & $\begin{array}{ll}\text { - } & \text { Tangible attendance in the online and offline learning environment } \\
\text { - } & \text { Willingness to establish online and offline relations with learners }\end{array}$ \\
\hline & $\begin{array}{ll}\text { - } & \text { Creation of supporting, warm, welcoming and unofficial } \\
\text { - } & \text { atmosphere } \\
\text { - } & \text { Ability and Willingness to create interactive content } \\
\text { - } & \text { To express learning expectations and goals clearly }\end{array}$ \\
\hline $\begin{array}{l}\text { Encouraging } \\
\text { individual } \\
\text { active learning }\end{array}$ & $\begin{array}{ll}- & \text { Ability to design individual learning activates } \\
- & \text { Students' individual management } \\
- & \text { Tendency and ability to design interactive courses } \\
- & \text { Employment of learners' previous knowledge and experience } \\
- & \text { Planning learning activates together with self- assessment and } \\
& \text { feedback } \\
- & \text { Encouraging students to search and undertake research } \\
- & \text { Preparing opportunities for activities on higher cognitive level } \\
- & \text { Willingness to make innovations in the teaching style } \\
- & \text { Investigating the characteristics and styles of learning among } \\
& \text { students }\end{array}$ \\
\hline $\begin{array}{l}\text { Development of } \\
\text { mutual } \\
\text { cooperation } \\
\text { and relations } \\
\text { among students }\end{array}$ & $\begin{array}{ll}- & \text { Ability to design and administer student discussion } \\
\text { - } & \text { Encourage students in participation in discussion } \\
\text { - } & \text { Encourage students to solve problems } \\
\text { - } & \text { Willingness to lead and facilitate rather than teaching } \\
\text { - } & \text { Creating opportunities for student group } \\
\text { - } & \text { Ability to manage work groups }\end{array}$ \\
\hline $\begin{array}{l}\text { Provision of } \\
\text { prompt } \\
\text { feedback and } \\
\text { creation of } \\
\text { motivation to } \\
\text { the student }\end{array}$ & $\begin{array}{l}\text { - } \quad \begin{array}{l}\text { Provision of prompt and appropriate feedback to the student } \\
\text { - }\end{array} \\
\text { Evaluation of students' achievement during and at the end of the } \\
\text { - } \quad \text { Willingness and ability to review courses based on student feedback } \\
\text { and course outcome } \\
\text { - } \quad \text { Positive views towards education and learning using technology }\end{array}$ \\
\hline $\begin{array}{l}\text { E-skills and } \\
\text { commitment }\end{array}$ & $\begin{array}{ll}\text { - } & \text { Ability to work with the required technologies } \\
\text { - } & \text { Willingness to cooperate with design and technology experts to } \\
\text { - } & \text { prepare learning content in multiple presentation } \\
\text { - } & \text { Ability to investigate student activities via technology } \\
\text { Responding to emails at the appropriate time }\end{array}$ \\
\hline
\end{tabular}

Table 4. Desirable characteristics of distance teacher.

The views, readiness level and eagerness of the instructor for distance learning projects secure the success of the course. Thus, in this model, the distance instructors need to be ready under the following conditions as they enter the learning environment. This readiness can be achieved by the eLearning design and production team: 
- Teaching how to perform the educational design of the course

- Teaching how to manage the class and how to interact

- Teaching the required technology

- Information and communication technology

Technology- based teaching falls down into two categories: online and offline communications. Online communications of the student with the instructor, other students and other learning materials prepare an environment for she/he that will lead to make him/her feel the community spirit and membership for better. She/he can benefit by the prompt and timely feedback via the instructor and the classmates such that $\mathrm{s} / \mathrm{h}$ can keep abreast of curriculum in coordination with others (Boils\& Bradly, 2001. Nguyen \& Kira, 2000). On the other hand, offline connections also assist students to have access to the curriculum in accordance with their job and family status on any occasion. Using these facilities, students have more time for thinking, participating in discussion, designing questioned, responding and performing the assignments. They can apply their acquired knowledge in real situations.

- Technology support and design group

Technological support and design play an important part in distance learning based on Technology. This assists the learner in the course of learning activities and removes his/her technological difficulties. It assists the teacher in designing and producing electronic courses, removing his/her technical problems during teaching.

\subsection{The teaching- learning process}

The teaching - learning process comprises of design and regulation of evaluation and learning activities. Learning activities refer to the set of opportunities which solidify and deepen learner's acquired knowledge in the course. Of the curriculum (Ajorgren and Fay, 2002) . Teaching- Learning activities and process in this model are based on an educational framework. These include: active learning, interactive learning and flexibility. This will provide feedback to promote the system at all stages of evaluation. In case students fail to do something, learning does not take place (Strauss, 2002). Thus active teaching-learning approaches are employs in individual and group fashion. In the active process, learners needs to act rather than study. The needs to write, discuss, solve problems and get involves in higher level activities such as analysis, synthesis and evaluation of thoughts. The more time learners spend on active learning, the better the learning will be. In the period of a course, there must be enough time for learners to search for concepts and fundamentals and hidden principles to explore their relations with previous experience and knowledge. If students lack the relevant previous experience, introducing the concept and principles will be far more difficult. Thus, the other issues emphasized in this model are consideration of previous knowledge, preparation of advance organizer and focusing on the learner and the main learning style. In addition, this model aims at creating an active learning environment and learner- centered orientation contemplating eight types of interaction which we discussed in earlier sections. Learners follow different learning styles. Research has shown that learning style is from among the design challenges and of distance learning presentation (Draves, 2000). Consideration of individual differences is one of the basic aspects in distance learning. This must be taken into consideration while designing and 
curriculum planning. Thus, group and independent activities have been considered for students. Likewise, interactive educational packages have multiple presentations which cover most appropriately the various learning styles. Students are capable of stopping lectures, taking notes, reading comprehension. The ability of online students to self- assesses and repeats the educational material, eradicates the course failure rates problem and reducing it significantly. Computer recording and saving allows students to follow the program individually and make progress in this regard. The ability to process responses which is constructs using evaluations and computer- aided education allows students to continuously provide feedback in the course of the program (Grush, 2002). Active learning should also promote learning at the level of metacogniotuion. At this level, the learner is conscious about the learning process. S/h understands the educational goals. She/he can recognize her/his abilities and weakness in the course of attaining the learning goes and is capable of monitoring progress towards these goals. Likewise, evaluation of the learner, in this model, falls down intro three parts: initial, formative and summative evaluation.

\subsection{Educational output}

Effective distance learning outputs in the present model include:

- Objective results: educational success

- Psychological results: improvement of communicative skills, positive views and satisfaction, time management abilities, development of thinking skills.

\subsection{Feedback}

Results of the outputs of system provide feedback for review and promotion of teachinglearning processes.

\section{Discussion \& conclusion}

Learning principles and theories transforms Distance education model, enriches the present models and creates new ones by the use of capabilities of information and communication technology. It also suggests new learning-teaching approaches in which the learner plays an important role. This model was formed on the basis of the systemic theory of distance education. The main components of the model are as follow: input (educational framework, the learner, the instructor, the Inputs including the educational framework, the learner, the teacher, the content development group and the Information and communication technology), The teaching- learning process (learner readiness, teacher readiness, learner activities and evaluation), Output (effective learning in the learners) and feedback.

This model places the learner at the center of the learning environment. Educational practitioners and professors should be committed to make each learner succeed. This is done to create deep and active learning which if from among the priorities of the current century higher education and theoretical educational principles of distance of distance learning and structuralism.

Thus, the atmosphere and the environment for the main learner should be created and learner responsiveness for self-learning should be enhanced. For this purpose, upon entering the learning environment, learners need to be reedy. In this model, active teaching- 
learning approaches were designed using information technology and communication. These include: writing, discussion, problem solving, and higher level cognitive activities as analysis, synthesis, evaluation and timely feedback. Online and offline connections provide the opportunity for feedback. Student interacts mutually with others, professors and experts. Most of the research and models designed for distance learning focus to a large extent on active - learning approaches (procedures (Miguel Batista \& Maria Martinez, 2006, Zarifsanayei, 2010). Education should proceed by more access to information and content. Interaction with others is paramount important in the in the gradual development personal understanding of the learner. Interaction with human and non human factors of the environment is from the integral parts of the high quality educational experiences. Thus, considering the theoretical foundations and the present missions of universities eight types of interaction are designed. This is indicative of the significant of crating learning and group learning communities in the world of information age being supportive of theoretical foundations selected in designing the learning model.

For the purpose of effective distance education, it is necessary to allow and accept the individual differences among learners. The proportion between learning styles and teaching methods improves the learning outcome. Therefore, the present model contemplates the inclusion of group and individual activities and educational packages in multiple presentations. From among other issue emphasized in the present model, one can refer to initial, formative and summative evaluation. In the distance learning environment, evaluation should be considers as part of learning process and its feedback should be applieds for the purposes of improving learning.

Finally, regarding the present study, considering the followings are recommended for the improvement of learning-teaching procedure in educational distance education planning of the universities:

1. Learner center: The learner should be at the center of learning environment and curriculum planning should be coordinated with their features and needs.

2. Communication: A key for effective learning that is interaction between students, professors and students, between students and content and participating in learning.

3. Flexibility: In planning a suitable learning environment, it should be independent of time and place and help the learner find the learning sources sooner.

4. Encouraging to active learning: Instead of presenting data, the students should actively participate in high cognitive learning activities such as discussion, problem solving, analyzing.

5. Regarding individual differences: In planning the learning activities, the styles of learning for students should be taken into consideration and various learning activities and communicative learning sources should be planned by multiple presentations to adjust these different styles.

6. Using online and offline information and communication technology.

7. Assessment in all the learning-teaching stages.

\section{References}

Aggarwal, 1. \& Regina B. (2000). Web-Based Education. In Web-Based Learning and Teaching Technologies: Opportunities and Challenges, edited by A. Aggarwal. Hershey: Idea Group Publishing. 
American Federation of Teachers. (2000). Distance education - Guidelines for good practice. Washington D.C.

Australian Flexible Learning Framework. (2003). Cross-cultural issues in content development and teaching online (Australian Flexible Learning Quick Guide Series): Australian Flexible Learning Framework, Available at: http://www.flexiblelearning.net.au/guides/crosscultural.pdf

Boettcher, J. (2007). Ten Core Principles for Designing Effective Learning Environments: Insights from Brain Research and Pedagogical Theory, Innovate Journal of Online education, vol3, issue3, available: http://www.innovateonline.info/index.php

Bransford، J. D. (2004). Critical Success Factors and Effective Pedagogy fore-learning in Tertiary Education, New Zealand Council for Educational Research, Available: http://ww.hpcnet.org/cgibin/global/a_bus_card.cgi?siteID=179462

Brown, A. \& Voltz, B. (2005). Elements of Effective e-Learning Design، International Review of Research in Open and Distance Learning. 6(1) available: http://www.irrodl.org/index.php/irrodl/article/view/217/300

Buford, J\& Harper, E. (2005). An Introduction to Designing and Delivering Courses and Programs at a Distance. In K. Doolet., J. R. Linder \& L. Dooly. Advanced Methods in Distance Education: Applications and Practices for Educator, Administrators, and Learners. London: Information Science Publishing.

Cerf, V. \& Schutz, C. (2002). Teaching in 2025: Education and Technology Transformed. In Evans, D. L., Bond, P. J., \& Mehlman, B. P. Visions 2020: Transforming Education and Training through Advanced Technologies. USA: Technology Administration Publications, U.S.

Chickering, A. \& Ehrmann, S. (1996). Implementing the seven principles: Technology as a lever. Retrieved January 23, 2003, Available: http:/ / www.tltgroup.org/programs/seven.html

Cho, S. K. \& Berge, Z. L. (2002). Overcoming barriers to distance training and education. Education at a distance, USDLA Journal, (16)1. Retrieved March 14, 2002, from http://www.emoderators.com/barriers/cho.html

Colakoglu, O.M. \& Akdemir, O. (2008). Motivational Measure of the Instruction compared: Instruction Based on the ARCS Motivation Theory versus Traditional Instruction in Blended Courses. In J. Luca \& E. Weippl (Eds.), Proceedings of World Conference on Educational Multimedia, Hypermedia and Telecommunications 2008 (pp. 48-53). Chesapeake, VA: AACE. Retrieved from: http://www.editlib.org/p/28375

Devi, P. (2006). An ICT-BASED DISTANCE EDUCATION MODEL, unpublished Doctoral dissertation, Victoria University of Wellington.

Ebrahimzadeh. Isa. (2008, December, 13) Cognitive concerns in providing electronic education facilities. Paper Presented in the second Distance education in Tehran University.

Farajollahi M, Zare H, Hormozi M, Sarmadi MR, ZarifSanaiey N. Effective distance teachinglearning in higher education. Iranian Journal of Research in Educational System. 2009;3(6):107-126

Garrison, R. (2000). Theoretical Challenges for Distance Education in the 21st Century: A Shift from Structural to Transactional Issues. International Review of Research in Open and Distance Learning 1 (1). 
Garrison, R., Terry, A., Walter, A. (2003). A Theory of Critical Inquiry in Online Distance Education. In Handbook of Distance Education, edited by M. Moore and W. Anderson. New Jersey: Lawrence Erlbaum Associates.

Gillani, B. (2000). Using the Web to Create Student-Centered Curriculum. In Issues in WebBased Pedagogy: A Critical Primer, edited by R. Cole. Westport: Greenwood Press.

Groof, J. \& Mouza, C. (2008). A Framework for Addressing Challenges to Classroom Technology Use. AACE Journal, 16(1), 21-46

Heinze, A., Procter, C. (2006). Online Communication and Information Technology Education. Journal of Information Technology Education vol 5, pp, 236- 250

Herrera-Batista, M.A. \& Gonzalez-Martinez, M. (2006). Considerations for the design of virtual learning environments: a proposal for instructional model based on cognitive functions and didactic strategies. In T. Reeves \& S. Yamashita (Eds.), Proceedings of World Conference on E-Learning in Corporate, Government, Healthcare, and Higher Education. Chesapeake, VA: AACE. Available: http://www.editlib.org/p/23875

Holmberg, B. (2003). A Theory of Distance Education Based on Empathy. In Handbook of Distance Education، edited by M. Moore and W. Anderson. New Jersey: Lawrence Erlbaum Associates.

Holmberg, B. (2001). Distance Education in Essence: An Overview of Theory and Practice in the Early Twenty-first Century. Oldenbury: Bibliotheks-und Information system der Universitat Oldenburg.

Institute for Higher Education Policy. (2000). Quality on the Line: Benchmarks for success in Internet-based distance education. Washington D.C. Retrieved May 8, 2001, Available at: http://www.ihep.com/Pubs/PDF/Quality.pdf

Keegan, D. (1993). Theoretical principles of distance education. Routledge studies in Distance Education. pp:75

Keppel, M. (2003). Making Explicit our Theories of Teaching and Learning: Designs that motivate our works as Designer. Paper Presents at the Interact, Integrate, and Impact: Proceedings of the 20th Conference of the Australasian Society for Computers in learning in Tertiary education. Adelaide, 7-10 December 2003.

Mendenhall, R. (2003). A Model and Principles for Effective Internet-Based Distance Education, unpublished Doctoral dissertation, Brigham Young University.

Miguel, B., Mcpherson, M. (2004). Developing Innovation Online Learning, London: Routledgfalmer.

Moore, M, G. \& Anderson, W, G. (2003). Handbook of Distance Education, Mahwah, New Jersey: Lawrence Erlbaum Associates, Publish.

Morphew, Valerie. (2000). Web-Based Learning and Instruction: A Constructivist Approach. In Distance Learning Technologies: Issues, Trends and Opportunities, edited by L. Lau. Hershey: Idea Group Publishing.

Morss, K. \& Murray, R. (2005). Teaching at university: a Guide for Postgraduates \& Researchers, New Delhi: Sage Publication.

Naidu, Som. (2003). Designing Instruction for e-Learning Environments. In Handbook of Open and Distance Learning 1 (1).

Nguyen, D. \& Dennis, S. K. (2000). Summative and Formative Evaluation of Internet-Based Teaching. In Distance Learning Technologies: Issues, Trends and Opportunities, edited by L. Lau. Hershey: Idea Group Publishing. 
Peters, O. (2003). Learning With New Media in Distance Education. In Handbook of Distance Education (pp 88), edited by M. Moore and W. Anderson. New Jersey: Lawrence Erlbaum Associates, Publishes.

Safavi, A. A. (2008). Developing Countries and E-Learning Program Development. Journal of Global Information Technology Management; 11, 3, 47.

Taylor, J. (2001, April1-5). Fifth generation distance education, Paper presented in 20th ICDE World Conference on Open Learning and Distance Education, Düsseldorf, Germany, Available: http://www.usq.edu.au/electpub/ejist/docs/old/vol4no1/ 2001docs/pdf/Taylor.pdf

The Quality Assurance Agency for Higher Education. (1999). Guidelines on the quality assurance of distance learning, Retrieved October 12, 1999 Available: http://www.qaa.ac.uk/public/dlg/contents.htm

Tuovinen, J. (2000). Multimedia distance education interactions. Education Media International, 37(1), 16-24.

Thompson, M \& Irele, M. (2003). Evaluating Distance Education Programs. In Handbook of Distance Education (pp 572), edited by M. Moore and W. Anderson. New Jersey: Lawrence Erlbaum Associates.

Vonderwell, S. (2003). An Examination of Asynchronous Communication Experiences and perspectives of Students in an online course: A Case Study. Journal of the Internet and Higher Education.6.p77-90

Watson, S. (2010). Increasing online interaction in a distance education, MBA: Exploring students' attitudes towards change. Australasian Journal of Educational Technology. 26(1), 63-84. http:// www.ascilite.org.au/ajet/ajet26/watson.pdf

Wedemeyer, C. (1983). Back Door Learning in the Learning Society. In Distance Education: International Perspectives, edited by D. Sewart, D. Keegan and B. Holmberg. London: Croom Helm.

Wegerif, R. (1988) the Social Dimension of Asynchronous Learning Networks. JALN. Vol 2 Issue 1.

ZarifSaniey N. assessing the criteria for the quality and effectiveness of e-Learning in higher. MEDIA (Magazine of E-learning Distribution in Academy, winter 2010, No 3, pp: 24-32. 


\title{
Open and Distance Learning in Dual Mode Universities: A Treasure Unexploited
}

\author{
Paul Birevu Muyinda \\ Department of Open and Distance Learning, \\ School of Distance and Lifelong Learning, \\ College of Education and External Studies, \\ Makerere University \\ Uganda
}

\section{Introduction}

Open and distance learning (ODL) has garnered increasing interest from not only lifelong learners but also traditional high school leavers. Conventional universities are repositioning themselves to become dual mode universities in order to satisfy the ensuing demand for ODL. Dual mode universities are those which offer both distance and on-campus based programmes of study (Aguti, 2009; Muyinda et al., 2009).

ODL is a relatively a young phenomenon in dual mode universities. Thus many of its would be key stakeholders in these universities are yet to fully appreciate and/or understand the modus operandi and treasures inherent in it. Consequently, in many dual mode institutions, ODL students have often been treated as second class students who are attended to, in all respects, only after attending to conventional students.

It is the intention of this Chapter to show the hurdles that ODL faces in dual mode universities with the hope of getting long lasting solutions to identified huddles. The Chapter also demystifies the benefits and values derived by dual mode universities in efficiently running ODL programmes. The Chapter shows that with deliberate initial investment in the necessary infrastructure, staff and student support services, the treasures of and potential for ODL programmes can be enormous. Limited or lack of investment in the aforementioned resources and activities has led to limited harnessing of the treasures and potentials for ODL programmes in dual mode universities. This Chapter chronicles the challenges and unexploited treasures and benefits of running ODL programmes in dual mode universities, with particular reference to Makerere University.

The rest of this Chapter is organized in 14 sections. In Section 2, the concept of distance learning is defined. Section 3 explores the concept of on-campus based learning. In Section 4 , we reiterate the concept of dual mode universities. In Section 5, we provide an account of Makerere University external programme. The organization of ODL at Makerere University and demand for and attrition on ODL programmes are given in Sections 6 and 7 respectively. In Section 8, we show how tuition is extended to ODL learners at Makerere University. The staffing and infrastructural position for ODL at Makerere University is 
given in Sections 9 and 10 respectively. In Section 11, the ODL student support system at Makerere University is elucidated while in Section 12, the strengths inherent in the Department of Open and Distance Learning (DODL) are provided. Section 13 provides the unexploited treasures of running ODL programmes. Recommendations and conclusions and future work are outlined in Sections 14 and 15 respectively.

\section{Distance learning}

Distance learning refers to a mode of study where a learner may complete all or part of an educational programme in a geographical location apart from the institution hosting the programme (Keegan, 1990). The final award given is equivalent in standard and content to an award programme completed on campus.

\section{On-campus based learning}

On-campus based learning refers to the traditional way of learning where learners attend full-time studies at the university. These learners are not separated at all in time and space from their institutions and lecturers offering them the tuition. At Makerere University, such programmes of study are also called 'internal' programmes. Makerere University used to offer only internal programmes until 1991 when distance learning programmes were introduced. About $80 \%$ of the student population at Makerere University is made up of internal learners. Thus the majority of processes, operations and policies are tuned towards the internal mode of study. Likewise academic, administrative and support staff's mindsets are skewed towards internal mode of study.

\section{Dual mode universities}

The introduction of distance learning programmes at Makerere University in 1991 turned Makerere into a dual mode university. Dual mode universities are universities which offer programmes of study either as distance or internal learning programmes or both. Usually, the curriculum for a programme being offered in both modes is the same. However, the duration for completing the programme may be a little bit longer on the external programme than on the internal programme. The same quality assurance measures are meted out on both programmes.

\section{Makerere University external programme}

ODL programmes at Makerere University have been packaged in a programme known as the Makerere University External Programme. As has already been indicated above, the origin of the External Programme is traced from 1991 when the University launched its two distance learning programmes, namely: Bachelor of Education (External) or B.Ed for short and Bachelor of Commerce (External) or B.Cox for short. According to Aguti (2009, p.219), the objectives for establishing the External Programme were to:

a. Increase University intake in some courses which meet urgent national needs;

b. Extend universal education; and

c. Extend use of University resources to eligible and interested people who could not pursue full-time courses and programmes at the University campus. 
By 1992, 246 students had been registered on the two pioneering distance learning programmes. By 2001, Makerere University realized the objectives of the External Programme as two more programmes were bankrolled on the External Programme. These were the Commonwealth Diploma in Youth in Development Work programme or CYP for short, and Bachelor of Science (External) or BSc. for short. In that year, the overall student enrollment on all the four distance learning programmes grew to about 8,000 students. The Department received substantial funding from the central administration and student support was at its best. The Department also received a grant from the Carnegie Corporation of New York and the World Bank through the I@Mak.Com Project to facilitate materials production and setup regional learning centers fully equipped with ICTs. ICT enabled learning centers were setup in Fort Portal, Jinja, Mbale, Lira and Kampala. Support and administrative staff were also recruited at these learning centers. At that time the Department blossomed with decentralized student support services such as tutorials at learning centers, submission of assignments at learning centers, constant physical and nonphysical outreach to students, materials production, materials distribution at learning centers and other designated places and effective student counseling and feedback. These support services offered flexible study opportunities to persons who would otherwise not be able to attend a fulltime education at the Makerere University main campus.

The flamboyant student support situation outlined above was however short lived. Over the years, the University started releasing less funds to the Department. As if that was not enough, in 2007 the University introduced a policy of reducing student numbers each year by $10 \%$. Though ODL programmes thrive well under circumstances of great student numbers as is espoused by Keegan (1990), ODL programmes were not spared from this killer policy. By August 2010, the number of places on all external programmes in all the years of study had reduced from over 8,000 to 6,350 . Of these, B.Cox was allocated 3,000 places, B.Ed - 2,000 places, BSc. - 750 places and CYP - 600 places.

The reduction in student numbers caused a reduction in funding and therefore a fall in student support services. By December 31, 2010, only 2,988 students (47\%) had registered for examinations out of the allotted 6,350 places which imply that the Department was operating below allotted capacity. In the last quarter of the 2010/11 academic year, the funding situation slightly improved because the new leadership in the University had stayed the policy of reducing student numbers. This led to a slight improvement in student support services, mainly in the area of proactive communication to students. As a result, there was a slight increase in the number of students who registered for the May/June 2011 examinations to 3,373 students. This increase shows that increased funding leads to increased proactive student support services which in turn leads to increased student retention levels. Proactive student support services characterise true ODL.

According to Otto and Writson (2005), the characteristics of a true external programme include:

a. The physical separation of the teacher and learner

b. Efficient student support systems

c. The use of specially designed self-study materials to act as tutors

d. Two-way communication between student and tutor to provide support services to a learner 

e. Use of ICTs for student support
f. Little or no use of learning groups, depending on one's location
g. Large student numbers

Whereas the above characteristics should rein in any true ODL dispensation, Otto and Writson (2005) found that Makerere University's external programme was characterized by:
a. Inadequate funding
b. Limited supply or lack of self-study materials
c. Inadequate student support services
d. Infrequent two way communication with students
e. Limited use of ICTs in their offering
f. Large dependency on-campus based residential (face-to-face) sessions
g. Poor and inappropriate infrastructure

The aspects characterizing the external programme at Makerere University have not in any way helped in fostering the development and growth of ODL at Makerere. An evaluation of the Makerere University External Programme conducted in 2005, with support from the Carnegie Corporation of New York, attributed the challenges facing ODL at Makerere University to the limited awareness by would be key stakeholders in the University, on the modus operandi of ODL (Otto \& Wrightson, 2005). Five years down the road, the limited understanding of the modus operandi of ODL activities at Makerere University has not shown any signs of improvement! In a letter responding to an application by the Coordinator of the BSc. programme for a scholarship for his MSc. in Zoology studies, the Human Resources Development Committee of Makerere University stated:

"The HRD Committee wonders how Zoology will be applied in the Department of Distance Education and unanimously decided that the scholarship not be granted. So we advise you to try other sources of funding"

(Makerere University, 2010a) ${ }^{1}$

The Human Resources Development Committee is composed of a number of top level managers in the University. For this Committee to have made the resolution in the above quote, indicates lack of understanding of the modus operandi of the DODL by many top level managers in Makerere University. The staff in question was not granted a scholarship even after making an appeal that he was the Coordinator of the BSc. programme where Zoology is taught as one of the disciplines.

At Makerere University, distance education is not offered as a discipline, but is used as a mode of study. It is an alternative mode of study to the on-campus mode. The staff in the DODL are drawn from varied disciplines and professions because of the multi-disciplinary nature of the Department. On the B.Cox and BSc. programmes, there are staff with business and science related qualifications. On the B.Ed programme, there are staff with science and education qualifications. On CYP, we have staff with social sciences qualifications. If the Department developed a programme in Bachelor of Laws (External), it would be imperative to have staff with a law qualification. This and many other basic facts are yet to be internalized by some University managers because their mindsets are tuned to on-campus mode of study.

${ }^{1}$ Cited with permission from the Coordinator BSc. Programme 
In their evaluation report of the Makerere University External Programme, Otto \& Wrightson (2005) attributed the limited understanding of the operations of the DODL to, among other things, lack of a policy and strategy for distance education at Makerere University. Therefore in 2006, the Carnegie Corporation of New York provided funds to develop a policy and strategic framework for Distance Education at Makerere University (Makerere University, 2006). The policy, whose drafting was completed in 2006, was only discussed and passed by Senate in July 2011. At the time of filing this Chapter, it had not yet been discussed and assented to by the University Council - the University's top governing organ.

Lack of a policy for ODL means that ODL at Makerere University is operated under a very fluid situation, to the detriment of effective student support services. This has led to high attrition levels and low demand for some distance learning programmes yet World over, universities are turning to distance learning programmes to increase access to flexible education and improve on their resource envelopes. This golden opportunity inherent in ODL programmes is acknowledged by some educationalists. In an informal conversation with the coordinator of the distance learning unit at the University of Nairobi, it was revealed that open and distance learning at that university is treated as the goose that lays the golden egg. The coordinator said,

"I usually receive special status whenever I visit my vice chancellor's office. My vice chancellor has realized that open and distance learning can sustain a dual mode university if well nurtured. My VC gives me immediate attention whenever I present any request for facilitating the operations of my unit."

Within Uganda, some education planners see the value of ODL. An education planner from the Ministry of Education and Sports said, “... If I were a top manager at Makerere University, I would have argued for the creation of a College of External Studies to strengthen the outreach arm of the University and improve the financial status of the University". ODL activities are conscripted at a departmental level with no direct representation to major decision making organs of the University. At this low level, advocacy for ODL at Makerere University is curtailed.

\section{Organization of ODL at Makerere University}

As has already been detailed, Makerere University is a dual mode University (Aguti \& Fraser, 2006; Muyinda et al., 2009). The DODL is mandated to manage all External programmes in the University. The Vision and Mission of the Department is, to offer a variety of relevant educational programmes of adults using a flexible approach that fully enhances access to open and lifelong education, particularly to those who would be unable to attend higher level education on fulltime basis. The Department runs open and distance learning programme on a collaborative arrangement with other units within the University offering similar programmes in the internal mode. In Makerere University, these partner units are commonly referred to as Collaborating Units.

As has already been pointed out, four distance learning programmes are on offer, namely: B.Cox, B.Ed, BSc. and CYP. The B.Cox programme is offered in collaboration with the College of Business and Management Sciences. The BSc. programme is offered in collaboration with the College of Natural Sciences. The B.Ed programme is offered in 
collaboration with the School of Education. The CYP programme is offered in collaboration with the College of Humanities and Social Sciences.

The DODL formerly known as the Department of Distance Education (DDE) is responsible for organizing, coordinating, managing and supervising all ODL programmes in the entire University. The DODL is under the School of Distance and Lifelong Learning (SoDLL) which is in the College of Education and External Studies (CEES). Specifically, the DODL is responsible for;

a. Training staff from the DODL and Collaborating Units in ODL pedagogy.

b. Managing the delivery of programmes offered by Makerere using the open distance and eLearning (ODeL) mode.

c. Initiating the design and development of ODeL programmes in Collaborating Units.

d. Co-ordinating the design and development of ODeL academic programmes.

e. Co-ordinating the development, production and distribution of quality ODeL study materials.

f. Co-ordinating the evaluation of ODeL programmes on a regular basis and disseminating findings there from.

g. Forging links and partnerships with organizations involved in ODeL delivery practice.

h. Developing and promoting the use of ICTs in ODeL programmes.

i. Easing feedback on students' academic records by having registrars dedicated to the processing and management of ODeL students' academic records.

j. Managing all administrative records of ODeL students.

k. Carrying out advocacy in ODeL at institutional and national level.

1. Marketing Makerere University ODeL expertise and study materials to various stakeholders.

m. Initiating market research for demanded ODeL programmes.

n. Co-ordinating and facilitating the continuing capacity-building for ODeL managers, administrators, and practitioners.

o. Managing its staff, infrastructure and resources in order to carry out all roles, through the development of effective systems.

p. Undertaking appropriate planning of both short- and longer-term, strategic dimensions for ODeL programmes, in collaboration with Collaborating Units.

q. Initiating policies and regulations for the usage of Makerere University ODeL study materials and resources by third parties, in conformity with institutional and national laws.

The Collaborating Units are responsible for;

a. Developing and implementing of the curricula.

b. Identifying academic staff to teach on the various courses.

c. Identifying and seconding writers and reviewers of the study materials.

d. Vetting and/or recommending study materials for purchase.

e. Carrying out progressive assessment of students.

f. Setting and marking examinations.

g. Presenting results to the University Senate.

h. Any other academic duties required of her.

The roles identified above show that a unit responsible for managing, coordinating and supervising ODL programmes has unique duties that require a unique mandate. Such a unit 
handles a multitude of unique pedagogic and administrative tasks. The tasks are vital as their non-execution leads to pseudo ODL programmes hence inability to harness the treasures and potentials therein. Dual mode universities are grappling with the problem of ensuring double standards, that is, permitting flexibility needed in ODeL programmes while at the same time maintaining the standards required in on-campus programmes. The end result has been following on-campus based standards, which in most cases suffocate the flexibility needed in ODL programmes.

\section{Demand for and attrition on ODL programmes}

In the Tables 1 to 4 below admission quotas allocated to different distance learning programmes per year of study and those that were actually admitted and registered are given with a view of determining the demand for and attrition on ODL programmes at Makerere University.

\begin{tabular}{|l|r|r|r|r|r|}
\hline Year/Cohort & $\begin{array}{r}\text { Allocated } \\
\text { Admission } \\
\text { Quota }\end{array}$ & Admitted & $\begin{array}{r}\text { Registered } \\
\text { As of 31 }\end{array}$ & $\begin{array}{r}\text { Attrition } \\
\text { December } \\
\text { (\%age) }\end{array}$ & $\begin{array}{r}\text { Demand } \\
\text { (\%age) }\end{array}$ \\
\hline Yr 1 $(2010 / 2011)$ & 1,200 & 1,031 & 755 & 27 & 86 \\
\hline Yr 2 $(2009 / 2010)$ & 600 & 591 & 416 & 30 & 99 \\
\hline Yr 3 (2008/2009) & 600 & 657 & 436 & 34 & 110 \\
\hline Yr 4 $(2007 / 2008)$ & 600 & 669 & 494 & 26 & 112 \\
\hline Total B. Com & & & $\mathbf{2 , 1 0 1}$ & Avg = 29 & Avg = 101 \\
\hline
\end{tabular}

Source: Academic Registrar's Office

Table 1. Enrollment on the Four Year B.Cox Programme.

As at $31^{\text {st }}$ December, 2010, the average attrition rate on the B.Cox programme was $29 \%$. As is expected, attrition rate increased from Year 1 to Year 3 cohorts but declined in Year 4 . The decline in attrition rate in Year 4 is attributed to the blanked amnesty given by the Academic Registrar to all students from 2004/05 academic year and below who had not completed their studies to come back and complete them before 31 University, 2010b). This good gesture from the Academic Registrar, cements the need for flexibility in administering ODL programmes. Flexibility in the running of ODL programmes increases throughput.

Table 1 further shows that the B.Cox programme is on high demand. On average, there was a demand of $101 \%$ of the allotted number of places. This implies that the number of students admitted on the B.Cox programme, in some academic years, exceeded the number of vacancies allotted to the programme. This vote of confidence demonstrates the high quality of the B.Cox programme. It calls for strengthening of the existing student support services on the programme. This also shows that the programme is well popularized in Uganda and beyond as it even attracts foreign students. This impressive picture is not replicated on the B.Ed programme as is shown in Table 2 below.

As at $31^{\text {st }}$ December 2010, the average attrition rates for the B.Ed programme was $43 \%$. The attrition rate for Year 1 and 2 remained constant at $41 \%$ and increased to $47 \%$ in Year 3 . This 


\begin{tabular}{|l|r|r|r|r|r|}
\hline Year/Cohort & $\begin{array}{r}\text { Allocated } \\
\text { Admission Quota }\end{array}$ & Admitted & $\begin{array}{r}\text { Registered as of 31 } \\
\text { December 2010 }\end{array}$ & $\begin{array}{r}\text { Attrition } \\
\text { (\%age) }\end{array}$ & $\begin{array}{r}\text { Demand } \\
\text { (\%age) }\end{array}$ \\
\hline Yr 1 (2010/2011) & 1,000 & 309 & 181 & 41 & 31 \\
\hline Yr 2 (2009/2010) & 500 & 438 & 257 & 41 & 88 \\
\hline Yr 3 (2008/2009) & 500 & 390 & 207 & 47 & 78 \\
\hline Total B. Ed & & & $\mathbf{6 4 5}$ & Avg = 43 & Avg = 66 \\
\hline
\end{tabular}

Source: Academic Registrar's Office

Table 2. Enrollment on the Three Year B.Ed Programme

high attrition rate has been attributed to increase in tuition fees from UGX 400,000 (USD 143) to UGX 800,000 (USD 286) per year, starting with the 2009/2010 Academic Year. This fees increase also provides the reason for the low demand (31\%) for the B.Ed programme in the 2010/2011 Academic Year. It is also said that the target clientele for the B.Ed programme is fast dwindling following competition from other universities offering similar distance learning programme.

Whereas the increase in fees was made with the view of availing resources for developing study materials, little gains have been realized in this arena especially on the B.Cox programme. This was mainly due to failure by the Department to realize the full release of funds to it from the central administration for materials production. Furthermore, financial constraints negatively affected the student support system, in that key activities in distance education such as student support at study centers, tutors' training workshops, etc. were long shelved.

Overall however, the B.Ed programme is reasonably demanded at an average of $66 \%$ of the allotted vacancies. This percentage could be increased if effective student support services were provided to enrolled students and wide publicity of the programme made within and outside Uganda.

The alumni of the B.Ed programme who number over 7,000 since 1991 have long demanded for the introduction of a Master of Education (External) programme. Plans are under way to develop B.A and BSc. Education programmes to run concurrently with B.Ed on the external programme so as to cater for fresh ' $A$ ' Level leavers who wish to have a Makerere University degree but cannot afford full time courses and fees attached. The B.Ed programme admits only holders of Grade IV Teacher Education diploma certificates. The demand and attrition on the BSc. programme is not any better as is shown in Table 3 below.

\begin{tabular}{|l|r|r|r|r|r|}
\hline Year/Cohort & $\begin{array}{r}\text { Allocated } \\
\text { Admission Quota }\end{array}$ & Admitted & $\begin{array}{r}\text { Registered as of 31 } \\
\text { December 2010 }\end{array}$ & $\begin{array}{r}\text { Attrition } \\
\text { (\%age) }\end{array}$ & $\begin{array}{r}\text { Demand } \\
\text { (\%age) }\end{array}$ \\
\hline Yr 1 (2010/2011) & 300 & 39 & 7 & 82 & 13 \\
\hline Yr 2 (2009/2010) & 150 & 44 & 24 & 45 & 29 \\
\hline Yr 3 (2008/2009) & 150 & 102 & 50 & 51 & 68 \\
\hline Yr 4 (2007/2008) & 150 & 107 & 54 & 50 & 71 \\
\hline Total BSc. & & $\mathbf{1 3 5}$ & $\mathbf{A v g}=\mathbf{5 7}$ & $\mathbf{A v g}=\mathbf{4 5}$ \\
\hline
\end{tabular}

Source: Academic Registrar's Office

Table 3. Enrollment on the Four Year BSc. Programme. 
Table 3 above shows that there has been declining demand for the BSc. programme since 2007/08 academic year to date. In 2008/09 Academic Year, tuition fees for the BSc. programme were increased from UGX 700,000 (USD 250) to UGX 900,000 (USD 321). This increase may have led to the increased attrition and low demand for the programme. The increasing attrition plus the declining demand on the BSc. programme forced the University to stay the commencement of 39 students who had been admitted on the programme in 2010/2011 Academic Year. Prior to the decision to stay the commencement of the 39 admitted students, only seven students had already registered resulting in an attrition of $82 \%$. The commencement of the 39 admitted students was stayed until the 2011/12 academic year when more students were admitted so as to get a break even student number.

Among all external programmes, the BSc. programme has the second highest average attrition rate of $57 \%$ and the lowest average demand of $45 \%$. Its attrition rate is only second to that of the CYP programme which is at an average of $79 \%$ (see Table 4 below). No exhaustive research has been carried out on the causal factor for the high attrition on and low demand for the BSc. programme but preliminary investigations have shown as follows:

a. The BSc. programme is not popularized among target audience hence the need for massive advertisement of the programme.

b. Just like any other distance learning programme, the BSc. programme has been affected by the poor student support system occasioned by the prevalent financial constraints. This has had a negative effect on the programme as currently enrolled students discourage would be applicant from joining the programme due to the poor support they receive.

c. The catchment for students who wish to offer BSc. programmes is small.

As is already mentioned above, attrition rate is worst on the CYP programme (see Table 4 below).

\begin{tabular}{|l|r|r|r|r|r|}
\hline Year/Cohort & $\begin{array}{r}\text { Allocated } \\
\text { Admission Quota }\end{array}$ & Admitted & $\begin{array}{r}\text { Registered as of 31st } \\
\text { December 2010 }\end{array}$ & $\begin{array}{r}\text { Attrition } \\
\text { (\%age) }\end{array}$ & $\begin{array}{r}\text { Demand } \\
\text { (\%age) }\end{array}$ \\
\hline $2010 / 2011$ & 300 & 204 & 52 & 75 & 68 \\
\hline $2009 / 2010$ & 300 & 338 & 55 & 84 & 113 \\
\hline Total CYP & & & $\mathbf{1 0 7}$ & Avg = 79 & Avg = 90 \\
\hline
\end{tabular}

Source: Academic Registrar's Office

Table 4. Enrollment on the Two Year CYP Programme.

Whereas the demand for the CYP programme stands highest at $90 \%$ of allotted places (Table 4 above), attrition rate on this programme is highest at an average of $79 \%$. This state of affairs can be explained by the low entry requirement for diploma programmes at Makerere University. Students with good 'A' Level grades place the CYP programme as their first choice programme when applying for entry into Makerere University. With their good grades, they are automatically admitted onto the CYP programme and as soon as they set foot into the University, they apply for change of programmes to programmes such as social sciences, social works and social administration, law, and others. Because they have good 
grades and they qualify for the programmes being changed to, they are permitted to change hence causing such a high (79\%) attrition rate. To avoid this scenario, the Department is in process of upgrading CYP diploma programme into a degree programme.

Generally speaking, the demand for ODL programmes at Makerere University is high. As at December 2010, Tables 1 through to 4 above show that the total available places on all ODL programmes were 6,350. Of these 4,919 were taken up at admission representing a percentage demand of $77.5 \%$. Whereas the demand is high, attrition rates are equally high. As at December 2010, there were 2,988 students registered on all the ODL programmes out of 4,919 admitted students representing an attrition rate of $60.7 \%$. According to Aaron and Writson (2005), this high attrition rate is due to several factors, including: 1) lack of policy for ODL at Makerere University; 2) limited resourcing for ODL activities, especially materials development, insignificant position of the DODL and over centralization of the student support services. When Makerere University addresses these challenges the demand for ODL programmes will rise and attrition rates will decline significantly. Increased funding to the DODL and the ratification of a policy for ODL at Makerere University are key issues that should be dealt with in the short run.

\section{How tuition is extended to ODL learners at Makerere University}

Each ODL programme at Makerere University is provided using self-regulated print-based modules. The modules are specially written with a number of activities aimed at stimulating self-study. The self-regulated print-based modules (distance education modules) are supplemented with two residential (face-to-face) sessions at the main campus, each of two (2) weeks, in a semester of seventeen (17) weeks. In effect, each student attends four (4) weeks of face-to-face session at the main campus in a semester of seventeen (17) weeks. The remaining two (2) weeks are used for completing final semester examinations.

The first face-to-face session is undertaken at the beginning of the semester while the second one is undertaken in the middle of the semester. For each face-to-face session, ODL students are invited from wherever they live or work to congregate at the main campus for the period of the face-to-face session. ODL students live and/or work in different parts of Uganda and neighboring countries. When they come to the main campus for face-to-face sessions, ODL students may reside within or nearby the University campus. All the students $(6,350$ No.) on the four ODL programmes may or may not be invited for a face-to-face session at the same time. However, B.Ed and BSc. students are invited for face-to-face sessions during secondary/primary school holiday time.

In the first face-to-face session, lecturers give an overview of the courses for the semester after which, take home assignments are given. Briefing sessions are also held in the first face-to-face session to communicate to students any salient administrative and/or academic issues. In the second face-to-face session, further guidance on the courses is given and students are given timed tests. In the last two (2) weeks of the semester, students write examinations in the courses on offer. Examinations are conducted from the main campus. The examinations are done at the same time as those of the internal programmes. This examination arrangement removes the flexibility required in ODL programmes.

In the remaining time of eleven (11) weeks when the students are not attending residential sessions (4 weeks) or undertaking examinations (2 weeks), students do independent study through self-study materials and group discussions. During this period, student-student, 
student-lecturer and student-university interaction is encouraged. The DODL offers academic, administrative and social support to the students through organized tutorials at study centers. Sometimes, when resources permit, ODL staff pay physical visits to students in their homes or workplaces to establish impediments to their studies with a hope of providing solutions. The visits are also intended to reduce the 'distance' in distance learning. The visits are mainly executed when staff are delivering or checking on study materials at different collaborating up-country libraries. The two way communication channel is always open between the students and Department during face-to-face or non face-to-face times. Sometimes, communication is made to and from students via electronic and non-electronic media. Electronic communication is accomplished using e-mails, mobile phones, Internet and radio. Non-electronic communication is provided through course handouts, brochures, fliers and face-to-face meetings or briefings. On the whole however, ODL at Makerere University relies more heavily on face-to-face tuition than on self-study materials.

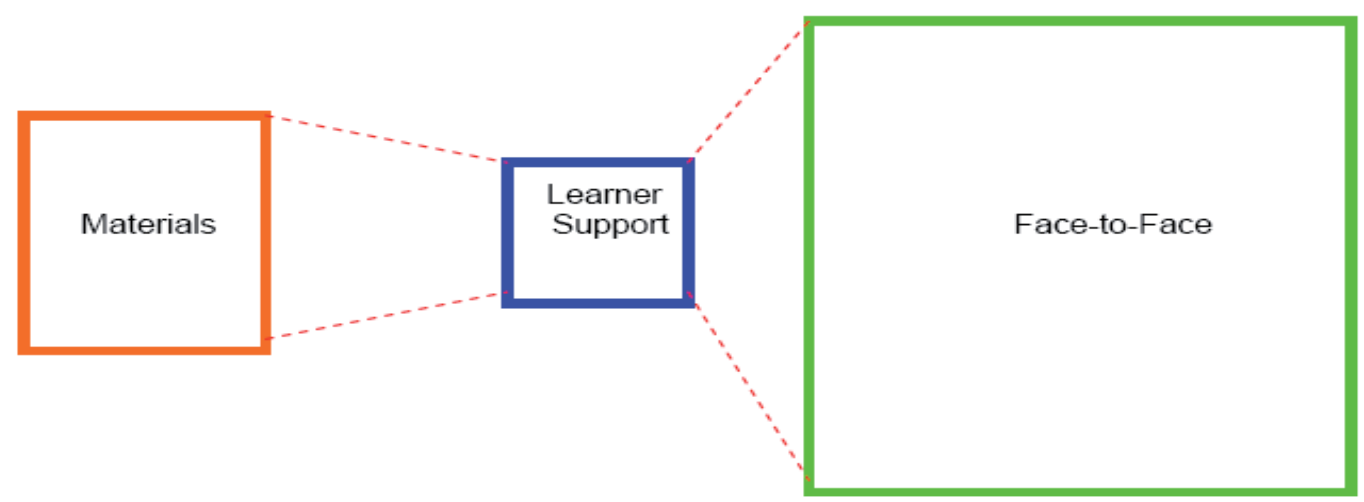

Source: Otto \& Wrightson, 2005

Fig. 1. Distance Learning Delivery Situation at Makerere University.

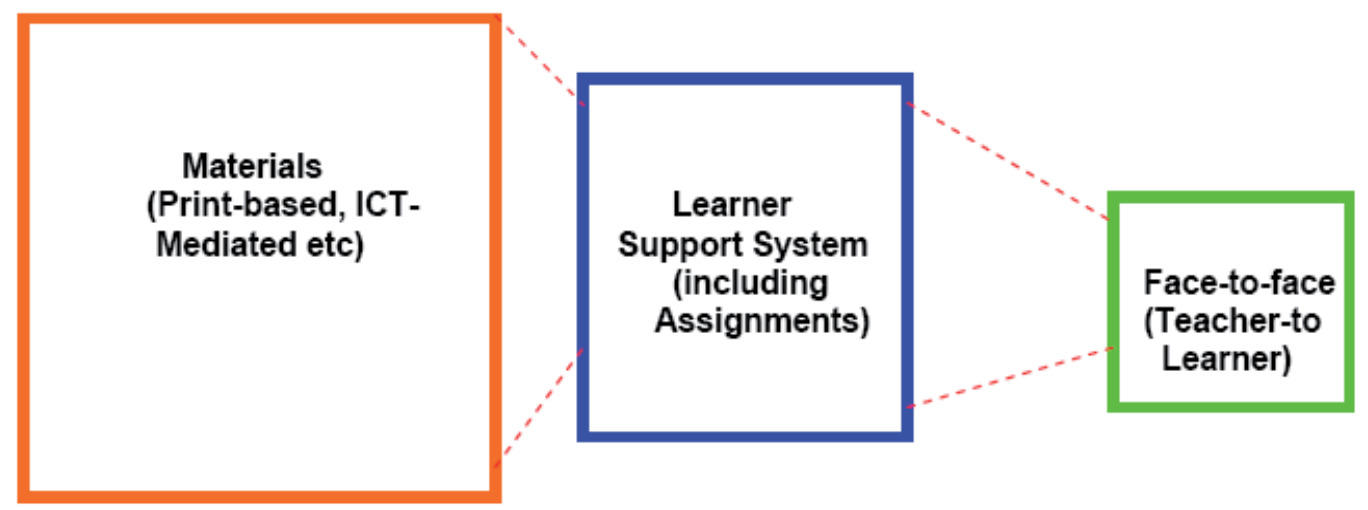

Source: Otto \& Wrightson, 2005

Fig. 2. Ideal Distance Learning Delivery Situation.

Makerere University is yet to fully partake of the ideal ODL model. The mental attitude of most faculties is still that of on-campus based learning and teaching. Adjusting this attitude to rhyme with the requirements of ODL is still a major huddle. 


\section{Staffing position for ODL at Makerere University}

As alluded to earlier, the teaching staff for the majority of courses on the ODL programmes is drawn from Collaborating Units. The DODL, which is supposed to manage and support 6,350 distance learners has only 10 fulltime academic staff on the ground. In addition to teaching, the 10 academic staff perform various administrative functions. During examination time, staff are assigned special responsibilities to ensure that examinations are run smoothly. The staff ensure that only fully registered students, with all requirements for sitting an exam, are let into the examinations venue. In so doing revenue loss is averted.

The Department has a staff responsible for coordinating all tutoring activities in the Department. The B.Cox programme has three coordinators. The B.Ed programme has one overall coordinator and three year coordinators. The BSc. programme has one coordinator. There is a staff responsible for coordinating ICT and e-learning services. One staff is responsible for coordinating materials production. Due to the large number of students, the academic staff coordinating various activities in the Department are assisted by a number of administrative and support staff. There are 35 administrative and support staff in the Department.

\section{Infrastructure position for ODL at Makerere University}

The 10 academic and 35 administrative/support staff running the DODL, which is supposed to manage and support 6,350 distance learners are housed in Nsubuga Block shown in Figure 3 below. Nsubuga Block is one of the antiquities of Makerere University as it was one of the first halls of residence for Makerere University built in 1922.

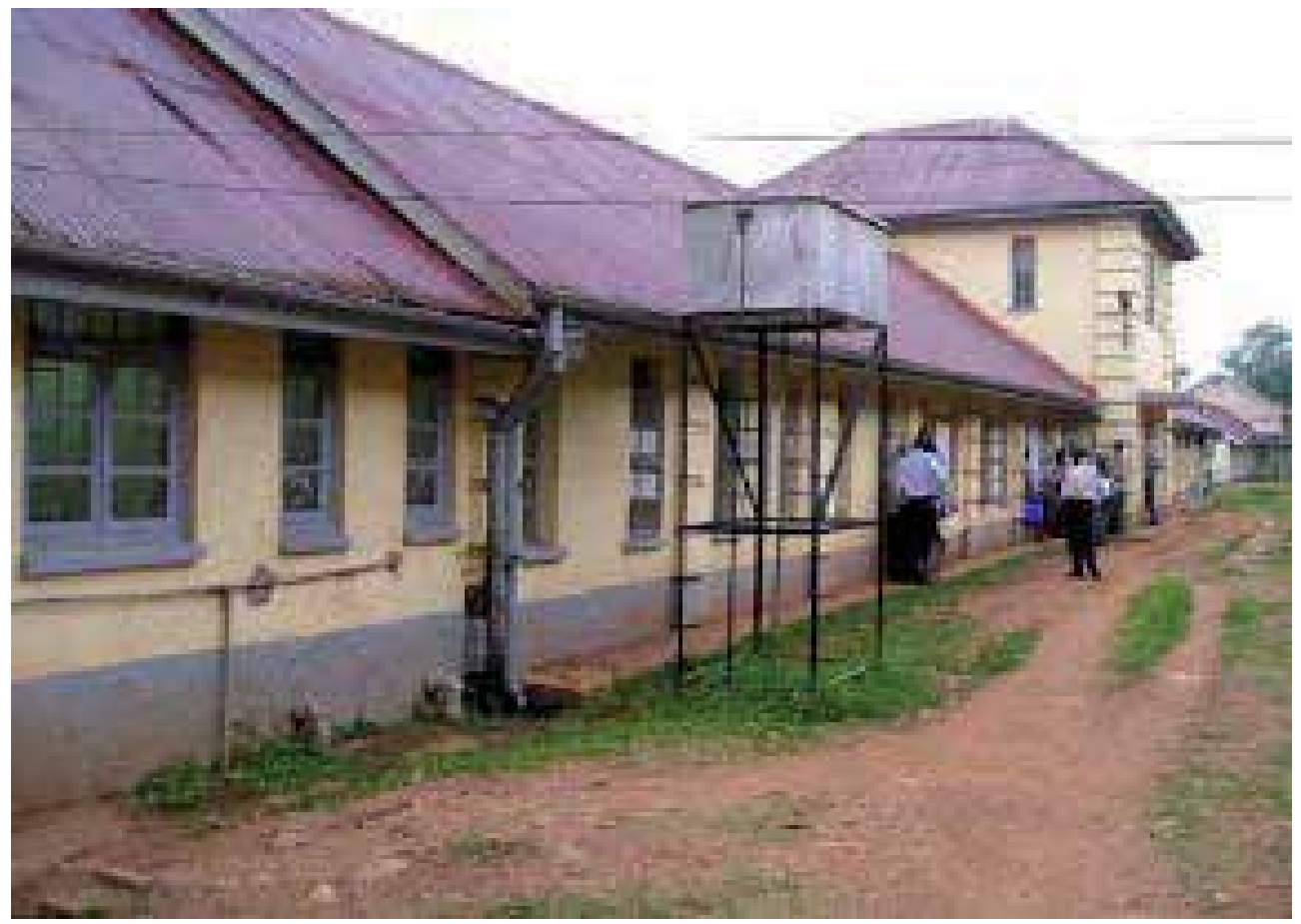

Fig. 3. The Rear View of Nsubuga Block. 
Since Nsubuga Block was originally meant to be a hall of residence, it is not suitable for the industrial like activities of ODL. Besides, Nsubuga Block is in dire need for renovation. Other than office space, Nsubuga Block does not have any lecture space to use during faceto-face sessions and examination time. The Department does not own any lecture space for tutorial/group discussion at the main campus or in regional study centers. Over the years, lectures, tutorials, group discussions, tests and examinations have been conducted in space hired from dining halls at Makerere University, lecture halls of other colleges and nearby secondary schools at very exorbitant rates (USD 25 per room per day and USD 40 for a hall per day). Regional centers are housed in rented premises. This has had a negative impact on the Department's budget. One would argue for the case of having face-to-face lectures, tests and examinations in lecture halls at the main campus, but during times when internal students are in session, this has proved to be impossible. The Department is looking for donors to help it get out of this infrastructure quagmire.

\section{ODL student support system at Makerere University}

Student Support refers to the culture of care accorded to an ODL student with the aim of ensuring that he/she accomplishes his/her study programme within the stipulated time. This care can be seen as a range of services to the student; for example, study materials provision, extending services nearer to the student, provision of up-to-date feedback to student's problems, synchronous and asynchronous interactions, tutorials, self-help study groups, counseling services, personal tutorship, and so on. Student support begins with preenrolment support to on-programme support.

At Makerere University, pre-enrolment support stops at calling upon prospective candidates to apply for admission into the external programmes. No further support is given at that level. Ideally, the university should be providing prospective applicants with information about the ODL mode of study and timely responses to all inquiries from interested parties. It should be following up the applicants that are not admitted and advising them on the way forward and having an enrolment advisor or persons performing the role of an enrolment advisor to track inquiries and applications and be in contact with the applicant and the administrators.

On-programme support and care at Makerere University is done by holding regular briefing session, educating learners and staff about the ODL mode of study, providing appropriate and regular information to learners, ensuring that regular contact is made with all learners and obliging tutors of ODL students to provide clear and useful feedback to learners in their assignment/coursework scripts. Further, tutors of ODL students are obliged to return assignment/coursework scripts to students in time to allow them internalize the feedback provided therein before undertaking examinations. Other on-programme support extended include: creating a friendly contact environment which ensures that learner needs and concerns are dealt with in a timely and effective manner, conducting and co-ordinating faceto-face sessions at the main campus, conducting examination sessions at the main campus and providing regular communications to students through the SMS broadcast systems and voice telephone calls. Makerere University is not doing the following on-programme student support services:

a. Providing special care for students with special needs, e.g. mothers, those with disabilities, etc. 
b. Decentralizing services such as admissions, registration and examinations at different learning centers.

c. Obliging all academic staff in the University to serve on ODL programmes as part of their normal duties.

d. Ensuring that each ODL academic staff has a substantial part of his/her course material provided online.

e. Ensuring that all University service units provide all registered students on ODL programmes with access to libraries, computer laboratories, lecture rooms/theatres, laboratories and other learning resources.

f. Ensuring that the University library provides flexible policies and services unique to ODL learners at all ODL centers, for example longer borrowing periods.

g. Equipping learning centers with all the necessary infrastructure and staff necessary for the smooth running of ODL programmes.

h. Regularly training university staff in ODL delivery methodologies.

i. Allocating a personal tutor to each ODL student.

j. Appointing tutors at learning centers to facilitate on ODL courses based on study materials developed for those courses.

k. Providing drop-in counseling services at each learning centre.

1. Providing ODL based study materials on all programmes.

The last item in the list of things Makerere University is not doing for on-programme student support deserves more mention. On the B.Cox programme, only 2 out of 56 courses $(3.6 \%)$ have materials written in distance education (self-study) mode. Distance education mode refers to materials that are self-regulated and are aimed at facilitating self (independent) study. Ironically, the B.Cox programme is one of the 'cash cows' of Makerere University. Lack of study materials on this programme has forced students admitted on it to relocate to Kampala so as to attend "evening coaching", a practice that is increasingly erasing the philosophy of ODL. An investigation into why materials for B.Cox programme have not been written reveals four main reasons: insufficient resources at the disposal of the Department to inject in materials development, study modules written for distance education programmes not being considered as full publication for promotion purposes, and until recently, there being few lecturers on ground hence huge teaching load that has left them with no time to write. On the B.Ed programme, $20 \%$ of the courses have study modules that have been reviewed, corrections done and are ready for editing and publishing. Those that are being written but are not complete cover $45 \%$ of the courses. About $35 \%$ of the courses on the B.Ed programme have no study modules written. The materials development outlook is different on the BSc. and CYP programmes. Sixty Percent and $100 \%$ of the courses on the BSc. and CYP programme respectively have fully written study modules. The study materials situation on the BSc. and CYP programmes is impressive because these two programmes received materials development funding support from Carnegie Corporation of New York and Common Wealth of Learning respectively.

\section{The strength of the DODL}

Many challenges have been alluded to in the foregoing exposition. These include, among others: highly centralized student support system, lack of or inadequate supply of ODL materials, inadequate and inappropriate staff establishment, inappropriate and inadequate 
infrastructure, lack of recognition of the unique nature of the DODL and lack of dynamism in offering of ODL programmes. Amidst all these challenges however, the Department can positively identify itself with the following strengths.

a. Considerable deposit of staff with ODeL pedagogy training: Through a series of short courses, the Department's staff have received ODL pedagogy training. Two (2) members of staff have PhDs in the field of ODeL while four (4) are at various stages of completing their PhD studies in ODeL related fields.

b. Ability to manage large students numbers ( $20 \%$ of the entire students' body).

c. Ability to continually grow the student numbers.

d. Collaborations: The Department has established numerous networks and collaborations with other institutions and organizations in running its programmes.

e. Study materials: The Department has now published nearly $20 \%$ of its study materials locally. The rest have been procured internationally from other academic institutions.

f. Existence of regional centers: The Department has regional centers all over Uganda in Arua, Lira, Jinja, Gulu, Mbale, Kabale, Fort-Portal, Kabale, Hoima and Kampala to provide services nearer the learners, especially in the provision of study materials.

g. ICT facilities: The Department has a computer Laboratory with 30 computers and 17 other computers in different offices. All these are networked and connected to the Internet.

h. Huge budget: ODL breaks even when critical mass of student numbers is realized. The ODL programme at Makerere University has reached this critical mass. Great student numbers mean great income. ODL programmes are generating enormous amounts of revenue for Makerere University.

These strengths can be harnessed to tap into the unexploited treasures of running ODL programmes.

\section{The unexploited treasures of running ODL programmes}

The social, economic and political environment in Uganda is increasingly encouraging fresh 'A' level leavers and lifelong learners to prefer the ODL mode of study. Presently, over $20 \%$ of Makerere University's student population is made up of distance learners. This population is contained in only 4 programmes (less than $1 \%$ of the entire programmes) of the university. At the current admission quotas, it is projected that 6,571 students shall be enrolled in the existing four external programmes over the next five years as is seen in Table 5 below.

In its strategic plan for 2008/09 - 2018/19, Makerere University intends to initiate 6 more ODeL programmes "in at least six faculties" (Makerere University, 2008, p.15). In each of these six programmes, an annual recruitment of 1,000 students per programme is anticipated. This shall give a total of 6,000 students per annum in the new ODeL programmes. When this is done, ODeL shall on average have an enrollment of 12,571 students per annum (6,571 (on existing programmes) plus 6,000 (on the proposed six programmes). This student number presents a golden opportunity for Makerere University in-terms of increasing access to higher education and providing the much needed financial muscle for running the University's activities. The revenue projections from the above enrolment scenarios are shown in Table 6 below. 


\begin{tabular}{|c|c|c|c|c|c|c|c|c|c|c|c|}
\hline \multirow{2}{*}{\begin{tabular}{|l} 
Programme \\
B.Cox
\end{tabular}} & \multicolumn{2}{|c|}{$2012 / 13$} & \multicolumn{2}{|c|}{$2013 / 14$} & \multicolumn{2}{|c|}{$2014 / 15$} & \multicolumn{2}{|c|}{$2015 / 16$} & \multicolumn{2}{|c|}{ 2016/17 } & \multirow{2}{*}{\begin{tabular}{|r}
$\begin{array}{c}\text { Yearly } \\
\text { Average } \\
\text { Enrolment }\end{array}$ \\
B.Cox
\end{tabular}} \\
\hline & Year 1 & 900 & Year 1 & 1000 & Year 1 & 1000 & Year 1 & 1000 & Year 1 & 1200 & \\
\hline & Year 2 & 900 & Year 2 & 950 & Year 2 & 950 & Year 2 & 950 & Year 2 & 980 & \\
\hline & Year 3 & 400 & Year 3 & 900 & Year 3 & 950 & Year 3 & 950 & Year 3 & 950 & \\
\hline & Year 4 & 350 & Year 4 & 400 & Year 4 & 800 & Year 4 & 800 & Year 4 & 950 & \\
\hline & Total & 2550 & Total & 3250 & Total & 3700 & Total & 3700 & Total & 4080 & 3,456 \\
\hline \multirow[t]{5}{*}{ BSc. } & Year 1 & 100 & Year 1 & 100 & Year 1 & 100 & Year 1 & 100 & Year 1 & 100 & \multirow{4}{*}{ BSc. } \\
\hline & Year 2 & 0 & Year 2 & 80 & Year 2 & 80 & Year 2 & 80 & Year 2 & 80 & \\
\hline & Year 3 & 25 & Year 3 & 0 & Year 3 & 75 & Year 3 & 75 & Year 3 & 75 & \\
\hline & Year 4 & 60 & Year 4 & 25 & Year 4 & 0 & Year 4 & 70 & Year 4 & 70 & \\
\hline & Total & 185 & Total & 205 & Total & 255 & Total & 325 & Total & 325 & 259 \\
\hline \multirow[t]{4}{*}{ B.Ed } & Year 1 & 900 & Year 1 & 900 & Year 1 & 980 & Year 1 & 980 & Year 1 & 980 & \multirow[t]{3}{*}{ B.Ed } \\
\hline & Year 2 & 350 & Year 2 & 800 & Year 2 & 850 & Year 2 & 950 & Year 2 & 950 & \\
\hline & Year 3 & 180 & Year 3 & 300 & Year 3 & 750 & Year 3 & 800 & Year 3 & 900 & \\
\hline & Total & 1430 & Total & 2000 & Total & 2580 & Total & 2730 & Total & 2830 & 2,314 \\
\hline \multirow[t]{3}{*}{ CYP } & Year 1 & 250 & Year 1 & 280 & Year 1 & 300 & Year 1 & 300 & Year 1 & 300 & \multirow[t]{2}{*}{ CYP } \\
\hline & Year 2 & 200 & Year 2 & 230 & Year 2 & 270 & Year 2 & 290 & Year 2 & 290 & \\
\hline & Total & 450 & Total & 510 & Total & 570 & Total & 590 & Total & 590 & 542 \\
\hline Total & $2012 / 13$ & 4615 & 2013/14 & 5965 & $2014 / 15$ & 7105 & $2015 / 16$ & 7345 & $2016 / 17$ & 7825 & 6,571 \\
\hline
\end{tabular}

Table 5. Projection for Existing ODL Programmes Based on Current Admission Quota.

In the next five years beginning 2012/13 to 2016/17, the average projected annual enrollment on the existing ODL programmes (shown in Table 5 above) shall be 6,571 students.

\begin{tabular}{|l|r|r|r|}
\hline Programme & Student No Per Year & Yearly Tuition (UGX) & Total (UGX) \\
\hline B.Cox & 3,456 & $1,000,000$ & $3,456,000,000$ \\
\hline BSc. & 259 & 900,000 & $233,100,000$ \\
\hline B.Ed & 2,314 & 800,000 & $1,851,200,000$ \\
\hline CYP & 542 & 980,000 & $531,160,000$ \\
\hline Proposed ODL Programmes & 6000 & $1,000,000$ & $6,000,000,000$ \\
\hline Total & & $12,071,460,000$ \\
\hline
\end{tabular}

Table 6. Annual Tuition Revenue from Existing and Proposed ODL Programmes.

At an exchange rate of UGX 2,800 to USD 1, Makerere University will be able to generate about $\$ 4.3$ million per annum from ODL programmes alone. This is a golden treasure Makerere University is yet to exploit. Just like any other investment, there must be an initial capital outlay into the ODL programmes before the projections in Table 6 above can be achieved. 


\section{Recommendations}

ODL activities are industry like. Once it is fully established, a distance learning dispensation has ability to sustain itself. Dual mode universities should invest in infrastructure (oncampus and off-campus) and study materials and human resources development for ODL.

Dual mode universities should put in place policies and strategies governing the day to day running and management of ODL programmes in their institutions. This will iron out the rifts and conflicts in the internal and distance learning modes of study.

Activities in distance learning units of dual mode universities are quite unique from those of sister departments offering contact tuition. To enable for the much needed flexibility, ODL units should be granted freedom and resources to execute their unique activities.

Due to increasing use of ICTs in ODL, delivery of ODL is rapidly evolving. Dual mode universities should permit this dynamism to flourish so as to benefit from modern forms of ODL delivery.

So as to embrace ODL, continuous sensitization about ODL amongst stakeholders is vital.

\section{Conclusions and future work}

This Chapter has highlighted the challenges of ODL in dual mode universities with particular reference to Makerere University. It has shown that adequate funding is the key to efficient student support services. With a proper ODL policy in place, ODL programmes themselves can generate funds that can sustain them and other activities of the universities where they belong. The Chapter has also shown that an on-campus based programme mindset is so awash in dual mode universities and is detrimental to the successful running of ODL programmes as staff treat ODL learners in a similar way as on-campus based learners. Despite all these challenges, ODL present enormous possibilities for increasing access to higher education and improving universities' balance sheets. When these basic facts are known, the unexploited potentials of running ODL programmes shall be harnessed. The future of ODL in dual mode institutions lies in recognizing the uniqueness of this mode of delivery by operationalising separate sets of policies and strategies for ODL and on-campus based learning.

\section{References}

Aguti, N. J. (2009). University Education for National Development: Makerere University's Dual Mode Experience. In S. Marshall, W. Kinuthia, W. Taylor (Ed.), Bridging the Knowledge Divide. Educational Technology for Development (pp. 215-229). Charlotte, NC: Information Age Publishing.

Aguti, N. J., \& Fraser, J. W. (2006). Integration of Information Communication Technologies (ICTs) in the Distance Education Bachelor of Education Programme, Makerere University, Uganda. Turkish Online Journal of Distance Education -TOJDE, 7(3), Article: 7.

Keegan, D. (1990). Open Learning: Concepts and Costs Successes and Failures. In R. M. Atkinson, C. (Ed.), Open Learning and New Technologies (pp. 230 - 243). ASET: Murdoch University Perth. 
Makerere University (Oct. 2006). Policy and Strategic Framework for Distance Education at Makerere University. Kampala: Makerere University.

Makerere University (2010a). Letter providing feedback to the Coordinator BSc. (External) Programme about his application for a Scholarship for a MSc. in Zoology. Kampala: Makerere University

Makerere University (2010b). A Circular to the Director IACE from the Academic Registrar Makerere University On Cases of Students who have Over Stayed in Academic Programmes. Kampala: Makerere University

Muyinda, B. P., Lubega, J., \& Lynch, K. (2009). A Model for Scaffolding Traditional Distance Learners for Constructivistic Online learning. Makerere University Journal for Higher Education (MAJOHE), 2(2009), 155-176.

Otto, A., \& Wrightson, T. (Oct, 2005). Makerere University Distance Learning Programmes Evaluation Report. Kampala: Makerere University. 


\section{Part 2}

Distance Education and Teacher Development 



\title{
Teacher Development Through Distance Education: Contrasting Visions of Radio Learning in South African Primary Schools
}

\author{
Charles Potter and Gordon Naidoo \\ University of the Witwatersrand, \\ Johannesburg and the Open Learning Systems Education Trust \\ South Africa
}

\section{Introduction}

This chapter focuses on shifts in vision which took place over the seventeen year life of the South African Radio Learning Programme, from an initial product based conception of curriculum to one which was process based. This was accompanied by shifts in implementation theory as well as implementation strategies, which are described and then analysed.

The initial aims of the programme were based on an interactive radio model originally applied in Nicaragua in 1974 (Perraton, 2000) and then replicated in a number of other developing countries in Latin America, Africa and Asia. Its initial radio curriculum was based on a teaching approach developed in Kenya, which was designed to raise the quality of English teaching in the first three years of primary school (Imhoof \& Christensen, 1986).

In Kenya, the curriculum involved a series of daily half hour audio lessons, which were used to introduce English to primary school children. These audio programmes were interactive in involving children in a variety of activities, which required to responses using English.

The radio lessons also involved music and movement, and were carefully designed to introduce core concepts and vocabulary. The programme was based on behaviourist principles, using distributed learning and repetition to ensure that concepts and vocabulary were internalised. The Kenyan radio learning programme can thus be characterized as a skills-based distance education programme, based on use of radio as a medium of instruction.

Like its Nicaraguan and Kenyan predecessors, the South African Radio Learning Programme (called "English in Action"), was introduced to Southern Africa using funds provided by USAID. The grant was provided to a South African NGO (the Open Learning Systems Education Trust) on the condition that technical advisers funded by USAID would train staff in radio lesson development as well as in programme implementation. The sponsors also required an evaluation design which included use of pre and post tests of English language competence, in line with the type of summative evaluation used to monitor previous implementations of interactive radio programmes in other countries. 
However, a number of shifts took place from this initial conception of a programme originally designed to implement an approach which had been tried and tested elsewhere in the world. Shifts initially took place from a purely measurement-based summative evaluation design, towards a more contextual, holistic, formative and multimethod approach to programme evaluation (Potter, 1993a; 1993b). The programme's behaviourist assumptions were also challenged (Leigh, 1995; Perraton, 2000), being replaced with a more responsive and process approach to curriculum development and evaluation (OLSET, 1995; Potter, Dube, Kenyon et al., 1995).

These changes are traced in the initial sections which follow.

\section{Initial implementation of the programme}

This section provides an overview of the implementation of the South African Radio Learning programme as outlined in its funding contract with USAID. The programme's brief was to offer direct support to the South African Department of Education in improving the quality of teaching in primary schools. This would be achieved by targeting the development of English language competencies in the junior primary phase, through the medium of interactive radio.

After an initial pilot (Leigh, 1992), 118 radio lessons were scripted in 1993 to support the teaching of English at Grade One level. These were implemented with 14500 learners in five regions of South Africa in 1993 (Potter \& Leigh, 1995; Leigh, 1995). This was followed in 1994 by the development of 130 radio lessons at Grade Two level. The lessons were of half an hour duration, and were recorded on audio-tapes.

As radio broadcasting in South Africa at the time was controlled by the national broadcaster (the SABC), initial implementation of the programme took place through the medium of audio-cassettes. These were packaged in cardboard boxes and delivered to the participating schools in each region by a regional coordinator, together with a radio tape-recorder and other classroom materials. These included a teacher's manual and printed classroom posters and alphabet friezes to support the radio lessons. As the tapes and materials were developed in stages over the year, the regional coordinator was able to establish ongoing personal contact with the teachers and principals of the participating schools.

The regional coordinator was also able during her visits to the schools, to act as adviser on matters relating to programme implementation. Her roles included observing lessons, suggesting ways of supporting the programme at classroom level, as well as ways of linking the programme and other facets of the curriculum. Participating teachers were encouraged in the process to make contact with each other, and to form teacher support groups. Workshops on use of the programme and on primary school teaching were also organized regionally, and then implemented through the school visiting and teacher support group structures.

By the end of 1994 when the initial funding grant provided to the programme by USAID came to an end, a network of teacher and school support had been set up across five provinces of South Africa, centred around materials distribution, teacher support groups and in-service training workshops to support the teaching of English at lower primary school level had been established. At the Grade One level, 118 radio lessons and supporting 
classroom materials, and at the Grade Two level 130 radio lessons and supporting classroom and print materials had been developed.

Plans were in place for the scripting of 180 radio lessons and the development of supporting learner materials to support Grade Three level implementation. Structures for curriculum development and for consultation with national and provincial Education Departments around curricular issues had also been established.

Underpinning these programmatic structures was a programme implementation theory (Weiss, 1998; Potter, 2005) reflecting a vision of educational change (Potter, 1992). This chapter focuses on a shift in this vision from a product to a process conception of curriculum (Hamilton, 1976, Stenhouse, 1975, 1980; 1981; Walker, 1969; 1971). As this shift took place in response to evaluation and is also reflected in the evaluation reports on the development of the programme over this period, the next section of this chapter focuses on the role of formative evaluation over the initial implementation phase.

\section{Changes in vision of the project team: Responses to formative evaluation of the programme during the initial funding phase}

\subsection{Evaluation design}

Like its predecessors using interactive radio in other parts of the world, the South African Radio Learning Programme was subject to evaluation for developmental and accountability purposes. The initial evaluation design was conceptualised as based on measurement involving development of a test of English language vocabulary which would be applied in pre and post-testing of learners in a number of schools involved in the programme. The performance of these learners would then be compared with pre- and post-test performance of learners in a similar number of contrast schools not involved in the programme. If learning gains could be demonstrated using audio-cassettes, this evidence would then be used to make the case to the national broadcaster to provide a national radio footprint to support national implementation of the programme.

At the time of the time of the programme's inception in 1992, a number of other projects in South Africa were also working to develop procedures for teaching English at the lower primary level (such as the Molteno project; MAPEP) and at the upper primary level (such as SELP; TELIP; TOPS; the Molteno Project; READ). In a context of rapid change in South African in its transition to democracy, the evaluation design was criticized as insufficiently responsive to context of South African schools, as well as the changes occurring in South Africa on both a socio-political and educational level. A broader contextually based evaluation design was then developed (Potter, 1993a), in which pre-and post-testing would form one element or strand. The design was evolved consultatively and responsively (Stake, 1983), and addressed six questions through use of multiple data sources and multiple methods (Potter, 1993a; 1993b), as follows:

Is the "English in Action" programme effective in teaching primary English?

Are teachers who use the programme empowered, supported in their jobs and assisted in professionalisation?

Is there acceptance of the programme by the community, inclusive of teachers, parents, principals and other stakeholders? 


Are radio and cassette efficacious as a delivery medium?
Is "English in Action" having an effect on the school environment?
Is the programme cost-effective, and are there economies of scale for national
implementation?

Table 1. Focusing Questions used in the 1993-1994 Formative Evaluation of the South African Radio Programme

To answer the evaluation questions, evidence from a number of sources was utilised. Qualitative data were gathered from school visits, classroom visits and observation of lessons, the reports of teachers, principals and parents concerning pupil progress, observation of teacher support groups, interviews with project staff and with teachers, and narrative case studies of the programme in the schools (Potter, Arnott, Mansfield, et al., 1993). Focus groups were also conducted in all regions in which the programme operated, involving a range of community stakeholders (Nene, 1993).

Quantitative data were also used to answer the evaluation questions, based on pre- and post-testing of learners (Arnott, Mansfield, \& Mentis, 1993a; 1993b) conducted in 71 schools (36 project and 35 matched comparison schools), and yielding evidence of significantly better performance on English language tests favouring the project schools ( $F=118,31(70)$; $\mathrm{p}<, 0001 ; \mathrm{R}=0,39$ ). In addition, an economic analysis was conducted, projecting the costs of radio learning in relation to different scales of implementation in terms of learner numbers, and comparing these data with alternative forms of instruction (Cobbe, 1994).

\subsection{Issues raised by the evaluators}

In their initial review of the programme in 1993, the evaluators focused on both product and process issues (Hamilton, 1976; Stenhouse, 1975; 1980; 1981, Walker, 1969; 1971). They reported that after a shaky start with respect to credibility, the programme had been successful in establishing an infrastructure and a body of materials which could form the basis for future work. The intervention was also regarded positively by both teachers and parents. However, it lacked a coherent conceptual and curricular framework in terms of both the classroom and teacher support sides of its work. Many of the staff also lacked qualifications and experience in second language teaching, which reflected in the approach to and type of materials being developed (Potter, Arnott, Mansfield et al., 1993).

Despite quantitative evidence of advantage among learners in the project schools in 1993, it was evident that there were major gaps both in the way in which the project's curriculum was being conceptualized, as well as a lack of relationship of many of the activities included in the radio lessons with the South African lower primary school curriculum. Recommendations were made that the team involved in the radio learning project should place emphasis on the development of a coherent theoretical, policy and curricular framework, which could guide its future work.

The initial evaluation report (Potter, Arnott, Mansfield et al., 1993) was critical of the programme's assumptions, its conception of curriculum, its behaviourist view of learning, and the technicist vision of educational change implicit in an attempt to improve education through increasing the English language skills of learners in the absence of focus on the context of school and classroom. A broader vision based on both product and process issues 
was necessary. At the same time, however, the evaluators commented that the infrastructure developed by the programme had promise.

Specific criticisms were that, while individual members of the project team were highly skilled in the technical side of materials writing and production, these activities were taking place in the absence a coherent policy framework as regards language teaching. There were similar gaps with respect to the teacher development side of the project's work. In both areas, there was a need for the development of a guiding programme theory, which would provide the necessary framework within which the work of the staff, and the overall innovation would take place.

The project team's response to an unfavourable initial evaluation was to focus on both teaching and learning issues, and to change its view of curriculum from a focus on the skills development of learners, to include focus on the professional development of their teachers in the context of school and classroom. This implied a focus on issues relating to classroom teaching and learning relative to teacher development (OLSET, 1995). As these involved major shifts within the programme's vision and focus, recommendations were made for ongoing internal, formative and process evaluation, in addition to external and summative evaluation (OLSET, 1995; Potter, Dube, Kenyon et al., 1995). .

In their second interim report in 1994, the evaluators were thus able to report that the programme had moved to address the conceptual and curricular issues raised in the initial 1993 report. This was evident both in the setting up of mechanisms in the programme for staff to meet and discuss the form of the materials and their usage, as well as in the appointment of a number of persons with qualifications and experience in second language teaching to assist with the development of the classroom side of the programme's work.

The teacher development side of the programme was also being addressed through the appointment of a teacher development coordinator to provide conceptual direction to the school and teacher support provided by the programme. The programme was thus developing an increasingly coherent curricular framework, and had also produced evidence of learning gains at school and classroom levels, both with respect to Grade One as well as Grade Two children (Potter, Arnott, Hingle et al., 1995).

For the reasons that these changes still needed to be implemented and their viability tested, the evaluators cautioned in their final evaluation reports (Potter, 1994a; Potter, Arnott, Hingle et al., 1995) that, despite evidence of significant learning gains favouring project learners at both Grade One and Grade Two levels (Arnott, Mansfield, \& Mentis, (1993b; Arnott, Mentis, \& Mansfield, 1994), both the radio learning project's classroom and inservice training curricula were not ready for wider implementation. It was suggested that what was required at the next stage should involve revision of the materials base, and implementation of the existing materials via various delivery media (e.g. via radio; via cassettes) in line with the open learning principles recommended in the project's blueprint (OLSET, 1995).

This would need to be accompanied by evaluation of the support processes and transactions necessary to successful implementation with teachers and in schools (Potter, Dube, Kenyon et al., 1995). It was thus envisaged that the development of both the classroom-based and teacher support curricula would need to take place simultaneously with revision of the project's existing materials base and ongoing materials evaluation (OLSET, 1995). 
Even at this early stage in the project's development (end 1994), the evaluators also noted that there was overwhelming evidence that teachers were supportive of "English in Action", and had used the materials to the benefit of their teaching, and their learners. With respect to in-service training of the teachers, there was value in the teacher support group structure developed by the project. With respect to the evaluation, teacher support groups had provided observational, focus group and case study data, suggesting a potential for interactive radio as a framework for teacher, school and community development, as well as wider possibilities for educational technology in curriculum development in the primary school. The teacher support groups also provided the project with a broad-based and country-wide basis for developmental work directed at both networking and empowerment (Potter, Dube, Kenyon et al., 1995).

\section{The end of the first funding phase}

The 1992-1994 evaluation of the programme culminated in the publication in 1995 of a file of the evaluation reports as well as a book of case studies of the work of project schools in the different different regions in which the programme was operating (Potter, 1994b; Potter \& Leigh, 1995). The evaluation documents included a curriculum blueprint developed by the project team at a workshop at the end of 1994 on which it was envisaged that the subsequent development of the radio learning programme would be based (OLSET, 1995).

Up to the end of 1994, the programme had been assisted by USAID funding, and by external technical consultants funded by USAID. Subsequent to the publication of the 1995 evaluation report, the external USAID-funded technical consultants returned to America. This marked a turning point from externally assisted to internally driven development in the project.

At the beginning of 1995, the programme moved forward based on new principles. These were based on a vision of interactive radio as involving a process of open learning focused on teacher and school-based development, which would accompany the provision of audio and print materials for learners in the classroom. This reflected a fundamental shift in the programme's theory from a skills-based or content-driven view, towards a product and process view of curriculum (Hamilton, 1976).

While these principles have relevance within the programme's implementation, they may have also have broader relevance to educational development and change more generally. The notions of product and process may have particular relevance to the planning of new interactive radio programmes based not only on issues relating to programme content, but also the processes through which curriculum materials become accepted by teachers and used. These issues are thus discussed in more detail in the sections following, as a basis for describing the South African Radio Learning Programme's subsequent growth to scale, and an overall evaluation of its large-scale implementation in schools.

\section{The programme's implementation theory post 1994}

\subsection{A shift from a product and skills-based conception to both a product and process conception of a radio learning curriculum}

Peter Buckland has provided an analysis of the influence of technicism on apartheid education, focused particularly on the assumptions underpinning the work of the de Lange 
Commission in the early 1980's (Buckland, 1984). Buckland draws on the work of Apple (1979) and Giroux (1981) to characterize technicism as applied in South African education in the apartheid era as:

"The treatment of social issues as technical problems open to technical solutions, the componential thinking implicit in the division of education into eighteen separate areas, the ahistorical approach and the orientation to the future all serve to rule out consideration of how schooling has been used to further political and economic ends. Knowledge is seen in terms of skills, with an 'appropriate value system' serving to legitimate the differentiated acquisition of such skills" (Buckland 1984, 383).

Buckland's analysis is pertinent to the behaviourist conception of the South African Radio Learning Programme's curriculum between 1992 and 1994, as well as the shifts in conception of curriculum which took place in the programme at the end of its first funding phase (OLSET, 1995). The assumptions of the project planners in 1992 can be characterized as technicist in the sense that the South African Radio Learning Project was initially planned with a focus solely on the form and content of the radio lessons, and their role in developing the skills of learners. It was assumed that English would be improved using principles of distributed learning in scripts applying principles of educational technology (Rowntree, 1974 ; 1982) with judgement of programme success being based on evaluation through pre and post-testing.

The problem with this vision was its simplistic and mechanistic logic (Stenhouse, 1975; 1980). Essentially, despite evidence in 1993 and 1994 that learners in project schools made greater learning gains than learners in non-project schools, the programme was heavily criticised by the evaluators for its behaviourist and technicist assumptions, the application of similar content to the Kenyan scripts by the scriptwriters without reference to the South African primary school curriculum or the needs of teachers who had borne the brunt of the apartheid struggle, and the project team's acontextual way of working as evidenced by lack of contact with others working in South African education (Potter, Arnott, Mansfield et al, 1993).

Given the conflict which had taken place in schools and in South African education over an extended period prior to the project's inception in 1992, the need was for a coherent intervention strategy based on the needs of teachers and schools over South Africa's transition to democracy. The programme's intervention model, however, did not focus on issues relating to the teaching of English as a second language. Nor was there mention of the skills of teachers, and the need for in-service training and support of teachers (Potter, Arnott, Mansfield et al., 1993).

In response to these criticisms, curriculum development took place in the project, and the programme was remodeled. The project team developed a curriculum blueprint at the end of 1994 (OLSET, 1995), reflecting very different assumptions. The project team was guided through the process by an experienced facilitator with considerable experience in teaching English as a second language in South African schools, who was versed in the literature on second language teaching and the bilingual classroom (e.g. Langhan, 1992; Willig, 1985), and who was able to juxtapose the needs for support and empowerment of teachers against a view of education focused on skills development in learners (MacDonald, 1990).

The curriculum document developed through this process (OLSET, 1995) reflected a vision of educational change as not only skills-based but person-centred. To undertake teacher 
development, a shift to a more process oriented view of curriculum as involving both teachers and pupils was necessary. The process of development envisaged would involve in-service training and classroom-based support for teachers as well as audio lessons and print media which could be used as a framework for educating learners. Linked to these elements would be formative evaluation, based on a vision of the developmental and empowerment possibilities in programme evaluation (Potter, Dube, Kenyon et al., 1995)

The shifts envisaged were in line with indications in the literature on process views of curriculum development (Hamilton, 1976; Stenhouse, 1975), in which curriculum theory and practice needed to be linked to be coherent (e.g. Grundy, 1987; Schwab, 1962; 1969; 1971; Walker, 1969; 1970; 1971). The view of curriculum in the programme's curriculum blueprint can be characterised as based on both a product and process view of curriculum development (Hamilton, 1976), in which education was assumed to be an interactional process, in which curriculum content was developed and curriculum change took place through the active participation of teachers (Hall, 1978; Hargreaves, 1992).

At issue was not only how teachers could become instrumental in changing both their practices as well as the quality of education in their schools and classrooms (Stenhouse, 1975; 1980; 1981). Also at issue was how democratic and empowering environments could be created at school level as well as within the broader educational system which were conducive to as well as directly supportive of change (Fetterman, 1993; 1994a; 1994b; Fullan 1982; Fullan \& Stiegelbauer, 1992; Hargreaves \& Fullan, 1992; MacDonald, 1971; 1977a; 1977b; Simons, 1987).

\subsection{Broadening conceptions of the radio learning curriculum: A teacher and a pupil curriculum}

Two contrasting conceptions of curriculum were thus evident in the way in which the work undertaken by the project team was conceptualised and implemented pre and post the end of apartheid education in 1994. There were also shifts in the vision of the project team, from a vision of educational change as dependent on well presented product (well conceptualised content and curriculum materials), to a vision of educational change as dependent on both product and process. The process issues not only influenced how interactive radio was conceptualised, but were also fundamental to the type of support provided by the programme at school and at classroom levels.

The initial(product) conception of the curriculum was as a set of distance education lessons which targeted learner skills and competence in English. The lessons were based on radio scripts, and the trials of the programme were conducted using tape recorders, initially in one area, and then over the next two years in five regions of South Africa. The aim of the programme was to provide a daily half an hour lesson which was both entertaining and interactive, through which English language competence would be developed. The audiotaped lessons formed part of a package of materials which included a radio taperecorder and supporting print materials. The print materials were a teacher's manual and classroom posters, as well as alphabet friezes to support the radio lessons.

The product and process conception of the curriculum was far broader. On the level of materials development, in response to the evaluators' criticism of the project team's initial conception of the curriculum as a set of audio/radio lessons in which the teacher played 
only a tangential role in the instructional process, the staff of the South African Radio Learning Programme revised their conception of the role of the teacher in the radio lesson. Work was undertaken both on the development of more open-ended audio lessons in which the teacher played a far more central role in supporting and supplementing the instruction provided, as well as on developing the teaching abilities and classroom organisational abilities of the participating teachers.

The project team also broadened the basis of the supporting print materials, which were designed for multi-use in other areas of the curriculum. By the end of 1994, it was evident that the project team had shifted from an initial conception of the learner curriculum as a set of half hourly distance education lessons, to a view of the usefulness of lessons and supporting materials in the context of classroom teaching received by learners in other areas of the curriculum and at all times in the day.

In addition, other process dimensions were added. Equally important in the teacher development process was both networking and personal support of teachers at school level. The issue in materials development was how to provide materials which would not only support a daily radio lesson, but would also be able to be used by the teacher as a basis for improving quality of teaching in other areas of the curriculum, as well as classroom organisation more generally. Materials provided by the programme would need to form a basis not only for learner usage, but also for broader support of teachers in the classroom..

The pivotal role of the regional coordinator in both the product and process dimensions is described in the section following.

\subsection{Providing a basis for networking and support: The role of the regional coordinator}

The initial conception of the regional coordinator's role in the project was product-related, focused on the half hourly radio lesson, with the aim of ensuring that the audio lessons were implemented regularly and as planned. As the programme was implemented in practice in the classroom and as regular contact with schools and teachers evolved, however, a broader and more process-related support role for the regional coordinator emerged over 1993 and 1994.

As the audiotapes and materials were developed in stages, the regional coordinator was able to establish ongoing personal contact with the teachers and principals of the participating schools. She was also able during her visits to the schools, to act as adviser on matters relating to programme implementation. This included observing lessons, suggesting ways of supporting the programme at classroom level, as well as ways of linking the programme and other facets of the curriculum.

The programme's formative evaluation design envisaged teacher support groups as integral to the development of the programme. Participating teachers were thus encouraged by the regional coordinator to make contact with each other, and to form teacher support groups. Visits to other schools and teaching of demonstration lessons then took place as part of the teacher support group structure. In addition, workshops on use of the programme and on primary school teaching were organized regionally, and then implemented through the school visiting and teacher support group structures.

Reflecting the shift to both a product and process-based vision of educational change, the role of the regional coordinator involved ongoing interactions with teachers, as well as 
providing support for ongoing interactions between teachers in the schools. These interactions were focused on the audio lessons, which formed the basis for a broader process of teacher support.

\subsection{Providing a basis for teacher development: Workshops, classroom visits and teacher support groups}

The initial (product-related) vision of the project team was that workshops would be provided to ensure that teachers were able to implement the radio lessons consistently and as intended, using the teacher's manual to do so. Classroom visitation would be provided as a way of ensuring that this took place.

With the introduction of teacher support groups over 1993 and 1994, however, a shift took place to a conception of curriculum in which both product and process were important. The structure of the audio lesson was conceptualised as a framework of content which could then provide a starting point for broader teacher development and support. The project team also focused on developing the types of support structures which could assist teachers to focus on and improve their classroom teaching. These included workshops, school and classroom visits, and teacher support groups.

The first teacher support groups were put in place as a way of enabling teachers to participate directly in the formative evaluation of the project (Potter, 1993a; 1993b). The potential of these for teacher development was then recognised by the project team, and by the end of 1994 workshops, school and classroom visiting, and teacher support groups formed the basis of the support structures offered by the project (OLSET, 1995). The revised curriculum structure thus involved workshops which brought teachers together regionally, visits by regional coordinators to schools and classroom, and teacher support groups as local support mechanisms. These would enable teachers to not only be visited by the project team, but also to visit each others' schools and classrooms, to observe teaching and to be involved in discussion of issues relating to the programme as well as classroom teaching and organisation. Classroom visits by the programme staff would thus complement teacher support group processes at school level.

By the end of 1994 when the initial funding grant provided to the programme by USAID came to an end, a network of teacher and school support had already been created centred around materials distribution, school and classroom visits, teacher support groups and in-service training workshops (eg. Potter, 1994a; 1994b). This reflected the broader shifts in vision which had taken place, from an initial conception based on supporting radio lessons, to a conception in which educational change could be assisted by providing both content and materials support, as well as support for the processes involved in the teaching of English at lower primary school level. Structures for curriculum development and for consultation with national and provincial Education Departments around curricular issues and in-service training of teachers were also established, as a basis for larger-scale implementation (OLSET, 1995).

\subsection{A vision of educational change encapsulating product and process: The 1994 curriculum blueprint}

At the end of the initial funding phase, a comprehensive statement reflecting these shifts in the vision of the project team was made in a document developed at a workshop at the end 
of 1994. This was then developed into a working paper, which created a curriculum blueprint for the subsequent implementation of the programme. Both the curriculum development exercise and the writing of the working paper were undertaken under the auspices of the project's newly established teacher development department, working under the guidance of a specialist in second language teaching (OLSET, 1995).

The blueprint was intended to be a statement of policy for the subsequent development of the programme, based on the experience gained over three years of initial implementation. The document focused on the following areas:

- The radio learning project instructional system

- The project's philosophy pertaining to an educational context in which:

a. Available resources were limited

b. A substantial number of teachers lacked adequate training

c. The curriculum in use was largely inappropriate

d. By and large the student/teacher ratio in schools was very high

e. Provisioning of material and human resources had frequently been inefficient.

- The type of consultation, research/development and evaluative processes necessary in this and context

- Uses of technology appropriate to this context

- English as second language subject and medium of instruction

- The aims of the OLSET radio learning programme with respect to children and their teachers.

The blueprint specified the type of radio learning curriculum and materials most likely to have influence on the quality of education of both learners and their teachers. A major focus lay on teacher development and support, using the multilingual classroom as a means to achieve a gradual a transition from initial literacy in the home languages towards use of English as a medium of instruction. As a blueprint for development based on the experience of the project team over 1993 and 1994, it went beyond traditional IRI models prevailing at the time (e.g. Imhoof \& Christensen, 1986; USAID, 1990; Learntech, 1994), in providing a detailed statement of how it would be possible to develop an interactive radio programme based on the principles and values of open learning.

\subsection{The radio learning programme's instructional system: Moving beyond traditional models of interactive radio instruction}

In the curriculum blueprint, the radio learning programme was conceptualized as using an audio-assisted communicative approach to teaching English a second language. As a distance educational instructional system, this would involve a number of linked elements.

The development and implementation of the radio learning programme would be based on two curricula. The first curriculum would be for children (learners), and the second for teachers.

The curriculum for the children involved in the programme would aim to:

- Provide a rich English language learning environment

- Create an environment for active participatory learning 
- Promote the understanding that learning can be fun

- Encourage creative and critical thinking

- $\quad$ Build on the student's own experiences and practices

- Promote language for personal expression and academic success

- Foster meaningful learning experiences between teacher and children, and among children

- Expose children to multiple models of natural English

- Attend first to the development of effective listening and speaking skills, followed by reading and writing skills.

As Leigh (1995) has pointed out, it was in the introduction of a second curriculum, for teachers, that the radio learning programme took new steps in relation to previous literature and approaches used in IRI (e.g. Imhoof and Christensen, 1986; Olsson, 2004; USAID, 1990). The model of the programme involved providing teacher support and development, as an integral part of the radio learning programme's implementation. It thus targeted teachers and their practices, as will be evident from Table Two below.

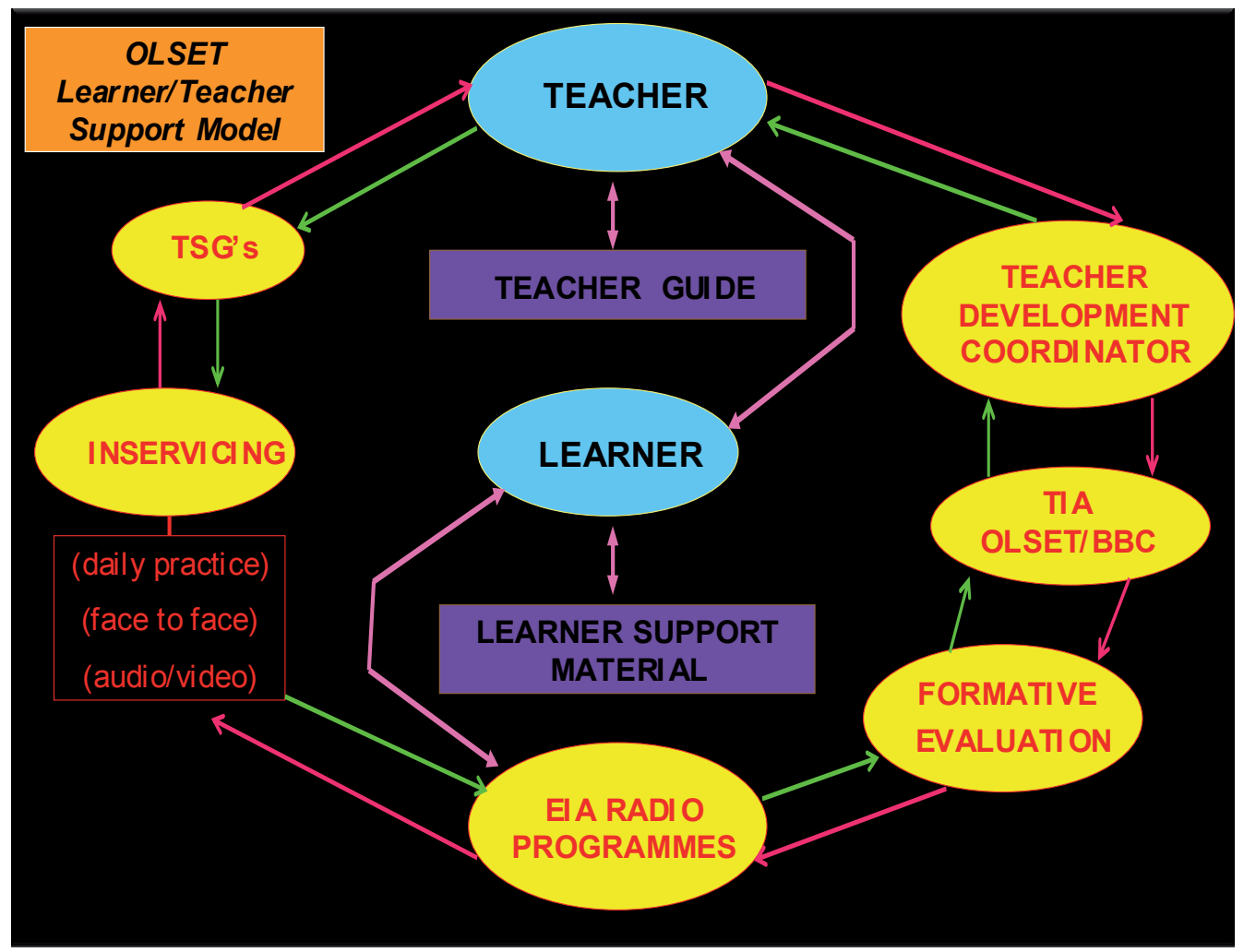

Table 2. The Radio Learning Project Instructional System

\subsection{The teacher development curriculum}

The curriculum for teachers involved in the programme was related to the following realities in the South African education system of the time (Hartshorne, 1992; 1996): 
- $18 \%$ of primary school teachers lacked professional qualifications

- $35 \%$ were professionally qualified with less than Grade 12

- $47 \%$ were professionally qualified with more than Grade 12

- Existing pre-service teacher training was often inadequate

- Appropriate teaching methodologies had often not been disseminated widely within the professional teaching community

- English was not the first language for virtually all the teachers

- Basic equipment and materials were lacking in schools

- Overcrowding was common. Many classes had a learner/teacher ratio of more than 65:1

- Authoritarian methods were still used in many cases to ensure management of large classes

- Rural schools were often understaffed.

The South African Radio Learning Programme's teacher development curriculum was conceptualised as a response to these contextual conditions. It was based on a theory of implementation involving ongoing support for and interaction with teachers, due to awareness on the part of the project team that simply developing new materials and telling teachers about new methods were not usually sufficient to bring about desired changes in classroom practice. A holistic approach was thus needed, in terms of which explicit links would be forged between radio, teacher, child, print materials, teacher support systems and classroom practice (Leigh, Naidoo \& Ramafoko, 1995).

To achieve this, teachers would need to become central to the process of development, through participation as partners in the radio lessons, through engagement in linking the content of the radio lessons with teaching in other areas of the curriculum, and through collaboration as equals in their professional development. A climate of collaboration and partnership would be what the OLSET teacher development curriculum would attempt to achieve (OLSET, 1995; Potter, Dube, Kenyon et al., 1995), through:

- Promoting the use of effective communicative language teaching methodologies in the classroom

- $\quad$ Promoting the use of learner centred teaching methodologies in the classroom

- Empowering teachers to use and extend their own approaches, activities and materials

- Strengthening the teacher's English-speaking skills

- Encouraging creative and critical thinking

- Fostering effective use of the programme's audio and classroom support materials.

\subsection{Using open learning principles as a basis for teacher development and support}

Robinson and Latchem $(2003,29)$ define open learning as:

- An organised educational activity

- Whose learners study by themselves for some of all of the time, in which

- Constraints on study are minimised in terms of access, time, pace and method of study, and in which on a concrete level

- Learners (in this case teachers) are provided with access to learning resources, advice, support and in many cases assessment of learning. 
In implementing the curriculum from 1994 to the present, the South African Radio Learning Programme's curriculum has been based on a number of the above features, as follows:

a. The aim of providing radio learning lessons (a distance education medium) provided the central thrust of the curriculum for both teachers and learners. The aim was to provide an organised educational activity so that learners could be supported to learn better, and teachers be supported to teach better.

b. It was envisaged that a framework would be provided for in-service training and support of teachers. The support provided would necessarily be intermittent, with the emphasis on teachers working to improve their practices. At times the process would evolve through discussion and reflection with the regional coordinator at classroom level, at times by workshops and teacher support group meetings, and at times through self evaluation as an integral part of the process of lesson planning and implementation.

c. The aim of providing in-service training and support of teachers was not to replace or supplant the system of formal training for teachers provided by the state system. In contrast to more formal state programmes whose aim was to certificate and provide accreditation for teachers, the South African Radio Learning Programme's aim was to provide an informal support system that met current needs of teachers. The aim in this was to supplement what the state education system was able to provide.

d. The South African Radio Learning Programme did not aim to offer formal certification for teachers, preferring to work non-formally through supportive contact and networking with teachers. The reason given by the programme director for this preference was that schools in the apartheid era were a site for struggle, and an ideological battlefield. The perceived priority for post-apartheid education was to get pupils back into the classroom and teachers back to teaching.

e. Within the structure of the national curriculum, the priority was to create a climate in which teachers and learners took responsibility for creating a culture of learning in each school and in every classroom. Initially, the project team's vision of curriculum was as a framework of radio lessons aimed at developing content knowledge (based on a oneway process involving transmission of knowledge from script-writer to child). Post 1994, the vision of the project team broadened. The aim post 1994 was to provide a framework for teaching and learning English that involved the teacher as an integral part of the process.

f. The broader vision of providing a curriculum for both teachers and learners was stated as a dual focus of the programme's work post 1994 (OLSET, 1995). For teachers, the curriculum was based on an agenda of ongoing contact and school-based support that was tangible and practical, as part of a wider project involving sharing ideas on what it meant to teach well. For learners, the curriculum was based on an agenda of low-cost and affordable learning experiences that were structured and focused yet at the same time fun.

g. The aim was to work as far as possible within the spirit and philosophy of the state curriculum as it applied in the foundation or junior primary phase of education. What was provided on the curricular level was tangible support for teachers in the form of a structured, well-planned, sequenced and carefully graded language programme, which introduced English to pupils whose mother tongues varied greatly.

h. The radio lessons thus formed a framework for learner and teacher development. Each lesson had specific aims and was designed to be compatible with the tenets of outcomesbased education. The lessons were found to be useful to teachers on a number of levels 
(DfID, 2004; Hunter, Nonyongo and Smith, 1998; Leigh, Naidoo \& Ramafoko, 1995; Ntshoe, 2000; Potter, 1994a; 1994b; Potter\& Silva 2002; Silva, 2008), both in introducing pupils to English through a series of engaging and fun activities involving stories, music, songs, and interactive language applications, as well as in providing teachers with examples of how outcomes-based lessons could be planned and applied.

The revised post 1994 curriculum has been characterized as designed on assumptions of multichannel learning (Anzalone, 1995; Dodds, 1995; Leigh, 1995; Leigh, Naidoo \& Ramafoko, 1995). It is, however, also possible to describe the programme as providing support in both product and process terms (Naidoo \& Potter, 1996; Potter, Naidoo \& Kenyon, 1998), as follows:

"The aim of OLSET's in-service training and support of teachers is not to replace or supplant the system of formal training for teachers provided by the state system. In contrast to more formal programmes whose aim is to certificate and provide accreditation for teachers, OLSET's aim is to provide an informal support system that meets the current needs of teachers and supplements what the state is able to provide. OLSET does not offer formal certification for teachers, preferring to work non-formally through contact and networking with teachers. The reason given for this preference is that schools in the apartheid era were a site for struggle, and an ideological battlefield. The perceived priority for post-apartheid education is to get pupils back into the classroom and teachers back to teaching. Within the structure of the national curriculum, the priority is also to create a climate in which teachers and learners take responsibility for creating a culture of learning in each school and in every classroom."

(Source: Potter, in Perraton, Robinson \& Creed, 2007).

In the remainder of this chapter, evidence will be presented that this more broad-based vision of educational change provided the basis for the wide-spread acceptance of the programme by teachers, principals and educational officials over the period of its implementation up to the end of 2009. It will also be argued that one reason for the programme's wide-spread uptake was that the programme focused on providing tangible support to learners and teachers at school and classroom levels; another was that it focused on enabling teaching improvement in a context in which there have been demands on teachers to change their teaching practices and align their lesson planning and assessment practices with the outcomes-based national curriculum; a third reason was that the programme has applied open learning principles as the basis for its ongoing contact with teachers and their schools.

\section{A vision of educational change involving product and process: Implementing the radio learning programme blueprint over the period 1995- 2001}

\subsection{Funding and donor support 1995-2000: Issues of sustainability}

The initial three year development of the radio learning programme was made possible through a grant from USAID in 1991. This was provided for purposes of undertaking a pilot phase to assess receptivity and impact of Interactive Radio Instruction (IRI). The yearly grants were made with the aim of developing of the skills of the project team in content 
development, materials production, teacher training, and independent formative and summative evaluations. Capacity to reach large numbers of schools and teachers was, however, limited by funding, which was an ongoing constraint.

The 1996 termination of USAID support for radio learning in South Africa negatively impacted the programme's organizational capacity through staff turnover. As Creekmore (2010) suggests, this tension was perhaps inevitable, given the nature of projects as temporary organisations (Turner \& Muller, 2003) linked to donor practices of periodic reassessment and prioritization of country strategy and attendant programme support.

After the USAID grant came to an end in 1996, the programme was fortunate in obtaining a grant from the Norwegian Embassy, which provided assistance to the programme through the NORAD basic education support programme. The budget was a generous one and linked to the scale that the programme was operating at the time. It provided for a degree of restaffing, as well as a modest expansion of radio learning programme services to schools.

\subsection{Growth in numbers of participating schools, teachers and learners}

Priority was initially placed on maintaining project visibility and credibility among the core constituency of radio learning programme teachers with whom the programme had previously had contact (ie teachers in schools which were already using the English in Action broadcasts for daily additional language teaching). What was unforeseen was that beside the need to focus on existing schools, there would be a continuous pressure and rising demands from teachers in other non-OLSET schools to be included in the programme. This was the case in each of the eight provinces in which the radio learning programme was working and is reflected in the exponential growth in teacher and pupil numbers refelected in Table Three below.

\begin{tabular}{|c|c|c|}
\hline Year & Teachers & Pupils \\
\hline $\mathbf{1 9 9 3}$ & 319 & 14249 \\
\hline $\mathbf{1 9 9 4}$ & 995 & 42747 \\
\hline $\mathbf{1 9 9 5}$ & 1440 & 72000 \\
\hline $\mathbf{1 9 9 6}$ & 2496 & 125000 \\
\hline $\mathbf{1 9 9 7}$ & 4540 & 227000 \\
\hline $\mathbf{1 9 9 8}$ & 4297 & 301124 \\
\hline $\mathbf{1 9 9 9}$ & 6257 & 312000 \\
\hline $\mathbf{2 0 0 0}$ & 6240 & 325000 \\
\hline
\end{tabular}

Table 3. Growth in Teacher and Pupil Numbers in the Radio Learning Programme over the Period 1993 - 2000

There were thus a number of tensions in relation to the scale on which the programme was implemented, versus the increasing demand for the programme's services in the schools, These tensions related to the reality that the budget, though generous at the outset, was not sufficient to meet the increasing demands for the project's services

In the circumstances, all available financial resources were put into the project's distance education intervention, with priority being placed on supporting schools in poor communities. One effect of this was that there were minimal resources available for 
ensuring the ongoing evaluation process central to content development and training. The project evaluation continued, albeit on a reduced scale, in the absence of resources. The internal evaluation function was performed on an ongoing basis through the interest of the consultants involved, on the basis of goodwill.

Thus, despite generous support from the international community, project sustainability remained tenuous over the period from 1995 to the end of 2000. There were also tensions in implementation which characterized OLSET's work during the five year period of Norwegian support. Increased numbers implied constrained financial resources. This, in turn, meant reduced external implementation. At the same time, there was a need for internal reorganization, as well as content and materials revision consistent with the demands of the Outcomes Based curriculum.

\subsection{Sustainability over the period 1998 and 1999}

Essentially, the programme was in the difficult situation of attempting to meet increasing demand with insufficient resources. In a climate of rapidly increasing numbers, the support provided was in many cases insufficient. In many areas, the programme staff were able to provide only a modicum of support to schools, and the programme was constrained to something of a 'holding pattern' rather than fully fledged expansion in keeping with a growing demand for the radio learning programme countywide.

The numbers of participating schools and teachers reached a ceiling in 1998. Once this ceiling was reached, the situation became increasingly difficult during 1999, especially as the programme's materials posters, readers and workbooks had a limited life, and were reaching the end of their life.

Implementation constraints thus had a severe impact on the ability of the project team to deliver support to the schools, as the growth in numbers had exceeded the financial resources and capacity of the programme. Despite these difficulties, classroom-based evaluation indicated that the programme still had wide-spread support among the teachers (Brand, 1998; Chippendall, 1998; Graham, 1998), while analysis of pretest/posttest data indicated that learners in schools in which the programme was implemented continued to make greater gains than those in matched comparison schools (Jacobson, 2001).

The tension between demand and resources, however, had inevitable effects on individual team members (de Reuck, 1999; Hoosen, 1999). Increasingly during the year 2000, there was a climate of financial insecurity in the programme. As international donor funding is normally provided for a fixed period, there was clarity that Norwegian funding could not be renewed, and attendant uncertainty as to whether the programme's management would be able to secure the financial support from additional donors necessary to continue its work. At the end of the year 2000, the hiatus in funding reached a critical point. As the Norwegian grant period came to an end, contracts could not be renewed, and several core members of the project team sought security of employment elsewhere in the private sector.

\subsection{Sustainability over the period 2000 and 2001}

It was evident over the year 2000 that the radio learning programme's financial position had reached the point where its sustainability was in question. On the one hand, there was 
clear need and demand from the schools for the programme's services, and evidence that the numbers of teachers and learners would increase rapidly were funding available. On the other, the programme lacked sponsorship on the scale necessary to adequately service the schools and teachers to which it was already committed, let alone extend its services to additional teachers.

The climate of financial uncertainty and the flight of critical programme staff members had effects on the quality of implementation in schools (Basson, 2000) and effectively eroded the developmental impetus of the programme. The loss of key staff members, in particular, eroded the programme's curriculum development capacities. Management's heightened fund-raising efforts had to be accompanied by radical deployment of those key staff who remained, into priority areas, while other areas of the programme's support had to be drastically curtailed.

Despite this, evidence from teacher interviews and questionnaires indicated that the teachers continued to support the programme (Masuku, 2000; Ntshoe, 2000). In addition, the programme attracted international attention, and was one of ten distance education projects across the world chosen by UNESCO for detailed case study (Perraton, 2000; Perraton, Robinson \& Creed, 2001).

\subsection{Increased international funding post 2001 for implementation at large scale}

The situation of extreme financial exigency extended over an eighteen month period from January 2000 to June 2001. At this point, British Department for International Development (DfID) took the decision to provide funding to the programme on a large scale. Given favourable international reviews of the programme's work (Perraton, 2000; Perraton, Robinson and Creed, 2001), a grant was provided to the project in July 2001, with the objective of taking the Radio Learning Programme to scale across South Africa.

DfID funding was linked to a set of explicit criteria, based on the programme's logical framework. The criteria were linked to specific aims, intended outcomes, inputs and outputs, reflecting the programme's implementation theory (Weiss, 1998; Potter, 2005).

Within the logical framework, the programme's aims as at July 2001 were to:

- improve the quality of teaching at primary school level

- increase the capacity of teachers to implement the new curriculum

- provide access to educational materials, and

- $\quad$ increase the level of engagement by learners.

The programme's inputs would include resources from direct funding, as well as contributions in kind from the provincial education authorities (eg contributions by seconded staff to in-service training and support of teachers), as well as from the national broadcaster (eg airtime; access to the SABC's national radio footprint). The programme's outputs would a curriculum for learners, and a curriculum for teacher development and support. For learners at Grade levels One to Three, the programme would provide one audio lesson per day for a total of 180 school days in a year. The radio lessons would be supported by classroom print materials.

The programme's outputs for teachers would involve a curriculum for teacher support. This was conceptualized as involving a number of elements including in-service teacher 
training workshops, in-school visits by regional coordinators and teacher support groups. However, it was acknowledged that this was an ideal, and that owing to the scale of the programme, the exact nature of teacher support provided would vary from region to region, reflecting the different skills and personalities of the nine regional coordinators involved in the programme (Potter \& Silva, 2002), as well as the inputs in the form of resources and support from educational officials provided by the different provincial education departments.

In terms of the intended outcomes specified in its funding proposals, the programme was working in terms of a number of additional specific outputs, including:

- provision of radios to schools

- $\quad$ providing radio broadcasts for mass access to programme content

- training teachers in implementation of the programme

- training teachers in outcomes based education

- integration of radio learning programmes into school timetables

- $\quad$ production and dissemination of complementary teaching and learning print materials

- broadening and deepening of the contents of the Radio Learning Programme to accord with the curriculum (at present Curriculum 2005)

- $\quad$ scaling up to deliver these services to a beneficiary base of 70000 teachers and 2500000 learners over 5 years, primarily in marginalized and rural areas

- engaging with educational officials in the national and provincial departments to achieve the above outcomes.

These aspects of the radio learning programme were embodied in the programme's logical framework as presented to its funders for the period July 2001 to June 2004, in which it was envisaged that evaluation would focus on the following indicators:

\section{A. Expansion of broadcast coverage of radio learning for teachers}

- Decisions by SABC and community radio stations to broadcast the radio learning programme

- Actual implementation of decisions to broadcast the programme

- Expansion in areas of the country able to access the radio learning programme broadcasts.

\section{B. Improvement in classroom practice in line with outcomes-based education methodology}

- Records of daily broadcasts in each area

- Comments from teachers and principals relating to timing, accessibility and clarity of broadcasts

- Records of regional coordinators' visits to schools

- $\quad$ Records of numbers of teacher support workshops, content covered and attendance at workshops

- Evidence of changes to radio scripts and learner support and teacher support materials

- Evidence of adequate distribution of materials to schools

- Evidence of usage by learners and teachers of radio broadcasts and support materials at school and classroom levels. 


\section{Improved rates of learner retention}

- Interviews with programme staff

- Classroom observation

- School-based case studies

- Self-reports from teachers

- Self-reports and comments from principals

- Focus groups with parents

- Performance tests

- Analysis of classroom work

- Teacher comments/responses in questionnaires

- Principals' comments/responses in questionnaires

- Analysis of planning documents

- Analysis of materials

- Analysis of classroom environments

- Analysis of timetables

- Analysis of classroom work.

\subsection{The programme's logical framework for implementation at large scale}

The project's logical framework implied upscaling the Radio Learning Programme countrywide to accommodate and provide material support to the most remote rural learners and teachers. Encouragement was also given to make the programme's experience in South Africa available via the BBC to other developing countries, via radio programmes focusing on issues in teaching.

The funding support provided at this point had the effect of transforming the Radio Learning Programme's way of working, providing it with the financial resources and donor backing to take the programme's implementation to national scale. Organisationally, the optimism and renewed confidence accompanying DfID longer term support, was palpable. It allowed for a four year projection of increased learner numbers and teacher support undertaken in conjunction with the education departments in all nine provinces of South Africa.

Given adequate resourcing, additional project team members were appointed and skills were able to be co-opted focused on increasing field implementation, teacher in-service training and support. In addition, it was possible to strengthen the partnerships with the $\mathrm{SABC}$ and the Provincial Departments of Education. In particular, the funding was directed at facilitating access of teachers and learners to increased in-service training and classroom support in both urban and rural schools, and in expanding the programme's outreach to encompass $11 \%$ of all schools and $9 \%$ of all teachers across South Africa.

Large-scale production of learner and teacher support resources was also possible through the increased funding. These resources were printed, made available for distribution and then disseminated to schools. In addition, increased institutional support from the SABC enabled schools to benefit from an increased radio footprint for EIA broadcasts. This was provided via five SABC regional Stations. 


\subsection{Acceptance of and positive response to the programme's work}

Issues relating to sustainability are common themes in work in educational development (Fullan, 1982; Fullan \& Stiegelbauer, 1991; Hargreaves, 1992; Hargreaves \& Fullan, 1992). They are also common themes in the literature on open and distance learning (Perraton 2000; Perraton, Robinson \& Creed, 2001; Robinson \& Latchem, 2003). In the case of the South African radio learning programme, its long-term sustainability was dependent on acceptance of its work by teachers and principals, and positive institutional response to its work by educational offficials and bureaucrats.

A feature of the programme post 1994 was its commitment to ongoing internal and formative evaluation. Longitudinal evaluation data indicated that, despite times of financial exigency leading to lapses in quality of programme implementation, teachers and principals were supportive of the programme as meeting the educational needs of teachers and learners. This continued as a recurrent theme in the programme's internal evaluation reports (Brand, 1998; Chippendall, 1998; Graham, 1998; Masuku, 2000; Ntshoe, 2000; Potter, 1994a; 1994b; 1995; 1999; 2000, 2001; 2002; Silva, 2008).

With increased funding, these data indicated that priority could be placed on distributing materials to schools in which teachers were likely to use the programme. Large-scale materials distribution was thus undertaken in conjunction with the educational authorities in the nine provinces in which the programme was working. Owing to the scale at which the programme was operating, many problems were encountered in the process of moving eleven tons of printed materials to individual schools, with the result that availability of materials in the schools was in many areas uneven.

Overall, however, despite comments made by a number of teachers which indicated that the support received at school level from the programme was not as extensive or consistent as they would have wanted, the evidence from teacher self-reports and case studies of participating schools indicated that the support provided by the radio learning programme was both tangible and valued. Of particular importance to teachers was the assistance provided in teaching English, as well as in enabling lesson planning and teaching aligned with the outcomes-based requirements of the national curriculum (Friend, Potter, Naidoo et al., 2010; Potter, Chand, Naidoo et al., 2008; Potter \& Naidoo, 2008; Silva, 2008).

Advocacy for the programme was thus wide-spread both among teachers and principals. This was both the case in 2001, when materials supply to the schools was more limited, as well as in 2003 when greater numbers of teachers were involved in the programme, and support to the schools was greater (Potter \& Silva, 2002; Silva, 2008).

Advocacy within the provincial education departments was also high, based on a perception on the part of educational officials that the programme's materials were assisting teachers in implementing outcomes-based education (OBE) at the primary school level (DfID, 2004). The issue of compatibility of the programme's curriculum with the outcomes of the national curriculum was also a recurrent theme in the programme's internal evaluation data (Potter, 2002). Essentially, bureaucratic acceptance rested on the fact that it was possible to justify the time on task of so many individuals engaged in the programme at school and classroom levels, due to the clear conceptual links between the programme's materials and other elements in the primary school curriculum in both years. 
By mid 2001, the programme had grown in scope from usage by 290 teachers and 14500 learners in 1993, to usage by an estimated 14500 teachers and 680000 learners nationally. At the end of 2002, the numbers of teachers and schools participating in the programme had increased substantially, as reflected in Table Four below (Naidoo, in Potter \& Silva, 2002, 6).

\begin{tabular}{|l|l|l|l|}
\hline Province & Schools & Teachers & Pupils \\
\hline Eastern Cape & 2226 & 2946 & 125332 \\
\hline KwaZulu/Natal & 1133 & 5661 & 229488 \\
\hline Limpopo & 645 & 991 & 51755 \\
\hline Gauteng & 473 & 1307 & 71019 \\
\hline North West & 1163 & 2112 & 83298 \\
\hline Mpumalanga & 1687 & 6094 & 239299 \\
\hline Free State & 249 & 2634 & 92707 \\
\hline Total & 7570 & 21745 & 892989 \\
\hline
\end{tabular}

Source: Naidoo, in Potter and Silva, 2002 p. 6

Table 4. Pupils, Teachers and Schools Participating in the South African Radio Learning Programme across Seven Provinces in 2002

By the end of 2003, the involvement in the programme across these provinces had grown to 30167 teachers and 1302728 learners, in terms of an implementation model in which educational officials in the participating provinces worked side by side with programme staff in providing in-service training and support to teachers at school level. At this point, given changes in funding with the diversion of British resources to support reconstruction in Iraq, DfID conducted its summative review of the programme, using a team of three DfID project officers (DfID, 2004).

\subsection{Developing partnerships with the educational authorities and the national broadcaster}

The DfID review focused on progress made in the programme over the whole funding period from July 2001 to June 2004, in relation to the objectively verifiable indicators and outputs in the Logframe (refer Table Five above).

As at 2004, The DfID reviewers noted progress made on each output in the Logframe (DfID, 2004). With respect to Output One in the Logframe, the programme had through its partnership with the SABC expanded to reach the following numbers of pupils and their teachers in the schools.

\begin{tabular}{|l|l|c|}
\hline Year & Teachers & Pupils \\
\hline $\mathbf{2 0 0 2}$ & 21745 & 892989 \\
\hline $\mathbf{2 0 0 3}$ & 30167 & 1302728 \\
\hline $\mathbf{2 0 0 4}$ & 52000 & 1820000 \\
\hline
\end{tabular}

Table 5. Estimated Teacher and Pupil Numbers Reached by the SABCs National Radio Footprint in the South African Radio Learning Programme over the Period 2002-2004

With respect to Output 4 in the Logframe, certain problems were noted in implementation with respect to distribution of radios and supporting print materials due to problems in the 
DFID procurement process as well as with shipping. This had knock-on effects into other areas of implementation, and also affected teacher support workshops. Based on their reading of internal and external programme documents and evaluation reports and the observations made by their project officers on programme site visits, the evidence suggested that all other outputs had either been achieved or had largely been achieved.

It was also noted that in terms of its sheer scale of operation, strategies for institutionalization of the programme were essential. At this level, the programme had achieved the support of the bureaucracy within the education departments, as well as the support of the national broadcaster. Both provided funding support for the programme's work in kind. The programme also continued to have wide-spread support at school level, both among teachers as well as among principals as key educational officials supporting innovation and change.

From the perspective of long-term sustainability, the 2004 DfID review highlighted the fact that the first and second levels of sustainability (ie wide-spread support from teachers and positive institutional response) had to a degree been achieved by the end of 2001 . The third level of sustainability (partnership with the educational authorities and the national broadcaster) had been partially achieved over the period of DFID funding. The fourth level (acceptance and advocacy by the bureaucracy, backed with protracted and sustained financial support) was not yet a reality.

\subsection{Funding at large-scale 2004-2009}

Over the period beween 2004 and 2009, the Dutch government funded the programme. The proposals for funding over this period continued to reflect the principles of

- providing access to the resources provided by the programme, for large numbers of teachers and learners

- focus on urban and rural schools

- focus on teacher and learner development

- $\quad$ work on curriculum implementation for both teachers and learners in partnership with the educational authorities and the SABC.

The proposals for funding over this period also focused on the necessity of the programme developing to the stage that it could provide support to South African schools as a longterm as opposed to a short-term commitment. To achieve this aim, the programme would need to work towards achieving financial sustainability by the end of 2009 .

In terms of established trends in the programme's model of implementation, available resources were directed into internal evaluation at school and classroom levels, as well as feasibility studies on the implementation of the programme's approach to IRI in other developing countries. Resources were utilised for:

a. Development of procedures for observation of teaching in classrooms, using PhotoVoice methodology (Potter, Chand, Naidoo et al., 2008).

b. Test development (Potter, Liccardo \& Naidoo, 2008; Malope, 2010).

c. Development of training materials for regional coordinators, reflecting the classroombased evaluation approach advocated by the programme (Potter \& Naidoo, 2008). 
d. Feasibility studies on the use of the programme's model of implementation and evaluation in other developing countries (Potter, Liccardo \& Naidoo, 2008; Potter \& Naidoo, 2009a).

The last-mentioned area of work was undertaken with a view to working with funding agencies and NGO's in other developing countries. It was also undertaken with a view to broadening the funding base of the programme, with the aim of ensuring its financial sustainability. Work was undertaken, for example, in Bangladesh (Potter, 2008) with a view to attempting to ensure a diversified funding base. This was not achieved. Multiple donor revenue streams are difficult to establish and particularly so for the South African Radio Learning Programme as radio learning is variously defined, and also falls outside of the programme focus of most donors.

Some idea of the demand for the programme's services subsequent to the provision of largescale funding by the international community in 2001 can be gained from Table Six below. Despite tensions between intention and practice, the programme's support was welcomed (Ntshoe, 2000), even in classrooms in which the programme's implementation was less than ideal (Basson, 2000). Based on advocacy from teachers, principals and educational officials, large numbers of schools in the urban, peri-urban and deep rural communities became involved in the programme.

With large-scale donor support from DfID in the United Kingdom between 2001 and 2004, and from the Dutch government over the period 2004 to the end of 2009, the programme was able in the year 2008 to provide support to an estimated 1,3 million learners and their teachers daily. This represented some $6 \%$ of all South African teachers working in an estimated $10 \%$ of all South African schools, as well be evident from the figures presented below.

\begin{tabular}{|l|l|l|}
\hline Year & Number of Teachers & Number of Pupils \\
\hline $\mathbf{2 0 0 1}$ & 15557 & 622280 \\
\hline $\mathbf{2 0 0 2}$ & 21745 & 892989 \\
\hline $\mathbf{2 0 0 3}$ & 30167 & 1302728 \\
\hline $\mathbf{2 0 0 4}$ & 52000 & 1820000 \\
\hline $\mathbf{2 0 0 5}$ & 38782 & 1357370 \\
\hline $\mathbf{2 0 0 6}$ & 36328 & 1272480 \\
\hline $\mathbf{2 0 0 7}$ & 34727 & 1389080 \\
\hline $\mathbf{2 0 0 8}$ & 32530 & 1301200 \\
\hline $\mathbf{2 0 0 9}$ & 32225 & 1289000 \\
\hline
\end{tabular}

Note: Figures based on estimates calculated from attendance at regional teacher support workshops organised jointly with the education authorities in all nine provinces of South Africa.

Table 6. Teacher and Pupil Numbers in the South African Radio Learning Programme over the period 2001-2009

However, despite achieving wide-spread support at school and departmental levels, and despite attempts at undertaking work internationally with the aim of funding the South African Radio Learning Programme, as at the end of 2009 financial sustainability was not achieved. While acceptance of the programme by teachers and its partnership with the education authorities indicated that the programme achieved a level of institutionalization as at 2009, the programme was still dependent on external funding, despite forming an 
integral part of the educational departmental structures with respect to in-service training and support to schools.

Given absence of financial support from the educational authorities, the programme's work in the schools came to an end at this point, after seventeen years of operation in the schools.

\section{Contrasting visions of radio learning in South African primary schools}

\subsection{A product-based versus a product and process-based vision of educational change}

The remaining sections of this chapter will attempt to contrast the type of responsive, contextual and process vision of educational change developed in the South African Radio Learning Programme post 1994 with the type of skills-based, mechanistic and technicist vision of educational change originally envisaged by the project planners. The reason for doing so is that our evaluative evidence indicates that the product and process vision of educational change based on open learning principles enabled the development of two parallel support curricula involving classroom materials plus informal in-service training and support to schools, which was accepted by many principals and teachers.

Many of the initial radio learning programmes (Bosch, 1998; Dock, 1998) were based on similar assumptions to those that informed the development of the South African Radio Learning Programme over its initial three years. At the outset after the programme's inception in 1992, the curriculum was informed by what can be characterized as a technicist vision of educational change, focused on the development of a package of radio lessons and supporting materials, through which a set of skills were introduced to learners.

Over 1993 and 1994, the vision of the project team changed. Product remained important, but only as a starting point to a process of educational change. The process was conceptualised as involving a flow of classroom transactions between teachers and learners. The role of the project team was to support a process of educational change.

This would be done by providing two parallel support curricula, both of which were necessary to improvement of quality of education in the schools. The one support curriculum was directed at the needs of teachers and the other at the needs of learners. Both curricula involved distance education, and both were informed by open learning principles.

We have already explored the shifts in vision which accompanied changes in conception of curricular principles in some depth. This analysis will be built on in the concluding sections of this chapter, in which the value of both a product and process approach to undertaking in-service training and support of teachers will be highlighted. The reason for doing so is that our evaluative evidence over a seventeen year period indicates that both product and process issues formed the basis for the programme becoming widely accepted by teachers and principals at school level. They also underpinned the perceived value of the programme by educational officials across the South African education system.

\subsection{Was a product and process curriculum perceived as valuable?}

Post 1994. the South African Radio Learning Programme focused on the development of two curricula, one for learners and the other for their teachers. The aim of the programme 
was to provide a framework for teaching and learning English which involves the teacher as an integral part of the process (Potter, 2002; Potter \& Naidoo, 2006; Potter \& Naidoo, 2010). For teachers, the curriculum was based on an agenda of ongoing contact and school-based support that was tangible and practical, as part of a wider project involving sharing ideas on what it meant to teach well. For learners, the curriculum was based on an agenda of lowcost and affordable learning experiences that were structured and focused, yet at the same time fun.

Our evaluative data from ongoing observation, interviews and school-based case studies suggests that many lower primary school teachers found the support provided by the programme valuable both in providing curriculum materials, as well as in improving their teaching of English. This helped in aligning their teaching to the requirements of the outcomes-based national curriculum. In providing a framework of audio lessons and classroom materials, as well as in providing support on a process level to teachers at school and classroom levels, the programme was well rated by both principals and by educational officials.

Our data suggest that advocacy for the programme was based not only on the perceived value of the radio lessons and print materials provided by the programme, but also on the practical guidance provided by the project team on how to work within outcomes-based education. This was operationalized through in-service training directed at how to use the classroom materials provided by the programme for teaching English across the curriculum, and also on how to teach more effectively.

These were recurrent themes in our data. There were also recurrent themes in our interview and focus group data relating to the value of the support provided to teachers at school level, the benefits from in-service training workshops and the value of teacher support meetings providing practical ways of improving quality of teaching and learning in the classroom.

Overall, the evidence presented in this chapter would thus suggest that the product-related and process-related support provided by the programme were perceived by teachers, principals and educational officials as positive. The partnerships developed with the educational authorities and the national broadcaster (the SABC) also enabled the programme to work at low cost with large numbers of schools, teachers and learners. However, given the scale of teacher and learner needs in South African schools, ongoing intervention and support at school and classroom level were necessary.

At the time the programme closed its doors at the end of 2009, the evidence would suggest that the development of the type of open learning envisaged in the project's 1994 blueprint was still very much a task in process. As others may wish to take up the type of process which this particular project team was not able to complete, the lessons learned from the work of the programme will be outlined in the concluding sections of this chapter.

\subsection{What roles did evaluation play in the development of the programme?}

The South African Radio Learning Programme was subject to formative evaluation from its inception, as well as regular external evaluations over its entire seventeen year life. The external evaluations indicated that the programme was successful in meeting its objectives 
over the seventeen year period it worked in different areas of the country (DfID, 2004, Hunter, Nonyongo \& Smith, 1998; Potter, 1994b; Potter, 1998; Silva, 2008).

Evaluation was important as there are clear indications that the project team responded to evaluative criticism. Had there not been evaluative criticism of the programme's behaviourist and technicist assumptions (Potter, Arnott, Mansfield et al., 1993), its course post 1994 would probably have been very different.

Would it have achieved as wide support from teachers? It is tempting to claim this, but it would be better to refer to evidence. Our data are filled with reference by teachers to the lack of support provided by the educational authorities. There was thus recurring evidence of need.

In terms of the project's response to teachers' needs, the initial response prior to 1994 was to focus on provision of audio lessons and supporting materials. In-service training and support of teachers were not part of the programme's vocabulary over its initial years of operation, for the reason that provision of well-conceptualised radio scripts and supporting print materials formed the priorities.

Post 1994, the programme continued to focus of provision of materials, but in addition focused on in-service training and support, basing its work in the schools on principles of open learning (OLSET 1995). These were applied in applied in both teacher and learner support curricula. The project's implementation model also focused on developing evaluative capacity among teachers in primary schools from Grades One to Three, using observation and reflection as a basis for improving teaching in the classroom.

The model post 1994 can thus be conceptualized as an extension of an initial focus on product to include a process dimension. Both the product and the product and process models involved both development and evaluation. Both in its initial years between 1992 and 1994, as well as post 1994, there were clear indications that the project team perceived both development and formative evaluation as linked. Between 1992 and 1994, the basis for the development of a participatory approach to teacher development was also laid in the teacher support groups and case studies which provided qualitative evidence on the programme's development at school level. This then developed to form the basis for classroom-based intervention (Potter \& Naidoo, 2008), involving project staff and teachers at a number of levels in documenting the programme in the schools (Leigh, Naidoo \& Ramafoko, 1995; Naidoo \& Potter, 1996).

Classroom-based participatory evaluation was also conducted for developmental and formative purposes (Friend, Potter, Naidoo et al., 2010; Potter, Chand, Naidoo et al., 2008). As part of this process, photographic case studies were conducted (Potter 1994a; Potter \& Silva, 2002), as well as classroom-based evaluations using photovoice procedures (Wang \& Burris, 1997; Wang, Yi, Tao et al., 1998). These were used to create a base of photographic evidence which then provided a basis for self-evaluation through classroom-based narrative and questioning (Potter \& Naidoo, 2008). This added to the types of internal evaluation which had been implemented in the South African Radio Learning Programme over the previous fifteen years (Potter \& Naidoo, 2006; 2009).

There were thus many insights which became possible through the variety of implementation and evaluative evidence gathered on the programme's work. Evidence 
from classroom observation as well as questionnaires administered in project schools (Potter, Chand, Naidoo et al., 2008); indicates that teachers perceived clear links between the programme's materials, the national curriculum, and the types of in-service training and support provided by programme staff. There were clear indications that continuing advocacy was based on the perceived value of both the programme's teacher and learner support curricula. Advocacy was also based on the wide-spread needs in South African schools for support and in-service training, which is introduced in tangible and practical terms.

\subsection{The programme's vision of educational change: Principles of open learning implemented in a circumscribed and limited way}

As Weiss (1998) has suggested, central to any programme is a theory. Underpinning the South African Radio Learning Programme's post 1994 implementation was a theory of change which assumed that teacher development could be undertaken through distance education and open learning (OLSET, 1995). In the model, daily interactive radio lessons would be beamed to schools via a national radio footprint provided by the SABC. Additional print materials supplemented by contact between programme staff and teachers would be being used as a means of providing ongoing support at school and classroom levels.

Over the period up to the end of 2004, the programme underwent rapid growth. Our evaluative data indicates clearly that the programme's growth to scale was needs-driven, reflecting a context in which historically, miminal in-service training and classroom support was provided to teachers. After the advent of democracy in the country in 1994, the move to outcomes-based education has introduced increased demands on teachers for change, without providing the day-to-day guidance and support necessary to make the new system workable at the level of the classroom (Jansen, 1997; Kgobe, 2000a; 2000b; Motala, 1997). In this context of underprovision (Chisholm, Motala, \& Vally, 2000) there was a high level of demand from teachers and schools for the South African Radio Learning Programme's services.

The project team's response was to attempt to undertake exponential growth in the programme, based on demand for school and classroom-based support from teachers and principals. In the context of a dearth of both educational materials and guidance and support from the educational authorities both for disadvantaged young learners and their teachers in under-resourced schools, the Radio Learning Programme's support activities were limited, applying principles of open learning in a limited way.

It is tempting to claim major successes from the project team's implementation model, given the evidence of wide-scale advocacy for the programme's work. It is perhaps wiser to suggest, as Silva (2008) has done, that the programme was able to meet its objectives, while at the same time providing support which was positively viewed by both teachers and principals for the reason that it contributed to their empowerment on a professional level.

On the positive side, teachers and principals continued to support the programme over its entire seventeen year life. The programme was able to meet its objectives in terms of broadening its schools base, while at the same time establishing contact with departmental officials as well as large numbers of teachers and learners (Potter, 1999). However, the 
central tension within the programme remained, stemming from external pressures to respond to expectations of OLSET support, at a time where, even at the time of the programme's greatest resourcing by the international community, access to donor resources was constant (Potter, 2001; Potter \& Naidoo, 2006).

\subsection{The programme's use of resources: A little to many as opposed to more to few}

It is also important not to gloss over the many tensions in the programme, given limited resources and lack of a national radio footprint supporting the programme over the first ten years of the programme's life. Over this period, quality of broadcasting as well as support to schools was in many cases compromised (Basson, 2000; Hunter, Nonyongo \& Smith, 1998; Naidoo \% Potter, 2007; Potter, 2000; 2001; Potter \& Naidoo, 2006).

The ethical dilemma was essentially whether to respond to large-scale teacher and learner needs at a critical juncture in the educational transformation process across the country as a whole, and at a time when other large-scale educational projects in South Africa had had to scale down or cease their work owing to funding and donor constraints (Bot and Schindler, 2000; Naidoo and Potter, 2007).

Despite the compromises, our longitudinal evidence from observation, interviews and school-based case studies indicates that even at the time it was most stretched financially, the South African Radio Learning Programme provided teachers with tangible and practical assistance in the form not only of individual lessons, but also a structure of supporting materials and guidelines on how these could be used for teaching across the curriculum (Potter, 2001; Naidoo and Potter, 2007). Both teacher and learner materials were clearly set out as part of a wider teacher and learner support curriculum, which was introduced in tangible and practical terms which teachers could understand.

Our longitudinal evidence indicates that even at the time when it was most highly resourced, the amount of support actually provided by the programme to the schools was limited. The programme's model was to provide low-cost, focused and clearly defined support to large numbers of teachers. While the in-service training and support provided was based on open learning principles, it cannot be claimed that the programme produced a model for how open learning principles which should be applied by others (unless others also believe in the need to provide low-cost, focused and clearly defined support to large numbers of teachers).

In our work in other developing countries, we found evidence indicating that the South African Radio Learning Programme's approach to teacher development could also be applied in other country contexts besides our own (Potter, 2008; Potter, Liccardo and Naidoo, 2008). However, it should be noted that had we been able to do so, the principles of open learning we would have applied in these contexts would also have been circumscribed and limited.

Our reason for doing so was that this was what we knew best, and also what we felt was ethical. The South African Radio Learning Programme chose the option of working in a limited way with large numbers of schools and teachers, rather than working with few schools and in-depth (Naidoo \& Potter, 2007). The choice was to provide minimal support to maximum numbers of beneficiaries. In addition to this circumscribed and limited model of 
support, the programme was also prescriptive in defining what teachers were expected to do in terms of providing outcomes-based education.

The model was thus one of a little to many, as opposed to more to just a few. The little included setting out clear guidelines on how to link the tangibles provided in the radio lessons and the classroom support materials to the more general demands for improvements and transformation of their teaching practices which were being made by the educational authorities on teachers.

\subsection{Interactive radio in a context of underprovision}

The context we experienced over a seventeen year period was one in which there was a dearth of support from the educational authorities. In this context of underprovision, our longitudinal data indicate that the types of limited material support to schools, and the use of these limited resources to support classroom process as well as teaching improvement were highly rated by teachers and principals (Potter, Chand, Naidoo et al., 2007; Silva, 2008). Despite the limitations of its approach to in-service training, the programme was thus able to achieve wide-scale advocacy among teachers, principals and educational officials across South Africa. The advocacy was consistent, even at those times when the programme's implementation was severely compromised.

Despite the tensions with implementation highlighted in this chapter, the programme was able to deliver tangible support to large numbers of schools, ultimately working in $11 \%$ of all South African schools. This was possible through the provision of a nation-wide radio footprint by the national broadcaster (the SABC), in a context in which there was reasonably well-developed infrastructure, in terms of roads, electricity and water, telephone lines, hospitals, clinics as well as schools. South Africa has been characterized as both a first and third world country. In this context, we would suggest that it was the combination of different forms of programme delivery using low end ICT's and the programme's provision of tangible and practical school and classroom-based support, which contributed to strong advocacy by teachers and principals at school level (Potter and Naidoo, 2009).

We would also suggest that the emphasis placed on ongoing internal (formative) and external (summative) evaluation contributed to the programme's ability to analyse and document the processes and tensions involved in its development (Hunter, Nonyongo and Smith, 1998; Naidoo \& Potter, 2007; Potter, 2002; Potter \& Leigh, 1995; Potter \& Naidoo, 2009a) This enabled the programme to draw on longitudinal evidence concerning learning gains (Jacobson, 2002; Potter \& Leigh, 1995), evidence concerning the ongoing grass-roots support of teachers and principals at school level (Ntshoe, 2000; Potter, C.S. \& Silva, 2002; Silva, 2008), and evidence concerning the strong advocacy of educational officials and bureaucrats (Potter \& Naidoo, 2009a).

In writing this chapter, we thus had available evaluative evidence drawn on an ongoing basis over seventeen years of contact with teachers, principals and schools. These data suggest that it was the primary advocacy of teachers and principals, supplemented by secondary sources of evidence based on observation of teaching in schools, which contributed to the perception among educational officials that "English in Action" was valuable. It provided in-service training and support for teachers and learners which was compatible with the policy of the South African educational authorities with respect to outcomes-based education (Naidoo, 2002; Ntshoe, 2000; Potter, Chand, Naidoo et al., 2007). 
In this context, our data suggest that acceptance of this educational innovation was gradual and incremental, and was based on acceptance of the value of the programme's work on multiple levels in the educational hierarchy (Fullan \& Stiegelbauer, 1991). Our data also indicate that there was particularly firm advocacy on the part of departmental subject advisers, many of whom worked with the programme staff in teacher in-service training workshops. Given acceptance of the programme by teachers and its partnerships with the education authorities and the SABC, the programme achieved a certain level of institutionalization (DfID, 2004). It developed to form an integral part of the educational departmental structures with respect to in-service training and support to schools. Nevertheless, sustainability remained a problem, with programme remaining dependent on international donor support, as opposed to financial support from the educational authorities.

\section{Drawing the threads together: What are the lessons learned and what can other projects take forward?}

As Creekmore (2010) has suggested, projects are transient, and have "a beginning and end" (Turner \& Muller, 2003, 1). In the South African Radio Learning Programme, sustainability remained a major tension over its entire life of the programme. The beginning was filled with optimism, while the end of the programme's work was unfortunate, but perhaps inevitable in the context of the funding crisis affecting the work of NGO's internationally.

The South African Radio Learning Programme was fortunate in attracting generous international donor support over a period of seventeen years. There were many areas in which the programme's implementation was limited and the support provided to schools and teachers less than perfect. On the basis of evidence from ongoing evaluation (Potter and Naidoo, 2009a; 2009b), it cannot be claimed that the programme's approach was the ultimate, nor that its work was ideal. Nevertheless, it can be claimed that the South African Radio Learning Programme had wide-scale influence over a period of seventeen years, and played a positive role in improving quality of teaching in large numbers of schools at lower primary school level. It also contributed to increased self-efficacy of teachers in terms of improving their ability to implement outcomes-based education in their classrooms.

On the product level, the programme's influence can be estimated in terms of the scale of the programme's outreach. As at the end of December 2009), over ten million learners in approximately $10 \%$ of all South African primary schools had been involved in the South African Radio Learning Programme's interactive radio lessons in the foundation phase of primary school, over a seventeen year period. From the programme's inception at the beginning of 1992 to 2000 the programme grew rapidly. Over period 2001 to end 2009 while the programme was supported at scale, there were an estimated 40000 primary teachers and 1.3 million learners across nine provinces who utilised the programme's materials annually.

On the process level, the influence of the South African Radio Learning Programme on teachers and schools is more difficult to estimate, for the reason that our data suggest that, despite support and endorsement from educational officials in all nine provinces, there were wide-scale variations in the way in which the programme was implemented at classroom level. It is clear from our data that the teacher and pupil support curricula developed by the 
programme were well tested in the field, having been developed, implemented and evaluated in the classrooms of large numbers of teachers.

What other projects can take forward is the evidence of positive response from teachers in large numbers of schools and classrooms to the provision of in-service training and classroom-based support by the project team. There was consistent evidence from our data that this was perceived to be beneficial, for the reason that the programme's model of open learning, though based on limited material support to schools, nevertheless addressed a number of needs, and provided the type of material and in-service training support which was not provided by the education system. A high level of advocacy for the programme's approach thus developed among teachers.

In schools and classrooms, our data also indicate that the influence of the programme on teacher practices took place not only in the half hour daily interactive radio lessons beamed nationally by the SABC, but also in the use of its materials for teaching English across the curriculum. In many classrooms, in addition, there was adoption by teachers of a focus on the type of classroom-based evaluation of teaching practices advocated by the programme over its seventeen year life (Potter, Chand, Naidoo and Friend, 2007; Potter and Naidoo, $2007 ; 2009 a ; 2009 b ; 2010)$. On the basis of perceived value and relevance, the programme was also endorsed by the principals at school level (Silva, 2008), those educational officials tasked with providing in-service training to teachers at provincial level (Potter \& Naidoo, 2010), and by the provincial and national educational authorities.

\section{Summary and conclusions}

This chapter has focused on teaching, learning and sustainability issues in distance education, by focusing on the development and implementation of an interactive radio learning programme implemented in $11 \%$ of all South African schools. It has highlighted changes which took place in the programme's vision, and in its curriculum over the seventeen year period of its implementation in schools. Our narrative has focused in particular on contrasting visions of radio learning and on shifts in the programme's implementation theory which took place over this period.

This chapter has highlighted a shift in vision of the project team from a skills-based view of educational change to a process vision of educational change based on open learning principles. The evidence from our evaluative data would suggest that the shift was from a product to a process view of curriculum (Hamilton, 1976; Stenhouse, 1975; 1980; 1981). This remained the central guiding principle on which the programme's theory of implementation was based over the fifteen year period post the advent of democracy in South African in 1994.

We have characterized this as a shift from a vision of educational change as product and skills-based to a product-based and process-related vision, in which curriculum content can form a basis for supporting teaching and learning in the classroom. We have also traced the programme's growth to scale, and suggested reasons for its acceptance by teachers and learners, as well as its endorsement by principals and educational officials, as it grew from providing support to an initial 360 teachers and 14500 learners under USAID funding in 1993, to an estimated 45000 teachers and 1800000 learners under maximal DfID funding in 2004, and an estimated 40000 teachers and 1300000 learners across all nine provinces of 
South Africa who utilised the programme's materials during its final year of operation in 2009.

Our data would suggest that both the product and process levels of the curriculum were successfully developed and implemented post 1994, in a large number of classrooms. With DfID funding, the programme expanded to implementation across all nine provinces, and in $11 \%$ of all South African schools. The programme's implementation over the final five year funding period was based on a model in which programme implementation was tied to use of participatory evaluation methods in providing in-service training to teachers at school and classroom levels. Our data would suggest that this approach had great potential. Our data would also suggest clear longitudinal indications of advocacy on the part of teachers, principals and educational officials. This evidence was tapped through interviews, questionnaires and focus groups, and was consistent over the entire seventeen year period of the programme's life.

In terms of use of radio as a way of reaching large numbers of teachers and schools, we have highlighted in this chapter clear longitudinal evidence of perceptions of the value of the curriculum materials, and of the benefit of the in-service training and support provided by the programme at school and classroom levels. However, sustainability remained a major problem and an unresolved issue in the programme. The South African Radio Learning Programme ceased its operation after seventeen years of implementation on a national level, at a time when it had achieved the advocacy of all nine provincial departments of education.

In terms of lessons learned, the relevance of the programme's work can be gauged not only from the extent of its outreach, but also from the endorsement of all nine provincial education departments across South Africa. Based on the advocacy of teachers, principals, and educational officials, the first level of institutionalization of the programme's work was achieved, involving the departmental and ministerial endorsement of the in-service involvement of large numbers of teachers in the programme's teacher support group activities and workshops, as well as the use of the programme's learner support materials by teachers as an integral part of their classroom teaching. Nevertheless, despite a memorandum of understanding from the Ministry of Education indicating the intention to continue the programme's work in five hundred primary schools, the second level of institutionalisation involving financial support from the educational authorities was not achieved.

On the teaching and learning level, the evidence we have presented in this chapter would thus support the research on school development indicating the importance of developing support and advocacy among multiple educational stakeholders (Fullan, 1982; Fullan \& Stiegelbauer, 1992; Hargreaves, 1992; Hargreaves \& Fullan, 1992). It would also support the resurgence of interest in radio learning and its potential in teacher development, particularly in developing countries (Bosch, 1997; 2001; Perraton, 2000; Perraton, Robinson \& Creed, 2001; 2007; Robinson \& Latchem, 2003). On the sustainability level, what is clear from our data is that the discontinuation of the South African Radio Learning Programme's work at the end of 2009 left a number of gaps in in-service training of teachers at primary school level across the South African education system.

It is our hope that the South African ministry of education and provincial education departments will move to address these needs in the future. It is also our hope that other 
educational projects will take forward lessons learned from the South African Radio Learning Programme's experience, in meeting the wide-scale needs of teachers for inservice training and support in this and other developing countries.

\section{References}

Anzalone, S. (Ed.). (1995). Multichannel Learning: Connecting All to Education. Washington DC: Education Development Center.

Apple, M. (1979). Ideology and Curriculum. London: MacMillan.

Arnott, A., Mansfield, J. \& Mentis, M. (1993) (a) 'Pre-Test Report of English in Action"'. In C.S Potter, and S. Leigh, (eds) English in Action in South Africa 1992-1994. Washington DC: Learntech and Johannesburg: Open Learning Systems Education Trust.

Arnott, A., Mansfield, J. \& Mentis, M. (1993) (b) 'A Summative Evaluation of OLSET's "English in Action" Radio Learning Programme'. In C.S Potter, and S. Leigh (eds) English in Action in South Africa 1992-1994. Washington DC: Learntech and Johannesburg: Open Learning Systems Education Trust.

Arnott, A., Mentis, M. \& Mansfield, J. (1994) 'A Summative Report on OLSET's “English in Action" Radio Learning Programme'. In C.S Potter \& S. Leigh (Eds.), English in Action in South Africa 1992-1994. Washington DC: Learntech and Johannesburg: Open Learning Systems Education Trust.

Basson, R. (2000) Radio Learning? A Descriptive Evaluation of 'What Actually Happens.' OLSET's Radio Learning Programme in Selected Soweto and Thembisa Schools. Johannesburg: Open Learning Systems Education Trust.

Bot, M. \& Schindler, J. (2000). Macro Indicators 1997: Update of the Baseline Study. In Kgobe, M.P. (Ed.), Transformation of the South African Schooling System: A Report of the First Year of Education 2000 Plus, a Longitudinal Study to Monitor Education Policy Implementation and Change. (pp 47-86).

Brand, E. (1998). Progressive Focusing of Research Questions for the Evaluation of OLSET's Radio Learning Programme: An Ethnographic Study. Johannesburg; Open Learning Systems Education Trust. Johannesburg: Centre for Education Policy, Development, Evaluation and Management.

Buckland, P. (1984). Technicism and de Lange: Reflections on the Process of the HSRC Investigation. In P. Kallaway, (Ed.), Apartheid and Education: The Education of Black South Africans. Johannesburg: Ravan Press.

Chippendall, R-J. (1998) Eyes and Ears on the Ground: Progressive Focusing of Research Questions for the Evaluation of a Radio Learning Programme. Johannesburg: Open Learning Systems Education Trust.

Chisholm, L., Motala, S. \& Vally, S. (2000). Review of Developments in South African Education, 1996-1998. In Kgobe, M.P. (Ed.), Transformation of the South African Schooling System: A Report of the First year of Education 2000 Plus, a Longitudinal Study to Monitor Education Policy Implementation and Change. Johannesburg: Centre for Education Policy, Development, Evaluation and Management.

Cobbe, J. (1994). Economic Report on English in Action. In C.S. Potter, \& S. Leigh, (Eds.), English in Action in South Africa 1992-1994. Washington DC: LearnTech and Johannesburg: Open Learning Systems Education Trust. 
Creekmore, M. (2010). A General Model for Understanding Projects among Collaborative Partnerships: A Case Study of Twanamo Papermaking. University of the Witwatersrand, Johannesburg: Wits Programme Evaluation Group Virtual Conference on Methodology in Programme Evaluation, http://wpeg.wits.ac.za Click Downloads.

De Reuck, J. (1999) A Look at OLSET's Radio Learning Programme - Themes and Notions from the Interviewing of Two Employees. Johannesburg: Open Learning Systems Education Trust.

DfID, (2004). DfID Project Progress Report: July 2004. Johannesburg: Open Learning Systems Education Trust.

Dodds, T. (1995). Multichannel Learning for Nonformal Education in Developing Countries. In S. Anzalone (Ed.), Multichannel Learning: Connecting All to Education. Washington DC: Education Development Center.

Friend, S., Potter, C.S.. Naidoo, G. \& Creekmore, M. (2010). Classroom-based Evaluation in the OLSET Programme: Using Photovoice as a Basis for Teacher Development. University of the Witwatersrand, Johannesburg: Wits Programme Evaluation Group Virtual Conference on Methodology in Programme Evaluation, http://wpeg.wits.ac.za Click Downloads.

Fullan, M. (1982). The Meaning of Educational Change. New York: Columbia University, Teachers College Press.

Fullan, M. \& Stiegelbauer, S, (1991). The New Meaning of Educational Change. London: Cassell Educational.

Giroux, H.A. (1981) Schooling and the Culture of Positivism: Notes on the Death of History. London: Routledge and Kegan Paul.

Graham, D. (1998) Ethnography in Action: Progressive Focusing of Research Questions -The OLSET Radio Learning Programme. Johannesburg: Open Learning Systems Education Trust.

Grundy, S. (1987). Curriculum: Product or Praxis. London: The Falmer Press.

Hall, B.L. (1978). Breaking the Monopoly of Knowledge: Research Methods, Participation and Development. In B.L. Hall and J. R. Kidd (Eds.), Adult Learning: A Design for Action. London: Pergamon Press.

Hamilton, D. (1976). Curriculum Evaluation. London: Open Books.

Hargreaves, A. (1992). Cultures of Teaching: A Focus for Change. In A. Hargreaves \& M. Fullan (Eds.), Understanding Teacher Development. New York: Columbia University, Teachers College Press.

Hargreaves, A. \& Fullan, M. (1992). Understanding Teacher Development. New York: Columbia University, Teachers College Press.

Hartshorne, K.B. (1992). Crisis and Challenge: Black Education 1910-1990. Cape Town: Oxford University Press.

Hartshorne, K.B. (1996). Education under the Government of National Unity: The Second Year, April 1995- April 1996. South African Journal of Science, 92 (11/12), 516-523.

Hoosen, S. (1999) Progressive Focussing through Interviewing and Analysis of Personal Accounts: Ethnographic Interviewing of OLSET Staff. Johannesburg: Open Learning Systems Education Trust.

Hunter, P., Nonyongo, E. \& Smith, R.L. (1998). Report of a Review of the Open Learning Systems Education Trust. Johannesburg: Open Learning Systems Education Trust. 
Imhoof, M. \& Christensen, P.R. (Eds.). (1986). Teaching English by Radio: Interactive Radio in Kenya. Washington DC: Academy of Educational Development.

Jacobson, P. (2001). Evaluation of a Radio Programme Teaching English as a Second Language to South African Primary School Learners. Unpublished Masters thesis. University of the Witwatersrand, Johannesburg.

Jansen, J. (1997). Why OBE will Fail. Paper presented at Conference on Perspectives on Outcomes Based Education. Durban: University of Durban-Westville.

Kgobe, M. (2000) (a). Case Study Report. In M. Kgobe (Ed.), Transformation of the South African schooling system: A report of the first year of Education 2000 Plus, a longitudinal study to monitor education policy implementation and change. (pp.87-118). Johannesburg: Centre for Education Policy, Development, Evaluation and Management.

Kgobe, M.P. (Ed.) (2000) (b), Transformation of the South African Schooling System: A Report of the First Year of Education 2000 Plus, a Longitudinal Study to Monitor Education Policy Implementation and Change. Johannesburg: Centre for Education Policy, Development, Evaluation and Management.

Langhan, D. (1992). Medium of Instruction: Models of Bilingual Education Implemented in Anglophone Sub-Saharan Africa: Policy, Implementation and Impact. Johannesburg: CEPD, South African National Education Policy Investigation (NEPI).

Learntech (1994). Interactive Radio Instruction: What it is, How it Works, and What is Needed to Get it on the Air. Washington DC: Learntech.

Leigh, S. (1992). The South Africa Radio Learning Project Final Report: "English in Action" A Pre-pilot Study March - June 1992. Johannesburg: The Open Learning Systems Education Trust in association with LearnTech/Real World Productions.

Leigh, S. (1995). Changing Times in South Africa: Remodeling Interactive Learning. Washington DC: Learntech, Learntech Case Study Series no. 8.

Leigh, S., Naidoo, G. \& Ramofoko, L. (1995). South Africa: Designing Multichannel Learning for Educational Renewal. In S. Anzalone (Ed.), Multichannel Learning: Connecting All to Education. Washington DC: Education Development Center.

MacDonald, B. (1971). The Evaluation of the Humanities Curriculum Development Project: A Holistic Approach. Theory into Practice, 10, 163-167.

MacDonald, B. (1977) (a). The Portrayal of Persons as Evaluation Data. In N. Norris (Ed.), SAFARI: Papers Two: Theory and Practice. Norwich: University of East Anglia, Centre for Applied Research in Education.

MacDonald, B. (1977) (b). A Political Classification of Evaluation Studies. In D. Hamilton, D. Jenkins, C. King, B. MacDonald and M. Parlett, (Eds.), Beyond the Numbers Game. London: MacMillan Education.

MacDonald, C. (1990). Crossing the Threshold into Standard Three in Black Education: The Consolidated Main Report of the Threshold Project. Pretoria: Human Science Research Council.

Masuku, S. (2000) Evaluation of the Radio Learning Project - Self-Efficacy, Locus of Control and Teacher Involvement: An Exploratory Study. Unpublished Masters thesis. University of the Witwatersrand, Johannesburg. 
Motala, S. (1997). From Policy to Implementation: Ongoing Challenges and Constraints. In

L. Chisholm, S. Motala \& S. Vally (Eds.), South African Policy Review 1993-2000 (pp. 387-414). Sandton: Heinemann.

Naidoo, G. (2002). Community Radio Case Study. Paris: UNESCO.

Naidoo, G. and Potter, C.S. (1996). Empowerment Evaluation in Teacher Development: Developing Equity in Educational Practice. Paper presented at the ASEESA conference on "Equity in Educational Assessment" held at the HSRC, Pretoria, October.

Naidoo, G. and Potter, C.S. (2007). Ethical Issues in Using Interactive Radio in South Africa. Open Learning: The Journal of Open and Distance Learning. 22, 2, 159-165.

Nene, S. (1993). OLSET's Focus Group Project August-September 1993: Preliminary Report. In C.S. Potter and S. Leigh (Eds.), English in Action in South Africa 1992-1994: A Formative Evaluation. Washington DC: LearnTech and Johannesburg: Open Learning Systems Education Trust.

Ntshoe, I. (2000) 'English in Action' in the Field. An Evaluation Report on OLSET's Radio Learning Programme. Johannesburg: Open Learning Systems Education Trust.

OLSET (1995). The OLSET Radio Learning Programme for Educational Development: Curriculum Document number 1, November 1994. In C.S. Potter, \& S. Leigh, (Eds.), English in Action in South Africa 1992-1994. Washington DC: LearnTech and Johannesburg: Open Learning Systems Education Trust.

Perraton, H. (2000). Open and Distance Learning in the Developing World. London: Routledge.

Perraton, H., Robinson, B. \& Creed, C. (2001). Teacher Education through Distance Learning: Technology, Curriculum, Evaluation. Paris: UNESCO.

Perraton, H., Robinson, B. \& Creed, C. (Eds.) (2007). International Case Studies of Teacher Education at a Distance. Oldenburg: BIS-Verlag der Carol Ossietsky Universitat.

Potter, C.S. (1992). Vision, Intention, Policy and Action: Dimensions in Curriculum Evaluation. Paper presented at HSRC International Conference on "Science and Vision", Pretoria, July, subsequently published in Journal of Educational Evaluation, Vol 8, 1-29, 1999.

Potter, C.S. (1993a). Evaluation Design for "English in Action". Johannesburg: Open Learning Systems Education Trust.

Potter, C.S. (1993b). Formative and Summative Evaluation Design for a Radio Learning Project. Journal of Educational Evaluation, 3, 1 (Spring), 3-30.

Potter, C.S. (1994a). An Evaluation of "English in Action": Second Interim Report, December 1994. Johannesburg: Open Learning Systems Education Trust.

Potter, C.S. (Ed.). (1994b). Case Studies of Radio Learning in Schools in Four Regions of South Africa. Johannesburg: Open Learning Systems Education Trust.

Potter, C.S. (1995). An Evaluation of "English in Action" in 1994: Findings, Issues and Recommendations. In C.S. Potter, \& S. Leigh, (Eds.), English in Action in South Africa 1992-1994. Washington DC: LearnTech and Johannesburg: Open Learning Systems Education Trust.

Potter. C.S. (1999). Evaluation Report on the Development of OLSET's Radio Learning Project as at December 1999. Johannesburg: Open Learning Systems Education Trust. 
Potter. C.S. (2000). Evaluation Report for Year 2000, on the Work of OLSET's Radio Learning Project in South Africa. Johannesburg: Open Learning Systems Education Trust.

Potter. C.S. (2001). Nine Years On: An Evaluation of the OLSET Radio Learning Project in South Africa. Johannesburg: Open Learning Systems Education Trust.

Potter, C.S. (2002). The Development of "English in Action" over Nine Years: Going to Scale in a Radio Learning Project. Johannesburg: Open Learning Systems Education Trust.

Potter, C.S. (2005). Measuring Outcomes. Vancouver: Commonwealth of Learning.

Potter, C.S. (2007). South Africa: Interactive Radio for Supporting Teachers of English as a Second Language. In H. Perraton, B. Robinson and C. Creed (Eds.), International Case Studies of Teacher Education at a Distance. Oldenburg: BIS-Verlag der Carl von Ossietsky Universitat.

Potter, C.S. (2008). Feasibility and Evaluability of IRI Implementation: An Evaluation Report on a Scoping Visit to Bangladesh. Johannesburg: Open Learning Systems Education Trust.

Potter, C.S., Arnott, A., Mansfield, J., Mentis, M. \& Nene, S. (1993). The Development and Implementation of "English in Action" in South Africa: An Interim Evaluation Rport, September 1993. Johannesburg: Open Learning Systems Education Trust.

Potter, C.S., Arnott, A., Hingle, I., Mansfield, J., Mashishi, L., Mentis, M. \& Nene, S. (1995). The Development and Implementation of "English in Action" in South Africa 19921994. Washington DC: Learntech and Johannesburg: Open Learning Systems Education Trust.

Potter, C.S., Chand, F., Naidoo, G. and Friend, S. (2007). Implementing Radio Learning in South African Primary Schools: Lesson Observation as a Basis for Formative and Summative Evaluation. Open Learning Systems Education Trust.

Potter. C.S., Dube, R., Kenyon, J. \& Naidoo, G. (1995). Empowerment Evaluation: An Application of David Fetterman's Approach. In Terre Blanche, M. (Ed.), A spanner in the works of the factory of truth. Johannesburg: University of the Witwatersrand, Department of Psychology and PSYSSA, Conference on Qualitative Methods.

Potter, C.S. \& Leigh, S. (Eds.). (1995). English in Action in South Africa 1992-1994. Washington DC: Learntech and Johannesburg: Open Learning Systems Education Trust.

Potter, C.S., Liccardo, S, \& Naidoo, G. (2008). Evaluation of an Open Learning Project in South Africa and Bangladesh. Pretoria: ASEASA International Conference, July.

Potter, C.S., Naidoo, G. \& Kenyon, J. (1998) External and Internal Perspectives in Programme Evaluation. Self Evaluation in Programme Development. $3^{\text {rd }}$ International Qualitative Methods Conference. University of the Witwatersrand, Johannesburg, September.

Potter, C.S. \& Naidoo, G. (2006). Using Interactive Radio to Enhance Classroom Learning: Reaching Schools, Classrooms, Teachers and Learners. Distance Education, 27, 1, 63-86.

Potter, C.S. \& Naidoo, G. (2009)(a). Evaluating Large-scale Interactive Radio Programmes. Distance Education, 30. 1, 117-142.

Potter, C.S \& Naidoo, G. (2009)(b). Use of Low-End ICT's as a Platform for Teacher Development: An Evaluative Case Study of an Interactive Radio Programme in 
South African Primary Schools. Proceedings: IMSCI09: The 2nd International MultiConference on Society, Cybernetics and Informatics. Invited paper. Orlando FA: July $10^{\text {th }}-13^{\text {th }}$. Pp. $58-63$.

Potter, C.S. \& Silva, A.S.F. (Eds.) (2002). Teachers in Action: Case Studies of Radio Learning in South African Primary Schools. Johannesburg: Open Learning Systems Education Trust.

Robinson, B. \& Latchem, C. (Eds.). (2003). Teacher Education through Open and Distance Learning. London: Routledge/Falmer and the Commonwealth of Learning. World Review of Distance Education and Open Learning Volume 3.

Rowntree, D. (1974). Educational Technology in Curriculum Development. London: Harper and Row.

Rowntree, D. (1982). Educational Technology in Curriculum Development (2nd ed.). London: Harper and Row.

Schwab, J.J. (1962). The Concept of the Structure of a Discipline. Educational Record, 43, 19720.

Schwab, J.J. (1969). The Practical: A Language for Curriculum. School Review, 78, 1, 1-24.

Schwab, J.J. (1971). The Practical: Arts of Eclectic. School Review, 79, 4, 493-542.

Silva, A.S.F. (2008). Educational Development and Empowerment: The Case of the Open Learning Systems Education Trust (OLSET) Unpublished $\mathrm{PhD}$ dissertation. University of the Witwatersrand, Johannesburg.

Simons, H. (1987). Getting to Know Schools in a Democracy: The Politics and Process of Evaluation. London: The Falmer Press.

Stake, R.E. (1983). Program Evaluation, particularly Responsive Evaluation. In G.F. Madaus, M. Scriven \& D.L. Stufflebeam (Eds.), Evaluation Models: Viewpoints on Educational and Human Services Evaluation. Boston: Kluwer-Nijhoff.

Stenhouse, L. (1975). An Introduction to Curriculum Research and Development. London: Heinemann.

Stenhouse, L. (1980). Curriculum Research and the Art of the Teacher. Curriculum, 1 (1), (Spring Issue).

Stenhouse, L. (1981). What Counts as Research? British Journal of Educational Studies, 29 (2) (June Issue).

Turner, J.R. \& Muller, R. (2003). On the Nature of the Project as a Temporary Organization. International Journal of Project Management, 21, 1-8.

USAID (1990). Interactive Radio Instruction: Confronting Crisis in Basic Education. Washington, DC: Agency for International Development: AID Science and Technology in Development Series.

Walker, D.F. (1969). A Case Study of the Process of Curriculum Development. San Francisco CA: Stanford University.

Walker, D.F. (1970). Toward More Effective Curriculum Development Projects in Art. Studies in Art Education, 11, 1-13.

Walker, D.F. (1971). A Naturalistic Model for Curriculum Development. American Journal of Education, 80, 51-65.

Wang, C., \& Burris, M. (1997). Photovoice: Concept, Methodology and Use for Participatory Needs Assessment. Health Education and Behavior, 24(3), 369-387.

Wang, C.C., Yi, W.K., Tao, Z.W. \& Carovano, K. (1998). Photovoice as a Participatory Health Promotion Strategy. Health Promotion International, 13, 1, 75-86. 
Weiss, C.H. (1998). Evaluation: Methods of Studying Programs and Policies (2nd ed.). Upper Saddle River NJ: Prentice-Hall.

Willig, A.C. (1985). A Meta-analysis of Selected Studies on the Effectiveness of Bilingual Education. Review of Educational Research, 55, 3, 269-317. 


\title{
Open and Distance Learning for Teachers' Professional Development: The English in Action (EIA) Model for the Global South
}

\author{
M. Mahruf C. Shohel \\ The Open University \\ United Kingdom
}

\section{Introduction}

Emerging technologies have been changing everything from the way people work to the way they communicate with each other or even spend their leisure time. For expanding Education for All (EFA) and achieving Millennium Development Goals (MDGs), new technologies in education are a crucial new area for policy makers and practitioners at all levels (UNESCO, 2005a). MDG 8 Target 5 is very precise - to develop a global partnership for development by making 'available the benefits of new technologies, especially information and communication technologies' (United Nations, 2010). Across the world, most countries have policies in place to promote effective expansion of the use of new technologies in education. As a developing country, new technologies have significant potential for the development of Bangladesh. However, in this chapter Bangladesh is presented as an example of such a country in the Global South.

Teachers are at the core of attempts to expand, improve and reform the education systems of any country. Over the last decade the global commitments to achieve EFA and MDGs have resulted in a marked expansion of school systems. However, there is a sense of crisis around the future of the teaching profession across the globe. Reports suggest that at least 18 million teachers are needed globally for achieving EFA and MDGs within the timeframe (UNESCO, 2007, 2008). Teacher education and training is therefore a burning issue in the countries of the Global South, such as Bangladesh, where the State has largely failed to provide basic education for its citizens. Evidences around the globe show, 'Countries that have achieved high learning standards have invested heavily in the teaching profession' (UNESCO, 2005b, 3).

Teachers' professional development is a career long process which involves going through a major transformation. Open and distance learning (ODL) systems are making an increasing contribution to the professional development of teachers as 'school standards and professional standards are inextricably linked, and the need for a teaching force that is flexible and adaptable to the impact of rapidly changing structures of work and leisure' (Moon, 1997, 8). Building on the opportunities offered by emerging technologies, open and distance learning has a potentially valuable role to play in teachers' professional development. 


\section{Teachers' professional development: The contexts of the Global South}

In the Global South, millions of children have no access to schooling and no opportunity to engage with any teacher at all. Teachers' professional development has become a policy priority for all nations across the globe. For most countries in the Global South there is an acknowledgement that the quality of teacher education and extent of the provision of training will need to be increased. In many countries explicit policies to improve the level of qualification, to establish meaningful forms of career long professional development and to enhance the status and education level of teachers are being put in place. The institutional structures and capacities are completely inadequate for providing quality teacher education as well as overcoming the challenges for the scale required of this century.

The provision of a high quality professional development programme for teachers in the Global South represents one of the critical educational challenges for the $21^{\text {st }}$ century. For instance, in Bangladesh, 1 in 5 teachers have no teaching qualification (UNESCO Institute for Statistics [UIS], 2006). The quality of education and training of teachers is central to the success of the EFA campaign worldwide and 'schools and teachers remain central to the achievement of a quality education process' (Yates, 2007, 2). Millions of unqualified teachers are already working in schools in the Global South. They need professional training and access to qualifications to improve their skills and knowledge. There is a pressing need for continuous professional development (CPD) programmes for teachers who are already qualified. If that is to be school based, then it follows that some form of supported self-study seems the only feasible and appropriate way forward (Moon, 2003).

The emerging technology is going to be a solution for teachers' professional development in meeting the crisis of inadequate teacher supply in the Global South. By using school-based training, the Teacher Education in Sub-Saharan Africa (TESSA) project is working for teachers and student teachers in 12 African countries. Led by the Open University (OU) UK, the TESSA project brings together 20 universities and organisations across those countries involoved, giving teachers access to high-quality resources which they can use to develop their own practices without leaving the school. As a result, TESSA's open educational resources (OER) provide ODL opportunities for disadvantaged teachers in remote areas, this way of training and developing their own skills and gaining resources is invaluable. The OU is also working in the South Asian countries, specially in Bangladesh to develop teaching and learning materials as well as teachers' professional development programmes. Teachers as specialists in learning recognise that the new technology which they will be exploiting in their own teaching have the potential to be an important means of their own professional development (Shohel and Banks, 2010). Therefore, the OU is creating opportunities of open and distance learning for teachers' by introducing mobile technologies for enhancing teaching and learning in resource constrained contexts.

School-based supported ODL provides a more effective way for the in-service teachers to put into practice compared to face-to-face traditional training away from their schools. Since supported ODL for teachers' professional development programme provides opportunities for teachers to apply and experiment with the pedagogical techniques that they are learning, rather than waiting until after the training period to do so. Similarly, case studies of teachers' professional development in the Global South show that open and distance learning can be used for all four components of teacher education such as for general education, to strengthen teachers' knowledge of the subject, in teaching pedagogy and child development, and as a guide towards good classroom practice (Perraton, 2007). 


\section{Definition of open and distance learning}

Open and distance learning (ODL) is defined as an educational process in which a significant proportion of learning takes place remotely and flexibly beyond the formal learning environment. Therefore it is organised educational activities, based on the use of learning materials, in which constraints on learning are minimised in terms of access, time and place as well as pace and method of study or any of these. However, open and distance learning is used as an umbrella term to include both concepts of distance education and open learning. Supported open and distance learning improves the potential for teachers to develop better links between new teaching practices, their own subject expertise and the application of the new methods in their own classrooms (Perraton et al., 2002) as well as becoming competent in using emerging technologies for teaching and learning purposes (Shohel \& Power, 2010).

According to the European Commission (1995):

'Open and distance learning (ODL) is concerned with the use of new resources (technical and/or non-technical) for rendering the learning process more flexible in terms of space, time, content, selection, access qualifications and teaching resources and/or for improving distance access to education systems. In this way, educational opportunities are extended to people who, because of their geographical, economic or socio-professional situation or because of a handicap, do not readily have access to the mainstream system of education. Open and distance learning can help overcome barriers to transnational mobility and develop a kind of virtual mobility.'

Open and distance learning involves a conceptual shift from the teacher to the learner and emphasises the importance of student-centred learning that means a 'shift in research and practitioner interest from teaching and instructional design towards learning and the particularity of individual student response' (Thorpe \& Grugeon, 1987). Therefore, open and distance learning focuses more on what the learner wants to learn, how the learner approaches learning and the socio-physical conditions for learning than what the learner should learn. To engage individuals in their learning processes, open and distance learning tries to motivate and empower for professional growth of individual teachers. However, supported open and distance learning is also preferable for other reasons such as scalability, sustainability and cost effectiveness compared with the traditional 'face to face' centre-based training approaches (Oliveira \& Orivel, 2003).

\section{Teacher development through open and distance learning}

Teachers across the globe have pursued the opportunities offered by open and distance learning. For example, in 1990s about 130,000 South African teachers which was one third of the total workforce were studying through the use of different open and distance learning courses (SAIDE, 1995). Also 200,000 Chinese teachers were supported by the Television Teachers College in upgrading their qualifications (McCormick, 1992). From 1970s to 1980s in the UK, tens of thousands of teachers upgraded their qualification to graduate level through the Open University (Moon, 1997).

In many countries where higher qualifications of teachers lead them to career opportunities and salary increases, teachers have been attracted to the access, flexibilities and low cost of open and distance learning opportunities. However, according to Perraton (2010:6): 
'open and distance learning has been widely used for initial teacher training, for students who enter the profession with a background in primary, secondary or tertiary education, but has often been organised on a one-off basis rather than as part of the established structure of teacher education'.

For example, an early ODL programme in Kenya was given the highest priority to raise teachers' own educational background to a certain level. A much more recent programme in Chile was designed to support the increasing use of information technologies in schools. It was entirely concerned with reorienting teachers for the changed curriculum. The current trend is to strengthen teachers' practical classroom skills; however, it is administratively difficult and likely to be costly to achieve (Perraton, 2010).

Open and distance learning has gone through a rapid evolution and embraced a changing trend of mobile technologies. These have been used for two purposes: to distribute teaching material to learners, and to allow interaction between learners and facilitators or among learners. Open and distance learning has also been used to support changes in the curriculum for each subject. It has played an important role in making teachers familiar with information and communication technologies. It has also been used to support teachers' professional development through structured programmes designed for specific groups of teachers, as well as provide opportunities for teachers to upgrade their skills. However, open and distance learning solutions have the advantages of interactive and non-interactive technological application, and it is recognised that in-school learning rather than out of school is the key to improvement for teaching and learning in the classroom.

In this era of technology, all forms of teacher education programmes are exploring the possibilities of using technology in context. By utilising new interactive forms of technology, open and distance learning has a great role to play in the process of teachers' professional development. New methodologies and technological tools are increasingly being integrated with new theoretical perceptions about the importance of combining the theoretical and practical elements in teachers' professional development at all levels.

Open and distance learning for teachers' professional development needs an integrated support system and according to Leach (1996) where:

1. Support should provide model learning environments;

2. Support should build on existing frameworks as far as possible and be consonant with the culture in which it is developed;

3. Support should be developmental and exploratory providing experience of a wide variety of teaching and learning opportunities;

4. Support should recognise and build on the variety of professional experiences of its participants;

5. Support should acknowledge both the private and professional aspects of learners' experiences and their interconnectedness in the development of learning; and

6. Support should have a firm base in schools and classrooms; it should be seen as an ongoing process across initial, induction and ongoing phases of teacher education.

The school is increasingly seen as a place for learning within new models of teachers' professional development programmes. Therefore, the development of new models of teachers' professional development programmes incorporate school contexts within the model. Supported open and distance learning is a successful and well-established teaching 
and learning strategy (Robinson \& Latchem, 2003) which has not been widely adopted yet in Bangladesh. The model which is the focus of this chapter is called the English in Action (EIA) Model and is currently being implemented in Bangladesh. The application of this supported open and distance learning model is distinctly different from the typical teacher training strategies which have been applied previously in Bangladesh.

\section{The Bangladeshi context}

Since the passing of the Compulsory Primary Education Act in 1990, considerable changes have been made to the formal education system in Bangladesh. As a result of legislation and government efforts, the enrolment rate increased from $60 \%$ to almost $91 \%$ in 2008 (UNICEF, 2009). But universal primary education, the second MDG of the UN has still to be achieved. The increase in numbers of newly enrolled students has made necessary the construction of more primary schools and the employment of many additional teachers. According to the governement agency, between 1990 and 2008 the number of primary schools rose from 47,000 to over 82,000; primary teacher numbers increased from 189,500 to 366,000 (BANBEIS, 2010).

Despite the fact that secondary education is neither compulsory nor free, there was also significant growth in the secondary education sector over the period 1990 to 2008. Again the number of schools rose from almost 10,500 to 18,750 with student enrolments more than doubling from 3 million to 6.8 million in 2008. Similarly secondary teacher mumbers increased significantly from 123,000 to more than 219,500 (BANBEIS, 2009). With such a concentration of newly appointed teachers in both primary and secondary education sectors, the provision of adequate and appropriate training became a key issue for teachers' professional development in Bangladesh.

Poor qualifications and lack of teacher motivation are major challenges for Bangladesh to provide a well-equiped teaching workforce. However, there have been a series of government's and non-state providers' initiatives aimed at significantly improving the quality of teaching and learning through both curriculum and pedagogic reforms in all sectors. The traditional and dominant way of teaching and learning in most schools in Bangladesh tends to focus on memorising facts.

In the primary education sector, the Second Primary Education Development Programme (widely known as PEDP II) resulted in the availability of the training being revised and extended for newly appointed teachers to improve quality. Approximately $24 \%$ teachers of the government primary schools and registered non-government primary schools are untrained (UNICEF, 2009).

In the secondary education sector, there has been a recent shift in emphasis from increasing quantity to increasing quality. There have been a number of dvelopmental projects; and reforms have been made to improve educational quality with the help of international development partners of the country. Since 1999, the initiatives such as the Secondary Education Sector Improvement Plan (SESIP), the Secondary Education Sector Development Project (SESDP) and the Teaching Quality Improvement Secondary Education Project (TQISEP) have been implemented. Through these initiatives, changes have been made to both pre-service and in-service teacher training for the secondary education sector (UNESCO, 2007). 


\section{English in Action (EIA) in Bangladesh}

The English in Action programme in Bangladesh is aimed at significantly improving the teaching of English in all sectors and is offering alternative forms of support including integrating information and communication technology (ICT) into different aspects of the school-based support systems.

The English in Action (EIA) programme is a major nine-year (2008-2017) development programme initiated at the request of the Government of Bangladesh and funded by the Department for International Development (DfID) for the Government of United Kingdom. It aims to equip twenty five million Bangladeshis with the skills to communicate in English to levels that enable them to participate fully in national economic and social activities and global opportunities (EIA, 2008). The project uses supported open and distance learning (sODL), media and mobile technologies to supplement and enhance the learning and teaching of communicative English among school students, teachers and adults in Bangladesh (Shohel \& Banks, 2010; Shohel \& Power, 2010).

There are four major strands to the EIA programme in Bangladesh: a). Primary Education: engaging students and teachers through innovative classroom resources. b). Secondary Education: empowering teachers to change their classroom practice. These interventions are school-based, delivered through supported distance learning and enhanced by mobile technologies. c). Adult Learning: enabling lifelong learning via interactive and digital media and d). Research, monitoring and evaluation (RME): evaluating on going projects and researching impacts of interventions. As a partner in the EIA programme, the Open University UK is involved in teachers' professional development programmes in Bangladesh.

There are three operational phases in the EIA project:

- Developmental research (2008-2011): to identify the most effective, scalable and sustainable model of supported open and distance learning for English-language teachers in Bangladesh, and the most appropriate forms of mobile technology to support this. Working with 400 teachers, $80 \%$ of whom will be teaching in rural schools.

- Upscaling (2011-2014): taking the most effective and cost-effective model of teachers' professional development forward at scale. Working with at least 12,500 teachers, from six national administrative divisions in Bangladesh. $80 \%$ teachers will be teaching in rural areas.

- Embedding (2014-2017): making the teachers professional development programmes available across bangladesh, through locally supported open and distance learning. The final phase of the project will require public-private partnership to provide a 'teachers' toolkit' of mobile technology, classroom resources and teachers professional development materials.

Before piloting the EIA intervention in main stream Bangladeshi school system, the prepilot study of the project was carried out at the Underprivileged Children's Educational Programs (UCEP) schools as a test-bed in the capital city Dhaka. The pre-pilot phase was carried out for one year (July 2009 to June 2010). 


\section{Underprivileged Children's Educational Programs (UCEP) Bangladesh}

The Underprivileged Children's Educational Programs (UCEP) is a leading non-government organization (NGO) in Bangladesh which provides general education and vocational training for working children. Currently over 30 thousand poor working children who have generally missed out on their primary education are studying in UCEP schools. Students are accepted into the programme no younger than age 10 for girls and 11 for boys. UCEP schools operate 3 shifts per day, each of 3 hours duration. As the children continue to work and earn while they attend school, this allows a child to choose a shift of his/her convenience, in consultation with their parents, to minimise the economic loss to the family for the children attending school. Each 3 hour shift is focused on general education but where possible examples are drawn from a technical context. For example, the English alphabet is taught through naming of craft tools - D for dividers, $\mathrm{H}$ for hammer. Stories in Bangla are linked to the discovery of inventions and the use of agricultural and other devices. After grade 8 UCEP continues Technical Education training on 16 professional trades (see UCEP, 2008 for more detail about these trades).

Students basically follow the National Curriculum and Textbook Board (NCTB) curriculum, both at primary and lower secondary level (grades 1 to 8 ). However, the curriculum has been abridged in a careful manner so that it remains comparable with that of national mainstream curriculum. The curriculum consists of Bangla (mother tongue), English, mathematics, vocational, social environment and hygiene. The students learn in a highly vocational and practical way using English where necessary as technical vocabulary (EIA, 2009). At the end of their training they are guaranteed a job. In contrast to the formal government system, these poor working children attend school regularly and complete their education. The attendance rate is over $94 \%$ and the drop-out rate is very low (UCEP 2008).

\subsection{UCEP teacher training}

After recruitment UCEP arranges training for the teachers. Most of the training is led by resource personnel from outside as well as some of the trainers from the organisation (who are from the field, who are normally divisional coordinators and School Administrators). Table-1 shows the in-service training provided by UCEP and their duration.

\begin{tabular}{|l|l|l|}
\hline & Training & Duration \\
\hline 1. & Teachers' Basic Training & $7-10$ days \\
\hline 2. & Effective Social Work Training & $3-5$ days \\
\hline 3. & Teaching and Learning Methodology Training & $3-5$ days \\
\hline 4. & Subject-based Training (Mathematics, English, Bangla and Science) & $3-5$ days \\
\hline 5. & Teaching Aid Training & $1-2$ days \\
\hline 6. & Children's Right and Child Psychology Training & $3-5$ days \\
\hline 7. & Gender and Development & $1-2$ days \\
\hline 8. & $\begin{array}{l}\text { Others: } \\
\text { Interactive Teaching Training } \\
\text { Child Participation Training }\end{array}$ & $\begin{array}{l}1 \text { day } \\
1 \text { day }\end{array}$ \\
\hline
\end{tabular}

Table 1. In-service trainings for the UCEP teachers 
The training programmes are arranged on the basis of availability of the teacher at a convenient time for the head office. Teachers attend the basic training after joining the organisation but not necessarily immediately after recruitment. After each training teachers go back to their respective schools to carry on with their job. There is no given time schedule for the next training, however teachers then attend the effective social work training, which is mainly concerned with relationships with children and interaction with their families to strengthen social activities. This training includes issues, such as what would be the strategy to work with the guardians, how the teacher will behave with the students, how to liaise with the community, and how to run the follow-up programme for the students. At some point teachers need to attend teaching and learning methodology training, which is mainly focused on pedagogy. Subject based training on Mathematics, English and Bangla follows, where a SA or an experienced teacher could be the trainer. Sometimes they arrange subject based training in science too depending on need. Sometimes UCEP arranges training on teaching aids- supplementary teaching and learning materials focusing on teaching material development and techniques for their use. Sometimes teachers are called for other training such as children's right training; gender and development training.

Sometimes teachers attend training outside their organisational setting. For instance, they were previously sent to the English language training programmes run by the British Council, as well as training abroad in India. In the beginning these kinds of trainings were for the School Administrators (SAs), but now teachers are also sent abroad for training, such as in India. Apart from these, the organisation also gives scope to the teachers to pursue their further education such as BEd, MEd or BBA, MBA programmes run by different universities in the evening shift or distance learning mode. According to the respondents of the pre-pilot study, many teachers were enrolled for further education programmes. The organisation does not provide any financial support for teaching qualifications but does not object to teachers achieving one. There is no obligation for the teacher to achieve teaching qualifications as UCEP provides trainings internally. In mainstream government schools there is an obligation for the teacher to achieve their teaching qualification in a certain time. There is no refresher training for UCEP teachers in terms of continuous professional development (CPD).

\section{School-based model for teachers' professional development}

Professional development is the process of improving staff skills and competencies needed to produce an excellent education for students (Hassel 1999). The teachers are always the centerpiece of educational change, being the active and powerful change agents who have the power to make a difference, both individually and collectively (Castellano \& Datnow 2000; Hurst 1999). As reform efforts need to place at the core of the processes of teaching and learning, they change significantly what happens in the schools. Yet teacher beliefs and attitudes about an innovation are the important consequences, concerns and context variables associated in determining new and different teacher behavior (Burke, Harste \& Short 1996; Kennedy \& Kennedy 1996; Laine \& Otto 2000; Ros \& van den Berg, 1999). Ultimately, the individual teacher determines the extent to which each innovation occurs.

Professional development sparks curiosity, motivation and new ways of thinking (Kent 2004). It is most effective when there is an ongoing process, which includes proper, well-designed training and an individual follow-up. It can deliver a purpose, cooperation, commitment and community (Langer 2000). It is about change and renewal. The focus must move from a 
location being primarily outside the school through training by experts to being in school where learning is embedded in the classroom, and from ad hoc development of skills to the production of content-specific skills and knowledge (Hutchens 1998). Successful professional development must be sustainable and overtime directly related to everyday teaching.

The EIA school-based support model for teachers' professional development (TPD) is a spectrum of carefully prepared information and communication technology (ICT) interventions for Bangladeshi teachers to empower them to change their classroom practice in schools. The pre-pilot phase was designed to encourage and support communicative language teaching (CLT). Media players were provided to the English language teachers, preloaded with video and audio language learning resources, along with battery-powered speakers for use in the classroom. The programme structure involved 12 modules, each centred on a particular activity designed to be taught in a secondary classroom. Each module demonstrated the activity, explored the principles underlying the activity, and encouraged teachers to use, adapt and extend this and similar activities. During the prepilot phase, (July 2009 - June 2010), the Secondary Teaching and Learning Programme (STLP) intervention was implemented in UCEP schools. This STLP was based on a range of 'blended' support systems (see Figure-1) for teachers such as an orientation workshop, a teacher guide, a multi-media player (iPod), cluster meetings of teachers on the programme, a pair of EiA teachers from each school, school visits from EiA staff giving feedback, and technical assistance. It was an experiential learning process for the implementing workforce as well as the teachers. However, pre-piloting in the UCEP schools were treated as a 'testbed' for the main stream piloting phase (Shohel \& Power, 2010).

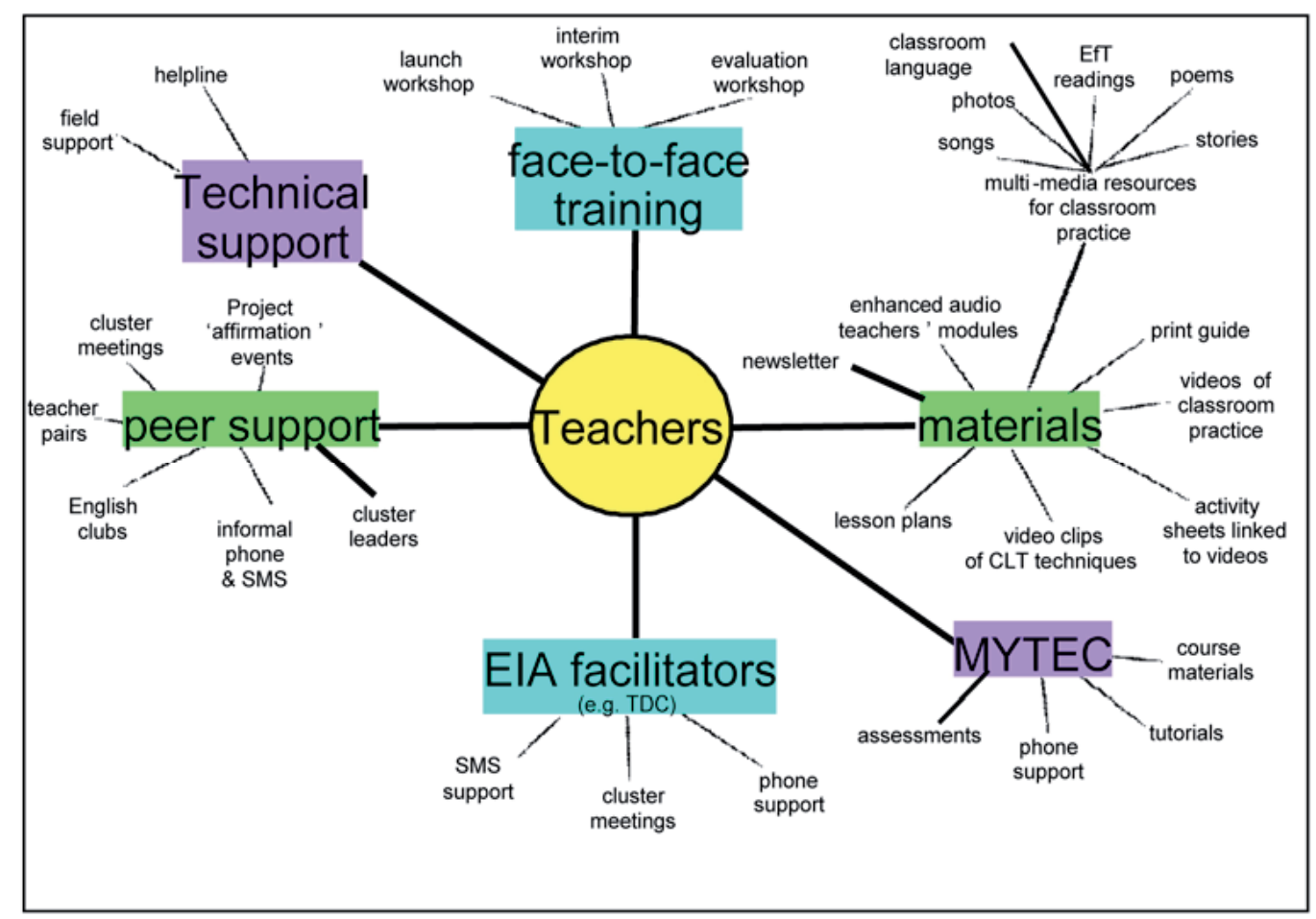

Fig. 1. School-Based Supported ODL Model for TPD (Shohel \& Banks, 2010) 
Looking at some aspects of the 'blended' TPD approach shown in Fig 1:

The orientation workshop was a part of the support systems in providing an induction by the EIA workforce to participating teachers. It was designed for introducing EIA itself and features of communicative language teaching (CLT). This workshop was not considered as a training session because it was just a get together for teachers with EIA people, to know each other. Basically it was the stepping stone for teachers to understand what was required for the success of the project.

The teachers were given a Teacher Guide which includes twelve modules of different CLT teaching and learning methods. This guide book also explained how to use the different audio and video materials stored on the multi-media player. This guide book always remained with the teachers so that whenever, they got time, they could skim through it. There was a section in this guide for classroom language; English phrases which they could easily use during their lessons.

Pair support was another key feature of the support model. Two teachers from each intervention school joined the EIA STLP and they were supporting each other and working together towards their joint professional development. Some new points evolved when they discuss in a pair regarding how they could organise their class, how they could engage students in the class or how they could make the lessons more attractive. It was a very effective way to quickly solve practical problems. For example, they could watch a microteaching lesson from the audio-visual resources on the iPod and discuss together which method could have been better for the specific lesson in their school contexts. Sometimes both of them discussed what kind of teaching aid they could have developed and they could also discuss how to deliver a lesson or use methods for a lesson which is not available in the iPod.

Teachers had regularly attended fortnightly cluster meetings for formal training on different modules from the teacher guide for helping them to develop their English language skills as well as to boost their confidence, keep up their motivation and support each other in using communicative English language practices in their classrooms. Teachers had to plan and demonstrate lessons in different groups in the cluster meeting. One group may miss something in the demonstration and the next groups could identify what could have been added to perform better. By way of preparation, teachers listen to modules from the iPod or read the module from the teacher guide before attending the cluster meeting. During feedback sessions in the cluster meeting, they could listen to others and share their own experience. It was important for experience sharing and reflecting on practice. Reflection was enhanced by the opportunity for teachers to engage in an Open University course based on the production of a teacher 'reflective diary'. The course, Make Your Teaching Experience Count (MYTEC) provided understanding of teaching and learning as well as additional motivation to engage in the EIA teacher development programme.

A series of School visits with feedback was arranged for keeping the teachers' focused on classroom practice and supporting the training implemented in classrooms. This process increased critical thinking of the teachers and it put a level of expectation on them to strive to improve their practice as suggested in the cluster meeting. The main advantage of the school visit was that teachers get face-to-face feedback, encouragement and support from the EIA resource persons. It also provided the EIA project staff with information regarding 
progress and the ability of the teachers to cope with the face-to-face training in the cluster meeting and how much they were achieving from the blended training programme. Another positive side of school visit was that it established better communication between the teachers and the trainers as a result teachers got solutions to their problems immediately. They could share their problems with the trainers instantly as they strive to implement CLT practice in their English language classroom. During this pre-pilot phase, the EIA model helped teachers to develop their English language skills in a different way through the school-based support systems so that they could use English confidently in the classroom.

In summary, during the orientation workshop teachers were briefed about the EIA intervention, strategies and materials. Teachers were given training on how to use the media player (iPod) and supporting materials. The teacher guide contained twelve modules on different pedagogical techniques including a section on classroom English explaining how those techniques could be used in their classroom contexts. Teachers were implicitly trained in the cluster meetings in how to use those modules in their classroom. At the heart of the EIA support model was the notion that teachers will achieve most of their professional development, not in face-to-face training workshops but back at home and at school; by working with new tools and materials, on their own and with their partner.

\section{Lessons learned from the UCEP intervention}

A key to successful educational change is the provision of appropriate 'incentives' in their context for teachers to improve their practice in the classroom. But it is also true that many features of the school system are maintained and supported by the institutional culture and socio-political context of the school (Shohel \& Howes, 2008). EIA as a major educational development programme in Bangladesh is creating a space for teachers to raise their voice and to be empowered. Therefore, EIA authority needs to be clear about what EIA can offer them as incentives for being an active EIA participating teacher apart from training and technological tools.

In the case of UCEP schools, teachers have many duties including delivering 5 to 6 lessons per day in 3 shifts schooling and following up 10 to 15 students per month if any student is absent from the lessons. Though the teachers enjoy taking part in the EIA intervention, according to the pre-pilot study respondents, it was very demanding for their time as well as very rewarding for them. Eventually they became heavily involved in the training activities and practicing their learning in schools (Shohel \& Banks, 2010).

With in the EIA support model, the use of innovative materials and tools enabled and supported the teachers' professional development activities at home and school. Teachers described repeatedly watching and listening to the materials, in quite a purposeful manner. Teachers particularly emphasised the value of this for developing their own pedagogic knowledge, as well as contributing directly to their own percieved English language proficiency, perhaps most notably in relation to pronunciation. Teachers attached a high value to the emphasis on classroom practice within the programme; this was seen to be a key aspect of support that the materials focus not just on ideas, but on how teachers could put ideas into practice (Shohel \& Power, 2010). 


\section{Policy recommendations for Bangladesh}

If the school achievement levels are to rise up to a certain standard then appropriate teacher education and training must be available for all teachers. It seems clear that there should be some sort of school-based professional development programme through technology enhanced open and distance learning such as multi-media player. However, children's 'cognitive achievement [...] increases as school expenditure, teacher education and school facilities are enhanced' (UNESCO 2005b, 228). Therefore, Bangladesh needs to invest more on teacher education including school-based technology enhanced teacher training, to provide quality education for its citizens.

The status of teachers in the community as well as the professional world and their involvement in policy development and implementation are as important as their academic qualification and training. Countries which perform well in offering quality education to their citizens have placed a high value on teacher education and CPD as well as social networking (UNESCO, 2005b). Teachers also enjoy high status in those countries.

In the context of Bangladeshi educational culture where education is seen as 'simple memorisation for an examination by both teachers and parents' (Banks 2009, 7) it is very difficult to bring changes in practice without making changes in policy and curriculum. As an emergent economy, 'the relevance of education to everyday life is paramount' (Banks $2009,7)$ in Bangladesh. So Bangladesh needs to focus on these issues to achieve the EFA and MDGs targets as well as strengthening its economy by developing its human resources. The lessons learned in Bangladesh can be adapted to language education in both global southern and northern countries alike.

\section{Implications for the Global South}

General concern and trends around teacher education and training relate to the resolution of the balance between theory and practice; the attempts to match the demand for and supply of teachers; the degree of central control of teacher education; the status, recruitment and output of teachers' (Morris and Williamson, 2000, 281). Successful teacher education and training could happen in the context of school, though there is no evidence of this happening in the Global South. Considering the urgency of teacher education and training, teachers' professional development should be school-based and it is essential to provide a stable policy basis for continuous development.

'Training models for teachers should be reconsidered in many countries to strengthen the school-based pre- and in-service training rather than rely on lengthy traditional, institutional pre-service training' (UNESCO, 2005b, 3). This kind of suggestion has been resistant by traditional teacher training institutes and sometimes supported by teachers themselves and their unions. However, 'It is only now that people are starting to listen to those who saw the shortage of qualified teachers as a major impediment to national development and that national and international authorities are beginning to realize that the achievement of the Millennium Development Goals and the Education for All objectives depends on the training of professionals capable of the long-term effort to promote education effectively, in particular through the training of teachers and managerial staff in the education system' (UNESCO, 2005b, 2). 
For doing so, school-based forms of open and distance learning using new communication technologies are the only viable way forward (Banks et al, 2009). 'Increasingly new modes of open and distance learning, including new information and communication technology application are seen as vital to new approaches to training provision on a large scale' (UNESCO, 2008, 2). School-based modes of supported open and distance learning, exploring ICTs are the only feasible way to make such provision widely available (Shohel \& Power, 2010).

\section{Conclusion}

The crisis of trained and qualified teachers in the Global South requires urgent responses from the national governments as well as the international development partners of the developing countries. The rapid expansion of education systems is creating difficulties in establishing coherent teacher supply policies. Investment in high quality teacher training programme design and implementation is necessary to realise the potential of new models of teachers' professional development programmes through open and distance learning such as the EIA Secondary Teaching and Learning Programme (STLP). Therefore, in response to the Government of Bangladesh, the Government of the United Kingdom came forward to help the country to train and develop the English language teachers as well as to provide opportunities and resources to access English language learning.

The pre-pilot EIA intervention in UCEP schools is a very fruitful initiative 'to secure a professionally trained, well-supported and highly motivated teacher workforce' in Bangladesh. The EIA intervention gives cause for optimism that the secondary education sub-sector in Bangladesh could be developed from current low quality teaching by putting resources in place through 'short term interventions completed by longer term institutionalisation and sustainable societal interaction' (Yates, 2007, 12) that will ensure the continuity of quality education which EIA is aiming for.

The future development of open and distance learning for teachers' professional development requires greater clarification of terms and purposes of learning. In a study of eleven distance teacher education projects, Perraton $(1993,385)$ suggests that 'two broad conclusions to emerge from the studies... where it has been possible to measure effectiveness, teacher training at a distance can be effective and that its costs tend to be lower than conventional education... where we have detailed figures it is reasonable to conclude that distance education programmes can be designed for teachers at a cost of between one third and two thirds of conventional programmes'.

The move towards more school-based, particularly technology-oriented and integrated open and distance learning courses calls for a greater level of support from experienced teachers locally as their mentors. A range of new courses are now appearing that integrate the school experience into the course frame work, for instance, Bangladeshi secondary school teachers were offered a course entitled 'Making Your Teaching Experience Count (MYTEC)' by the Open University, UK. The first cohort of this teachers group has been awarded their course completion certificate in 2011.

Advantages and disadvantages of open and distance learning models certainly provide more important basis for further comparative studies on those models in their own terms as well as in comparison with more conventional models. It has been suggested that school- 
based support systems through open and distance learning for enhancing teachers' professional knowledge which have implications in developing countries such as Bangladesh for language learning (Shohel and Shrestha, 2010). However, it remains still unclear to many practitioners whether the increasing power, affordability and availability of mobile technologies can be harness to enhance effective open and distance learning activities based on the classrooms of the resource constrained Global South contexts.

\section{Acknowledgment}

The author would like to thank UKAID for funding the EIA programme and the UCEP Bangladesh authority for allowing him to carry out the research in their schools. He is also indebted to the colleagues from the EIA Base Office in Dhaka, Bangladesh who supported him enormously during the fieldwork of the research on pre-pilot intervention of the project. He also thanks the School Administrators and teachers of the UCEP schools who took part in research activities and helped him to understand their professional and school contexts.

\section{References}

BANBEIS. (2010). Trend Analysis. Dhaka, Bangladesh: Bangladesh Bureau of Educational Information and Statistics. Retrived on 15.05.2010 from http://www.banbeis.gov.bd/trend_analysis1.htm.

Banks, F. (2009). Technological literacy in a developing world context: The case of Bangladesh, the PATT-22: 'Pupils Attitude Towards Technology' Conference, Delft, Netherlands, August 24-28, 2009.

Burke, C., Harste, J. C. \& Short, K. G. (1996). Creating classrooms for authors and inquirers, Portsmouth, United Kingdom: Heinemann.

Castellano, M. \& Datnow, A. (2000). Teachers' responses to success for all: How beliefs, experiences, and adaptations shape implementation, Education, American Educational Research Journal, Vol.37, No.3, pp. 775-799.

EIA. (2008). English in Action Project- Project Memorandum. Dhaka, Bangladesh: English in Action.

European Commission (1995). Socrates: A Vademecum. Brussels, Belgium: European Commission.

Hassel, E. (1999). Professional development: Learning from the best. Oak Brook, United States: North Central Regional Educational Laboratory.

Kennedy, C. \& Kennedy, J. (1996). Teacher attitudes and change implementation, System, Vol.24, No.3, pp. 351-360.

Laine, S. W. M. and Otto, C. (2000). Professional development in education and the private sector: Following the leaders. Oak Brook, United States: North Central Regional Educational Laboratory.

Leach, F. (1996). Learning in Practice: Support for Professional Development, In: A. Tait and R. Mills, (Ed.), Supporting the learner in open and distance learning. London, United Kingdom: Longman.

McCormick, R. \& Scrimshaw, P. (2001). Information and Communications Technology, Knowledge and Pedagogy, Education, Communication and Information, Vol.1, No.1, pp. 37-57. 
McCormick, R. (1992). Distance higher education in China, Unpublished PhD Thesis. Milton Keynes, United Kingdom: The Open University.

Moon, B. (1997). Open Learning and New Technologies in Teacher Education: New paradigms for development, European Journal of Teacher Education, Vol.20, No.1, pp. 7-31.

Moon, B. (2003). A retrospective review of the national case studies on institutional approaches to teacher education, In: B. Moon, L. Vlasceau, and L. C. Barrows, (Ed.), Institutional approaches to teacher education within higher education in Europe: Current models and new developments. Bucharest, Hungery: UNESCO.

Oliveira, J. B. \& Orivel, F. (2003). The Cost of Distance Education for Training Teachers. In B. Robinson, and C. Latchem, (Eds.), Teacher Education through Open and Distance Learning. London, United Kingdom: Routledge Falmer/The Commonwealth of Learning.

Perraton, H. (2010). Teacher Education: The Role of Open and Distance Learning. Vancouver, Canada: Commonwealth of Learning.

Perraton, H. (Ed.) (1993). Distance Education for Teacher Training. London, United Kingdom: Routledge.

Perraton, H., Creed, C. \& Robinson, B. (2002). Teacher Education Guidelines: Using Open and Distance Learning. Paris, France: UNESCO.

Perraton, H., Robinson, B. \& Creed, C. (Eds) (2007). International Case Studies of Teacher Education at Distance. Oldenburg, Germany: BIS-Verlag.

Robinson, B. \& Latchem, C. (Eds.). (2003). Teacher Education through Open and Distance Learning. London, United Kingdom: Routledge Falmer/The Commonwealth of Learning.

SAIDE. (1995). Teacher Education Offered at a Distance. Johannesburg, South Africa: South African Institute of Distance Education (SAIDE).

Shohel, M. M. C. \& Banks, F. (2010). Teachers' professional development through the English in action secondary teaching and learning programme in Bangladesh: Experience from the UCEP schools, Procedia Social and Behavioral Sciences, Vol.2, No.2010, pp. 5483-5494.

Shohel, M. M. C. \& Howes, A. J. (2008). Informality of teaching and learning in nonformal schools: Socio-cultural processes as mesosystems of student development, Education 3-13, Vol.36, No.3, pp. 293-309.

Shohel, M. M. C. \& Power, T. (2010). Introducing Mobile Technology for Enhancing Teaching and Learning in Bangladesh: Teacher Perspectives, Open Learning, Vol.25, No.3, pp. 201-215.

Shohel, M. M. C. \& Shrestha, P. N. (2010). Mobile Technology in Communicative Language Teaching (CLT) Practice in Bangladesh: Experience from the UCEP Schools, the XIV Congress on Comparative Education Societies, Istanbul, Turkey, June 14-18, 2010

Thorpe, M. \& Grugeon, D. (Eds) (1987). Open Learning for Adults. London, United Kingdom: Longman.

UIS. (2006). Teachers and educational quality: Monitoring global needs for 2015. Montreal, Canada: UNESCO Institute for Statistics.

Underprivileged Children's educational programs (UCEP). (2008). Transforming underprivileged children into productive human resource. Retrieved on 29.06.2009 from http://www.ucepbd.org/index.htm. 
UNESCO, (2005a). Mobile Learning for Expanding Educational Opportunities. Workshop Report. Bangkok, Thailand: UNESCO Asia and Pacific Regional Bureau for Education.

UNESCO. (2005b). Education for All: The quality imperative (Summary). EFA Global Monitoring Report, Paris, France: United Nations Educational, Scientific and Cultural Organisation.

UNESCO. (2007). Secondary Education Regional Information Base: Country Profile- Bangladesh. Bangkok, Thiland: United Nations Educational, Scientific and Cultural Organisation.

UNESCO. (2008). Supply, retention, preparation and career long professional development of teachers in E9 countries. Paris, France: United Nations Educational, Scientific and Cultural Organisation.

UNICEF. (2009). Quality Primary Education in Bangladesh. Dhaka, Bangladesh: United Nations Internation Children's Emergency Fund.

United Nation, (2010). Develop a Global Partnership for Development. Retrieved on 28.05.2010 from http://www.un.org/millenniumgoals/global Retrieved on $15 / 01 / 2010$.

Yates, C. (2007). Teacher education policy: International development discourses and the development of teacher education. Paris, France: United Nations Educational, Scientific and Cultural Organisation. 


\section{Part 3}

Distance Learning Pedagogy 



\title{
Self-Regulated Learning Activities: Supporting Success in Online Courses
}

\author{
Maureen Snow Andrade \\ Utah Valley University \\ USA
}

\section{Introduction}

Although most higher education institutions offer some form of distance education (Parsad \& Lewis, 2008), learners may struggle with this mode of learning due to insufficient independence and discipline. Success in these contexts requires learner self-regulation, or the ability to control the factors and conditions that affect learning (Dembo, Junge, \& Lynch, 2006). The Model of Self-Regulated Distance Learning (Andrade \& Bunker, 2009, 2011b) has been successfully applied to online distance English language courses to increase learners' self-regulation, capacity for autonomy, course persistence, and language proficiency (Andrade \& Bunker, 2011a). The model, based on the theories of transactional distance (Moore, 1972, 2007) and self-regulated learning (Schunk \& Zimmerman, 1994; Zimmerman, 1994; Zimmerman \& Risemberg, 1997), provides a framework to guide course designers and teachers in helping learners develop self-regulated learning behaviours as they master course content. The model is applicable to any course or content area. This chapter briefly reviews the theoretical underpinnings of the model and research that demonstrates its effectiveness. It then shares approaches and activities that can be embedded into distance courses to meet learners' diverse needs and educational backgrounds. These activities are illustrated with examples of distance English language courses and learners.

\section{Theoretical model}

Moore's theory of transactional distance involves three components: structure, dialogue, and autonomy. Structure consists of the objectives, assignments, due dates, textbook, schedule, and other organizational elements in a course. Dialogue involves interaction with the teacher, peers enrolled in the course, and agents of the institution. It might include email, telephone, video conferences, and written and oral assignment feedback. Autonomy has been defined numerous ways, but can best be conceptualized as involving two key components - choice and capacity. Choice refers to the learner's freedom to make decisions about learning, specifically setting goals, selecting materials, determining how and what to study, and evaluating performance (e.g., see Holec, 1981; Hurd, 1998b, 2005; Little, 1991, White, 2003). When learners do not have much input related to a course, the level of autonomy is low. In these cases, structure is high, meaning that decision-making about what and how to learn are controlled within the course or by the teacher. 
Capacity refers to the learner's ability to be self-directed in terms of being an active learner, taking control, and awareness and use of learning strategies (e.g., see Garrison, 2003; Holec, 1981; Hurd, 1998a; Vanijdee, 2003; White, 2003). When learners have the capacity to be autonomous, they are more likely to achieve success in a distance learning context. When structure and dialogue are high, the "transactional distance" (Moore, 2007, p. 90) between the learner and the teacher decrease; the level of autonomy also decreases. Although high levels of structure and dialogue may provide necessary scaffolding and support for learners, these components should ideally lead to the learner building capacity for independence and needing less structure and dialogue to be successful.

Self-regulated learning is closely related to capacity as it involves learner self-direction and responsibility. It provides a framework for how learners can control the learning process. Self-regulated learning involves six dimensions: motive (e.g., reasons for learning, goals, self-talk, rewards/punishments), methods (e.g., learning strategies), time (e.g., time management, when to study), physical environment (e.g., identification and elimination of distractors), social environment (e.g., help, collaboration, communication), and performance (e.g., evaluation, reflection, goal revision) (Dembo et al., 2006; Schunk \& Zimmerman, 1994; Zimmerman, 1994; Zimmerman \& Risemberg, 1997). Learners who manage these dimensions and show evidence of being self-regulated are academically successful (Dembo et al., 2006). The term self-regulated learning has some advantage over the concept of autonomy because it emphasizes how to develop responsibility for learning and related behaviours. The dimensions provide a specific structural framework upon which to base course activities and strategy instruction. Self-regulated learning encompasses "the practical steps taken by learners to manage their own learning" (Hurd, 2005, p. 10).

Figure 1 depicts how interaction with structure and dialogue, course content, and related self-regulated learning activities contribute to the development of self-regulation and learner success (e.g., see Andrade \& Bunker, 2009, 2011a, 2011b). Learners begin a course with initial levels of self-regulated learning, commitment, and language proficiency (or knowledge of course content). In the English language courses described in this chapter, dialogue is provided through instructor feedback, e-mail, discussion groups, and live tutoring (the latter offers interactive language practice). Structure occurs through the study guide with instructions and links to course materials, the calendar with assignment due dates, audio and video presentations, and the textbook. Self-regulated learning activities, designed to provide goal-setting, application, and reflection opportunities, are included for each of the six dimensions. As students work with the course materials, learn and practice the language, and participate in self-regulated learning activities, they increase their selfregulation, capacity to be responsible and make appropriate choices with decreasing amounts of guidance, likelihood of persisting, and language proficiency or subject area knowledge. The model advances the practice of distance learning by providing a framework, based on established theories, by which to enhance learner success.

The model has the potential to positively affect distance learning in a variety of contexts and disciplines. Although some distance courses have utilized or studied self-regulated learning components such as motivation, reflection, metacognition, and goal setting to aid student success (e.g., see Bothma \& Monteith, 2004; Chang, 2005; Hurd, 2000, 2005; Murphy, 2005; Tobias, 2006; Thang, 2005; van den Boom, Pass, \& van Merrienboer, 2007), the framework depicted in Figure 1 and as described by Andrade and Bunker (2009, 2011a, 2011b) provides 


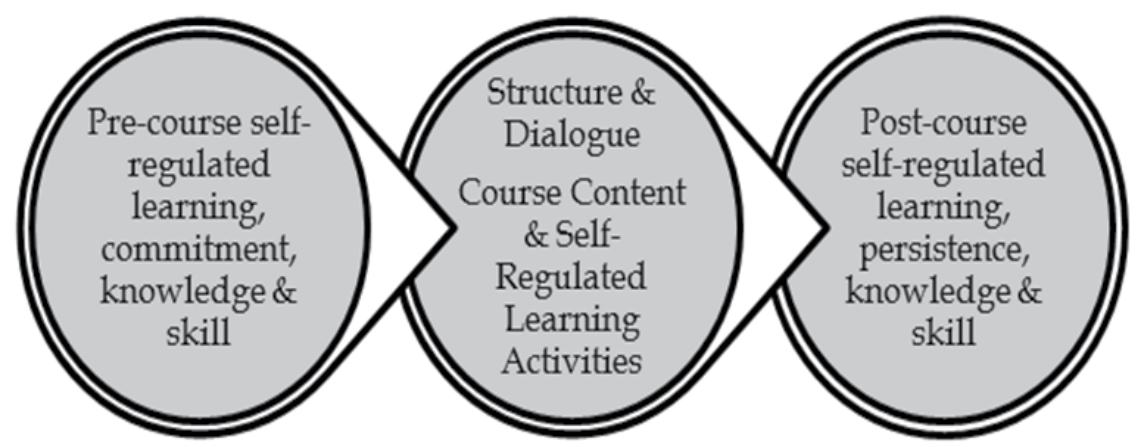

Fig. 1. Steps to self-regulation for distance learners.

designers, teachers, and students with guidance for addressing needs, strengthening weaknesses, and realizing success. The model is applicable to any content area or course. Course designers must consider the six dimensions of self-regulated learning and how to integrate them into course materials to develop and enhance learner responsibility.

\subsection{Effectiveness of the model}

A qualitative study consisting of 20 distance English language learners enrolled in a high intermediate level reading/writing course provides evidence of the model's effectiveness (Andrade \& Bunker, 2011a). Data was collected through reflective journals in which learners reported increased self-regulation, persistence, and English proficiency. As learners participated in the self-regulated learning and language activities in the course, they reflected on their performance in their journals, specifically their goals and strategy use. The self-regulated learning dimension of performance, or monitoring and evaluating progress in order to refine goals, was the primary purpose of the assignment. The journals were submitted to the teacher at various points during the course.

An analysis of these journals indicated a number of themes related to self-regulated learning and the dimensions. Learners reported that they had increased responsibility for their learning in the following ways: identifying their purpose for learning and understanding the importance of setting and achieving goals (motive), applying various study strategies (methods of learning), tracking and prioritizing their use of time (time), identifying appropriate times and places for study (physical environment), and recognizing that seeking help from tutors and teachers is a positive behaviour (social environment). The dimension of performance was embedded in the journal assignment itself.

Autonomy in the course was supported as learners had a choice of self-regulated learning activities based on an initial survey that helped them identify their strengths and weaknesses related to the dimensions. Learners selected an initial dimension on which to focus and corresponding activities to assist them in developing needed strategies. For instance, for the dimension of social environment, learners could choose from four activities-seeking help, preparing for a tutoring appointment, preparing for a teacher conference, or interacting with classmates. Choices related to the dimension of time included recording activities for 24 hours, prioritizing activities, evaluating time use, and organizing time. (More information about these activities is included in the Approaches and 
Activities section of the chapter.) Leaners were also offered relevant activities for the dimensions of motive, methods of learning, and physical environment. As they completed the activities of their choice and evaluated their performance (the sixth dimension of selfregulated learning), they revised their goals, set new goals, and continued to monitor their progress. They were required to do one activity each week and report on the experience in their learner journals, which they submitted to the teacher. When they felt they had made sufficient progress with one dimension, they could work on another. They had a variety of choices involving the dimensions, the activities, and the number of activities they participated in for each dimension.

The survey and related activity choices modelled the idea of taking responsibility for learning outcomes rather than depending on direction from the teacher. Structure was provided, as mentioned earlier, through various course components (e.g., study guide, calendar, due dates) as was dialogue in the form of announcements, e-mail reminders and assignment feedback, but choices were provided and the amount of structure and dialogue given varied across learners with the teacher being mindful of supporting the development of self-regulated learning.

A key structural element of the course was the study guide, which provided objectives, an overview of course content and tasks for each week, an estimate of the amount of time it would take to complete readings and assignments, instructions, study tips, and links to course materials, which were available in the learning management system. Icons in the study guide represented the various elements of the course such as "communicate," "self-check," "submit assignments," and "tests and quizzes." These icons were easily recognized and used consistently to help learners identify the various sections of the study guide and corresponding information. The study guide served as the teacher's voice in the course and was comparable in many ways to what a teacher would say in the classroom to instruct and support learners. Dialogue was sometimes provided to the entire class, as in the case of general feedback about an assignment or clarifications of an upcoming task, but it was also individualized in the form of e-mails to learners who were behind schedule or missing assignments, for instance. Thus, structure, dialogue, and autonomy were variables in the course that were managed in such a way as to support the learner yet promote self-regulation.

Overall, the study demonstrated that the model, designed to increase learners' levels of selfregulation and proficiency in the content area (in this case, English language ability) through interaction with course materials, self-regulated learning activities, and varying amounts of structure and dialogue, was effective in helping learners overcome challenges related to the distance learning mode. Learners reported that the self-regulated learning activities resulted in higher test scores and grades and improved learning skills and English proficiency. The following quotation illustrates:

Actually, there are many choices and strategies to use in this distance education course. Those include daily schedule, using study guide and text book, place to study, strength and weaknesses being a language learner, and getting help. According to my experience these are the important factors that can help me in this online course.

Limitations of the study include self-reported data and a small sample size. One of the findings that must be addressed in future iterations of the course is learners' depth of reflection and the conceptualization of goals. Some learners formed very broad goals such as 
improving their vocabulary and grammar or becoming a better reader, but did not identify specific sub goals or strategies related to these general areas. This can be addressed through teacher feedback to the learner journals as well as the inclusion of additional examples of goals, sub goals, and strategies within the course. However, overwhelmingly, students demonstrated not only awareness, but clear understanding, of the six dimensions of selfregulated learning and how to apply them to their English language studies. Related to methods of learning, one learner indicated: "I preview the course materials before I begin working on each unit (Study Guide, textbook, Blackboard); I will look at the assignments that will be due before I start working in each unit." Others indicated plans to apply the components of self-regulated learning beyond the course: "I'll keep applying them [selfregulated learning strategies] into every phase of my learning journey."

\section{Approaches and activities}

Learners' diverse needs, including linguistic, cultural, and educational backgrounds, must be considered when planning course content and activities. Learners from countries across the globe are enrolled in the distance English language courses described in this chapter. Countries include Norway, Nigeria, China, Mongolia, Cambodia, India, Indonesia, the Philippines, Thailand, Japan, Korea, Taiwan, Hong Kong, Saipan, Tonga, Kiribati, Papua New Guinea, the Dominican Republic, and Chile, to name a few. Course design must take into account how to accommodate learners from various time zones, with differing levels of computer access and literacy, English language proficiency, study skills, and familiarity with distance learning. Perhaps the greatest differences we have encountered among learners is their technological knowledge base, which ranges from those who are true digital natives to those who need to access a computer at an internet café or get help from someone they know in order to navigate course technology. Knowing this, our courses are designed to accommodate a range of skill levels and largely focus on the use of basic Word processing tools and PDF documents to accommodate variations in internet speed, web accessibility, equipment, and software.

Due to cultural backgrounds and educational experiences, learners have a range of expectations for learner and teacher roles, which affect the learning process. One of the situations we have encountered is that many learners, across countries and cultures, are accustomed to teacher-centered instruction. Distance learning requires that learners possess a degree of independence and discipline. Thus, the idea of self-regulated learning, choice in activities, and monitoring performance may be new to learners. Differing cultural backgrounds also serve as the basis for interesting perspectives on readings and related discussions.

Beyond this, learners also have diverse purposes, concerns, and individual situations. Some learners can work on a course daily while others may only be able to access it on a weekly basis due to employment situations. This section focuses on approaches and activities for addressing learners' needs and assisting their development as self-regulated learners, and consequently, their success in distance course work.

\subsection{Preliminary design decisions}

Prior to designing actual course activities, and particularly those specific to self-regulated learning, other decisions must be made. One of the first of these is to determine whether the 
course will be synchronous (learners progressing through the course together, often with scheduled whole or small group activities via text and voice chat, video, television, or telephone) or asynchronous (learners doing assignments on their own with interaction activities not dependent on learners connecting simultaneously to course learning systems). With learners from all over the world, or at least across several time zones, which is typical of many distance learning contexts, an asynchronous approach may be appropriate although some synchronous activity can be built in through live peer or tutor interactions that accommodate learners' time zones and schedules. If regular interaction and fixed assignment due dates are characteristic of the course and learners are expecting to work independently without interaction, however, this will affect their reactions and adjustment to the course. To address differing expectations, information about course design and content must be clearly communicated prior to enrollment and after the course begins.

Course designers and instructors must also have a sense of prospective learners' access to and familiarity with technology. In cases where learners have challenges with power outages, expensive fees for internet use, or limited computer access, printed materials can be provided or other accommodations made. Some learners in our courses only have access to a computer and the internet once a week. We addressed this by providing a printed study guide and textbook (to accommodate lack of available, on-going computer access and power failures), and a CD-ROM (so as to not be dependent on the internet). Learners can work from these materials and do word processing and assignment uploads when they have access to a computer at an internet café, place of employment, or friend's home. Before they enroll, learners should be informed of the types of technology they will need to use (i.e., webcams, learning management systems, live interaction tools) so that they will be prepared with the necessary skills for the course from the beginning and will not fall behind and become frustrated due to unfamiliarity with technology-based tasks and learning systems. If learners do not have these skills, designers and instructors can provide related tutorials in the first week or so of instruction and gradually introduce course assignments and their related formats and technology on an on-going basis.

Another key area to address, as it impacts learners' reactions to and attitudes about selfregulated learning course components, is views about learning and learner/teacher roles. Learners may be accustomed to either a passive or an active role, summative rather than formative assessments, a negative or positive opinion of help seeking, teacher-centered or learner-centered instruction, dependence on an authority figure or independence, an external or internal source of motivation, rote learning as opposed to critical thinking, face to face interaction in contrast to technology-based social networking, and an externally set daily learning schedule rather than a variable self-created schedule. These factors all have an impact on student learning and success.

To address these cultural, educational, and individual differences, perspectives, and dispositions in the learning environment, the course designer and instructor must be aware of and ready to accommodate and ameliorate factors that affect academic achievement and successful learning outcomes. The institutional infrastructure (i.e., technology help, information sources, learning assistance) must also be designed to provide needed support. Familiarity with learners' backgrounds and expectations is critical prior to course design and can be accomplished through a needs analysis. If not part of the course itself, an assignment that asks learners to share previous experiences, expectations, motivations for 
taking the course, and goals should be arranged by the instructor. This type of activity may be introduced as part of the motive dimension of self-regulated learning. In any case, course technology, content focus, and learning philosophies (including the emphasis on selfregulated learning) must be provided to learners preliminary to enrollment and early on in the course to prevent surprises and ensure the course is a good fit. It should also be addressed on an on-going basis as learners interact with each other and the instructor through discussion boards, presentations, e-mail communications, reflective journals, and live tutorials, as applicable.

\subsection{Self-regulated learning activities}

Possible types of activities corresponding to the six dimensions of self-regulated learning are indicated in Table 1. These have been used in distance English language courses. Course designers and teachers must consider student needs and specialized content characteristics as these will inform the choice, design, and structure of the activities. For instance, distance language learning has always been more problematic than acquiring knowledge in other subjects due to the need for interaction (Hurd, 2006). Second language acquisition theory indicates that learners must not only have comprehensible input (Krashen, 1985) (i.e., sources of reading and listening appropriate to the learner's proficiency level), but also

\begin{tabular}{|l|l|}
\hline Motive - Why? & $\begin{array}{l}\text { Purpose: to determine reasons for learning; analyze strengths and } \\
\text { weaknesses; set goals } \\
\text { Activities: diagnostic instruments; surveys; reflection; discussion } \\
\text { and video posts; live interactive conferences; self-talk analysis; value } \\
\text { identification }\end{array}$ \\
\hline $\begin{array}{l}\text { Methods of } \\
\text { Learning - How? }\end{array}$ & $\begin{array}{l}\text { Purpose: to expand knowledge and use of effective learning } \\
\text { strategies; improve long-term memory \& retrieval } \\
\text { Activities: evaluation; use of course materials; discipline-specific } \\
\text { learning strategies; scaffolding \& modeling; resources \& guides; } \\
\text { study skill tips }\end{array}$ \\
\hline Time - When? & $\begin{array}{l}\text { Purpose: to improve time management; increase self-esteem and } \\
\text { sense of competence } \\
\text { Activities: analysis of use of time; logs and records; prioritization }\end{array}$ \\
\hline $\begin{array}{l}\text { Social Environment } \\
\text { - With Whom? }\end{array}$ & $\begin{array}{l}\text { Purpose: to utilize sources of help; seek collaboration; improve } \\
\text { communication } \\
\text { Activities: e-mail; chat; social networking; blogs; live conferencing; } \\
\text { learn from experts and successful peers; modeling; role play }\end{array}$ \\
\hline $\begin{array}{l}\text { Physical } \\
\text { Environment - } \\
\text { Where? }\end{array}$ & $\begin{array}{l}\text { Purpose: to restructure the physical environment to make it } \\
\text { conducive to study } \\
\text { Activities: analysis of environment; distracter classification; } \\
\text { restructuring of the environment }\end{array}$ \\
\hline $\begin{array}{l}\text { Performance } \\
\text { - What? }\end{array}$ & $\begin{array}{l}\text { Purpose: compare performance and goals; analyze \& revise goals } \\
\text { Activities: regular reflections; self-progress reports; teacher and peer } \\
\text { feedback }\end{array}$ \\
\hline
\end{tabular}

Table 1. Example self-regulated learning activity types. 
opportunities for output (Swain, 1995), or the opportunity to negotiate meaning, make input comprehensible, get feedback, and modify discourse to effectively communicate (Long, 1996). Additionally, English language learners are often accustomed to passive learning modes rather than critical thinking, synthesis of knowledge, risk-taking, and learner responsibility, and thus must be encouraged to engage, interact, and use the language for communicative and problem-solving purposes. Foreign language courses in the Open University system in the U.K. contain strategy instruction to promote learner autonomy and success (Hurd, 2005), recognizing the challenges of distance learning and the potential unfamiliarity of learners with needed language learning and general study strategies. Regardless of content area, course activities supportive of learner success, in the form of selfregulated learning, can be embedded in the course.

Recognizing the needs of distance learners, many of whom are non-traditional in that they are older, employed, responsible for dependents (e.g., see Chen, Gonyea, \& Kuh, 2006), unfamiliar with technology-based learning, returning to education after time away, and may have misgivings not only about the distance format but also their ability to be successful, self-regulated learning activities can be designed to strengthen learner responsibility, increase knowledge and application of strategies, and alleviate fears. In the case of distance English language learners, we carefully designed activities to engage students in practicing English as they increase their levels of self-regulation. The activities focus on learning strategy awareness and application and provide opportunities for input and outputrequired components of language acquisition; in this way, content learning needs and selfregulated learning development complement each other.

Course designers may also want to provide learners with an array of activities from which to select in order to support the development of autonomy. Online distance courses lend themselves well to learner choice. To implement this, an assessment can be included that helps learners identify their strengths and weaknesses pertaining to the six dimensions of self-regulated learning. They can then select appropriate activities to address areas of weakness. At various intervals during the course, learners should reflect on their performance related to course content and their progress with the dimensions to determine how they might adjust their goals and associated methods of learning.

Our 15-week high intermediate level reading/writing course focuses on the development of language skills for academic purposes as most of our learners have the goal of pursuing post-secondary studies in an English-speaking country. For each level of language proficiency (i.e., low intermediate to high advanced), learners can choose from skill-based courses such as reading, writing, listening/speaking, or a content-based language course (e.g., biology, religion). The learning objectives for the high intermediate reading/writing course, as an example, focus on comprehension of academic readings through building vocabulary knowledge and reading strategies (e.g., previewing, finding the main idea, skimming and scanning, recognizing inferences and opinions, synthesizing and applying information, using graphic organizers, understanding word forms and grammatical constructions, etc.), and improving their writing ability in terms of organization, development of ideas, and grammatical accuracy at the paragraph and short essay level.

The students are also assigned study partners and groups and use the technology available in the learning management system such as e-mail, chat, and discussion forums to interact and practice their language by responding to ideas and exercises based on the course materials. 
The technology-enhanced interactions are introduced gradually and varied throughout the course as are the study partners and groups. An initial assignment involves learners creating a home page within the learning management system and posting an introductory video clip or a written introduction and picture of themselves. They also participate in a live weekly interactive tutoring session in which they discuss an assigned topic and ask logistical questions about the course. Learners take an initial placement test that indicates their language proficiency level (i.e., low/high intermediate or low/high advanced). They also take reading, writing, and vocabulary pre- and post-tests and have unit tests measuring the reading skills they have practiced. They submit various drafts of writing assignments for each unit in the course and receive feedback from a peer tutor and the instructor using a word processing tracking tool. The writing assignments are scored with a rubric.

The course begins with a learner self-assessment of the dimensions. From there, learners choose an initial dimension on which to focus and activities within that dimension. They complete a self-regulated learning activity each week and write a journal reflection. Instructors respond to the content of the journal but not to the language use as the purpose of the activity is to gain fluency in writing, have a specific purpose for communicating, and above all, to express understanding and application of the dimensions. The instructors score the journals according to a rubric which emphasizes the depth and thoroughness of the reflection and overall ability to communicate. Half way through and at the end of the course, learners focus on the dimension of performance by reviewing their success at attaining their goals and determining how to make adjustments. In this way, language practice (e.g., writing) and self-regulated learning development complement each other.

The next section outlines practical, easy-to-implement activities for distance language courses with ideas for how these can be applied more broadly. Each dimension is explicated and illustrative examples provided regarding how learners can develop related skills.

\subsubsection{Motive}

Motive is conceptualized as purpose for learning. It involves the learner determining reasons for enrolment in a specific distance course and what the learner hopes to attain as a result. It also encompasses the source of motivation - internal or external. Learners often believe that the instructor is responsible for motivating them (Dembo \& Eaton, 2000) rather than recognizing that self-motivation leads to greater levels of achievement. Related to this dimension, learners identify their motive for learning, set specific goals, examine their selftalk (i.e., internal thoughts and verbalizations regarding beliefs in their ability to be successful), and consider possible rewards and punishments for their behaviours (Dembo \& Eaton, 2000; Dembo et al., 2006; Dembo \& Seli, 2008). Learners who enrol in distance courses do so for a variety of reasons, including convenience, preference for self-paced learning, and a desire for independence (e.g., see Chen et al., 2006). These reasons for choosing distance learning must be accompanied by goal setting and other strategies that help learners sustain and increase levels of motivation. Distance learners may not have the benefit of external sources of motivation, such as the incentive of being prepared before facing their teacher and peers in class several times a week, thus it becomes easier to relax and lose momentum.

\subsubsection{Reasons for learning}

One activity we have used to help learners identify their reasons for learning is to listen to a video clip of an inspirational speaker and his experiences learning English. The speaker is a 
well-respected and known figure to the learners. He explains how he grew up in East Germany and learned Russian in school (Uchtdorf, 2006). The Russian language was difficult, but when his family moved to West Germany and he was required to learn English, he found it to be impossible until he realized that to attain his dream to be an airline pilot, he would need to be fluent in English. His motivation, persistence, desire, and ability to learn English completely changed.

Learners' English language skills are developed as they listen to and read excerpts from the talk and respond to specific questions in writing. They reflect on the content of the speech and apply it to their own English language learning situations. As they respond to the speakers' ideas and reflect on their reasons for learning, they identify with greater clarity the depth and source of their motivation. For example, one learner stated:

From doing this activity, I learnt that setting different goals affect our life. Before setting goals, we need to weigh many things. For example: ability and times. ... Setting goals is meaning I have a dream, an ideal. It means that I decided to make more effort for my future. Setting goals is also helping me to recognize what I want to do. Let me remember how important of my future.

Autonomy is supported as learners choose to either listen to or read the talk, and to listen to or read it in its entirety rather than only the clip in the lesson. For other content areas or academic disciplines, autobiographies, biographies, or recordings of professionals, experts, researchers, and theorists might be used in a similar way. Learners can engage in live chat or discussion board activities related to their response to these sources of information.

\subsubsection{Goal setting}

Goal setting is critical to the dimension of motive and the basis for strategy development related to the other dimensions. For instance, English language learners might set a goal to increase their active use of academic vocabulary. This broad goal would be accomplished through sub goals such as becoming familiar with the Academic Word List, assessing knowledge of words on the list, identifying research-based methods of learning vocabulary, and then selecting one or two of these methods to apply to vocabulary acquisition. Specific strategies might include use of word cards, study of word parts, or dictionary use. These would be implemented according to guidelines for effective ways to utilize these strategies.

One of the self-regulated learning activities in our course provides learners with the opportunity to identify their values, or principles that guide their lives, and how these values are related to their long-, intermediate-, and short-range goals. They determine if and how these values are related to the course and improving their English language proficiency. In their learner journals, they write a description of their experience working through the guiding questions (i.e. what they learned about their values, which values are most important to them, which values relate most closely to the content of the course, why it is important to identify values before setting goals, and how values and goals are related to motive). They then identify appropriate goals and timelines for goal accomplishment. Related to goal setting, one learner commented:

The values that are important to me are as follows: family, God, service, education, and self-respect. The value that is the most important to me in this course is education. This course helped me write English accurately before getting in to the college.... The reasons 
I need to know my goal is that I would like to set each step to accomplish the goal I set

.... I will try my best to study harder. [This activity] woke me up to study hard.

Goal-setting can help learners in any course identify what they seek to accomplish through the course and the incremental steps they must take to achieve their desired end result.

\subsubsection{Methods of learning}

Methods of learning help learners acquire information and store it in long-term memory. High-achieving learners possess a variety of learning strategies and know how to use them effectively (e.g., see Dembo \& Eaton, 2000; Dembo et al., 2006; Dembo \& Seli, 2008). They understand that using one or two strategies in all situations is ineffective. Learning methods range from those that are less beneficial such as rehearsal, or copying notes, reciting, and underlining, to those that support making connections between new material and previously learned information. The latter include elaboration, which involves paraphrasing, summarizing, creating analogies, and posing and answering questions as well as methods for organizing information such as mapping and outlining. In distance courses, methods of learning are essential as learners do not have the benefit of face-to-face interaction with the instructor, who could provide additional guidance beyond what is available in the course, thus they need a variety of methods of learning to access and comprehend material on their own.

\subsubsection{Use of course materials}

In all courses, familiarity with the parts of the textbook, supplemental resources, the online course management system, and other resources are important, but for a distance course, this is critical. Learners must understand how the course is organized within a learning management platform, where to locate relevant course materials, and how to submit assignments. Teachers and classmates may not be readily accessible to answer questions. Methods of learning related to using the course materials set a strong foundation for the implementation of strategies leading to in-depth learning. Also relevant are good reading strategies as much information in a distance course is communicated through the written form.

In our course, learners examine a list of reading strategies and evaluate themselves on their ability to apply these strategies to their use of the course study guide and textbook. Examples of effective reading strategies include previewing assignments and due dates, predicting what comes next, writing down questions, taking notes, identifying main ideas, completing exercises, and measuring comprehension. As part of the self-evaluation, learners rate levels of ability related to each strategy - what they do always, sometimes, or neverand determine their strengths and weaknesses. They consider what has worked well for them in the past, what might be particularly effective in the distance course, and which strategies are new and need to be learned. They then set a related goal and indicate how they will begin to learn about and implement the strategy they have selected. The next step is to write a description of their experience with this activity in their learner journal. One learner commented: “The strategies I use are to find any reading helps in the study guide or text book (hints, objectives, definitions, boldface or italic print summaries, tables or figures), but not very often is to predict (guess) what will come in the next section." This learner recognizes a familiar strategy and one she could adopt in the future to improve her learning. The activity builds language skills-reading, writing, communicating-as well as self- 
regulated learning. Courses in any discipline can incorporate study strategy instruction and practice specifically designed to support learner success.

\subsubsection{Preferences for learning}

Another area that lends itself well to language acquisition and learning in general is increasing awareness of learning preferences. In our English language courses, learners complete an activity that helps them determine their preferred methods for gaining proficiency in English such as talking to friends, watching television, studying grammar, playing games, practicing English outside of class, interacting with friends or native speakers, having the teacher point out their mistakes, obtaining language input through reading or listening, or practicing pronunciation. These items are organized into sets, which are categorized according to learning types (i.e., authority, communicative, analytical, concrete) (e.g., see Scharle \& Szabó, 2000).

The categories are based on Gardner's $(1983,2004)$ multiple intelligences theory, which encompasses types of intelligences such as visual-spatial, bodily-kinesthetic, musical, linguistic, logical-mathematical, interpersonal, and intrapersonal, as well as on the personality dimensions of extraversion and introversion and preferred logic approaches (i.e., deductive, inductive). After the evaluation process, learners analyse their preferences and how this information can help them be a better student, language learner, and distance learner. As with the other activities, they reflect on their experience with the activity in their journals. The effectiveness of this activity is illustrated by the following journal excerpt, which also illustrates how this individual benefits from the social environment:

I like studying with people. The more people I have, the more understanding I gain. It means that working or studying with people is better than studying independently. . . . For instance, my teacher assigns me to write a proposal about scholarship and I do not know how to write it. In this case, I need to ask for information from someone who knows how to do it. Those people will help me find the ideas and help me correct my drafts.... When I work on a group assignment I never feel lost for ideas because my group members share their concepts. Moreover, I could get help from my team members when I need more explanation on any task. Another important point that I could get from my group is emotional support. ... . To sum up, self-study would never be my learning style.

A wide range of learning preference instruments are available or can be adapted to fit the needs of various courses and subject areas. As demonstrated by the English language learning example, surveys can be tailored to reflect content or skill areas. The Strategy Inventory for Language Learning (Oxford, 1990) is a useful resource for language learners to create awareness and expand knowledge of possibilities. More general learning preference measures can also be administered to help learners in all contexts understand how they learn (e.g., see http://www.lth3.k12.il.us/rhampton/mi/mi.html for multiple intelligences instruments). For distance learners, understanding their learning preferences can help them make appropriate choices related to course options and strategies needed for mastery of the material.

\subsubsection{Time}

The dimension of time involves managing time, avoiding procrastination, and prioritizing activities. Learners who manage their time well have better academic achievement, higher 
self-esteem, and a greater sense of competence than those who do not (Dembo \& Eaton, 2000; Dembo \& Seli, 2008). When effective time management results in achievement of learning outcomes, learners have positive feelings about themselves and their abilities. This reinforces their motivation to make effective use of their time and apply themselves to their studies. Procrastination can be a way for learners to protect their identity from failure (Ferrari, 1991). If a learner procrastinates and gets a poor grade, the learner can attribute it to lack of time rather than lack of ability. Time use strategies include working on a task for a short period of time rather than ignoring it, thus building momentum to continue working (Ellis \& Knaus, 1977), and changing dishonest self-talk (Ferrari, Johnson, \& McKown, 1995). The latter involves not convincing oneself that it is too late to complete a task or that one does one's best work at the last minute. A more positive approach is to tell oneself that it is not too late to start and that time is important to doing a thorough job on a task. This type of self-talk results in improved attitudes, motivation, and behaviour. Learners can improve their use of time through instruction. This is particularly critical to success in a distance course as learners are largely on their own to set goals, manage and complete assignments, divide learning tasks into manageable parts, and determine their own schedules.

\subsubsection{A record of time use}

To help our learners recognize how they use their time, they engage in an activity in which they record their activities for a 24-hour period. Then they analyse their use of time-how they used it, what surprised them, what they learned, how they waste time, and where they could find more study time. They write about their findings in their journals. For some, this straightforward activity is a real eye-opener. One learner reported the following:

While I am keeping track of my activities for 24 hours, I learned that "Time is a precious thing." From this activity, I am able to know what I did in a whole day. I can see my worst time and my best time. For example, I used most of my time for watching TV; sleeping at evening time; teaching my nephew; going to my friend's house; and reading the student guide. And what surprises me? Watching TV and sleeping at evening time took more of my day than I expected.

A variation to the exercise is to ask learners to organize their use of time into categories. Categories might include essential things (eating, sleeping, working), necessary things (spending time with family, caring for loved ones), and nice-to-do things (sports, watching television, hobbies, visiting with friends) (categories adapted from Beck, 2010). What individuals consider essential, necessary, and nice-to-do will vary, but this exercise helps them prioritize and manage their time. They can then plan how they will use their time in the next week, and list and prioritize their activities based on the categories. At the end of the week, they evaluate and revise their plan for the next week as needed.

\subsubsection{Time use strategies}

Strategies for time use are also critical to success in distance learning courses. Although these are important in all learning contexts, distance courses have greater flexibility, thereby giving learners more autonomy over when and for how long to study. The lack of a structured schedule, however, can lead to procrastination and be a deterrent to success. Learners may have limited dialogue with the instructor and other learners, and course structure may be loose in some cases, thus learners must determine how much time is 
needed to complete assignments and how to plan and schedule related tasks. The following list provides some general guidelines for use of time (adopted from Dembo \& Seli, 2008).

- Set a regular daily study time, as though attending a face-to-face class.

- Determine what to work on during the study time-reading, review, specific assignments, or interaction activities.

- Evaluate the level of difficulty and amount of time needed for tasks-those that are easy and can be done quickly and those that are more difficult and will take more time. Begin difficult tasks and those that will take more time early. Break them into steps and work on them incrementally. For example, writing a research paper involves finding relevant articles, reading and taking notes, synthesizing ideas, drafting, formatting references, and so on. Decide ahead of time which of these tasks to work on during the set study time.

- Make use of short periods of available time to review notes, organize study materials, preview readings and exercises, plan, or do e-mail correspondence.

- Work ahead-look at the course assignments for the upcoming week and major assignments and their due dates. Complete what needs to be done and then continue to the next day's assignment. Aim to get ahead of schedule and begin working on major course assignments. Working ahead makes unexpected problems such as illness or minor emergencies more manageable.

These strategies can be shared with learners in pre-enrollment information, the course study guide, or instructor e-mails and announcements. In our course study guides, we include study tips related to the assignments. The tips are brief pointers to help learners approach tasks effectively and efficiently and improve success. Time use and other strategies can also be topics for pair and group interactions, writing assignments, or even be included on tests. For example, a bonus test question might be, "How did you manage your time to prepare for this test?" This helps learners reflect on their performance. As instructors reinforce the importance of all the dimensions of self-regulated learning, students will begin to understand and value them. They will develop the ability for effective learning and recognize strategies that are efficacious in distance learning contexts.

\subsubsection{Physical environment}

Distance learners must create their own learning and study spaces. They do not have the advantage of instruction in a classroom and may not have accessibility to a library or similar environment that is largely free from distractions as do traditional students. As such, the dimension of physical environment is of critical importance. This dimension involves the learner's ability to restructure the physical environment so that learning can be effective (Dembo \& Eaton, 2000; Dembo et al., 2006). Learners need to locate places to study that are quiet and free from distractions. Specific strategies for eliminating distractions might be turning off cell phones, e-mail notification alerts, music, and television. Learners may also want to identify a particular time of day most conducive to concentration. For some, this is early in the morning or late at night when they are free from responsibilities in the home. Others may decide to go to internet cafes to upload assignments at non-peak times to avoid the noise. Another consideration for distance learners is ensuring that they have sufficient computer skills to engage in the tasks in the course. If not, computer problems can distract from the ability to access and complete assignments. In addition to external distractors in 
the form of noise and interruptions, internal distractors such as personal concerns and anxieties also play a role. In both cases, learners must increase their awareness of where and why these distractors occur and take steps to eliminate them.

\subsubsection{Study behaviours}

Distance language learners in our courses who complete the initial self-assessment related to the six dimensions and determine that controlling the physical environment is one of their weak areas have the option of several related activities. One of these is to complete a chart in which they list the various places they study and what they do in this location (e.g., internet café-e-mail communications). They then view a series of statements describing how well they study in each location (e.g., I can work on my studies without being interrupted. I can begin studying immediately. I can concentrate.). They use a rubric with a score ranging from 1 to 5 depicting to what degree the statement describes their study behaviour. Next they respond to a series of questions guiding them in an analysis of their findings (e.g., Which location did I rate the best? Do I study well in more than one location? How can this information help me improve the places where I study?). The last step, as always, is to write a description of their experience with the activity in their journals. The value of this activity is indicated by one learner as follows:

For me, evaluating my study environment is so important to change the way of my study. ... There are four study locations chosen for my environment evaluation such as at my office, at internet shop, my house, and my friend's office. . . . With no doubt, the evaluation showed me my high and low points in each location. In evaluation result, studying at my office gives me the lowest outcome in the above four places. . . . In reality, the answer from this evaluation will tell my poor study and guide me how to develop or change my study environment if I would like to get successful in my study.

\subsubsection{Attention and concentration}

Learners can also benefit from a better understanding of attention and concentration. Attention refers to controlling "awareness of events in the environment," and concentration to the "continual refocusing on a perceived stimulus or message" (Dembo \& Seli, 2008, p. 167). In other words, learners are attentive when they are not distracted by the environment or their own emotional and physical needs. They concentrate by continuing to refocus on a learning task. To improve ability in both areas and manage distractors, learners can be made aware of appropriate strategies and set goals for implementing and monitoring their use of these strategies. The following list of strategies is adopted from Dembo and Seli, 2008.

- $\quad$ Study in a designated area free from noise and distractions.

- Control distractions by making sure the space is physically comfortable (temperature, light, furniture) and that disruptions will not occur (leave an automated phone or email message indicating availability after a certain time, put a "do not disturb" sign on the door, etc.).

- Attend to physical needs by eating, drinking, or taking a short nap before studying. Avoid studying at times with increased likelihood of hunger and sleepiness.

- Alternate learning tasks and subject areas and take short breaks every hour.

- Resolve worries and concerns prior to studying if possible.

- Use active learning techniques such as asking questions, outlining, summarizing, notetaking, and mentally reviewing materials to increase concentration. 
- Set goals for what aspects of a task or assignment are to be accomplished in particular time frame.

- Have an overall plan for time use during the week, leaving blocks of time to work on specific courses or assignments.

As learners engage in the use of these strategies, they should continue to evaluate the challenges they have, the causes of these challenges, and the effectiveness of the strategies they are using, and make modifications in their study plans, time use, or physical environment as appropriate.

\subsubsection{Social environment}

The social environment aspect of self-regulated learning involves seeking help from social sources such as peers, instructors, and tutors, and non-social sources, including reference books, the textbook and study guide, and the internet (Dembo \& Eaton, 2000; Dembo \& Seli, 2008; Zimmerman \& Kitsantis, 1997). Self-regulated learners have the ability to determine when to work independently or seek help from others. They recognize when they have difficulty learning and need assistance and how collaboration with peers can be advantageous to completing learning tasks and accomplishing goals. They view seeking assistance as a positive strategy to help them learn successfully rather than viewing it as a negative reflection on their ability. When learners focus on mastery of the subject matter, set goals, and have positive views of their academic ability, they are more likely to seek help (Dembo et al., 2006). Learners need to acquire a positive attitude about seeking help and possess the necessary social skills to interact with other students effectively, work in groups productively, ask questions, and get help from their professors, tutors, and staff in learning support centers. The technology associated with distance learning readily supports and enhances use of the social environment and enables interaction and help-seeking. Online discussions, instructor office hours, shared narrated presentations, peer commentary on writing drafts, and various group projects are all relatively easy to accomplish, and can be used by course designers and instructors to create community among distance learners.

\subsubsection{Teach one another}

Learner attitudes toward help-seeking are important. Learners' educational and cultural backgrounds as well as their individual learning experiences affect their dispositions for seeking help. If they are accustomed to a system of competition and ranking related to learning, collaboration with peers may be unfamiliar and uncomfortable. Similarly, if they are not familiar with a free exchange of ideas and challenging the ideas of others (including those of the instructor), they may not value what other learners have to offer in terms of understanding course concepts.

The classroom environment-whether virtual or face-to-face-must be established as a safe space in which to ask questions, express lack of understanding, and share knowledge. This is supported in a distance learning environment as learners are separated physically, thereby creating a greater feeling of anonymity. However, one deterrent to establishing such an environment is when learners believe that all knowledge and information resides with the teacher and that they cannot learn from their peers, who lack expertise and experience. This perception must be overcome in order for the social environment to be an effective learning tool. 
One institution's model of distance learning is designed to encourage learner self-regulation. The learning model on which all courses are based encompasses three steps (Brigham Young University Idaho, 2007). First, learners prepare for discussion by reading and studying course materials for the unit. Next, they teach each other by posting questions in the online course management system and responding to the questions of their peers. They may have responsibility to lead a discussion on an issue related to the topic and to reply to a set number of posts from other learners. The instructor monitors the discussion and responds to individual learners but in a way that does not limit or take control of the interaction so as to allow the learners to process and understand the material together. The instructor encourages learners to solve problems collaboratively by directing them to seek help from each other. The last step is to ponder and evaluate the learning experience for the week. This step consists of responding to specific questions related to the content and its application, and reflecting on the overall learning experience and how it could be changed or improved in the upcoming week.

In keeping with the theory of transactional distance (Moore, 1972, 2007), mentioned earlier in connection with the model of self-regulated distance learning, the lesson design described has sufficient structure to guide learners and give them direction. It encourages dialogue among learners and the instructor. Learners are provided with choices to support their capacity for autonomy, or self-direction, and learn strategies for becoming self-regulated. The instructor models how to respond appropriately to discussion posts in a way that respects diverse positions and opinions rather than indicating if answers are right or wrong. In this way, learners begin to develop more confidence in their own abilities as learners and in the viability of help from their peers. The instructor also holds weekly live office hours using Adobe Connect, thus furthering opportunities for dialogue.

\subsubsection{Tutorial preparation}

Learners can show responsibility for their learning by preparing for appointments with tutors and instructors, regardless of whether these appointments are face-to-face or through technology. In our distance language learning courses, learners have a weekly live tutorial session. To make this use of the social environment more efficacious, learners complete a worksheet that outlines the steps they need to take related to the appointment: be prepared, participate, ask questions, and practice. Being prepared focuses on doing the assignments for the week, writing down related questions to ask in the tutoring session, and making note of the date and time for the appointment. The steps of participating and asking questions involve making the learners aware that this is an opportunity for them to practice their speaking skills and having them record three things that they learned or found interesting from the session as a result of asking questions. The final step, practice, focuses on learners identifying two things they understand better as a result of the session and how they will use what they learned to improve their language proficiency. Similar steps can be followed for interacting with the instructor during office hours or collaborating with peers on assignments.

After the tutor session, learners compare how they prepared for appointments in the past with how they prepared when guided by the steps, how they can practice the skills learned in the session, and what they can do next time to prepare for their appointment. Thus they are reflecting, monitoring their performance, and setting and revising their goals. The effectiveness of this assignment is demonstrated by the following learner quotation: 
Tutor session is one of my favorite parts. This is the time where I can practice my English, in speaking and listening. Before meeting and talking to my tutor, I did prepare myself by reading the assignment and read things that I'm going to talk to my tutor. . . . My tutor will give time to ask on things that I do not know, she will give me opportunity to share my ideas, or tell something on the topic. . . . Even I can learn something else like new phrases and words from her while she's speaking or the correct pronunciation. I'm not ashamed to ask her on things I do not know. I think this is a great opportunity for us as distance learners. My tutor also reminds me to do the home works and ask me to email the teacher or her when I have problems or difficulties during the course. I'm so grateful and thankful for my tutor. She's a great support to me.

\subsubsection{Performance}

The dimension of performance involves self-observation and evaluation. It is an on-going process as learners increase awareness of self-regulation, select and implement strategies, compare goals with achievement, and determine the effectiveness of their methods of learning. They need to ensure that their self-appraisals are accurate, as denial of the need to change will result in no improvement (Dembo \& Eaton, 2000). As instructors guide learners, they must encourage or require them to apply new methods of learning rather than reverting to those that are familiar.

The concept of metacognition, defined as "thinking about thinking" (Anderson, 2002, p. 2), has some overlap with the dimensions of self-regulated learning, and particularly, the dimension of performance. Similar to performance, metacognition connects various aspects of effective learning with an evaluative procedure. Metacognition has been described as a five-stage recursive process that involves preparing and planning, selecting and using appropriate strategies, monitoring, orchestrating, and evaluating (Anderson, 2002). The first stage involves setting goals and sub goals (cf. motive). Goal achievement depends on selecting appropriate strategies and knowing when to apply them (cf. methods of learning). As learners monitor their performance, or think about how they think and learn, they determine which methods are most appropriate and effective (cf. performance). They also orchestrate the use of strategies by applying multiple methods of learning and making associations among them (cf. methods of learning).

The evaluation stage (cf. performance) involves four parts which correspond to and assess learner effectiveness related to all five stages of metacognition. Learners review what they want to accomplish (preparing and planning), the strategies they are using (selecting and using appropriate strategies), their usefulness (monitoring), and additional strategies that may prove effective (orchestrating). The six dimensions of self-regulated learning as compared to the five stages of metacognition are broader in scope (i.e., cognition, metacognition, motivation, and behaviour) and specify additional categories (i.e., physical and social environment, time). These components are extremely relevant to distance learning. The stages of metacognition are useful, however, in conceptualizing how learners can think about the way they learn, and as such, are relevant to the dimension of performance. As with the stages of metacognition, the six dimensions of self-regulated learning are recursive. As learners set goals, apply strategies, consider their environment and use of time, they are continually reflecting, monitoring, and evaluating their performance. 


\subsubsection{Learning plans}

As part of the process of becoming self-regulated, learners should formulate a learning plan. This can be initiated as they consider their purposes for learning; identify their strengths and weaknesses through self-analysis and reflection; select and apply strategies related to learning, time, and physical/social environment; and consider the degree to which their performance results in goal achievement. Such a learning plan should involve four cyclical steps: self-observation and evaluation (i.e., identification of problems related to learningwhen, where, how often; effects of the problem; and contributing factors), goal setting and strategic planning (i.e., selection of strategies and when to use them), strategy implementation and monitoring (strategies used, when, how recorded and monitored, changes made), and strategic-outcome monitoring (Dembo \& Seli, 2008). The last stage involves asking questions such as "Did I accomplish my goal?" "Which strategies were the most and least helpful?" "What adjustments do I need to make?"

The ultimate goal of all of the activities and strategies provided to learners in a course is to develop their ability to regulate, or take responsibility for, their learning behaviours rather than the teacher monitoring progress (Dembo et al., 2006). A learning plan might consist of checklists, progress logs, tally sheets, or charts. In our distance language learning courses, learners chart their increases in reading speed and comprehension, track grammatical errors marked on their papers to find recurring weaknesses, and complete listening logs that provide a summary sentence and document the source of the material, length of time involved, and the number of times they listened to the excerpt. Learners also receive completed rubrics and feedback sheets from tutors and instructors. Similar activities and approaches can occur in any course to help learners monitor their progress, and make use of teacher feedback, comments, or test scores. The learning plan can take a variety of formats and encompass different sources of information, but at minimum, should be a record of goals and sub goals related to a learning challenge, strategies used, progress made, goal revisions, and goal achievement.

\subsubsection{Reflective journal}

Each self-regulated learning activity in our English language courses involves monitoring and evaluating performance. As learners complete a self-assessment or activity related to one of the dimensions of self-regulated learning, they are guided through a set of structured questions, rubrics, or charts designed to help them analyse their performance. Additionally, after completing all of the steps related to the activity, including the analysis stage, they write in their journals about the experience they had with the activity and what they learned from it. The instructor provides commentary on the journal entries, being careful to not give directives or make critical or judgmental remarks. The goal of the journal is to evaluate performance. Similar measures of performance might include think aloud protocols in which learners record (verbally or in writing) their thought processes as they perform a task with the goal of identifying reasons for their choices (e.g., see Anderson, 2004).

The journal also provides practice with written English. It is an authentic communicative situation in which the learner is conveying information to an audience. The learner is also applying and practicing good writing techniques, thereby reinforcing what has been taught in the course. In any distance course, writing is a useful method of learning in that it provides learners with the experience of expressing what they know about a topic. This act 
of expression aids long-term memory of the ideas and content and also serves to help learners identify what aspects of the content may need to be reviewed or better understood. The following excerpt from a learner's journal demonstrates increased awareness as a result of the dimension of performance:

Time goes very fast. It is good for me to look back. My time management is better than before. Since I can plan my time more useful. It gives me a great power after finishing all my work after following the timetable. Second, I can put more attention on my study, since I have a good environment that is my bedroom. It is tidy for me to study and do my homework. After cleaning my bedroom, it is easy for me to find out some useful English book to study. I am sure I will use these method to improve my English .... Although sometime I will be tired, I still get more power to go forward. Since I can feel satisfy after improve my study means.

\section{Conclusion}

This chapter has reviewed key findings from the literature on self-regulated learning and autonomy and applied them to distance learning. In particular, it has presented a model for self-regulated distance learning and research findings supporting the model. Example activities have been provided to demonstrate how the model can be applied to help distance learners develop strategies related to the six dimensions of self-regulated learning: motive, methods of learning, time, physical environment, social environment, and performance. In the case of English language learning courses, the use of embedded self-regulated learning activities results in improved language proficiency, satisfied learners, and increased capacity for self-regulation and autonomy. The pedagogy incorporated by this innovative course design model addresses the dual needs of learners to master content and develop learning skills and strategies. The latter allows learners to be successful in achieving their goals. The model does not prescribe specific pedagogical activities; these can be developed to fit the context and learner using the six dimensions of self-regulated learning as guidelines.

\section{Acknowledgment}

I would like to acknowledge Dr. Ellen Bunker, her course design team, and the distance learning course instructors in the English as an International program at Brigham Young University Hawaii for their vision and diligent efforts in designing and teaching courses that support the development of self-regulation and student success.

\section{References}

Anderson, N. J. (2002). The Role of Metacognition in Second Language Teaching and Learning. ERIC Clearinghouse on Languages and Linguistics (ED No. 463659), Washington, DC

Anderson, N. J. (2004). Developing metacognitive awareness, In: Extensive Reading Activities for Teaching Language, J. Bamford, \& R. R. Day, (Eds.), pp. 175-180. Cambridge University Press

Andrade, M. S., \& Bunker, E. L. (2011a). Developing Self-Regulated Distance Language Learners: A Promising Practice. Proceedings of the Fourth Annual Self-Regulated Learning in Technology Enhanced Learning Environments, Barcelona, Spain

Andrade, M. S., \& Bunker, E. L. (2009). Language learning from a distance: A new model for success. Distance Education, 30, 1, pp. 47-61 
Andrade, M. S., \& Bunker, E. L. (2011b). The role of self-regulated learning and TELEs in distance education - Narrowing the gap. In: Fostering Self-Regulated Learning Through ICTs, G. Dettori \& D. Persico, (Eds.), pp. 105-121. Hershey, PA: IGI Global

Beck J. B. (2010, April 29). Choose ye this day to serve the Lord. Proceedings of the 2010 BYU Women's Conference, Provo, Utah, April 29-30. Available from: http://lds.org/library/display/0,4945,9118-1-5187-1,00.html

Bothma, F., \& Monteith, J. L. dK. (2004). Self-regulated learning as a prerequisite for successful distance learning, South African Journal of Education, 24, 2, pp. 141-147

Brigham Young University Idaho. (2007). Learning Model. Brigham Young University Idaho, Rexburg, Idaho

Chang, M. M. (2005). Applying self-regulated learning strategies in a web-based instruction - An investigation of motivation perception. Computer Assisted Language Learning, 18(3), 217-230

Chen, P. D., Gonyea, R., \& Kuh, G. (2006). Learning at a distance: engaged or not? Innovate, 4,3, pp. 1-7, Available from: http://innovateonline.info/pdf/vol4_issue3/ Learning_at_a_Distance-_Engaged_or_Not_.pdf

Dembo, M. H., \& Eaton, M. J. (2000). Self-regulation of academic learning in middle-level schools. Elementary School Journal, 100, 5, pp. 473-490

Dembo, M. H., \& Seli, H. (2008). Motivation and Learning Strategies for College Success: A SelfManagement Approach (3rd ed.). Lawrence Erlbaum, New York

Dembo, M. H., Junge, L.G., \& Lynch, R. (2006). Becoming a self-regulated learner: Implications for web-based education. In: Web-based learning: Theory, research, and practice, H. F. O’Neil, \& R. S. Perez, (Eds.), pp. 185-202. Lawrence Erlbaum Associates, Mahwah, New Jersey

Ellis, A. \& Knaus, W. J. (1977). Overcoming Procrastination. New American Library, New York

Ferrari, J. R. (1991). Self-handicapping by procrastinators: Protecting self-esteem, social esteem, or both? Journal of Research in Personality, 25, pp. 245-261

Ferrari, J. R., Johnson, J. L., \& McCown, W. G. (1995). Procrastination and Task Avoidance: Theory, Research, and Treatment. Plenum, New York

Gardner, Howard. (1983, 2004). Frames of Mind: The Theory of Multiple Intelligences. Twentieth Anniversary Edition. Basic Books, New York

Garrison, R. D. (2003). Self-directed learning and distance education. In: Handbook of Distance Education, M.G. Moore \& W.G. Anderson, (Eds.), pp. 161-168. Lawrence Erlbaum, Mahwah, New Jersey

Holec, H. (1981). Autonomy and Foreign Language Learning: Council of Europe. Pergamon Press, Oxford

Hurd, S. (1998a). Autonomy at any price? Issues and concerns from a British HE perspective. Foreign Language Annals, 31, 2, pp. 219-230

Hurd, S. (1998b). "Too carefully led or too carelessly left alone?" Language Learning Journal, 17, pp. $70-74$

Hurd, S. (2000). Helping learners to help themselves: The role of metacognitive skills and strategies in independent language learning. In: Current trends in modern language provision for non-specialist linguists, M. Fay, \& D. Ferney, (Eds.), pp. 36-52. London: The Centre for Information on Language Teaching and Research (CILT) in association with Anglia Polytechnic University (APU)

Hurd, S. (2005). Autonomy and the distance language learner. In: Distance Education and Languages: Evolution and Change, B. Holmberg, M. Shelly, \& C. White, (Eds.), pp. 119. Multilingual Matters, Clevedon, United Kingdom 
Hurd, S. (2006). Towards a better understanding of the dynamic role of the distance language learning: Learner perceptions of personality, motivation, roles, and approaches. Distance Education, 27, 3, pp. 303-329

Krashen, S. (1985). The Input Hypothesis: Issues and Implications. Longman, London

Little, D. (1991). Learner Autonomy 1: Definitions, Issues, and Problems. Authentik, Dublin

Long, M. (1996). The role of the linguistic environment in second language acquisition. In : W. Ritchie, \& T. Bhatia, (Eds.), Handbook of Second Language Acquisitions, pp. 413468. Academic Press, San Diego, California

Moore, M. G. (1972). Learner autonomy: The second dimension of independent learning. Convergence, 5, 2, pp. 76-88. Available from: http://www.ajde.com/Documents/ theory.pdf

Moore, M. G. (2007). The theory of transactional distance. In : Handbook of Distance Education, M. G. Moore, (Ed.), 2nd ed., pp. 89-105. Lawrence Erlbaum, Mahwah, New Jersey

Murphy, L. (2005). Critical reflection and autonomy: A study of distance learners of French, German and Spanish. In : Distance Education and Languages: Evolution and Change, B. Holmberg, M. Shelley, \& C. White, (Eds.), pp. 20-39. Multilingual Matters, Clevedon, United Kingdom

Oxford, R.L. (1990). Language Learning Strategies: What Every Teacher Should Know. Heinle \& Heinle, Boston

Parsad, B., \& Lewis, L. (2008). Distance Education at Degree-Granting Postsecondary Institutions: 2006-07. National Center for Education Statistics, U.S. Department of Education

Scharle, À, \& Szabó, A. (2000). Learner Autonomy: A Guide to Developing Learner Responsibility. Cambridge University Press

Schunk, D. H. \& Zimmerman, B. J. (Eds.). (1994). Self-Regulation of Learning and Performance. Lawrence Erlbaum, Hillsdale, New Jersey

Swain, M. (1995). Three functions of output in second language learning. In: For H.G. Widdowson: Principles and practice in the study of language, G. Cook, \& B. Seidlhofer, (Eds.), pp. 125-144. Oxford University Press

Thang, S. M. (2005). Investigating Malaysian distance learners' perceptions of their English proficiency courses. Open Learning, 20, 3, pp. 243-256

Tobias, S. (2006). The importance of motivation, metacognition, and help seeking in webbased learning. In: Web-Based Learning: Theory, Research, and Practice, H. F. O'Neil, \& R. S. Perez, (Eds.), pp. 203-220. Lawrence Erlbaum, Mahwah, New Jersey

Uchtdorf, D. F. (2006, April). The power of a personal testimony. Ensign. Available from: http://lds.org/ensign/2006/11/the-power-of-a-personal-testimony?lang=eng

van den Boom, G., Paas, F., van Merrienboer, J. J. G. (2007). Effects of elicited reflections combined with tutor or peer feedback on self-regulated learning and learning outcomes. Learning and Instruction, 17, pp. 532-548

Vanijdee, A. (2003). Thai distance English learners and learner autonomy. Open Learning, 18, 1 , pp. $75-84$

White, C. (2003). Language Learning in Distance Education. Cambridge University Press

Zimmerman, B. J. (1994). Dimensions of academic self-regulation: A conceptual framework for education. In : Self-regulation of learning and performance, D. H. Schunk \& B. J. Zimmerman, (Eds.), pp. 3-21. Lawrence Erlbaum, Hillsdale, New Jersey

Zimmerman, B. J., \& Risemberg, R. (1997). Self-regulatory dimensions of academic learning and motivation. In G. D. Phye (Ed.), Handbook of academic learning: Construction of knowledge, pp. 105-125. Academic Press, San Diego, California 


\title{
Strategically Integrating Blended Learning to Deliver Lifelong Learning
}

\author{
John Wall \\ Waterford Institute of Technology \\ Ireland
}

\section{Introduction}

One of the key challenges emerging that is likely to have a significant impact on education in the future is the rapidly changing environment of higher education. Costs continue to rise; budgets are typically shrinking, while demands for new services are growing. This is one of the drivers for an increasing need for distance education with pressure coming not only from non-traditional students seeking flexible options but also from administrative directives to cut costs as well as private providers and corporate universities.

Too often the implementation of computer-based learning has been based on solutions, which are developed based on the latest technological solutions rather than established learning theories (Sloan, 1996). There are many examples of unsuccessful initiatives using technology to address learning needs.

Designing, developing and deploying programmes that are well organised, use multimedia to engage the learner using various intelligences, capturing the experiences and knowledge of the learners, while incorporating and promoting interactivity and training instructors to facilitate online delivery, demands a strategic decision to be made and adequate resources be made available. Blended or hybrid learning can address the potential shortcomings of a purely e-learning approach but only in the context of educators taking a strategic approach and planning appropriately.

With the broad choice available in terms of multimedia based learning solutions there is an increased recognition that it is down to finding the right blend and making sure it is well prepared that is key to attracting, retaining and motivating learners (Trasler, 2002). Blended learning can offer the advantages of both traditional classroom delivery and e-learning. Blended learning can affect the way people learn, can help to promote the experiential learning experience and enable or empower the learner. However, this is a complex undertaking. The challenge is how to configure the blended learning approach. Using a blended learning approach may overcome many of the concerns staff in educational institutions may have with integrating technology as part of the delivery of learning and also help "mitigate" the considerable costs that may be incurred in going to a totally online delivery model.

Successful e-learning participants are highly motivated and self-directed, intellectually more mature, self-disciplined, older, serious and interested in coursework from which they will materially benefit (Schweizer, 2004). A study by Ramsden and Brown (2008) highlights that 
throughout the European Union (EU) indicates that up to 2029 the percentage of 18-20 year olds will decline by over $14 \%$. As the demographic profile of the population changes it is likely that a further demand for lifelong learning opportunities will exist. James-Gordon et al. (2003) suggest that the fastest growing sector in educational terms is busy professionals seeking education to advance their careers, increase their self development and/or salaries.

Given the traits of lifelong learners striving to balance a number of challenges in terms of work life balance and their thirst to engage in further up-skilling and learning opportunities, the formulation of a strategic framework which strikes a balance between the traditional instruction and the use of technology in both the delivery and support of learning must acknowledge that all learners have different cognitive preferences. Structuring the blend to effectively meet pedagogical differences is a prerequisite to designing an effective blend.

\section{E-Learning}

Electronic learning or e-learning, is a term most often used to describe computer-based learning support systems and periodically associated with advanced distributed learning technology. It also can be considered as any virtual act or process used to acquire data or information, or to create knowledge (Bennett and Bennett, 2008). The emphasis in the past with e-learning has been on the "e" i.e. the electronic technology (Hamid, 2002). Factors that need to be considered in developing learning material using technology include (i) learner attitudes, (ii) technological advances and technological constraints, (iii) the skills of instructors in working with technology, (iv) the content to be learned, (v) the quality of the instructional material and (vi) the interactions that take place between students and the instructor and the students themselves (Landen, 1997; Martinez et al., 2007). To promote the use of e-learning the emphasis needs to be less on the technology and more on the "experience", "engagement" and other high level contexts (Hamid, 2002).

Consideration of the pedagogy is vital when attempting to understand the application of elearning in practice (Mehanna, 2004). Matching cognitive and learning styles with instructional presentation strategies may have an important role to play in enhancing the learner's learning experience (Ford and Chen, 2001). An example of this is a study by Ross and Schulz (1999) that found in a study of the effect of learning styles on learning outcomes, that there was a significant effect of learning style upon learning outcomes and that certain types of learners are at risk of not performing well with certain forms of computer based instruction.

\section{Understanding learning}

The preferred learning style of the individual is important for learning to be more effective when one is considering using technology based learning for a new skill, increasing knowledge and sharing information (James-Gordon and Bal, 2001 and Ahmed, 2000). Different cognitive style groups benefit from different types of multimedia presentation (Ghinea and Chen, 2003). One of the most attractive features of computer based instruction is its capacity to individualise instruction, present content in a variety of ways (e.g. text, audio, video, and graphics) and allow the user to progress at his or her own pace (Ross and Schulz, 1999). The attractive feature of classroom instruction is that the instructor has the flexibility to change the instructional methodology immediately if the circumstances are appropriate. 
Harvey and Beards (2004) in a review of e-learning in Scottish further and highereducation, found that it is very easy to execute e-learning badly and this is more likely to happen if technology and not pedagogy is allowed to drive the process. Detractors of elearning focus their criticism in five areas; (i) participant isolation online, (ii) high participant dropout rate, (iii) the increased time and money to create and teach online courses, (iv) intellectual property rights and (v) the pedagogical soundness of e-learning (Schweizer, 2004). These are key areas that academic managers must address from a strategic perspective at the outset of any technology facilitated delivery of lifelong learning initiative.

Zhang et al. (2004) stated that it is important to realise that there are advantages and disadvantages associated with traditional instruction versus e-learning in delivering learning, summarised in table 1.

\begin{tabular}{|c|c|c|}
\hline & $\begin{array}{l}\text { Traditional Classroom } \\
\text { Learning }\end{array}$ & E-Learning \\
\hline Advantages & $\begin{array}{ll}\text { - } & \text { Immediate feedback } \\
\text { - } & \text { Being familiar to both } \\
\text { - } & \text { Motivstructors and students } \\
\text { - } & \text { Cultivation of a social } \\
\text { community }\end{array}$ & $\begin{array}{ll}\text { - } & \text { Learner-centred and self-paced } \\
\text { - } & \text { Time and location flexibility } \\
\text { - } & \text { Cost-effective for learners } \\
\text { - } & \text { Potentially available to global } \\
\text { - } & \text { audience } \\
\text { - } & \text { Archimited access to knowledge } \\
& \text { knowledge reuse and sharing }\end{array}$ \\
\hline Disadvantages & $\begin{array}{ll}\text { - } & \text { Instructor-centred } \\
\text { - } & \text { Time and location } \\
\text { - } & \text { constraints } \\
\text { More expensive to deliver }\end{array}$ & $\begin{array}{l}\text { Lack of immediate feedback in } \\
\text { asynchronous e-learning } \\
\text { - Increased preparation time for } \\
\text { the instructor } \\
\text { - Not comfortable to some people } \\
\text { - Potentially more frustration, } \\
\text { anxiety and confusion }\end{array}$ \\
\hline
\end{tabular}

Source: Zhang et al. page 762004

Table 1. Traditional Classroom Learning Versus E-learning

There are a wide variety of technologies, ranging from print medium to sophisticated media-rich content delivered over the Internet, which can be used as primary or supportive delivery systems for distance learning programmes. Furthermore number of issues can contribute to the failure of any e-learning initiative including; (i) technologies failing to deliver, (ii) costs growing exponentially, (iii) teaching remaining untransformed, (iv) staff support not adequate, (v) time release to develop material not considered, (vi) management and (vii) systems disputes (Latchem, 2005; Alexander, 2001 and Ruiz et al., 2007).

Schweizer (2004) identified a number of features that should be allowed for in order for participants to benefit from e-learning. These are outlined in table 2. 


\begin{tabular}{|l|l|}
\hline Feature & Description \\
\hline $\begin{array}{l}\text { Effective e-learning } \\
\text { programmes are well } \\
\text { organised }\end{array}$ & $\begin{array}{l}\text { Contemporary research demonstrates that the organisational } \\
\text { structure of e-learning class, the communications management } \\
\text { system employed and the strategies for knowledge sharing are } \\
\text { all positively related to the participants' achievement. }\end{array}$ \\
\hline $\begin{array}{l}\text { Effective courses use } \\
\text { multimedia to engage } \\
\text { the learner through } \\
\text { different senses and } \\
\text { capitalise on a variety } \\
\text { of intelligences }\end{array}$ & $\begin{array}{l}\text { In addition to conventional text and classroom discussion, } \\
\text { multimedia (i.e. audio and video clips, animation, games, } \\
\text { audio/video lectures or vignettes, PowerPoint presentations, } \\
\text { video conferencing and simulations) must be integrated into } \\
\text { the programme. }\end{array}$ \\
\hline $\begin{array}{l}\text { E-learning courses that } \\
\text { incorporate } \\
\text { interactivity promote } \\
\text { higher learning }\end{array}$ & $\begin{array}{l}\text { Interactivity or the ability of participants to use courseware to } \\
\text { correct misunderstandings of material they have used to } \\
\text { correct knowledge by using courseware to identify what new } \\
\text { information should be explored. }\end{array}$ \\
\hline $\begin{array}{l}\text { Effective courses } \\
\text { require instructors to be } \\
\text { trained in the online } \\
\text { delivery of learning }\end{array}$ & $\begin{array}{l}\text { Instructors should view themselves as facilitators. They must } \\
\text { communicate effectively with participants, personalise the } \\
\text { learning environment, act as a discussion leader and manage } \\
\text { the course. An effective online instructor must be able to write } \\
\text { well and provide unambiguous directions to individual } \\
\text { participants and groups. Instructors need to create } \\
\text { collaborative, interactive learning opportunities. }\end{array}$ \\
\hline \multicolumn{2}{|l}{}
\end{tabular}

Source: Schweizer (2004)

Table 2. Features to Help Participants Benefit From E-learning

The complexity with e-learning is that while it is a well established term; (i) there are many definitions of e-learning, (ii) there are numerous forms of communication available as part of e-learning and (iii) both individuals and instructors display a broad range of skill sets and experiences in using technology as part of learning. Formulating a framework that enables higher education to recognise these complexities and still deploy a successful programme is a key challenge this paper attempts to address.

\section{Blended learning}

In a traditional classroom situation, the instructor has the opportunity to adapt the instruction to suit individual needs that is not available when material is delivered online (Logan and Thomas, 2002). Blended learning is an approach to the delivery of learning that involves a combination of delivery methods and in some cases learning methodologies (Sloman, 2007). The alternatives available with blended learning may be formal and informal, people based and technology based, team-based and independent and discoveryorientated and directive. Blended learning may include many forms of learning tools such as real-time virtual / collaborative software, self-paced Web-based courses, electronic performance support systems (EPSS) embedded within the job task environment and knowledge management systems (Singh, 2003). Some key factors that continue to pose challenges are; 
i. How does one build a blend?

ii. How can a blended approach be delivered?

iii. How are the roles of educators and participants changed in a blended environment?

iv. How to evaluate the blend?

In selecting among the varying technologies within distance learning, a question should not necessarily be, what is the best technology, but rather what combination of media are the most appropriate considering learner and instructor characteristics, instructional goals and strategies, learning environments, and the availability of resources? Through configuring technology in the context of delivering blended learning, the opportunity exists to bridge the gap between industry and the requirements of learners wishing to access lifelong learning opportunities

Learning how to; (i) integrate new technologies in an instructional setting, (ii) when to use them and (iii) why they should be used, always lags the introduction of the technology itself (Kilby, 2001). It is therefore difficult to say that there is one correct model for deploying blended learning that is most effective.

Key drivers in formulating this framework in the delivery of lifelong learning are; (i) appreciating the pedagogy of learning, (ii) reviewing the technologies that are available to deliver e-learning (iii) acknowledging the myriad of challenges management and staff in educational institutions face in deploying blended lifelong learning and (iv) recognising the role of industry, professional bodies and the drivers in maintaining the status of lifelong learning.

One key challenge facing educational institutions is to engage students and staff in an active and flexible learning environment. Technological advances and the Internet have opened up new opportunities for educational providers to configure traditional classroom and technology assisted learning to promote and encourage access to lifelong learning opportunities. The Internet provides new opportunities and promises potential for distance education worldwide (Shen and Scott, 2004).

\section{Integrating technology in blended lifelong learning}

Research by Collis and can der Wende (2002), Reisman et al. (2001) and DG Education and Culture of EU Commission (2004) suggests that there are different models and phases that educational institutions embrace with respect to incorporating technology in the delivery of teaching and learning. More innovative and flexible approaches will be required to sustain these educational institutions looking to the future. The growth of the Internet and web 2.0 technologies, coupled with the emergence of a new student population and in many cases a decline in real terms in government funding makes it a strong case for educational institutions to look at new methods and approaches to delivering learning. Key in the delivery of this is how staff can be empowered to meet this challenge.

\section{Supporting the Instructor}

Sun et al. (2007) suggest that instructors' attitude towards e-learning has a key influence on driving the success of any e-learning initiative. Lehner et al. (2003) argue that electronic education should not attempt to replace traditional education, but rather support both staff 
and students through the provision of services that facilitate teaching, learning and education-related administrative tasks. The most important component in the deployment of a blended learning programme is to recognise the role of the instructor and the new roles and responsibilities that the instructor must take on.

However, integrating more sophisticated technologies requires a strategic decision, to train, support and adequately reward staff involved in such initiatives. For instructors, there is a significant adjustment required in their role. Berge (1998) and Vrasidas and Zembylas (2004) suggest that instructors are often asked to develop programmes using technology to support their deliver without the proper skill-sets or supports in place. Staff enablers as identified by this research include further up-skilling, support in the creation of web pages and support in the use of synchronous technologies such as voice over IP (VoIP) and web technologies. Greater flexibility, learning and integration of new technologies, and providing feedback in a more flexible manner are all roles that management in institutions must facilitate. In summary, if these challenges are addressed, synchronous communication technologies such as whiteboards or VoIP can play a key role in the successful deployment of programmes.

The instructor has a key role to play in the successful delivery of a blended learning programme. The instructor's engagement will be a key determinant of the success or otherwise of any blended learning initiative. For educational institutions, the challenge is in communicating effectively to the wider community the details and features of these types of programmes and ensuring the programme is effectively structured and delivered. Adams (2004) suggests that computer based learning has three elements; (i) hardware, (ii) software and (iii) 'underware' - the pedagogy that underpins the e-learning development. Tham and Werner (2005) would suggest that as educators there is a requirement for a variety of skills sets or "hats" including (i) a technological hat, (ii) a pedagogical hat and (iii) a social hat.

\section{Online instructional skills}

Tham and Werner (2005) highlight studies that indicate that instructors in an online environment must fulfil many roles or "hats". These hats include:

- A technological hat - educators must understand the application software and also the implications of technology for adopting different strategies in teaching. Using the available technology to enhance student learning is not an easy undertaking.

- A pedagogical hat - with a virtual classroom the tool/applications used to monitor or raise the intellectual skills of students requires the instructor to adopt the right tools and not simply use the tools that are available. Creativity is elementary to design of a course that brings students closer in an online environment.

- A social hat - in an online environment for the instructor to establish a rapport with students the technical communication tools should be used to establish a friendly, cohesive and comfortable learning environment.

Senior management in institutions must harness the power of technology to deliver the curriculum to lifelong learners while recognising that the set of instructional skills required are quite different, the cohort of students are different and the role of the institution, instructor and student must adopt to this changing dynamic. 


\section{Challenges for educational management}

It is incumbent on management in higher education to make a strategic decision on the role of technology in the delivery of learning. If the strategic decision is to embrace technology in the delivery of learning, then budgets need to be dedicated to resourcing appropriately the technological infrastructure, support and training mechanisms and appropriate rewards and recognition systems for staff involved in the delivery of programmes.

For staff new to this type of programme delivery, some training should be provided to guide instructors on how to manage a course and to create online content. Given that most institutions will start with a learning management system (LMS) as the fundamental hosting framework for the delivery of these types of programmes, sufficient training should also be provided on the deploying of the features within these systems.

In deploying these types of programmes effectively there is a "hardware" perspective, i.e. technological component, that needs to be considered, and a "software" perspective, i.e. the various instructional roles and approaches, that the instructor must assume. Based on the literature review and the analysis of the programme in Waterford Institute of Technology (WIT) in Ireland, strategically there are a number of key steps that should be considered in deploying initiatives of this type. These are outlined in table 3.

\begin{tabular}{|c|l|l|}
\hline Step & Action Point & Some Key Choices \\
\hline 1 & Recognise and reward staff & $\begin{array}{l}\text { Nature of rewards systems and provide } \\
\text { adequate technical and training support }\end{array}$ \\
\hline 2 & Selection of LMS & Open solution versus vendor solution \\
\hline 3 & $\begin{array}{l}\text { Ensure all staff are trained in using } \\
\text { various features of the LMS }\end{array}$ & $\begin{array}{l}\text { Have appropriate support infrastructure to } \\
\text { provide training and support to the group }\end{array}$ \\
\hline 2 & Presentation programme & PowerPoint \\
\hline 4 & Creating web-pages & HTML Editor \\
\hline 5 & Voice over IP solution & Skype \\
\hline 6 & Application Sharing & Open source versus vendor solution \\
\hline
\end{tabular}

Table 3. Steps to Enable Delivery of a Blended Learning Programme

As funding mechanisms continue to change and rapid advances in information and communications technology (ICT) continue to transform the way education is delivered, developing a framework to deploy learning to address the diverse lifelong learning needs of professionals presents a challenge. Adopting ICT to support and facilitate the development of educational programmes is at various stages of the technological adoption cycle in higher education. It represents in many cases an unknown and as such carries significant risk in terms of costs if not deployed successfully. A review of the literature suggests that there is no unique formula to apply for the successful development and delivery of blended learning. For many institutions the new technologies that are available represent largely additional expenses that are difficult to quantify (Twigg, 2003). Coupled with this, the range of cost estimates that can be incurred in the development of e-learning vary, from small financial resources required to huge financial commitment (Mayer, 2003).

With the growing acceptance of e-learning technologies and the increasing need of access to remote learning opportunities, administrators of higher-level institutions face; (i) 
technological, (ii) organisational, (iii) pedagogical and (iv) cultural challenges in helping to integrate these changes (Howell et al., 2004). This research supports the work of Forsyth (2003), which suggests that students and tutors have different support needs as outlined in figure 1.
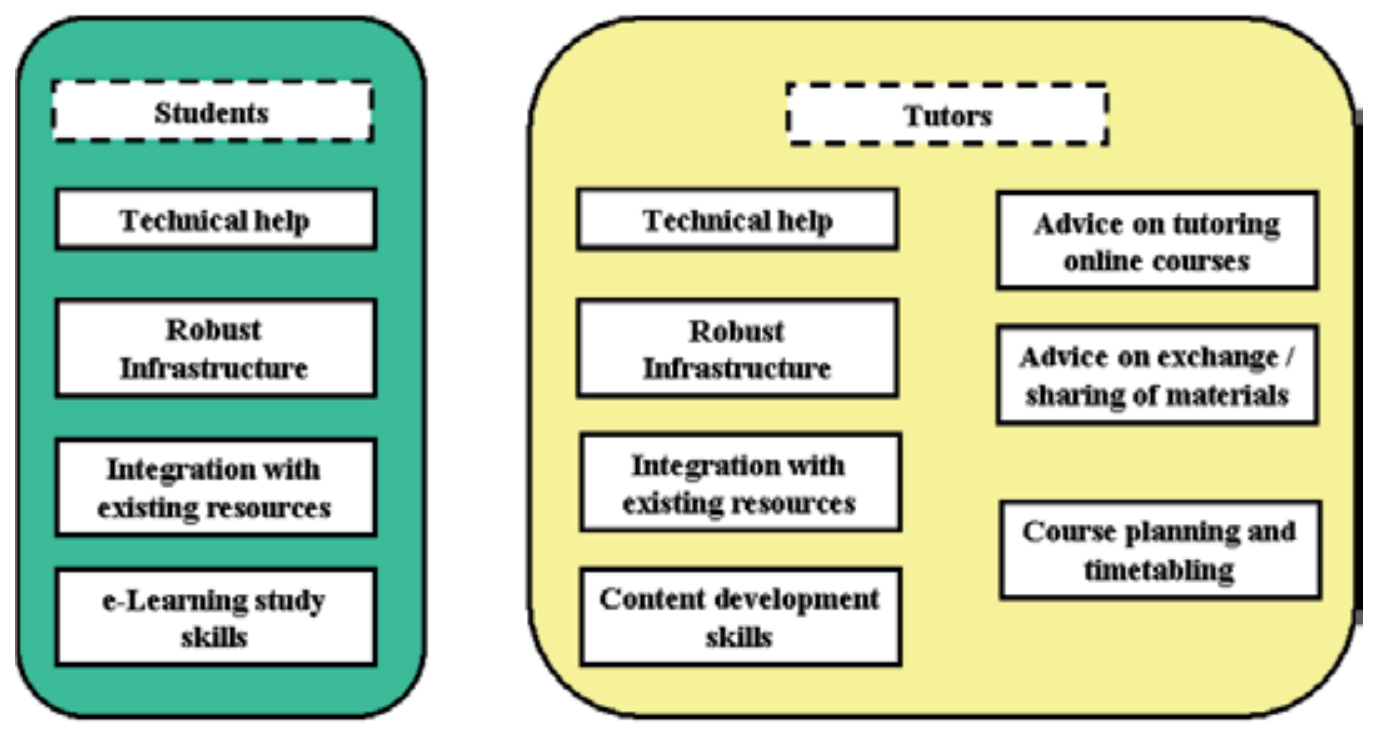

Source: Forsyth (2003)

Fig. 1. Summary of Tutor and Student Support Needs

The design, development and implementation of e-learning in the delivery of learning can represent a significant investment without any guarantee of success. Therefore it is vital that a strategic approach is embraced in deploying any initiative using technology. Embracing a strategic approach can result in the successful deployment of a blended programme meeting the needs of professionals.

As demonstrated earlier in the literature and succinctly captured by Sadler-Smith et al. (2000), individuals who involve themselves in continuing professional development (CPD) are likely to have clear preferences for different learning methods and activities. These are key considerations in developing e-learning programmes addressing the CPD needs of learners.

The integration and interaction of (i) technology, (ii) traditional instruction, (iii) the instructor and (iv) the participant are key components in any blended learning programme. Based on a review of the literature and previous initiatives, "flexibility" captures the most significant change that must be embraced for a blended learning CPD approach to be successful. Educational institutions, individual instructors and participants must become flexible in the successful collaboration and delivery of a blended programme.

As identified by Thomas (1995) and Browell (2000), the benefits to higher education in becoming involved in providing lifelong learning include; (i) offering the potential for closer links with industry and the professions, (ii) opportunity for funding to carry out research and consultancy and (iii) information feeds back into undergraduate programmes to ensure relevance to industry requirements. 
To capitalise on this research and bridge the gap between, (i) higher education, (ii) the requirements of the various professional bodies and (iii) the needs of industry, there are a series of steps that should be undertaken. These are:

1. Establish and test the infrastructure and framework which will act as the host platform for the technology-facilitated lifelong learning initiative

2. Establish the appropriate learning outcomes and competencies required by the professional bodies

3. Determine the breakdown of traditional and online delivery of the learning. As part of this, ensure that as many methods of instruction and learning as possible, i.e. both formal and informal methods of learning, are incorporated

4. Ensure that the content delivered will be recognised by the professional bodies, industry, regulatory bodies and individual as eligible as part of CPD. For educational institutions, this means building links with the professional bodies and ensuring the quality of the delivered learning will meet both the competencies and learning outcomes required by multitude of stakeholders

Through the execution of these various steps, an effective programme of lifelong learning, meeting both the professional institutions and industry's learning needs can be deployed. Educational institutions are in a better position than most to capitilise on this through the formal quality assurance systems that exist in the sector and in individual institutions, through undergraduate programmes developed which fulfil the criteria of the various professional bodies to meet industry needs.

\section{Framework for blended learning}

Developing and deploying an initiative to deliver lifelong learning addressing the continuing learning needs of professionals can be a challenging task, which can consume considerable time and resources without any guarantee that the outcome will be successful. The creation of effective online resources, also identified as important, is a complex challenge that educational institutions and educators continue to face.

The term blended learning has been widely adopted to depict combinations of face-to-face and technology-based learning (Stubbs et al., 2006). No two blended learning designs are identical, which introduces the great complexity of blended learning (Garrison and Kanuka, 2004). Both previous research and the analysis that has been undertaken in this exploration, indicate that in the development of a framework for deploying blended lifelong learning is a complex undertaking. However, it may be useful to construct a framework that will assist in deploying lifelong learning. This framework, outlined in figure 2 , is constructed around four key parameters:

1. Participants

2. The delivery of the instruction

3. Online learning

4. Traditional Instruction.

Blended learning offers institutions the opportunity to engage in using technology in conjunction with traditional delivery to offer learning. 


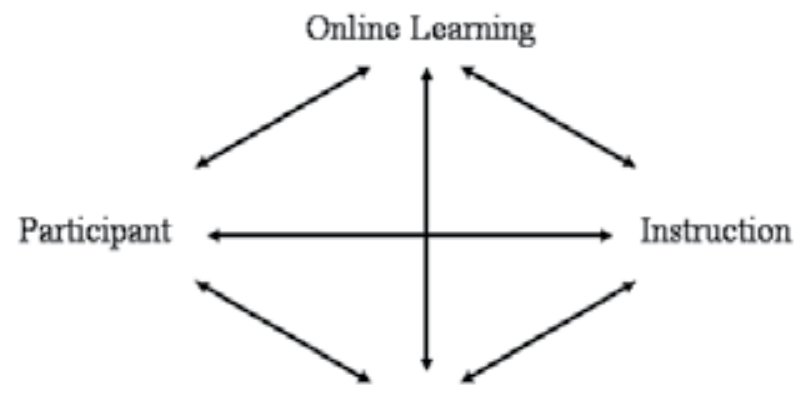

Traditional Leaming

Fig. 2. Framework of Parameters in Blended Learning

There is a balance to be struck between online learning and traditional learning and between the participant and the relationship formed with the instructor as part of any module to be delivered. A change in any one of these parameters has consequences for any other elements of the framework. The emphasis on instruction method, the balance of online to traditional instruction and the degree of directed and independent learning will change, based on the individual's learning preferences, the material to be learned, the skills, ability and instructional methodology of the instructor and the prior experience of the individual.

Campbell et al. (2007) identify the selection of appropriate models and strategies for elearning as one of the top 10 teaching and learning issues facing higher education. Wall and Ahmed (2008) outlines a proposed framework for deploying blended learning lifelong learning, identifying milestones, looking at key aspects of each milestone, suggesting possible activities to be undertaken to address the key aspects identified and identifying the possible benefits as a result, outlined in table 4 .

\begin{tabular}{|c|l|l|l|}
\hline Milestone & Aspect & Key Considerations & Potential Benefits \\
\hline 1 & $\begin{array}{l}\text { Appreciate the } \\
\text { learning process }\end{array}$ & $\begin{array}{l}\text { Appreciate that everyone } \\
\text { learns differently, so use } \\
\text { multiple instructional } \\
\text { methodologies. } \\
\text { Recognise that a "one size fits } \\
\text { all" approach will not work. } \\
\text { Individuals have different } \\
\text { prior learning experiences. } \\
\text { Use Learning Style Profiling } \\
\text { Tool(s). }\end{array}$ & $\begin{array}{l}\text { Instructors are aware that } \\
\text { various instructional } \\
\text { methodologies in both the } \\
\text { classroom and online } \\
\text { environment can enhance the } \\
\text { learning experience. } \\
\text { Can plan instructional } \\
\text { methods to capture peer } \\
\text { learning. }\end{array}$ \\
\hline 2 & $\begin{array}{l}\text { Learning } \\
\text { Management } \\
\text { System }\end{array}$ & $\begin{array}{l}\text { system in organisation. } \\
\text { Invest in LMS, either } \\
\text { purchase or use open sources } \\
\text { system. }\end{array}$ & $\begin{array}{l}\text { An established protected } \\
\text { environment with a series of } \\
\text { resources, administrative } \\
\text { functions and tools that can } \\
\text { act as the platform for more } \\
\text { sophisticated development } \\
\text { and integration of resources } \\
\text { over time. }\end{array}$ \\
\hline
\end{tabular}




\begin{tabular}{|c|c|c|c|}
\hline Milestone & Aspect & Key Considerations & Potential Benefits \\
\hline 3 & \begin{tabular}{|l|} 
Agree \\
standards in the \\
delivery of \\
material
\end{tabular} & $\begin{array}{l}\text { Posting notes on LMS. } \\
\text { All communication through } \\
\text { LMS. } \\
\text { Assignments posted through } \\
\text { LMS. } \\
\text { Use a voice over IP } \\
\text { communication platform. }\end{array}$ & $\begin{array}{l}\text { Consistency from the } \\
\text { participants' perspective. } \\
\text { Different possible } \\
\text { communications platforms } \\
\text { that address learners' needs, } \\
\text { increasing flexibility and } \\
\text { overcoming any sense of } \\
\text { isolation and ensures that } \\
\text { participants are continuously } \\
\text { engaged. }\end{array}$ \\
\hline 4 & \begin{tabular}{|l|} 
Agree \\
breakdown of \\
classroom and \\
online elements
\end{tabular} & $\begin{array}{l}\text { Once module has been } \\
\text { designed and learning } \\
\text { outcomes agreed, agree on } \\
\text { elements that will be } \\
\text { delivered in a traditional } \\
\text { setting and the elements that } \\
\text { may be delivered online. }\end{array}$ & $\begin{array}{l}\text { Overcomes the sense of } \\
\text { isolation that participants } \\
\text { may experience. }\end{array}$ \\
\hline 5 & Assessment & $\begin{array}{l}\text { Agree breakdown of } \\
\text { assessment methodologies. } \\
\text { Attempt to integrate } \\
\text { assessment with work. }\end{array}$ & $\begin{array}{l}\text { More engaged with work / } \\
\text { improves work performance. } \\
\text { Can encourage work-based } \\
\text { learning. }\end{array}$ \\
\hline 6 & $\begin{array}{l}\text { Agree dates for } \\
\text { traditional } \\
\text { delivery and } \\
\text { programme of } \\
\text { work at the } \\
\text { commencement } \\
\text { of the } \\
\text { programme }\end{array}$ & $\begin{array}{l}\text { Appoint a leader to } \\
\text { coordinate the scheduling of } \\
\text { assignments, dates for } \\
\text { delivery of traditional } \\
\text { instruction and online } \\
\text { instruction and collaboration. }\end{array}$ & $\begin{array}{l}\text { Participants can plan both } \\
\text { work and private life, as they } \\
\text { are informed in advance, for } \\
\text { the times when formal } \\
\text { traditional instruction takes } \\
\text { place well in advance. }\end{array}$ \\
\hline 7 & $\begin{array}{l}\text { ICT } \\
\text { infrastructure of } \\
\text { participants }\end{array}$ & $\begin{array}{l}\text { Survey participant's ICT } \\
\text { ability and infrastructure } \\
\text { both at work and home. } \\
\text { Consider including purchase } \\
\text { of laptop or distribution of a } \\
\text { CD with requisite course } \\
\text { material and software } \\
\text { loaded. }\end{array}$ & $\begin{array}{l}\text { Understanding of IT ability } \\
\text { and infrastructure of the } \\
\text { participants may help in } \\
\text { tailoring some elements of } \\
\text { the instructional } \\
\text { methodologies to better meet } \\
\text { participants' needs and } \\
\text { circumstances. }\end{array}$ \\
\hline 8 & $\begin{array}{l}\text { Provide } \\
\text { adequate } \\
\text { induction }\end{array}$ & $\begin{array}{l}\text { Develop guides. } \\
\text { Using of LMS. } \\
\text { Voice over IP } \\
\text { communication. } \\
\text { Relevant software packages. } \\
\text { Library infrastructure / } \\
\text { remote access facilities. }\end{array}$ & $\begin{array}{l}\text { Less administrative and } \\
\text { communication challenges } \\
\text { once programme is up and } \\
\text { running. }\end{array}$ \\
\hline
\end{tabular}




\begin{tabular}{|c|c|c|c|}
\hline Milestone & Aspect & Key Considerations & Potential Benefits \\
\hline 9 & $\begin{array}{l}\text { Use of multiple } \\
\text { methods of } \\
\text { communication } \\
\text { with } \\
\text { participants }\end{array}$ & $\begin{array}{l}\text { Email (both work and } \\
\text { student email). } \\
\text { LMS. } \\
\text { Mobile devices. } \\
\text { Voice over IP } \\
\text { communication. }\end{array}$ & $\begin{array}{l}\text { Emails to work act as a } \\
\text { reminder to participants. } \\
\text { VoIP allows for collaboration } \\
\text { and collaborative learning to } \\
\text { take place. } \\
\text { Use of video and audio } \\
\text { presentations where } \\
\text { appropriate can facilitate } \\
\text { collaborative learning. } \\
\text { Discussion boards or blogs } \\
\text { can be an effective learning } \\
\text { resource. }\end{array}$ \\
\hline 10 & $\begin{array}{l}\text { Plan in social } \\
\text { events }\end{array}$ & $\begin{array}{l}\text { Informal get-together for } \\
\text { meal or drinks events at } \\
\text { commencement and } \\
\text { throughout the programme. }\end{array}$ & $\begin{array}{l}\text { Breaks down barriers. } \\
\text { Participants may find it } \\
\text { easier to contribute } \\
\text { particularly in the online } \\
\text { environment as barriers have } \\
\text { been broken down. } \\
\text { Allows for further } \\
\text { networking opportunities. }\end{array}$ \\
\hline 11 & $\begin{array}{l}\text { Creation of } \\
\text { online resources }\end{array}$ & $\begin{array}{l}\text { Can be costly and staff } \\
\text { delivering the programme } \\
\text { may not have the expertise to } \\
\text { develop sophisticated online } \\
\text { resources. } \\
\text { Strategic decision to set aside } \\
\text { funding on a continuing } \\
\text { basis to facilitate online } \\
\text { resource development and } \\
\text { training. }\end{array}$ & $\begin{array}{l}\text { Can enhance the learning } \\
\text { experience when } \\
\text { instructionally-effective } \\
\text { resources are developed. } \\
\text { Research integration of } \\
\text { existing available resources. }\end{array}$ \\
\hline 12 & $\begin{array}{l}\text { Look at new / } \\
\text { novel methods } \\
\text { to focus on } \\
\text { active learning }\end{array}$ & $\begin{array}{l}\text { Use of problem based } \\
\text { learning; integrate existing } \\
\text { developed resources such as } \\
\text { games / simulations as part } \\
\text { of modules / assessment. }\end{array}$ & $\begin{array}{l}\text { Encourages collaborative and } \\
\text { peer learning. } \\
\text { Allows for informal learning } \\
\text { to take place. }\end{array}$ \\
\hline 13 & $\begin{array}{l}\text { Recognition of } \\
\text { the effort of } \\
\text { staff delivering } \\
\text { modules }\end{array}$ & $\begin{array}{l}\text { Provide adequate training. } \\
\text { Allow staff sufficient time to } \\
\text { develop resources. } \\
\text { Provide adequate reward } \\
\text { scheme. } \\
\text { Staff required to be more } \\
\text { flexible in dealing with } \\
\text { participants. }\end{array}$ & $\begin{array}{l}\text { Staff more motivated. } \\
\text { New skills sets developed. } \\
\text { Broadens the institution's } \\
\text { reach into industry. }\end{array}$ \\
\hline
\end{tabular}

Source: Adopted from Wall and Ahmed (2008)

Table 4. Proposed Framework for Deploying CPD 
It is fundamental at the outset to appreciate the learning process (1). By acknowledging that learning is complex, instructors and educational institutions should be open to new ideas / increased flexibility. The use of a learning style profiling tool such as Kolb's LSI can assist in making instructors aware that there are many learner types and plan for a variety of instructional strategies, ensuring that the benefits of understanding the variety of learner types. Establishing the appropriate infrastructure (2) and standards of delivery (3) will ensure a minimum standard of consistency. This still recognises that instructors may be at different levels of confidence and experience in the use of technology in the delivery of learning. It will also encourage instructors who gain confidence to become more sophisticated and advanced in their use of technology over time.

By agreeing the breakdown of classroom and online elements (4) prior to the commencement of the programme, instructors know what is expected and participants can plan how to integrate formal CPD into their work and personal life. It helps to plan dates and times for traditional delivery (6) far enough in advance. By focusing explicitly on assessment (5) at the outset, instructors can plan a coherent assessment strategy and an evenly distributed workload can be achieved. Recognising the ICT infrastructure (7) of the participants' highlights at the outset any potential problems, allowing for these challenges to be overcome / mitigated early on the programme. This will help in providing an appropriate level of induction (8), ensuring a smooth delivery and administration of the programme. The use of multiple methods of communication (9) allows for the integration of both asynchronous and synchronous communications and also acknowledges the variety of possible learning styles recognised by (1) earlier. The usefulness of social events (10) should not be under-estimated. As well as breaking down barriers, it can help build community and morale on the programme.

Identifying the creation of online resources (11) as a discrete milestone, challenges institutions to take a strategic approach to deploying blended CPD. Searching for new / novel methods to encourage active learning (12) helps to build on the experiential learning of the group and encourages a continuous search for new instructional approaches. Finally, recognising the key role of staff (13) will ensure the initial and ongoing level of success or otherwise of the blended approach.

Much of the research into deploying e-learning initiatives suggests that it is a complex undertaking and that educational institutions are at various stages in the development and deployment of technology-facilitated initiatives. This proposed framework is based on the research carried out in deploying a new blended learning CPD programme. The framework suggests that through appropriate planning and by scoping out the key aspects as outlined in the framework, that were identified as part of this initiative, a template is postulated that may be embraced by other educational institutions who wish to deploy these types of programmes.

\section{Conclusion}

The Internet and the continued development of technological infrastructure to support lifelong learning create new challenges and opportunities for both participants of lifelong learning programmes and instructors on these programmes. However, while a number of factors related to the integration of the technology will always need to be considered, it is 
important to bear in mind that technology is only a tool by which the training will be delivered. It is never the technology alone that one can attribute as the reason for failure in any e-learning project. Either a poor understanding of learning theories, a lack of appreciation of the learning styles of different learners or poor consideration of instructional design will contribute to failure.

There is an opportunity for higher education to strategically address this through the formulation of lifelong learning programmes using e-learning. Developing both the infrastructure and content to deploy technology-enabled learning is a resource intensive and time consuming exercise. The challenge remains in developing a suitable framework that integrates technology in the delivery of lifelong learning, while addressing the concerns of work and personal commitments of learners and the issues those new technologies present, in terms of pedagogical, technical and financial challenges to both management and staff in educational institutions.

Deploying blended learning is a complex and demanding undertaking from a pedagogical and technological perspective which places new roles and responsibilities on both the participant and the instructor. In one respect the costs can be prohibitive and can stymie an initiative principally due to the fear of unknown costs without any assurance of a successful outcome. Conversely, if planned for appropriately as part of blended learning, technology may be effectively harnessed as part of deploying blended lifelong learning. The frameworks suggested in this paper are an attempt to address these challenges through a structure that recognises the complexity involved and attempts to address the uncertainty that exists by putting a series of milestones in place in deploying an initiative.

\section{References}

Adams A. M., Issues and Innovations in Nursing Education Pedagogical underpinnings of computer-based learning, Journal of Advanced Nursing, Vol. 46, No. 1, 2004, pp 5 - 12

Ahmed V., The Effectiveness of Computer Assisted Learning in Construction, PhD. Thesis, 2000, Loughborough

Alexander S., E-Learning developments and experiences, Education and Training, Vol. 43, No. 4/5, 2001, pp $240-248$

Bennett A. and Bennett D., e-learning as energetic learning, Vine, Vol. 38, No. 2, 2008, pp 206 $-220$

Berge Z. L. Barriers to online teaching in post-secondary institutions: can policy changes fix it?, 1998, Online Journal of Distance Learning Administration, Vol. 2, No. 1, available at

http:/ / www.westga.edu/ distance/Berge12.html accessed 3rd November 2004

Browell S., Staff development and professional education: a cooperative model, Journal of Workplace Learning, Vol. 12, Iss. 2, 2000, pp 57 - 65

Campbell J., P. Oblinger D. G. and Colleagues, Top-Ten Teaching and Learning Issues, 2007, Educause Quarterly, No. 3, 2007

Collis, B. and van der Wende, M.[Eds., 2002]., Models of Technology and Change in Higher Education: An international comparative survey on the current and future uses of ICT in Higher Education, Centre for Higher Education Policy, Twente University, 2002, Netherlands, available to download at http:/ / www.utwente.nl/cheps/publications accessed 19th May 2004 
DG Education and Culture, Studies in the Context of the E-learning Initiative: Virtual Models of European Universities (Lot1) Draft Final Report to the EU Commission, 2004, available to download at http:/ / www.elearningeuropa.info/index.php?page=doc\&doc_id=5082\&doclng=1 accessed January $15^{\text {th }} 2005$

Ford N. and Chen S. Y., Matching/mismatching revisited: an empirical study of learning and teaching styles, British Journal of Educational Technology, Vol. 32, No. 1, 2001, pp $5-22$

Forsyth R., Supporting e-learning: an overview of the needs of users, The New Review of Academic Librarianship, 2003, pp 131 - 140

Garrison D. R. and Kanuka H., Blended learning: Uncovering its transformative potential in higher education, Internet and Higher Education, Vol. 7, Iss. 2, 2004, pp 95 - 105

Ghinea G. and Chen S. Y., The impact of cognitive styles on perceptual distributed multimedia quality, British Journal of Educational Technology, Vol. 34, Iss. 4, 2003, pp $292-406$

Hamid A. A., e-learning Is it the " $\mathrm{e}^{\text {" }}$ or the Learning that matters?, The Internet and Higher Education, Vol. 4, 2002, pp 311 - 316

Harvey B. and Beards D., E-learning in Scottish further and higher education, Education and Training, Vol. 46, No. 6/7, 2004, pp 353 - 360

Howell S. L., Saba F., Lindsay N. K. and Williams P. B., Seven strategies for enabling faculty success in distance education, Internet and Higher Education, Vol. 7, 2004, pp 33 - 49

James-Gordon Y. and Bal J., The effects of technology-based learning on design engineers and the organisation, Industrial and Commercial Training, Vol. 33, No. 5, 2001, pp $167-174$

James-Gordon Y., Young A. and Bal J., External environmental forces affecting e-learning providers, Marketing Intelligence and Planning, Vol. 21, Iss. 3, 2003, pp 168 - 172

Kilby T., The direction of Web-based training: a practitioner's view, The Learning Organisation, Vol. 8, No. 5, 2001, pp 194 - 199

Landen M., The role of technology in education and training, Industrial and Commercial Training, Vol. 29, No. 7, 1997, pp 230 - 235

Latchem C., Failure - the key to understanding success, British Journal of Educational Technology, Vol. 36, No. 4, 2005, pp 665 - 667

Lehner F., Nosekabel H. and Lehmann H., Wireless E-Learning and Communication Environment: WELCOME at the University of Regensburg, E-Services Journal, Vol. 2, Iss. 3, 2003, pp $23-42$

Logan K. and Thomas P., Learning Styles in Distance Education Students Learning to Program, Proceedings $14^{\text {th }}$ Workshop of the Psychology of Programming Interest Group, Brunel University, 2002, pp 29 - 44

Martinez R.-A., del Bosch M., Herrero M. and Nuno A. Psychopedagogical components and processes in e-learning. Lessons from an unsuccessful on-line course Computers in Human Behavior, Vol. 23, 2007, pp 146 - 161

Mayer R. E., The promise of multimedia learning: using the same instructional design methods across different media, Learning and Instruction, Vol. 13, 2003, pp 125 - 139

Mehanna W. N., e-Pedagogy: the pedagogies of e-learning, Association for Learning Technology Journal, Vol.12, No. 3, 2004, pp 279 - 29 
Ramsden B. and Brown N., The future size and shape of the higher education sector in the UK: demographic projections, Universities UK, 2008

Reisman S., Dear R. and Edge D., Evolution of Web-based distance learning strategies, The International Journal of Education Management, Vol. 15, No. 5, 2001, pp 245 - 251

Ross J. and Schulz R., Can computer-aided instruction accommodate all learners equally?, British Journal of Educational Technology, Vol. 30, No. 1, 1999, pp 5 - 24

Ruiz J. G., Teasdale T. A., Hajjar I., Shaughnessy M. and Mintzer M. J., The Consortium of ELearning in Geriatrics Instruction, Journal of American Geriatrics Society, Vol. 55, No. 3, March 2007, pp $458-463$

Sadler-Smith E., Allinson C. W. and Hayes J., Learning Preferences and Cognitive Style Some Implications for Continuing Professional Development, Management Learning, 2000, pp 239 - 256

Shen Q. and Scott D., A web-based online postgraduate programme in project management, International Journal of IT in Architecture, Engineering and Construction, Vol. 2, Iss. 1, 2004, pp $47-60$

Schweizer H., E-Learning in Business, Journal of Management Education, Vol. 28, No. 6, 2004, pp $674-692$

Singh H., Building Effective Learning Programmes, Educational Technology, Vol. 42, No. 6, 2003, pp $51-54$

Sloan B., The Use of Computer-Assisted Learning in the Education and Training of Construction Professionals, The Organisation and Management of Construction: Shaping Theory and Practice, Vol. 3, 1996, pp 334 - 347

Sloman M., Making sense of blended learning, Industrial and Commercial Training, Vol. 39, No. 6, 2007, pp 315 - 318

Sun L., Williams S. and Liu K., Knowledge Construction in e-Learning: designing an eLearning environment, Proceedings of the 5th International Conference on Enterprise Information Systems, Angers, France, Vol. 4, 2003, pp 111 - 118, available to download at http://www.ais.reading.ac.uk/papers/conKnowledge\%20Construction\%20in\%20eLearning2003.pdf accessed 15th April 2006

Tham C. M. and Werner J. M., Designing and Evaluating E-Learning in Higher Education: A Review and Recommendations, Journal of Leadership and Organizational Studies, Vol. 11, Iss. 2, 2005, pp $15-26$

Thomas E. J., Developing continuing education and training in European universities, Journal of European Industrial Training, Vol. 19, Iss. 4, 1995, pp 11 - 16

Trasler J., Effective learning depends on the blend, Industrial and Commercial Training, Vol. 34, No. 5, 2002, pp 191 - 193

Twigg C., Improved Learning and Reducing Costs: New Models for Online Learning, Educause Review, September/October 2003, pp 28 - 38

Vrasidas C. and Zembylas M., Online professional development: lessons from the field, Education and Training, Volume 46, Number 6/7, pp $326-334$

Wall J. and Ahmed V., 2008, Lessons learned from a case study in deploying blended learning continuing professional development, Engineering Construction and Architectural Management, Vol. 15, No. 2, pp 185 - 202

Zhang D., Zhao L., Lina Z. and Nunamaker J. Jr., Can E-learning Replace Classroom Learning?, Communications of the ACM, Vol. 47, No. 5, May 2004, pp $74-79$ 


\title{
Distance Learning: Modern Approaches to Engineering Education
}

\author{
Boris Kruk and Olga Zhuravleva \\ Siberian State University of Telecommunications and Information Sciences \\ Russia
}

\section{Introduction}

Pedagogy, as the science of education, learning and human development, originates from the ideas of Demokrit (460 BC -370 BC), Socrates (469 BC-399 BC), Platon (427 BC -347 BC) and Aristotle (384 BC - 322 BC). Erasmus Rotterdamus (1465 - 1536) is considered the first educator and John Amos Comenius (1592 - 1670) is the founder of didactics. Until recently classical pedagogy has dominated in education. Classical pedagogy based on didactic of John Comenius when a teacher being the bearer of a great volume of systematized information conveys this information to a student and the student has to master this considerable volume of knowledge.

In recent years due to globalization of the world labor market and increased competition in all fields of economics and business, the development of a new system of education has become a very important issue. This new system must respond to challenges of the present and rely on modern pedagogic technologies, up-to-date means of learning process informatization and network models of learning. Starting from the end of the 20th century to the beginning of the 21st century classical pedagogy has been replaced by pedagogy implementing a new paradigm of education, which is oriented on an individual and meets ideas of humanization in education (Savery \&. Duffy, 1995; Jacobson et al, 2006)

Rapid development of the Internet and multimedia has given a strong incentive to the creation of a new pedagogy and new pedagogic technologies. Today one can have the Internet access from anywhere in the world. The use of the Internet and multimedia technologies in education is becoming more and more popular among the majority of population. The advantages of computer- or web-based education over traditional classroom education include the ability to: study while at work, remain in one location with no need to travel; plan own training, attend courses across physical, political, and economic boundaries. In turn, higher education institutions obtain modern educational tools at their disposal. Distance-learning, e-learning and m-learning provide individualized learning, individual oriented approach and humanization of learning.

The modern educational paradigm provides the following important aspects. It requires the establishment of new subject-object relations between students and teachers who are involved in learning process provided that self-directed, personal-oriented and studentcentered teaching methods are used. It becomes necessary to consider pedagogic value and 
pedagogical usefulness of electronic educational environment. It also requires alterations in information interaction between students and teachers in new educational environment.

This chapter presents some important aspects of modern approaches to engineering education. The Section 2 describes the model of the network educational system, based on the Internet technologies, and learning process maintenance system with its support by automated subsystems. The Sections 3.1 and 3.2 describe issues of management of students' learning-cognitive activity by means of introduction of self-directed learning (SDL), specify the cognition process as an iterative process of obtaining new knowledge and introduce dynamic training elements (DTE) designed on the principle of the cybernetic model of cognitive process. The Sections 3.3 and 3.4 demonstrate the usage of remote access laboratories and analyze issues of pedagogic value and pedagogical usefulness of electronic educational environment. The Section 3.5 discusses issues of information interaction between students and teachers in new educational environment. The section 4 suggests the new method of quality evaluation of distance learning process. The section 5 contains conclusions and discussions. In the Appendix the best practice of applications of modern approaches to engineering education is described.

\section{Distance learning technologies and maintaining process}

\subsection{Model of educational system based on the Internet}

The principal participants of distance learning process are students, teachers-tutors and managers of an educational process. Using the Internet-technologies students can be in any corner of the Earth and have access to information resources of the university via a global network. Also teachers are not obliged to work with students, being in the university building. Nowadays one may have an access to the Internet from one's home, a car, while on board a plane etc. The necessary condition for organization of the Internet-training is availability of a Web-server, a database and a management system of training at university. In order to organize the network training activity via the Internet three conditions should be met: creation of information-educational environment, organization of feedback between students and teachers and management of training process (Day \& Foley, 2006; Sakkopoulos et al., 2006; Spoelder, 1999).

Fig. 1 shows the model of the network educational system in the form of a cube with network technologies, based on the Internet channels, incorporated into its foundation. The second layer of this cubic model presents information technologies implemented in the Internet. At last, the third layer of the cube and its top presents to the educational technologies incorporated in the triune educational system that includes electronic educational environment, means for information interaction and means for management of training process.

Internet channels and such tools of information technologies as hypertext, multimedia, Webservers; transmission facilities in the form of e-mail, teleconferences, file transfers; software for PCs stand for basic elements of a distance educational system in the cubic model on fig. 1. Basic elements of the educational system such as electronic teaching materials forming the educational environment; communication means used for contact and control of knowledge; management facilities of training process including database management system, automated workplace of the teacher, electronic dean's office are created on the basis of didactic properties and functions of initial elements. 


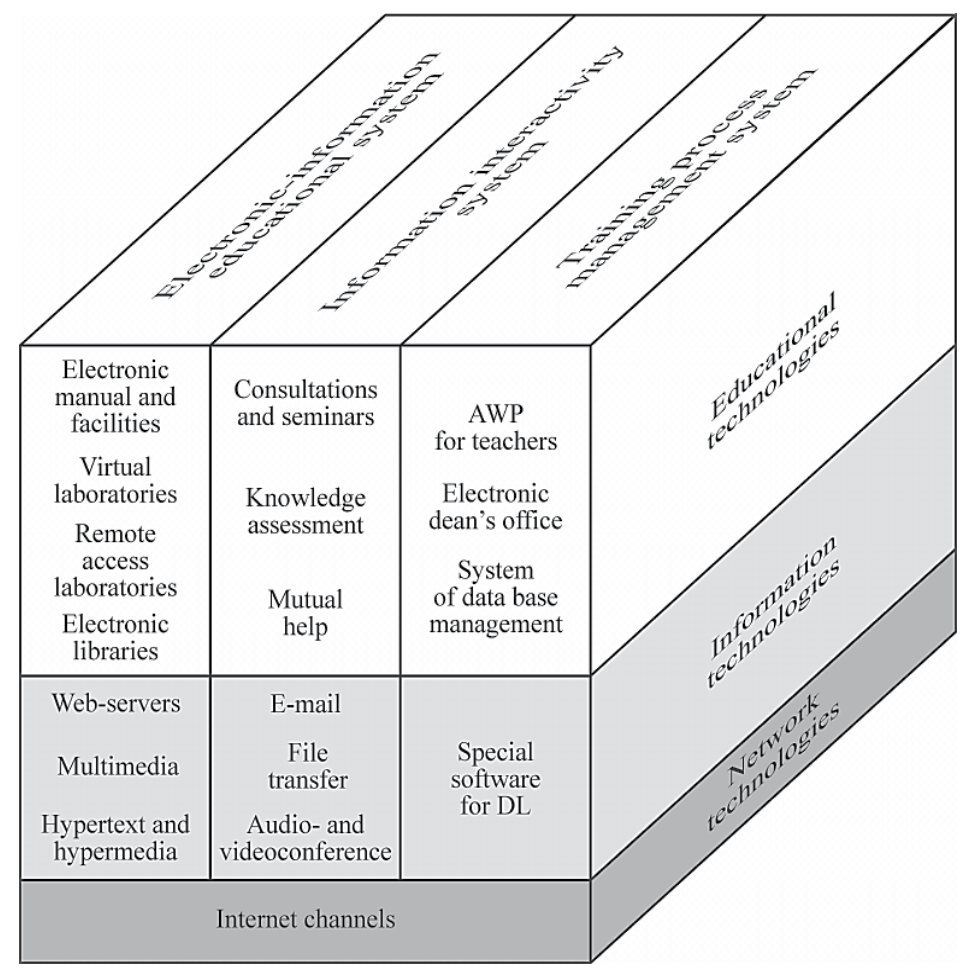

Fig. 1. The model of the network educational system based on network information technologies.

\subsection{Learning process maintenance}

To provide of the Internet-training process organization and its management, a corresponding environment should be created: organizational-administrative maintenance; technical maintenance; methodical maintenance; marketing maintenance; legal maintenance; financial-accounting and economic maintenance (fig. 2).

The important elements of training process organization are preparation and constant updating of an educational material on a Web-site. It should meet the requirements of selfsufficiency (i.e. to contain all necessary for independent studying), interactivities (i.e. to provide the maximal information interaction between a trainee and an educational institution), availability (i.e. to give an opportunity of access to any available resources), motivation (i.e. to interest a trainee to work with a material), multimedia (i.e. to use the text, figures, sound, animation, video, etc.). All this demands greater time inputs for performing functions of the control over preparation and updating of an educational material.

Development and administrative support of a database plays a significant role because the number of trainees can reach several thousand persons, the number of disciplines can change from several tens up to several hundreds. The duty of the personnel, engaged in training process planning, includes drawing up curricula of courses, schedules of study, timetables of tests and examinations, i.e. preparation of all planning documentation without which a training process is impossible. Preparation of curricula, schedules, timetables can be 


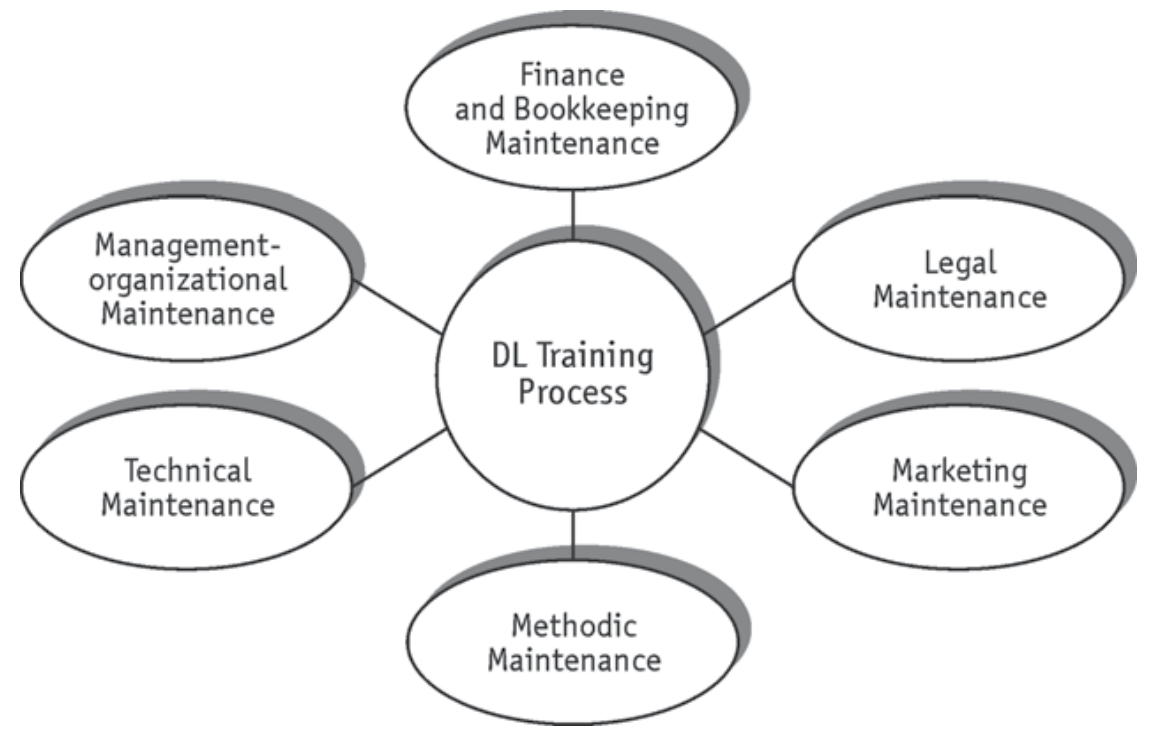

Fig. 2. Organization of the Internet-training process.

done manually by the personnel or by means of various automated tools. In any case all necessary documents should be placed on a Web-server available to various categories of users.

The primary means of public communication is a forum. Unlike the electronic bulletin board, which is an unidirectional means of communications, a forum, as well as an e-mail, make it possible to organize public communication. A trainee can ask any question and receive appropriate explanations. Distance learning based on telecommunication and information technologies needs serious technical support. Availability of a local network and several servers in leads to the necessity to administrate of a network and servers. It means that it is necessary to exercise the complex of technical and organizational activities on support of viability of a network and servers and maintenance of their normal operation. It is well known that the main carrier of the educational information is the Web-server. Webpages containing a teaching material and information needed to organize a training process should be created and function on the Web-server. Lest the information become outdated on the Web-pages, it should to be updated constantly.

To organize an electronic testing, it is necessary to develop the program shell which would make possible to enter and change the contents of tests easily must be developed, in which it is possible to put. Such program shell make it possible to check tests by means of automated supervising programs located on a server, and handled without participation of teachers in this process. The main concern of teaches is to follow up-to-date information technologies. However, in real life the situation is warring: a great number of teachers has never used the e-mail and never or very seldom worked in the Internet. Some of the teachers do not know how to use a computer. It is a rather serious program and it can be solved only by teachers' practical training. The keystone to success in the organization the Internet-training is a constant methodical support of training process, permanent training of teachers' and exchange of experience between teachers. 
Educational services in the Internet-training system are chargeable, as a rule. Thereby educational institutions put their production on the market of educational services. These are the basic steps of marketing activity aimed at a the final goal: to admit students, course participants, named afterwards trainees, to the educational institution and sign study contracts with them.

The educational institutions with a wide network of branches, and as result, a great number of students, faced serious problems at early stages of distance learning introduction. It was necessary to cope with processing of plenty of documents by limited staff effort. It was not easy to monitor the training process on a regular basis and to track the fulfillment tasks done by each student who followed individual schedules of training. Thus, the process of distance learning administrating required automation. The characteristic of a program complex "the electronic dean's office" is availability of various subsystems.

Subsystem of user authorization identifies the process of the users work with the Internettraining system. It checks the entered name and the password of a user and allows viewing the information. The block of authorization forms only that information which is needed for a particular user (administrator, student, teacher). It is aimed at facilitating user's work.

Subsystem of user access rights' assignment is meant for the system administrator. It allows the administrator to adjust the level of access to information resources for each particular user. Access to the given block is provided only for the exclusive users having the rights of the administrator. To get an access to the closed parts of the Web-site the passwords are needed. They are assigned automatically by means of the subsystem of users' passwords assignment. To create passwords special algorithms similar to encoding ones are used. It is done to get reliable means of the information protection.

Subsystem of input and editing information about students has the name "Student". Using this system, the administrator can enter and edit all necessary information about students: personal data (First, middle and last names, date of a birth, address, phone, E-mail), education background (the name of the educational institution one graduated from), place of employment (name of an enterprise, address, contacts).

Subsystem of input and editing of teachers' data has the name "Teacher". Besides a surname, the first name and patronymics of a teacher, his/her contact data (phone, E-mail, etc.), the list of the disciplines supervised by the teacher and codes of student's groups are placed in the database. The administrator is the user of this subsystem.

Using the subsystem of the students' progress' record, the administrator can enter and edit the data: about current and final progress of students; deadlines for submitting the tasks to the teacher to be check; timetables of tests and examination; examination and tests results, and also terms and results of final tests and examinations. This subsystem has the name "Progress".

Subsystem of teaching load's record is used to count the amount of tasks done by students the teacher has checked, their the group code, names and disciplines. A similar subsystem demands storage of files with students' works and files with teachers' reviews. It is worth mentioning, that not all institutes of higher education dare adopt the automated teaching load account. The administrator and the teachers are the users of this subsystem. 
Subsystem of curricula's revision gives an opportunity to edit the list of disciplines studied in every semester on all specialties of distance learning, to establish all kinds of studies on each discipline, to connect each studied discipline with certain teachers. For users' convenience the search engines and filtrations of the information are built in the subsystem. The administrator is the user of this subsystem.

Subsystem of reports' generation serve to get such reports as: lists of students in groups, the information showing progress of each student in group and in subject and etc. This subsystem include a search engine and filtrations of the information which help to find and filter an information about particular student progress easily and quickly. The administraror and the teachers are the users of this subsystem.

\section{Modern approaches to engineering education}

\subsection{Management of students' learning-cognitive activity}

Human need to explore the surrounding world makes an individual to learn lifelong. Educational need includes two components: need to receive information and need to explore the surrounding world, which are not one and the same. Satisfaction of information need relates to obtaining and use of information, but satisfaction of cognitive need relates to obtaining and use of knowledge. Analysis of the information - knowledge correlation allows one to understand that information activity of an individual relates to his/her perception and use of this information in the process of communication, while cognitive activity means creative activity, which is aimed at obtaining new knowledge. The formation of the subject's or the student's thesaurus results from the activity aimed at meeting the information and cognitive needs. An individual has to direct his/her learning-cognitive activity.

A self-direction of student's learning-cognitive activity has become important since interneteducation, distance-learning, e-learning and m-learning came up. In these models of education a student is to become a true subject of a learning activity and at the same time a student is to remain an object of a teacher's control. A student, as the subject, should form his/her learning-cognitive activity, but this activity is to be realized within the framework of a model developed by a teacher. The key role of the modern learning process is assigned to a student personality, which in the process of learning-cognitive activity is considered on one hand as the object of the teacher's control and on the other hand, as the subject capable of self-direction. Initially a teacher is a directing subsystem while a student is a directed one.

The goal of Self-Directed Learning (SDL) is to develop a student personality when he/she acquires knowledge in the particular subject field. Personal development means step-bystep action from learning under the teacher's control to self-directed learning and from SDL to self-learning. As a result abilities for self-education, self-discipline and self-developments are formed. The essence of SDL is that a teacher should direct the process of a student's selflearning activity formation (Ellis, H.J., 2007; Splitt, F.G., 2003).

The concept of SDL is based on subject-object relations in the process of training-informative interaction. When distributing subject and object roles a criterion of subject - object information interaction should be taken into account. Activity analysis implies ascertainment of activity source, its direction and who it is aimed at. To whatever extent the 
student's initiative is demonstrated, the student's need in obtaining learning information will not be satisfied, if there is no source of information or no bearer of information, i.e. the teacher. Since the organizer of a learning process is a teacher, the teacher may be considered as the subject of a learning process. In this case the student acts as the object of a learning process, for his/her sake the subject starts producing information.

The term "interaction" implies counter activity: actions like "object-subject". The moment of interaction happens when the subject, who conveys information, receives information about the object's state via feedback channels and, what is most important, the subject learns of the changes, which occur in the object at the end of interaction. The feedback allows the teacher to improve methods and means of teaching.

Learning and education mean control of human knowledge. Mechanism of learning and education is subject-object relations in info-interaction. The goal of learning and education is to teach an individual to solve nonstandard problems, which require unconventional approach. In turn, students are supposed to have high level of intelligence and abilities to think independently. The main objective of any learning is to form student's intelligence and prepare the student to a certain intellectual (professional) activity. Intelligence cannot develop out of info-interaction. The analysis of subject-object relations shows that this activity is based on the following circumstances. Cognition process occurs due to specific mechanism which is termed information interaction. Info-interaction rests on subject-object relations established between the subject (teacher) and the object (student). An object's activity depends on a subject's activity: a teacher may reduce student's cognitive interest or on the contrary, develop a student's interest to the level on which high intellectual abilities are formed. If there is a feedback channel from an object to a subject, the subject can improve the object's learning-cognitive activity and create conditions for SDL.

When the conditions needed for SDL are created, the most essential thing for an object is his/her ability for self-direction, self-control, self-education and self-development. In this case, the student is transformed into a true subject of learning-cognitive activity; furthermore activity of the student's information interaction is considerably increasing. Only an active person proving to be an individual in learning and influencing the whole learning process and progress in learning may act as the subject of learning-cognitive activity.

One of the major problems for teachers is to create an educational environment that allows students to direct their own learning-cognitive activity (Garofalakis et.al., 2002; Gick \& Holyoak, 1987; Glaserfeld, 1989). Self-directed learning assumed particular importance at the time when on-line learning came into existence (Evans \& Sabry, 2003; Dearholf et al., 2004). According to the theory of self-directed learning, a student builds his/her own learning and cognitive activity within the framework of the model developed by the instructor (Petridis et al., 2003; Spoelder, 1999).

\subsection{A cybernetic approach to cognitive evolution: the DTE model}

As an example one of facilities to implement the self-directed learning process in the on-line course using dynamic training elements (DTE) have been designed on the principle of the cybernetic model of cognitive process management (Bannan-Ritland, 2002; Krouk \& Zhuravleva 2009). With DTE introduced into the learning process students can direct their 
own learning process. Used in on-line learning, students learn to solve practical problems faster, to understand the theory much better, than they do when they solve the standard problems and do the usual exercises offered in the standard circuit theory course. The use of DTE as a supplement to the regular classroom setting may improve this situation by creating a self-directed learning environment and achieving the goal of adaptive learning (Bannan-Ritland, 2002; Hsiung, 2006). Self-directed learning with DTE is a person-oriented and student-centered teaching method. Heidi J.C. Ellis points out (Ellis, 2007) that SDL allows students to determine their learning requirements and goals, to select resources to achieve these goals and to assess the results of the learning process.

Some terms should be defined before proceeding further. Imagine that a student performs multiple actions aimed at changing certain qualities of the object or environment of interest, and every time receives an external correction of his or her actions. Consequently the student reacts to this information coming to his or her brain. The process of formation of the student's reaction based upon his/her own multiple actions and the external corrections can be named the learning process. The external correction can be made by the instructor (or the program) who knows what the desired reaction from the student should be. Thus in the learning process the student is provided with additional information as to whether the reaction is right or wrong. If there is no external correction of the student's action, i.e., if the student is not provided with additional information whether the reaction to the change of the object or environment qualities is right or wrong, then this cognition process can be termed self-learning (or learning without an instructor). The formation of the student's knowledge by cognitive evolution is considered to be the primary goal of the self-learning process.

The process of a student's cognitive evolution based on the accumulation of incoming information to the low initial level of a student's knowledge is called the process of a student's adaptation to a studied course-material (Gick \& Holyoak, 1987). Thus, the most typical feature of adaptation consists of accumulation and immediate use of incoming information aimed at increasing a student's current level of knowledge. When information is continuously delivered to a person, a certain reaction is developed to incoming signals. This is a way of the person's cognition of the environment formation. The method of cognition is based on the method of trial and error. Multiple trials and external correction of these reactions results in evolution of cognition. This evolution is the process of the student's adaptation to the environment.

The cognition process is an iterative process of obtaining new knowledge. In the initial cognition stage the student has to estimate unknown parameters of the process or the environment. For this purpose the information received in the previous supervision should be generalized. The induction is a creative stage of scientific cognition. Various hypotheses are forming in the student's head. When a certain hypothesis is chosen the transition to the next stage of scientific cognition - hypothesis checking - occurs. It is the next iteration. Each iteration brings benefit. When the number of iterations is increased it is becomes possible to create the best hypothesis. As the information about the process or environment increases, the probability, that each subsequent estimation or hypothesis would be confirmed, grows. Essentially, the sequences of hypotheses, which have already been confirmed by experience, can promote generation of a new hypothesis. Each successful hypothesis repeatedly succeeds the research. Iterative processes are inherently evolutional and make possible to 
reach consecutive movement to the purpose. The combination an inductive conclusion and method of trial with the subsequent check of hypotheses leads to the increasing conformity of hypotheses to the logic of process and provides better "understanding" of environment.

If the logic of scientific cognition described above is put in the cybernetic model, it becomes possible to realize all private and global aims of training sequentially - formation of a trainee's thesaurus and his/her intelligence. While training it is more preferable to study processes or environment by means of simple models. The easier studied models the higher their value for training. It means that, when forming dynamic frames in the cybernetic model of training, it is needed to represent processes or environment being studied in the form of set of simple models as far as possible. Such rule is justified by the fact that for simple models require the smaller number of iterations to draw an inductive conclusion, in comparison with complex models. Due to this fact the probability of search of the proved hypotheses raises. This principle known under the name «Occam edge» originated in XIV century and passed the test of time. It should be emphasized, that the inductive cognition demands addition of new information. This new information must distort the previous one about the process or environment minimally. It is important when managing a trainee's selflearning process by means of cybernetic model.

The definitions cited above agree with psychology-pedagogical researches of the human cognitive process. In order to clarify how the DTE written in this chapter differs from many other training programs, let us observe behavior of a child taking their first steps. How does this child form his/her knowledge of his/her environment? As information from the external environment repeatedly influences the child's brain, an intelligent reaction is developed to incoming signals. In the case of the child, the "trial and error" method is the method of cognition. Multiple trials done by the child, and the constant correction of his/her reaction, lead to the goal - the child's cognition has evolved. This training approach and the ensuing cognitive evolution is natural for a human. The highest phase of this process is when a person based on current observations, forecasts the behavior of the object of interest for a future, not yet happened moment. This point can be called the phase of knowledge formation.

Teenagers playing videogames learn extremely rapidly as they play. At a heuristic level, teenagers deduce the logic of game and its rules by using only a single method of cognition - the method of trial and error. Within several minutes they can easily predict the behavior of any object on the screen; this process is an example of the evolution of cognition as the result of self-directed learning.

The principle of DTE stimulating the above processes of self-learning and adaptation can be presented by the cybernetic model of interaction between a student and a computer program shown in Fig. 3. The central link of the learning element is a dynamic self-learning frame, being created on the monitor display. The frame displays the properties of an object designed on the basis of the mathematical model of the object or on real properties of an object, connected to a user's PC via the Internet.

A student, considered in this case as a subject of management of his/her learning-cognitive activity, has an opportunity to change the parameters of the object or environment at each iteration and thus to operate the dynamics of the learning frame. As mentioned above, the basis of the cybernetic model of the DTE is a dynamic self-learning frame, the dynamic state 


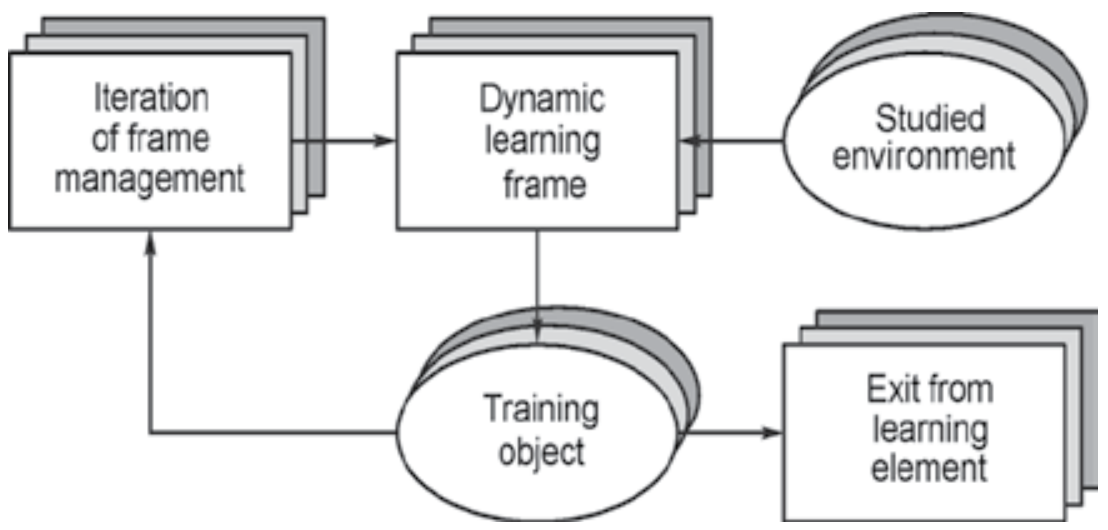

Fig. 3. A cybernetic model of self-directed cognitive process in the dynamic training element with a self-learning dynamic frame.

of which is changed by a student as he or she iterates the parameters that control dynamics of the frame. The major feature of this model is feedback between the subject of management (the object of the training) and the dynamic self-learning frame. When using such a model, the basic process of self-learning takes places by accelerated evolution of the student's cognition. Availability of feedback in the model provide easy application of the method of trial and error, which results in a transition to the top stage of cognition - to the prediction of the dynamics of the object being investigated for the next iteration of the operating parameters. This process leads to the student's heuristic awareness of laws, concepts, and the like, being incorporated into their structured, formal knowledge. It should be pointed out, that the process of self-learning with a cybernetic model is very individual and does not fit set time frameworks. As seen from Fig. 3, the student operates the process of cognition independently, choosing parameters of management that are convenient only to him/her, and spending as much time, as he/she needs to complete self-learning.

The dynamic training element with the self-learning frame, created on the basis of the cybernetic model of self-learning, qualifies the same didactic requirements as other training elements. A training element should reflect an independent and completed portion of the material and should have its own menu. This element should contain some fields in the dialogue window which would make it possible to keep up a dialogue with the student. The dialogue should be an option available to the student. The form in which the self-learning dialogue is conducted should imply that the student has the priority in decision-making. A learning element with a self-evaluation dynamic frame to evaluate progress in training is shown in Fig.4. To do this the self-learning frame is replaced by the self-evaluation dynamic frame.

The idea behind the new element is the following. The student has to examine the object or environment and enter the results of his/her research into the computer. Then the achieved level of cognition of the object is displayed on the dynamic frame, giving the student the opportunity to evaluate his/her self-learning process, and to correct the input. It might seem that this dynamic element of self-evaluation is the same as existing knowledge control programs, which point out any error in the answer, and suggest trying again (Dearholf et.al., 2004; Petridis et.al., 2003). The crucial difference, however, is that in this learning 


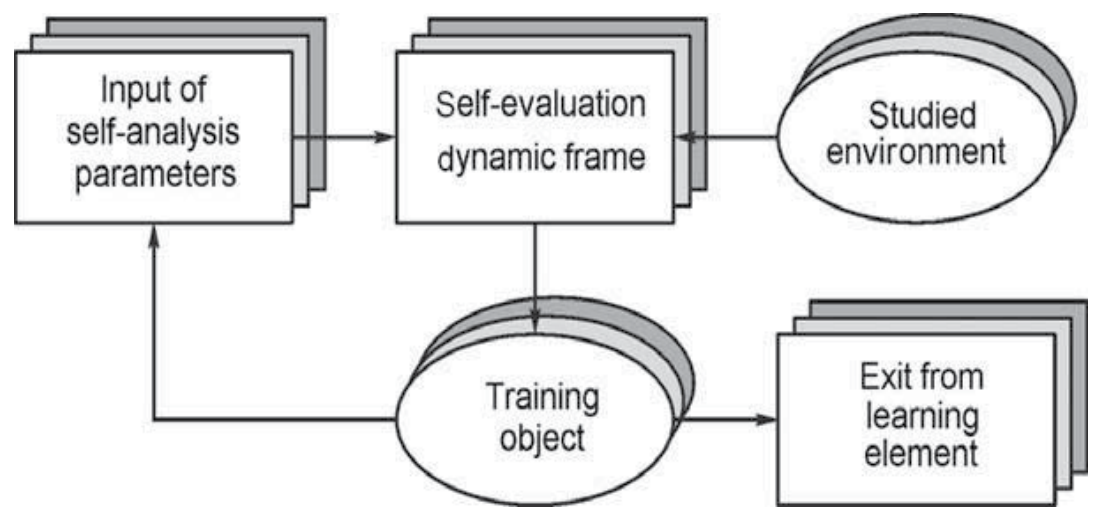

Fig. 4. A cybernetic model of the self-analysis process management in the dynamic training element with a self-evaluation dynamic frame.

element there is no such program which judges whether the object, its properties and the behavior have been correctly described. There is no "teacher". The student' actions are evaluated not by the program, but by the student himself/herself. The student can see the results of his/her actions and the reaction of the object (or the environment) to the student's actions simultaneously. If the student is not satisfied with the reaction of the object (or environment), he or she corrects the actions, i.e., enters new parameters until the desired state of the object (or environment) would be achieved. The student's evaluation of the accuracy of his/her actions is a continuation of the self-learning process.

\subsection{Remote access laboratory}

At present time real experiments in a laboratory for an analog and digital electronic course are very often replaced by computer simulation by using special software for training. However, to train qualified engineers a skill for real physical process investigating with real equipment is needed. Computer simulation can only expand the experiment, but cannot replace it. In the distance form of education additional difficulties of organizing carrying on laboratory works on real equipment arise. In this case the installation for carrying on laboratory works fundamentally differs from traditional one - a student has to have a laboratory in domestic conditions. One of new guidelines creates an automated laboratory with remote access (Bohne et al., 2002). In this case, device controls and indicators are located on the screen of the student's personal computer, which is connected to the Internet. To provide executing of laboratory works with a remote access the test bench must be available, i.e. supplied by modern equipment and controlled by computer via the Internet (Borisov et al., 2006). This test bench can be located at a campus research laboratory, or at a research institute, or at an enterprise. It allows studying modern devices, systems and networks, which are difficult of access even in the internal form of education. Another advantage of this technology is the possibility of multiple students work with one test bench simultaneously. Installation flowchart for a laboratory is represented on Fig. 5.

Installation consists of a server connected to the Internet, DAQ device, multiplexer, and studied circuits. The server is connected to the NI-6008 module which is an inexpensive DAQ system produced by National Instruments. The module is connected via USB interface. 


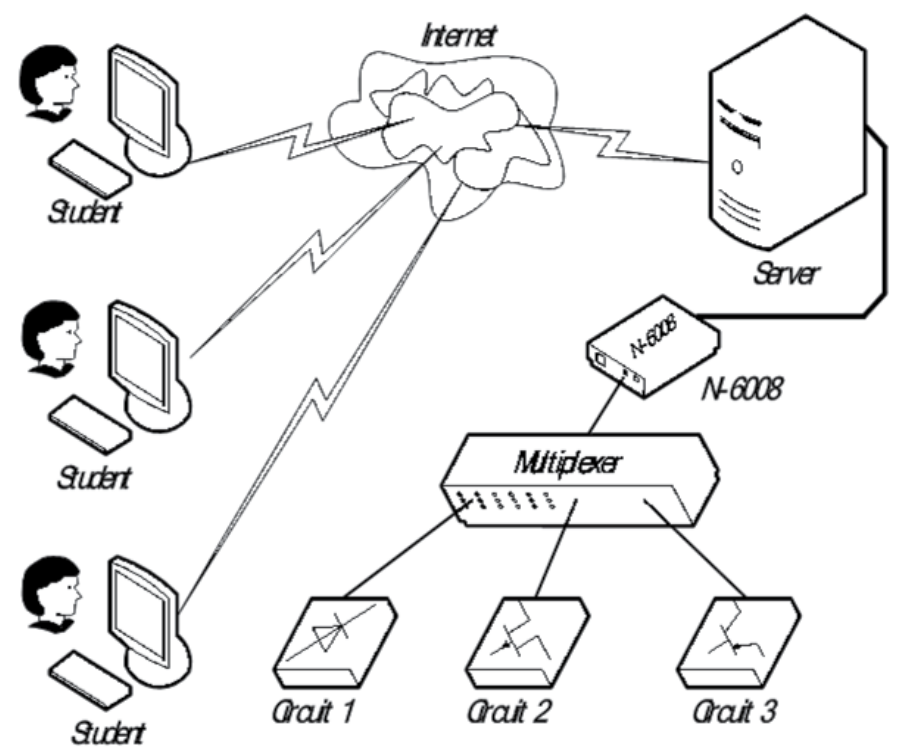

Fig. 5. Laboratory installation flowchart.

It is represented by 8-channel 12-bit ADCs, 2 DACs, and 12 I/O lines. The research circuit assembling is done by a multi channel switchboard (analog multiplexer) which is controlled by DAQ's digital I/O lines. When the student chooses certain laboratory work to execute, commutation of corresponding ADC inputs and DAC outputs occurs giving a possibility to research circuit. DAC is used as software controlled power supply, and ADC measures voltages and currents at necessary circuit points. Let's take a look at the laboratory installation elements interaction by the example of measuring semiconductor diode characteristics. The student runs special client software on his computer.

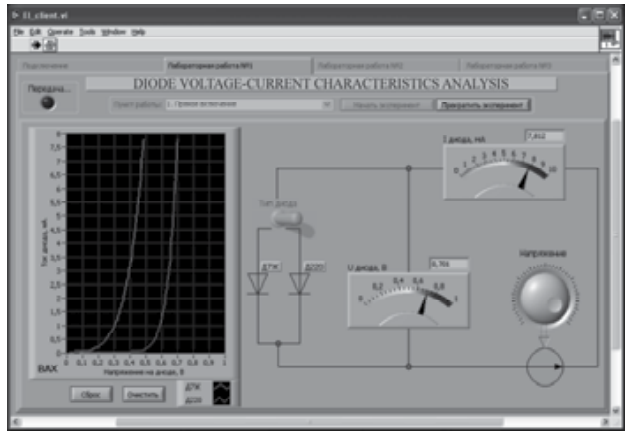

Fig. 6. Diode voltage-current characteristics analysis window.

In this menu the student types the server's name (www.leso.sibsutis.ru) which test bench is connected to, his name, last name, and group number. Then he chooses laboratory work no. 1. As a result a window with diode voltage-current characteristics analysis appears ( Fig. 6). By means of the switch one of diodes (siliceous or germanium) is connected to the measuring circuit. In this case, to the remote test bench the real corresponding diode is 
connected. Then the student turns a power supply regulator knob and observes voltmeter. At the same time the voltage-current characteristic graph is plotted automatically. To compare the characteristics of two different diodes it is possible to plot both their graphs on one screen. Then the student copies of the experiment result to his report.

Fig.7 represents the laboratory work window to analyze bipolar transistor characteristics. In this circuit two adjustable power supplies are used. Supply $E_{b}$ sets constant base current. When supply $E_{c}$ changes, one characteristic graph is plotted. To measure the family of characteristics several constant base currents should be set in series.

One of the important advantages of the suggested technology is ability to research temperature influence on transistor output characteristics. In this laboratory installation an ability of circuit analysis on alternating current in real time is provided. Examples of such laboratory works are represented on Fig. 8 and 9. Fig.8 represents the window of FET amplifier analysis. This circuit allows visually analyze gate bias voltage influence on amplifier's nonlinear distortions. Fig. 9 represents the window of half-wave diode rectifier analysis in time domain.

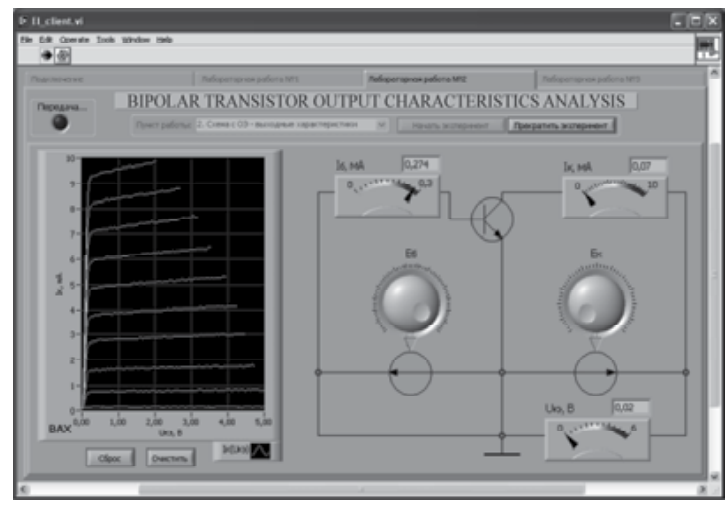

Fig. 7. Bipolar transistor output characteristics analysis window.

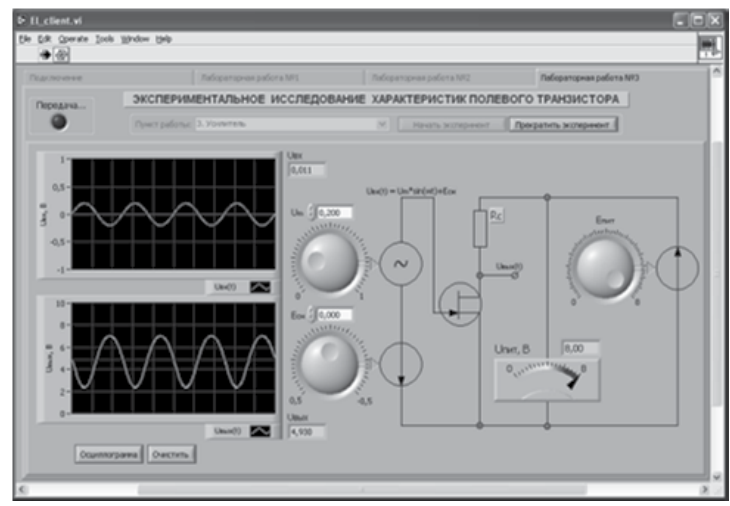

Fig. 8. FET amplifier analysis window.

The software consists of two parts - a client software and a server one. As a basis of network interaction it was decided to choose protocol TCP/IP well-provided for delivery. 
The server part is Win32 executable that has been developed in Delphi 7 environment. The server accepts clients on TCP port, controls multiplexer which switches research circuit; it also controls ADC and DAC of DAQ device NI-6008. Communication with the device is conducted by means of a software layer which is distributed with NI-DAQmx drivers from National Instruments. According to the developed protocol of data transmission between the server and the client, at first the client sends some request to the server and waits for the answer. Meanwhile the server processes the request and sends the response (including measured data). The data received by the client are visualized on the student's screen. Much attention has been paid to minimize traffic through the Internet while developing clientserver protocol since many students still connect to Internet via slow modem lines. To minimize latency between sending request and receiving measured data the Nagle algorithm on established TCP/IP connection is disabled.

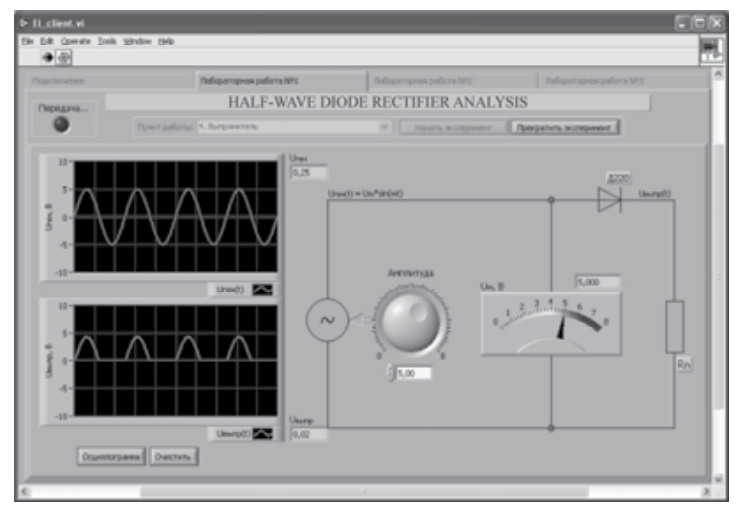

Fig. 9. Half-wave diode rectifier analysis window.

One of problems of laboratory installation was realization of ability for several students to work simultaneously with different laboratory works. The solution consists in temporal distribution of clients' requests, for example, by means of using unblocked TCP socket on the server application. In this case, requests query is controlled by operating system. Due to that more than 10 students can work with the laboratory installation simultaneously with no problems. To accommodate quality control of the executed laboratory work by the student, server stores in special database an information about who and when has been connected, and how many laboratory works the student done during the session, and how much time it took for the student to do it. This information is available for an instructor via the web interface.

The client part of the software was developed in Lab View 7.1 environment (Travis, 2004 ). Lab View was chosen because it has a large base of different well-visualized devices which make it possible to measure a student's work intuitively. Also Lab View has a native support for TCP/IP protocol. Let's take a look at a small part of application source which was designed for the semiconductor diode analysis in direct inclusion laboratory work (window appearance look at Fig.9). The network benchmark results show that the network load utilization does not exceed 3 kilobytes per second in most cases, even while executing the most intensive laboratory work like "rectifier". Time between sending request and receiving response practically is completely defined by network latency. It helps a student to 
do a laboratory work easily via slow modem communication lines and even via mobile internet technology GPRS.

The laboratory set (Fig. 10) is a printed circuit board with a single-chip microprocessor $\mathrm{ADuC} 842$ located on it with light diodes, semi-segment displays, a temperature sensor and a keyboard connected to the microprocessor. Special software running on the server is able to record the necessary downloading file in the microprocessor's internal memory from any computer located in any part of the world and connected to the Internet. This special software was developed with PHP, dojo Ajax library, and Delphi 7. The advantage of this laboratory set is a possibility to observe the operation of an experimental set in real time via the Internet. For this reason a web camera is directed at the set and a special software uninterruptedly broadcasts image received from the camera to the Internet. Another advantage is that a student doesn't need any special software to use this laboratory except Kiel-C IDE for firmware building. The firmware can be downloaded into the microcontroller in the window of any Internet browser and the image can be watched in the same window.

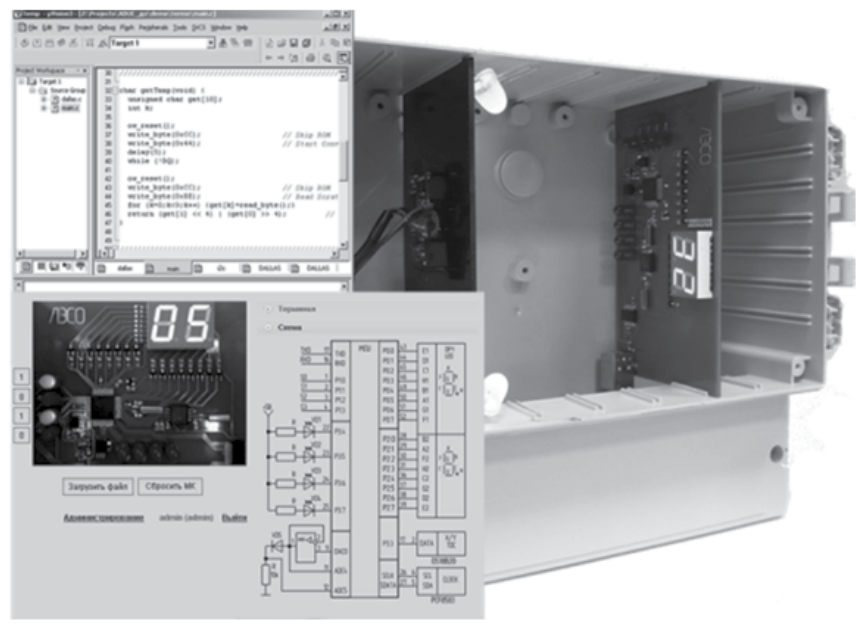

Fig. 10. Remote access laboratory to research microprocessors.

Programmable logic device PLD is one of the most prospective devices of digital circuit technology. PLD does not require any sophisticated technological manufacture. PLD is configured on a programmer's desk with the help of a PC. That is why sometimes this technology is called "manufacture on the desk". For this reason PLD is most optimal when learning digital circuit technology. In order to design a digital device of any complexity a student just draws its circuit on the PC display by the instrumentality of the Aletra's Quartos II software. The hardware part of the laboratory (Fig.11) is a printed circuit board with PLD and a web camera directed to the laboratory. The printed circuit board and the web camera are connected to the server with the Internet access. To identify logic states on the PLD's outputs light diodes are used. Control signals are transferred to PLD's inputs by a special microcontroller.

Digital electronic remote access laboratory can be used to teach design fundamentals of digital devices and carry out research on the basis of programmable logic devices. 


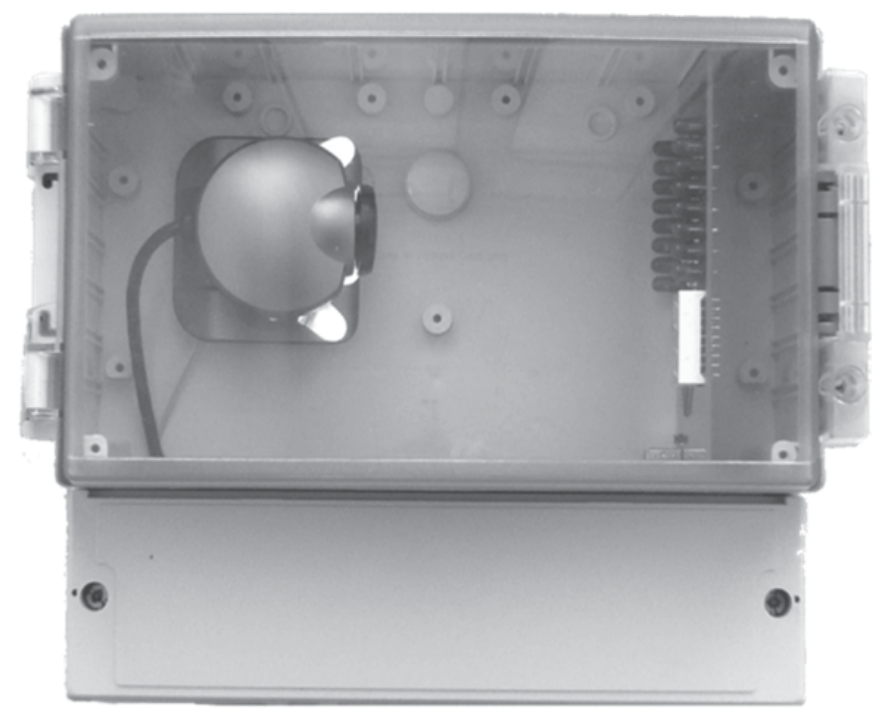

Fig. 11. Remote access laboratory based on PLD.

To access the laboratory an Internet browser is used. A configuration file of any complexity designed in a Quartus II computer-aided design environment. On the uploading page a student can specify the path to the configuration file of PLD, he can upload the file into the remote stand and observe functioning through the web camera. Thus a student located at any distance from the laboratory can design real digital devices and watch their functioning by means of the web camera.

\subsection{New requirements to e-learning environment}

An e-learning information-educational environment acts as a tool of subject-object information interaction to form student's fund of knowledge - thesaurus, which accumulates enriched during the life span and becomes a basis of any kind of activity. An individual's ability to use accumulated knowledge in order to achieve a certain objective testifies to his/her intelligence. The student's information interaction with training material underlies form of intelligence and knowledge, i.e. the student's thesaurus. Therefore it is very important to investigate axiological characteristics of an e-learning environment.

In traditional interpretation the value means ability of an object and a thing to satisfy some requirements of an individual. The more the individual is satisfied, the higher the value is. Similar to this, the characteristics of the information-educational environment which allows students to use this environment to achieve their set objectives act as a pedagogical value. It should be noticed that one and the same information-educational block can have different pedagogical value from the point of its use for various learning objectives. The use of a "student-centered" teaching model instead of a traditional "teacher-centered" model and applying methods stimulating student's cognitive activity immensely raises the pedagogical value of information-educational environment. Also multimedia demonstrations and simulators make an outstanding contribution to the pedagogical value of the informationeducational environment. These tools help students who do not studying in the class to 
learn correct pronunciation of foreign words, be involved in a live work platforms right from their PC desktops, to see historic events and handle complex mechanisms and processes.

Another axiological category, namely, pedagogical usefulness of a teaching material is closely associated with the category of pedagogical value. The pedagogical value is a more general characteristic than the pedagogical usefulness. For example, the student, who downloads an archived file to his/her PC, can be aware of how valuable the information on that file is. However, through the lack of the software, which unarchives files, this information becomes absolutely useless for the student. There are two categories of value: potential and actual. It is possible to notice that the pedagogical usefulness is an actual pedagogical value. In other words, the information, which is useful to achieve a learning objective, is of actual value. It is necessary to understand clearly that the degree of actualization of pedagogical value depends on a number of factors and personal characteristics of a student, i.e. the object of the information interaction. The larger fund of knowledge and the more sophisticated thesaurus a student possesses, the more successfully the student uses the information received in order to achieve a learning objective or, in other words, the more useful this information is for the student.

The pedagogic value of the information-educational environment is not an invariant axiological category. Horizontal and vertical alterations are typical of the informationeducational environment. Horizontal alterations mean that pedagogical value of the information-educational environment is acknowledged not only by individuals or small social groups, who benefit a lot from the teaching material, but by the general pedagogic community and many students. Vertical alterations of this category lead to increase or decrease of pedagogic value of information materials. Upward motion has a subjunctive meaning and relates to the information updated by the doer while downward motion has an imperative meaning and relates to the process when the information becomes outdated and when the most destructive factor is time. The decrease of the pedagogical value does not happen at once, as a rule. This is a rather long process stipulated by new information appearance in a concrete subject field. For example, the replacement of analog telecommunication technologies by digital ones has resulted in the drastic decrease of pedagogical value of many textbooks, which had been used widely in Telecommunications before. The same happened to many Russian textbooks in Economics and Management, since Russia had shifted to Market Economy. In many cases the process when the information becomes outdated is inevitable, therefore the producers of electronic teaching materials should evaluate and measure pedagogic value of their e-teaching materials in order to improve them and make them pedagogically valuable.

In the system of distance learning and e-learning the pedagogical value of teaching material is influenced by the character and means of a subject-object information interaction, such as the interaction between the teacher (tutor) and the student, between separate students and student classes. It also involves the interaction with e-teaching material. For this, e-teaching material should be "tuned" to an uninterrupted "dialogue" with the student. The more opportunities the student has to direct his/her process of cognition by interactive means, the higher the actualization degree of pedagogical value of teaching material is. In other words, the pedagogical value of teaching material acquires great importance. There are two types of interaction. They are: direct interaction when the teacher conveys information to the 
student, and indirect interaction when information is conveyed and apprehended without the teacher. In any type of interaction the main factor is to establish the feedback. The feedback checks the student's reaction to provided information and ability to use it in order to improve a learning process. The feedback makes the process of information interaction among the subject and the object synchronous. The delay in feedback results in asynchronous interaction. Participation in chats and videoconferences are good examples of synchronous direct interaction and instant evaluation of students' answers by teaching program is an example of synchronous indirect interaction. Asynchronous information interaction occurs, for example, in the form of participation in Web-forums, disputes in discussion rooms. Introduction of feedback, that supports student's ability to learn efficiently, considerably increases the potential value of the electronic teaching material.

Whatever high pedagogical value the e- teaching material has been provided with, the most important factor in distance learning is to transfer information. When the information flow is reduced during transmission, an information interaction can become worse, therefore, the pedagogical value of a teaching material can be decreased. While a citizen in a big city has an opportunity to use telecommunication channels of good capacity and transmission rate, a citizen of a remote town is sometimes doomed to have very slow channels. Even a highspeed modem does not provide good connection with the Web-server in the Internet. However, despite low transmission rate, an outdated software and the lack of a reliable Internet provider citizens of remote towns can join the distance learning process, but they will not be able to observe a multimedia part of the teaching material on the Web-server and they will not have a full access to all information recourses. Therefore, it will take a lot of time to receive any information that at best will annoy students or at worst, they will quit learning. The actual value of the teaching material will decrease to zero and the teaching material will become absolutely useless. Of course, the information theory suggests the methods against poor information interaction.

Various information barriers or info-barriers impede the travel and comprehension of information flows. In the information theory this term is used to denote the range of objective and subjective factors, which influence the process of information transfer to the object of interaction. It is clear that info-barriers diminish potential value of the teaching material. A short description of some info-barriers is cited below. One can speak of geographical and technical info-barriers, which results in weak interaction and hence decrease of teaching materials' value because of remote location of towns and lack of proper facilities. Thesaurus info-barrier has been also mentioned, when an accumulated fund of knowledge is not enough to understand teaching material. Terminological (language) barrier takes place, if the terms used in a textbook are not clear and unknown to an information user. Some of psychological and communication info-barriers are associated with mistrust to new methods and technologies of training, and with special perception of nonverbal methods of training. There is a whole range of situational info-barriers, which may happen in certain situations, for example, when the amount of information does not correspond to the time that an object of the information interaction has. There is a considerable amount of other information barriers that occur while learning in an electronic environment. The objective of info-barriers analysis and search of ways of how to overcome or eliminate them is very important because it is related to the increase of pedagogical value of the electronic educational environment. 


\subsection{Alterations in info-communication activity of subjects' of learning}

In e-learning, distance learning and m-learning students receive psychological support from their communication activity. Being isolated from an educational institution and lacking constant communication with teachers and students, a student may experience psychological discomfort, and suffer from isolation and neglect in comparison with other students. Therefore, for these types of learning it is very important to set up constant contacts of students who are geographically isolated from the administration of an educational institution, teachers and colleagues. Such communication contacts allow teachers to answer students' questions promptly, to identify difficulties that students face with, and render them assistance by making an impression of constant communication between individuals and geographically isolated groups. For students these communication contacts help students to compare their progress in learning with the progress of other students and to render mutual assistance.

In human communication a personality plays a very important role. For many students the personality of a teacher determines their attitude to the subject they learn. Participants of interpersonal communication influence each other through facial expressions, gestures and voice timbres. Nonverbal communication increases the efficiency of the communication process. When shifting to new types of learning, it is necessary to take measures compensating the lack of interpersonal communication. Educational process should be considered as interpersonal and dialogue interaction in "teacher-student" and "studentstudent" systems aimed at forming of theoretical and practical thinking and developing the personality of a future specialist. Dialogue lays the foundation of educational process by turning it into a mutual cooperation favoring the mutual development of all participants involved in this process. The lack of communication activity in learning may result in several problems: lack of interpersonal contacts among the participants involved in a learning process; inability to create favorable psychological climate and comfortable conditions for learning; lack of efficient control for students' mastering the material, inability to organize students to work in a team; inadequate perception and interpretation of teaching materials; interest decrease in learning up to a complete vanishing of motivation to learn through new technologies.

A full-fledged communication activity among students is impossible without teaching them the means and characteristics of a text presentation as the main means of verbal communication via the Internet, without teaching students to overcome information barriers in a personal contact with the teacher in the Internet and also without teaching participants of a learning process the Internet communication etiquette. The Internet affords many opportunities to organize communication: e-mail; discussion groups; two-side audio conferencing (NetMeeting, internet Phone, Powwow); two-side video conferencing (NetMeeting); group desktop conference (Intel ProShare), group text chat (NetMeeting, Microsoft Chat); whiteboard (NetMeeting); discussion forum; bulletin board. Via the Internet various kinds of electronic communication can be organized. They are the following: informing of students (bulletin board, student portfolio, visit cards); individual and group consultations for students (e-mail, mailing lists, news group, audio- and video conferences, forums, chats); electronic workshops (mailing lists, group news, chats, econferences, forums); teamwork in small groups (forums, whiteboard); student mutual help (e-mail, mailing lists, news group, conferences, forums, chats); monitoring of student's 
progress (e-mail, chats). In order to organize efficient distance learning via the Internet one should take into account characteristics of the telecommunication environment and human behavioral features in this environment. New communication environment creates new learning situations and new learning relations (Chou, 2003; Regueras et al., 2009).

\section{Quality evaluation of distance learning}

The difference between the distance educational technology and traditional in-class one is that a object of teaching (referred to as a student further on) has an access only to the network electronic teaching materials and the network means of communication with an subject of teaching (referred to as a teacher further on) (Dearholf et al., 2004; Evans \& Sabry, 2003). The role of the teacher in the given educational system changes considerably as compared to a traditional style of teaching. In the distance pedagogical system the teacher's aim is to create such electronic information-educational environment, which together with the information communication means could provide opportunities for direction and selfdirection of a students' learning-cognitive activity. It means that students, being the objects of a training effect, must transform to subjects with developed abilities for self-learning, who are willing to direct the learning process themselves. In other words when using distance technologies the new paradigm of education is used: namely, the teacher does not transfer knowledge, but stimulate students to develop their own learning-cognitive activity (Splitt, 2003)].

In new conditions the teacher acts as a highly qualified manager of the learning process, an organizer and an intermediary between a new educational environment and learners.

Electronic educational environment created by the teacher in the distance pedagogical system provides opportunities for students to direct their own learning-cognitive activity, determines principle of formation and development of students' thesaurus and intellect which in turn, determines a specialist's ability to be in professional activity. There is a fairly close link between professional competence of the teacher, who deals with a distance learning environment, and the process of thesaurus phylogeny (i.e. the process of building cognitive skills, circulating in certain community or its part, for example in a group of students). Indeed, research on the thesaurus in ontogeny (i.e. in a person) makes it possible to determine a learner's individual abilities, while research on the thesaurus in phylogeny (i.e. in a group) demonstrates pedagogical abilities of a teacher: the higher professional competences of a teacher engaged in distance learning, the better indexes of a collective thesaurus formation in a group of students.

In pedagogical publications the majority of authors are unanimous that various tests and assignments can be used as basic tools for evaluation of the collective thesaurus of a group of students. Quantity indicators for evaluation of a group thesaurus and methods of indicators' measurement are offered bellow. Relative frequencies of correct solutions can be used as indices to learners' individual thesauruses:

$$
p_{c o r}=\frac{m_{c o r}}{m_{c o m}} \cdot 100 \%,
$$

Where $m_{\text {cor }}$ is the number of correct solutions, $m_{\text {com }}$ is the total number of assignments. 
Calculating the average value of $\bar{p}_{c o r}$ of these parameters by the formula:

$$
\bar{p}_{c o r}=\frac{\sum_{i=1}^{N} p_{c o r i}}{N},
$$

where $\bar{p}_{\text {cori }}$ is the relative frequency of correct solutions of $i$-th student;

$N$ is the number of students in a group, we obtain the indicator of the state of the collective thesaurus for the learning group.

On the basis of the received data it is possible to build a diagram showing what number of students has reached this or that level of the indicator. Fig. 18 shows the curves built for two groups.

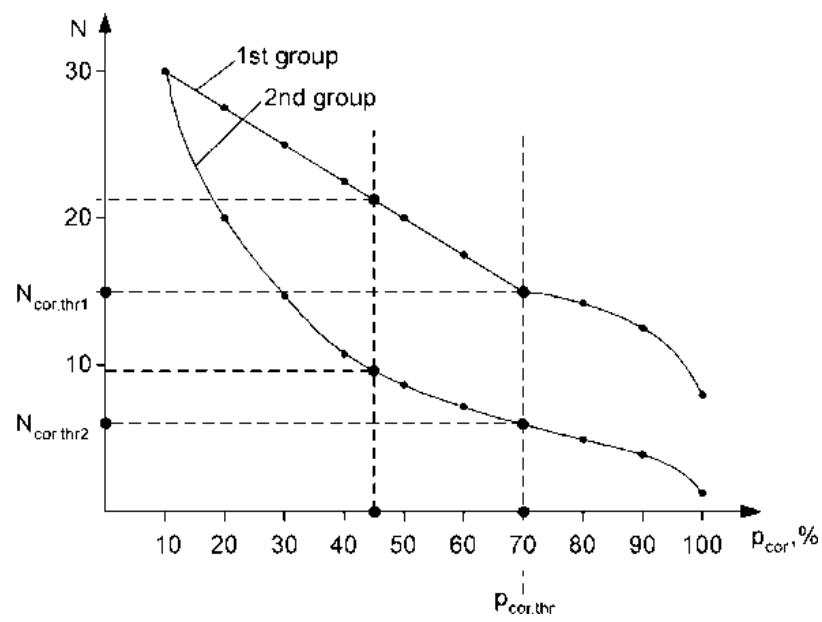

Fig. 12. Curves of the level of group learning.

It would be appropriate to name these curves as the curves of the level of group learning.

It is possible to set a threshold value of the relative frequency of correct solutions, for example, $p_{\text {cor.thr }}=70 \%$ as it is demonstrated on fig. 18, and define the number of the students $N_{c o r}$.thr who coped with the assignment at this level. Then one more indicator of the state of the collective thesaurus could be formulated - coefficient of group learning

$$
K_{\ln }=\frac{N_{c o r} \cdot t h r}{N} \cdot 100 \% \text {. }
$$

The higher the coefficient of group learning, the higher the quality of learning is.

Pedagogical literature distinguishes three basic learning goals. The learning goal of the first, the lowest level, is to give knowledge to students. The learning goal of the second level is to teach students to apply this knowledge, i.e. transform the knowledge gained into abilities. Finally the top step or the learning goal of the third level is to provide students with professional skills. According to this classification it is possible to make evaluation of how efficiently the learning group has achieved learning goals. For this purpose assignments for 
evaluation of three specified levels have to be developed. The number of assignments for each level should be sufficient for its estimation.

The following criteria could serve as indicators of goals achievement:

- coefficient of knowledge

$$
K_{k n}=\frac{n_{1}}{n_{c o m 1}} \cdot 100 \%
$$

- coefficient of ability

$$
K_{a b}=\frac{n_{2}}{n_{c o m} 2} \cdot 100 \%
$$

- coefficient of skills

$$
K_{s k}=\frac{n_{3}}{n_{\text {com } 3}} \cdot 100 \%,
$$

Where $n_{1}, n_{2}, n_{3}$ are the number of assignments solved correctly by a student of the 1st, 2 nd and 3rd levels, correspondingly;

$n_{\text {com } 1,}, n_{\text {com } 2}, n_{\text {com } 3}$ - total number of assignments of the 1st, 2 nd and 3rd levels.

In order to obtain the parameter of a group learning goals achievement one can define the average values

$$
\bar{K}_{k n}=\frac{\sum K_{k n i}}{N} ; \bar{K}_{a b}=\frac{\sum K_{a b i}}{N} ; \bar{K}_{s k}=\frac{\sum K_{s k i}}{N},
$$

Where $K k n_{i}, K a b_{i}, K s k_{i}$ are coefficient of knowledge, abilities and skills of $i$-th student.

To compare the quality of distance learning of various groups, the diagrams, showing what number of students from the group reached this or that level of knowledge, abilities or skills, can be built. For an example, the diagrams for indicator of $K_{k n}$ for two groups are shown in Fig. 13.

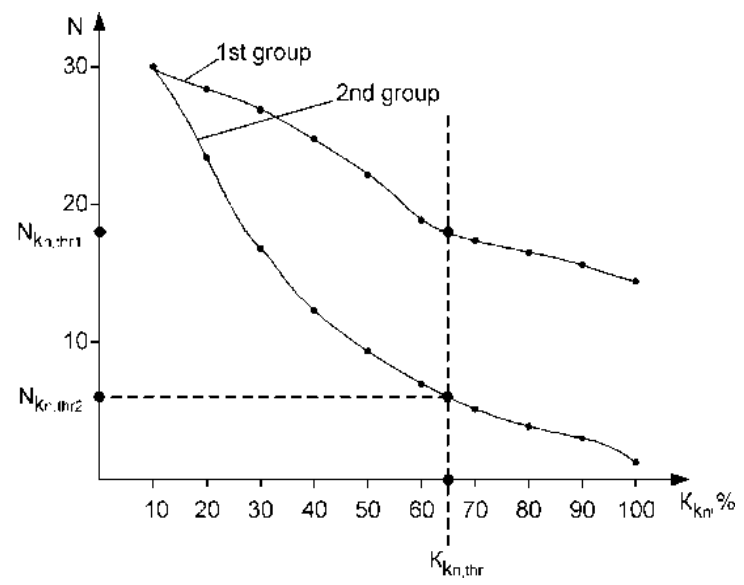

Fig. 13. Curves of the level of group knowledge. 
These curves can be named the curves of the level of group knowledge. Similarly the curves of the level of group abilities and curves of the level of group skills can be built.

Following the diagrams it is possible to find out the number of students who reached the threshold levels $K_{k n . t h r}, K_{a b . t h r}$ and $K_{s k . t h r}$, and to evaluate the achievement of learning goals by the whole group at any of their three levels by means of the following coefficients:

- coefficient of the level of group knowledge

$$
K_{k n . g r}=\frac{N_{k n . t h r}}{N} \cdot 100 \% \text {; }
$$

- coefficient of the level of group ability

$$
K_{a b . g r}=\frac{N_{a b . t h r}}{N} \cdot 100 \% \text {; }
$$

- coefficient of the level of group skill

$$
K_{s k . g r}=\frac{N_{s k . t h r}}{N} \cdot 100 \%,
$$

Where $N_{k n . t h r}, N_{a b . t h r}$ and $N_{s k . t h r}$ are the number of the students who reached respective threshold levels $N_{k n . t h r}, N_{a b . t h r}$ and $N_{s k . t h r}$.

Higher group indicators $K_{k n . g r, ~} K_{a b . g r}$ and $K_{\text {sk.gr }}$ testify to a better achievement of learning goals by students of a group.

Thus, the results of this research showed that the measurement of quantity indicators of collective thesaurus in groups, which are taught at a distance by means of electronic teaching materials developed by teachers, make it possible to evaluate the quality course levels.

\section{Conclusions and discussions}

The authors of this paper explore alterations in subject - object relations between a teacher and a student in a new educational paradigm when students direct their own learningcognitive activity. Herewith a student is transformed from an object of the teacher's influence to a true subject of a learning-cognitive activity. When implementing new pedagogical technologies such as distance learning, e-learning and m-learning, one of the major problems for teachers is to create educational environment that would allow students to direct their own learning-cognitive activity. As an example, one of facilities to implement the self-directed learning process into the on-line course using dynamic training elements (DTE) have been designed on the principle of the cybernetic model of cognitive process management.

At the Siberian State University of Telecommunications and Information Sciences (SibSUTIS), Novosibirsk, Russia, a range of dynamic training elements have been developed for the course "Fundamentals of Circuit Theory": introduction to harmonic oscillations; vector representation of harmonic oscillations; symbolic representation of harmonic oscillations; vector diagram; series- and parallel oscillating circuits; periodic signal 
spectrum; transient response in circuits with linear and resistive elements; nonlinear resistive elements; self-sustained harmonic oscillator (Lin, 2006).

At the Circuit Theory department of the Siberian State University of Telecommunications and Information Sciences the research to obtain a quantity index for evaluation of the DL course quality have been conducted. Electronic teaching materials consisted of an electronic textbook including DTE's, virtual laboratory works, assignments published on the Website of the distance learning server.

Two groups of students have been involved in the research: an experimental group who used dynamic training elements during their practical classes, and a control group, who learnt by using traditional methods aimed at solving typical problems. The primary goal of the research was to measure the quantity indicators of groups' collective thesaurus by means of the DTE's, remote and virtual labs and another above proposed method. The students from both groups were given the same test assignments evaluating two levels of learning goals achievement: knowledge and abilities. Average relative frequencies of correct solutions $\bar{p}_{c o r}$ for students from the first group was $\bar{p}_{c o r}=79,8 \%$, at the same time, for students from the second group this value was equal to $\bar{p}_{c o r}=65,3 \%$. Dependences of the number of $N$ students on relative frequencies of correct solutions for two groups have been built (Fig.14).

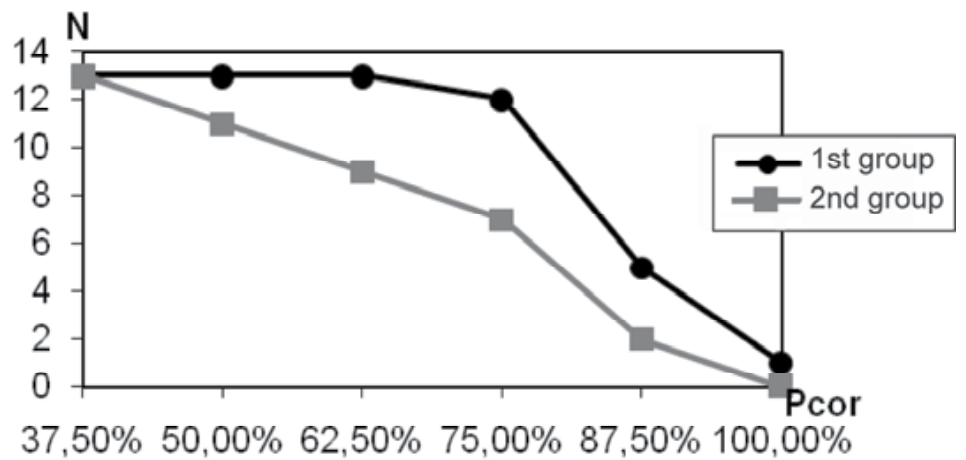

Fig. 14. Distribution of students in groups depending on relative frequencies of correct solutions.

It is possible to set a threshold value of the relative frequency of correct solutions, for example, $p_{\text {cor.thr }}=75 \%$ and to determine the threshold value the number of $N$ students, whose

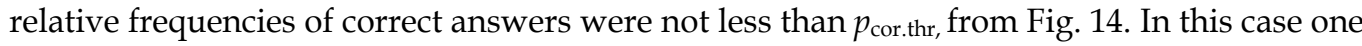
can calculate the value of the group learning coefficient

$$
K_{\ln }=\frac{N_{c o r: t h r}}{N} \cdot 100 \%,
$$

where $N$ - the total number of students in a group.

For the first group of students the given coefficient was $K_{l n}=92,3 \%$, and for the second group $K_{l n}=53,8 \%$. 
Therefore, obtained results show that students from the first group showed a higher level of the collective thesaurus.

The further goal of the research was to find out of which of examined groups demonstrated the best knowledge and abilities. For this purpose each group was provided with two types of assignments. One assignment contained the tasks, allowing evaluate knowledge of students, whereas another one contained the tasks, allowing evaluate abilities.

The average value of the gained knowledge coefficient in the first group $\bar{K}_{k n}=87,5 \%$ was considerably higher than in the second one $\left(\bar{K}_{k n}=62,5 \%\right)$. The average coefficient of abilities gained by the first group $\left(\bar{K}_{a b}=67,3 \%\right)$ was also higher than in the second group $\left(\bar{K}_{a b}=44,2 \%\right)$.

Dependences of the number of students from the coefficient of the gained knowledge have been built (Fig. 15).

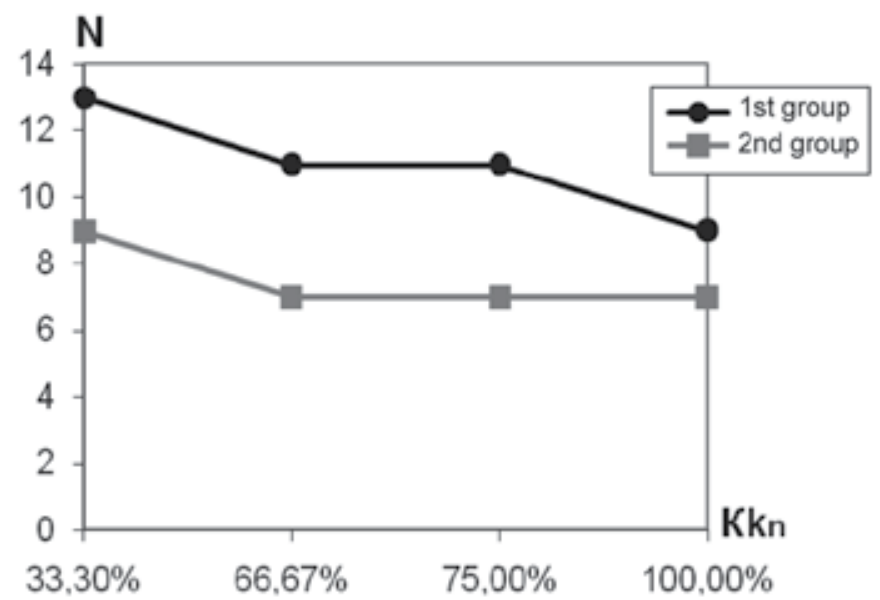

Fig. 15. Distribution of students in groups depending on the coefficient of knowledge.

Taking the threshold value of the coefficient of the gained knowledge $K_{l n . t h r}$, for example 75 $\%$, one can determine the number of students $N_{l n . t h r}$, whose coefficient of knowledge was not below this threshold value, and calculate the coefficient of learning goals achievement at the level of knowledge

$$
K_{k n . g r}=\frac{N_{\text {ln } . t h r}}{N} \cdot 100 \%
$$

For the first group this coefficient was $K_{k n \cdot g r}=76,9 \%$, and for the second one $-K_{k n \cdot g r}=53,8 \%$. In Fig. 16, distribution of number of students of both groups depending on coefficient of abilities is built. Coefficients of learning goals achievement at the level of knowledge for the threshold value $K_{a b . t h r}=75 \%$ were $53,8 \%$ for the first group and 30,7 \% for second one. 
It should be noted that the cybernetic approach to the design of dynamic training elements makes the process of self-learning adaptive, i.e., it allows students use the information gained while training to enrich their knowledge base. The use of DTE makes it possible for students to take an active role in their training, and keeps them motivated, which greatly increases the efficiency of training. This is the main pedagogical effect of the DTE application.

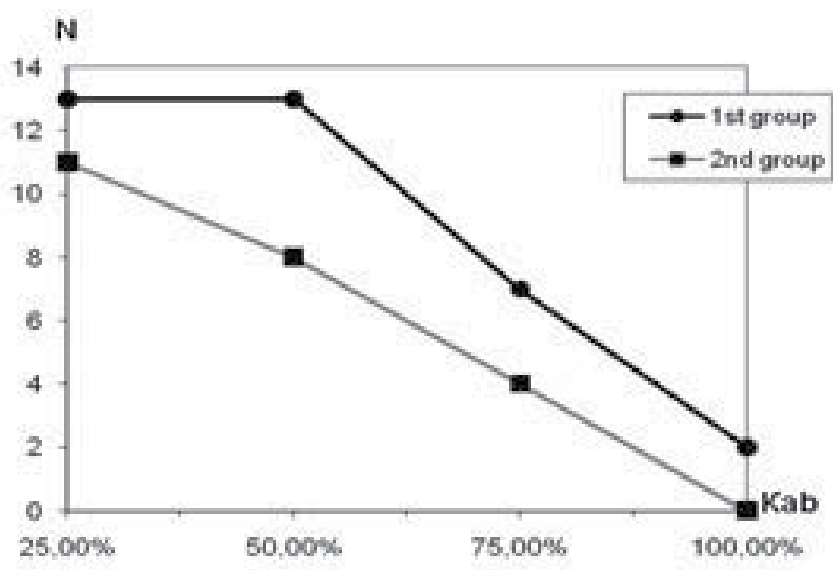

Fig. 16. Distribution of students in groups depending on coefficient of abilities.

In 2009-10 on the department of technical electronics at SibSUTIS statistical researches among students were conducted. Under results of these researches laboratory training on remote access laboratory received many favorable comments. One hundred of students took part in questioning, and 73 of them estimated laboratory training as excellent (Fig. 17).

It is very important to explore axiological characteristics of electronic educational environment, its pedagogical value and pedagogic usefulness. Pedagogical value of electronic learning material is influenced not only by the phase providing information, but by the phase transmitting information. Different information barriers impede travel of information flows and their perception. These barriers reduce potential value of learning material. In new educational technologies (distance-learning, e-learning and m-learning) students receive strong psychological support through their communicative activity. Deficiency of communicative activity in learning results in inability to create favorable psychological climate and comfortable conditions for learning; decrease of interest in learning up to complete vanish of motivation to study through new technologies. The network educational communication is effective as it is based on a subject-subject model, where mutual interaction of subjects takes part. The arrangement of effective education in new educational environment requires considering characteristics of this environment as well as behavior of a person in this environment. New educational environment brings about new learning situations and relations.

The Siberian State University of Telecommunications and Information Sciences (SibSUTIS) has been using the e-learning technologies for higher education services for almost 10 years. The number of students distance studying at the workplace is steadily increasing (fig. 18). 


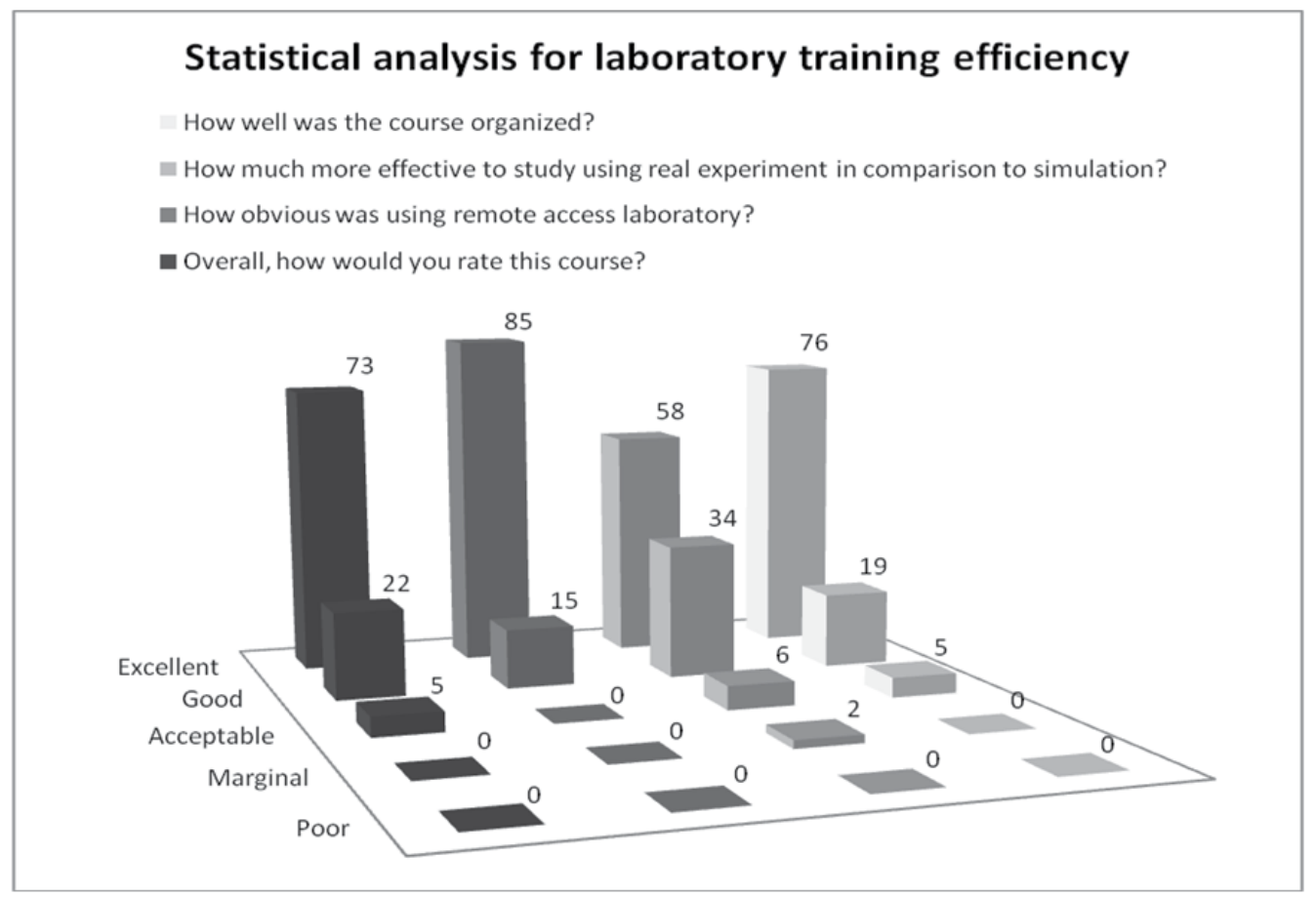

Fig. 17. Statistical analysis for laboratory training efficiency.

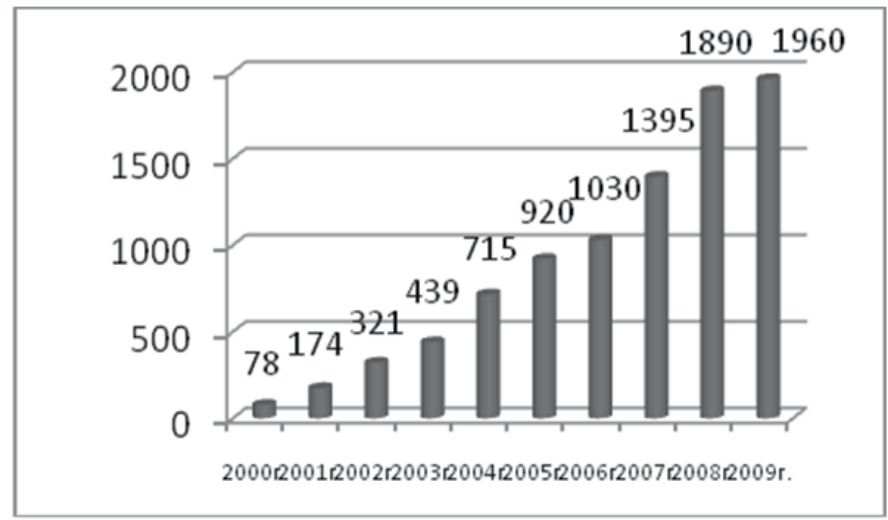

Fig. 18. Dynamics of telecom enterprise employees' enrollment for distance learning.

From the students, who are graduating the corporate distance university, $23 \%$ have been fully satisfied; $58 \%$ have been mostly satisfied and only $19 \%$ have been partially satisfied with the electronic educational environment. It is worth mentioning that there has been no unsatisfied graduated student this year as well as previous years. The articles and notes related to the distance learning in university written by students or those who have completed the distance university are regularly published in corporate editions and publications. 


\section{Appendix - The best practice of application of modern approaches to engineering education}

\subsection{DL courses for CIS countries}

The liberalization of telecommunications field has resulted in strengthening the competition among alternative telecommunications operators. The development of infocommunication technologies has stimulated internal competition amongst interchangeable services. These changes have brought new approaches, models and instruments of business management into force, required new decision making in the field of policies and regulatory issues, technology and ICT awareness, corporate management and expected professional development of decision-makers as well as senior level officials in the Telecommunications Sector of CIS countries. International Telecommunications Union (ITU) has set up the network of world Centers of Excellence $(\mathrm{CoE})$ with the aim to promote the knowledge accumulated by the international community in the telecommunication sphere among ITU country-participants. Taking into account the successful implementation of Centers of Excellence in five ITU regions (Africa, Asia \& Pacific, Americas and Arab region), the decision to implement a sixth Centre of Excellence has been taken for CIS and EUR regions.

This Centre of Excellence plays a unique role in developing telecommunications in the CIS region, by making contributions in keeping the sector at the cutting-edge and giving opportunity to the countries to offer services best-suited for the development of the information society. Accordingly, the CoE strengthens and improves the facilities needed to develop and consolidate high-level competencies related to telecommunications policy development, regulatory issues, telecommunication management, new technologies and services in accordance with requirements and expectations of the region. The CoE must focus on the organization and presentation of excellent training programs designed for government authorities, senior managers, operators and service providers, to facilitate the development of telecommunications in the region. The $\mathrm{CoE}$ seeks to bring into operation a network of excellence among potential content providers (e.g. universities, training centers, etc.) and to service providers and technology providers already established in the region to give practical advice and render assistance for program. Within the framework of the Centre of Excellence project for the CIS countries it has been decided to bring into operation a network of excellence amongst potential content providers, like universities and training centers, which could provide on-line solutions The following telecommunications institutions famous in the CIS countries have been selected as the potential content providers: Moscow Technical University of Communications and Informatics in Moscow (MTUCI, Russia), Siberian State University of Telecommunications and Information Sciences in Novosibirsk (SibSUTIS, Russia), Alma-Ata Energy Institute (AEI, Kazakhstan), Tashkent University of Information Technologies (TUIT, Uzbekistan), Kiev Institute of Communications (KIC, Ukraine), Higher State College of Communications in Minsk (HSCC, Belarus).

One of content providers in "Corporate management" for the CIS countries is the CoE on the basis of the Siberian State University of Telecommunications and Information Sciences, SibSUTIS (Krouk \& Sitnikov 2002; Krouk\&Zhuravleva,2003). The service of organizing a learning process in this $\mathrm{CoE}$ has the following functions: planning the learning process (drawing up a schedule of electronic consultations, examinations, tests and tutorials) and implying functions of an Access Administrator, a Dispatcher of learning process and a 
Database Administrator. Most often these functions are performed by the same person. The technical support service in the DL system is the most expensive one because it consists of skillful personnel and exploits expensive equipment. This service consists of: programmers, who provide interactive communication, develop software for DL and elaborate databases; specialists in multimedia; network and web-server specialists whose aim is to provide a regular work of all servers, access to Web-servers over the Internet, video conferences, operation of a local network, protection of information against any fatal errors, and introduce new DL technologies.

The learning material of the course is divided into self-instructional units. This structure allows step-by-step learning, each step pays attention to a particular unit. The learning objectives of the course and each unit are clearly determined. The learning material is selfsufficient and trainees can do all types of training work and achieve stated learning objectives. The material is self-study oriented. Trainees have an opportunity to make calculations, solve different problems, and do practical exercises. The structure of the learning material contributes to the interaction of a trainee, and allows him/her communicate with trainers, tutors, specialists, and other course participants. Every unit has self-assessment questions and tasks, which would make it possible for a trainee to check his/her progress and mastery of the learning material. The learning program provides trainees with tests, which are checked and evaluated by trainers. The learning material is also provided with access devices such as course guides, course curriculum, trainers' email addresses and reference materials. A number of case studies, which require analysis and decisions making by trainees, are included in the learning program. To discuss those problems with other participants, trainees have access to a Web conferencing system offline taking into account different time zones. To manage trainees' study there is a billboard, on which one may put all general information. All materials are issued in HTML, with all necessary hyper references for convenient navigation through a course material. Trainees may see learning materials both online and in an autonomous regime.

The main objective of distance learning is to provide interactive training. For this purpose, dynamic Web pages are elaborated on the Active Server Pages platform. Integrated application of ASP and databases provides trainees with an access to resources of the Web site as well as gives information about grades received in the learning process, possible failures, and current assignments. On the basis of ASP, VBScript, and JavaScript, programs for distance testing of trainees have been developed. The software for group work in virtual class and case study, which help to hold discussions on learning issues with forum and chat technologies, is elaborated in the DL CoE. Communication activity provides such support for trainees who are far from the institution and cannot attend classes as communication with administrative staff, trainers, tutors, and other course participants. It makes possible for trainers to answer trainees' questions quickly, reveal their difficulties as well as render immediate assistance, form a sense of constant community among a dispersed group of trainees, compare their own study progress with that of other course participants, and give mutual assistance. On the developed site one of the main means of communication is the email. By email trainees send their papers to the DL CoE. By email they send questions and receive answers and reviews of accomplished assignments. For the convenience of trainees the email is mounted in a learning module, thereby making it possible to send messages (a question, an accomplished assignment, a draft, a project, etc.) without interrupting the work 
in the learning module. The other channels of communication are a debating forum and a billboard.

In 2009 about 250 participants from 10 countries took part in the courses held in DL Centre of Excellence on the basis of SibSUTIS. The quality of training was evaluated by questioning trainees. All course participants were provided with questionnaires to evaluate the quality of training in accordance with ITU requirements. Processing of questionnaire results allowed us to draw the following conclusions: almost all course participants were of a very high opinion of the quality of training; they pointed out that the course was up-to-date and expressed their interest in it; and the course turned out to be very useful for enterprise employees' practical work.

\subsection{The corporate DL course for telecom company managers}

Another example of modern approaches to engineering education, namely, the corporate elearning course for top and middle managers of the telecommunication company will be described. The management of "Sibirtelecom" Public Corporation of the Russian Holding Company "Svyazinvest" took a decision to hold retraining of top and middle managers of the company. This large company has its departments in 11 areas of the Siberian federal district and numbers more than 40000 employees. Siberian State University of Telecommunications and Information sciences (SibSUTIS) - the large branch-wise university located in territory of the Siberian federal district - became an educational institution capable of offering effective programs and methods of training (Krouk \& Zhuravleva, 2004).

First of all the e-learning course content has solved corporate queries and has been adapted to the market. Besides, it also focused on the future interests of the corporation and the development of this market. In whole e-learning course consists of 5 modules and is meant for training within 6 months period (600 hours). The teaching time of each module makes 120 hours. Of them 96 hours are set aside on network training which takes about one month (with 4 hours per day), and 24 hours a short internal session. Such a learning containing both distance components and full-time tuition examinations is called blended learning. The e-learning course is based on modular concept on the basis of interdisciplinary approach. The course program is an integral program in which various teachers' activity is completely coordinated. The electronic-educational environment of this e-learning course aims students at self-managing personality-oriented learning, provides an informational interaction between students.

In the e-learning course nonconventional methods of training based on partnership represented by the process of an interactive dialogue in the conversional form, collective discussion of various situations (case-study), team work at joint projects and etc. have been used. The entire teaching material of the e-learning course is mostly connected with direct professional activity of employees. The practical e-learning course component contains special tasks which must be performed during the course by company employees. During the e-learning course the trainees communicate with teachers, the colleagues, the company experts by means of built-in in the module e-mail. Trainees and teachers get acquainted using the "visiting" cards system with photos. Acquaintance between students and formation of virtual class begins with a forum of acquaintance. Each module is provided with a feedback in the form of consultations, checks of practical tasks performance, testing 
and control of knowledge, questioning of trainees. As the program is oriented on adult people, it is provided with group discussion of studied problems and tasks performed in modules. At internal sessions methods of work in small groups are used.

To evaluate the training quality and efficiency of educational activity at corporate university the system of an integrated monitoring of an educational process has been implemented. After the students complete studying the material of each distance module they are asked to express their opinion about distance educational process. The questionnaire contains three kinds of questions: evaluation of distance learning organization, evaluation of electronic teaching materials quality and evaluation of trainees' survey. Each trainee should evaluate convenience of work with an educational site, the quality and completeness of communication with colleagues and an administrator of an educational process by fivepoint scale; to draw the conclusion about completeness and quality of electronic teaching materials, and also to state the degree of distance learning.

The analysis of the results has shown that almost all participants expressed satisfaction with web-site, access to it, service information on the web-site and cooperation with the manager of an training process. Trainees practically had no claims to the quality of teaching material on a distance learning web-site. Gradually in the process of training students completely adapt to a distance learning form, therefore they evaluate efficiency and quality of thee-learning course at the end of training higher than at the beginning. During the e-learning course collective discussion of a particular practical problem with a teacher on a forum is repeatedly organized. It is worth mentioning that students get more satisfied with some problem discussion at a forum by the end of studying $(4,82$ points at the end of studying contrary to 3, 29 points at the beginning). Similarly, satisfaction from the dialogue with the colleagues at the end of studying was estimated higher than at the beginning (4, 86 points contrary to 3,9 points). In process of studying trainees realize that the given training improve their professional work $(4,45$ points contrary to 3,71 points at the beginning). It is obvious that students have coped with electronic discussions and have been able to comprehend better the teaching material and their studying became more effective. On the average, managers have evaluated the e-learning distance course to the 4,86 points and are assured that it would be useful for their colleagues to take a similar e-learning course (4,86 points).

The expert evaluation of the quality and learning efficiency that was given at each grade level by the teachers participating in educational process was the third element of complex monitoring of the educational process system. In their conclusions it is underlined that training materials given in educational modules have caused genuine interest of the learners. It proves that the course is actual and of practical importance for listeners. At the lessons practical estimations have been conducted, special situations (cases) have been studied and investigated, business games have been played. Making task solutions trainees used the data of the "Sibirtelecom" and other enterprises. Students took the most active part in trainings, demonstrated high level of analysis of problems offered to discussion competence.

The fourth and one of the most fundamental monitoring elements has been the score rating evaluation of the student's educational activity results. Not only managers' evaluation of this program is an evidence of the successful work of the network corporate university, but also positive comments by corporate publications. The majority of these managers had career development. 


\subsection{DL education on communication engineering and computer science}

Over the last ten years, perhaps, no sector of Russian national economy has undergone such a revolutionary shock as telecommunications one. In the technical development of this sector there have been five qualitative leaps: the element base of the equipment was replaced (instead of lamps and transistors there were digital very large integrated circuits); principles of the equipment operation have changed (the outmoded analog principle has been replaced by modern digital one) ; principles of communication networking have changed (instead of slow switching of channels superfast switching of packages with speech and video information have come into operation); the transmission medium has changed (instead of electric signals transmitting by metal conductors light beams on optical fibers have been transmitted); automated control systems of networks have been introduced. In this connection ten years ago the problem of mass retraining of the technical and administrative personnel of telecommunications sector came to the fore. There might have been a threat of "a personnel collapse" without solving this problem.

In 2000 the Siberian State University of Telecommunications and Information sciences has launched the corporate distance university. The employees of the telecommunication companies and corporations can graduate in telecommunication, information and economics from the corporate distance university. It aims its educational services at the telecommunication sector of the Russian economy, and also of the CIS countries. The basic consumers of services are such large stock companies, as "Sibirtelekom" and "Uralsvyazinform" (60\%). As for other companies: "Dalsvyaz", "The Northwest Telecom", "Volgatelekom", "Centrtelekom", "Kazakhtelecom" its a share is about 40\% of all consumed educational services.

The main participants of an educational process in a corporate distance university are students, teachers-tutors and managers of educational process. A necessary condition for the Internet-learning organization is availability of a Web-server, database and management system of training process at the university. Introduction of e-learning technology into educational process has demanded introduction of Learning Process Maintenance procedure shown in fig. 2. Support system for e-learning at the workplace fulfills functions which include design of learning courses, teaching of students using the Internet, management of training process, support of e-library. In the process of e-learning organization three categories of users take part. They are students, teachers and administrators of training process. The support system for the e-learning at the workplace provides communication between the users and the administrators of a training process.

Content of e-learning courses developed by teachers get archived and are stored on the server. The database server is used to manage the e-learning database which contains data about students, teachers, managers, curricula, learning specialties, subject, learning progress and teachers' reviews. The Web-server provides access to the e-learning recourses for all categories of users. The Web-server's functions include publishing of information, reference and learning materials; access to the database and storage of learning materials. The server of a remote laboratory allows students to work with devices and equipment in the remote access mode. The storage of a student's works includes all works performed by students and sent by email as archived files. In order to send student works and information teachers and managers use a special mail service. Automated workplaces for students, teachers and e- 
learning administrators are workstations where browsers provide the access to the elearning recourses. The support system for the e-learning at the workplace, which ensures students' training process, starts with a student identification, which is made by entering a login and a password. If identification is done successfully, the student gets authorization to information and learning materials of the current semester.

The support system for the e-learning at the workplace provides students with administrators' and teachers' contact information; allows to send emails; gives recommendations how to work with Microsoft Office and archiving programs, which are used in the e-learning; provides students with the access to the e-learning curricula, tutorials and e-learning forum. The function "copy the learning courses" makes it possible for students to download an archived file with the learning materials of the selected subject into their own PC. Once the file is dear hived, students get a local mini-website, which contains all necessary materials for successful learning. The function "sending the performed tasks" makes it possible for students to send files with the performed learning tasks to the e-learning server in order to get registered in the database and to place their learning tasks into the storage of student's tasks. The student's tasks stored on the server become available to a teacher for checking and to an administrator to control training process. As it is very important for the students to be aware of their learning progress, the system includes "monitoring of student's progress". Functions of the support system for the e-learning at the workplace for teachers are the following: once being identified, the teacher gets the access to the e-dean's office, where the teacher may get the list of student's works assigned for a particular subject. The e-dean's office's page contains filters, which allow a quick search for a certain student's task using such search criteria as student's name, surname, code of his/her group, subject name, category of a student's task (all, checked, unchecked). Every line of the list contains data of one student's tasks including links to a student's email, a file with performed tasks and a student's personal information. The function "check" is used to open the page to make a revision and send the task to a student.

On the ground of the above described structure and functions of the support system for the e-learning at the workplace, one may arrive at a conclusion that application of the e-learning based on the Internet technologies makes it possible to organize a training process within the university education, as well as to administer it thoroughly.

E-learning via the Internet becomes more and more appealing.

\subsection{An international project promoting language learning and intercultural communication}

Businesses want employees to have international experience, administrations want their civil servants to communicate in a European context and institutions of higher learning encourage their students to study abroad. Yes, we live on a multicultural continent and Europeans have recognized the importance of other cultures. They are no longer a source of conflict but a cornucopia of knowledge and wisdom. Recognizing and accepting this fact is the first and important step on the way to greater European cohesion, but it is not sufficient. Our multicultural world requires extensive intercultural communication. We need more than a side-by-side existence of different cultures. What we want is a fruitful exchange 
between cultures and nations. It is the aim of EMA-4-MOODLE, an Erasmus Mundus Project to promote such positive communication.

The aim of this project was to facilitate international mobility for European and nonEuropean students by offering them tools that will help them overcome these difficulties. These tools are specifically adapted on-line language courses and intercultural documents. Project partners are developing four language courses: in French, German, Russian and Slovak. The courses are being implemented on the LMS Moodle (Hörbarth, 2007). The language courses are based on an original film made in each partner country. The film is broken into stages a foreign student at a particular institution has to go through in order to succeed his integration into the new educational system. The film consists of 10 parts lasting for about 10 minutes each and is provided with the subtitles in the original and English languages. The most common situations that foreign students may face when they come to study abroad are shown in the films. The students can see the buildings of the university, accommodation conditions, people actually working and students actually studying there so when they come they would not feel as total strangers; they would have an idea of where to go and what to do. This project has been supported by the European Commission.

\section{References}

Bannan-Ritland, B. (2002).Computer-Mediated Communication, Elearning and Interactivity: A Review of the Research Quart. Rev. Distance Educ., vol. 3, no. 2, pp. 161-179, 2002.

Bohne, A.; Fatlin, N. \& Wagner, B. (2002).Self-Directed Learning and Tutorial Assistance in a Remote Laboratory, Proceedings of Interactive Computer Aided Learning Conference (ICL 2002), Villach, Austria, Sep. 25-27, 2002.

Borisov A.A.; Popov N.V. \& Shauerman, A.A. (2006). "Foundations of making virtual laboratories in engineering education," International Workshops and Tutorials on Electron Devices and Materials EDM'2006, pp. 180-181, 2006.

Chou, C. (2003) Interactivity and Interactive Functions in Web-Based Learning Systems: A Teaching Framework for Designers, Br.J.Educ.Technol., vol. 34, no. 3, pp. 265-279, 2003.

Day, J.A.; Foley, J.D. (2006).Evaluating a Web Lecture Intervention in a Human- Computer Interaction Course, IEEE Trans. Educ., vol. 49, no. 4, pp. 420 - 431, Nov. 2006.

Dearholf, D.W.; Alf, K.J.; Halpin, R.F.\& OliverR.L. (2004).Foundational Aspects of StudentControlled Learning: A Paradigm for Design, Development and Assessment Appropriate for Web-Based Instruction, J.Eng. Educ., vol. 93, no. 2, pp. 129-138, Apr. 2004.

Ellis, H.J.C. (2007). An Assessment of a Self-Directed Learning Approach in a Graduate Web Application Design and Development Course, IEEE Transactions on Education, vol. 50, no.1, pp. 55-60, Feb. 2007.

EvansC.\& Sabry, K.(2003). Evaluation of the Interactivity of Web-Based Learning Systems: Principles and Process, J. Innovations Educ. Teaching Int., vol. 40, no. 1, pp. 89-99, 2003. 
Garofalakis,J.; Sakkopoulos, E.; Sirmakessis S. \& Tsakalidis, A.(2002).Integrating Adaptive Techniques into Virtual University Learning Environment,Proceedings of IEEE Int. Conf. Advanced Learning Technologies, pp.28-33, 2002

Gick M.L. \& Holyoak, K.J. (1987). The Cognitive Basis of Knowledge Transfer, Transfer of Learning: Contemporary Research and Applications, S.M. Cornier and J.D. Hagman, Eds.New-York: Academic, pp. 9-46, 1987.

Glaserfeld, E. (1989). Cognition, Construction of Knowledge and Teaching, Synhese, vol.80, pp.121-140, 1989.

Hsiung C. L. (2006) An Internet-based graphical programming tool for teaching power system harmonic measurement,IEEE Trans. on Educ., vol. 49, no. 3, pp. 404-414, 2006.

Hörbarth, U. (2007) Konstruktivisitisches Lernen mit Moodle, Boizenburg, 2007.

Jacobson, M.; Raja, L.; Said, A. \& Rehman, H. (2006). Introducing design skills at the freshman level: structure design experience, IEEE Trans. on Educ., vol. 49, no. 2, pp. 247-253, 2006.

Krouk, B. I.;Sitnikov, S. G. (2002).Intergovernmental DL Training Center in Telecommunications, Information Technologies, Economics and Business for CIS Countries,Magazine "Human Recourse Development" published by BDT ITU, July \#88, p.25-33, 2002.

Krouk, B. I. \& Zhuravleva, O. B. (2003). DL Training Center in Telecommunications for CIS Countries,IEEE Communications Magazine, vol. 41, \#7, p. 31-32, 2003.

Krouk, B. I. \& Zhuravleva. O. B. (2004). Distance Learning Program to Raise Skills of Managers from Russian TelecommunicationEnterprises, IEEE Communication Magazine, Vol.42 ,\#5, p.30-31, 2004.

Krouk, B. I. \& Zhuravleva. O. B. (2009). Dynamic Training Elements in a Circuit Theory Course to Implement a Self- Directed Learning Process, IEEE Trans. Educ., vol. 52, no. 3, pp. $394-400,2009$

Lin, H.C. (2006). An Internet-Based Graphical Programming Tool for Teaching Power System Harmonic Measurement", IEEE Trans. Educ., vol. 49, no. 3, pp. $404-414$, 2006.

Petridis, V.; KazarlisS. \&Kaburlasos, V.G. (2003). ACES: An Interactive Software Platform for Self-Instruction and Self-Evaluation in Automatic Control Systems, IEEE Trans. Educ., vol. 46, no. 1, pp. 102-110, Feb. 2003.

Regueras, L.M.; Verdu, E.; Munoz, M.F.; Perez, M.A. \& Castro,J.P. (2009).Effects of Competitive E-Learning Tools on Higher Education Students: A Case Study, IEEE Trans. Educ., vol. 52, no.2, pp. 279-285, May 2009.

Sakkopoulos, E.; Lytras, M. \&Tsakalidis, A. (2006).Adaptive Mobile Web Services Facilitate Communication and Learning Internet Technologies, IEEE Trans. Educ., vol. 49, no. 2, pp. 208 - 215, May 2006.

Savery, J.R.; Duffy, T.M.(1995). Problem-Based Learning: An Instructional Model and its Constructivist framework, Educ. Technol. Res. Devel.vol. 35, pp. 31-38, 1995.

Splitt, F.G.(2003). The challenge to change: on realizing the new paradigm for engineering education,J.Eng. Educ., vol. 92, no.2, pp.181-187, April 2003. 
Spoelder, H.J.W. (1999). Virtual instrumentation and virtual environments," IEEE Instrum. Meas. Mag., vol. 2, no. 3, pp. 14-19, 1999.

Travis, J. (2004).LabVIEW for Everyone (second edition). Moscow: PriborKomplekt, 2004. 


\title{
Assessment Methods of Student Learning in Web-Based Distance Courses: A Case Study
}

\author{
Jon R. Hufford \\ Texas Tech University \\ USA
}

\section{Introduction}

Higher education has been challenged for several years now to show with empirical evidence that it is committed to improving student learning. The United States Department of Education's Commission on the Future of Higher Education issued a report in 2006 titled A Test of Leadership: Charting the Future of United States Higher Education. The report makes recommendations for educational reform. A portion of a summary in the report states that "improved accountability is vital to ensuring the success of all the other reforms we propose. Colleges and universities must become more transparent about cost, price, and student [learning] success outcomes, and must willingly share this information with students and families" (U.S. Dept. of Education, 2006, pp. 4, 14-15). The Commission's report has had a significant impact on campuses across the United States.

All of the regional higher education accreditation organizations made changes in their standards in response to the Commission's report, and these changes are chiefly responsible for the trend toward student learning-outcomes assessment in the United States. ${ }^{1}$ Some of the standards of these regional organizations relate to distance courses and, among other things, have influenced the way they are assessed. Distance learning faculty are now using student learning-outcomes assessment methods in their courses because of this new emphasis on assessment and the inclusion of distance courses in the efforts of many colleges and universities to assess their programs and courses. ${ }^{2}$ The data collected from these assessment efforts is being used to improve student learning, the content of the courses, and the teaching skills of the instructors. Unfortunately the experiences of instructors in assessing what distance students are learning in their courses are not well documented in the professional literature. Distance learning faculty with this experience should share their assessment findings with colleagues who need to know which methods are working successfully and which are not, and how the assessment process can be used to improve learning and teaching.

\footnotetext{
${ }^{1}$ Student learning-outcomes assessment focuses on empirically measuring student performance, which is called outcomes. It requires that students demonstrate that they have learned the required skills and content taught in the course.

${ }^{2}$ Distance learning (also called distance education) is a method of studying in which lectures are broadcast or classes are conducted by correspondence or over the Internet, without the students needing to attend a school or college.
} 
This chapter is in the form of a case study. It examines student learning-outcomes assessment methods that are suitable for Web-based courses, and points out some of their strengths and weaknesses as seen from the perspective of the online learning environment. The author concentrates on those assessment methods used by instructors at Texas Tech University Library in a one-hour, Web-based credit course developed to teach research skills to distance students. ${ }^{3}$ After reviewing the various categories of methods available, the course instructors decided to use those that they thought offered the greatest potential for assisting them in reaching the course's assessment goals, comprised implementation processes that promised to be relatively easy to use and not so time-consuming, and included attributes that would facilitate student use. The course instructors' method for using assessment data to improve their course is demonstrated by way of examining the data collected in the fall of 2010 to determine findings that could help identify problems that need to be fixed in order for improvement to take place. Also, the study examines how the questions in the course's assessment tests are linked to the course learning-outcome objectives and Association of College and Research Libraries competency standards.

Before examining assessment methods, the author briefly discusses background issues that the distance learning instructors of Texas Tech Library regularly address during the early stages of planning the assessments that are used in their course each year. These issues can be understood as questions that instructors must answer during the planning process. Some of the questions are what role will standards play in assessment, what learning theories underlie the assessment and instructional strategies, and how will assessment match the course's learning objectives and instructional strategies? The Texas Tech instructors' discussion of the issues and determination of the assessment methods to be used occur in the context of a structured yearly cycle of planning, developing, marketing, implementing, assessing, and improving all aspects of the course.

\section{Literature review}

Searches in several bibliographic resources using the keywords "higher education," "distance learning" or "distance education," and "assessment" yield a large number of articles, books, documents, and other materials on assessment. Some of these materials are guides, manuals, or action plans; articles on the need to integrate assessment into education; or reports of accreditation trends in higher education. Other materials found discuss strategies used to gain support for or to develop assessment programs, or report on statewide assessment programs of higher education curricula without the details of any particular assessment projects. The author found a less numerous group of articles that in some way or another discuss assessment of student learning in distance courses, including those that report the actual experiences of distance learning instructors in assessing student learning in their courses. Though a few of these articles report on studies that did not take place in a higher education environment, higher education faculty involved in distance learning should be aware of these studies because of their pertinence in the developing field of distance learning in higher education.

${ }^{3}$ Web-based learning (also called online learning, e-learning, or electronic learning) comprises all forms of electronically supported learning and teaching. The information and communication systems, whether networked or not, serve as specific media to implement the learning process. 
One of these articles addresses the research needs of distance learning, and others describe recently developed online systems or approaches that assess in one way or another student learning outcomes. Oncu and Cakir (2011) examine the priorities and methodologies of research in online learning environments. The authors maintain that distance learning lacks research goals that, if observed, would lead to a better understanding of the impact of online learning environments on students. They propose four research goals for online learning concerned with learning achievement, engagement, and retention. Their goals are "(a) enhancing learner engagement and collaboration, (b) promoting effective facilitation, (c) developing assessment techniques, and (d) designing faculty development programs." The authors discuss some research work in these areas, and recommend research methods that are suitable for pursuing their goals. Su et al. (2011) report on the testing at three Taiwanese universities of an online portfolio assessment and diagnosis scheme (OPASS) that assists teachers in automatically assessing and diagnosing students' abilities in performing scientific inquiry. OPASS generates reports that diagnose learning problems and provide suggestions for improvement based on teacher-defined assessment input for the scientific inquiry experiment. Udo et al. (2011) propose a modified SERVQUAL instrument for assessing e-learning quality. The instrument measures five dimensions: assurance, empathy, responsiveness, reliability, and Website content. Analysis of the data collected from 203 elearning students who participated in a pilot study of the instrument revealed that four of the dimensions (excepting reliability) played a significant role in the students' perceived elearning quality. The authors point out that perceived quality affects student satisfaction with their e-learning, and is an indicator of future intentions to enroll in online courses. Sima et al. (2007) discuss the eMax Knowledge Assessment System developed by the Intelligent Knowledge Management Innovative Center of IBM Hungary and the John Von Neumann Faculty in Informatics at Budapest Tech. eMax can evaluate students' open-ended short answers including a few sentences or partially solved mathematical problems. ${ }^{4}$

A few online assessment systems or approaches are rather unique. Costagliola et al. (2009) discuss an approach to online testing that enables instructors to monitor learner behavior and test quality. The approach involves examining logging data related to learner interaction with the system during the execution of online tests and exploiting data visualization techniques to identify information useful for improving the assessment process. It focuses on discovering learners' behavior patterns and the conceptual relationships among test items. Hayes and Ringwood (2009) report on the development of a system used to authenticate telephone-based oral examinations. The authors assert that the system can, in turn, be used to confirm a student's ability in relation to submitted assignments and online test results and that it is an effective deterrent against plagiarism.

Portfolio creation is conducive to developing students' skills in documenting and tracking their learning, developing an integrated and coherent record of their learning experiences, and improving their self-understanding. Bhattacharya and Hartnett (2007) discuss a system that assesses the learning that takes place during the design and development of students' eportfolios. Caldarola and MacNeil (2009) review the similarities and differences in student cheating among the various assessment methods. They then investigate cheating indicators and predictors, and the methods available for detecting cheating on examinations. Also,

${ }_{4}^{4}$ Open-ended questions allow for a spontaneous, unstructured answer. 
they offer an analysis of the testing guidelines of the International Testing Commission and of several major universities, and a review and evaluation of several remote examination proctor systems in the United States along with recommendations for their use in various distance learning environments.

A limited number of actual assessments of what students are learning in online courses have been reported in the literature. Hufford and Paschel (2010) report on the experience gained by instructors at Texas Tech University Libraries while developing and implementing preand post-assessment tests that were administered in the distance learning section of a library research course taught in the fall of 2009. The assessment's findings were used to improve student learning, the course content, and teaching in the course's online section. Foster and Drew (2009) discuss student learning-outcome assessment that took place in an astrobiology course taught at the University of Florida. Pre- and post-tests along with "knowledge" assessments were used to evaluate the students' perceived and actual learning experiences. The course used both traditional classroom and distance learning technologies. The assessment's pre-testing indicated that the students had little prior knowledge of key astrobiology concepts. However, post-testing showed significant improvements in their comprehension of the subject. The assessment also revealed that, because of taking the course, the students developed confidence in writing on science topics as well as reading and understanding the primary literature of astrobiology. Brown and Hanks (2008) report on an innovative online workshop designed to assess and improve the writing skills of students enrolled in distance learning gerontology classes. Student learning assessment included Web-based writing evaluations in both pre- and post-tests. Urtel (2008) explores whether differences in academic achievement indicators exist between students taking a traditional classroom course and a distance learning course. The final grades; rates of D, F, and $\mathrm{W}$ grades; and end of term course and instructor evaluations of three-hundred and eight-five students enrolled in a course offered both in a classroom (116 students) and at a distance (269 students) were studied. The course content, instructor, textbook, and assessment methods were similar for both delivery formats. Student demographic information was included in the data analyses. Ivanitskaya et al. (2008) review the results of tests that assessed the library research skills of off-campus students. The investigators used a "Research Readiness Self-Assessment" test as a pre- and post-test in an off-campus Master's degree class at Central Michigan University. In particular, they investigated the impact that pre-tests have on the effectiveness of library instruction when students are given feedback on their pre-test performance. Similarly, Mulherrin et al. (2004) review the results of pre- and post-tests taken by students. The tests were taken by distance students enrolled in LIBS 150, a one-hour credit, elective library skills course offered at the University of Maryland. The tests were administered as one phase in the development of the course and proved to be an important factor in its eventual success.

\section{Aim and scope}

For several years now, Texas Tech University Library has offered a one-hour credit course titled "Introduction to Library Research" (LIBR 1100) to undergraduates. The course teaches the basics of library research and targets freshmen, though sophomores, juniors, seniors, and even an occasional graduate student enroll in the course. Most of the Information Services librarians participate as instructors. Several sections are offered each fall semester, 
and two or three sections in the spring. Each semester at least one of the course's sections is taught online to distance students. There are no classroom meetings for the distance students. The entire course is taught on the Internet using the Blackboard Course Management System to students located across Texas and in some cases out-of-state.

Every term, the distance section of the course has been evaluated by students enrolled in the section in terms of the course content and instructor. The evaluations are done on printed, machine-readable forms. All credit bearing courses taught under the auspices of Texas Tech University must be evaluated using this form. The data collected on the forms is subjective and, in any case, is not the kind that can be used to assess what students have learned. Nevertheless, the course's instructors regularly consult student input recorded on the evaluations. This consulting takes place every year during the summer when the instructors revise and improve the course.

The instructors of LIBR 1100 have used more objective assessment methods to find out what their students are learning. They began measuring student learning outcomes with pre- and post-assessment tests in the fall of 2008 and have used the tests ever since. The intent of the tests is to determine as objectively as possible whether students enrolled in the distance section are learning what the instructors teaching the section intend for them to learn. Other assessment methods used in the online section of the course are practicum assignments that require the performance of skills, an annotated bibliography project, and quizzes. While the quizzes and pre- and post-assessment tests evaluate students' knowledge of the course's subject content, the practicums and annotated bibliography test the performance of skills.

This study briefly examines assessment methods that are suitable for Web-based courses, including online quizzes, tests, and exams; online discussions and other similar kinds of networked learning; problem-based learning and case-based reasoning; role playing; assessing practical skills; and laboratory experiences. The author then goes on to carefully examine those methods used to assess student learning in the Web-based distance learning course taught at Texas Tech University Library, highlighting experience gained by the instructors while developing and implementing pre- and post-assessment tests, online quizzes and exams, and authentic performance assessments that have been administered in the course. Student assessment data collected by all of the instruments employed in the fall of 2010 are analyzed, and this analysis is meant to demonstrate how the instructors' yearly cycle of developing and improving the course operates. The importance of linking assessment questions to course learning objectives and nationally recognized competency standards is also demonstrated.

The study's discussion of the various assessment methods used in the Library's online course represents a contribution to the limited documentation available in the professional literature on student learning-outcomes assessment projects that have taken place in the online distance learning environment. The assessments' findings, though relevant to one academic institution, nevertheless will enhance distance learning faculty's understanding of how the assessment process can be used to improve learning, teaching, course content, and delivery. Other important contributions are identification of assessment methods that work well in the online learning environment and an explanation of how assessment planning can fit into a yearly cycle that includes planning, developing, marketing, implementing, assessing, and revising an instructional program. 


\section{Background}

The instructors who teach LIBR 1100 participate as team members in the process of continuously discovering student needs and expectations and improving the course's content, teaching, and learning. This team effort has evolved over the years into a structured yearly cycle of planning, developing, marketing, implementing, assessing, and improving all aspects of the course. The data collected from the various assessment methods play an important role in the process. The instructors recently started using the seven stages of Megan Oakleaf's (2009) instruction assessment cycle as a resource to assist in improving their process. These stages include reviewing learning goals, identifying learning outcomes, creating learning activities, enacting learning activities, gathering data to check learning, interpreting data, and enacting decisions (Oakleaf, 2009, pp. 541-545). The stages are incorporated into the process when and where feasible. In the near future, Blackboard Learn, the assessment module in Blackboard, will be used to track students enrolled in LIBR 1100 and will facilitate accurate reporting of the Library's impact on the learning and teaching that takes place at Texas Tech University (Oakleaf, 2011, pp. 76-77).

\subsection{Planning and designing assessment}

Gunawardena and LaPointe (2003) identify questions that all distance learning instructors should answer during the early stages of planning the assessments that will be used in their online courses. These questions are:

- What role will standards play in assessment?

- What learning theories underlie the assessment and instructional strategies?

- How will assessment match the course's learning objectives and instructional strategies?

- What process, product, or use of resources must the students demonstrate?

- What will be considered evidence of learning in the course?

- What tools and resources are needed to support the students as they complete the assignments?

- Will assessment be based on independent or collaborative learning?

- Will the assessment be self-paced or timed?

- Will students complete the same assignments?

- Can students choose from an instructor-provided selection of assignments?

- What kind of coaching and managing will be required?

- Will remediation and supplemental help be provided?

- Will students require feedback before proceeding to the next assignment?

All sorts of unforeseen situations could adversely impact the successful implementation of assessment in an online distance learning course. Therefore assessment should be planned and designed carefully and thoroughly before implementation takes place. Answering the questions listed above during the process of planning goes a long way towards assuring successful implementation of the assessment. The instructors of LIBR 1100 use this list of questions to assist them in planning their assessment goals, a task which takes place during the "summer planning" stage of their yearly cycle.

The LIBR 1100 instructors are always on the lookout for any conflicts or inconsistencies among the answers to these questions. Conflicts or inconsistencies may lead to course 
failure if they are ignored. A self-paced course may not be successful if collaborative projects or weekly class discussions are required. Independent project assignments may cause diminished participation in class discussions. Assigning weekly projects may cause delays and a backlog of work for the instructors. This last conflict could result in some students proceeding to subsequent assignments before receiving important instructor feedback and grades. In looking for conflicts and inconsistencies during assessment planning, plagiarism must be an ever present concern instructors of online courses must face. Are the assessment methods designed to discourage, if not eliminate, cheating. LIBR 1100 instructors have found the list of questions to be a very helpful tool that facilitates successful assessment planning.

Additional considerations in planning assessment for online distance learning courses include the role communications technology will play. Does the technology facilitate the successful implementation of assessments? Multimedia technology provides multiple formats that appeal to a variety of learning styles. Graphics, images, maps, audio, and video used to convey course content or incorporated into learning activities can also be posted in online tests. Do these multimedia formats slow down the response rates of the system? Students want technology that works well and quickly, and enhances their learning. These technology concerns must also be addressed during assessment planning.

\subsection{Kinds of online assessment}

\subsubsection{Quizzes and tests}

Instructors often assign students quizzes or tests to assess their knowledge of facts or understanding of concepts. They may or may not be timed, proctored, or graded. They can be taken online using a course management system like Blackboard, mailed to the students' homes, or proctored at some designated location by an authorized individual. Identity and security issues are major concerns that should be taken into consideration when planning a test that will be taken at a distance. Some instructors use security checks such as retinal scans; facial identification using thermographs; voice, palm, or fingerprint recognition; or, in the case of tests that require writing, analyses of the writing performed at intervals throughout the term. However, the technologies supporting these options can be expensive. Accessing quizzes and tests with passwords or generating a different test for each student who logs in may provide at least some degree of security in Web-based testing. However, these options are not completely secure against cheating. In the final analysis, the instructor never knows for sure who is taking tests at a distance. This drawback has also been an ongoing concern of instructors who teach in traditional classrooms. Nevertheless quizzes and tests constitute an effective way to test knowledge and understanding.

\subsubsection{Online chats and discussions}

Online chats and conference calls between students and instructor provide opportunities for discussion, negotiation of meaning, validation of understanding, and assessment. Some instructors place significant weight on the quality of student participation in these chat and conference discussions. They enable the instructor to discover what students are thinking and to determine if any of the students are having problems learning. With this kind of information the instructor is able to give help on the spot and provide remediation. 
Assessment of student contributions during chats or discussions can sometimes be challenging despite their obvious instructional benefits. For example, instructors may not always be available to monitor discussion sessions. Online course management systems such as Blackboard provide quantitative measures that report the number of times each student accesses a discussion and the total number of conference comments read and posted. However, the number of times discussions are accessed or comments are posted reflects neither the quality of the student's participation in the online class discussion nor the degree to which the students learned or met the requirements of the course. Therefore, instructors must always participate as a monitor if effective assessment is to take place.

\subsubsection{Problem-based learning and case-based reasoning}

In some distance learning courses the application of knowledge to solve an authentic problem in the Web-based environment is assessed. ${ }^{5}$ Problem-based learning and casebased learning often require students to find information in order to solve a problem that is encountered by practitioners of the discipline. The search for information can involve reading or listening; conducting interviews or experiments; searching for information in libraries, databases, and Websites; or the acquisition of experience through service learning. ${ }^{6}$ Assessment of student performance and learning in problem solving assignments can be problematic when done at a distance. Again, such things as security and accountability are major concerns that should be worked out during the planning process.

\subsubsection{Role playing}

Role playing using either Web technology or interactive television (ITV) is another way of assessing the application of knowledge in the real world. It is important for instructors to state the goal of the role playing, define its problem, set the scene, create the roles, and assign them. Students research the problem, their roles, and perhaps set goals for their role. Instructors, sometimes with input from students, establish the grading rubric. Assessment in this category can also be problematic, depending on how well the assessment procedure has been planned. Also, expensive technology is often required for this method of assessment.

\subsubsection{Practical skills and laboratory experiences}

One of the most challenging areas of assessment is figuring out how to assess practical skills or laboratory experiences at a distance. The instructor who gives these kinds of assignments must consider all accountability issues, especially if certification at a distance is involved.

\footnotetext{
${ }^{5}$ In problem-based learning students study a subject in the context of complex and realistic problems. Working in groups, they identify what they need to know and how and where to access new information that may lead to resolution of the problem. The role of the instructor is that of a facilitator. Case-based learning is similar. It involves complex problems created to stimulate classroom discussion and collaborative analysis. Through interaction, students explore realistic and specific situations. As they consider problems that require analysis, they strive to resolve questions that may have no single answer.

${ }^{6}$ Service learning is a method of teaching, learning, and reflecting that combines academic classroom curriculum with meaningful service, frequently youth service, throughout the community.
} 
During the planning process he or she must first determine whether a practical skill can realistically be assessed at a distance. If this is impossible, the instructor should make arrangements for the assessment to be conducted in the presence of a qualified person. An example of a case where a qualified person should be present for assessment is airline pilot training. While simulators provide safe practice sessions, flying skills can be demonstrated and assessed only when flying an actual airplane with an assessor present. ${ }^{7}$

\subsubsection{Assessment in the online section of LIBR 1100}

The instructors who teach the distance section of LIBR 1100 have used various assessment methods over the years, some of them consistently from one year to the next. The annotated bibliography assignment and the practicums are used regularly and represent authentic assessment of skills the instructors believe are important for the students to learn. They are interrelated. The students complete the practicums in an ordered series and are graded on how well they do on each one. However, in doing the practicums, they are actually performing the research and documentation that are required in the annotated bibliography assignment. The students begin early in the term choosing a topic, creating a thesis for a fictitious paper that the bibliography supports, and determining keywords and strategies for searching databases that they use to find sources for their bibliography. When they reach the point where they begin compiling their bibliography, the students have to choose a standard style manual from a small selection of two or three and use it to establish the citations in their bibliography. The final step is writing annotations for their citations, and this requires reviewing the sources.

This work is done one step at a time following a process the instructors have built into the course. Not only does the process help students learn how to do research and create an annotated bibliography that includes several different kinds of sources for their topic but it also enables the instructor to monitor the students' acquisition of knowledge and development of research skills step by step so that remediation can be offered at any time during the research process and also to monitor for cheating and plagiarism.

The majority of the distance students enrolled in LIBR 1100 over the years have done well on the practicums and annotated bibliography assignment. Perhaps this is because several of the course readings explain how to do the research required by the assignments. The one weakness is that grading rubrics have not yet been developed for the instructors to use when grading them. Such rubrics would assure a more uniform procedure for grading students, more effectively assure that the course learning-outcomes objectives are being met, and could even be used by the students for guidance in what they are expected to do to successfully complete the assignments. Development of grading rubrics for all the practicums and the annotated bibliography assignment began in the summer of 2011.

In addition to the authentic performance assessment accomplished by way of the practicums and bibliography, the distance section of LIBR 1100 has several reading assignments available on the course's Blackboard site. The readings are titled "Campus Libraries and the

\footnotetext{
7 Several ideas and examples discussed in section 4.2 come from Gunawardena, C. \& LaPointe, D. (2003). Planning and Management of Student Assessment, In: Planning and Management in Distance Education, S. Panda, (Ed.), pp. 195-205, Kogan Page, ISBN 0-7494-4068-6, London, UK
} 
Research Process," "Writing a Thesis Statement," "Search Strategies," "Controlled Vocabulary," "Proper Citing," "Ethical Use of Information," “The Information Cycle," "Newspaper Articles," "Popular Magazines and Scholarly Journals," "Documents and Books," "Encyclopedias," and "Critical Evaluation of Sources." The "Information Cycle" reading assignment provides structure for the three reading assignments that follow it. These readings provide information on how to search databases. The students use these databases to find sources on the topic they choose for their annotated bibliography. Quizzes following the required readings are used not only to assess comprehension but also to reinforce course content. The students are also required to participate in discussions. However the discussions are not assessed.

The instructors of LIBR 1100 decided to begin measuring student learning outcomes with pre- and post-assessment tests in the fall of 2008, and have continued using the tests each term. The intent of the tests is to determine as objectively as possible whether students enrolled in the distance section of LIBR 1100 are learning what the instructors teaching the section intend for them to learn. Specifically, the pre- and post-assessment tests focus on determining what distance students are learning from studying the reading assignments, so they also conduct the kind of knowledge assessment that the quizzes perform, though more thoroughly.

Each of the student learning-outcome objectives of LIBR 1100's distance section specifically address one or more of the Association of College and Research Libraries (ACRL) Information Literacy Competency Standards for Higher Education (See Table 1 for the ACRL Information Literacy Competency Standards for Higher Education and their performance indicators). Objective one, "Students will be able to identify and articulate their information needs," covers Standard one, including most, if not all, of the performance indicators listed under that Standard. Objective two, "Students will develop a knowledge base regarding the collections and services of the Texas Tech University Libraries," is meant to respond to all of the performance indicators in Standard two. Objective three, "Students will use information effectively to accomplish research goals and to develop life-long learning," addresses standard four, including all of its performance indicators. Objective four, "Students will demonstrate the ability to critically evaluate and ethically apply information" is meant to respond to all the performance indicators of Standards three and five.

Similarly, each pre- and post-assessment test question addresses particular ACRL Information Literacy Competency Standards, performance indicators, and course learningoutcome objectives. Questions one and five address Standard two, performance indicator 2.2 (course outcome objective 2) (See Tables 2 and 3 for the relationships between the course outcome objectives, the Standards, and test questions, and for the measurements of success in teaching the course content based on what the student answers to the test questions indicate they had learned). Questions two, eight, nine, ten, and eleven are meant to respond to Standard two, performance indicator 2.1 (course outcome objective 2). Questions three and seven address Standard three, performance indicator 3.2 (course outcome objective 4). Questions four and fifteen address Standard two, performance indicator 2.3 (course outcome objective 2). Questions six and thirteen address Standard one, performance indicator 1.2 (course outcome objective 1). Finally, Questions twelve and fourteen address Standard two, performance indicator 2.5 (course outcome objective 2). 
Standard One

The information literate student determines the nature and extent of the information needed.

Performance Indicators

1.1 The information literate student defines and articulates the need for information.

1.2 The information literate student identifies a variety of types and formats of potential sources for information.

1.3 The information literate student considers the costs and benefits of acquiring the needed information.

1.4 The information literate student reevaluates the nature and extent of the information need.

Standard Two

The information literate student accesses needed information effectively and efficiently.

Performance Indicators

2.1 The information literate student selects the most appropriate investigative methods or information retrieval systems for accessing the needed information.

2.2 The information literate student constructs and implements effectivelydesigned search strategies.

2.3 The information literate student retrieves information online or in person using a variety of methods.

2.4 The information literate student refines the search strategy if necessary.

2.5 The information literate student extracts, records, and manages the information and its sources.

Standard Three

The information literate student evaluates information and its sources critically and incorporates selected information into his or her knowledge base and value system.

Performance Indicators

3.1 The information literate student summarizes the main ideas to be extracted from the information gathered.

3.2 The information literate student articulates and applies initial criteria for evaluating both the information and its sources.

3.3 The information literate student synthesizes main ideas to construct new concepts.

3.4 The information literate student compares new knowledge with prior knowledge to determine the value added, contradictions, or other unique characteristics of the information.

3.5 The information literate student determines whether the new knowledge has an impact on the individual's value system and takes steps to reconcile differences. 
3.6 The information literate student validates understanding and interpretation of the information through discourse with other individuals, subject-area experts, and/or practitioners.

3.7 The information literate student determines whether the initial query should be revised.

Standard Four

The information literate student, individually or as a member of a group, uses information effectively to accomplish a specific purpose.

Performance Indicators

4.1 The information literate student applies new and prior information to the planning and creation of a particular product or performance.

4.2 The information literate student revises the development process for the product or performance.

4.3 The information literate student communicates the product or performance effectively to others.

Standard Five

The information literate student understands many of the economic, legal, and social issues surrounding the use of information and accesses and uses information ethically and legally.

Performance Indicators

5.1 The information literate student understands many of the ethical, legal, and socio-economic issues surrounding information and information technology.

5.2 The information literate student follows laws, regulations, institutional policies, and etiquette related to the access and use of information resources.

5.3 The information literate student acknowledges the use of information sources in communicating the product or performance.

Table 1. ACRL Information Literacy Competency Standards for Higher Education with Their Performance Indicators.

\section{Methodology}

Megan Oakleaf (2008, pp. 234-240) explains that instructors involved in information literacy instruction use "fixed-choice" tests and performance assessment (a.k.a. authentic assessment) most often to measure student learning in their courses, including distance learning courses. She identifies traditional models and behavioral theories of learning and educational measurement that serve as the theoretical basis for fixed-choice tests and relates them to early $20^{\text {th }}$ century principles of scientific measurement. Fixed-choice tests include multiple-choice, matching, and true/false questions. They are conducive to quantitative assessment. On the other hand, performance or authentic assessment is based on constructivist educational theories which posit the idea that knowledge is created or "constructed" by individuals rather than passed on fully-formed from teacher to student. Learning, according to this theory, takes place through engagement and interaction in the real world, problem solving, critical thinking, and knowledge creation. Performance 
assignments are conducive to qualitative assessment. Both of these kinds of assessment can be readily matched with educational or learning standards and course learning-outcome objectives.

The quizzes and pre- and post-assessment tests in LIBR 1100 belong for the most part to the fixed-choice test category. The grading of these tests is therefore readily accomplished by the Blackboard system the instructors use to teach the course. However, the instructors must review, and occasionally edit, the machine-graded quizzes because of a handful of "fill-in" questions. On the other hand, the pre- and post-assessment tests are completely machine graded. As mentioned earlier, all of the questions in the quizzes and pre- and post-tests are matched to the course learning-outcome objectives, and test what the instructors want their students to learn and know. Since the course's learning-outcome objectives address the ACRL Information Literacy Competency Standards for Higher Education, along with their performance indicators, the questions in the pre- and post-assessment tests and the reading assignment quizzes also address the Standards.

LIBR 1100's practicums and the annotated bibliography assignment are authentic assessment methods that assess performance. Students complete these assignments successfully by performing several research tasks or operations. Completion of the bibliography represents an accomplishment that the instructors believe reflects a significant part of what is done when one performs library research. Therefore the students acquire several skills as they complete the practicums and the annotated bibliography. These performance assignments are also matched to the course's learning-outcome objectives and address some of the ACRL Standards and their performance indicators.

The findings and conclusions of this study relating to the quizzes, practicums, and annotated bibliography are based on grades assigned by the instructor. Though the grades for the quizzes are initially created automatically by Blackboard, the instructor reviews the answers and may revise the grades because of the "fill-in" questions. However the practicums and bibliography are graded without the benefit of any automatic system or the use of grading rubrics. The study's findings and conclusions relating to the machine-graded pre- and post-assessment tests are based on analysis of the input of the five students who took both tests. These students are treated as a single group. The reported frequencies and percentages of correct and incorrect answers pertain to the entire group of participating students. The students' answers on both tests were downloaded from the section's Blackboard site to a Microsoft Excel spreadsheet. The author used formulae available on the Excel software to tabulate all the data and determine the averages.

The pre- and post-tests were graded as an incentive for the students to try to do well. By taking the pre-assessment test the students could earn up to 15 points toward their final grade, and by taking the post-assessment test they could earn up to 75 points. Both the preand post-assessment tests contain the same questions. The instructors feel that the fourteen weeks between taking the tests is a sufficient period of time for their students to forget the questions answered in the test at the beginning of the semester. They plan to update the test regularly with new and revised questions and use it every semester. Also, the order of the questions will be regularly changed.

Tables 2 and 3 show the relationships of the course outcome objectives, the ACRL Information Literacy Competency Standards for Higher Education, along with their 


\begin{tabular}{|c|c|c|c|c|c|c|c|c|c|c|c|c|c|c|c|c|c|c|c|c|c|}
\hline $\begin{array}{l}\text { LIBR } 1100 \\
\text { Outcome } \\
\text { Objective }\end{array}$ & $\begin{array}{l}\mathrm{ACR} \\
1.1 \mathrm{et} \\
\text { the o }\end{array}$ & $\begin{array}{l}\text { etc. } i \\
\text { outc }\end{array}$ & $\begin{array}{l}\text { den } \\
\text { ome }\end{array}$ & $\begin{array}{l}\text { tifie } \\
\text { e obj }\end{array}$ & $\begin{array}{l}s \text { th } \\
\text { ecti }\end{array}$ & $\begin{array}{l}\text { St } \\
\text { ve. }\end{array}$ & racy & Per & form & Iance & e Inc & $\begin{array}{l}\text { dicat } \\
\text { Perfo }\end{array}$ & $\begin{array}{l}\text { tors } \\
\text { orma }\end{array}$ & ance & Indi & & r nur & umbe & er ad & $\mathrm{ed} \mathrm{b}$ & \\
\hline 1 & 1.1 & 1.2 & 1.3 & \begin{tabular}{|l|}
1.4 \\
\end{tabular} & & & & & & & & & & & & & & & & & \\
\hline 2 & & & & & 2.1 & 2.2 & 2.3 & 2.4 & 2.5 & & & & & & & & & & & & \\
\hline 3 & & & & & & & & & & & & & & & & & 4.1 & 4.2 & 4.3 & & \\
\hline 4 & & & & & & & & & & 3.1 & 3.2 & 3.3 & 3.4 & 3.5 & 3.6 & 3.7 & & & & 5.2 & 5.3 \\
\hline
\end{tabular}

Table 2. Relationship of LIBR 1100 Course Outcome Objectives to ACRL Information Literacy Performance Indicators.

\begin{tabular}{|c|c|c|c|c|c|c|c|c|c|c|c|c|c|c|c|c|c|c|c|c|c|c|}
\hline \multirow[t]{2}{*}{\begin{tabular}{|l|} 
Assessment \\
Test \\
Question \\
\end{tabular}} & $\begin{array}{l}\mathrm{AC} . \\
\# / \#\end{array}$ & RL I & nfor & $\begin{array}{l}\text { mati } \\
\text { es p } 1\end{array}$ & ren I & iter & acy & Perfo & orma & ance & Ind & icat & & & & & & & & & & \\
\hline & 1.1 & \begin{tabular}{|l}
1.2 \\
\end{tabular} & 1.3 & 1.4 & 2.1 & 2.2 & 2.3 & 2.4 & 2.5 & 3.1 & 3.2 & 3.3 & 3.4 & 3.5 & 3.6 & 3.7 & 4.1 & 4.2 & 4.3 & 5.1 & 5.2 & 5.3 \\
\hline 1 & & & & & & $\begin{array}{l}40 / \\
100 \\
\end{array}$ & & & & & & & & & & & & & & & & \\
\hline 2 & & & & & $\begin{array}{r}80 / \\
80 \\
\end{array}$ & & & & & & & & & & & & & & & & & \\
\hline 3 & & & & & & & & & & & $\begin{array}{r}80 / \\
80 \\
\end{array}$ & & & & & & & & & & & \\
\hline 4 & & & & & & & $\begin{array}{r}40 / \\
60\end{array}$ & & & & & & & & & & & & & & & \\
\hline 5 & & & & & & \begin{tabular}{|l|}
$100 /$ \\
100
\end{tabular} & & & & & & & & & & & & & & & & \\
\hline 6 & & \begin{tabular}{|l|}
$80 /$ \\
100 \\
\end{tabular} & & & & & & & & & & & & & & & & & & & & \\
\hline 7 & & & & & & & & & & & \begin{tabular}{|r|}
$20 /$ \\
80
\end{tabular} & & & & & & & & & & & \\
\hline 8 & & & & & \begin{tabular}{|l|l}
$60 /$ \\
100 \\
\end{tabular} & & & & & & & & & & & & & & & & & \\
\hline 9 & & & & & $\begin{array}{c}100 / \\
80\end{array}$ & & & & & & & & & & & & & & & & & \\
\hline 10 & & & & & $\begin{array}{r}20 / \\
40 \\
\end{array}$ & & & & & & & & & & & & & & & & & \\
\hline 11 & & & & & \begin{tabular}{|c}
$100 /$ \\
100 \\
\end{tabular} & & & & & & & & & & & & & & & & & \\
\hline 12 & & & & & & & & & $\begin{array}{r}60 / \\
60\end{array}$ & & & & & & & & & & & & & \\
\hline 13 & & $\begin{array}{r}80 / \\
80\end{array}$ & & & & & & & & & & & & & & & & & & & & \\
\hline 14 & & & & & & & & & $\begin{array}{r}20 / \\
80\end{array}$ & & & & & & & & & & & & & \\
\hline 15 & & & & & & & $\begin{array}{l}80 / \\
100\end{array}$ & & & & & & & & & & & & & & & \\
\hline
\end{tabular}

Table 3. Pre-test and Post-test Scores Based on Test Questions and Performance Indicators.

performance indicators, and the assessment test questions. Each pair of pre- and postassessment scores in Table 3 (the pre-assessment score before the slash, followed by the post-assessment score) corresponding to the question number in that row is meant to serve as a rough measure of how well the students knew or had learned a particular learning point addressed by the corresponding question and standard. A higher score on 
the post-assessment test question than on the pre-assessment question indicates that the students as a group had learned this outcome objective and standard performance indicator.

Each question in the test has one correct answer. Because the study's findings are based on comparisons of pre- and post-assessment answers, both for individual questions and in their aggregate, and since no cross tabulation tables are used to test relationships between variables, no statistical analysis other than the determination of totals and averages is necessary.

The pre- and post-assessment method of student learning outcomes is recognized as a legitimate way to measure what students are learning in class (Kidder, 1981, p. 45; Hernon, Dugan, \&Schwartz, 2006, p. 137; Diamond, 2008, p. 163; Black \& Wiliam, 2006; McMillan, 2001, 56-89). Often this method is administered as tests with questions, whether multiple choice, true or false, short-answer, or open-ended, and with the purpose of testing students' skills or what they know. Some instructors employing this method have used the same set of questions in both pre- and post-tests to evaluate a single group of students, and they made the effort to administer the pre-test before the course content was taught and the posttest at the very end of the course.

As with all testing methods, the reliability and validity of the pre- and post-test method for determining accurate measurements of what students have learned is entirely dependent on the test itself. The integrity of the questions, the test's design, and its method of application affect the reliability and validity of a testing instrument. In his 1993 article "Evaluating Library Instruction: Doing the Best You Can with What You Have," Donald Barclay provides an interesting examination of pre- and post-tests and the kinds of questions that instructors could include in such tests (Barclay, 1993, p. 197-198, 201). He concludes his article with the observation that, though assessment may not always meet the highest standards of scientific rigor, this should not deter instructors from implementing them. Early attempts at assessment can serve as a spur to begin the process of continuous improvement in the quality of the assessment.

\section{Findings}

Six students were enrolled in the distance section of LIBR 1100 in the fall of 2010. Five of these students actively participated in all the course assignments. One student hardly participated at all and received several 0 point scores. All of the study's findings are based on the input of the five students who actively participated. They were required to take 12 quizzes and could earn a maximum of 8 points on eleven of the quizzes and five points on one of them. Table 4 includes the students' scores on all 12 quizzes. The great majority of the questions on the quizzes were graded automatically by Blackboard. However, the instructor who taught the online course in the fall of 2010 reviewed the handful of fill-in questions and, using her own judgment, determined whether the fill-in answers were correct or not. She did not use a grading rubric while reviewing the questions.

The students also took 6 practicums, and their scores on these are reported in Table 5 . Practicum one required the students to determine a thesis for their annotated bibliography assignment. Practicum two required that they find books on the topic of the thesis using keywords derived from the thesis statement. They searched for the books in online catalogs. 


\begin{tabular}{|c|c|c|c|c|c|c|c|c|c|c|c|c|}
\hline $\begin{array}{l}\text { Quiz } \\
\text { Number }\end{array}$ & 1 & 2 & 3 & 4 & 5 & 6 & 7 & 8 & 9 & 10 & 11 & 12 \\
\hline $\begin{array}{l}\text { Student } \\
\text { Number }\end{array}$ & \multicolumn{10}{|c|}{} \\
\hline 1 & 8 & 8 & 8 & 8 & 8 & 7 & 8 & 8 & 8 & 8 & 8 & 5 \\
\hline 2 & 8 & 6 & 8 & 8 & 8 & 8 & 8 & 8 & 8 & 8 & 8 & 5 \\
\hline 3 & 8 & 8 & 8 & 8 & 8 & 6 & 7 & 8 & 8 & 8 & 8 & 5 \\
\hline 4 & 8 & 6 & 6 & 7 & 8 & 6 & 7 & 7 & 7 & 7 & 7 & 5 \\
\hline 5 & 8 & 6 & 6 & 7 & 6 & 6 & 6 & 7 & 7 & 8 & 7 & 4 \\
\hline $\begin{array}{c}\text { Highest } \\
\text { Possible } \\
\text { Score }\end{array}$ & 8 & 8 & 8 & 8 & 8 & 8 & 8 & 8 & 8 & 8 & 8 & 5 \\
\hline
\end{tabular}

Table 4. Student Scores on Quizzes (fall 2010).

Practicum three required that they find government documents on their topic using appropriate databases. Practicum four required that they find magazine and newspaper articles, and practicum five that they find articles in scholarly journals. Finally, practicum six required that they find appropriate Websites on their topic using a search engine such as Google to find them. All of their sources were found online using the Internet and, after the students created accurate citations for them using either the American Psychological Association or the Modern Language Association style manual, became a substantial portion of their annotated bibliography assignment. All the practicums were graded by the instructor who did not use a grading rubric. The maximum number of points possible for each of these practicums was 20 .

\begin{tabular}{|c|c|c|c|c|c|c|}
\hline $\begin{array}{c}\text { Practicum } \\
\text { Number }\end{array}$ & 1 & 2 & 3 & 4 & 5 & 6 \\
\hline $\begin{array}{c}\text { Student } \\
\text { Number }\end{array}$ & \multicolumn{7}{|l|}{} \\
\hline 1 & 20 & 20 & 20 & 20 & 20 & 20 \\
\hline 2 & 20 & 20 & 20 & 19 & 19 & 20 \\
\hline 3 & 20 & 20 & 19 & 18 & 19 & 20 \\
\hline 4 & 20 & 20 & 15 & 18 & 10 & 19 \\
\hline 5 & 20 & 19 & 17 & 6 & 19 & 18 \\
\hline $\begin{array}{c}\text { Highest } \\
\text { Possible } \\
\text { Score }\end{array}$ & 20 & 20 & 20 & 20 & 20 & 20 \\
\hline
\end{tabular}

Table 5. Student Scores on Practicums (fall 2010).

Five students completed the annotated bibliography assignment. Three A's (the scores were 95,95 , and 90 out of 100 possible points) and two B's (88 and 85) were awarded, with a score of 90 or higher corresponding to an A letter grade and a score of 80 to 89 corresponding to a $\mathrm{B}$ letter grade. The instructor determined these scores and letter grades using her own judgment without the use of a grading rubric or an automatic system. 
An average score of the group of five students who took both the pre- and post-assessment tests was determined by adding the percentages of the students who answered each question correctly and then determining the average of the total. The average score on the pre-assessment test was 64 percent, and the average score on the post-assessment test was 82.7 percent. Thus, as a group, the students increased their average score by 18.7 points from pre- to post-assessment. This improvement was encouraging.

Table 6 includes questions one and fourteen on the pre- and post-assessment tests. These two questions illustrate the kinds of questions found on the tests and the choice of answers the students could choose from. Also they both illustrate the handful of questions the students, as a group, did poorly on in the pre-assessment test and then significantly improved on in the post-assessment test.

\begin{tabular}{|c|c|c|c|c|c|}
\hline \multicolumn{6}{|c|}{$\begin{array}{l}\text { Question } 1 \\
\text { What are the } 3 \text { Boolean operators? }\end{array}$} \\
\hline \multicolumn{6}{|c|}{$\begin{array}{l}\mathrm{PR}=\text { Pre-Assessment } \\
\mathrm{PO}=\text { Post-Assessment }\end{array}$} \\
\hline \multicolumn{6}{|l|}{$\begin{array}{l}a \text { - Add } \\
\text { b - If } \\
c \text { - Not } \\
d \text { - Then } \\
\text { e - And } \\
\text { f - Or } \\
\text { g-Sum }\end{array}$} \\
\hline PR-1 & Frequency & Percent & PO-1 & Frequency & Percent \\
\hline $\begin{array}{l}\text { Correct } \\
(c, e, f)\end{array}$ & 2 & 40 & $\begin{array}{l}\text { Correct } \\
(\mathrm{c}, \mathrm{e}, \mathrm{f})\end{array}$ & 5 & 100 \\
\hline Incorrect & 3 & 60 & Incorrect & 0 & 0 \\
\hline \multicolumn{6}{|c|}{$\begin{array}{l}\text { Question } 14 \\
\text { What information is needed for a book citation? }\end{array}$} \\
\hline \multicolumn{6}{|c|}{$\begin{array}{l}\mathrm{PR}=\text { Pre-Assessment } \\
\mathrm{PO}=\text { Post-Assessment }\end{array}$} \\
\hline \multicolumn{6}{|c|}{$\begin{array}{l}\text { a - Credentials, revisions, date of publication } \\
\text { b - Author, title, date, publisher information } \\
\text { c - Author, title, publisher, volume and issue number, date }\end{array}$} \\
\hline PR-14 & Frequency & Percent & PO-14 & Frequency & Percent \\
\hline $\begin{array}{l}\text { Correct } \\
\text { (b) }\end{array}$ & 1 & 20 & $\begin{array}{l}\text { Correct } \\
\text { (b) }\end{array}$ & 4 & 80 \\
\hline Incorrect & 4 & 80 & Incorrect & 1 & 20 \\
\hline
\end{tabular}

Table 6. Test questions 1 and 14 and their pre- and post-assessment results. 
Considerable improvement was made on the first question in the post-assessment survey. The students were asked to identify the three Boolean operators. Forty percent of the group answered the question correctly in the pre-assessment test, and 100 percent answered it correctly in the post-assessment test (See Table 3 for a summary of pre- and post-assessment test scores). Eighty percent of the students answered the second question correctly on both the pre-assessment test and the post-assessment test. Question two asked the students to identify the least likely resource for finding citations to articles. The answer was the Texas Tech University Libraries' online catalog.

Question three asked the students what to look for in determining the authority of an Internet site. Eighty percent answered the question correctly in both the pre-assessment test and the post-assessment test. Question four was challenging for the students. When asked to identify the correct statements in a list that included supposed examples of a book's call number, an ISBN number, a citation to a book, a citation to an article, and a URL address, only 40 percent (two students) answered the question correctly by identifying the correct examples on the list in the pre-assessment test and 60 percent (three students) answered it correctly on the post-assessment test.

Question five asked the students to identify the "word search" that would give them books most directly related to gang violence. One-hundred percent of the students correctly identified "gangs AND violence" as the correct answer in the pre-assessment test and 100 percent also selected the correct answer in the post-assessment test. The results of this and the first question in the test suggest that, by the end of the course, all the students in the group understood what Boolean operators were and how they worked. However, it would also seem that question five is probably too easy and should be replaced by a more difficult question.

Eighty percent of the students could identify primary research sources in question six in the pre-assessment test, and 100 percent in the post-assessment test. Considerable improvement took place on question seven. The students were asked to identify "typical scholarly research sources" from a list. Twenty percent of the students selected the correct answer in the pre-assessment test, and 80 percent selected the correct answer in the post-assessment test.

In question eight, 60 percent (three students) in the pre-assessment test and 100 percent in the post-assessment test correctly identified the kinds of information that can be found in the Texas Tech University Libraries' online catalog. All of the students answered question nine correctly in the pre-assessment test, thus indicating that they were aware that full-text magazine articles cannot be found in the catalog. Eighty percent answered this question correctly in the post-assessment test. This indicates regression in learning for this particular bit of knowledge. Question ten asked the students which of two databases-ABI/Inform or Lexis-Nexis Academic Universe-contained full-text newspaper articles. Twenty percent identified the correct answer (Lexis-Nexis Academic Universe) in the pre-assessment test, and 40 percent did so in the post-assessment test. This would indicate that the majority of the students are not aware of the content of this particular database and perhaps the content of databases in general.

All of the students did well on question eleven in both the pre- and post-assessment tests. This question required knowledge of the difference between PDF and HTML full-text 
documents. Perhaps question eleven is also too easy. Question twelve asked the students to examine a citation to a journal article and identify its citation style. Modern Language Association style was the correct answer. Sixty percent of the students answered the question correctly in the pre-assessment test, and 60 percent did so in the post-assessment test.

Most of the students did well on question thirteen and could identify the features of an annotated bibliography. Eighty percent of the students answered this question correctly in the pre-assessment test, and 80 percent did so in the post-assessment test. Question fourteen asked "What information is needed for a book citation." Twenty percent answered question fourteen correctly in the pre-assessment test, and 80 percent did so in the post-assessment test. Apparently the students had learned something about book citations in the course. Question fifteen asked which statements were correct in a list that supposedly included two citations, an ISBN number, a URL address, and a call number. Eighty percent of the students answered the question correctly in the pre-assessment test, and 100 percent in the postassessment test.

\section{Conclusions}

This case study examined student learning-outcomes assessment methods that are suitable for Web-based courses. It concentrated on those assessment methods used by instructors at Texas Tech University Library in a one-hour, Web-based credit course developed to teach library research skills to distance students. The instructors selected these methods because they thought that the methods offered the greatest potential for assisting them in reaching the course's assessment goals, included implementation processes that promised to be relatively easy to accomplish, and had attributes that the students would find user-friendly and that would discourage plagiarism. The study also reported the planning process the course instructors follow each year in identifying assessment methods appropriate for their course, in developing and implementing the methods, and how they use the data collected by the assessments to improve the course.

The instructors who teach the library research course participate as team members in the process of continuously improving the course's content and the teaching and learning that occurs in the course. This team effort has evolved over the years into a structured yearly cycle of planning, developing, marketing, implementing, assessing, and improving the course. Among other things, reviewing learning goals, identifying learning outcomes, creating learning activities, enacting learning activities, gathering data to check learning, interpreting data, and enacting decisions occur in this planning cycle. The data collected from the various assessment instruments play an important role in the process because the findings that come from the data help to identify where improvement is needed. Blackboard Learn, the assessment module in Blackboard, will soon be used to track the progress of students enrolled in the online course and will facilitate accurate reporting of the Library's impact on the learning and teaching that takes place at Texas Tech University.

Data collected by the assessment instruments employed in the fall of 2010 disclosed findings that were consulted during the summer of 2011 when plans for improving the learning and teaching experiences that would take place in the fall of 2011 were made. All five students did well on all the quizzes. Scores ranged from six to eight points with a maximum possible 
score of 8 for eleven of the twelve quizzes. The students' scores for one quiz which had a maximum possible score of five points ranged from four to five points with four of the students receiving five points. Each question on these quizzes tested a teaching point the instructors wanted their students to learn, and the quiz scores indicate that, for the most part, the students learned these points. Automatic grading by Blackboard for the great majority of the questions assured that instructor bias would not affect these scores. Therefore one can assume that the students learned what they were expected to learn from the course reading assignments. The only concern would be that perhaps some of the quizzes might have been too easy for the students, especially quiz one where all the students answered all of the questions correctly.

As mentioned earlier, the six practicum assignments and the annotated bibliography assignment represent authentic assessment of how well students can perform tasks and accomplish projects that are regularly performed by individuals involved in library research. The instructors who developed these assignments felt confident they had created carefully thought out instruments for assessing what they wanted students enrolled in the "Introduction to Library Research" course to learn to perform. The scores on the practicums would indicate that for the most part the students had learned to perform the tasks and projects quite well. With the exception of three, the scores ranged from seventeen to twenty out of a maximum possible score of twenty on all six of the practicums. Seventeen represents 85 percent of twenty. The exceptions were scores of six, ten, and fifteen.

The LIBR 1100 instructors who taught in the fall of 2010 are very satisfied with their students' scores and believe much of what they wanted their students to learn was learned. The one weakness they identified with the way the course was taught was that there was no grading rubric for the instructors to use in grading the practicums, the annotated bibliography, and the handful of fill-in questions on some of the quizzes. Since the Texas Tech University Library instructors take turns teaching the online course, there was concern that these assignments were not being graded consistently. The instructors therefore began developing a grading rubric in the summer of 2011.

The instructors were also rather satisfied with the pre- and post-assessment data. The five students increased their group average score by 18.7 points from pre- to post-assessment. This indicates that they learned several of the teaching points the instructors wanted them to learn. They improved their scores on 8 of the 15 questions in the post-assessment test. In addition, two other questions were answered correctly by all the students in both tests. Six of the questions received the same number of correct answers in both the pre- and post-assessments. Fourteen of the questions in the post-assessment were answered correctly by a majority of the students and one question was answered incorrectly by a majority of the five students. The poor performance on this question indicates that many of the students need to learn more about online databases, and Lexis-Nexis in particular. The way the instructors teach or optimize the learning of databases will be revised for next year. Also, some of the questions were apparently too easy. They should be replaced with more challenging questions. And it appears that greater attention should be placed on teaching the students how to identify numbers and symbols they will run across during their research. These include such things as book call numbers and International Standard Book Numbers (ISBN). 
What must the instructors who teach the distance section of LIBR 1100 do to increase still more the learning that takes place in their section? In chapter one of her book Tools for Teaching, Barbara Gross Davis maintains that, "in designing or revising a course, faculty must consider what material to teach, how best to teach it, and how to ensure that students are learning what is being taught" (Gross Davis, 2009, p. 3-18). Starting with this introductory statement, she then offers strategies meant to help faculty "make decisions about the content of their course, the structure and sequence of activities and assignments, the identification of learning outcomes, and the selection of instructional resources." The instructors of LIBR 1100's distance section are using Dr. Gross Davis' strategies as one of their aids in developing their course. In addition, they want to continue the process they started in 2008. Each summer, in preparation for teaching in the fall and spring semesters, they plan to meet and agree on what is important for their students to learn. Once they have agreed on what is important, the instructors plan to review the course and, where needed, improve it and bring it up-to-date. During this review, they intend to examine the previous year's assessment data and use the findings revealed by the data to help them decide what needs to be changed. The course's continuous development must include revising all course goals, learning outcome objectives, the course syllabus and schedule, reading assignments, practicums, and quizzes, and writing new materials for added content. Each year, after the course is revised, the instructors need to develop valid assessment instruments that will gauge how well the students are learning what the instructors want them to learn (McMillan, 2001, p. 56-75). The instructors believe that the assessment methods used in 2010 worked well. However, there are other ways to assess including, but not limited to, a final examination, a portfolio assignment, or use of a standard test.

If the decision is made to continue using pre- and post-assessment tests, future test questions should be determined using a pedagogically sound method, and the instructors need to make sure that the teaching points addressed by all the questions are covered in the course's reading assignments and practicums (Gross Davis, 2009, p. 362-372). In an effort to incorporate active learning into the course, the instructors of LIBR 1100 designed practicums that required the students to use databases, Websites, and other mainly online resources to fulfill the requirements of the assignment (Wexler \& Tinto, 2005; Lang, 2008, p. 43-61). These practicums also proved effective in teaching students content. Several of the questions that were answered correctly by more students in the post-assessment test than in the preassessment test assessed specific teaching points the students had learned by doing the practicums. The instructors had previously been concerned about having too many practicums for a one-hour credit course. Perhaps, instead of adding more of them, existing practicums could be expanded to include two or more teaching points addressed in the questions.

Finally, the librarians teaching the distance section of LIBR 1100 must be sure their students have the means to learn the teaching points covered by the test questions (Erickson, Peters, \& Strommer, 2006, p. 87-100). One way to do this is through carefully prepared scripts explaining each teaching point addressed in a test question. The scripts could be included among the tools and teaching aids that the instructors refer to during their instructordirected online chat sessions. This practice should assist in reinforcing the learning (Erickson et al., 2006, p. 87-100). Above all, great emphasis should be placed on reviewing the course and its learning-outcome goals every year, and improvements should be made when appropriate. 


\section{Further research needed}

Reports of research on the experiences of instructors in assessing what distance students are learning in their online classes are not well represented in the literature. This is unfortunate because instructors who want to enhance the learning that takes place in their courses and to gage that learning through assessment can benefit immensely from the experiences of their colleagues at other institutions. It is this kind of literature that would enable them to determine what methods work best and how the assessment process is used to improve teaching and learning. It is time for student learning-outcome assessment in Web-based distance courses to flourish.

\section{References}

Barclay, D. (1993). Evaluating Library Instruction: Doing the Best You Can With What You Have. RQ, Vol.33, No.2, (1993), pp. 197-198, 201, ISSN 0033-7072

Bhattacharya, M. \& Hartnett, M. (2007). E-portfolio Assessment in Higher Education, Proceedings of the 37th Annual Frontiers in Education Conference, Milwaukee, Wisconsin, USA, October 10-13, 2007

Black, P. \& Wiliam, D. (2006). The Reliability of Assessments, In: Assessment and Learning, J. Gardner, (Ed.), pp. 119-131, Sage, ISBN 978-141-2910-50-7, London, UK

Brown, P. \& Hanks, R. (2008). Implementing an Online Writing Assessment Strategy for Gerontology. Educational Gerontology, Vol.34, No.5, (2008), pp. 397-399, ISSN 03601277

Caldarola, R. \& MacNeil, T. (2009). Dishonesty Deterrence and Detection: How Technology Can Ensure Distance Learning Test Security and Validity, Proceedings of the $8^{\text {th }}$ European Conference on E-Learning, pp. 108-115, Bari, Italy, October 29-30, 2009

Costagliola, G., Fuccella, V., Giordano, M. \& Polese, G. (2009). Monitoring Online Tests through Data Visualization. IEEE Transactions on Knowledge and Data Engineering, Vol.21, No.6, (June 2009), pp. 773-784, ISSN 1041-4347

Diamond, R. (2008). Designing and Assessing Courses and Curricula: A Practical Guide (3rd ed.), Jossey-Bass, ISBN 978-047-0261-34-7, San Francisco, USA

Erickson, B., Peters, C. \& Strommer, D. (2006). Teaching First-Year College Students (Rev. \& expanded ed.), Jossey-Bass, ISBN 978-078-7964-39-9, San Francisco, USA

Foster, J. \& Drew, J. (2009). Astrobiology Undergraduate Education: Students' Knowledge and Perceptions of the Field. Astrobiology, Vol.9, No.3, (April 2009), pp. 325-333, ISSN 1531-1074

Gross Davis, B. (2009). Tools for Teaching (2nd ed.), Jossey-Bass, ISBN 978-078-7965-67-9, San Francisco, USA

Gunawardena, C. \& LaPointe, D. (2003). Planning and Management of Student Assessment, In: Planning and Management in Distance Education, S. Panda, (Ed.), pp. 195-205, Kogan Page, ISBN 0-7494-4068-6, London, UK

Hayes, B. \& Ringwood, J. (2009). Authenticating Student Work in an E-Learning Programme via Speaker Recognition, Proceedings of the $3^{\text {rd }}$ International Conference on Signals, Circuits and Systems, pp. 576-581, Medenine, Tunisia, November 6-8, 2009

Hernon, P., Dugan, R. \& Schwartz, C., (Eds.). (2006). Revisiting Outcomes Assessment in Higher Education, Libraries Unlimited, ISBN 978-159-1582-76-2, Westport, Conn., USA 
Hufford, J. \& Paschel, A. (2010). Pre- and Post-Assessment Tests for the Distance Section of LIBR 1100, Introduction to Library Research. Journal of Library Administration, Vol.50, Nos.5\&6, (July, 2010), pp. 139-158, ISSN 0193-0826

Ivanitskaya, L., DuFord, S., Craig, M. \& Casey, A. (2008). How Does a Pre-assessment of Offcampus Students' Information Literacy Affect the Effectiveness of Library Instruction? Journal of Library Administration, Vol.48, Nos.3\&4, (2008), pp. 509-525, ISSN 0193-0826

Kidder, L. (1981). Selltiz, Wrightsman and Cook's Research Methods in Social Relations (4th ed.), Holt, Rinehart and Winston, ISBN 978-003-0435-66-9, New York, USA

Lang, J. (2008). On Course: A week-By-Week Guide to Your First Semester of College Teaching, Harvard University Press, ISBN 978-067-4028-06-7, Cambridge, Mass., USA

McMillan, J. (2001). Classroom Assessment: Principles and Practice for Effective Instruction (2nd ed.), Allyn and Bacon, ISBN 978- 020-5297-51-1, Boston, USA

Mulherrin, E., Kelley, K., Fishman, D. \& Orr, G. (2004). Information Literacy and the Distant Student: One University's Experience Developing, Delivering, and Maintaining an Online, Required Information Literacy Course. Internet Reference Services Quarterly, Vol.9, Nos.1\&2, (2004), pp. 21-36, ISSN 1087-5301

Oakleaf, M. (2008). Dangers and Opportunities: A Conceptual Map of Information Literacy Assessment Approaches. portal: Libraries and the Academy, Vol.8, No.3, (July 2008), pp. 233-253, ISSN 1531-2542

Oakleaf, M. (2009). The Information Literacy Instruction Assessment Cycle: A Guide for Increasing Student Learning and Improving Librarian Instructional Skills. Journal of Documentation, Vol.65, No.4, (2009), pp. 539-560 ISSN 0022-0418

Oakleaf, M. (2011). Are They Learning? Are We? Learning and the Academic Library. Library Quarterly, Vol.81, No.1, (January 2011), pp. 61-82, ISSN 0024-2519

Oncu, S. \& Cakir, H. (2011). Research in Online Learning Environments: Priorities and Methodologies. Computers \& Education, Vol.57, No.1, (2011), pp.1098-1108, ISSN 0360-1315

Sima, D., Schmuck, B., Szollosi, S. \& Miklos, A. (2007). Intelligent Short Text Assessment in eMax, Proceedings of the $8^{\text {th }}$ IEEE Africon Conference, Windhoek, Namibia, September 26-28, 2007

Su, J., Lin, H., Tsong, S. \& Lu, C. (2011). OPASS: An Online Portfolio Assessment and Diagnosis Scheme to Support Web-Based Scientific Inquiry Experiments. TOJET: The Turkish Online Journal of Educational Technology, Vol.10, No.2, (April 2011) pp. 151-173, ISSN 1303-6521

Texas Tech University, Office of the Provost. (February 21, 2011). Core Curriculum Committee Charge and Organization, Texas Tech University Website, August 15, 2011, Available from: http://www.depts.ttu.edu/provost.councilscmtes/ccc/index.php

Udo, G., Bagchi, K. \& Kirs, P. (2011). Using SERVQUAL to Assess the Quality of E-Learning Experience. Computers in Human Behavior, Vol.27, No.3, (May 2011), pp. 1272-1283, ISSN 0747-5632

United States Department of Education. (2006). A Test of Leadership: Charting the Future of U.S. Higher Education--a Report of the Commission Appointed by Secretary of Education Margaret Spellings, U.S. Department of Education, Washington, D.C., USA 
Urtel, M. (2008). Assessing Academic Performance between Traditional and Distance Education Course Formats. Educational Technology \& Society, Vol.11, No.1, (2008), pp. 322-330, ISSN 1436-4522

Wexler, D. \& Tinto, P. (2005). Active Learning Inside and Outside the Classroom: Creating Multiple Learning Spaces with Technology. In: University Teaching: A Reference Guide for Graduate Students and Faculty (2nd ed.), S.L. Tice, N. Jackson, L.M. Lambert \& P. Englot. (Eds.), pp. 57-75, Syracuse University Press, ISBN 978-081-5630-79-1, Syracuse, N.Y. 


\section{Part 4}

\section{Distance Learning Students}





\title{
An Analysis of the Search Skills of Online Graduate Students as the Basis for the Development of Appropriate Instructional Strategies
}

\author{
Olabisi Kuboni \\ UWI Open Campus, The University of the West Indies \\ Trinidad and Tobago
}

\section{Introduction}

Many advocates of online teaching and learning contend that one of the major benefits of studying in an online environment is the access it provides to a vast amount of resource material. No longer are students limited to what is available in their own institutions; rather, given the constantly expanding capacity of the world wide web (WWW), there is virtually no limit to the resources that students can draw on to support their learning. While this is certainly a major advantage, many practitioners concur that it also presents significant challenges for the graduate student, given a situation where, as online learners, they are assuming almost complete responsibility for all aspects of the multi-faceted task of locating, selecting, evaluating and using information as required in the various areas of their study.

In recognition of the possible difficulties that students could encounter in carrying out this task, there have been several generic guidelines developed. Students are expected to follow these guidelines and apply them to the specific discipline-related task that they are required to complete. Thus, they would conduct the search to identify appropriate resources, evaluate these resources and make notes in relation to the topic or area of study for which the search is being conducted. While acknowledging the value of such guidelines, it is being argued that this prescriptive approach is not always appropriate for all students, and that a more bottom-up approach should be considered.

This study is therefore intended to analyze students' efforts at sourcing, selecting and extracting information relative to an essay topic. The overall purpose is to assess these efforts against a defined standard as a preliminary step towards the generation of instructional strategies that may be more effective in assisting students in developing more effective skills for identifying, gathering and using information from online sources.

\section{Context of the study}

The Graduate Programmes Department (GPD) of the Open Campus of the University of the West Indies (UWI OC) has recently begun offering fully online programmes at the postgraduate diploma and Masters' levels. The main body of its student population is located in 
the fifteen Caribbean countries that support the parent institution, the University of the West Indies. The GPD is therefore aware of the need to provide optimum support for this distributed body of students who, though having the opportunity for interpersonal interaction through the web-based learning management system, must assume a high level of responsibility for their learning.

The main qualification for entry into either type of programme is an undergraduate degree. Many of those admitted would have also obtained this qualification through the online delivery facility of the Open Campus. Nonetheless, given the increased demands of study at the graduate level, and the fact that these mature students may not have a sustained postsecondary formal education experience, the GPD considered it important to include a compulsory three-week orientation programme to assist students in strengthening their capability to undertake graduate study in an online environment.

\subsection{The annotated bibliography}

One segment of the orientation course was the preparation of an annotated bibliography. The following overview provided the rationale and overall purpose of the activity:

For most of your essay writing, you will need to identify and select information based on the topic you are required to write about. You will draw that information from various sources. As an online student, you will find that most of your searches will take place online. For this activity, you will source material based on an essay topic and you will prepare an annotated bibliography based on the material sourced. You will also review and apply guidelines for referencing the materials sourced.

Four essay topics were provided and students were required to select one for the purposes of undertaking this activity. Specifically, they would write an annotation for each of four (4) sources selected to address the selected essay topic. This activity was to be carried out in teams of two.

The following guidelines were provided to support the task:

Even before you begin the search for resources, you need to get a clear understanding of the topic for which you will be conducting the search. Here are some questions you may ask yourself as you undertake this task:

- Do I understand the topic taken as a whole?

- Do I have any prior knowledge and/or experience that I can draw on to write about this topic?

- What exactly am I expected to do with this topic? What task am I expected to carry out as I write about this topic?

- What are the key words that I should pay special attention to?

- Are there any related terms and/or synonyms that I should also consider?

- What type of resources should I use to carry out the search for information on this topic?

Each annotation was expected to be between 100 - 150 words long.

Additional resource material to support the activity was drawn from two online websites. 
One was the Online Information Literacy (OIL) programme and specifically Module 2 - the Annotated Bibliography. The OIL module was divided into three segments namely search for resources, cite information, write and present. One subsection under the heading 'Search for Resources' was 'Searching the WWW', with information provided on the following areas:

- $\quad$ Search Engines

- Choice and Use of Keywords

- What's a directory

- Evaluating websites

- Invisible Web

http://oil.otago.ac.nz/oil/module2.html

The second was the Purdue Online Writing Lab and its section on Annotated Bibliographies. This resource identified the three main tasks to be undertaken when doing an annotation as summarize, assess, reflect. It also outlined the format to be used when writing the annotation, including the following:

The annotations: The annotations for each source are written in paragraph form. The lengths of the annotations can vary significantly from a couple of sentences to a couple of pages. The length will depend on the purpose. If you're just writing summaries of your sources, the annotations may not be very long. However, if you are writing an extensive analysis of each source, you'll need more space.

You can focus your annotations for your own needs. A few sentences of general summary followed by several sentences of how you can fit the work into your larger paper or project can serve you well when you go to draft.

http://owl.english.purdue.edu/owl/resources/614/01

To complement the primary resource materials drawn from the websites, students were advised to review Chapter 5 of Crème and Lea's 2003 e-publication, Writing at University. In particular, they were advised to pay close attention to two sections of that chapter, namely 'Choosing reading for an assignment' and 'referencing and plagiarism'.

It should be noted that while the materials provided were organized relative to the objectives to be attained, much of it was in the form of resources from the two websites identified earlier and these were not necessarily specifically tailored to meet the requirements of the learning activity of the orientation course. While some attempt was made to provide guidance on how to use these resources, students were still required to do their own selection based on their understanding of the overall task.

\subsubsection{The annotated bibliography and information literacy}

The writing of an annotated bibliography falls within the broad range of information literacy tasks. The Chartered Institute of Library and Information Professionals (CILIP) of the United Kingdom defines the broader set of skills as follows:

Information literacy is knowing when and why you need information, where to find it, and how to evaluate, use and communicate it in an ethical manner. http://www.cilip.org.uk/get-involved/advocacy/information-literacy/Pages/ definition.aspx 
The definition that is most commonly referred to is that developed by the American Library Association (ALA). One point to be noted is the way the ALA frames its definition as an attribute of the information literate person. Thus, it states,

To be information literate, a person must be able to recognize when information is needed and have the ability to locate, evaluate and use effectively the needed information. (1989) http://archive.ifla.org/IV/ifla70/papers/059e-Campbell.pdf

While this area of skill-building has always been considered key in formal education, it has assumed special significance for online learners given the fact that for most of these learners, the physical library, with all the human resources that are an integral part of that facility, is no longer available. The one-on-one support of the human library information specialist is no longer a feature of education in the web-based environment. Further the vast increase in the quantity of accessible information on the Internet, means that an even higher level of information literacy capability is required of students if they are to be successful in their information-searching, evaluating and using tasks.

The writing of annotated bibliographies was included in the orientation course for graduate students preparing to begin a fully online programme of study, since it embodies all the key information literacy skills and serves as an effective vehicle to allow students the opportunity to develop those skills.

This study is based on an analysis of the annotations prepared by the students who participated in the course conducted in January 2011. The course was itself a fully online course.

\section{Literature review}

Whatever their differences in orientation about teaching and learning in the online environment, one position on which practitioners and theorists find common ground, is that learning is the primary activity taking place in the environment and should be the focus of study and practice aimed at improving the online student experience.

Ally (2004) is very clear about this. He asserts,

The goal of any instructional system is to promote learning. Therefore, before any learning materials are developed, educators must, tacitly or explicitly, know the principles of learning and how students learn. This is especially true for online learning, where the instructor and the learner are separated. The development of effective online learning materials should be based on proven and sound learning theories....

Learning strategies should be selected to motivate learners, facilitate deep processing, build the whole person, cater for individual differences, promote meaningful learning, encourage interaction, provide feedback, facilitate contextual learning, and provide support during the learning process. (p.6)

It can be argued that the definitions of information literacy outlined above, as well as the guidelines provided for doing the annotated bibliography are more biased towards articulating the tasks that should be undertaken to develop competency than to providing strategies to support learners as they set about to build knowledge and skills. Some may argue that the task-identification approach used in formulating definitions and providing 
instruction does not go far enough to address the core learning capabilities that are required if students are to function to their fullest potential as information literate persons. This issue of the need to focus on learner needs is also a concern of practitioners and analysts in the field of information literacy. The work of two analysts will be examined in this regard. Even though the context of their concern is not the online environment, their fundamental perspectives are very relevant.

Shelley (2009), even though writing about skills development in the face-to-face context, offers some thoughts that are equally applicable to the online. Making the case that "critical thinking or higher-order thinking is a crucial component of achieving information literacy", she asserts,

The concept of information literacy should go far beyond users' acquisition of banked skills. The competence to execute a keyword search in a specific database, navigate a library catalog, or memorize a certain call number does not indicate users are able to think on their feet. Users who are truly information literate have the capacities to solve problems, think independently, and they are able to structure their own research processes once they leave the classroom.

In light of the above, she recommends, inter alia, the use of strategies to stimulate students' intellectual curiosity in seeking information, motivate students to exercise systemic thinking, apply exploratory questions toward an area of interest. Shelley's work is somewhat superficial and largely prescriptive rather than analytical and evaluative. Nonetheless, it represents an important departure from the conventional task-focused approach to articulating the competencies required for developing information literacy.

Kavanagh (2011) reports on a study conducted over a three-year period aimed at evaluating the effectiveness of an information literacy module integrated into subject-specific academic programmes. This approach of integrating or embedding instruction about information literacy into a course being studied is, according to Kavanagh, regarded by library information specialists as being more effective than the generic approach. The development of a marketing plan, done as a group project, was the area of study selected. The main assessment was the development of a plan to introduce a new product to the Irish market. Each group was also required to keep a research strategy log to document the library resources used to conduct secondary market research and to find academic articles for their marketing plan. The author justifies the inclusion of the log this way:

This allowed the library team to assess each group's research process rather than its results, thereby ensuring that those groups who chose a product for which market research information was not readily available were not penalized for the unavoidable absence of market research reports from their reference list. (p.8)

A handout was prepared to assist groups in undertaking the research strategy activity. The author acknowledges that it did not have the desired effect in the first year of the project since most groups did not submit a log. Improvements were made to the tool in the second year and the submission rate in both the second and third years increased. However, in her conclusion, the author seems to suggest that the log strategy was not as successful as initially hoped for, since students continued to find the exercise difficult. It is not the purpose of this paper to assess the strengths and/or weaknesses of the strategy employed to ensure that students prepared the log. What is important here is that learners were provided 
with the opportunity to articulate and engage in acts deemed appropriate when the focus is on the process of the learning activity, rather than exclusively on its task-specific outcome.

This study was developed to assess the extent to which prospective students of the UWI Open Campus' online graduate programmes were engaging in the learning process in a manner that would facilitate their attainment of the stated outcome of producing annotated bibliographies. To this end, content analysis methods were used to analyze the annotations produced by teams of students as part of their participation in the orientation course that was developed to assist them in strengthening their competency to engage in online learning at the graduate level.

\section{Research questions}

In light of the foregoing, a research study was conducted, based on the following research questions:

1. How competent are incoming online graduate students of the UWI Open Campus in sourcing material related to an essay topic and developing annotated bibliographies on the materials sourced?

2. What preliminary instructional strategies can be gleaned from the analysis of these annotations?

Based on these questions, the following sub-questions were generated:

1. How capable are these prospective graduate students at identifying and interpreting key terms?

2. How capable are the students at analyzing a complex essay topic?

3. How capable are the students at selecting appropriate segments of material sourced relative to the requirements of an essay topic?

4. What summary-writing skills do these students display?

5. What are the areas of weaknesses that need to be addressed through instruction?

\section{Limitations of the study}

There are two limitations that should be noted about this study. The researcher did not read any of the source materials. Thus the annotations were examined without direct reference to the documents on which they were based. While this may be regarded as a disadvantage in one sense, it was felt that annotations can stand on their own, capable of communicating the information required by those accessing them. This researcher did not consider it necessary to refer to the sources in order to assess the annotations themselves.

In the instructions provided in the study guide, students' attention was drawn to the three broad tasks that the Purdue OWL website highlighted for developing the annotation, namely summarize, evaluate and reflect. The analysis done for this study focused on the summarizing aspect only for two reasons. First, in most annotations, there was no evidence of the other two dimensions. In the few instances where there was an attempt at the evaluative, these were largely not in keeping with the core requirements of such a task. This will be explored in more detail later. Given this situation, the researcher decided to concentrate on the summarizing aspect of the annotation. While this may be regarded as a 
limitation, it was also felt that doing the summary was a substantial multifaceted undertaking and that much can be gained by examining it in its own right.

\section{Methodology}

Content analysis methods were employed for both data collection and data analysis. In describing the research method of the study therefore, no distinction is made between procedures used for data collection and those used for data analysis since one set flowed seamlessly into the other.

\subsection{Overview of research method}

A mixed-methods approach was employed in the design of this study; thus methodology combined quantitative and qualitative as well as inductive and deductive approaches.

\subsubsection{The quantitative and qualitative in content analysis}

In some circles, the issue of whether content analysis should be viewed as a quantitative or qualitative method for the analysis of text data is still an area of debate. Wesley (2011) considers it important to bring the debate to the fore and makes the following assertions:

First ... no research topic is inherently qualitative or quantitative ... the subject matter itself does not determine which tradition should be employed. Second, specific methodologies do not belong solely to one tradition or the other. Surveys can be quantitative or qualitative, as can ... content analysis ... (p.126)

He then proceeds to explain the conditions in which each applies. He states,

Because quantitative research involves numbers, frequencies, intensities, and other measurements of degree, it is particularly well suited to questions of How much?, How often?', and How many? By contrast, qualitative research deals best with questions involving conditions, norms, and values. (p.126)

This researcher holds the view that there is value in adopting Wesley's perspective. To this end, Hosti's (1969) broad definition, as cited in Stemler (2001), was considered appropriate for this study. Specifically, Hosti viewed content analysis as "any technique for making inferences by objectively and systematically identifying specified characteristics of messages". http://pareonline.net/getvn.asp? $\mathrm{v}=7 \& \mathrm{n}=17$. Reference to 'any technique' suggests that both qualitative and quantitative techniques qualify.

\subsubsection{The inductive and the deductive}

Hsieh and Shannon (2005) use their interpretation of qualitative analysis as the backdrop for their comprehensive discussion of the approaches to conducting this form of content analysis, describing three approaches namely the conventional, the directed and the summative. It is beyond the scope of this chapter to explore this aspect of their work in any detail. What should be noted though is that these approaches are essentially enhancements of the inductive and deductive approaches that entail emergent coding techniques, with categories being identified from themes and patterns emerging from the data, and a priori 
techniques, where categories are established prior to the analysis based on some theory or previously determined themes. (Stemler, 2001).

\subsubsection{Broad analysis considerations}

Finally, the study took into account the six questions proposed by Krippendorff (1980) and cited by Stemler (2001), which according to the original author, every content analysis must address. The six are,

1. Which data are analyzed?

2. How are they defined?

3. What is the population from which they are drawn?

4. What is the context relative to which the data are analyzed?

5. What are the boundaries of the analysis?

6. What is the target of the inferences?

All of these questions are addressed, whether explicitly or implicitly, in various aspects of the study.

\subsection{Sampling procedures}

As indicated earlier, the study was undertaken to examine the annotated bibliographies produced by prospective students of the Open Campus' online graduate programmes. Students, working in groups of two, were required to select one of three essay topics and produce an annotated bibliography comprising four annotations to inform the writing of the essay on the selected topic.

For the purposes of this study, the researcher selected work submitted in relation to one essay topic only. The selected essay topic was as follows:

The mobile phone is making more significant changes to people's lifestyles in contemporary times than the landline equivalent did in an earlier era. Do you agree with this assertion?

Of the teams that selected this topic, a random selection was done to identify the assignments of ten of them. Some of the selected teams did not complete the required quota of four annotations, thus the number of annotations available for analysis was thirty-six.

\subsection{Defining the unit of analysis}

In each annotation, the sentence was identified as the unit of analysis. This element was selected to make available the smallest possible unit that could be viewed as a meaningful whole in its own right. While smaller and more limited elements, such as words and phrases, were also identified for analysis, it was their role and function in the context of the sentence that made the analysis possible.

For the purpose of the study, the sentence was deemed to be a single unit of meaning comprising three sub-elements namely the verb, the agent of the verb and the extension of the verb. While some of the sentences in the annotations met these criteria, others did not. Many of the sentences in the annotations produced by the student-teams were more complex, combining more than one unit of meaning as defined above. In such cases, the existing sentence was subdivided to yield units that met the requirement as outlined above. 
For example, the last two examples of Exhibit 1 below were both combined into a complex sentence in the annotation but for the purpose of this study are deemed to be separate units of meaning. In addition, where a pronoun is used in a follow-up sentence in the original, the noun to which it refers is inserted to ensure that the meaning is clearly conveyed.

\section{Exhibit 1: Examples of units of meaning}

MP5: The article compares landline and mobile phones.

MP20: Mobile phones have provided lots of fun and convenience to people's lives.

MP115: This article outlines succinctly the anachronistic nature of the landline phone.

MP116: It [the article] delves into experiments conducted.

MP117: [It] cites pertinent statistics based on research conducted by the European Commission.

The verb was viewed as the sub-element that served as a bridge between the other two subelements and in the process holding the sentence together as a meaningful whole. The agent only comes to light through its association with the verb. Additionally, it is the verb that gives coherence and structure to the additional information contained in the extension.

To prepare the units of meaning for subsequent analysis, each was organized according to the three sub-elements described above and as shown in Table 1.

\begin{tabular}{|l|l|l|l|}
\hline Data ID & Agent of verb & Verb & Verb Extension \\
\hline MP5 & The article & Compares & Landline and mobile phones \\
\hline MP20 & Mobile phones & Have provided & Lots of fun and convenience to people's lives \\
\hline MP115 & This article & $\begin{array}{l}\text { Outlines } \\
\text { succinctly }\end{array}$ & $\begin{array}{l}\text { The anachronistic nature of the landline } \\
\text { phone. }\end{array}$ \\
\hline MP116 & It [the article] & Delves & Into experiments conducted. \\
\hline MP117 & And [It] & Cites & $\begin{array}{l}\text { Pertinent statistics based on research } \\
\text { conducted by the European Commission }\end{array}$ \\
\hline
\end{tabular}

Table 1. Division of unit analysis into three sub-elements.

Based on this method, 164 units of meaning were identified in the thirty-six (36) annotations selected for analysis.

\subsection{Data analysis procedures}

As indicated earlier, quantitative and qualitative, as well as inductive and deductive strategies were employed in data analysis. Data analysis was also conducted at a primary and secondary level.

\subsubsection{Primary level analysis}

The deductive approach was taken to analyse the data at this level, driven by features inherent in the essay topic as well as approaches related to the writing of an annotation. Thus, an a priori approach was taken to generating codes that would form the basis for further analysis. The following were the areas of analysis undertaken at the primary level: 
- $\quad$ Frequency count of key terms of essay topic as observed in the units of meaning.

- Frequency count of key terms used in relation to one another in the same unit of meaning.

- Classification and coding of the main verb relative to its use in the annotation.

- Classification and coding of the units of meaning relative to their function in the annotation.

\subsubsection{Secondary level of analysis}

At the secondary level, the analysis shifted to the inductive and was purely qualitative. The codes generated at the primary level, in association with the key terms identified, formed the basis for making observations about likely strategies that students were employing to produce the annotations.

The above provided the framework within which the actual data analysis was undertaken.

\section{Data analysis, findings and discussions: Primary level analysis}

This section focuses on the analysis undertaken at the primary level only. It reports on the analyses conducted, the findings generated from those analyses and seeks to provide some tentative interpretation of those findings.

\subsection{Frequency count of key terms}

A word or short phrase, appearing in the annotations, was considered a key term, depending on its function in the essay topic. Specifically words that served as indicators of the areas for which the search was to be conducted, were considered key terms. Main verbs, that is those verbs that served as anchor for the whole unit of meaning were not included as a key term and were accounted for separately. The key terms identified were 'mobile phone', 'people's lifestyles', 'significant changes' and 'landline'.

Where only part of the term was used, for example 'mobile' or 'lifestyle' or where the expression was completed, as in 'landline phone', these were also accepted as meeting the criteria of a key term. Also accepted were pronouns referring to any of these nouns or noun phrases. Additionally, synonyms of these expressions, for example 'cell phone', 'fixed lines', 'people's daily life' , 'the lives of citizens', 'changing effects'were accepted.

While principal verbs did not qualify for inclusion as key terms, there was one situation where a verb and its synonyms in the verb extension were seen as warranting inclusion as key terms. In these limited cases, the idea of 'change' expressed as a verb in the verb extension, was counted as a key term (See Exhibit 2).

Exhibit 2: Examples of 'change' as a verb included as a key term

MP 51: How the cell phone's ever changing capabilities ... have changed the way people conduct business.

MP 58: ... how the use of mobile phones affect the lives of citizens.

Table 2 provides a frequency count of the appearance of each of the terms, inclusive of their synonyms, in the annotations selected for analysis. It should be noted that these appeared primarily in the verb extension. 


\begin{tabular}{|l|l|}
\hline \multicolumn{1}{|c|}{ Key terms (incl. synonyms) } & Count \\
\hline Mobile phone & 118 \\
\hline Landline phone & 31 \\
\hline People's lifestyle & 32 \\
\hline Change & 19 \\
\hline
\end{tabular}

Table 2. Frequency count of key terms in annotations.

In terms of direct referencing therefore, one cannot ignore the stark difference between the number of times 'mobile phone' appeared compared with the number recorded for each of the other three terms.

While one cannot be sure of the factors that gave rise to this situation, it is evident that, in students' interpretation of the essay question, the term mobile phone emerged as the primary term that they needed to focus on. It is also likely that this term was the main key word used to guide their search for sources relative to the essay topic. Alternatively, to the extent that other key words were used, and appeared in the documents sourced, these were not accorded the same importance in the constructing of the annotations and were largely ignored.

\subsection{Frequency count of key terms in relation to one another}

When one looks at the essay topic closely, it becomes evident that what is needed is not simply that all key terms should be equally represented in the annotations, but that they should be used in relation to one another. This way of viewing the terms is mirrored in the topic itself. It can be argued that one important way of showing that relationship is to use the relevant terms in the same sentence, or, in the context of this study, in the same unit of meaning. This only happened minimally between the term 'mobile phone' and any of the other terms.

A further examination shows that of the thirty one (31) times that the term 'landline' appeared, it was used in the same unit of meaning with the 'mobile phone' twenty eight (28) times. What this indicates is that of the few student teams that recognized the landline phone as an important component of their search, the majority of them also considered it important to recognize a relationship between the two communication devices.

The following are examples of how relationships manifested themselves in the annotations.

\section{Exhibit 3: Examples of units of meaning showing two terms in relation to each other}

MP 17: Relevant background information is given about how it [the mobile phone] has made significant changes to people's lifestyles as compared to the fixed line.

MP 103: [The case study] is about managing communications repertoire in relation to mobile versus landline.

MP128: Also, this source presents information in relation to the number of households which may be considered cell phone only or landline only households.

It is important to note that at this stage of the analysis, no attention is paid to the nature of the relationship and whether the way terms are used in relation to one another, adequately serves the requirements of the essay topic. All that is acknowledged is that by using the terms in close proximity to one another, there is a recognition of a relationship. 


\subsubsection{Possible factors impacting lack of attention to relationships}

Any reading of the essay topic would reveal that the intention was that the two technologies would be compared on the basis of their impact on people's lifestyle. However it is likely that two factors may have influenced the focus on one at the virtual exclusion of the other.

One factor may have been the structure of the topic. One notes that 'mobile phone' is in a beginning dominant position and thus, is positioned to impose that dominance on the mind of the undiscerning reader. In contrast, 'the landline equivalent' does not enjoy a similar dominant status: even though there is an intention to establish a comparison and contrast between the two technologies, the two are not in close direct proximity to each other to make that intention clear. The expression 'landline equivalent' is far removed from its counterpart, occupying a weaker position towards the end of the sentence.

Reinforcing this contrast in status as defined by the structure of the sentence is the high profile and widespread usage that the mobile phone enjoys as an emerging technology in contemporary times. It is likely that this socio-cultural factor may also have influenced students to focus more attention on the newer device. Whatever the reason, it would appear that factors influencing students' perceptions about what has emphasis and what does not, in an essay topic warrants some examination.

\subsection{Classification and coding of principal verb}

The principal verb was isolated for analysis as it was felt that, in light of its role of introducing the core content of the unit of meaning, it would embody features that could shed light on the nature of the follow-up content. This expectation of the verb emanates from the hierarchical arrangement as presented in various taxonomies, the most well-known being Bloom's Taxonomy.

Closer examination showed that there was a wide variety in verbs used across the 164 meaning-units. However this variety was not matched by any significant variation in the functions they performed. Essentially, all verbs were used in a reporting capacity, linking the source of the information with the actual information reported. In this regard, the agent of the verb was typically either the author, or the name of the type of the source document (article, paper, chapter). Following are examples of the verb performing the task outlined above.

\begin{tabular}{|l|l|l|l|}
\hline Data ID & Agent of verb & VERB & Verb Extension \\
\hline MP29 & $\begin{array}{l}\text { She [the } \\
\text { author] }\end{array}$ & HIGHLIGHTS & $\begin{array}{l}\text { The point that cell phones may have been } \\
\text { originally intended as gadgets. }\end{array}$ \\
\hline MP32 & Chitali Sinha & ARGUES & $\begin{array}{l}\text { That mobile phones are quickly becoming an } \\
\text { affordable, useful and accessible tool to } \\
\text { marginalized communities. }\end{array}$ \\
\hline MP38 & Mark Hickey & ANALYZES & $\begin{array}{l}\text { The impact of wireless technology ... emphasizing } \\
\text { on the effect it has brought on developing nations. }\end{array}$ \\
\hline MP55 & $\begin{array}{l}\text { She [the } \\
\text { author] }\end{array}$ & POSTULATES & $\begin{array}{l}\text { That the mobile phone provides the user with } \\
\text { more benefits than the landline phone. }\end{array}$ \\
\hline MP154 & The report & FOCUSES ON & $\begin{array}{l}\text { How makers of cell phones, unlike landline, have } \\
\text { come up with more enticements ... }\end{array}$ \\
\hline
\end{tabular}

Table 3. The reporting role of the principal verb. 
Even when higher order verbs were used, for example, 'analyzes' and 'argues', their use was not done in a way to reveal the higher order processes inherent in the meaning of the term. Essentially therefore, like the others, theirs was an information-transmission role.

While the above reflects the way verbs were used in the data collected, there was a minority set that did not conform to this pattern. In these cases, the agent of the verb was some entity or situation that the unit of meaning was making some statement about. Two examples are as follows:

\begin{tabular}{|l|l|l|l|}
\hline Data ID & Agent of verb & VERB & Verb Extension \\
\hline MP23 & The use of cell phones & HAS REDUCED & $\begin{array}{l}\text { The chance of people conversing with } \\
\text { strangers. }\end{array}$ \\
\hline MP48 & Mobile technology & IS EVOLVING & On a daily basis. \\
\hline
\end{tabular}

Table 4. Exception to standard verb function.

\subsection{Classification and coding of units of meaning}

Except in a few cases, all of the essential meaning-bearing content of the annotations was contained in the verb extension. This was not unexpected since students were basically following the standard format for writing an annotation, as already observed in the coding of the principal verb. This data was analyzed to identify the nature of the content students were using to construct the summaries that, as mentioned before, comprised the annotations. In this phase of the analysis, the deductive approach continued to apply not only with reference to the essay topic but also against the backdrop of established criteria for writing a summary. However, the inductive was also applied at this stage since one also needed to examine attributes inherent in the text to identify what they revealed about the strategies the students were using to construct their summaries. Based on a preliminary review, four categories of text were identified.

\subsubsection{Category \#1 - Overview}

One category was viewed as providing overviews about what the original document was conveying about the topic or object of interest. A unit of meaning was classified as an 'Overview', if it appeared to be painting a broad picture of some item or object within it. In the context of this study, that item or object was, in most cases, one of the key terms identified earlier, or a combination of more than one of these terms. While this was the typical situation, in a few cases, other terms occupied this position. Whether as a single item or as a combination, this entity was deemed to be the focal point in the Overview. A second feature of the unit of meaning classified as an Overview was that, in relation to the focal point, it only provided broad information without going into specific details. However, in the third feature, some element of the text in the unit, served as an indicator of specifics about the focal point that would come later in the annotation.

Exhibit 4 demonstrates the analysis outlined above. Note too that, as stated earlier, it is the verb extension that is the basis for this analysis. 
Exhibit 4: Analysis of category \# 1 text

Data ID:

Verb extension

Key terms:

Focal point:

Indicator of likely

follow-up specifics:

DataID:

Verb extension

Key terms:

Focal point:

Indicator of likely

follow-up specifics:

Data ID:

Verb extension:

Key terms:

Focal point:

Indicator of likely

follow-up specifics:

Data ID

Verb extension

Key terms:

Focal point:

Indicator of likely

follow-up specifics:
MP15

... the change that the mobile phone has made on citizens by creating new forms of expression

change, mobile phone

combination of 'change' and 'mobile phone'

new forms of expression

\section{MP39}

... also two major ways in which mobile phones has brought about changes in lifestyle.

mobile phones, changes, lifestyle.

all three terms combined

two major ways.

\section{MP89}

... the results of a survey questionnaire ... designed to assess the motivation of college students who use the mobile phone to connect with family and friends.

mobile phone

combination of 'college students', 'mobile phone', 'connect with family and friends'

assess motivation

MP103

About managing communications repertoire in relation to mobile versus landline

mobile, landline

combination of 'mobile' and 'landline'

managing communications repertoire

\subsubsection{Category \# 2 - Superimposition}

Segments that fell within the second category were essentially linguistic constructions that closely mirrored the content and structure of the essay topic. Such constructions seemed to represent a strong effort to ensure that one did not drift far away from the perceived requirements of the task, and that one stayed on target and 'answered the question'. The term 'superimposition' was used to define these segments since their close resemblance to the essay topic suggested that rather than delving into the content of the selected article, the student generated segments of the text for the annotation based largely on a rearrangement of substantial portions of the essay topic. This presumed strategy thus meant that the act of writing the annotation was largely a superficial activity that entailed little or no engagement with the content of the selected source material. 
In terms of its core attributes, a superimposition shared some similarities with the overview. First both were constructed around a focal point, which, in turn, was constituted out of one or a combination of the main terms. Both provided general information about the focal point. However, the critical distinction between the two was that, because the superimposition was so completely defined by the essay topic, it did not allow room for meaningful elements capable of forecasting well-defined additional information. In this regard, it is important to note that it is not that there were no additional elements; rather that if there were, they were largely non-descript and lacked the level of meaning and the force required to set the stage for further expansion.

Exhibit 5: Analysis of Category \#2 text

Data ID:

Verb extension:

Main Terms:

Focal point:

Indicator of likely

follow-up specifics:

Data ID:

Verb extension:

Main Terms

Focal point:

Indicator of likely

follow-up specifics:

Data ID:

Verb extension:

Main terms:

Focal Point:

Indicator of likely

follow-up specifics:

Data ID:

Verb extension:

Main terms:

Focal point:

Indicator of likely

follow-up specifics:
MP4

... mobile phone has dramatically transformed lifestyle in the last decade.

mobile phone, transformed, lifestyle

combination of 3 main terms.

none identifiable

MP17

... ways in which mobile communications have transformed people's lives

mobile communications, transformed, people's lives

combination of 3 key terms.

none identifiable.

MP24

... many detailed paragraphs on the impact mobile phones have on people's lives.

impact, mobile phones, people's lives

combination of 3 key terms.

none identifiable

MP118

... the notion that mobile phones have so profoundly impacted people's lifestyles.

mobile phones, impacted, people's lifestyles

combination of 3 main terms

none identifiable.

One additional point about this category warrants further attention. Given the closeness between the overview and the superimposition categories, there was the possibility of a blurring of the boundaries between them. Earlier, it was noted that the defining feature separating the two was the absence or almost complete absence of an indicator in the superimposition type of unit that pointed towards subsequent details. Thus, except in 
instances where there were actually no additional meaning-words in the text, the decision to locate the segment of text in one or other category was a judgment call.

One example of this was the decision to include MP39 in the Overview category and MP17 in this category. Both verb extensions are almost identical and the term 'ways' appears to perform the same function in both. The reason for the different classification was that in MP39, the phrase 'two major ways' was regarded as a credible indicator of follow-up specifics, while 'ways' in MP17, was not.

Ultimately, even though acknowledging the need to justify classification of these borderline cases, one can also argue that even within the Overview category, some terms may have been more efficient follow-up indicators than others.

\subsubsection{Category \# 3 - Detail}

Verb extensions included in this category were viewed as providing specific details relative to the overall topic or theme of the annotation. In an ideal situation, such details would hinge on indicators identified in the Overview. For the purpose of this analysis however, there was no backward linkage and extensions were included in this category based solely on the criteria outlined above. It should also be noted that in all cases the entire verb extension constituted the detail.

Exhibit 6: Analysis of Category \#3 text

Data ID: $\quad$ MP6

Specific detail: $\quad$... facts that persons are giving up their landline phones for mobile phones.

Data ID: $\quad$ MP75

Specific detail: $\quad$... that the advent and use of cell phones have broken down the boundaries that once separated work and family affairs.

Data ID: $\quad$ MP88

Specific detail: $\quad .$. how younger teens use the mobile phone to create their external social networks from home.

Data ID:

MP119

Specific detail: $\quad \ldots$ [the notion] that percentages of households with no landline phones are on the increase across major European countries.

\section{Data ID: $\quad$ MP143}

Specific detail: $\quad$... how individuals responded to the availability of telephones whether privately owned or for public use.

It is likely that some or all of the segments that were identified for this category were extracted verbatim from the source material. While this sort of reproduction is not to be encouraged, it should not detract from the fact that specific details were considered as important elements to be included in the construction of the annotation. Two other points deserve attention.

The first relates to the absence of the other key terms of the essay topic from these verb extensions. This is in sharp contrast to those classified in the other two where there were a 
high proportion of key terms or their close synonyms. Of particular interest here is that while no direct mention is made of 'people's lifestyles' or 'changes' or other terms that closely resemble them, a large proportion of the examples were clearly representative of changes in lifestyle brought about by the social impact of the movement from the landline to the mobile phone.

The second point pertains to the classification itself. Some may argue that MP88 would fit more into the Overview category than this one. Given the interpretation of 'Overview' given earlier, one can argue that this phrase could lead to more specific details outlining the ways in which teens use their mobile phones for the purpose specified. While acknowledging this possibility, the decision was taken to include it as a detail of the broader more general and inclusive issues contained in the essay topic. Thus, even though it can yield its own details, in the context of this study, it is being treated as a specific detail.

\subsubsection{Category \#4 - Assertions}

Items included in this final category are essentially assertions or generalizations that convey a clear position and were presented as if the writer was convinced that they could not be challenged. In this regard, even though the identity of the author was not usually revealed in the assertion, one can conclude that assertions represented the personal position of those who articulated them.

Preliminary analysis of the data set suggested three attributes inherent in this form of language use.

First, the agent of the verb was the entity about which the assertion was being made. It therefore stood out since, in the typical structure of the sentence in an annotation, it is the author of the source material, or the material itself that was the agent carrying out the act embodied in the verb. Secondly, the verb itself was in the present tense, or present perfect, conveying a sense that the claims made were timeless and universally relevant. Thirdly, there was no link to any source to substantiate the claims made.

While in the preceding categories, the verb extension was sufficient to represent the core attributes of the language type, in the case of assertions, the entire meaning unit was required, since the agent of the verb was needed to complete the meaning, as discussed above.

Exhibit 7: Analysis of Category \#4 text

Data ID Assertion

MP20 Mobile phones have provided lots of fun and convenience to people's daily life.

MP48 Mobile technology is evolving on a daily basis

MP70 Mobile phones seem to have taken over the communication market.

MP108 The article categorically suggests that the use of cell phones are (sic) now empowering students to become self-directed learners.

MP148 Educators can take advantage of many special features of the mobile phone to improve learning in the classroom.

MP149 School administrators can create measures to improve discipline in the school through the use of the mobile phone. 
Data MP70 was recognized as a member of this category, in spite of the somewhat tentative nature of the verb. The decision to include it was based on the fact that other attributes of the assertion were evident and the strength of the second part of the verb phrase could be viewed as overshadowing the caution in 'seem'. Data MP108 was also acknowledged as a member of this category, notwithstanding the inclusion of 'the writer' as the apparent source. One wonders whether there was any evidence in the source material to support this 'categorically' stated fact.

\subsubsection{Category \# 5 - Unclassified data}

The majority of the data were classified in one or other of the categories identified above. However there was a small minority that did not fit any of them. These remained unclassified. Two examples are as follows.

\begin{tabular}{|l|l|}
\hline Data ID & Unclassified meaning units \\
\hline MP73 & This book excerpt is based upon findings derived from a series of surveys. \\
\hline MP93 & He used two papers to scrutinize his research. \\
\hline MP134 & Sun Kyong Lee pointed out that media uses were based on different studies. \\
\hline
\end{tabular}

Table 5. Unclassified data.

In light of the foregoing, Table 6 presents the frequency count of the codes generated from the classification of the meaning units.

\begin{tabular}{|l|l|l|}
\hline Code & Number of units of meaning & $\mathbf{\%}$ \\
\hline Overview & 56 & $34 \%$ \\
\hline Superimposition & 12 & $7 \%$ \\
\hline Detail & 58 & $35 \%$ \\
\hline Assertion & 19 & $12 \%$ \\
\hline Unclassified & 18 & $11 \%$ \\
\hline
\end{tabular}

Table 6. Frequency count of codes emerging from units of meaning.

To the extent that the writing of overviews and the selection and writing of details are two important tasks in the construction of an annotation, the evidence is that these two skills were well represented in the data set. Together they accounted for $69 \%$ of the meaning-units coded. However, it should also be noted that they were not used in relation to one another: one did not see the typical pattern of overview followed by supporting details in a given annotation. Instead both were used across different annotations.

In terms of summary writing for an annotation, the issue arises whether all relevant aspects of this skill were accounted for in the data set. 


\section{Discussion of emergent themes: Secondary level analysis}

Further analysis of the data was carried out to determine what they revealed about the overall annotation-writing strategies of the students. Five such strategies were detected.

The first pertains to the approach adopted for identifying and selecting source material on which to write the annotations. Given the vast difference in terms of usage between the term 'mobile phone' and the other four, one may infer that the dominant search strategy employed highlighted that term above all the others. It is beyond the scope of this chapter to investigate how students approached the task of identifying key terms that would guide their search, and more specifically, how they decided which terms to include for the search.

A close examination of the essay topic seems to suggest that the term 'mobile phone' was in the dominant position at the beginning of the topic statement and that this, coupled with its heightened popularity in the wider society may have influenced the greater attention it received from students. What ever may have been the factors, it is evident that the search strategies used warrant further investigation.

As noted earlier, the tasks of writing overviews and highlighting perceived relevant details were generally well represented in the data set analysed. Given that these are widely regarded as core components of the more complex task of writing a summary, one may infer that students had knowledge of and were practicing these two summarizing techniques. However, as noted earlier, students' knowledge did not seem to extend to the acknowledged relationship between the two.

One exception to this general pattern was observed in the following three meaning-units , taken from a single annotation:

\begin{tabular}{|l|l|}
\hline Data ID & Meaning Unit \\
\hline MP89 & $\begin{array}{l}\text { Chen discusses the results of a survey questionnaire ... designed to assess the } \\
\text { motivation of college students who use the mobile phone to connect with } \\
\text { family and friends. (Overview) }\end{array}$ \\
\hline MP90 & $\begin{array}{l}\text { The results reveal that the mobile phone is helpful for students to gain } \\
\text { socialization skills, coordinate with their families, and remain vibrant } \\
\text { participants in a social network. (Detail) }\end{array}$ \\
\hline $\begin{array}{l}\text { Chen's research also shows that, contrary to initial expectations that the } \\
\text { mobile phone would lead to isolation and independence of young people } \\
\text { from their families, it seems to increase the involvement and socialization } \\
\text { with their families. (Detail) }\end{array}$ \\
\hline
\end{tabular}

The writer of this annotation was displaying a competency level in the writing of summaries that was of a higher standard than that exhibited by the other writers.

Looking at the overview in particular across the entire data set, it appeared that at times, this element served as a default strategy when students found it difficult to draw out the meaning of the details of the source material. 
The following are to be noted in this regard:

\begin{tabular}{|l|l|}
\hline Data & Meaning Unit \\
\hline MP84 & $\begin{array}{l}\text { The focus was on three research questions which sought to examine the } \\
\text { influences of generation and lifestyle factors to mobile phone. }\end{array}$ \\
\hline MP143 & $\begin{array}{l}\text { This document explains the impact telephones had on the lives of people in } \\
\text { earlier times. }\end{array}$ \\
\hline
\end{tabular}

Whether or not an overview was required at that point in the respective annotations, it would appear that detailed information had been suppressed and students were resorting to vague, non-specific utterances that were largely devoid of the core essence of the content of the source material.

A third area of interest emerged in what appeared to be a strategy to ensure the relevancy of the content of the annotation. It can be argued that some students seemed to be making a conscious effort to ensure that their output was consistent with the requirements of the essay topic. In short, they wanted to ensure that they were 'answering the question'. As noted earlier, this sometimes meant the direct transfer of key terms from the essay topic into the annotation, as reflected in the items included in the category defined earlier as 'superimposition'. This superficial approach meant that the annotation itself was not able to reflect the essence of the source material on which it was based.

A fourth area of interest was the use of assertions by some students in which they appeared to be advancing propositions as if they (the propositions) were emanating from the source material. One wonders whether this resort to what was essentially a personal position, through the use of the 'grand statement', derived from an inability to accommodate openended thought and the need to remain in the comfort zone of clearly-defined factual information.

The use of assertions may have also been propelled by an orientation towards more prescriptive rather than analytical modes of thinking, as implied in the tendency towards providing a solution in MP148 and MP149. Overall, what appears to be the case here is a need to define knowledge within firm boundary lines and it can be argued that the assertion provided the required mechanism for doing so.

Finally, the data analysed appeared to reveal a likely weakness in students' capacity to engage in relational thinking that was able to observe and deal with elements of a body of knowledge in a manner that allowed a focus on the elements in interaction with one another rather than singly and sequentially. Such an approach to thinking would demonstrate an appreciation of the Gestalt principle of the whole being greater than the sum of its parts and conversely, the significance of viewing the parts in the context of the whole. As noted earlier a large proportion of the meaning units analyzed were focused on the mobile phone only. Even when the focus extended to include the landline phone, the context in which the two were being discussed bore little relation to that espoused in the essay topic.

Additionally, when the use of these technologies was shown as impacting life style changes, it was the impact of the mobile phone only that was focused on. For example, even though 
acknowledging the quality of the segment of the annotation identified as MP89 to MP91 earlier, it should still be noted that here the focus is only on the role of the mobile phone in fostering the development of socialization skills in young people. The same pattern is evident in MP75. Indeed it can be argued that the weaknesses observed earlier in the searching strategies employed may also be traced back, at least partially, to a limited capability for relational thinking.

Finally, the question may also be asked whether all relevant summary-writing strategies as they pertain to the writing of annotations were present in the data analyzed. In this regard, it is important to note that students were required to develop the annotated bibliography in relation to a specific essay topic that they would write on subsequently. It was not being developed in relation to a general topic of interest. To the extent that there is a distinction between the two, and that there are additional strategies that apply in the first scenario that are not required in the second, this distinction was not evident in the data analyzed.

\section{Conclusions}

One of the main factors that influenced the decision to undertake this study was the perception that the outcome-oriented task-focused approach to providing guidelines for assisting students in developing information literacy skills, may not be sufficient to address the fundamental process skills that students need to apply in order to achieve the intended outcome. This view was also shared by the two library information specialists cited. In particular, one recalls Kavanagh's (2011) discussion about the research strategy log. This view also resonates with Ally's (2004) assertion that the developer of online materials must select learning strategies that, inter alia, promote meaningful learning and provide support during the learning process. It is envisaged that the findings of this study can provide a useful starting point for taking the design of information literacy instruction for online graduate students beyond the level of task-identification.

\section{References}

Ally, M. (2004). Foundations of educational theory for online learning. In T. Anderson and F. Elloumi (Eds.). Theory and Practice of Online Learning. Athabasca: Athabasca University. Chapter 1, pp. 3-31. http://cde.athabascau.ca/online_book .

Crème, P and Lea, M.R. (2003). Writing at University (2nd. ed). UK: Open University Press.

Kavanagh, A. (2011). The evolution of an embedded information literacy module: using student feedback and the research literature to improve student performance. Journal of Information Literacy, 5(1), pp. 5-22. Retrieved October 72011 from http://ojs.lboro.ac.uk/ojs/index.php/JIL/article/view/LLC-V5-I1-2011-1

Shelley, A. (2009). Beyond buzz words and skill sets: the role of critical thinking in information literacy. Library Student Journal. Retrieved October 72011 from http://www.librarystudentjournal.org/index.php/lsj/article/view/110/233\#topd iv

Stemler, Steve (2001). An overview of content analysis. Practical Assessment, Research $\mathcal{E}$ Evaluation, 7(17). Retrieved October 7, 2011 from

http:/ /PAREonline.net/getvn.asp?v=7\&n=17 . 
Wesley, Jared J. (2011). Observing the political world: quantitative and qualitative approaches. In K. Archer and L. Berdahl (Eds.) Explorations: A Navigator's Guide to Research in Canadian Political Science,( 2nd Ed. ) Toronto: Oxford University Press. Chapter 6, pp. 123-144. 


\title{
The Role of Self-Efficacy, Control Beliefs and Achievement Goals on Learning Among Distance Learners
}

\author{
Clarence $\mathrm{Ng}$ \\ Griffith University \\ Australia
}

\section{Introduction}

Distance learners' motivation is inherently significant to distance learning. From the early days of distance education through correspondence courses to today's online delivery using internet technologies, distance educators often assume that distance learners will study learning materials, complete carefully designed activities, attend optional tutorials, seek help, and work on assessment items within a distance learning course. This assumption is valid when distance learners are motivated and self-regulatory. Nevertheless, the high dropout rate and low completion rate commonly found in different distance learning courses and programs warn us against making unrealistic expectation on distance learners (Rovai, 2003). A lack of motivation has often been taken as the main reason for early dropout among distance learners. Certainly, there is a need to understand what motivates learners to engage in distance learning and how to build on these motivational characteristics to develop an engaging learning environment for distance learners (Hurd, 2006).

Distance educators and researchers have already recognised the importance of motivation in distance learning (e.g. Morgan, Taylor \& Gibbs, 1982). Several empirical studies (e.g. Dearnley \& Matthew, 2000; Lyall \& McNamara, 2000; Richardson, 2007; Sankaran \& Bui, 2001) have confirmed the critical role of motivation for distance learners who often need to juggle various work and family commitments simultaneously while completing their studies. In a recent discussion, Simpson (2008) argued that it is important to incorporate motivation as an essential component for the provision of learner support within a distance learning system. Nevertheless, the study of motivational and learning processes has focused mainly on on-campus students. Until recently few studies have explored the complex relationships between motivation and learning among distance learners. The current study focused on understanding distance learners' goals and their relationship with strategy use and learning attitudes using an achievement goal framework. The research on distance learners' motivation using this dominant framework is at its beginning stage; few studies are available (e.g. Eppler \& Harju, 1997; Ng, 2006 \& 2008). Using a sample of Chinese distance laerners, the current study contributed significantly to our undestanding of distance learners' motivation from this important theoretical perspective. 


\section{Theoretical framework: Achievement goal theory}

Achievement goal theory provides the theoretical framework guiding the design of the current study. Achievement goals are students' perceived cognitive purposes that define why and how students engage in learning. Different goals are associated with a different pattern of cognition, affect and behaviour (cf. Dweck, 1986; Kaplan \& Maehr, 2007). Early studies on achievement goals focused on contrasting the effects of two single categories of achievement goals, mastery versus performance goals. Mastery goals orient students to learn for the sake of improvement and comprehension; whereas performance goals orient students to focus on achievement and relative ability. Previous studies consistently showed that mastery goals were always associated with adaptive learning outcomes such as higher levels of efficacy belief, persistence, effort expenditure, task value and frequent use of cognitive and regulatory strategies, and expectedly better achievement. In contrast, performance goals were less adaptive and tended to link with lower achievement levels (e.g. Ames, 1992; Ames \& Archer, 1988; Dweck, 1986; Greene \& Miller, 1996; Meece, Blumenfeld \& Hoyle, 1988; Nolen, 1988; Pintrich, 1989; Pintrich \& De Groot, 1990; Pintrich \& Garcia, 1991).

However, the effects of performance goals on learning and achievement are open to debate and research evidence is far from conclusive. Achievement goal researchers like Elliot and Harackiewicz (Elliot, 1997; Harackiewicz, Barron \& Elliot, 1998) argued that the detrimental effects of performance goals should be confined to those focusing students on avoiding performance, such as avoiding revealing one's lack of ability. In contrast, performance goals with an approach orientation, such as getting a good result, should have positive effects on learning and motivation. The debate on the nature of performance goals has therefore led to the separation of performance goals into finer categories-performance-approach and performance avoidance goals. Subsequent empirical evidence (Elliot \&Harackiewicz, 1996; Skaalvik, 1997) showed that negative effects of performance goals were confined to those with an avoidance orientation whilst positive effects were found among performance goals with an approaching orientation. Therefore adopting multiple goals, that is holding both performance-approach goals simultaneously with mastery goals will have enhancing effects on learning and achievement.

More recently, other goals researchers have proposed an extended multiple goal perspective and showed that students learn with goals in addition to those focusing on mastery and performance concerns. For example, Valle, Cabanach, Núñez, González-Pienda, Rodríguez, and Piñeiro (2003) found a group of multiple-goal Spanish undergraduates, endorsing mastery, performance and social reinforcement goals simultaneously, alongside with two groups of single-goal students, orienting towards performance and mastery respectively. This group of multiple-goal students used more deep strategies than did performanceoriented students and had a better achievement than did both mastery- and performanceoriented groups. The study of Suárez Riveiro, Cabanach \& Valle (2001) provided another example in which they examined four goals, namely, task, self-enhancing, self-defeating and work avoidance goals. Suárez Riveiro and her colleagues found three groups of multiplegoal Spanish-speaking students, which differed in the use of cognitive, self-regulatory and motivational strategies. The current study aligned with these previous studies and examined distance learners' diverse goals for learning. It is believed that distance learners hold goals focusing not just on mastery and performance. 
Another major development related to the debate on the nature of performance goals is the notion of mediation. Dweck in its initial formulation of achievement goals suggested that the effect of achievement goals may be mediated by students' self-efficacy level. Dweck (1986) hypothesed that performance goals link with a maladaptive learning pattern when self-efficacy is low. However, when self-efficacy is high, performance goals are more likely to link with a more adaptive pattern of learning. Dweck assumed that self-efficacy will not mediate the effects of mastery goals. Based on an experimental study, Elliot and Dweck (1988) found empirical support for Dweck's mediator hypotheses. However, subsequent studies (e.g. Harackiewicz et al., 2000; Kaplan \& Midgley, 1997; Miller, Behrens, Greene \& Newman, 1993) failed to confirm the mediating role of self-efficacy on the effects of performance goals. Contrary to Dweck's prediction (1986), interaction effects between selfefficacy and mastery goals were found (e.g. Kaplan \& Midgley, 1997). More recently, Braten, Samuelstuen and Stromo (2004) added to this line of research and explored the role of selfefficacy in mediating the effects of avoidance forms of performance goals on self-regulation. Self-efficacy is by far the most important variable mediating the effects of performance and other achievement goals. Other mediators such as task difficulties (Grant \& Dweck, 2003) and level of uncertainty (Darnon et al., 2007) have been examined. In the current study, the main concern was whether distance learners' efficacy beliefs will moderate the effects of goals on learning. In addition, the present study extended the current research on achievement goals and examined the role of another important mediator, control beliefs, on the effects of goals on learning.

\subsection{The current study}

To frame distance learning from an achievement goal perspective, distance learners' motivation is accordingly defined as cognitive purposes for learning and achievement. Few studies (e.g. Eppler \& Harju, 1997; Ng, 2006 \& 2008) in distance learning have utilized the achievement goal framework to researching distance learners and their learning processes. $\mathrm{Ng}$ (2008) used an extended multiple goal perspective and classified distance learners into different types of goal users. One of the most important contributions in this previous study is that distance learners have goals other than mastery and performance considerations. The extant literature on distance education shows that distance learners often learn with goals focusing on personal development, career advancement and different social considerations (e.g. Cochrane, 2000; Dearnley \& Matthew, 2000; Cannon, Umble, Steckler \& Shay, 2001; Lyall \& McNamara, 2000; Miller \& Smith, 1998; von Prummer, 1990; Wilson \& Bagley, 1999).

According to the studies of Harackiewicz and her colleagues (e.g. Barron \& Harackiewicz, 2001; Harackiewicz, Barron, Tauer, Carter \& Elliot, 2000), different type of goals will have independent effects on learning. Different goals can provide different forms of motivational supports that help distance learners maintain their focuses or cope with the demands of learning in the midst of diverse life circumstances. For example, personal development goals orient distance learners to learn for the sake of developing confidence, opening up horizons and furthering one's development (cf. Dearnley \& Matthew, 2000). Distance learners holding these goals will hold positive attitudes towards learning and be willing to expend effort and use adaptive strategies. Work-related goals focus distance learners on how their learning promotes career advancement and the development of work-related knowledge (Dearnley \& Matthew, 2000; Lyall \& McNamara, 2000). These goals heighten distance 
learners' concerns with the products of learning in relation to important career considerations. As such, these goals drive distance learners to focus on the utility value of learning and therefore can be treated as extrinsic to the learning process. These goals will probably be associated with a less engaged pattern of learning characterized by effort retreat, the use of less adaptive strategies and the development of a less favourable attitude towards learning. Also, this study included social enhancement goals, which focus learners on enhancing their social status through distance learning. This social consideration is culturally significant for Chinese distance leaners because bringing glory to one's family is an important cultural reason for learning in Chinese societies (Salili, 1997). These culturally significant social goals should provide learners with additional motivation. Because these social concerns focus more on the product of learning-enhacning social status, it is asssumed that they will be associated with positive learning attitudes. However, their positive effects on learning and regulatory strategies will be limited.

In addition to examining the effects of these goals on learning, the second aim of this study is to examine the moderation role of efficacy and control beliefs on the effects of goals on learning and attitudes. Previous studies on achievement goals have focused exclusively on moderation effects of self-efficay on performance-approach goals. Seldom other goals have been taken into considersation. This present study adds to this stream of research by examining the moderation role of efficacy beliefs on distance learners' mastery goals, workrelated goals and social enhancement goals. Given the significant result in Kaplan and Midgley (1997), this present study assumed that efficacy beliefs will enhance the positive effects of mastery goals on strategy use and learning attitudes. In other words, a strong efficacy belief will boost the positive effect of mastery goals on effective use of adaptive strategies and development of a positive learning attitude. Previous studies have not considered mediation effect of efficacy beliefs on work related goals and social enhancement goals on learning. Work-related goals and social enhancement goals in this study were conceptualised as less adaptive goals and will direct learners to focus away from the learning process onto the product, therefore it was assumed that a strong sense of efficacy beliefs will dampen the negative impact of these goals on strategy use and learning attitudes. Finally, following Dweck's theorisation (1986), this study assumed that distance learners' performance-approach goals will be associated with adaptive strategies and attitudes when their efficacy beliefs are strong

Another important contribution of the present study was examining the mediation effects of control beliefs. Given that distacne learners are expected to learn independently, it is essential for them to have strong control beliefs and consider that they are in control of their learning. Roblyer (2000) found that students who selected to take distance education considered control over learning pace an important factor. This present study assumed that distance learners' control beliefs will act as an important mediator. In particular, the hypothesised mediation effects of efficacy beliefs on goals discussed above were also held for control beliefs. In other words, a strong sense of control beliefs will enhance the positive effects of performance-approach goals and mastery goals on learning. When less adaptive goals like work-related goals are in question, a strong sense of control beliefs will dampen their negative effects on strategy use and leanring attitudes. These hypothetical relationships are consistent with the study of Darnon et al. (2007) in which experimental results indicated that the effects of performance-approach goals were mediated by the level 
of uncertainty manipulated through negative feedback on abilities and conflicting judgement offered by a disagreeing peer.

In short, this present study was among the few studies that have applied achievement goal theory to researching motivation in distance learning. It adds to the literature of distance learning in two important ways. First, this study explored goals in addition to those focusing on mastery and performance concerns. Second, it examined the interaction between motivational beliefs and goals on learning and attitudes. Currently, there is no published research that has investigated the complex interaction between motivational beliefs and goals among distance learners.

Two important research questions in this study were:

1. What are the relative importance of efficacy beliefs, control beliefs and various forms of achievement goals on learning?

2. To what extent the effects of achievement goals are moderated by efficacy beliefs and control beliefs?

\section{Method}

This study used a mailed survey method to collect distance learners' responses to a questionnaire examining their motivational beliefs, goals, strategies and attitudes towards learning of an educational psychology course.

\subsection{Participants}

550 distance learners enrolled in an educational psychology course offered by a distance learning university in Hong Kong were asked to complete a questionnaire. This educational psychology course focused learners on understanding child development and learning. Distance learners were expected to study a set of self-instructed learning units and assigned readings covering importnat topics related to child development and learning. In terms of assessment, learners were required to complete four written essays and sit for an end-ofyear examination. This course provided learenrs with optional bi-weekly tutorials held in different learning centres. Each tutorial group consisted of 25 learners and a tutor. The main focus of the tutorial was to provide learners with a chance to interact with other learners and discuss important issues covered in course materials, readings and assignments.

Together with an invitation letter, the questionnaire was mailed to the distance learners two months after the course started. Distance learners were required to send back the completed questionnaire using a stamped envelope provided within two weeks. 334 learners $(60.73 \%)$ responded and sent back the completed questionnaires.

Distance learners in this sample were comprised of 274 (82\%) female and 46 (13.8\%) male learners. $14(4.2 \%)$ learners did not give any information about their gender. Concerning age, 4 learners (1.2\%) were below 20, 139 learners (41.6\%) in 21-30 age band, $103(30.8 \%)$ in $31-40$ age band, $72(21.6 \%)$ in 41-50 age band, $4(1.2 \%)$ in 51-60 age band, and finally $1(0.3 \%)$ learner was in the age band of 61 or over. 11 (3.3\%) learners did not give any information about their age. The age spans were regrouped into three categories: young adults (30 or below), mature adults (30-40), and older adults (41 and above). A set of ANOVA analyses 
showed that distance learners in these three age groups differed with each other in masterydevelopment goals $\left(\mathrm{F}_{(2,318)}=6.97 ; p<.001\right)$, performance-approach goals $\left(\mathrm{F}_{(2,320)}=5.30 ; p<.005\right)$, and social enhancement goals $\left(\mathrm{F}_{(2,316)}=3.01 ; p<.05\right)$. The age factor was therefore controlled for in the regression analyses.

\subsection{Measure}

This section explains the measures used to assess different major constructs in this study. A questionnaire was designed to assess distance learners' motivatioal beliefs, goals, strategies and learning attitudes. Sample items for each constructs were included in the Appendix. Participants responded to each item on a five-point Likert scale $(1=$ strongly disagree; $5=$ strongly agree). Cronbach's alpha values of these constructs ranged between .65 and .83 .

\subsubsection{Goals}

This study assessed three achievement goals: mastery goals, performance-approach goals and performance-avodiance goals. These items were adapted from previous achievement goal research (Ames \& Archer, 1988; Bouffard, Boisvert, Vezeau, \& Larouche, 1995; Meece et al., 1988; Young, 1997). In addition, three important goals for distance learners were included in the survey: personal development goals, work-related goals and social enhancement goals. Items that assessed these three goals were taken from $\mathrm{Ng}$ (2008). A factor analysis using varimax rotation method was conducted to evaluate the underlying structure of these goals. The result produced 4 distinctive factors with eigenvalues of ranged between 1.32 and 4.39 . In total, these four factors accounted for $53.85 \%$ of total variance. Factor 1 included a combination of items focusing on developing knowledge and promoting personal development. This factor was labelled as mastery-development goals. Factor 2 contained items solely on achieving a high level of performance and was therefore labelled as performance-approach goals. Factor three included mainly items assessing distance learners' concern for career advancement and attaining higher qualification. This factor was labelled as extrinsic work goals. The final factor contained items assessing the intention to meet parental expectation and social norms for high achievement. This factor was therefore labelled as social enhancement goals. Items with loading less than .40 were not included in forming these factors.

\subsubsection{Learning strategies}

Learning strategies in this study included deep and surface strategies. Eight items assessing these contrasting strategies were taken from Biggs' SPQ (1987). Deep strategies focused distance learners on spending time and effort to ensure deep understanding and comprehension. Surface strategies draw distance learners away from learning engagement by expending minimal effort and time on learning.

\subsubsection{Regulatory strategies}

Eight items were adapted from Pintrich's MSLQ (1993) to assess learners' use of selfmonitoring strategies. In addition, this study included several important self-regulatory strategies: time management, effort management, and help-seeking strategies. Each strategy was formed by using corresponding items in Pintrich's MSLQ (1993). 


\subsubsection{Attitude}

Attitudes involved items assessing learners' interest, enjoyment and perceived values of the of doing the course they enrolled. 8 items were taken from $\mathrm{Ng}$ (2008).

\subsubsection{Motivational beliefs}

Motivational beliefs included learners' efficacy and control beliefs. Efficacy beliefs assessed learners' perceived confidence in completing the distance learning course they enrolled. Control beliefs assessed learners' belief of their own abilities in pacing their studies and learning different concepts using appropriate strategies. Items assessing these motivational beliefs were taken from Pintrich's MSLQ (1993).

\section{Results}

Table 1 shows the means and standard deviations for all the variables in this study. Table 2 shows the correlation findings among these variables. Mastery-development goals were positively associated with deep and all forms of self-regulatory strategies. They were also associated positively with learning attitudes, efficacy and control beliefs. As expected, these goals were negatively related to surface strategies. Extrinsic work-related goals were associated with the use of deep and effort management strategies. Also, these goals were

\begin{tabular}{|l|l|l|l|l|l|l|l|l|l|l|l|l|l|l|}
\hline & $\mathrm{M}$ & $\mathrm{SD}$ & 1 & 2 & 3 & 4 & 5 & 6 & 7 & 8 & 9 & 10 & 11 & 12 \\
\hline $\begin{array}{l}\text { 1. Mastery- } \\
\text { development goals }\end{array}$ & 3.83 & .51 & - & & & & & & & & & & & \\
\hline $\begin{array}{l}\text { 2. Extrinsic work } \\
\text { goals }\end{array}$ & 3.82 & .76 & $.18^{*}$ & -- & & & & & & & & & & \\
\hline $\begin{array}{l}\text { 3. Performance- } \\
\text { approach goals }\end{array}$ & 3.32 & .78 & $.11^{*}$ & $.22^{* *}$ & -- & & & & & & & & & \\
\hline $\begin{array}{l}\text { 4. Social } \\
\text { enhancement goals }\end{array}$ & 3.14 & .63 & $.45^{* *}$ & $.21^{* *}$ & $.29^{* *}$ & -- & & & & & & & & \\
\hline $\begin{array}{l}\text { 5. Deep strategies } \\
\text { 6. Surface }\end{array}$ & 3.19 & .53 & $.45^{* *}$ & $.13^{*}$ & $.19^{* *}$ & $.17^{* *}$ & -- & & & & & & & \\
\hline strategies & 2.95 & .70 & $-.19^{* *}$ & n.s. & n.s. & n.s. & $-.28^{* *}$ & -- & & & & & & \\
\hline $\begin{array}{l}\text { 7. Self-monitoring } \\
\text { strategies }\end{array}$ & 3.15 & .48 & $.32^{* *}$ & n.s. & $.24^{*}$ & $.17^{* *}$ & $.63^{* *}$ & $-.24^{* *}$ & -- & & & & & \\
\hline $\begin{array}{l}\text { 8. Time } \\
\text { management }\end{array}$ & 2.89 & .76 & $.19^{* *}$ & n.s. & $.19^{* *}$ & n.s. & $.37^{* *}$ & $-.16^{* *}$ & $.47^{* *}$ & -- & & & & \\
\hline $\begin{array}{l}\text { 9. Effort } \\
\text { management }\end{array}$ & 3.56 & .62 & $.24^{* *}$ & $.12^{*}$ & $.16^{* *}$ & n.s. & $.38^{* *}$ & $-.15^{* *}$ & $.43^{* *}$ & $.37^{* *}$ & - & & & \\
\hline 10. Help seeking & 3.14 & .72 & $.15^{* *}$ & n.s. & $.13^{* *}$ & n.s. & $.39^{* *}$ & $-.21^{* *}$ & $.38^{* *}$ & $.27^{* *}$ & $.28^{* *}$ & -- & & \\
\hline 11. Attitudes & 3.57 & .56 & $.65^{* *}$ & $.21^{*}$ & n.s. & $.24^{* *}$ & $.60^{* *}$ & $-.28^{*}$ & $.41^{* *}$ & $.21^{* *}$ & $.29^{* *}$ & $.21^{* *}$ & -- & \\
\hline 12. Efficacy beliefs & 3.07 & .55 & $.32^{* *}$ & $.16^{* *}$ & $.33^{* *}$ & $.19^{* *}$ & $.42^{* *}$ & $-.20^{* *}$ & $.44^{* *}$ & $.28^{* *}$ & $.30^{* *}$ & $.28^{* *}$ & $.39^{* *}$ & -- \\
\hline 13. Control beliefs & 3.74 & .54 & $.36^{* *}$ & $.20^{* *}$ & $.13^{* *}$ & $.13^{* *}$ & $.42^{* *}$ & $-.17^{* *}$ & $.33^{* *}$ & $.19^{* *}$ & $.32^{* *}$ & $.30^{* *}$ & $.49^{* *}$ & $.51^{* *}$ \\
\hline
\end{tabular}

Note $1:{ }^{*} p<.05 ;{ }^{* *} p<.01$

Table 1. Descriptive statistics, reliability scores and correlation analyses. 
positively related to learning attitudes, efficacy and control beliefs. Performance approach goals were associarted with the use of adaptive strategies including deep, self-monitoring, time management, effort management and help-seeking strategies. Despite that these performance considerations were correlated positively with efficacy and control beliefs, they were not associated with learning attitudes. Finally, the correlation analyses showed that social enhancement goals were associated with self-monitoring strategies only. These goals were positively related to learning attitudes, efficacy and control beliefs. Taken together these analyses showed that there was a close relationship between goals, the use of strategies, learning attitudes and motivational beliefs. Mastery-development goals had the strongest correlation with adpative learning strategies, regulatory strategies and learning attitudes.

Prior research on achievement goals (e.g. Miller et al., 1993; Kaplan \& Midgley, 1997) showed that students' self-efficacy is an important predictor in the use of learning strategie and will moderate the effects of achievement goals on learning. In this study, both efficacy and control beliefs were assumed to moderate the effects of various goals on strategies and attitudes. Both efficacy and control beliefs were included in the regression models to assess their relative predictive ability as compared to different types of goals. Two sets of hierarchically ordered regressions were conducted: 1. Regressing efficacy beliefs, mastery development goals, extrinsic work goals, performance-approach goals and social enhancement goals on learning strategies, self-regulatory strategies and learning attitudes; 2. Regressing control beliefs, mastery-development goals, extrinsic work goals, performance-approach goals and social enhancement goals on learning strategies, self-regulatory strategies and learning attitudes. To control for the effects of age difference, two dummy-coded age variables were entered in the first step, followed by efficacy or control beliefs in step two, the four goals in step three, and the interaction terms were entered in the final step. Following Aiken and West (1991), all the predictor variables were centred and the interaction terms were constructed using these centred variables. Dependent variables were kept in their original metric. The centring procedure reduces multicollinearity among first order variables and the interaction terms. Table 2 shows the standardised coefficients in the regression equations. The predictors including dummy-coded age groups, efficacy or control beliefs, the four goals and goal $x$ belief interaction explained a significant amount of variance (as indicated in $\mathrm{R}^{2}$ ) in the use of learning strategies, self-regulatory strategies, and learning attitudes.

This study expected to find significant interaction terms between efficacy beliefs and the four goals on the use of learning strategies, self-regulatory strategies, and learning attitudes. Contrary to our prediction, the current results did not provide any support to these hypothesised interactions. Regression analyses did not locate any significant interactions.

Table 3 shows the result when control beleifs was taken as a mediator replacing efficacy beliefs. As can be seen, the results showed that this variable moderated the effects of extrinsic work goals and mastery-development goals on learning strategies and attitudes. Following Aiken and Wesr (1991) these significant interactions were interpreted first before examining the main effects. These significant interactions indicated the following:

1. Extrinsic work goals predicated negatively the use of deep strategies and such a relationship was less pronounced when control beliefs were strong;

2. Extrinsic work goals predicted positively the use of surface strategies and this relationship was weakened when control beliefs were strong;

3. Mastery-development goals predicted negatively the use of surface strategies and this relationship was more pronounced when control beliefs were strong; 
The Role of Self-Efficacy, Control Beliefs and

\begin{tabular}{|c|c|c|c|c|c|c|c|}
\hline Predictors & Deep & Surface & \begin{tabular}{|l|} 
Self- \\
monitoring
\end{tabular} & Time & Effort & $\begin{array}{l}\text { Help } \\
\text { seeking }\end{array}$ & Attitudes \\
\hline \multicolumn{8}{|l|}{ Step 1} \\
\hline Age 1 & -.06 & $.13^{*}$ & -.02 & -.14 & -.07 & .06 & $-.16^{*}$ \\
\hline Age 2 & $.20^{*}$ & -.08 & .11 & .09 & .07 & $.15^{*}$ & .07 \\
\hline \multicolumn{8}{|l|}{ Step 2} \\
\hline Age 1 & -.03 & .12 & .02 & -.11 & -.05 & .08 & $-.13^{*}$ \\
\hline Age 2 & $.18^{*}$ & -.07 & .10 & .08 & .06 & $.14^{*}$ & .05 \\
\hline Efficacy beliefs & $.39^{* *}$ & $-.19^{* *}$ & $.43^{* *}$ & $.28^{* *}$ & $.28^{* *}$ & $.27^{* *}$ & $.36^{* *}$ \\
\hline \multicolumn{8}{|l|}{ Step 3} \\
\hline Age 1 & .004 & .07 & .03 & -.12 & -.05 & .08 & -.04 \\
\hline Age 2 & $.16^{\star \star}$ & -.05 & .10 & .08 & .02 & $.13^{*}$ & -.01 \\
\hline Efficacy beliefs & $.26^{* *}$ & $-.17^{* *}$ & $.34^{* *}$ & .21 & $.17^{*}$ & $.22^{*}$ & $.19^{* *}$ \\
\hline \begin{tabular}{|l}
$\begin{array}{l}\text { Mastery-development } \\
\text { goals }\end{array}$ \\
\end{tabular} & $.34^{\star *}$ & $-.23^{* *}$ & $.20^{* *}$ & .11 & $.23^{* *}$ & .09 & $.62^{* *}$ \\
\hline $\begin{array}{l}\begin{array}{l}\text { Performance-approach } \\
\text { goals }\end{array} \\
\end{array}$ & .08 & .000 & $.13^{*}$ & $.15^{* *}$ & $.17^{*}$ & .07 & -.08 \\
\hline Extrinsic work goals & .01 & .08 & $-.11^{*}$ & -.07 & .08 & -.01 & $.13^{*}$ \\
\hline \begin{tabular}{|l|}
$\begin{array}{l}\text { Social enhancement } \\
\text { goals }\end{array}$ \\
\end{tabular} & -.05 & $.16^{*}$ & .01 & -.06 & $-.20^{* *}$ & -.03 & -.09 \\
\hline \multicolumn{8}{|l|}{ Step 4} \\
\hline Age 1 & .002 & .08 & .03 & -.12 & -.06 & .07 & -.04 \\
\hline Age 2 & $.16^{*}$ & -.04 & .11 & .09 & .02 & $.13^{*}$ & -.01 \\
\hline Efficacy beliefs & $.28^{* *}$ & $-.16^{*}$ & $.35^{* *}$ & $.22^{* *}$ & $.17^{*}$ & $.22^{*}$ & $.20^{* *}$ \\
\hline $\begin{array}{l}\text { Mastery-development } \\
\text { goals }\end{array}$ & $.35^{* *}$ & $-.22^{* *}$ & $.20^{* *}$ & .11 & $.23^{* *}$ & .08 & $.63^{* *}$ \\
\hline $\begin{array}{l}\begin{array}{l}\text { Performance-approach } \\
\text { goals }\end{array} \\
\end{array}$ & .07 & .000 & $.13^{*}$ & $.15^{*}$ & $.16^{*}$ & .07 & -.09 \\
\hline Extrinsic work goals & .01 & .07 & $-.11^{*}$ & -.08 & .09 & -.01 & $.14^{*}$ \\
\hline \begin{tabular}{|l}
$\begin{array}{l}\text { Social enhancement } \\
\text { goals }\end{array}$ \\
\end{tabular} & -.07 & $.18^{*}$ & -.01 & -.07 & $-.21^{*}$ & -.05 & -.09 \\
\hline Efficacy $x$ Mastery & .04 & .04 & -.05 & -.003 & .04 & -.02 & .000 \\
\hline Efficacy $x$ Performance & -.09 & -.03 & -.03 & .001 & -.04 & -.02 & -.07 \\
\hline Efficacy x Extrinsic work & .03 & -.10 & -.01 & -.02 & .06 & .05 & .03 \\
\hline $\begin{array}{l}\text { Efficacy } x \text { social } \\
\text { enhancemen }\end{array}$ & .07 & -.04 & .11 & .07 & .04 & .08 & -.03 \\
\hline
\end{tabular}

Note. ${ }^{* *} \mathrm{p}<.0001 ;{ }^{*} \mathrm{p}<.005$

(1) $\mathrm{R}^{2}=.05, \mathrm{p}<.0001$ for Step $1 ; \mathrm{R}^{2} \Delta=.15, \mathrm{p}<.0001$ for Step $2 ; \mathrm{R}^{2} \Delta=.10, \mathrm{p}<.0001$ for Step 3; $\mathrm{R}^{2} \Delta=.01, \mathrm{p}=.29$ for Step 4

(2) $\mathrm{R}^{2}=.04, \mathrm{p}<.005$ for Step $1 ; \mathrm{R}^{2} \Delta=.04, \mathrm{p}<.001$ for Step $2 ; \mathrm{R}^{2} \Delta=.05, \mathrm{p}<.005$ for Step 3; $\mathrm{R}^{2} \Delta=.01, \mathrm{p}=.33$ for Step 4

(3) $\mathrm{R}^{2}=.02, \mathrm{p}=.103$ for Step $1 ; \mathrm{R}^{2} \Delta=.18, \mathrm{p}<.0001$ for Step $2 ; \mathrm{R}^{2} \Delta=.05, \mathrm{p}<.0001$ for Step $3 ; \mathrm{R}^{2} \Delta=.01, \mathrm{p}=.50$ for Step 4

(4) $\mathrm{R}^{2}=.04, \mathrm{p}<.005$ for Step $1 ; \mathrm{R}^{2} \Delta=.08, \mathrm{p}<.0001$ for Step 2; $\mathrm{R}^{2} \Delta=.03, \mathrm{p}=.06$ for Step 3; $2 \Delta=.005, \mathrm{p}=.80$ for Step 4

(5) $\mathrm{R}^{2}=. .02, \mathrm{p}=.10$ for Step $1 ; \mathrm{R}^{2} \Delta=.08, \mathrm{p}<.0001$ for Step 2; $\mathrm{R}^{2} \Delta=.07, \mathrm{p}<.0001$ for Step 3; $\mathrm{R}^{2} \Delta=.01, \mathrm{p}=.53$ for Step 4

(6) $\mathrm{R}^{2}=.02, \mathrm{p}=.08$ for Step $1 ; \mathrm{R}^{2} \Delta=.07, \mathrm{p}<.0001$ for Step $2 ; \mathrm{R}^{2} \Delta=.01, \mathrm{p}=.56$ for Step $3 ; \mathrm{R}^{2} \Delta=.01, \mathrm{p}=.67$ for Step 4

(7) $\mathrm{R}^{2}=.04, \mathrm{p}<.001$ for Step $1 ; \mathrm{R}^{2} \Delta=.13$, $\mathrm{p}<.0001$ for Step $2 ; \mathrm{R}^{2} \Delta=.33$, $\mathrm{p}<.0001$ for Step $3 ; \mathrm{R}^{2} \Delta=.01, \mathrm{p}=.52$ for Step 4

Table 2. Regression analyses 1. 


\begin{tabular}{|l|l|l|l|l|l|l|l|}
\hline Predictors & Deep & Surface & $\begin{array}{l}\text { Self- } \\
\text { monitoring }\end{array}$ & Time & Effort & $\begin{array}{l}\text { Help } \\
\text { seeking }\end{array}$ & Attitudes \\
\hline Step 1 & & & & & & & \\
\hline Age 1 & -.07 & $.14^{*}$ & -.02 & $-.14^{*}$ & -.07 & .05 & $-.16^{*}$ \\
\hline Age 2 & $.19^{*}$ & -.08 & .11 & .09 & .07 & $.14^{*}$ & .07 \\
\hline Step 2 & & & & & & & \\
\hline Age 1 & -.04 & .12 & .01 & -.13 & -.05 & .07 & $-.13^{*}$ \\
\hline Age 2 & $.16^{*}$ & -.06 & .09 & .07 & .04 & .11 & .02 \\
\hline Control beliefs & $.36^{* *}$ & $-.18^{*}$ & $.29^{* *}$ & $.16^{*}$ & $.30^{* *}$ & $.32^{* *}$ & $.43^{* *}$ \\
\hline Step 3 & & & & & & & \\
\hline Age 1 & .02 & .09 & .01 & -.13 & -.05 & .07 & -.05 \\
\hline Age 2 & $.15^{*}$ & -.04 & .10 & .08 & .02 & .12 & -.02 \\
\hline Control beliefs & $.23^{* *}$ & $-.17^{*}$ & $.21^{* *}$ & .11 & $.21^{* *}$ & $.29^{* *}$ & $.24^{* *}$ \\
\hline Mastery-development goals & $.33^{* *}$ & $-.23^{* *}$ & $.22^{* *}$ & .13 & $.20^{*}$ & .05 & $.60^{* *}$ \\
\hline $\begin{array}{l}\text { Performance-approach } \\
\text { goals }\end{array}$ & $.14^{*}$ & -.04 & $.22^{* *}$ & $.21^{* *}$ & $.21^{* *}$ & .11 & -.04 \\
\hline Extrinsic work goals & .00 & .09 & $-.11^{*}$ & -.07 & .06 & -.04 & $.11^{*}$ \\
\hline Social enhancement goals & -.03 & $.15^{*}$ & .02 & -.05 & $-.18^{*}$ & -.01 & -.07 \\
\hline Step 4 & & & & & & & \\
\hline Age 1 & -.03 & .10 & .00 & $-.14^{*}$ & -.06 & .06 & -.06 \\
\hline Age 2 & $.13^{*}$ & -.03 & .10 & .08 & .01 & .11 & -.04 \\
\hline Control beliefs & $.20^{* *}$ & -.10 & $.19^{* *}$ & .10 & $.21^{*}$ & $.29^{* *}$ & $.21^{* *}$ \\
\hline Mastery-development goals & $.34^{* *}$ & $-.23^{* *}$ & $.22^{* *}$ & .12 & $.21^{*}$ & .06 & $.61^{* *}$ \\
\hline $\begin{array}{l}\text { Performance-approach } \\
\text { goals }\end{array}$ & $.12^{*}$ & -.03 & $.21^{* *}$ & $.20^{*}$ & $.19^{*}$ & .11 & -.05 \\
\hline Extrinsic work goals & .02 & .07 & -.10 & -.06 & .08 & -.03 & $.13^{*}$ \\
\hline Social enhancement goals & -.04 & $.17^{*}$ & .02 & -.03 & $-.20^{*}$ & -.04 & -.08 \\
\hline Control x Mastery & -.08 & $.17^{*}$ & -.04 & .11 & -.03 & -.09 & -.09 \\
\hline Control x Performance & .00 & -.04 & .02 & -.03 & .07 & -.03 & -.06 \\
\hline Control x Extrinsic work & $.15^{*}$ & $-.17^{*}$ & .08 & -.002 & -.06 & .05 & .08 \\
\hline $\begin{array}{l}\text { Control x social } \\
\text { enhancement }\end{array}$ & -.02 & .001 & -.01 & -.09 & .05 & .07 & -.02 \\
\hline Note**p<.0001;*p 005 & & & & & & & \\
\hline
\end{tabular}

Note. ${ }^{* *} \mathrm{p}<.0001 ;{ }^{*} \mathrm{p}<.005$

(1) $\mathrm{R} 2=.06, \mathrm{p}<.0001$ for Step $1 ; \mathrm{R} 2 \Delta=.13, \mathrm{p}<.0001$ for Step 2; R2 $\Delta=.11, \mathrm{p}<.0001$ for Step 3; R2 $\Delta=.02, \mathrm{p}<.05$ for Step 4

(2) $\mathrm{R} 2=.04, \mathrm{p}<.005$ for Step 1; R2 $\Delta=.03, \mathrm{p}<.005$ for Step 2; R2 $\Delta=.05, \mathrm{p}<.005$ for Step 3; R2 $\Delta=.04, \mathrm{p}<.005$ for Step 4

(3) $\mathrm{R} 2=.02, \mathrm{p}=.10$ for Step 1 ; R2 $\Delta=.08, \mathrm{p}<.0001$ for Step 2; R2 $\Delta=.10, \mathrm{p}<.0001$ for Step 3; R2 $\Delta=.01, \mathrm{p}=.63$ for Step 4

(4) $\mathrm{R} 2=.04, \mathrm{p}<.005$ for Step $1 ; \mathrm{R} 2 \Delta=.03, \mathrm{p}<.005$ for Step 2; $\mathrm{R} 2 \Delta=.05, \mathrm{p}<.005$ for Step 3; $\mathrm{R} 2 \Delta=.02, \mathrm{p}=.29$ for Step 4

(5) $\mathrm{R} 2=.01, \mathrm{p}=.11$ for Step 1; R2 $\Delta=.09, \mathrm{p}<.0001$ for Step 2; R2 $\Delta=.07, \mathrm{p}<.0001$ for Step 3; R2 $\Delta=.01$, $\mathrm{p}=.58$ for Step 4

(6) $\mathrm{R} 2=.02, \mathrm{p}=.10$ for Step 1; R2 $\Delta=.10, \mathrm{p}<.0001$ for Step 2; $\mathrm{R} 2 \Delta=.01, \mathrm{p}=.37$ for Step 3; R2 $\Delta=.01$, $\mathrm{p}=.53$ for Step 4

(7) $\mathrm{R} 2=.04, \mathrm{p}<.005$ for Step 1; R2 $\Delta=.18, \mathrm{p}<.0001$ for Step 2; R2 $\Delta=.29, \mathrm{p}<.0001$ for Step 3; R2 $\Delta=.02, \mathrm{p}<.05$ for Step 4

Table 3. Regression analyses 2.

Now, let us examine the main effects shown in Table 2 and 3. In the case of efficacy beliefs, the analyses below focused on the regression model resulted from Step 3 because there was 
no significant interaction effects between efficacy and goals. As for control beliefs, the analyses focused on the regression model in Step 4 in which several cases of significant interactions between control beliefs and goals were located.

These two regression models showed that efficacy and control beliefs were important predictors of learning strategies, regulatory strartegies and learning attitudes. In particular, learners' efficacy beliefs predicted positively the use of deep strategies $(\beta=.26, p<.001)$, selfmonitoring strategies $(\beta=.34, p<.001)$, time management strategies $(\beta=.21, p<.001)$, effort management strategies $(\beta=.17, p<.001)$, help-seeking strategies $(\beta=.22, p<.001)$, and finally a favourable learning attitude $(\beta=.19, p<.001)$. Learners' efficacy beliefs predicted negatively the use of surface strategies $(\beta=-.17, p<.001)$. A similar pattern of predicted relationships was found between control beliefs and learners' learning and attitudes. In particular, learners' control beliefs predicted positively the use of deep strategies $(\beta=.20, p<.001$, Step 4$)$, regulatory strategies $(\beta=.21, p<.001)$, effort management strategies $(\beta=.21, p<.001)$, helpseeking strategies $(\beta=.28, p<.001)$, and finally, a favourable learning attitude $(\beta=.24, p<.001)$. In short, these findings confirmed that efficacy and control beliefs were significant cognitive factors in the learning process for distance learners.

Another major aim of the current study was to explore the relative importance of various goals on learning among distance learners. The relative importance of these goals in predicting the use of learning, self-regulatory strategies and learners' attitudes towards learning was analysed based on the main effects while taking into consideration the effects of efficacy and control beliefs in the regression equations. After controlling for the level of efficacy and control beliefs, mastery-development goals were the most important variable predicting the levels of deep strategies $(\beta=.38, p<.001$ controlling for efficacy levels; $\beta=.34$, $p<.001$ controlling for control beliefs), effort management strategies $(\beta=.25, p<.001$ after controlling for efficacy beliefs; $\beta=.21, p<.001$ controlling for control beliefs) and learning attitudes ( $\beta=.61, p<.001$ controlling for both efficacy and control beliefs). In addition, mastery-development goals predicted positively the use of self-monitoring strategies $(\beta=.21$, $p<.001$ controlling for efficacy beliefs; $\beta=.22, p<.001$ controlling for control beliefs). As expected these adaptive goals predicted negatively the use of surface strategies $(\beta=-.23$, $p<.001$ controlling for both efficacy and control beliefs).

Performance-approach goals predicted positively the use of self-monitoring strategies $(\beta=.13$, $p<.001$ controlling for efficacy beliefs; $\beta=.21, p<.001$ controlling for control beliefs), time management strategies $(\beta=.15, p<.001$ controlling for efficacy beliefs; $\beta=.20, p<.001$ controlling for control beliefs), and effort management strategies $(\beta=.16, p<.001$ controlling for efficacy beliefs; $\beta=.19, \quad p<.001$ controlling for control beliefs). These results suggest that distance learners focusing on outperforming others will learn in an organised and regulated manner.

Extrinsic work goals did not predict the use of learning and self-regulatory strategies. These work goals however predicted positively learning attitudes $(\beta=.13, p<.001$ controlling for both efficacy and control beliefs). This result confirmed the extrinsic nature of these goals to learning. Distance learners holding these goals focused more on the product of learning in relation to their career concerns.

Finally social enhancement goals predicted positively the use of surface strategies $(\beta=.16$, $p<.001$ controlling for efficacy beliefs; $\beta=.17, p<.001$ controlling for control beliefs) but 
negatively the use of effort management strategies $(\beta=-.20, p<.001$ controlling for both efficacy and control beliefs). These results suggest that these social goals will lead distance learners to reduce their effort in learning by using surface strategies. Unexpectedly, these social goals did not show to have positive effects on learning attitudes.

Taken together, regression analyses found that mastery-development goals were the most significant variable predicting an adaptive pattern of strategy use and learning attitudes. As expected, performance-approach goals were associated with an adaptive pattern of strategy use. Also as expected, extrinsic work goals did not predict significantly the use of learning and self-regulatory strategies. As for social enhancement goals, the current results showed clearly that these goals were maladaptive to learning. Overall, these results confirmed the relative importance of adaptive goals such as mastery-development goals and performanceapproach goals on learning and attitudes among distance learners.

\section{Discussion}

This study set out to examine the role of various goals and motivational beliefs on learning among distance learners. It adds to the distance learning literature by examining different goals that distance learners hold and the complex interaction relationship between motivational beliefs and goals.

As expected, both efficacy and control beliefs were significant in predicting the use of learning and regulatory strategies, except for time management strategies. These results indicate that for this group of distance learners a strong sense of efficacy and control beliefs was associated with an engagement pattern that was characterised by adaptive strategy use. These two motivational beliefs also predicted distance learners' attitudes towards learning indicating that a stronger sense of efficacy and control beliefs was associated with learning enjoyment, interest and valuing of learning. To be motivated, distance learners need to feel efficacious and certain about their learning progress.

Another major aim of this study is to examine the moderation effects of efficacy and control beliefs on the impact of goals on strategy use and attitudes towards learning. This study found nonsignificant interaction effect between self-efficacy and various goals included in this investigation. In other words, a strong sense of efficacy beliefs would not enhance the positive effects of adaptive goals such as mastery and performance-approach goals. Neither would a strong sense of efficacy beliefs dampen the negative effects of less adaptive goals such as extrinsic work goals and social enhancement goals.

It should be pointed out that contrary to Dweck's experimental study (Dweck, 1986; Elliot \& Dweck, 1988), the current study examined distance learners' perceptions of learning at a rather general level. Dweck's study found significant interaction between self-efficacy and performance-approach goals on learning by requiring students in an experimental setting to complete clearly-defined academic tasks. Subsequent studies (e.g. Harackiewicz et al., 2000; Kaplan \& Midgley, 1997; Miller et al., 1993) using correlational design examining the moderation hypotheses at a rather general level did not found significant interaction between self-efficacy and performance goals on learning and achievement. The current nonsignificant results aligned with these correlational studies.

While the level of task specificity may be taken as an explanation for contradictory results between Dweck's study and the current study, a more critical factor may have been the 
salience of performance emphasis. Elliot and Dweck (1988) have created a high level of performance salience focusing participants to their perceived abilities to complete a specific experimental task. In this type of highly controlled setting, one's performance concerns and the demand of performance demonstration are heightened. Students' perceived level of efficacy will therefore be a crucial factor in moderating their performance goals on learning and achievement. Similarly, Church, Elliot \& Gable (2001) and Braten and colleagues (2004) based on empirical evidence argued that the mediation role of self-efficacy with goals on learning will be more salient in a highly competitive and evaluative learning environment that focuses on relative performance. The participants and their learning context in the current study were radically different from these previous studies that used on-campus undergraduate students learning in a competitive environment or completing experimental tasks according to a set explicit performance criteria. Rather, the distance learning environment in this study promoted a mastery-focused orientation. Distance learners in this study engaged in their courses through distance learning mode in which face-to-face contact with other learners were limited to optional fortnightly tutorials. Distance learners are expected to complete the assigned readings and learning materials on their own, taking into consideration a suggested time-schedule for monitoring the progress themselves. In other words, the chance for distance learners to compete with each other was limited. Therefore, it can be argued that a lack of emphasis on relative performance might have led to the nonsignificant mediation effect of efficacy beliefs with goals, especially performanceapproach goals, on strategy use and learning attitudes.

Not only did the distance learning environment promoted mastery, the current sample of distance learners also held strong mastery goals $(\bar{X}=3.82)$. A mastery-focused learning system coupled with mastery-focused personal motivation would probably allow learners in this study to engage in adaptive patterns of strategy use and attitudinal development regardless of their level of efficacy beliefs (Dweck, 1986; Kaplan \& Midgley, 1997). Kaplan and Midgley (1997, p.431) when concluding their study examining the moderation hypotheses stated that "in an environment in which learning goals were emphasised more, level of perceived competence might become less influential for students with a predominant learning goal orientation". In other words, mastery goals and mastery learning environment have predisposed distance learners to an adaptive pattern of strategy use and learning attitudes regardless their level of efficacy beliefs.

In contrast, the present study found several counts of significant interaction results between control beliefs, extrinsic work goals, and mastery goals. These significant results, though limited, confirmed the hypotheses set for the interaction between control beliefs and goals. These significant mediation effects indicate clearly that control beliefs will enhance the positive effects of adaptive goals such as mastery-development goals and dampen the negative effect of less adaptive goals, in this case, extrinsic work goals. These results suggest that control beliefs are critically important for distance learners. Within a distance learning system, distance learners are free to determine as to when they learn, how they learn and for what reasons they learn. A strong sense of control for distance learners means that they will be able to regulate their learning pace, determine the appropriate use of learning and regulatory strategies and adopt different goals for learning. This study showed that a strong sense of control beliefs enabled learners to use fewer surface strategies and more deep strategies even when holding extrinsic work goals that draw them away from engaging in the learning process. As for the case of mastery-development goals, a strong sense of control 
beliefs simply enhanced the positive effects of these adaptive goals and led the learners to use fewer surface strategies.

Previous studies have examined the moderation effects using middle school students and young adolescents (e.g. Harackiewicz et al., 2000; Kaplan \& Midgley, 1997; Miller, Behrens, Greene \& Newman, 1993). The current study provided empirical evidence on the moderation hypotheses among mature distance learners, which certainly added to our limited knowledge on the role of mediators on the effect of goals on learning. The present results focused us on the critical role of different moderators in distance learning. While the current study failed to find significant interaction between efficacy beliefs and goals on learning, the discussion above has highlighted the mastery-oriented nature of distance learning as an important factor that needs to be considered in examining the interaction effects. Certainly more research is needed to tease out the moderation effects of efficacy beliefs with goals among distance learners. In particular, our knowledge on extrinsic work goals and social enhancement goals are still rather limited. More research is required to understand how these goals operate in the learning process among distance learners.

The significant moderation effects of control beliefs reminded us the importance of considering additional mediators salient in a specific learning context. An experimental study conducted by Darnon and colleagues (2007) provided relevant empirical evidence showing that different forms of uncertainty created through negative feedback on performance or conflicting evaluation moderated the effects of performance-approach goals on learning. Within a distance learning system, tutor's disconfirming feedback on assessment may pose a significant threat to control beliefs (cf. $\mathrm{Ng}, 2009$ ) and heighten a certain level of uncertainty. In addition, future research should extend the current investigation to cover different type of dependent measures and examine the moderation hypotheses within different level of task specificity. Two important dependent measures are distance learners' persistence and achievement levels. Will strong efficacy or control beliefs act as a buffer against the negative impact of less adaptive goals such as extrinsic work goals on persistence and achievement? In addition, the current study focused on learners' motivation and learning at the course level without referring to specific academic tasks. Future studies should consider the moderation hypotheses using more specific academic tasks such as sitting for an end-of-course examination that highlights performance demonstration and the critical importance of efficacy and control beliefs.

With regard to the predictive importance of goals, the regression models consistent with past achievement goal research showing that mastery-development goals, and to a lesser extent performance-approach goals, were associated with adaptive patterns of strategy use and learning attitudes. These results were achieved after controlling for the effects of both efficacy and control beliefs. The significance of mastery-development goals was demonstrated in the associated engaged pattern characterising by adaptive use of strategies. The use of regulatory strategies, and more specifically, effort management strategies indicate that distance learners focusing on mastery and development goals will be more likely to persist and continue investing effort on learning despite obstacles and problems. Performance-approach goals in this study were also positively related to these strategies. In addition these goals focused learners on time management and organisation. Extrinsic work goals did not predict any of the strategies. The interaction results indicated that extrinsic work goals were probably associated with a maladaptive pattern of strategy use, which to a 
certain extent, would be moderated by control beliefs. However these goals were not utterly detrimental to learning. Distance learners' career concerns were associated with a positive attitude towards learning. In other words, while a concern for career advancement will not associate learners with effective use of strategies, such a concern helps learners develop a positive attitude towards learning. Finally, social enhancement goals were found to have negative impact on learning as these goals were associated with surface strategies and the decrease in effort management. These associations seem to go against the Chinese collectivistic culture that places motivational significance on meeting social norms and fulfilling parental expectation on academic achievement. While it is not clear whether these social concerns would have positive impact on learners' achievement in this study, the present results indicate that a focus on enhancing social status and meeting social expectation will draw learners away from meaningful engagement and persistence.

Barron and Harackiewicz (2001) in a seminal paper argued that different achievement goals will have independent effects on learning and achievement, which can be assessed using the main effects of predictors in regression analyses. The current results clearly indicate that different goals had significant independent effects on learning and attitudes. Overall, the current findings suggest that goals that focus distance learners on the learning process are associated with adaptive use of strategies. In contrast, goals that draw distance learners away from the learning process and focus on the learning product do not predict the use of learning and regulatory strategies. Pintrich (2000) when discussing the nature of multiple goals argued that different goals will lead to different learning pathways and hence resulting in different learning experiences. The current results clearly support this notion of "multiple-goals, multiple-pathways". Distance learners focusing on mastery-development goals will certainly engage in and experience distance learning differently compared to those focusing on various career considerations ( $\mathrm{Ng}$, 2008).

Barron and Harackiewicz (2001) also proposed that different goals may interact with each other. An additional regression analysis was conducted examining the interaction effects between different goals in this study. The result was nonsignificant, indicating that these goals did not interact with each other. In other words, a high level of performanceapproach goals would not enhance the positive effects of mastery-development goals. However, $\mathrm{Ng}$ (2008) using a clustering procedure found that distance learners are capable of endorsing a multitude of goals simultaneously. Future studies should continue to explore the potential interaction effects between goals on learning and engagement among distance learners.

\section{Conclusion}

This paper looked into the significant role of motivation in distance learning using an achievement goal framework. The results showed that conceptualising distance learners' motivation as motivational beliefs and goals adds to our understanding of distance learners' motivational and learning characteristics. Of course, the correlation nature of the current study does not allow for the analysis of causal ordering between beliefs, goals, strategies and attitudes. The culturally-specific and female-dominated sample prevents generalisation of the current findings. Further research should examine the relationship of these important variables using longitudinal design and include distance learners from other cultural contexts. The lack of achievement data was another major limitation in the current study. 
Future studies need to examine the effects of these important motivational variables on distance learners' achievement level. In particular, it will be interesting to examine if extrinsic work goals will be associated with a high level of achievement.

Understanding distance learners' motivation will have practical implications for designing an engaging learning environment to support distance learners. In particular, the current findings suggest that building a distance learning system that promotes a mastery focus, encourage high performance, addresses personal development needs, and reinforces efficacy and control beliefs are fundamental to motivating distance learners to learn.

Ames (1992) have discussed various classroom dimensions that promote mastery and engagement, such as the nature of task, authority, evaluation, and recognition. Using this perspective, distance educators can engage in a self-reflective process and ask critical questions, such as: Will distance learners find the learning units, activities and assigned readings interesting, challenging and helpful in developing their self-efficacy? Have the course and assessment items designed in such a way that distance learners are given abundant opportunities to develop independence, autonomy and choice? Is the learner support system effective in assisting learners to regulate their learning and progress? Are timely feedback on their progress and performance in the course provided to distance learners?

These are important questions for distance educators who intend to create a motivating and engaging distance learning environment. Certainly, more research is required to look into the nature of distance learners' motivation in order to inform distance educators to make evidence-informed decisions on these critical questions. The current study has contributed to this effort by researching distance learners' motivation using an achievement goal perspective.

\section{Appendix}

Mastery-development goals (5 items; Cronbach Alpha value=.75)

- I do in this course because I want to learn something new.

- I found a sense of personal satisfaction in doing this course.

Performance-approach goals (2 items; Cronbach Alpha value=.65)

- In this course, I would like to show that I am more capable than other students.

- I want to get a good result in this course.

Extrinsic work goals (3 items; Cronbach Alpha value=.77)

- I take this course because it helps my career advancement.

- I take this course because I want to gain the related professional qualification.

Social enhancement goals (4 items; Cronbach Alpha value=.66)

- $\quad$ Acquiring the knowledge in this course will enable me to help others and contribute to the society.

- I believe that my parents will be honoured when I do this course and its associated degree programme. 
Deep strategies (4 items; Cronbach Alpha value=.70)

- While studying this course, I think of real life situations to which the materials that I am learning would be useful.

- In reading new materials, I find that I'm continually reminded of the materials I'd already viewed before I am satisfied.

Surface strategies (2 items; Cronbach Alpha value=.66)

- I think browsing around is a waste of time, so I only study what's given out in tutorials or in the course outlines.

- I learn the materials in this course mainly by rote, going over and over them until I know them by heart.

Self-monitoring strategies (8 items; Cronbach Alpha value=.77)

- When I am confused, I'll read the relevant topics again.

- When I find it difficult to understand some of the topics, I'll change my usual study pattern and re-read the materials again.

Time Management (2 items; Cronbach Alpha value=.68)

- I make good use of the study time for this course.

- I find it hard to stick to a study schedule.

Effort Management (2 items; Cronbach Alpha value=.61)

- Even when the study materials are dull and uninteresting, I manage to keep working until I finish.

- I work hard to do well in this course even if I don't like what we are doing.

Help seeking (2 items; Cronbach Alpha value=.76)

- When I don't understand the materials in this course, I ask my tutor or others for help.

- I try to identify students in my group whom I can ask for help if necessary.

Learning attitudes (7 items; Cronbach Alpha value=.83)

- I think the materials in this course are relevant to my job.

- The content of this course promotes personal development and is relevant to my daily lives.

- I found this course very interesting and enjoyed the time spent on it.

Efficacy Beliefs (3 items; Cronbach Alpha value=.72)

- I believe I will receive an excellent grade in this class.

- I'm certain I can understand the most difficult concepts and theories presented in the course.

Control beliefs (3 items; Cronbach Alpha value=.65)

- If I study in appropriate ways, then I will be able to learn the materials in this course.

- If I try hard enough I will understand the course materials. 


\section{References}

Aiken, L. S., \& West, S. G. (1991). Multiple regression: Testing and interpreting interactions, Sage Publications, ISBN 0803936052, Newbury Park, C.A.

Ames, C. (1992). Achievement goals and the classroom motivational climate. In: Student perceptions in classroom, D. H. Schunk \& J. L. Meece (Eds.), pp. (327-348), Lawrence Erlbaum, ISBN 978-0-8058-0982-4, Hillsdale, NJ.

Ames, C., \& Archer, J. (1988). Achievement goals in the classroom: Students' learning strategies and motivational processes. Journal of Educational Psychology, Vol.80, No.3, pp. 260-267, ISSN 0022-0663

Barron, K. E. \& Harackiewicz, J. M. (2001) Achievement goals and optimal motivation: testing multiple goal models, Journal of Educational Psychology, Vol.80, No.5, pp. 706-722, ISSN 0022-0663

Biggs, J. (1987). Student approaches to learning and studying, Australian Council for Educational Research, ISBN 0855634162, Melbourne.

Bouffard, T., Vezeau, C., \& Bordeleau, L. (1998). A developmental study of relation between combined learning and performance goals and students' self-regulated learning. British Journal of Educational Psychology, Vol.68, No.3, (Sept 1998), pp.309-319, ISSN 0007-0998

Braten, I., Samuelstuen, M. S., \& Stromso, H. I. (2004). Do students' self-efficacy beliefs moderate the effects of performance goals on self-regulatory strategy use? Educational Psychology, Vol.24, No.2, (April 2004), pp.231-247, ISSN 0144-3410

Cannon, M. M., Umble, K. E., Stechler, A., \& Shay, S. (2001). "We're living what we're learning": Student perspectives in distance learning degree and certificate programs in public health. Journal of Public Management Practice, Vol.7, No.1, pp. 4959, ISSN 1078-4659

Cochrane, C. (2000). The reflections of a distance learner 1977-1997. Open Learning, Vol.15, No. 1, pp. 17-34, ISSN 0268-0513

Darnon, C., Harackiewicz, J. M., Butera, F., Mugny, G., \& Quamzade, A. (2007). Performanceapproach and performance-avoidance goals: When uncertainty makes a difference. Personality and Social Psychology Bulletin, Vol.33, No.6, pp. 813-827, ISSN 0146-1672

Dearnley, C., \& Matthew, B. (2000). A group of nurses experience open learning: Exploring the impact. Open Learning, Vol.15, No.2, pp. 191-206, ISSN 0268-0513

Dweck, C. S. (1986). Motivational processes affecting learning. American Psychologist, Vol.41, No.10, pp. 1040-1048, ISSN 0003-066X

Elliot, A. J. (1997) Integrating the 'classic' and 'contemporary' approaches to achievement motivation: a hierarchical model of approach and avoidance achievement motivation, In: Advances in motivation and achievement, Vol. 10, M. L. Maehr \& P. R. Pintrich (Eds), ISBN, (Greenwich, JAI Press Inc).

Elliott, E. S., \& Dweck, C. S. (1988). Goals: An approach to motivation and achievement. Journal of Personality and Social Psychology, Vol.54, No.1, (Jan 1988), pp. 5-12, ISSN 0022-3514

Elliot, A., \& Harackiewicz, J. (1996). Approach and avoidance achievement goals and intrinsic motivation: A mediational analysis. Journal of Personality and Social Psychology, Vol.70, No.3, (March 1996), pp. 968-980, ISSN 0022-3514

Eppler, m. A. \& Harju, B. L. (1997) Achievement motivation goals in relation to academic performance in traditional and non-traditional college students, Research in Higher Education, Vol.38, No.5, pp. 557-573, ISSN 0361-0365 
Greene, B. A., \& Miller, R. B. (1996). Influences on achievement: Goals, perceived ability, and cognitive engagement. Contemporary Educational Psychology, Vol.21, No.2, (April 1996), pp. 181-192, ISSN 0361-476X

Grant, H., \& Dweck, C. S. (2003). Clarifying achievement goals and their impact. Journal of Personality and Social Psychology, Vol. 85, No.3, (Sept 2003), pp.541-553, ISSN 00223514

Harackiewicz, J. M., Barron, K. E. \& Elliot, A. J. (1998) Rethinking achievement goals: When are they adaptive for college students and why? Educational Psychologist, Vol.33, No.1, pp. 1-21, ISSN 0046-1520

Harackiewicz, J. M., Barron, K. E., Tauer, J. M., Carter, S. M., \& Elliot, A. J. (2000). Short-term and long-term consequences of achievement goals: Predicting interest and performance over time. Journal of Educational Psychology, Vol.92, No.2, (June 2000), pp.316-330, ISSN 0022-0663

Hurd, S. (2006). Towards a better understanding of the dynamic role of the distance language learner: learner perceptions of personality, motivation, roles, and approaches. Distance Education, Vol.27, No.3, pp. 303-329, ISSN 0158-7919

Kaplan, A., \& Midgley, C. (1997). The effect of achievement goals: Does level of perceived academic competence make a difference? Contemporary Educational Psychology, Vol. 22, No.4 (Oct 1997), pp. 415-435, ISSN 0361-476X

Lyall, R., \& McNamara, S. (2000). Influences on the orientations to learning of distance education students in Australia. Open Learning, Vol.15, No.2, pp. 107-121, ISSN 0268-0513

Meece, J. L., Blumenfeld, P. C., \& Hoyle, R. H. (1988). Students' goal orientations and cognitive engagement in classroom activities. Journal of Educational Psychology, Vol.80, No.4, (Dec 1988), pp. 514-523, ISSN 0022-0663

Miller, C., \& Smith, C. (1998). Professional development by distance education: Does distance lend enhancement? Cambridge Journal of Education, Vol.28, No.2, (June 1998), pp. 221-230, ISSN 0305764X

Miller, R. B., Behrens, J. T., Greene, B. A., \& Newman, D. (1993). Goals and perceived ability: Impact on student valuing, self-regulation, and persistence. Contemporary Educational Psychology, Vol.18, No.1 (Jan 1993), pp. 2-14, ISSN 0361-476X

Morgan, A. R., Taylor, E., \& Gibbs, G. (1982). Variations in students' approaches to studying. British Journal of Educational Technology, Vo.13, No.2, (May 1982), pp.107-113, ISSN 0007-1013

$\mathrm{Ng}$, C. H. (2006). The role of achievement goals in the completion of a course assignment: Examining the effects of performance-approach goals and combined goals. Open Learning, Vol.21, No.1, pp. 33-48, ISSN 0268-0513

$\mathrm{Ng}$, C. H. (2008). Multiple goals learners and their differential patterns of learning. Educational Psychology, Vol.28, No.4, pp. 439-456, ISSN 0144-3410

$\mathrm{Ng}$, C. H. (2009). Profiling learners' achievement goals in completing academic essays. Educational Psychology, Vol.29, No.3, pp. 279-296, ISSN 0144-3410

Nolen, S. B. (1988). Reasons for studying: Motivational orientations and study strategies. Cognition and Instruction, Vol.5, No.4, pp. 269-287, ISSN 0737-0008

Pintrich, P. R. (1989). The dynamic interplay of student motivation and cognition in the college classroom, In: Advances in motivation and achievement, Vol.6, M. L. Maehr \& P. R. Pintrich (Eds.), pp. (117-160), JAI Press, ISSN 0749-7423, Greenwich CT. 
Pintrich, P. R. (2000). Multiple goals, multiple pathways: The role of goal orientation in learning and achievement. Journal of Educational Psychology, Vol.92, No.3, (Sept 2000), pp. 544-555, ISSN 0022-0663

Pintrich, P. R., \& De Groot, V. (1990). Motivational and self-regulated learning components of classroom academic performance. Journal of Educational Psychology, Vol.82, No.1, (March 1990), pp. 33-40, ISSN 0022-0663

Pintrich, P. R., \& Garcia, T. (1991). Student goal orientation and self-regulation in the college classroom, In: Advances in motivation and achievement Vol. 7, M. L. Maehr \& P. R. Pintrich (Eds.), pp. (371-402), ISSN 0749-7423, JAI Press, Greenwich CT.

Pintrich, P. R., Smith, D. A. F., \& Garcia, T. (1993). Reliability and predictive validity of the motivated strategies for learning questionnaire (MSLQ). Educational and Psychological Measurement, Vol.53, No.3, (autumn 1993), pp. 801-813, ISSN 0013-1644

Richardson, J. T. E. (2007). Motives, attitudes and approaches to studying in distance education. Higher Education, Vol.54, No.3, pp. 385-416, ISSN 0018-1560

Roblyer, M. D. (2000). Is choice important in distance learning? A study of student motives for taking internet-based courses at the high school and community college levels. Journal of Research on Computing in Education, Vol.32, No.1 (Fall 1999), pp. 157-171, ISSN 0888-6504

Rovai, A. F. (2003). In search of higher persistence rates in distance education online programs. Internet and Higher Education, Vol.6, No.1, (Jan 2003), pp. 1-16, ISSN 10967516

Salili, F. (1997). Explaining Chinese students' motivation and achievement: A sociocultural analysis. In: Advances in motivation and achievement, Vol. 9, M. L. Maehr \& P. R. Pintrich (Eds.), pp. (73-118), ISSN 0749-7423, JAI Press, Greenwich, CT.

Sankaran, S. R., \& Bui, T. (2001). Impact of learning strategies and motivation on performance: A study in web-based instruction. Journal of Instructional Psychology, Vol.28, No.3, (Sept 2001), 191-198, ISSN 0094-1956

Simpson, O. (2008). Motivating learners in open and distance learning: do we need a new theory of learner support? Open Learning, Vol.23, No.3, pp. 159-170, ISSN 0268-0513

Skaalvik, E. (1997). Self-enhancing and self-defeating ego orientation: Relations with task avoidance orientation, achievement, self-perceptions, and anxiety. Journal of Educational Psychology, Vol.89, No.1, (March 1997), pp. 71-81, ISSN 0022-0663

Suárez Riveiro, J. M., Cabanach, R. G., \& Valle Arias, A. (2001). Multiple-goal pursuit and its relation to cognitive, self-regulatory, and motivational strategies. British Journal of Educational Psychology, Vol.71, No.4, (Dec 2001), pp. 561-572, ISSN 0007-0998

Valle, A., Cabanach, R. G., Núñez, J. C., González-Pienda, J., Rodríguez, S., \& Piñeiro, I. (2003). Multiple goals, motivation and academic learning. British Journal of Educational Psychology, Vol.73, No.1, (March 2003), pp. 71-87, ISSN 0007-0998

von Prummer, C. (1990). Study motivation of distance students: A report on some results from a survey done at the FernUniverstat in 1987/88. Research in Distance Education, Vol.2, No.2, pp. 2-6,

Wilson, V., \& Bagley, L. (1999). Learning at a distance: The case of the community pharmacist. International Journal of Lifelong Education, Vol.18, No.5, (Sept-Oct 1999), pp. 355-369, ISSN 0260-1370

Young, A. J. (1997). I think, therefore I'm motivated: The relations among cognitive strategy use, motivational orientation and classroom perceptions over time. Learning and Individual Differences, Vol.9, No.3, pp. 249-283, ISSN 1041-6080 


\title{
Differences and Similarities in Approach Between Classroom and Distance Learning
}

\author{
Ingrid Helleve \\ University of Bergen \\ Norway
}

\section{Introduction}

This chapter will focus on differences and similarities between classroom and distance learning. What should count as learning and knowledge when information is available for everybody all the time? What are the consequences of these questions for teachers? These are questions that will be dealt with throughout the chapter. The aim of this Norwegian study is to single out what characterises productive interactions in ICT- (Information and communication technology) supported communities of learners, based on research from three different case studies. The study is based on the assumption that when teachers are designing and guiding learning communities there are some common features across agegroups and learning environments. Common for the three communities is that educational technology is supposed to serve as a space for collaborative writing activities. Across classrooms and distance learning there are some basic differences and similarities that will be discussed and illustrated through three different studies carried out between pupils in a classroom, on-campus students and distance learning students. The first study is carried out in 2nd grade in primary school where the students were supposed to write common texts by means of stand-alone-computers in the class-room. The next study deals with the experiences of 10 campus students in a blended environment. The students met every day, but were also supposed to collaborate online. The third study deals with distance learning. A group of five students called themselves the "magic group." They were student teachers who were supposed to publish portfolios and give feedback to each other. The research methods that are used are observations of the activities in the classroom, interviews and analysis of written texts. The conversation taking place when the pupils were writing common texts by means of the computers were recorded and analysed. The written online material is based on portfolios, feedback processes and online discussions. Further pupils, students and teachers in all three studies are interviewed. The aim of this chapter is to look across the borders of distance- and classroom learning in search of differences and similarities.

\section{Why organized teaching and learning?}

Schools as we have known them for hundreds of years have gathered people for the purpose of learning. Educational institutions are organized social societies. Currently it is relevant to raise the question of how to legitimize organized teaching and learning in a 
society that is surrounded by technology. If the main objective of going to school is to collect information it is reasonable to question if this is still a state of reasons for going to school. People have access to artefacts that can give immediate answers to all kinds of questions. Human beings are connected through social networks and media. Gee (2005) raises the question of why schools in future when students are more computer literate and learn better from the Internet-world than their teachers. Has the traditional school and organized learning situations as we have known them for generations outlived their purpose? According to Säljö (2000) computers represent the most serious challenge to the traditional classroom as we have known it for hundreds of years. The computer as an artefact in the classroom has changed the rules of the game. The traditional communication pattern between teachers and pupils is altered. The teacher is not necessarily the one who knows the correct answer. On the contrary information technology is much more familiar for the young generation than the older ones. The concept communication has two different meanings. The first refers to communicare as transfer or hand over. The second is communico which means to make something a common property (Erstad, 2010). The traditional classroom is characterized by the pattern of communication known as IRE (initiative, response, evaluation), or transfer. The teacher asks a question. The pupils answer and the teachers evaluate the answer. The role of the computer is to hand over information, to give instructions, to ask for correct answers and to care for as much control as possible. Communication understood as making something a common property means that the teacher should contribute to build a learning community. The term community of learners refers to communities where the main purpose is advancement of learning. A community of learners is independent of age. The learners may be any kind of group that is gathered for the purpose of learning; pupils in a classroom, students or visitors in a museum. This means that a community of learners might as well be an online community as a face to face meeting-place. (Brown, 1994; Brown \& Campione, 1994; Matusov \& Rogoff, 1995; Wubbels 2007; Helleve, 2009b). But what is learning?

\section{Learning understood as productive interactions}

Greeno, Collins and Resnic in their influential chapter on Cognition and Learning in Handbook of Educational Psychology (1996) refer to three traditions when it comes to conceptualisation of knowledge: In a behavioristic/empiristic perspective learning is seen as acquiring and applying associations. In a cognitive/rationalist view learning means to be able to acquire and use conceptual and cognitive structures. Finally the situative/ pragmatist-socio-historic perspective understands learning as a means to become attuned to constraints and affordances through participation. The computer can support all these ways of understanding learning. In the first case the computer is understood as a tutor or an instructor. In the second as a tool for individual knowledge building, and in the third the technology is seen as a mediating artefact for learning. Koschman (1996) uses the concept paradigm to explain the difference in perspectives on learning. The situative/pragmatist perspective claims that collaborative activities, creativity and argumentation are fundamental for learning through participants' sharing and constructing new knowledge. Through collaborative activities students are able to solve problems that are beyond the limits of what they would possibly have managed on their own. Productive interactions are depending on interaction between social aspects and the technology. Educational technology has the possibility for building new spaces inside the physical space. Productive 
interactions are the combination of the students' willingness to collaboration, assignments that open for creativity and argumentation and the technology. There are no correct answers. Opposite one question opens new questions in a creative dialogue. Creativity, reflection and imagination as well as argumentation and reasoning are valued in the understanding of the concept productive interactions (Helleve, 2009b).

\section{Productive interactions in a $2^{\text {nd }}$ grade classroom}

The following is an example of productive interactions illustrated by children in a $2^{\text {nd }}$ grade classroom in primary school (Helleve, 2003). The class in which this research was conducted participated in a national action research project called "Collaborative writing by means of ICT" (Trageton, 2000). An articulated aim for the project was that students were to write collaborative texts supported by educational technology. Altogether 14 Norwegian schools participated in this project. I was curious to know more about collaboration and learning strategies in communities of learners supported by ICT, so I decided to choose one of these classes for my fieldwork. The class consisted of 24 eight year old pupils, and the teacher. There were two computers available. Two pairs of pupils wrote collaborative texts by means of educational technology on each of the days that I made my observations. The other pupils wrote collaborative texts by means of pencil and paper. The fieldwork was conducted within six months. During this period I spent one day, consisting of four lessons, each week together with the pupils and the teacher in the classroom. Each school day started with a meeting. During this meeting which I called the reflection hour, the teacher encouraged the pupils to share some personal experiences either from leisure time or from school. Also at this time she shared the goals for the learning activities she had designed for the day with the pupils. The pupils were asking questions and discussing these plans. The teacher then continued by telling a story to the class. After she had finished the story the pupils were supposed to do some activities in a workshop based on what she had told, or they were going to continue on her story. The pupils in the $2^{\text {nd }}$ grade were observed through two different kinds of collaborative writing activities by means of a computer. The research questions were: What kind of learning strategies do the pupils develop, and what kind of interaction is created between pupils and between pupils and the teacher when the computer is the third collaborator? The first is called experience story, and the second creative story. In the experience story the pupils were asked to give an account and write a report from their collaborative activities in the workshop. The creative story asked the pupils to continue writing the story the teacher had initiated. She suddenly stopped when the story was most exiting and left to the pupils to compose the rest of the story together. The fact that they had a common aim through the text they were supposed to write made it more meaningful to compose this text together than writing alone. Through interviews most of the pupils claimed that they preferred collaborative to individual writing. One of the arguments the pupils had was that they shared a common aim. The pupils also experienced to be more creative and innovative when they wrote together. One of the girls said: "You become more imaginative. You become more like an innovator. It is like having two imaginations".

\subsection{The performance of the assignments}

The results of this study showed that it was possible to divide the children's oral communication into three different categories depending on the performance of the 
exercises (Mercer \& Fischer, 1997; Helleve, 2003). The three categories are called discussional talk, cumulative talk and explorative talk. Discussional talk means that the co-operation between the members breaks down, or that no real communication takes place. Some pupils never managed to compose a story. In cumulative and explorative talk, on the other hand, the group members share a basic confidence and there is a willingness to co-operate. When this willingness to collaborate exists the further division into additional categories depends on the actual performance of the exercises. What were the pupils asked to write about? Cumulative talk means that the participants gained knowledge through accumulating shared knowledge. They described what they had done in the workshop. There was no room for disagreement, creativity or imagination. A statement from one of the members was confirmed by the other. In cumulative talk the dialogue is based on confirmations and repetitions. There is little room for the participants' own opinions, and therefore also limited learning potential. Explorative talk is also based on confidence and positive attitudes between the group members, but in contradiction to cumulative talk, the explorative talk opens for discussions, dialogue and different opinions. When the teacher had started a thrilling story and suddenly stopped she opened for imagination, creativity and disagreement. One example was about a cat which was alone at home. Two pupils continued on the story where the cat fell down from the shelf and into the soup. They wrote a story where the cat managed to enter the room where there was a cake on a shelf close to the ceiling and a bowl of soup on the floor. A question for discussion was if the cat was going to drown in the soup or not. The argumentation or conflict was based on trust and confidence. The pupils used their creativity and imagination. Explorative talk has therefore a greater learning potential, the potential of creating new knowledge. The challenge for the teacher is to perform assignments the students can solve by giving each other this kind of mutual support. Every day the teacher in $2^{\text {nd }}$ grade started with an initial meeting where she shared her aims and plans with the pupils. Furthermore, her concern was how to prepare for learning activities the pupils could write about later. More then ever the teacher has to be able to foresee the consequences and to know his or her pupils' abilities and qualifications. "When the pupils go to the computer my job is done" said the teacher in this $2^{\text {nd }}$ grade. As a researcher I discovered a pattern where the teacher had planned for basic confidence, sharing aims and common experiences. The learning process was characterised by the pupils' willingness to collaboration, assignments that opened for creativity and argumentation and the technology which are basic for productive interactions.

\section{A study of campus students in a blended environment}

Bridget Somekh (2007) raises the question: Why ICT? Are collaborative activities that enhance open dialogues, creativity, reflection and argumentation depending on computers? Educational technology can offer collaborative spaces that are qualitatively different from physical rooms. The example from the primary classroom shows that a text that is composed by two authors is qualitatively different from an individual text written by one person by means of pen and paper. The product of the writing process was a shared honour for both pupils. The final text was always referred to as "our" text. The pupils were proudly showing their product saying: "Look what we have written".

Another example that can answer the question: Why technology? is from teacher education. Data collection is made within the local part of the national teacher education programme; 
PLUTO (Program for teacher education, technology and change) (ITU, 2000- 2003a) INVITIS (2000-2003) (Innovation by means of ICT in education of language teachers) at the University of Bergen in Norway (ITU, 2000-2003b). The students were on campus and did not understand why they had to do all the online activities. Parliamentary Proposition no. 27; (2001-2002) the so-called "Quality reform" (MER, 2001) concerning higher education in general, and the National Law for Teacher Education (MER, 2002) initiated great changes in formative assessment, a closer follow up of the individual student, and learning activities supported by ICT. The aim of the INVITIS project was to develop an alternative model for the education of language teachers. This model was to create a platform for language teachers' abilities to become creative and innovative in the traditional classroom. The different themes in pedagogy like classroom management were dealt with in lectures for the entire group of 80 students, in face-to-face discussions in seminar groups, and in digital portfolios where the students gave feedback to each other. The semester started with an Introduction week for the seminar groups. During the theoretical part of the study the students met face-to-face once or twice a week. The aim was to establish confidence, to become familiar with the main goals of teacher education and the INVITIS- project, and to learn how to use the technology. In order to prepare for the online collaboration, students in the basic groups had to write texts and give feedback to each other face-to-face. Participation in seminar groups as well as on-line activities was compulsory. Based on a procedure decided by the teacher educator, each student gave feedback to two peers on each assignment in the portfolio. Face-to-face as well as on-line discussions took place either between the members of the seminar groups or in the subject- related groups. The research questions of this study was if, and eventually how, the educational technology had been a support for the students' learning process.

The students' motivation for using ICT was low by the beginning of the study. By the end of teacher education however, some of the students saw that there were qualitative differences making ICT and LMS (Learning Management Systems) suitable for productive learning processes not just for distance learning, but also for campus students. The activities they mention are portfolios with feedback from peers and asynchronous discussions. According to the students these activities opened for collaboration and deeper reflection. Through the reflective process the students became more open-minded for other students' ideas and also to get new ideas. Concerning the asynchronous discussions one student said:

"I have become much more positive to the ICT supported activities even though I still think it should be used with intelligence. To share texts and thoughts has been very nice. I used to be very negative. It was impossible for me to understand why we could not sit around a table and discuss. But now I see that a virtual discussion is something quite different from a face to face discussion".

An important reason was that the online discussions and feedback processes opened for a deeper reflection because there was a distance in time and space. The students did not have to respond immediately, but could wait and think before they pressed the button. Other groups of students were favoured than in ordinary rooms. In face-to-face discussions one or two students often dominate the discussion. Online discussions offer time for reflection before the students have to react to the other students' utterances. One student said: 
"It is another kind of process. You get more time for reflection when you participate in the asynchronous discussions. It is something else to write. You have to think more. I often write my answers to the discussion immediately, but I wait a while before I send it. In the meantime I do some housework before I press the button".

The distance in space also meant that they had to form the other person without actually seeing her. This means that the students experienced the computer to have transparent abilities, making it easier to understand the other students' opinions. The utterances were not isolated, but linked together over time like a chain of thoughts, possible to trace backwards. This gave them an opportunity to go deeper into the text, grasping the other student's thoughts and feelings. The fact that they first had to read the other students' texts or statements before responding was an important distinction between face-to-face and online feedback. Reading and writing meant that they had to go deeper into the essence of utterances. Another argument was that what is written into an online context is impossible to erase. The text leaves the writer and becomes the group's property. One student says: "You stress your words more because you know they will be standing there for ever". Because the students knew each other well, online collaboration seemed to contribute to an extra dimension in their understanding. In pedagogy the starting point for the virtual discussions was a topic related to pedagogical theory and practice initiated by the teacher educator. This could either be an open question, or an article everybody had to read. One student mentioned the question "What is learning in your opinion"? as an example of a suitable discussion topic. She argued that there was no correct answer to this question, but still everybody had their own theories and opinions. Another fact mentioned by one of the students, was that everybody had to participate in the online discussions. In face-to-face discussions one or two students often dominate. Gradually, the students realized that the closed space or room in the LMS became a sort of "treasure chest". All the texts and feedback from others were stored within the computer. But, as one of the students said, this was something she had to experience when she was compiling her own presentation portfolio. She concluded:

"It is very nice to have this archive there. It is there inside like a property chest. You can enter the "room" whenever you want and the archive expands all the time. Perhaps the teacher educators told us when we started as student teachers, but I did not understand it. We thought it was silly, but gradually we understood that we could find something there".

Summing up, some students saw that asynchronous text based activities had a potential for productive learning supporting face-to-face collaboration. Discussions and feedback from peers opened for reflective processes that made them more conscious of their own opinions and beliefs, and for other students' points of view. The process of writing and reading other students' texts opened for a deeper reflection than speech and could not possibly have taken place in an ordinary classroom without technology (Helleve \& Krumsvik, 2009).

\section{Differences between classroom learning and distance learning}

The previous paragraph showed that the campus students in a blended environment were unable to understand why they had to use ICT when they could speak to each-other instead. 
In a classroom the teacher has to create a need for using the technology as a means of communication. In distance learning there is no need for adjustment or motivation. Actually the distance makes the difference. Technology is the media that makes communication and learning possible. Communication understood as transfer as well as making something a common property is necessary. The Norwegian educational context is characterised by an increasing focus from politicians on goal achievement, accountability and market orientation. Results from tests like PISA and TIMMS have created an international educational competition of which Norway does not come out at the top. There is a strong belief in ICT as a support for learning. The political program for digital competence (MER, 2003) underlined that within 2008 Norway should be ranked on top of the world list when it comes to technology as a tool for learning. That goal is reached. All Norwegian pupils in upper secondary school are given a computer from the political authorities since 2007. The National Curriculum plan in 2006 (MER, 2006) states that digital competence is one of five basic competences together with reading, oral expression, writing and mathematics. The fact that all pupils have their own computer on their desk every day is a great challenge for the teachers. When teachers enter the classroom for a new lesson they are met by a row of backs of pupils who are deeply concentrated with computer supported activities mainly in form of social media. Some teachers have managed to change their way of teaching and adjust it to the new artefact while most teachers continue the way they have done before. Research shows that the pattern of IRE (information, response, evaluation) is still dominant in many classrooms. Teachers are passing information to the pupils, they ask questions, and evaluate the answers. In line with Greeno, et al (1996) the computer is understood as a tutor or an instructor. LMS is mainly used for messages and instructions. ITU monitor (Arnseth, et al 2007) revealed that there is still no depth in pedagogical reflection on the use of ICT among teachers in Norwegian schools. For teachers it is easy to send messages to pupils and parents through learning management platforms. In Norway It's learning is most commonly used. The system is constructed to support individual communication. Research shows that for some schools acquiring an LMS combined with use of e-mail seems to be the only aim of digitalized school development (Kløvstad, et al 2005; Krumsvik 2006, 2007). Learning management systems (LMS) open for possibilities for control. Plans for longer or shorter periods are stored and distributed from the teacher. Pupils receive instructions about their homework. Perhaps the greatest challenge for teachers as well as pupils when the IRE pattern is practiced in the classroom is the temptation of using social media. Continuing there is a struggle going on in classrooms between teachers and pupils when it comes to open screens and use of social medium. Student teachers describe from practicum that some pupils are online all the time. This happens in spite of the teacher's continuing requests to stop. When the teacher approaches the pupils change screen picture for a moment, but when he returns to his desk they immediately return to Facebook. Their social relations are more and more connected through the virtual world. Virtual friends join them in the classroom and they are only one click away. This is a constant problem for teachers who are presenting structured information (Erstad, 2010). The entrance of the computer on each desk has altered the communication pattern within the classroom. The old pattern of individual communication based on transfer and reproduction is kept alive, while the computer has strengthened a sense of suspicion, possibilities for control and crossing interests between pupils and teachers. The computer is supporting and strengthening an authoritarian pedagogy. Educational technology as part of a learning community changes nothing in 
itself. In fact the opposite can be true. The technology has qualities that can revitalise the most rigid learning activities from pedagogy of the past. Larsen (1998) is concerned with the same problem. He argues that if educational technology is adjusted to the traditional way of teaching or what he calls to "put electric power" on traditional methods this is going to conserve old ways of teaching and stop necessary pedagogical development.

Another important difference is the body-less communication in distance learning. There are possibilities for visualization through solutions like i.e. Skype. However, the immediate effect of eye contact, the possibility for reading body language, and for immediate reaction on behaviour is absent in virtual communication. Vetlesen (2003) makes a distinction between strong and weak mutuality and claims that there are some important differences between face-to-face meetings and virtual meetings. According to him face-to-face meetings are characterized by strong mutuality and virtual written communication by week. When people meet face-to-face they react upon each other not only based on the words that are said, but also on the nonverbal expressions and the way the other person acts. Normally all these levels act in harmony and one level tend to support the other in a way that helps us to understand the other person. Lack of confidence is aroused if there is a discrepancy between the three levels. When people meet the perception of concurrence or discrepancy comes immediately without any hesitation. The immediate interpretation is impossible in written online communication. Another concern according to Vetlesen is that the ethical appeal of caretaking is much less strong and powerful in virtual communication. When people meet face-to-face the degree of vulnerability and exposure is high. There are some basic ethical and relational principles in education like i.e. respect and obligation that are fundamental for teaching and learning. What about the relational aspects of education when it comes to distance learning?

\section{Distance learning experienced as a magic process}

In this paragraph I want to return to the question of what learning is like, and to the understanding of the concept community of learners. Learning understood as productive interactions builds on some basic principles of what a learning community is. These principles are similar across the borders of classrooms and distance learning. Intersubjectivity understood as having something in common, arena for respectful disagreement and human agency are concepts that are useful in order to illustrate the foundation and maintenance of a learning community (Matusov, 2001; Rommetveit, 2008; Helleve, 2009b). I want to illustrate the similarities between distance learning and classroom learning through the study of a group of student teachers who called themselves the "magic group" (Helleve, 2007). The concept magic refers to the reflective and productive learning process five student teachers experienced. This study was conducted among 20 distance learning student teachers who lived geographically spread over a large area. They had finished their master studies and were working as unqualified teachers. During this period as PGCE students they were supposed to study pedagogy and didactics in two subjects combined with practicum. The students started with a seminar where they stayed together for three days. The aim of the seminar was to get to know the other students and to become aware of the aims of the project. The data-material in the study of "the magic group" is concerned with pedagogy. Most of the study programme was based on collaboration by means of the computer. The 20 students were divided into four groups and each group had their own 
closed space within an LMS for collaboration. Within this closed space they were expected to publish 15 texts for their portfolio and to give and receive feedback on these texts from their peers. The teacher and the five students in the group were the only ones who had access to the closed area. The portfolios they created were based on their texts and on critical feedback from the other group members. The portfolio was compiled from assignments given by the teacher educators. Since all the students were working as teachers, it was possible to relate the exercises to their own practice in the classroom, as well as to the pedagogical theory they were supposed to read. The students were asked to respond critically to texts written by two other students in their group. After a few weeks one of the groups claimed that they experienced the learning process to be more productive than any of them had experienced earlier. By the end of the year one of the students described the learning process as magic. This made me as a researcher curious to understand more. My research questions were: What are the most important assumptions for the productive learning process that the "magic group" experienced? And: What are the most important consequences for teacher educators in future planning of net-based studyprogrammes for distance learning student teachers? Through interviews the students were asked to describe why they experienced the learning process so meaningful. They all mentioned as very important that they had a basic confidence before they started their netbased work. The initial meeting was important. One of the students said when they met face-to-face after some months: "I had a strong feeling of coming home. This was my group. Or rather this was our group". Moreover, they had two strong members who defined the benchmarks and set positive standards for the work. Those who were probably less dedicated from the beginning developed a strong obligation like another student: "Knowing that the other members spent a lot of time on my text I just had to do the same, otherwise I would never have done it." The group experienced that similarity as well as difference, was important for successful collaboration. Similarity related to mutual respect, engagement, obligation and sensitivity, difference related to age, gender, geographical location, schools, age of pupils, subjects they were teaching, and nationality. But most of all they seem to appreciate the fruitful and productive learning process they experienced when they were discussing with people who had different opinions when it came to beliefs, attitudes and values.

\subsection{The performance of the assignments}

What I as a researcher found was that the same conditions were present as I had seen in the $2^{\text {nd }}$ grade. This made me curious to see if this also concerned the performance of the assignments made by the teacher. When I analyzed the students' texts and feedback process I noticed that there were several similarities. First, it was possible to divide the material into two different categories; informative and creative assignments. The informative assignments asked the students to collect information. An example is: "Choose one of the educationalists from our curriculum. Please make a brief survey of what he represents and discuss the practical consequences of his theories. You may include your own experiences in your survey." For this assignment, the student repeats or reconstructs what he has read. The creative assignments also ask the students for information, but additionally they challenge the students' personal opinions and values. An example of a creative assignment is: "Is teaching a vocation for which you do not need any formal education? In your opinion, what is a professional teacher? Please give theoretical reasons for your answers." The students have to reflect and argue. Second, the 
performance of the assignments has immediate consequences for what kind of feedback the other students are going to give. The informative assignments lead to cumulative feedback. Cumulative feedback gives limited room for disagreement and reflection because it does not challenge the students' personal attitudes or values. One of the students said:

"You had to agree and repeat what the others said or just stop the whole conversation. There was no room for dialogue. It had to be a monologue. And I thought, 'Where is my place in this?' It was confusing."

The creative assignments on the other hand open for explorative feedback. Explorative feedback, which results from creative assignments such as the one above, gives rise to and opens up for critical questions and objective disagreement, and leads to new, common knowledge. The students disagreed with each other and discussed their deepest beliefs, professional identity, and mission. The nature of the net-based discussion, as compared to real life discussion, was visualized by the student who expressed that he had to sharpen his thoughts and opinions on what the other students had written. He experienced much deeper conversations than if they had been sitting around a table because they could read long rows of thoughts that others had ruminated. In classroom teaching as well as distance learning the teacher has to be conscious of the influence the performance of the assignments has on the students' choice of learning strategies (Helleve, 2007).

\section{The three case studies}

The case studies are rooted in three very different contexts. Based on an idle glance you would believe that there were few if any similarities between a classroom for $2^{\text {nd }}$ grade children and a group of grown up student teachers living geographically far away. And of course there are apparent differences. Still, the main impression of the research is that there are more similarities than differences. In this study learning is understood as meaning created in the tension between different voices, learning is not only accomplished through interaction; it consists of these interactions. Thus the term productive embraces the process as well as the product of learning (Lillejord \& Dysthe, 2008). So what does the term productive interactions mean in this study? The common background for all the three case studies was that students were supposed to collaborate on text-writing. In the study of the pupils through composing collaborative texts and in the studies of the student teachers through composing portfolios, giving feedback to each other and online discussions. The underlying expectations were that through collaboration the students should learn to argue and reflect. The study of the pupils in the classroom and the study of the distance learners show that whether the interactions are going to be productive or not, is partially dependant on the way that the assignments are performed. Productive interactions in the study of the pupils are visualised through the creative story that enhance explorative talk. These assignments encourage the students into a dialogue characterised by disagreement, argumentation and imagination. They are sharing understanding through a co-construction of knowledge. The students are also interacting when they are composing the experience stories. Still the interaction expressed through cumulative talk is limited because the students are only asked to collect information about what they have done. They are simply sharing the information about their common experience. There is no challenge or encouragement to argumentation and 
creativity. Cumulative as well as explorative talk are characterised by interaction. However, cumulative talk is limited because the students have to repeat and reproduce information. Explorative talk, on the other hand, enhance productive interactions; the possibility for argumentation and creativity. Another question is what characterises the opposite situation when there is no interaction between the members? When the communication between the members broke down as described through the discussional talk, I chose to call this counteraction. In the study of the distance learners the students gave feedback to each other on texts written for their portfolio. Of fundamental importance to the "magic group" success is their interaction. However, the difference in the way the assignments are constructed decides if the students are going to collect common information or if they are challenged to engage in productive interactions. When the students are challenged on their values and attitudes as professional teachers they meet in the inter-subjective space that Rommetveit (1979) calls a temporarily shared social world. What makes the interaction productive is that they are challenged to a reflective dialogue with people they trust, but with whom they still disagree. Sara, one of the distance learners said that she thought of the other members' different opinions as guests. And then she thought: "What do the guests want from me? Will they be staying in my head for ever or will they disappear"? And from that point of view she gave feedback to the other members' texts, like guests. The concept reflective dialogue expressed through explorative talk and explorative feedback is used as an equivalent to what I have described as productive interaction. Thus the performance of the assignments is one element that characterizes productive interactions. The study of the students in the blended environment is only based on interviews with the student teachers, not on observations of the collaborative activities. What the students claim is that the productive learning or productive interactions that are important for them as future teachers are asynchronous discussion and feedback from peers. Summing up there seems to be some basic implications for development of productive interactions that are similar across classroom learning and distance learning in the three case studies.

\section{Important preconditions for productive interactions}

Experiences from the three different studies show how the computer can be used as a tool for collaborative writing activities for students of different age groups; for students who meet every day as well as students who are distance learners. The fact that the groups and the activities in this study are so different makes the findings more general (Wegerif, 2007). Educational technology offers a new kind of room or an inter-subjective space for collaboration. The space might be compared to what (Engeström, 1998) calls a zone of possibilities that can help learners to renew existing knowledge and where both the individual's personal zone and the group's common zone develop according to the process of interaction (Wasser \& Bresler, 1996; Hoel 2001). The fact that the texts become a common and not an individual property is discussed by Wegerif (2007). Referring to societies where oral, rather than written communication has been the norm, he claims that these cultures possess a kind of common wisdom that is absent in cultures where individual writing is more common. Educational technology by its nature offers a common space for sharing texts that makes common reflection possible. The computer has the ability of storing collaborative texts, in what one of the informants in one of the studies called a "treasure chest". Another fact is that these collaborative texts might be there for ever. Consequently 
there is a continuous possibility for re-working of the texts. Independent of time students and teachers can visit these texts and respond to them. Again this illustrates how, in online collaboration, students have more time for reflection before they respond to other students' utterances than in oral collaboration. Accordingly the notion time and space differ from face-to-face meetings. Wegerif claims that online discussions and collaborative activities might be more egalitarian than face-to-face collaboration. The same fact is stated by students in the study of the blended environment who claim that it is easier to respond to other students' utterances in a virtual discussion.

What the study also shows is that confidence is fundamental for collaborative writing activities supported by educational technology. Whether the students are placed in front of a stand-alone computer in a class-room, or are collaborating through their computer at home, trust and faith in peers seems to be essential. This finding corresponds to other researchers results (Hoel, 2003; Sjøhelle, 2007; Wegerif, 2007). The willingness to be honest and open up, which again is a precondition for productive interactions, should be based in confidence. Other research shows that online collaboration often is characterized by anxiety, mainly because online collaborators lack the possibility of "reading" body-language (Burbules \& Callister, 2000). Consequently the willingness to share and invest the inner thoughts is more limited than in face-to-face collaboration. An important precondition for online collaboration seems to be that the space within the LMS is closed for everyone other than the included members and the teacher. The most important issue for students in this study seems to be to get know each other and to have established a sense of common faith and obligation that makes collaborative writing worthwhile. The fact that the collaborative activities should be limited to the selected group seems to be a common feature throughout the studies. The way the educational technology is used as a collaborative artefact in the primary classroom ensures that nobody else than the teacher and the students are participating. Students and the teacher, who share the basic notions of inter-subjectivity, should be the only participants. Research shows that in many situations students want to avoid difficulties and conflicts and choose not to be involved in dialogues ( Burbules \& Callister, 2000; Andriessen et al 2003; Koschmann, 2004).

When the students start the ICT-supported collaborative activities they enter a world of their own. In the study of the young pupils I used the metaphor "a helmet made of glass" to illustrate that the students went into their own world. The teacher regarded her job as fulfilled when the pupils went to the computer. They left her influence in a way. The most important finding from the SLANT-project (The Spoken Language and New Technology) also revealed that the communication taking place in front of the computer-screen was the result of a long process consisting of teachers' designing the programme, then communicating and sharing plans and ideas with the students (Wegerif \& Mercer, 1997; Wegerif, 2007). In traditional face-to-face education in a classroom the teacher has the possibility of intervening and stopping the activities. When students are collaborating by means of educational technology their orientation is towards the computer-screen either they are in the same classroom or they are at home with their own computer.

Summing up, this study shows that educational technology is suited for collaborative writing; composing texts, giving feedback to other students' texts, as well as discussions. Due to its interactive abilities the computer offers an arena for collaborative reflection. The texts become independent of time and space because they are always available, 
something which might make it easier for students to contribute. Still the findings underline the importance of fundamental confidence and responsibility between students in ICT supported collaboration. Finally the study shows that designing for communities of learners supported by ICT, raises challenges for teachers that are common across all areas whether these represent the stand-alone computers in the classroom, or online collaboration as well as across different age groups. Some of these challenges are discussed in the next paragraph.

\section{Challenges for the teacher}

In all the three studies the students had the opportunity to meet face-to-face before they were expected to collaborate by means of the computer. This meeting seems to function as a melting pot where they got to know each other and gained confidence. When the three different studies are compared some general findings concerning the teachers' design of communities of learners supported by ICT seem to emerge. The findings show themselves in different ways throughout the three studies. However, there are some general principles. Before the teacher meets the students he or she has normally made a plan or a design for the activities. The crucial moment for creating a learning community is what I choose to call the initial meeting. The teacher may either take the full responsibility for the activities or abdicate. The alternative is to create a learning community with shared responsibility between students and teacher. If the students are to learn through respectful disagreement and common creativity the collaborative writing seems to be depending on a chain of activities. The preconditions are grounded on a stepwise development. When designing the teacher should be aware of the fact that the establishment of the community is fundamental for how the learning process is going to turn out. I have decided to call this the initial meeting. The initial meeting might be the start of the "writing-day" as in the study of the pupils' classroom or the initial meeting for student teachers in the other two studies. In the study of the distance learners the students also stressed the importance of confidence: ". You have to know each other because you cannot read body language when you are online" according to one of them. Two main concerns seem to be important in the initial part of group establishment. The first is to establish confidence between the members of the society. The second is to share a concern for development of common activities and aims. These basic concerns are rooted in the initial meeting and appear to influence the collaborative activities the students are participating in later. During these meetings the students across the studies had to show some of their personal attitudes. They were either playing together or they were talking about their experiences from their leisure time or family life. What happened during these first meetings was that students and teachers had to open up and learn to know each other as human beings. The foundation for the development of common agency (Matusov, 2001) seems to lie in the initial meeting. Students and teacher come to share a personal concern for each other. According to the experiences of the students in this study, basic trust and confidence seem to be decisive for the further collaboration. The concepts interaction and counteraction are used to illustrate the difference concerning human relations. This moment is crucial for faith and confidence and the establishment of intersubjectivity (Rommetveit, 1985, 2008).

The second concern is the development of common aims and for sharing responsibility for the learning activities or the subject. In the study of the campus students they missed the 
opportunity of sharing the aims and responsibility for the ICT supported activities. One student says:

"What I reacted to most was that we heard a lot from the teacher educators about pupil's autonomy and pupils' interests and how important it was to speak to them, take them seriously and listen to them. But as students we experienced quite the opposite. So I felt no kind of motivation".

The teacher left the students without telling them why they had to do all the different ICT supported activities. They were left on their own. In the other two studies the initial meeting was used as a meeting arena where the students and the teacher were sharing goals. This does not mean that the teacher met without any plans for the activities. What it means is that the teacher through the design had made a plan. Through the initial meeting, the teacher shared his or her plans with the students permitting the students access and potential ownership to the aims. They got a shared focus for the activities (Matusov, 2001). The students in the blended environment missed the opportunity to share the aims of the activity. This turned out to be a significant problem for many of them. They simply did not understand why they had to do all the ICT-supported activities.

According to the findings the initial meeting between teacher and students is decisive for the development of the further collaborative process. The term initial is here understood as the moment when the teacher initiates the activities for the group. This might be every day or during a longer period of time. The initial meeting is critical for establishing a common basis or platform for further collaboration. The initial meeting has a double purpose. It serves as a foundation for development of common human agency as well as a basis for development of common aims for the learning activities. The shared responsibility and mutual obligation seems to be important. Tom in the distance-learning study says:

"Knowing that the other members spent a lot of time on my text I just had to do the same. Otherwise I would never have done it".

Three different notions of inter-subjectivity are relevant in order to explain the concept; as having in common, as an arena for respectful disagreement and as human agency (Matusov, 2001). The notions of inter-subjectivity as having in common and as human agency are relevant for understanding the importance of the activities in an educational context understood as a community of learners in all three studies. The third analytical concept is respectful disagreement as a reflective tool for understanding a community of learners. Referring to Bakhtin (1981) there seems to be an agreement underpinning the fact that different perspectives drive dialogues (Mercer, 1995; Engle \& Conant, 2002; Hattie \& Timperley, 2007). Based on an article of Lillejord \& Dysthe (2008) the question on whether a conflict or a dispute is productive or unproductive is raised. A common finding for all the three studies is that it seems to be important to have a confident basis for collaboration. Otherwise counteraction and no collaboration is the result. If this sense of trust is present the students seem to develop productive interactions from disagreement as well as agreement. In the study of distance learning the students explicitly claim that they appreciate difference and different opinions. The pupils in $2^{\text {nd }}$ grade might well disagree, but what seems to be just as important is the possibility of using creativity and imagination. Students in the study seem to develop productive interactions from arguing 
with peers they disagree with but still have confidence to. Creativity and imagination is also important when students are challenged beyond the limits of what they could possibly have managed on their own. Another important finding is that the assignments the students are going to answer or the tasks they are going to solve are performed in a way that enhance the possibility for creativity and different opinions. The students in the blended environment asked for assignments without any correct answers. They had discovered the productivity of being creative together.

\subsection{Where should the teacher be?}

Designing and conducting group activities has always been a challenge for teachers. When should she leave the students to work on their own, and when should she intervene or just be available? The challenge of designing for collaborative activities supported by ICT is no less complicated. According to Webb \& Cox (2004) teachers in ICT supported education should be able to plan activities that enable students to exercise control over their learning and to provide appropriate support or scaffolding when students need it. When the students are collaborating in these three case studies, it is the result of a long process. Still in the design of the programme the teacher should be aware and conscious of how the performance of the assignments should facilitate or block the aim of the teaching and learning programme. If the aim is to support creativity and argumentation then this has to be built into the activities and the expected outcome in terms of the way the assignments are performed as in the creative story and the creative assignment. This is important in all kinds of group activities, but even more in ICT supported activities where students are left alone with the computer.

Throughout the three studies, findings show that the students want the teacher to be an active part of the collaborative process. The small pupils clearly stated that they wanted the teacher to read and comment their texts and to be available when they needed her. The campus-students express that they want the teacher to read their texts, to make comments and to be there. The teacher should be the only person outside the group with admittance to the closed space within the LMS. The study shows that the students missed the teacher who was absent.

"I missed the teacher who could conduct the process. We were fumbling. We thought maybe we had misunderstood the articles, and when we gave feedback it was perhaps not so fruitful as it might have been.

They missed the teacher's participation. The students claim that even though the teacher has another position when students are collaborating online and in distance, he or she should still be watching the learning activity and the process going on, and be a "visible" participant in the groups. The theory of a community of learners is based on the fact that the teacher should have a double responsibility. As well as carrying responsibility for the design, the teacher should be oriented towards the students' activities (Matusov \& Rogoff, 1995; Rogoff \& Gardener, 1999). This means that the teacher should not take control of all the activities taking place. Nor should the teacher abdicate and leave the responsibility to the pupils alone. In a community of learners teacher and students have a shared responsibility for learning. The first is for the teacher to contribute to building a confident learning society. Second, the teacher needs to take into account that the collaborating 
confident group should be similar in relation to mutual respect and obligations, but different when it comes to experiences and values. Third, that the assignments connected to the portfolio are decisive for the learning process. If the students are asked to collect information, as in the informative assignments, there is limited or no room at all for disagreement, argumentation, creativity and reflection. The students should be exploring the zone of possibilities (Engeström, 1998) and creating new knowledge (Paavola, Lipponen \& Hakkarainen, 2005). Fourth, the students should know that the teacher is watching the process and is closely involved and cares, even if the students are doing most of the work on their own.

\section{Future research}

The fact that there is a discrepancy between visionary policy initiatives and change in classroom practice concerning educational technology means that there is a strong need for further research in the field of ICT and learning within education contexts on different levels. Further research as classroom observations, observations of conversations in front of stand-alone-computers and online learning conversations is necessary. This study shows that designing for productive interactions in ICT supported learning communities, means that teachers have to undertake more complex pedagogical reasoning than in faceto-face contexts. In the studies described in this chapter the teacher is designing and guiding learning communities where the aim of the activity is collaborative writing. Obviously there is a need for further research on the teacher's position in other kinds of ICT supported learning activities and subjects. Another finding concerning the position of the teacher is that when students collaborate by means of educational technology the teacher has a more peripheral position than in ordinary classrooms. Still the students want the teacher to be present even in distance learning. A question for further research should be what this presence means in different situations. When should the teacher leave the students to work on their own and when should she intervene or be available?

The study also shows that as a parallel to teachers' change in teachers' position the position of the students change as well. The focus of this study is on what characterises productive interactions. Other research shows that students often avoid conflicts and discussions and choose not to be involved in online dialogues (Taylor, 1991; Burbules \& Callister, 2000; Andriessen et al 2003; Koschmann, 2004). Given the extensive and increasing use of online communication in education I think there is a strong need for further research in why intended collaboration often ends in counteraction or discussional talk.

\section{Conclusion}

Through this chapter I have argued for learning understood as productive interactions built into learning communities that might as well be inside classrooms as far away. Why should students need a teacher when they are more digitally literate themselves and are able to collect all kinds of information in one second? My answer is that the ethical and intersubjective aspects that a learning community is built on perhaps are more important in the digital age than ever before. How should children and young people learn to take care, to feel obliged or to have respect for others if there were no teachers to organize and prepare the learning conditions? The body-less communication that ICT is based on may promote 
cheating and lack of confidence. This chapter has shown that educational technology may open for new possibilities but also for great challenges. If the computer is used as an instructor it is more authoritarian than any human being. If it is used for making knowledge a common property it has great possibilities. My conclusion is that there are more similarities between classroom learning and distance learning than there are differences. The challenge is the consciousness of how to utilize the technology.

\section{References}

Andriessen, J., Baker, M., \& Suthers. D. (2003). Arguing to learn. London. Kluwer Academic Publishers.

Arnseth, H. C., Hatlevik, O., Kløvstad, V., Kristiansen, T., \& Ottestad, G. (2007). ITU-Monitor 2007. Skolens digitale tilstand 2007 [ITU Monitor The Digital Condition in School 2007; in Norwegian]. Oslo. Forsknings- og kompetansenettverk for IT i utdanning.

Bakhtin, M. (1981). The Dialogic Imagination. Texas. Texas University Press.

Brown, A. (1994). The Advancement of Learning. Educational Researcher 23(8), 4-12.

Brown, A. \& Campione, J. (1994). Guided discovery in a community of learners. In: K. McGilly (Ed.). Classroom lessons: integrating cognitive theory and classroom practice (pp. 229-270). Cambridge, MA. Bradford Books.

Burbules, N.C., \& Callister, T. (2000). Watch IT: The risks and promises of information technology for education. Boulder, CO. Westview Press.

Engeström, Y. (1998) Den nærmeste udviklingssone som den basale kategori i pædagogisk Psykologi, in: M. Hermansen (Eds) Fra læingens horisont. Århus, Klim.

Engle, R. A.,\& Conant, F. C. (2002). Guiding Principles for Fostering Productive Disiplinary Engagement: Explaining Emergent Argumentation in a Community of Learners Classroom. Cognition and Instruction, 20(4), 399-483.

Erstad, O. (2010). Digital kompetanse i skolen- en innføring. Oslo. Universitetsforlaget.

Gee, P. G. (2005). Semiotic Social Spaces and Affinity Spaces; From The age of Mythologies to Today's Schools. In D. Barton \& K. Tusting (Eds.).Beyond Communities of Practice (pp. 214-232). London. Cambridge University Press.

Greeno, J.G., Collins, A.M., \& Resnick, L.B. (1996). Cognition and learning. In D.C. Berliner \& R.C. Calfee (Eds.). Handbook of Educational Psychology (pp. 15-46). New York. Macmillan.

Hattie, J. \& Timperley, H. (2007). The Power of Feedback. Review of Educational Research, $77(1), 81-112$

Helleve, I. (2003). Samspel med data? [Interaction with the computer? in Norwegian]. Nordisk Pedagogik, 3, 161-170.

Helleve, I. (2007). In an ICT-based teacher- education context: Why was our group "The magic group"? European Journal of Teacher Education, 30(3), 267-284.

Helleve, I. (2009a). Theoretical foundations of teachers' professional development I Ola

Lindberg \& Anders Olofsson (red.). Online learning Communities and Teacher Professional Development New York: Information Science References. 1-20.

Helleve, I. (2009b). Productive Interactions in ICT supported Communities of Learners. Dissertation for the degree of philosophiae (PhD). Bergen. Universitetet i Bergen. 
Helleve, I. \& Krumsvik, R. (2009). If Innovation by means of Educational Technology is The Answer- What should the Question be? In R. Krumsvik (Ed.). Learning in the digitized society. New York. Nova Science Publishers.

Hoel, L. T. (2001). Ord på vandring [Wandering words; in Norwegian]. In O. Dysthe (Ed.). Dialog, samspel og læring [Dialogue, Interaction and Learning; in Norwegian] (pp. 269-289). Oslo. Abstrakt Forlag.

Hoel, T. L. (2003). Dialogen i fleksibel retning. [Dialogue in a flexible direction; in Norwegian]. I Y. Fritze, G. Haugsbakk \& Y. T. Norkvelle (Eds.). Dialog og nærhet. IKT og undervisning [Dialogue and closeness. ICT and education; in Norwegian]. (pp. 56- 76) Kristiansand.Høyskoleforlaget.

ITU (2000-2003a). The INVITES-project[INVITES-prosjektet]. Retrived October 23rd from: http://www.itu.no/filearchive/fil_Sluttrapp_INVITIS.pdf

ITU (2000-2003b). The PLUTO-project[PLUTO-prosjektet]. Retrived October 23 ${ }^{\text {rd }}$ from: http://www.itu.no/Prosjekter/1079504497.79/view

Kløvstad, V., Erstad, O., Krisitansen, T., \& Søby, M. (2005). ITU Monitor 2005. På vei mot en digital kompetanse i grunnopplæringen. [ITU Monitor 2005. Towards a digital competence in primary education; in Norwegian]. Rapport 2/2005. Oslo. Universitetsforlaget.

Koschmann, T. (1996). CSCL: Theory and Practice of an emerging paradigm. New Jersey. Lawrence Erlbaum Associates Publishers.

Koschmann, T. (2004). CSCL: Argumentation, and Deweyan inquiry: Argumentation is Learning. In: J. Andriessen, M. Baker \& D. Suthers (Eds.). Arguing to learn.Confronting Cognitions in Electronic Learning Environments. (pp. 261-267). Dordrecht. Kluver Academic Publishers.

Krumsvik, R.J. (2006). ICT in the school. ICT-iniated school development in lower secondary school. The degree doctor philosophiae. Dr.philos. [The degree doctor philosophiae; in Norwegian]. Bergen. University of Bergen. Norway.

Krumsvik, R.J. (2007). Skulen og den digitale læringsrevolusjonen.[The digital learning revolution in school; in Norwegian]. Oslo. Universitetsforlaget.

Larsen,S. (1998). IT og nye læreprocesser. [ICT and new learning processes; in Danish]. Hellerup. Steen Larsen.

Lillejord, S. \& Dysthe, O. (2008). Productive learning practice- A theoretical discussion based on two cases. Journal of Education and Work, 21(1), 75-89.

Matusov, E., \& Rogoff, B. (1995). Evidence of Development from People's Participation in Communities of Learners In J. H. Falck \& L. D. Dierking (Eds.). Public Institutions for Personal Learning (pp. 97-104). American Association of Museums Technical Information service.

Matusov, E. (2001). Intersubjectivity as a way of informing teaching design for a community of learners classrooms. Teaching and Teacher Education, 17(4), 383-402.

MER (2003).[Undervisnings-og forskningsdepartementet] [UFD]. The Program for digital competence 2004-2008 [Program for digital kompetanse 2004-2008]. Retrieved October 23, 2008, from:

http://odin.dep.no/kd/norsk/satsingsomraade/ikt/045011-990066/dok-bn.html 
MER (2006). [Undervisnings-og forskningsdepartementet] [UFD]. National curriculum plan [Kunnskapsløftet, in Norwegian] Retrieved May 18, 2010, from:

http://www.regjeringen.no/nb/dep/kd/tema/grunnopplaring/kunnskapsloeftet .html?id=1411

Mercer, N. (1995). The guided construction of knowledge. Clevedon. Multilingual Matters.

Mercer, N., \& Fisher, E. (1997). Scaffolding Through Talk. In: R. Wegerif \& P. Schrimshaw (Eds.). Computers and Talk in Primary Classrooms. Clevedon. Multilingual Matters.

Paavola, S., Lipponen,, L., Hakkarainen, K. (2005). Episptomological Foundations for CSCL: A Comparison of Three Models of Innovative Knowledge Communities. Retrieved 18

Rogoff, B. \& Gardener, W. (1999). Adult Guidance of Cognitive Development. In: B. Rogoff \& J. Lave (Eds.). Everyday Cognition. Development in Social Context (pp. 95-117). Lincoln. Harvard College.

Rommetveit, R. (1979). On the architecture of intersubjectivity. In R. Rommetveit \& R. M. Blaker (Eds.). Studies of language, thought and verbal communication (pp. 93-107). New York. Academic Press.

Rommetveit, R. (1985). Language acquisition as increasing linguistic structuring of experience and symbolic behaviour control. In J.V. Wertsch (Ed.). Culture, communication and cognition: Vygotskian perspectives (pp. 183-204). Cambridge. Cambridge University Press.

Rommetveit, R. (2008). My meeting with the cognitive revolution (at MIT) in the early Seventies, and the development of the concept Intersubjectivity. Paper presented at Rommetveitseminaret. Stord Haugesund University College. 12.06.

Sjøhelle, D. (2007). Læringsfellesskap og profesjonsutvikling. [Learning communities and professional development]. Doktoravhandling for graden Philosophiae Doctor. [The degree doctor philosophiae; in Norwegian]. Trondheim. NTNU.

Somekh, B. (2007). Pedagogy and Learning with ICT. London. Routledge.

Säljö, R. (2000). Lärande i praktiken; et sociokulturelt perspektiv. [Learning in Practice in a sociocultural perspective; in Swedish]. Stockholm: Prisma.

Taylor, C. (1991). The Malaise of Modernity. Canada. Stoddart Publishing Co. Ltd.

Trageton, A. (2000). Millioner av muligheter med 29 bokstaver. [Billions of possibilities with 29 letters; in Norwegian]. Norsklæreren, 5, 28-31.

Vetlesen, A. J. (2003). Det forpliktende møtet. [The obliging meeting; in Norwegian] In Y. Fritze, G. Haugsbakk \& Y. Nordkvelle (Eds.), Dialog og nærhet: IKT og undervisning ¡Dialogue and presence: ICT and education; in Norwegian」(pp. 76-94). Kristiansand: Høyskoleforlaget

Wasser, J. D. \& Bresler, L. (1996). Working in the Interpretive Zone: Conceptualizing collaboration in qualitative research teams. Educational researcher, 25(5), 5-15.

Webb, M. \& Cox, M. (2004). A Review of Pedagogy Related to Information and Communication Technology. Technology, Pedagogy and Education, 13(3), 235-286.

Wegerif, R. (2007). Dialogic Education and Technology. Lausanne. Springer.

Wegerif, R. \& Mercer, N. (1997). A Dialogical Framework for Researching Peer Talk. In R. Wegerif \& P. Schrimshaw (Eds.). Computers and Talk in Primary Classrooms (pp. 4965). Clevedon. Multilingual Matters. 
Wubbels, T. (2007). Do we know a community of practice when we see one? Technology Pedagogy and Education, 16(2), 225-233. 


\title{
Distance Learning and the Low-Income Student
}

\author{
Angela Benson ${ }^{1}$, Joi L. Moore ${ }^{2}$, Nicole Norfles ${ }^{3}$ and Carolyn Starkey ${ }^{4}$ \\ 1 University of Alabama \\ ${ }^{2}$ University of Missouri \\ ${ }^{3}$ Council for Opportunity in Education \\ ${ }^{4}$ University of Alabama \\ USA
}

\section{Introduction}

In a country where postsecondary education traditionally results in social and economic advancement, 54 million working American adults lack a college degree (Pusser et al., 2007). Statistically, these adults are more likely to be low-wage earners. In 2009, the median earnings for young adults (25-34) with a bachelor's degree was $\$ 45,000$, while the median was $\$ 21,000$ for those without a high school diploma, $\$ 30,000$ for those with a high school diploma, and $\$ 36,000$ for those with an associate's degree. This indicates that young adults with a bachelor's degree earned over $100 \%$ more than those without a high school diploma, $50 \%$ more than those with high school diplomas, and 25\% more than young adults with associate's degrees (Aud et al., 2011). In addition, the median earnings of young adults with a master's degree or higher was $\$ 60,000$, which was $33 \%$ more than the median for young adults with a bachelor's degree (Aud et al., 2011). Given these numbers, it is not surprising low income and working adults explore (or are encouraged to explore) postsecondary education. The route to degree entry and completion is not easy though.

According to Pusser et al. (2007), the challenges faced by adult learners place them at great risk of failing to complete courses and degrees. Adults not only learn differently than the young, they learn for different reasons (Green, 1998), including what they need to know, how they can take control of learning, what their prior learning experiences are, and why they need to learn (Huang, 2002; Knowles, 1984). Traditional undergraduate education is often inflexible and inconvenient for their schedules and lifestyles. Obligations, such as caring for family or work, are among the main barriers for adult/mature students to enroll in courses (Tones, Fraser, Elder, \& White, 2009). These financial, family, and work concerns lead adult learners to nontraditional postsecondary programs, including distance learning (Pusser et al., 2007), because they provide a practical, convenient, and economical opportunity for those who are unable to participate in residential options (Yoon, 2003).

The definition of distance education as proposed by Holmberg (1995) situates it as an instructional delivery method that could be beneficial for low income and working learners. Holmberg defined distance education as:

the learning-teaching activities in the cognitive and/or psychomotor and affective domains of an individual learner and a supporting organization. It is characterized by 
non-contiguous communication and can be carried out anywhere and at any time, which makes it attractive to adults with professional and social commitments. (p. 181)

This chapter describes an exploratory research project that investigated the experiences of low-income and working students enrolled in postsecondary distance study for the purpose of gaining insight to help in the development of instructional and non-instructional interventions to enhance their persistence to graduation. Because of the growing use of Internet-based technologies to facilitate distance learning, the project focused primarily on students enrolled in online study.

Moore et al. (2011) note the need for clarity in the use of the terms distance learning and online learning and their relationship to each other. For this chapter, we define distance education as "some form of instruction [that] occurs between two parties (a learner and an instructor), [that] is held at different times and/or places, and uses varying forms of instructional materials" (Moore et al., p. 130). Online learning, in this chapter, is defined as distance learning mediated primarily by synchronous and/or asynchronous Internet technologies, such as email, discussion boards, chat rooms, and course management systems. Thus, for purposes of this chapter, online learning is considered a subset of distance learning such that all online learning is distance learning but all distance learning is not online learning. For example, print-based correspondence study is a form of distance learning but it is not a form of online learning.

Hybrid/blended is a term used to describe learning environments that use elements of distance learning along with elements of traditional face-to-face learning. The instructional strategies used in hybrid/blended courses typically combine a face-to-face learning environment with computer-mediated activities such as videoconferencing, chats, discussion boards, and tutorials. In addition, using a hybrid/blended approach may encourage instructors to reduce the number of face-to-face sessions for more instructor-tostudent interaction via the Internet.

\section{Relevant literature}

To identify a framework from which to investigate low-income student experience in online learning environments, the related literature was reviewed. This review identified five areas of concern: the prevalence of distance and online education, factors related to student pursuit of online study, student preparation for online study, student online course experiences, and factors related to student success in online courses.

\subsection{Prevalence of distance and online learning}

The landscape of postsecondary distance learning has changed in the last ten years with distance courses shifting more to online delivery modes using Internet technologies. This section presents the current status of postsecondary distance course and program offerings and associated student enrollments.

\subsubsection{Course and program offerings}

In the most recent study of distance education at degree-granting postsecondary institutions in the United States, Prasad and Lewis (2008) found that two-thirds of all institutions offered 
online, hybrid/blended, or other distance education courses for the academic year 20062007. For the two-year level, the study revealed that $97 \%$ of public institutions and $16 \%$ of private for-profit institutions offered undergraduate distance courses. At the four-year level, $87 \%$ of public institutions, $51 \%$ of private not-for-profit institutions and $50 \%$ of private forprofit institutions offered undergraduate distance courses.

Sixty-two percent of institutions offered online distance education courses. At the two-year level, $96 \%$ of the public institutions and $15 \%$ of private for-profit institutions offered online undergraduate distance courses. At the four-year level, $86 \%$ of public institutions, $47 \%$ of private not-for-profit institutions and $52 \%$ of private for-profit institutions offered online undergraduate distance courses.

Prasad and Lewis (2008) found that only one-fourth of the institutions offered fully online undergraduate degree programs. At the two-year level, 39\% of public institutions and $7 \%$ of private for-profit institutions offered online undergraduate degree programs. At the fouryear level, $40 \%$ of public institutions, $16 \%$ of private not-for-profit institutions and $27 \%$ of private for-profit institutions offered online undergraduate degree programs.

Prasad and Lewis' (2008) findings are summarized in Table 1. The numbers clearly indicate that while institutions are providing online undergraduate courses at a high rate $(62 \%)$, they are providing fully online programs at a much lower rate $(25 \%)$.

\begin{tabular}{|c|c|c|c|}
\hline & $\begin{array}{c}\text { Offering } \\
\text { Undergraduate } \\
\text { Distance Courses }\end{array}$ & $\begin{array}{c}\text { Online Undergraduate } \\
\text { Courses }\end{array}$ & $\begin{array}{c}\text { Fully Online } \\
\text { Undergraduate } \\
\text { Degree Programs }\end{array}$ \\
\hline Overall & 66 & 62 & 25 \\
\hline 2-year public & 97 & 96 & 39 \\
\hline $\begin{array}{l}\text { 2-year private, } \\
\text { for-profit }\end{array}$ & 16 & 15 & 7 \\
\hline 4-year public & 87 & 86 & 40 \\
\hline $\begin{array}{l}\text { 4-year private, } \\
\text { not-for-profit }\end{array}$ & 51 & 47 & 16 \\
\hline $\begin{array}{l}\text { 4-year private, } \\
\text { for-profit }\end{array}$ & 50 & 52 & 27 \\
\hline
\end{tabular}

Table 1. Percentages of institutions involved in undergraduate distance education, Prasad and Lewis (2008).

Prasad and Lewis (2008) also found that nearly all of the institutions rely on online asynchronous delivery (92\%) over synchronous delivery (31\%). Asynchronous technologies were used to a large extent in $75 \%$ of the institutions that offered college-level creditgranting distance education courses and to a moderate extent in $17 \%$. Only $12 \%$ of these institutions used synchronous Internet-based technologies to a large extent while $19 \%$ used them to a moderate extent. 
Ninety-three percent of two-year level public institutions used asynchronous Internet-based for instruction to a moderate or large extent. At the four-year level, 90\% of public institutions, $90 \%$ of private not-for-profit institutions and $95 \%$ of private for-profit institutions used asynchronous Internet-based for instruction to a moderate or large extent. For two-year level public institutions, $28 \%$ used synchronous Internet-based activities for instruction to a moderate or large extent. At the four-year level, $42 \%$ of public institutions, $32 \%$ of private not-for-profit institutions and $13 \%$ of private for-profit institutions used synchronous Internet-based for instruction to a moderate or large extent. These figures are summarized in Table 2.

\begin{tabular}{|c|c|c|}
\hline & $\begin{array}{c}\text { Asynchronous } \\
\text { Internet-based } \\
\text { Technologies } \\
\text { (Used from a Moderate to } \\
\text { Large Extent) }\end{array}$ & $\begin{array}{c}\text { Synchronous } \\
\text { Internet-based } \\
\text { Technologies } \\
\text { (Used from a Moderate to Large } \\
\text { Extent) }\end{array}$ \\
\hline Overall & 92 & 31 \\
\hline 2-year public & 93 & 28 \\
\hline $\begin{array}{l}\text { 2-year private, } \\
\text { for-profit }\end{array}$ & - & - \\
\hline 4-year public & 90 & 42 \\
\hline $\begin{array}{l}\text { 4-year private, } \\
\text { not-for-profit }\end{array}$ & 90 & 32 \\
\hline $\begin{array}{l}\text { 4-year private, } \\
\text { for-profit }\end{array}$ & 95 & 13 \\
\hline
\end{tabular}

Table 2. Percentages of institutions Involved in undergraduate distance education, Prasad and Lewis (2008).

Prasad and Lewis (2008) also found that the most common factors cited as affecting distance education decisions to a major extent were meeting student demand for flexible schedules $(68 \%)$, providing access to college for students who would otherwise not have access $(67 \%)$, making more courses available (46\%), and seeking to increase student enrollment $(45 \%)$. This finding agrees with Holmberg (1995) that distance learning is a vehicle to serve adults with professional and social commitments.

\subsubsection{Distance and online enrollment}

In terms of enrollment, during the 2006-2007 academic year, there were 9.8 million enrollments in distance courses. Of those, 4.8 million were enrolled at public two-year institutions, 2.6 million at public four-year institution, 1.1 million at private not-for-profit four-year institutions and 1.1 million at private for-profit four-year institutions (Aud et al., 2011). In 2007-08, about 4.3 million undergraduate students, or $20 \%$ of all undergraduates, took at least one distance education course. Approximately 0.8 million, or $4 \%$ of all undergraduates, completed their entire program through distance education. 
A higher percentage of students at private for-profit institutions (12\%) completed their entire program through distance education than students at either public institutions or private not-for-profit institutions (both 3\%). Similarly, a higher percentage of students at private for-profit 4-year institutions took their entire program through distance education $(19 \%)$ than students at any type of institution, ranging from $2 \%$ at public less-than-2-year, public 4-year, and private for-profit less-than-2-year institutions to $8 \%$ at private for-profit 2year institutions (Aud et al., 2011). The numbers are summarized in Table 3.

In the Aud et al (2008) study, distance education courses included live, interactive audio- or videoconferencing; prerecorded instructional videos; webcasts; CD-ROMs or DVDs; or computer-based systems accessed over the Internet. Distance education did not include correspondence courses as in the Prasad and Lewis (2008) study.

\begin{tabular}{|l|c|c|}
\hline & $\begin{array}{c}\text { Distance Course Enrollment } \\
\text { (millions) }\end{array}$ & $\begin{array}{c}\text { Distance Program Enrollment } \\
\text { (percent) }\end{array}$ \\
\hline Overall & 9.8 million & $4 \%$ \\
\hline \multicolumn{2}{|c|}{} & $2 \%$ \\
\hline Two-year, public & 4.8 million & $8 \%$ \\
\hline $\begin{array}{l}\text { Two-year, private, } \\
\text { For-profit }\end{array}$ & - & $2 \%$ \\
\hline \multicolumn{2}{|c|}{} & $2 \%$ \\
\hline Four-year, public & 2.6 million \\
\hline $\begin{array}{l}\text { Four-year, private, } \\
\text { Not-for-profit }\end{array}$ & 1.1 million & $19 \%$ \\
\hline $\begin{array}{l}\text { Four-year, private, } \\
\text { For-profit }\end{array}$ & 1.1 million & $2011)$ \\
\hline
\end{tabular}

Table 3. Distance education course and program enrollment (Aud et al., 2011).

\subsection{Pursuit of online study}

In order for students to pursue online study, they must know that the option exists. Once they become aware that online study is an option, they must choose to enroll. This section presents an overview of the literature related to student awareness of online study options and factors that influence their decision to enroll.

\subsubsection{Program awareness}

In a national study of adult learners enrolled in two-year community and technical colleges, four-year public institutions and four-year private institutions, Noel-Levitz (2005) found that general program awareness is gained by adult learners from the following sources (listed in descending order of importance): institution web site; online catalog; printed catalog and brochures; student/graduate contact; family/friend recommendations; employer recommendations; information session; workplace information; national college search web site; recruiting phone calls from college representatives; newspaper; and television. Interestingly, although adult learners value the convenience and flexibility of 
distance learning, the availability of online classes is not a strong factor in program selection (Noel-Levitz, 2005). In a national survey of educational support organizations (ESOs) serving low-income students, Benson (2007) found that advisers often do not recommend online classes to clients, citing the lack of support and structure in online environments.

\subsubsection{Program decision}

Adult learner postsecondary enrollment decisions are influenced by the following factors (listed in descending order of importance): convenient time and place for classes; flexible pacing for completing a program; ability to transfer credits; cost; reputation of institution; requirement for current or future job; ability to design personalized program; credit for learning gained from life and work experience; availability of financial assistance; distance from campus; availability of online courses; tuition reimbursement from employer; program accreditation by professional organization or trade group; encouragement/incentive from supervisor; courses held at employment site; availability of child care; and labor union support (Noel-Levitz, 2005). In a study of engineering students, Dutton et al. (2001) found that when comparing preferred mode of instruction survey results, online learners found school/work timing conflicts, commuting difficulties, and learning pace/time flexibility to be more important than traditional face-to-face learners. However, O'Lawrence (2006, p. 48) reports that students:

see online technologies as providing new opportunities and preventing a drive to attend a class, so that they can remain in their homes or workplaces, and yet participate in learning activities, interact with most of the people in class, exchange information more frequently, and establish friendships with other students.

Other influences on an adult student's decision to pursue online study include a variety of prior learning and work experiences; integration of new concepts with prior knowledge while interacting with students with similar work experiences; practical applications of knowledge; control over their learning environment and the opportunity to showcase their talents to a group; and ability to participate voluntarily in the learning experience ( $\mathrm{O}^{\prime}$ Lawrence, 2006).

\subsection{Preparation for online study}

Student preparation for online study has two components: readiness to participate in the online course and access to funds to pay for online study. This section presents an overview of the literature related to online study training and financial preparation.

\subsubsection{Training and orientation}

Universities and instructors should not assume that students are computer literate. One reason that directors of ESOs do not recommend online learning for their clients is the students' lack of appropriate computer skills (Benson, 2007). Carriuolo (2002) found that in 2001, 300 to 400 students at the Community College of Rhode Island enrolled in a computer basics course (i.e., how to use a mouse), suggesting a widespread need for computer training among potential online students. Benson (2007) found that Southwestern ESO, an educational support organization for low-income and under-represented students, administers a distance learning readiness assessment to their students and then an 
introductory computer course prior to their enrolling in any online course. Southwestern believes that this training contributes significantly to the success of their students in online learning and accounts for the growth in their online distance education program (Benson, 2007). Lynch (2001) recommends an orientation course that simulates Web-based delivery and incorporates adult learning theory, readiness self-assessment, reflection on the online experience, and community building as its basic components. Although Carriuolo (2002) reported daily use of the computer in her workplace, she still struggled with the electronic requirements of her online course. She suggests that online nontraditional students need hands-on hardware and software training (Carriuolo, 2002).

\subsubsection{Financial preparation}

Most financial aid programs are designed for the traditional undergraduate student who is a recent high school graduate and attends school full time (Ashburn, 2007). Because many adult students took only one or two classes at a time, little financial aid is available to them. Only one third of adult students received student loans, less than one third receive grants or scholarships, and nearly a third revealed that they were unaware that financial aid was available to them (Pusser et al., 2007). Other options available to learners included personal savings or employer support (Ashburn, 2007; Tu, 2004).

\subsection{Online course experiences}

Online courses can be described by the interaction types. This section presents an overview of the student online course experience by addressing four interactions: teacher, peer students, course content, and institutional.

\subsubsection{Teacher interactions}

Kleiman (2004) asserts that the process of online teaching is different from the process of traditional teaching. The online teacher essentially empowers learners through what, how, when, and where to learn decisions ( $\mathrm{Tu}, 2004)$, and options usually not available to traditional students. Richardson and Swan (2003) found that student satisfaction with an instructor is related to the students' perceptions of social presence. Furthermore, Carriuolo (2002) suggests that a learner's relationship with a professor can be a "life-altering" experience, because the mentorship could result in advice based on an individual's strengths and weaknesses. Coombs-Richardson (2007) believes that it takes the instructor, course content, and student working together to ensure learning for online classes. She has developed strategies that ensure her students have a positive and successful online learning experience. These strategies include providing a timely response to students; quick turnaround of assignments; individual attention to needy students; timeline flexibility with personal contact if necessary; warm and friendly online atmosphere; and personal responses to assignments (Coombs-Richardson, 2007). Proactive instructor interactions applied by Lim (2004) include frequent questioning to access learning level and timely progress reports.

\subsubsection{Peer interactions}

The learning community of a classroom is based on the student-to-student exchange of information. The need for peer interaction for effective learning is a reason cited by ESO 
directors for why online study is not a good option for their students (Benson, 2007). Yet, O'Lawrence (2006) reports that adult learners see online technologies as providing opportunities for student-to-student interaction, frequent exchange of information, and the likelihood of new friendships with other students. Coombs-Richardson (2007) also noted student appreciation of peer discussion board interactions. Brown (2001) found that the necessary elements to create friendship, community, or camaraderie were present but generally required a greater length of time to establish. An initial face-to-face orientation session for the class would provide an opportunity for social interaction that could then be maintained electronically (Carriuolo, 2002).

\subsubsection{Course content interactions}

The most influential factor affecting study success positively in an online course is clarity of content resulting in instructional effectiveness (Lim, 2004; Lim, Morris \& Kupritz, 2007). Instructional effectiveness is defined as "clear and concise learning content," "usefulness of class assignment and projects," and "review and repetition of learning (Lim, 2004, p. 1063)." Sixty percent of students participating in the study defined instructional ineffectiveness as "lack of instructional clarity to explain the learning content" and "difficult learning content" (Lim, 2004, p. 1062). Students determined that the four most significant factors in instructional effectiveness were (1) content level and clarity; (2) usefulness of activities; (3) feedback and interaction; and (4) amount of content workload. Coombs-Richardson (2007), Lim (2004), and O'Lawrence (2006) found that students want useful and practical applications of the theory learned in online study, both in class and in the outside world. In addition, Lim (2004) suggests using reflective activities that will allow learners to apply their learning to personal situations. Additionally, online study depends to some degree on print to convey course content, and nontraditional undergraduates often have low levels of literacy (Carriuolo, 2002). Among the least favorite activities of online students are the required reading assignments (Coombs-Richardson, 2007). Lim (2004) speculates that the instructional effectiveness of online courses is influenced by each individual student's instructional readiness.

\subsubsection{Institutional interactions}

Pusser et al (2007) stipulate that high-risk adult learners have four primary needs in their postsecondary institutions: (1) guides and mentors; (2) financial aid; (3) a peer community; and (4) a guided and specific academic plan. Varying circumstances of adult learners require institutions to provide convenient and affordable access to postsecondary education (Pusser et al, 2007). LaPadula (2003) concluded that successful online programs offered students the same opportunities and services as found in traditional face-to-face programs and suggested that these services should be offered at a distance and in an asynchronous format. Benson (2007) suggests that public university systems need to be more responsive to flexible learning options or risk losing students to for-profit institutions that are market-driven.

\subsection{Success perspectives}

Three perspectives must be addressed when considering success in online study: individual student characteristics, online course characteristics and online support organization characteristics. This section presents an overview of the literature related to these three perspectives. 


\subsubsection{Student success}

Dutton et al. (2001) found that undergraduates who completed an online course did significantly better than their counterparts in an equivalent lecture course. Although the online students were less likely to finish a course, they were able to gain knowledge through meaningful activities. O'Lawrence (2006) concluded that the most significant factor hindering adult learner success is the lack of self-discipline and time-management skills of some students. He also cites lack of peer contact and low literacy levels as contributing factors to a lower success rate (O'Lawrence, 2006). Yukselturk \& Inan (2006) identified sufficient study time, personal problems and program affordability as the three most important factors affecting student retention in an online course.

\subsubsection{Successful online course}

In an online course evaluation conducted by Coombs-Richardson (2007), students were asked to rank twelve course components in order of importance. The three most important components of online courses to students were individual observations, discussion board activities, and the instructor's personal contacts through announcements, email, etc (CoombsRichardson, 2007). Other components, listed in the order of importance, are schedule flexibility, instructor feedback, assignment turnaround, content, technical assistance, course calendar, essays/reports, reading assignments, and online exams (Coombs-Richardson, 2007). O'Lawrence (2006) concludes that extensive preparation is required to create a successful online course and recommends that future research activities include in-depth evaluation and assessment of online courses in the following areas: ease of access, media attentions or exaggerations, the role and interest of the private sector, the increased demand for online courses by education and business, and the effectiveness of online learning activities.

\subsubsection{Successful online support organization}

Willging and Johnson (2004) found that student rationale for leaving online programs is similar to those given for leaving traditional face-to-face programs. Although there was no evidence that suggested online environment-specific online issues were primarily responsible for dropout, students included technology, lack of human interaction, and communication problems are reasons for leaving online programs (Willging and Johnson, 2004). Yukselturk \& Inan (2006) reported that lack of feedback and support for the online learning process and lack of response to student difficulties were negative items reported by students in a study that examined the factors affecting the dropout rate for online learning programs. MacDonald \& Thompson (2005) found that high quality support is crucial to successful online learning experiences. Critical support includes introduction of learning technologies and software applications progressively, building technology and learning skills and $24 / 7$ access to online and other university support services i.e. technical assistance. Online learner support services not only connect students to the university and improve the quality of the academic experience, but also scaffold student success through the development of self-directed learning skills (Ludwid-Hardman and Dunlap, 2003).

\subsection{Summary}

The reviewed literature framed this research project around six components: the prevalence of distance and online education (A), factors related to student pursuit of online study (B), 
student preparation for online study (C), student online course experiences (D), factors related to student success in online courses (E), and personal impact of online study (F). Based on this review, project explored the student online course experience in four segments: preenrollment experiences $(\mathrm{B}, \mathrm{C})$ in-course experiences $(\mathrm{D})$, and personal impact $(\mathrm{F})$.

\section{Purpose and research questions}

The purpose of this research is to describe the experiences of low income and working adult students who are enrolled in online undergraduate study. The research frames the experience in four segments: environment, pre-enrollment experiences, in-course experiences, and personal impact. The research questions guiding this work are:

1. How do low income and working adult students enrolled in online study describe their pre-enrollment experiences?

a. Why do these students decide to pursue online undergraduate study?

b. How do these adult students prepare for online study?

c. How do these adult students finance their online study?

2. How do low income and working adult students enrolled in online study describe their in-course experiences?
a. How do these students describe their teacher interactions?
b. How do these students describe their peer interactions?
c. How do these students describe their course content interactions?
d. How do these students describe their institution interactions?

3. How do low income and working adult students enrolled in online study describe the personal impact of online study?

a. How has studying online shaped their perspectives of what it takes to be a successful online learner?

b. How has studying online impacted their lives?

\section{Research methods}

A qualitative case study design was used for this exploratory research. The case and participants were chosen using Patton's (1990) intensive form of purposeful sampling, in which information-rich cases that demonstrate the phenomenon of interest intensively are selected. The case was Southwestern ESO, an educational support organization serving lowincome students enrolled in online postsecondary study at a local four-year college and a local two-year college. Four program staff members were interviewed to capture the environmental conditions that characterized their students' online experience. Seven students were interviewed to capture their pre-enrollment experience, in-course experience, and personal impact of online study. Two of the students also served on the staff. Their interviews consisted of questions related to both of their roles. All interviews were of $60-90$ minutes in duration. The interviews were recorded and transcribed. Pseudonyms were created for the program name, the staff participants and the student participants. The transcripts were analyzed using Merriam's (1997) process of coding and categorization with the qualitative software analysis program, NVivo. For triangulation, program documents, including program brochures and client/student orientation packets, were also collected and analyzed. 


\section{Description of program and participants}

\subsection{Program: Southwestern ESO}

The participants in the research study were staff and students of an on-campus educational support organization, Southwestern ESO, specifically dedicated to serving adult low-income students enrolled in postsecondary study. The organization provided computer training, tutoring and online study awareness.

Southwestern ESO is housed at Southwestern Flagship University, a Carnegie-designated Doctoral/Research University-Intensive institution with an enrollment of more than 27,000 students. Southwestern Flagship University is the premier university in a southwestern state with three universities and four community colleges. The vision of Southwestern ESO is to provide "An environment where every adult can successfully pursue a program of postsecondary education." Its' services include entry and re-entry counseling, academic advising, tutoring, and career planning. The ESO serves approximately 2000 clients (students and potential students) in a county with 1.7 million residents representing $70 \%$ of the state's population. The county includes a major metropolitan city, where Southwestern Flagship University and Southwestern County Community College are located, and a farreaching rural community that both schools serve.

Southwestern ESO has a staff of ten: a program director, an assistant director, two counselors, two advisers, an office manager, two student workers and a clerical support person. With the exception of the office manager and clerical support person, all members of the staff are directly involved in new client orientation, or "intake," as it is referred to by ESO staffers. Some of the intake sessions occur in the Southwestern ESO office on the Southwestern Flagship University campus, but many of them occur off-site at locations more easily accessible by clients. For example, one counselor conducts intake at a reservation about fifty miles from the ESO office while another visits a military installation about twenty miles from the campus. Because of the number of clients that the ESO serves, the intake sessions are typically group sessions with 12-15 clients. During these sessions, clients are provided an intake folder containing information about the program and its services, including a client application for ESO services form, an ESO program flyer, a financial aide booklet, an academic survival handout with tips for being a successful student, enrollment procedures for Southwestern Community College, and a survey assessing client readiness for online study. Because of the large Hispanic population served by the ESO, the ESO provides two versions of its intake folder: a general intake folder and an English-as-a-Second-Language (ESL) intake folder.

ESO clients ready for postsecondary education are typically directed to Southwestern County Community College or Southwestern Flagship University for study. Southwestern County Community College is a good option for most ESO clients because of its open admissions policy, low tuition ( $\$ 40 /$ credit-hour) and robust offerings of online programs and courses. Enrollment directly at Southwestern Flagship University (\$96/credit-hour) is typically reserved for students with some postsecondary experience, recent high school graduates, and those without work demands. Of course, the ESO helps to facilitate student transfer from Southwestern County Community College to Southwestern Flagship University. 


\section{Program Staff Participants}

Program Director. Paula, a white female in her early fifties, is the program director of Southwestern ESO. She is married with a young daughter. Her introduction to online learning began when her daughter was three-years old. At the time, she was an instructor at a college in a town about forty minutes from her home. Her eldest son, who taught online at the time, encouraged her to try the new form of teaching because it would eliminate her commuting time and give her some flexibility in her teaching. Paula holds a doctorate in history.

Program Assistant Director. Nathan, a Native American male in his early thirties, serves as the assistant director of Southwestern ESO. He's working on a graduate degree in higher education administration. He was introduced to online learning through his work at Southwestern ESO.

Program Tutor and Student. Juanita, a 29-year old Hispanic female, is a military spouse with a young daughter. She holds associate degrees in general studies with an emphasis in business administration and in liberal arts. Both degrees were attained at a New Mexico community college while she was working full-time as a bank teller, and both included online courses. She is now a full-time advisor for Southwestern ESO. Her major job functions include performing client intake and providing translation services to program staff and students. She also does all the data processing. Prior to becoming an advisor, she served the organization as a student worker for two years. Before she enrolled in her first online class her computer and Internet experience consisted of playing games on her home computer, which had Internet access. She considered her familiarity with the computer and the Internet as "basic." She is working on her bachelor's degree through on online program at an out-of-state midwestern college.

Program Tutor and Student. Len, a 31-year-old Native American male who resides on a reservation about 50 miles from the Southwestern ESO main office, is a full-time student and part-time student worker for the ESO. His primary work location is an office on the reservation, which works well for him since he is the primary caretaker for his 70-year-old mother with whom he resides. He's spent one year in college in Utah and one year in Nevada before dropping out for 8-9 years. Now he is back to finish his degree. His major is business administration with an emphasis in management information systems because he loves working with computers. After he gets his degree, he wants to work on the reservation as the Management Information Systems (MIS) specialist. Presently, that work is handled by companies 50 miles away whose services are expensive and not very timely. He has had a home computer and Internet access for about three years, but he does most of his schoolwork in his office on the reservation. Len has taken a number of online courses at Southwestern County Community College and is now taking online and on-campus courses at Southwestern Flagship University.

\subsection{Student participants}

In addition to Len and Juanita, four other students participated in the study.

Sarah is a 44-year old single white female. She attended a California community college to study nursing after high school, but left a semester before graduating because she decided she didn't like it. She continued her full-time job at Montgomery Wards after leaving school 
and work there until Wards closed. For the last eleven years, she has worked as a telephone customer service for the same company. She does not like her work so she is going back to school to prepare for a job that will take her into retirement. She wants to study psychology and start a private practice. She has dial-up Internet access at home and her Internet experience consists mostly of conducting transactions on eBay.

Omar is a 38-year old career military (17 years in) Black male. He has an associate degree in personnel administration and munitions systems from the Air Force. He is a noncommissioned officer (NCO) working in personnel systems, where he maintains training records of Air Force personnel. After retiring from the service in three years, he knows he will need a second career and wants to become a teacher and maybe get into radio. While he knows a lot, he feels he needs the credential of a degree to enable him to get a "good paying job" when he gets out. He wants to have that degree in hand when he retires. He has dial-up service at home. His wife is taking online classes through the University of Phoenix.

Martha is a Caucasian female senior citizen, who refused to give her age because people "make assumptions when they learn your age." She retired to her current state 12 years ago with her husband of 40 years after living in California for more than 30 years. Her husband died five years ago leaving her alone and confused. After about two years of grieving, she decided, "He ain't comin' back. And so, I had to get on with my life." She decided to go to school to learn Word and Excel "just to keep myself busy," but taking a class turned into getting a degree when one of her teachers encouraged her to take a Math class. She's almost finished with a database programming degree at the community college and has started a degree in business at the local university. Before she graduates, she would like to get a job at the university so that she can begin working her way through the system to a full-time permanent position in the computer department as a database person. She is concerned about age discrimination. Before she started school she owned a Mac, but purchased a PC recently because "that's what all the school people were using." She has cable Internet service and goes online when she needs information, but she is not "sitting there, clicking all the time."

Paul is a 40-year old Caucasian male. He graduated high school in 1982 and spent about two years in a California community college in 1991-92, where he left before attaining any credential. In Spring 2003, he decided to quit his full-time job, take a part-time job (20 hours/week) and go back to school full-time. He is in a nuclear medicine program and plans to go into radiation therapy. His primary mode of Internet access is cable modem service for $\$ 29 /$ month, including a $\$ 10 /$ month discount offered by the community college.

Wendy is a 28-year-old Caucasian female. She graduated from a Washington college in 1997 with a degree in speech communications with a minor in technology. Life situations brought her to her current state where she "fell into social work" by taking a job as a resource manager and case worker at a non-profit organization that helps the working poor get the basic education they need in order to get those higher paying jobs that have opportunities for advancement. Because she enjoys her work so much, she decided to pursue a master's in social work. After she gets her MSW, she wants to pursue a career in social work administration where she can shape social policy at the national and state level. She is now taking her first online class. She does not have a home computer, nor does she have Internet access, but she has both at her parents' home and at her job. 


\section{Findings}

The study findings are presented as five themes which address the research questions: 1) reasons for enrolling in online study; 2) preparation for online study; 3) financing online study; 4) experience in the online course; 5) success in online courses; and 6) and the personal impact of online study.

\subsection{Reasons}

Convenience and flexibility were the most frequent reasons cited by participants for pursuing online study. As Juanita explained:

Being a parent, wife, and having to work, online just seemed to be a lot better option for me, because it was something that I was able to do from home. And it was something that I was able to fit into my schedule.

As evidence of the growing presence of online courses on college campuses, Wendy enrolled in her first online course, because the professor she wanted for the course was teaching the content online. She says, "So it was actually more that I wanted to take a class from that particular professor, versus [just taking an] online [course]."

Paul chose online courses to supplement his on-campus course load. "I just show up for my classes during the day. And if I'm at school and I have time, I'm gonna be looking at stuff [for my online courses]. I know if I have deadlines for the online courses, I can go home and try to get those done."

Martha found online courses a good way to get in more courses in a semester. She did not have to worry about time conflicts as she did with on-campus courses.

Some students were reluctant to enroll in online study and only did so because they of the encouragement they receive from staff. Nathan, the program assistant director, recalled:

I had one student who I had pushed to get into an online course because she needed to fulfill some requirements. She was hesitant. She came from a community college and had not taken online courses. . . But it worked out a lot better for her. She's a single mother and this was just a lot easier for her. And so, she said she's going to look for more [online courses].

Warren was one of the students the ESO motivated to consider online study. He explained his introduction to online study:

I really didn't know that the university offered it, but Nathan here told me about [during intake], you know, just to look into it. So that's when I decided to look into it, and I just researched and went online to see what I needed, the system requirements, everything else, and took a little quiz on there to see if I was okay to take it, you know.

\subsection{Preparation}

The ESO has a two-pronged approach to making students aware of the online study option. First, during intake clients are made aware of the option and allowed to complete the distance learning readiness assessment. The results are discussed with the intake counselor 
and a decision is made about whether to pursue online options. Second, the program provides an introductory computer course to get students comfortable with using a computer prior to enrollment in any online course.

In addition, the participants were provided additional information about online learning after enrolling in an online course. According to Juanita,

The community college where I came from, they actually had [a face-to-face] orientation, and actually when you enroll for an online class, you have to attend a [a 30-minute] orientation class. It was in a classroom setting. And everyone that was enrolled for an online class had to attend. And sit through their orientation on how you get on their blackboard, how you contact the instructor, how the syllabus and everything was located in there. And so, that was a requirement in order to go through with the online class.

The other participants described online sessions completed in their homes. For Paul, it was "a virtual tour thing that you can do on the computer," while Martha "went into WebCT. . .and just went over a few of the guidelines on how to access your assignments, how to look up different areas."

\subsection{Financing}

Four of the participants (Juanita, Wendy, Paul and Len) were financing their study with a combination of grants and loans. Martha, a senior citizen, was exempt from tuition and fees. Omar, an army man, was eligible for tuition assistance and the GI bill. Sarah was using her company's tuition assistance plan for her core courses. However, she will need loans when she starts taking courses in her major area, because the courses she's chosen are not covered by her employer. Interestingly, the grant/loan participants found that grants could fully support their community college coursework, while loans needed to be added to continue study at the four-year school because of the difference in tuition and fees. These loan amounts escalated for participants who were unable to get the online coursework they needed to complete the four-year degree at an in-state school. These students found themselves enrolling in out-of-state schools and paying out-of-state fees or enrolling in expensive, for-profit schools like the University of Phoenix and Education Direct.

Nathan was concerned about the financial burden associated with attendance at out-of-state and for-profit institutions, but he had to balance those concerns with the needs of ESO clients to obtain postsecondary education. He explained:

I personally don't limit our students from considering the University of Phoenix if they're able to pay for it. That's the big, big questions there. I think it's a good alternative if they're able to do that, especially the ones who are working full-time and have a family. And that's exactly who the University of Phoenix caters to. . So we don't usually track our students in that direction unless they have some type of financial aid, or are able to pay for it, because they're going to be looking at a lot of loan debt. . We don't like to see that for our low-income students.

Juanita, who wanted to obtain a bachelor's degree, could not find an appropriate online program at Southwestern Flagship University or any other state school. Though concerned about the financial burden she would incur by attending an online program at an out-of-state 
or for-profit school, she was forced to consider both options. She explained, "I've gone to school for five years and never had had to take out any type of loans because I don't want to go into debt. And being low-income, that's something that, you know, I wanted to keep far away until it was a necessity. And that's where I'm at." If she were attending school in her home state, a Pell Grant would cover the full costs of her tuition and books. For the out-of-state school she has chosen, she does not qualify for financial aide and has to rely on loans.

\subsection{Online course experience}

The seven student participants shared similarities in their course experience as well as differences. These similarities and differences revolved primarily around course design and student interactions.

\subsubsection{Course design}

Course design varied across participants' courses. Juanita reported that "At the community college I attended, all their classes seemed to have the same format," while at the four-year college course design "depends on maybe how the teacher wants to teach the class and what they want to use. It changes [from instructor to instructor]." Martha described a course that made little use of course management system:

What it was is that he would email us the lesson, we'd have to download it, and then we'd have to go work on it. So it was like we had a book, and he had maybe I'm gonna say 50 questions. And you had to read the book in order to answer the questions.

Sarah's experience involved television:

Once a week the instructor emails you a question and study guide for the week, what you're supposed to read, and then, you watch Channel 71 here. And that's your weekly course... The instructor does your whole course; you take notes from that, and you can rewind it. I loved it.

Paul described a course that made more use of online tools and resources:

So Music Appreciation was really fun for me. They had videos that they would watch, that you would watch 12 sessions or so. My Political Science also had the videos and so did the World Literature class. So you could see the instructor and stuff. I think the ones that were most interactive. ... And especially the English class. You know, there was a lot of everything. There were online e-books that we could read, along with the videos and stuff like that.

An aspect of online course design that was especially effective for the participants was the archived lectures and instructor presentations. Juanita explained,

I honestly think that the only difference between having the classes online for me, is that everything that the instructor lectures on, it's recorded right there. And when it's in the classroom session, if you're writing down something and he's already moved on to something else, you've already lost maybe a minute or two of something he's said, that you can't rewind and look at, as to what he said. And for me, when it's online, I'm a very black and white-You know, I see it and there it is, and you know, that's how. I'm 
a very visual person when it comes to learning, and I just feel more comfortable in an online setting.

Len thought he learned more online because of the design format:

I think I learned more online. . . Because there's more material presented. I mean, instead of going to a class Monday, Wednesday, and Friday from 9:00 a.m. to 10:00 a.m., and sitting in there listening to lecture and writing it down, that's all that was given. But online, you read the text, which you read in the class too. You read that text. And then, there was all these little things, you know, that you can go on, and if you needed more help there's always links to other places, to get extra, added-I thought that was more than just reading the book and listening to the professor.

\subsubsection{Student interactions}

The participants' experiences were similar in that they all expected and experienced a high level of interaction with the instructor in all their courses. Interaction with other students was not a given for their online courses. Juanita explained, "In my community college classes, basically everything was more of student-teacher relations. And here at the university, it's always been students as a whole, students with the instructor."

Paul was encouraged to "come and see" his instructors, a benefit for students like him who take a blended schedule of both online and on-campus courses.

So if I had the opportunity, then I would, you know, definitely go over. The English teacher I saw once a week. The others I at least tried to meet. And sending private emails back and forth, I never had a problem with that. I was always comfortable with asking questions, or if I wasn't sure about something. And they were always really nice and responded pretty quickly actually. I never really had to wait for anybody for days.

E-mail was a primary means of communicating with instructors, and prompt responses were the norm.

Because Sarah had easy access to the campus, she was able to schedule study meetings at local eateries with students in her online courses. "There was also a discussion board where you can post. And the instructors would also post." Some of Paul's courses made use of "weekly chats" where students could interact with each other and the instructor.

\subsection{Success in online learning}

How to succeed online learning is very important for the student with little experience with this delivery mode. The participants identified three characteristics students needed for success in online courses: discipline, initiative, and technology self-efficacy.

\subsubsection{Discipline}

All the participants considered student discipline important. According to Paul, "I think the biggest thing is discipline. Don't wait until the last minute, you know, 'cause it really is up to you to get the assignments done and on a timely basis." Len added:

If they're a freshman student, I don't think I would encourage online until they actually took a class because it actually-I mean, to me, it's more of a discipline thing for me 
because I don't think online classes are for everybody, to be honest with you. Because it took a lot of discipline from me, but I've been through other classes, and so, I want to do this, so that's why I made myself do this...I would like to say it would be for all the students, but like I said before, I think it's for students who are more in control, more disciplined in doing work on their own.

\subsubsection{Initiative}

Initiative, also referred to as aggressiveness and self-motivation, was also identified as important for success. Martha provided this advice:

You have to have a certain type personality to do online and not be fearful or not be hesitant or, you know, not be afraid that you won't know the answer. So you have to pursue it the best way you can. But you have to know that the internet has a wealth of information on your particular course. . . They have to be almost aggressive, not assertive, but they have to be aggressive, because - and they have to want to accomplish goals. And I'm talking male/female.

Sarah agreed:

I think you need to be kind of on your-How do I put this? An independent learner, and just study. And there's always someone there for you. Phone or email, or you can go to their office. You feel like you still have like classmates, because you go on the message board. So don't let that frighten you, that you won't have a teacher there in front of you to ask questions. It's kinda like you still have a class, but it's just at home.

\subsubsection{Technology self-efficacy}

The participants stressed the importance of students enrolling in online study having a working knowledge of computers and the Internet along with comfort working online. According to Len, "So I think the first thing, you know, they need to learn about is computers and how to use the internet." Juanita encourages those counseling and supporting low-income students to:

Just to continue to be supportive of someone, especially if they do not know anything about computers, just to help them by referring them to places that offer free computer, limited classes, you know, limited basic computer classes or, you know, where they can improve their skills on them, and just to encourage them to not give up. I know sometimes some people, you know, we live in a world of technology, and a lot of times people assume that you should know something about computers. And if you come from a low income family like I did growing up, we didn't have that option of having a computer in the house. And I actually didn't have my first computer until maybe 6 years ago, and even then I was about 23, and at that time, you know, a person could own a computer and still not know anything about it. So it's just maybe just continuing to offer support for them and encourage them.

\subsection{Personal impact of online learning}

Participants were asked to assess the impact of online study on their lives. Two students, Juanita and Len, acknowledged that they would not have been able to work on their degrees without the online option. Juanita explained: 
with me being a military spouse and having a child and moving, I've been able to move in the middle of the semester and still take my classes and continue my education from one state to another. Whereas if I didn't do that, then I'd have to leave school, classes, and start all over again.

For Len, who has to take care of his home-bound mother, money was a big issue, "I probably would not have been able to afford to drive back and forth and you know, I had a very good, running vehicle to drive back and forth and spend the time in town."

The other participants expressed that while they would have been able to pursue their degree, it would have taken them much longer to do so without the online option. The flexibility of when to interact with the course, instead of a fixed meeting time at a physical location, allows students to modify their schedules for more learning opportunities.

\section{Conclusions}

Although family or work obligations (Tones et al., 2009) and income are a few of the main barriers for adult students to enroll in courses, the student experiences in this research project serve as an example that low-income and working adults can be successful in a distance education course. From these students' experiences, we gain insight into effective learning environments that support the needs of working adults.

\subsection{Lessons learned}

\subsubsection{About the program}

The students in this research project were served by a well-organized and multi-faceted support organization. Southwestern ESO had four defining characteristics:

1. The program administrators had experience teaching and/or taking online courses. Their experience gave them a positive attitude towards online study and how it could be beneficial to the students they served. As a result, they directed students to this option. Further, when students were reluctant to pursue the new avenue, the administrators were able to address their concerns from a personal perspective in addition to directing them to program supports for online study.

2. Even though their students were enrolled online, Southwestern ESO provided face-toface contact with students as needed. During intake, students either came to the ESO office or ESO staff went to the students. This type of personal contact provided clear evidence to students that Southwestern ESO would be there when needed.

3. Southwestern ESO supported students' transition from the community college to the four-year university. This support throughout the college career was important in helping students to persist in postsecondary education.

4. Southwestern ESO provided face-to-face and online training, along with an orientation session to prepare students to study online. By providing these preparation activities, the program reduced some of the apprehension that students had towards being able to be successful studying online. 


\subsubsection{About the students}

All of the students in this research project were pursuing postsecondary education as a way of advancing themselves financially and professionally. None of them considered themselves anything beyond computer novices before they enrolled in online study; two of them did not have a home computer or Internet access. They chose the online option for a variety of reasons. The military wife and mother chose online study because it suited her life as a mother who needed to be home with her children and a military wife who moved from base to base. The senior citizen chose online courses to supplement her on-campus courses as a way of completing her degree faster.

\subsubsection{About financing}

Access to flexible learning options and cost of attendance were related for the students in this research project. Although students used grants to cover their cost of attending the community college because it was fairly inexpensive, loans had to be added to their portfolio to cover the cost of attendance once they transitioned to a four-year school. Students and ESO administrators acknowledged that limited online and distance degree program offerings at the local public university forced students to consider out-of-state and for-profit institutions, where the cost of attendance was higher than at the local public university. One student chose an out-of-state institution that cost more because the local university did not offer a distance degree in her area of study.

\subsubsection{About the course experience}

Students in this research project experienced different flavors of online learning. For one student, online learning was a weekly e-mailed lesson. For another student it was e-mail and televised video lectures. Another student's course used a course management system. One feature of online courses that three of the six participants commented on favorably was the video lectures. Whether these were accessed online through the computer or viewed on television, students appreciated the ability to re-play and stop/rewind the lectures as needed. In addition, the feature really helped with note-taking.

In this project, students had more online interactions with professors than with students. Some students reported being encouraged to visit instructors in their offices, which was only possible because they lived within driving distance of the campus. These same students also scheduled face-to-face study groups with other students.

Two students in this project used online courses to supplement their face-to-face schedule of courses. These students found it easy to obtain extra credits by taking online courses, because they did not have to worry about conflicts with other campus courses on their schedules. Being able to take a blended schedule of campus-based and online courses allowed students to complete degree requirements faster.

Students appreciated the pre-course and in-course training they received. Training/ orientation for online courses important to students; some students are reluctant to study online because it is new to them. 


\subsubsection{About success}

Discipline, initiative, and technology self-efficacy emerged as keys to success in online learning. Because of the discipline required to complete and submit work on a timely basis, the students did not think online learning was for all students. One student was particularly concerned about freshmen taking online courses. The students saw initiative as important because the teacher is not physically there to guide you through every step of the work you have to get done. While acknowledging that everything students needed to complete assignments was present in the online course materials and the online tools provided (discussion board, for example), some students would be uneasy about accessing the help they needed. These students also felt that students pursuing online study needed a degree of comfort and knowledge with using a computer and the Internet. They felt these skills could be learned, but that the new student would need support as they went through the learning process.

\subsubsection{About personal impact}

All the student participants felt that having access to online courses was required for them to meet their goals for a degree. The four students with full-time jobs did not think they would have been able to pursue postsecondary study without the online option. The two nonworking students felt that having access to online learning allowed them to complete their degree requirements faster, thereby entering the job market sooner.

\subsection{Implications for practice}

The lessons learned from this research have the following implications for practice:

1. There is a need for increased fully online undergraduate degree program options by public institutions. Prasad and Lewis (2008) found that institutions are offering individual online courses at a much higher rate than they are offering fully online degree programs. Public institutions must make this change or continue to force students who can least afford it to find more expensive out-of-state and for-profit options.

2. Institutions must make their local communities aware of their online options, financial aide opportunities and educational support services. In this research project, Southwestern ESO took on this function.

3. Institutions must prepare themselves to have on-campus students and distance students competing for seats in their online courses. As shown in this research, campus students take a blended approach to scheduling by including both campus-based and online courses. In many cases, online courses will be comprised of campus students and distant students, two populations requiring different types of support. In research conducted with of students enrolled in graduate study, Skopek and Schuhmann (2008) found that obstacles related to geographical proximity are concerns for distant students enrolled in courses with on-campus students. Because they are physically further from faculty, they have fewer opportunities to interact with faculty and peers face-to-face than on-campus students.

4. Do not restrict all interactions in an online course to be mediated by Internet technologies. The students participating in this research experienced a variety of online 
course offerings that used Internet tools and non-Internet tools. For example, one course had students view televised lectures. Another course may provide DVDs to students.

5. Consider developing an online support organization or division devoted to support online students. While students in this research project lived in close proximity to the institutions offering their online courses, institutions cannot depend on this being the same situation for all online students. Based on the Self-Direct Learning Model (Grow, 1991), learners are within four distinct stages that range from learners needing an authority to direct them (Stage 1) to learners who are motivated and capable of directing their learning process either alone or with an expert's help (Stage 4). Sarah's comments regarding being an "independent learner" illustrates a Stage 4 perspective while still knowing that you can receive assistance and direction from the instructor. For a novice online learner, this may be unfamiliar perspective. However, with structured support from distance education organization, students can be better prepared for their first experience. This support comes in the form of training or orientation courses to introduce students to the activities, management, and selfdirected responsibilities necessary for distance learning.

6. The interface design for organizing information can impact student success. As noted in the research of Moore, Downing, and York (2002), online instructors should be mindful that their online course organization of materials might not match the mental model of the students. Juanita's comment regarding how courses at 4-year universities have different organization schemes whereas the online community colleges look the same relates to the multiple course phenomenon (Moore, et al., 2002). When students are accessing more than one online course in the same Content Management System (CMS), such as Blackboard, Angel, Moodle, Sakai, they can easily become disoriented when searching for course content. As a result, this phenomenon illustrates how content organization can impact students' satisfaction level with the course, which can sometimes result in low attrition and negative course evaluations.

\subsection{Future research}

There are two major limitations of the research presented in this chapter that indicate areas where future research should be directed. The first limitation of the study is that it focuses on seven students associated with a single educational support organization. Future research should broaden the study to include more students, both students enrolled in online study and students choosing not to enroll in online study. Including both groups of students in the study will provide more insight into how students make choices about whether to enroll online. Future studies should also include more educational support organizations. Online student needs can be met in a variety of ways. By including multiple educational support organizations researchers can begin to investigate and evaluate the different support models for effectiveness.

The second limitation of the study is that it takes a snapshot of the student experience at one point in time. Future research should include a longitudinal study that follows students from the beginning of the postsecondary study through its completion. Such a study would provide insight into student persistence and attrition as well as a more developed view of the student experience. 
While the study presented in this chapter took a qualitative approach to the student experience, future research that addresses these research questions from a quantitative perspective would be valuable. Such research in conjunction with qualitative experiential data would provide a richer and broader understanding on the online study experience for these students.

\section{References}

Ashburn, E. (2007, April 13). Mapping the misunderstood population of adult students. Chronicle of Higher Education 53(32). A35.

Aud, S., Hussar, W., \& Kena, G. (2011). The Conditions of Learning 2011. (U.S. Department of Education, National Center for Education Statistics, NCES 2011-033). Washington, DC: U.S. Government Printing Office.

Benson, A. (2007). An exploratory story of online postsecondary education for low-income working adults: A view from education support programs. Journal of Negro Education (76)1, 17-30.

Brown, R. (2001). The process of Community-Building in Distance Learning Classes. Journal of Asynchronous Learning Networks (5)2, 18-35. Available at http://www.aln.org/publications/jaln/v5n2/pdf/v5n2_brown.pdf.

Carriuolo, N. (2002). The nontraditional undergraduate and distance learning: is higher education providing a portal or just a keyhole to social and economic mobility? Change 36(6), 56-61.

Coombs-Richardson, R. (2007, Winter). Personalizing distance learning. Kappa Delta Pi Record, 71-75.

Dutton, J., Dutton, M. and Perry, J. (2001, January). Do online students perform as well as lecture students? Journal of Engineering Education (90)1, 131-136. Available at http://www4.ncsu.edu/unity/users/d/dutton/public/research/online.pdf.

Green, J. (1998). Androgogy: teaching adults. (B. Hoffman, Ed.) Encyclopedia of Educational Technology: Available at http://coe.sdsu.edu/eet/Articles/andragogy/start.htm.

Grow, G. (1991). Teaching learners to be self-directed. Adult Education Quarterly, 41(3), 125-149.

Huang, H.-M. (2002). Toward constructivism for adult leaners in online learning environments. British Journal of Educational Technology, 33 (1), 27-37.

Kleiman, G. (2004). Meeting the need for high quality teachers: e-learning solutions. U.S. Department of Education. Available at

http://www.ed.gov/about/offices/list/os/technology/plan/2004/site/documen ts/KleimanMeetingtheNeed.pdf

Knowles, M. (1984). Andragogy in action: applying modern principles of adult education. San Francisco: Jossey Bass.

LaPadula, M. (2003). A comprehensive look at online student support services for distance learners. The American Journal of Distance Education, (17(2), 119-128.

Lim, D. (2004). The effect of flexible learning schedule on online learners' learning, application, and instructional perception. In Academy of Human Resource Development International Conference: Symposium 49-1 (pp. 1060-1066).

Lim, D.H., Morris, M. \& Kupritz, V.W. (2007). Online vs. Blended Learning: Differences in Instructional Outcomes and Learner Satisfaction. Journal of Asynchronous Learning Networks, 11(2), 27-42 
Ludwig-Hardman, S. and Dunlap, J. (2003). Learner support services for online students: scaffolding for success. International Review of Research in Open and Distance Learning (4)1-15.

Lynch, M. (2001, November/December). Effective student preparation for online learning. The Technology Source, November/December 2001. Available at http://technologysource.org/article/100/.

MacDonald, C. \& Thompson, T. (2005). Structure, content, delivery, service, and outcomes: quality e-Learning in higher education. International Review of Research in Open and Distance Learning 6(2), 1-25.

Merriam, S.B. (2001). Pillars of adult learning theory. New Directions for Adult and Continuing Education (89).

Merriam, S.B. (1997). Qualitative research and case study applications in education: Revised and expanded from case study research in education. San Francisco: Jossey-Bass.

Moore, J. L., Dickson-Deane, C. \& Galyen, K. (2011) E-Learning, Online Learning, and Distance Learning Environments: Are They the Same? The Internet and Higher Education, 14,129-135.

Moore, J. L., Downing, R., \& York, D. (2002). Organizing instructional content for Webbased courses. Does a single model exist? Quarterly Review of Distance Education, $3(3), 269-281$.

Noel-Levitz. (2005). The 2005 national adult learners satisfaction-priorities report. Iowa City: CAEL. Retrieved from the ERIC database.

O'Lawrence, H. (2006, May). The influences of distance learning on adult learners. Techniques: Connecting Education and Careers 81(5), 47-49.

Patton, M. Q. (1990). Qualitative evaluation and research methods (2nd ed.). Newbury Park, CA: Sage Publications.

Prasad, B. \& Lewis, L. (2008). Distance Education at Degree-Granting Postsecondary Institutions: 2006-2007. (U.S. Department of Education, National Center for Education Statistics, NCES 2009-044). Washington, DC: U.S. Government Printing Office.

Pusser, B., Breneman, D., Gansneder, B., Kohl, K., Levin, J., Milam, J., and Turner, S. (2007, March). Returning to learning: adults' success in college is key to America's future (Lumina Foundation for Education New Agenda Series). Indianapolis: Lumina Foundation for Education.

Richardson, J. and Swan, K. (2003). Examining social presence in online courses in relation to students' perceived learning and satisfaction. Journal of Asynchronous Learning Networks (7)1, 68-88.

Skopek, T.A. \& Schuhmann, R.A. (2008). Traditional And Non-traditional Students In The Same Classroom? Additional Challenges of the Distance Education Environment. Online Journal of Distance Learning Administration 11(1).

Tones, M., Fraser, J. Elder, R., \& White, K. (2009). Supporting mature-aged students from a socioeconomic background. Higher Education: 505-529.

$\mathrm{Tu}, \mathrm{C} . \mathrm{-H}$. (2004). Online collaborative learning communities. Westport: Libraries Unlimited.

Willging, P. and Johnson, D. (2004, December). Factors that influence students' decision to dropout of online courses. Journal of Asynchronous Learning Networks (8)4. Available at http://sloanc.org/publications/jaln/v8n4/pdf/v8n4_willging.pdf.

Yoon, S. (2003). In search of meaningful online learning experiences. New Directions for Adult and Continuing Education (100), 19-3.

Yukselturk, E. \& Inan, F. (2006). Examining the factors affecting student dropout in an online certificate program. Turkish Online Journal of Distance Education 7(3), 76-88. 


\section{Part 5}

\section{Distance Learning Educational Tools}





\title{
Web-Application for Engineering Graphics - An Example of a Distance Learning Tool
}

\author{
Lourdes Rubio and Belén Muñoz-Abella \\ University Carlos III of Madrid \\ Spain
}

\section{Introduction}

The new global communication systems and their integration in all media communication, together with their potential interactivity, are changing our culture and are introducing new questions and challenges in the educative system. The teaching practices are strongly impacted by the development of the new technologies, not only because they influence the professional skills of the teachers, but also because of the roll they have assumed in the global university context.

Although these new techniques are arising in the last years in the university education, the teaching-learning processes are based mostly on that of the 15th century. There is still a dominance of printed over the audiovisual and computer media in the transmission of knowledge.

The idea is then, how to incorporate, in a pedagogical way, these new technologies as useful tools for the presence and distance learning. The possibilities that the virtual environments offer, as potential spaces of collaboration for the learning processes and also for the professional training, are only an example of the great opportunities of these new technologies in the university education.

The use of computer systems for the development of teaching activities is quite recent, but the evolution of their use is very fast. In fact, in a short period of time (few years) the computers have changed their use from being the helping tool of the teachers in the classrooms to being the main character in the distance learning process through the wide world web, in what is called the e-learning.

The distance learning or the e-learning is a new way of education developed thanks to the new information technologies and internet. It is based on the easy distribution of educational materials and communication tools to create a learning frame. There are plenty of definitions for distance learning, but all of them are based in the same idea: it can be thought of as education or training delivered to individuals who are geographically dispersed or separated by physical distance from the instructor using computer and telecommunication facilities (Bélanger \& Jordan, 2000) or as other authors describe, it is a process to create and provide access to learning when the source of information and the learners are separated by time and distance, or both (Honeyman \& Miller, 1993). It also can 
refer to a type of education where students work on their own at home or at the office and communicate with faculty and other students via e-mail, electronic forums, videoconferencing, chat rooms, bulletin boards, instant messaging and other forms of computer-based communication as the United States Distance Learning Association says (USDLA, 2011).

This technology allows the student to access to interactive and multimedia web courses supported on communication media and allows the on-line collaboration and change of the studied materials. At the same time, it guaranties the tuition education by an expertise that follows the progress of the students, providing orientation and motivation and solving doubts among others. Through internet, the learning process is a just-in-time learning where and when the student needs it. This is one of the main advantages of Internet: the users can get abilities and knowledge regardless of timetables and schedules and with no need of displacements from the office or from home. So the advantages of the e-learning can be summarized in three: time flexibility, cost efficiency for students, and a great number of users at the same time.

\section{Distance learning of engineering graphics}

When teaching basic subjects of undergraduate engineering courses, such as Descriptive Geometry and Technical Drawing, it is necessary to introduce new technologies that help the students learning. Learning can be achieved using the traditional face to face way or by the most recent remote way by means of what is called e-learning or distance learning.

One of the first things an undergraduate in engineering has to study, as part of the core matters of knowledge, is Technical Drawing or Engineering Graphics as the threedimensional (3D) perception of the students in those technical programs is based on Descriptive Geometry. Descriptive Geometry involves the study of different representation systems and more specifically the Orthographic Projection. The orthographic projection, derived from the Gaspard Monge Descriptive Geometry, gives the foundations of the Engineering Drawing and is usually included in most first years of engineering studies. The main disadvantage of the representation systems is that they are based on the work with the projections of the objects and not with the 3D objects directly. Therefore, the students have to develop, if they do not have, the ability to think spatially and operate in the plane in pencil and paper.

The traditional core technical subjects, as Technical Drawing, can be helped to be taught and, what is more important, to be understood by the students by the new technologies and by the new design tools. Any activity in this sense is not enough to help the students to acquire the skills to see and work in 3D. As any other undergraduate courses, Engineering Graphics has to adapt, as well, to the new procedures of distance learning. Many researchers and teachers are involved in this new trend but not many references have been found by the authors (Toledo \& Rojas, 2001; Rubio et al., 2007; Morales et al., 2009; Rubio et al., 2010) in which the distance learning is applied to the aforementioned technical field. It is therefore very important to develop tools or/and web applications that allow the introduction of this kind of subjects to the distance learning through the Internet.

The main goal of distance learning in Engineering Graphics or Descriptive Geometry is to search for alternative methods to improve the education-learning process of multiple 
projection systems focused on high school or undergraduate university programs. Two aspects have to be taken into account:

- From the student point of view: as mentioned before, the students have to cope with two realities, the objects and their projections. It is a pedagogical target to decrease the conceptual distance between them, as part of the Descriptive Geometry learning process. The student has to became the observer of the object positioning himself at different points of view and has to be able to establish the connection between the Orthographic Projection and the object and backwards, being able to see the reversibility of the process. At the end, the student has to develop the ability to communicate with a nonverbal language as it is the Technical Drawing.

- From the teacher point of view: although Descriptive Geometry is based on clear conventions, which should create a very easy learning environment, difficulties arise due to the lack of $3 \mathrm{D}$ perception of the students. The animated presentations and drawings should be a perfect complement for the teaching activity as they allow short explanations with a very little amount of contents lost.

\section{The methodology}

To cover the aforementioned main aspects, a computer-aided tool that allows learning the foundations of Orthographic Projection (Monge Projection) has been developed. In a first stage the tool was thought to be used as a support in the classrooms for undergraduates in Engineering Bachelor Programs. In a second stage, due to the requirements of the students, the tool changed its target and was focused to the use on-line, taking advantage of the open access to the Internet with no special software requirements.

\subsection{The web site}

When designing and building a web site it is crucial to do a very good planning which includes establishing the aim and the scope very precisely, considering the potential audience, taking into account the available resources, and preparing a good navigation schedule inside the site (Marques, 2011; Pardo, 2011).

As everybody knows, the web navigation structure can be defined as the way the pages of the site are placed with respect to their links. The ability to capture audience in a web site depends on the design of the site itself. The best the design, the greater the audience. Any site design is based on pages as in a book, although the design of both structures is very different. In a book, the pages are chained and the procedure to find the information is to look for it in the index or through the lecture. In the web site, there are links between the pages so that the way to find the information is to jump from one page to another using those links. Therefore, the navigation system should be very clear in order to prevent the user to get lost and to facilitate the knowledge of where he or she is at any moment in order to come back to the initial position. The links between pages allow the classification of the navigation system in linear, hierarchical or complete (Fig. 1). The navigation system chosen for the created web site is the hierarchical one, which shape is like a branched tree. This type of navigation system is that recommended for sites with different but not many matters. Each branch of the tree is dedicated to a single part of information of the site. Generally, when a user gets to one of the head pages there are several links to the other pages and reversely, the navigation system usually has links to the head pages. 


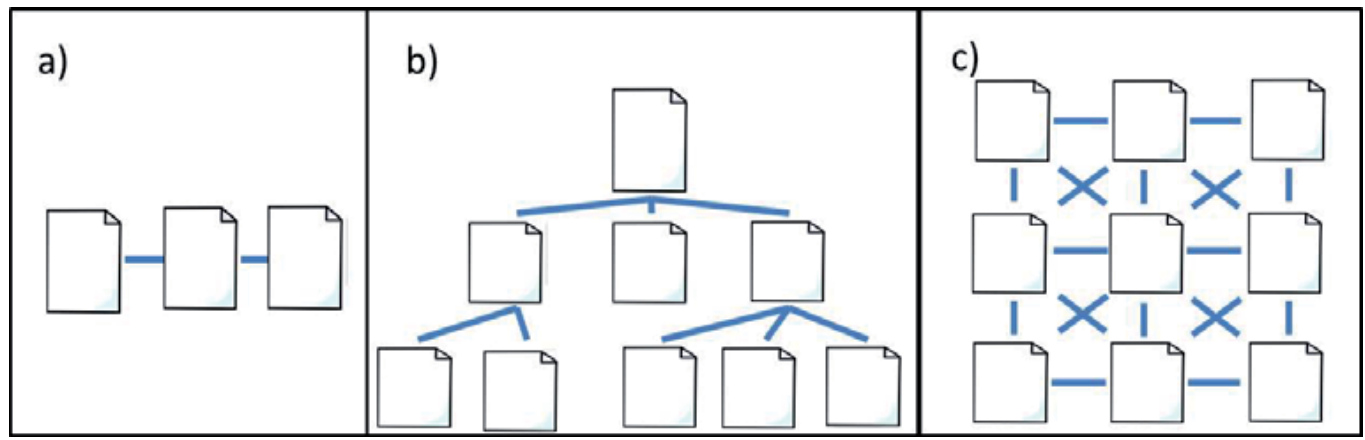

Fig. 1. Different navigation systems a) lineal, b) hierarchical, and c) complete

\subsection{The software packages}

Two different software packages have been used in order to develop this new web-site application for teaching Descriptive Geometry: Flash ${ }^{\circledR}$ and Dreamweaver ${ }^{\circledR}$. A very short explanation on their use is done in the following sections.

\subsubsection{Flash}

The software Flash ${ }^{\circledR}$ (Reinhardt, 2004) is a commercial application whose main objective is to generate animations for the web using vectors. The properties of the software fit very well with the development of the project. On the one hand vector graphics are used and secondly, there is a direct interaction of the user with the animations. Flash ${ }^{\circledR}$ works creating vector illustrations, that is, mathematical representations of straight lines, curve lines, colours and positions. One advantage of the vector illustrations is that the quality of the illustration does not depend on the resolution. Another advantage is that they have the ability to be downloaded very fast as their weight is really small compared with other illustrations with equivalent map of bits. Every example developed for the web application does not weight more than $80 \mathrm{~Kb}$ which is very interesting for the students because they can open them in an easy way, even with narrow band Internet.

There is still another advantage for the students and it is that the licence is needed for the creation of the files, or the exercises in our case, but not for the visualization of the files. Flash compiles the executable file .exe or the file .swf that can be executed from the most known web navigators with just an open plugin available for most of them. The estimations are that $80 \%$ of the computers can visualize Flash applications so that every documentation developed using Flash can be easily used by any student any where.

\subsubsection{Dreamweaver}

The software Dreamweaver ${ }^{\circledR}$ (Lowery, 2001) is also a commercial application that provides the user with many tools that help very much in the activity of the design and the creation of web sites. With this kind of software the user is able to create very complex web sites, with thousands of pages, animations and sounds with very little knowledge on programming. In the development of this web site, the authors have used the Cascade Style Sheets (CSS) as they improve the web documents design and presentation. In general, the 
Style Sheet is a set of instructions that indicates how the pages should appear or how the contents should be shown within them. Any change in the style sheet will produce an immediate change in the appearance of the pages no need to do it in each one. In this way, contents and appearance are completely separated, which helps very much the design work.

\section{The developed web application for engineering graphics}

\subsection{Objectives}

The main objective of the web site is the on-line publication of tutorials for the Descriptive Geometry study. The potential users of the web site are undergraduate students of engineering and students of Descriptive Geometry in general (Rodriguez de Abajo, 2007; Rubio \& Muñoz-Abella, 2011).

The tutorials are divided into theoretical resumes of the fundamentals of Orthographic Projection (Monge Projection) and a collection of exercises with animated step by step solutions, that helps the students to understand de course. The application presented here gives support to the master classes as intended, and also allows the utilization in the elearning process, or the distance learning, by those students who are far away from the teaching places.

As mentioned before, the application merges the use of two commercial software packages which allows first, the preparation of the animations of the exercises in light and easy-to-use files, and secondly, the organization of the contents in a very friendly web site.

Together with the animated 2D solutions of the exercises, the application shows the 3D animated solutions, that constitutes an original contribution to the web applications on the field of Descriptive Geometry teaching.

\subsection{Structure}

The web site is divided into three parts: main page, theoretical concepts and solved exercises (Fig. 2).

The main page is the home of the web site and can be considered as the main entrance to the web application. In Fig. 3 a) and b) both versions in Spanish and in English are shown. In this first page, as can be seen, the objectives of the application are given. This page is intended also to give the instructions for the use of the application in a very short and easyto-understand manner. In the top and in the left side of the main page a set of buttons allows the navigation to the different pages and places of the site. Those at the top are the links to the theoretical resumes and those at the left side guide the users to the animated step by step solutions of the exercises.

The second part of the web site is devoted to the theoretical resumes of the Orthographic Projection. The resumes are organized in pages by sections with the fundamentals of the subject. So, there is a section or a page for the fundamentals related with the point, there is another one for the straight line, for the plane and so on. As mentioned before, the way to move from one section to another is making use of the buttons at the top of the page. An example of this theoretical part is shown in Fig.4. 


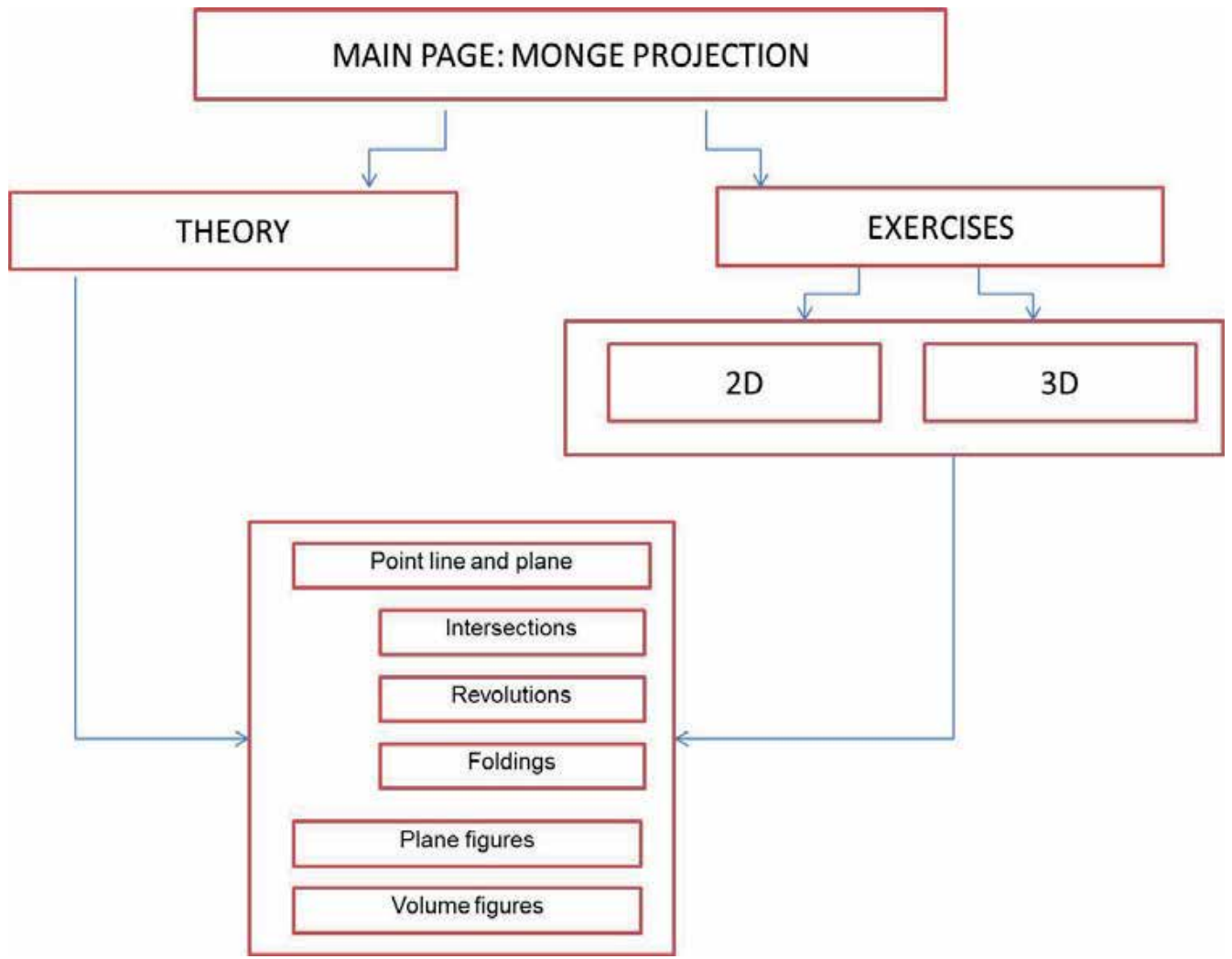

Fig. 2. Scheme of organization of the web site

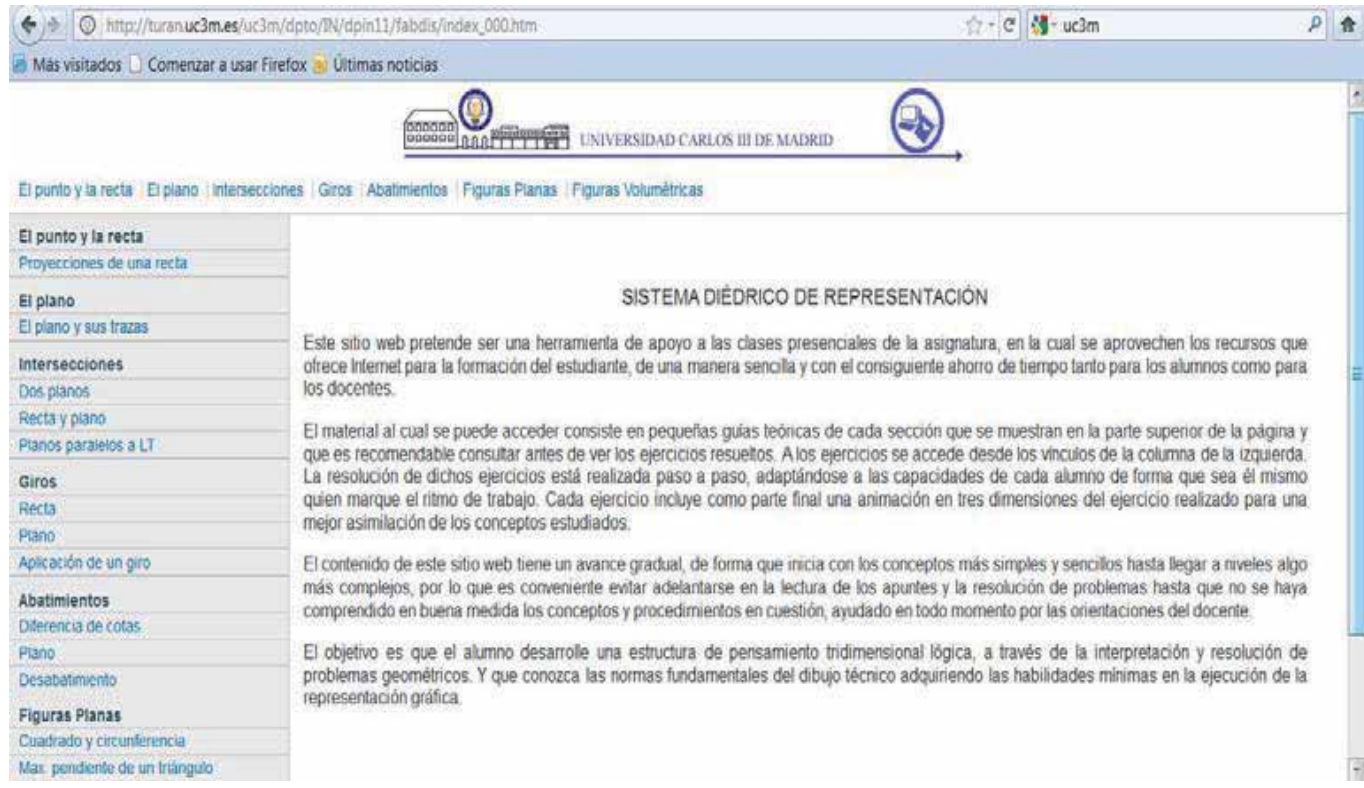

Fig. 3a. Main page of the application (Spanish version) 


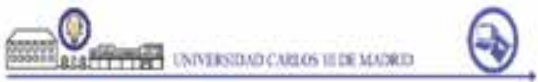

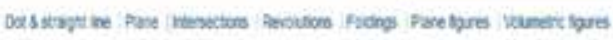

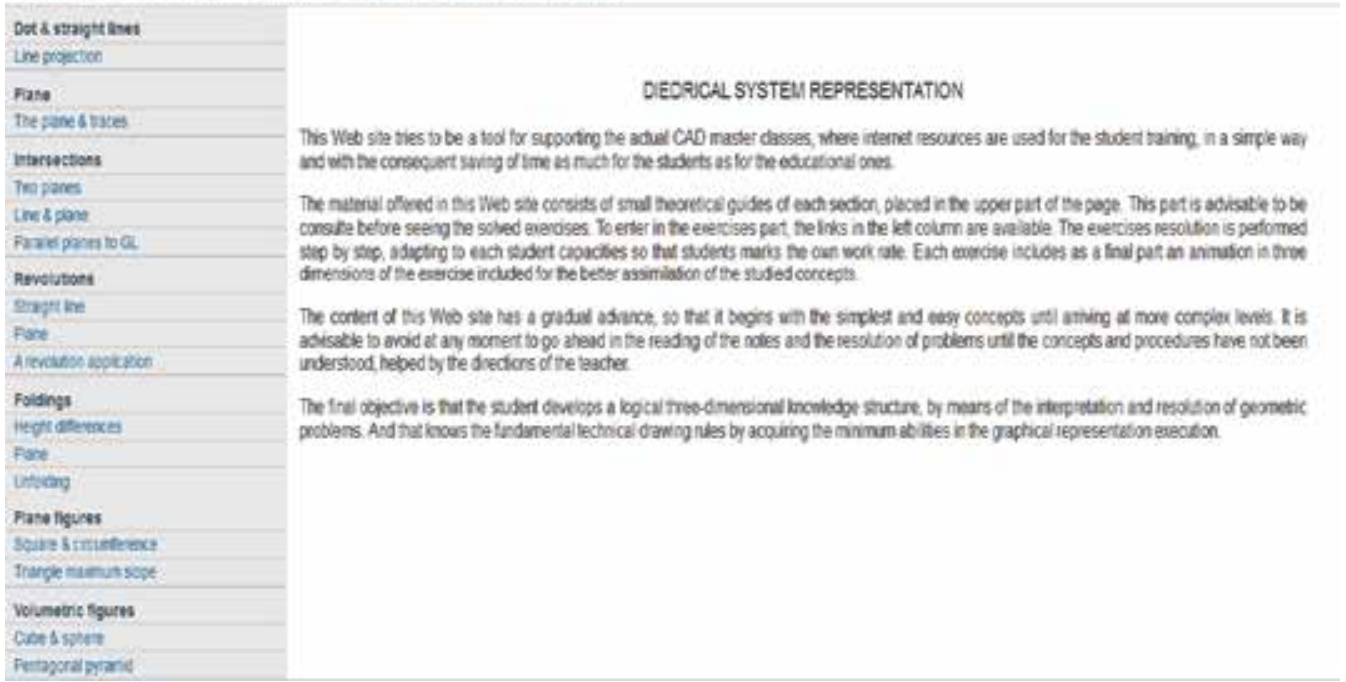

Fig. 3b. Main page of the application (English version)

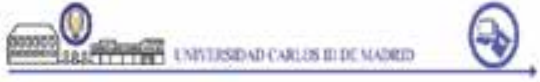

\begin{tabular}{|c|c|c|}
\hline Dot altragtine : Rant Itenecture & Ferolitere & Poichos Pase fores I bunetx fores: \\
\hline Oots rovergtines & \multirow{5}{*}{\multicolumn{2}{|c|}{ 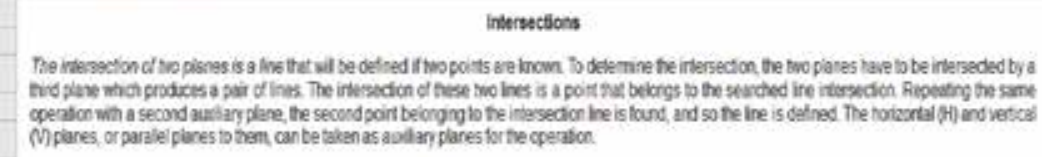 }} \\
\hline Une prokicton & & \\
\hline Fure & & \\
\hline Thepanestros & & \\
\hline Inersactsont & & \\
\hline
\end{tabular}

Tive pionet

Unestane

Fandiareate $\alpha$

Doveltions

Siragtine

Duse

Arescation oppicrior

Feidinge

roplidereses

Funt

unowsing

Fucefoures

Soan 3 chonterns

Trande naningoget

Veisunstigarn

Ose isines:

Perfogores parso

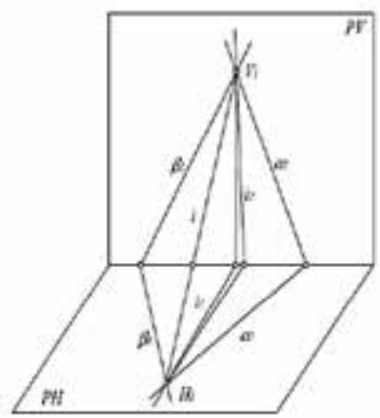

Fig. 4. Example of the theoretical contents page: intersections concepts

The last part of the web site is dedicated to the exercises, the most practical part of the site, and probably the most helpful part of the site for the students. It contains the animated solutions of the exercises. To get the solutions, the users have to use the aforementioned buttons of the left hand side of the main page. 
The explained application can be used by any student providing he knows the link and, as it was said before, the application is used by our students as a distance tool for their personal work, especially enhanced within the European Higher Education Area (EHEA) and the reforms of the Bologna Process introduced recently in most of the European Universities. For the distance learning usage, the application is included on a platform in which the contact with students is done permanently through e-mail and electronic forums supervised by professors.

\section{Example exercise}

The most interesting part of the web site is the analysis of the step by step animated solutions of the selected exercises, fifteen in total. Each exercise is explained along the animation in each step. In order to explain how the application is organized, different snapshots of the solutions of one exercise, taken as an example, are going to be shown.

The step by step solution for the aforementioned exercise is shown in Figures 5 to 12. Each figure is a single image of the sequence of the animated solution that the student can follow, and as can be seen, contains some simple messages that help to understand the examples and the theory involved. In all these snapshots, the original colours of the application have been changed for the sake of clarity of the figures.

For example Fig. 5 is the first image of the exercise and contains the statement of a problem corresponding to the section of "plane figures" or "2D shapes".

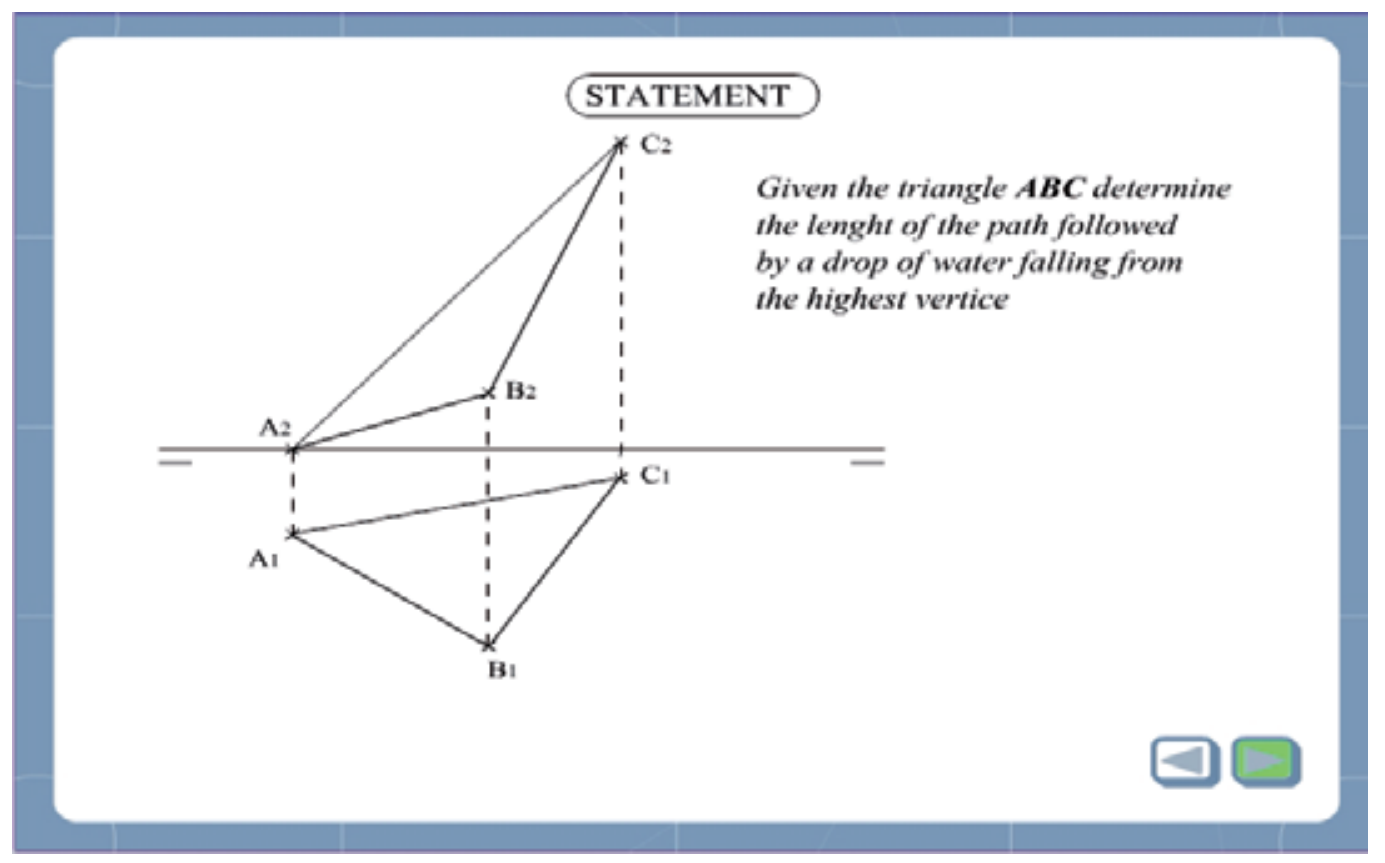

Fig. 5. The exercise statement 
From Fig. 6 to Fig. 12 different snapshots of the animated solutions are presented. In each one, the part of the drawing corresponding to the current step is coloured in light colours (originally in orange in the application) while the previously drawn lines are represented in black. When a step has finished, a little arrow in the right bottom corner of the screen is illuminated in green, which indicates that the new step can start. In this way, the students can think or imagine, before starting the new animation sequence, how the solution will continue. The end of the proposed 2D exercise solution is shown in Fig. 12. In this snapshot, every line represented during the previous step in now drawn in black.

Once the problems have been solved in the 2D option, all the exercises proposed in the web site are solved, for a better understanding and following the same steps which guided the $2 \mathrm{D}$ solution, but in a 3D animation. The example of the 3D animation of the same exercise is shown in the snapshots from Fig. 13 to 19. The 3D animated solution is a particularly interesting characteristic of the application because it helps the students to connect the $2 \mathrm{D}$ solutions of the problems, which are those they have to draw in pencil and paper, with the real 3D problem.

In Fig. 13 the transformation of the 2D statement to the 3D one is shown. Fig. 14 to 19 show the snapshots of the 3D solution following the same steps than the 2D solution. In Fig. 19 the final drawing represents the solution in 3D which coincides with that obtained by $2 \mathrm{D}$ Orthographic Projection. The figures in 3D help the student to understand the main concepts of each part of the subject.

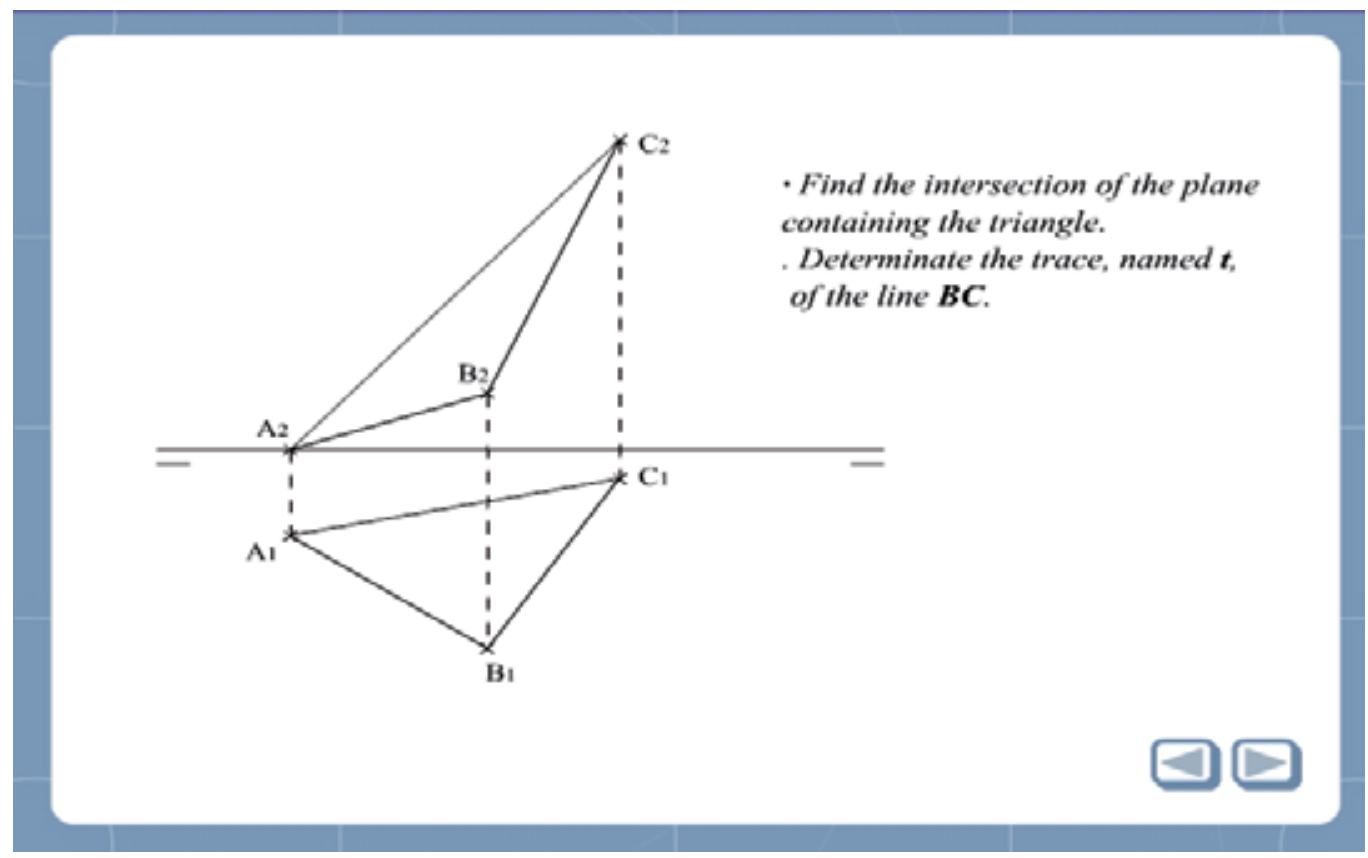

Fig. 6. Explanation of the exercise statement 


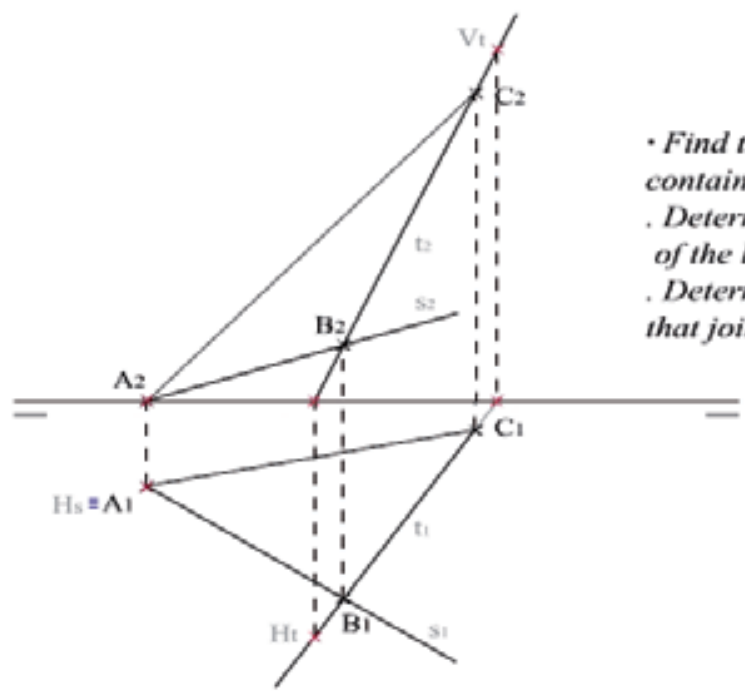

Find the intersection of the plane containing the triangle.

Determinate the trace, named $t$. of the line $\boldsymbol{B C}$.

Determinate the trace of line $\mathbf{s}$, hat joints $\boldsymbol{A}$ and $\boldsymbol{B}$.

Fig. 7. First snapshot of the animated solution

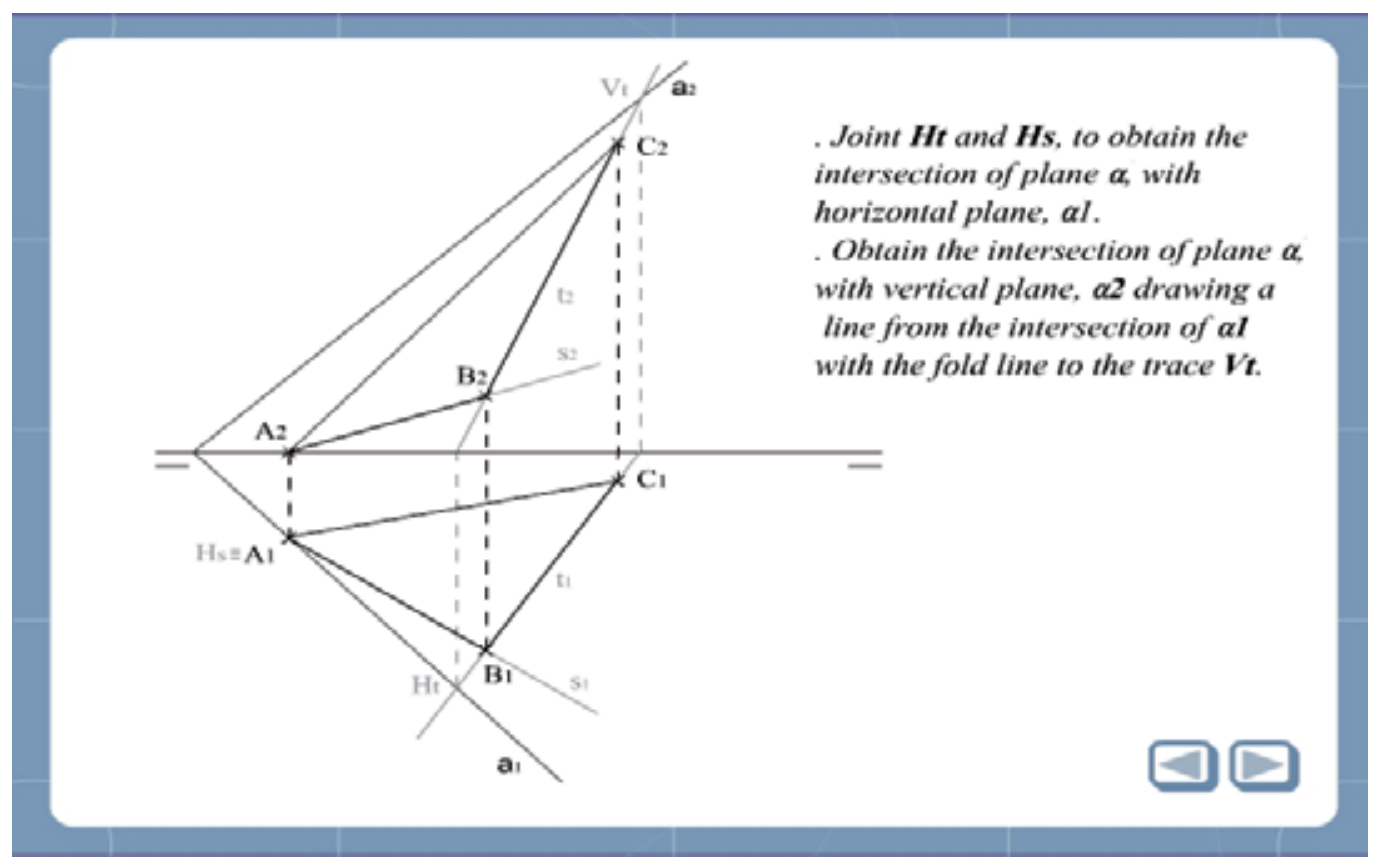

Fig. 8. Second snapshot explaining how to get the traces of the plane of the triangle 


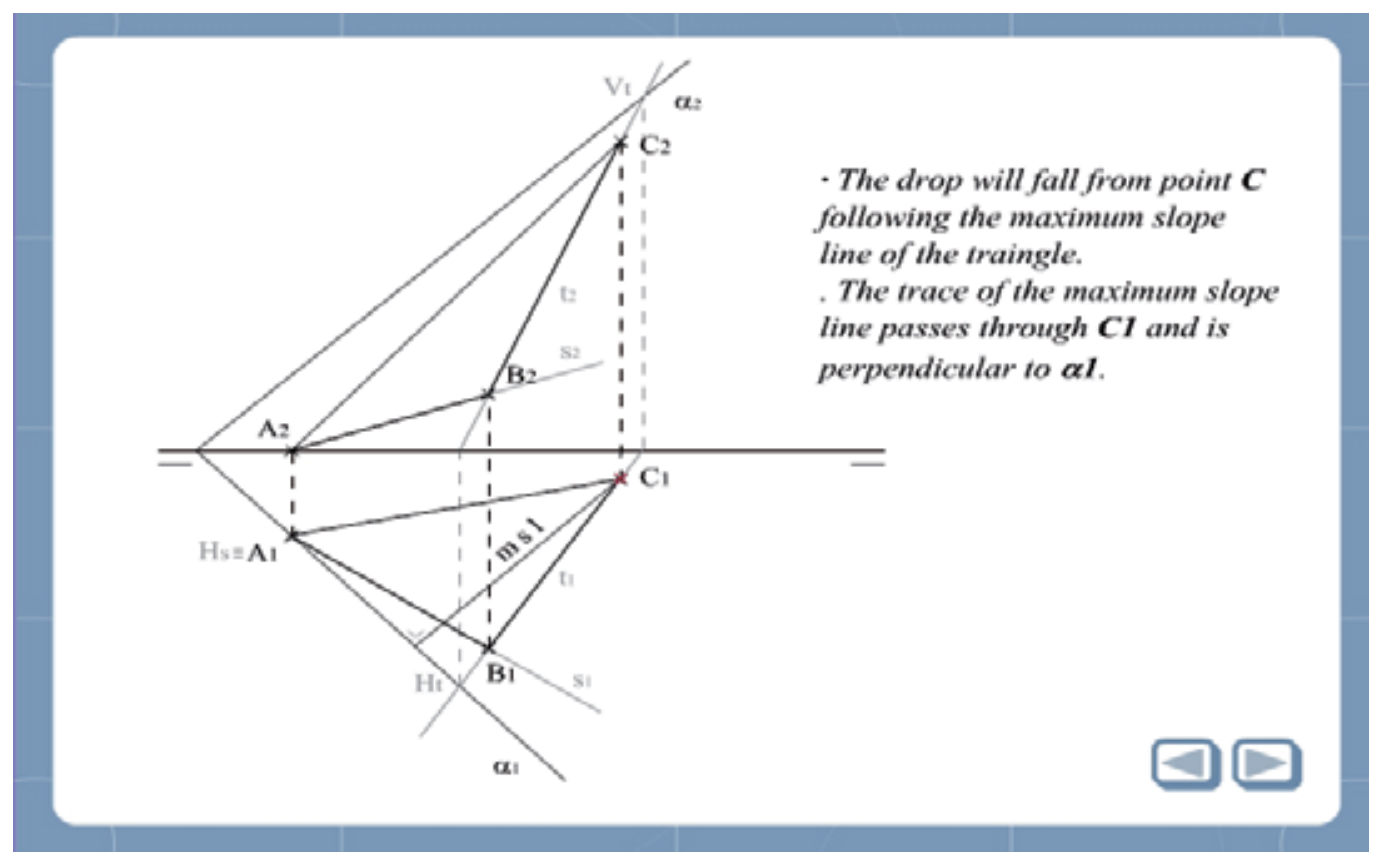

Fig. 9. Third snapshot with the explanation of the maximum slope line of a plane

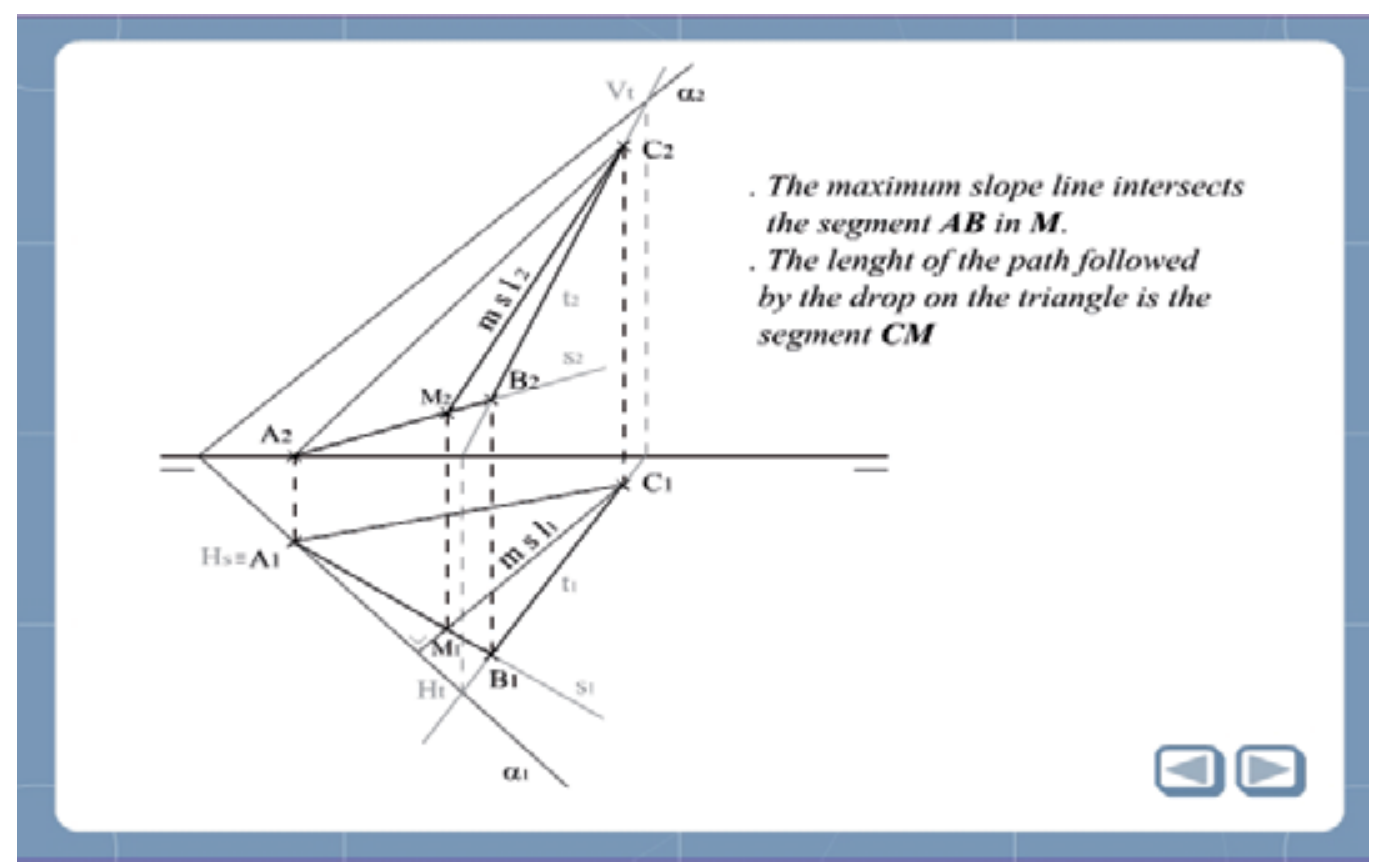

Fig. 10. Fourth snapshot with the indications for drawing the msl of the triangle 


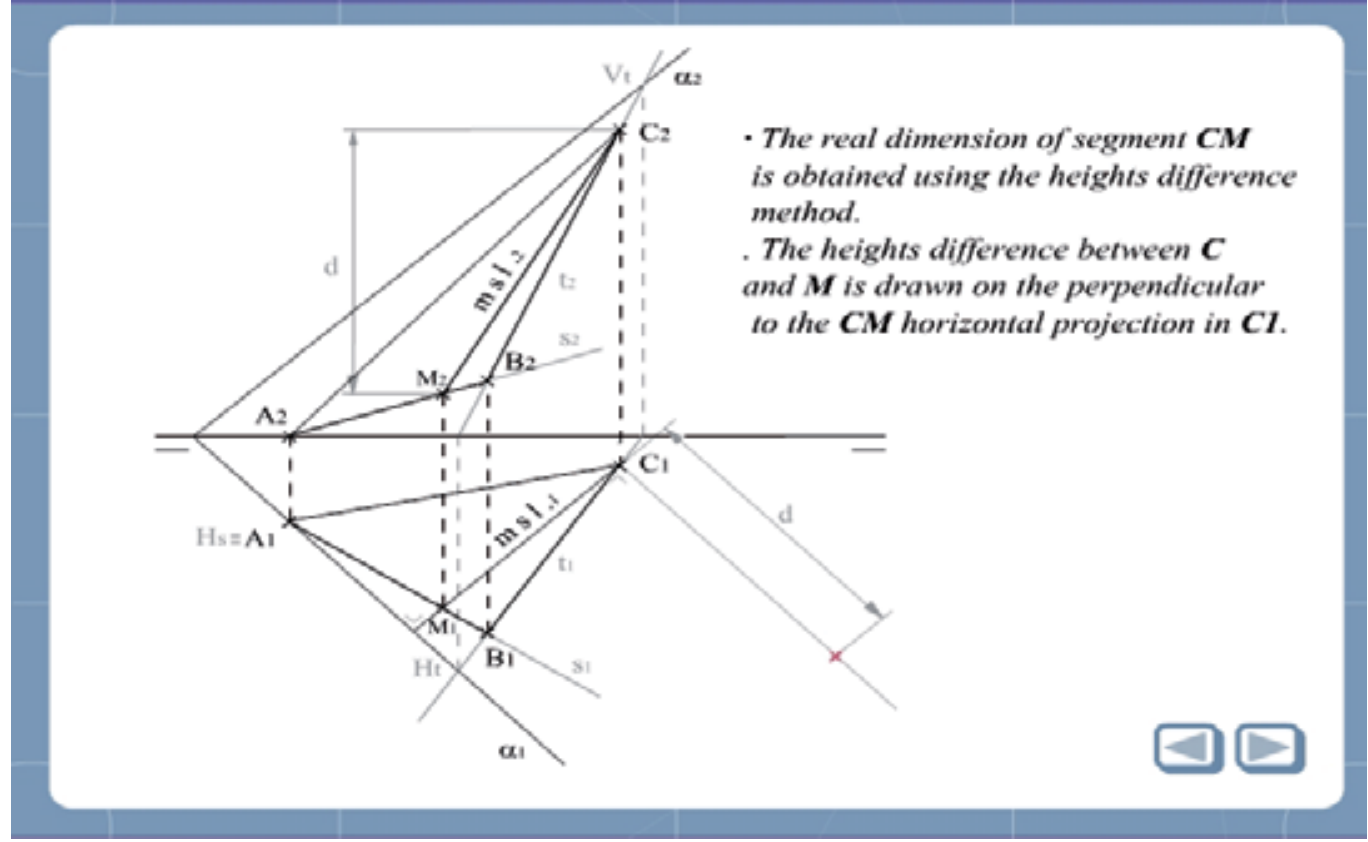

Fig. 11. Fifth snapshot for the determination of the real size of the path

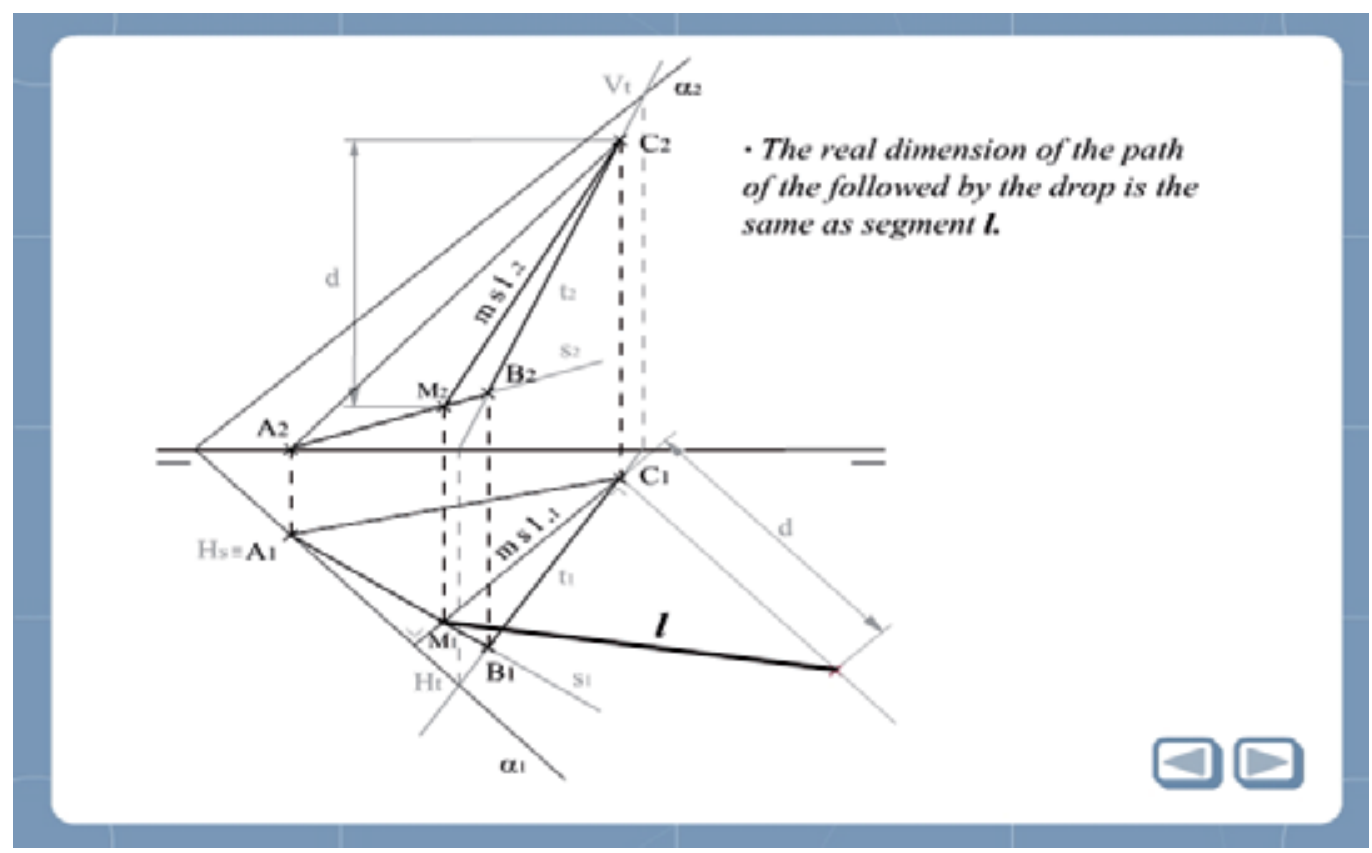

Fig. 12. The last snapshot of the animated solution 


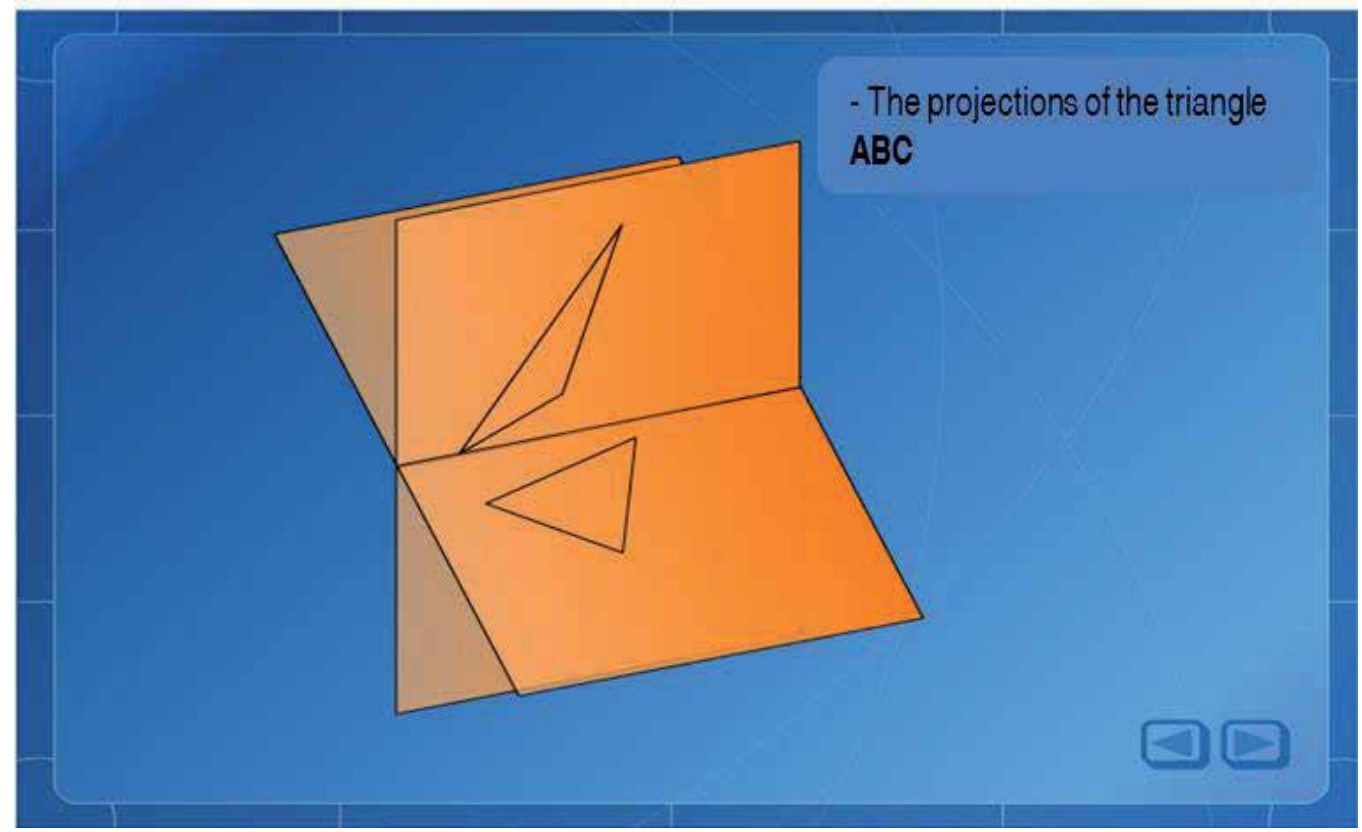

Fig. 13. Transformation of the statement from $2 \mathrm{D}$ to $3 \mathrm{D}$

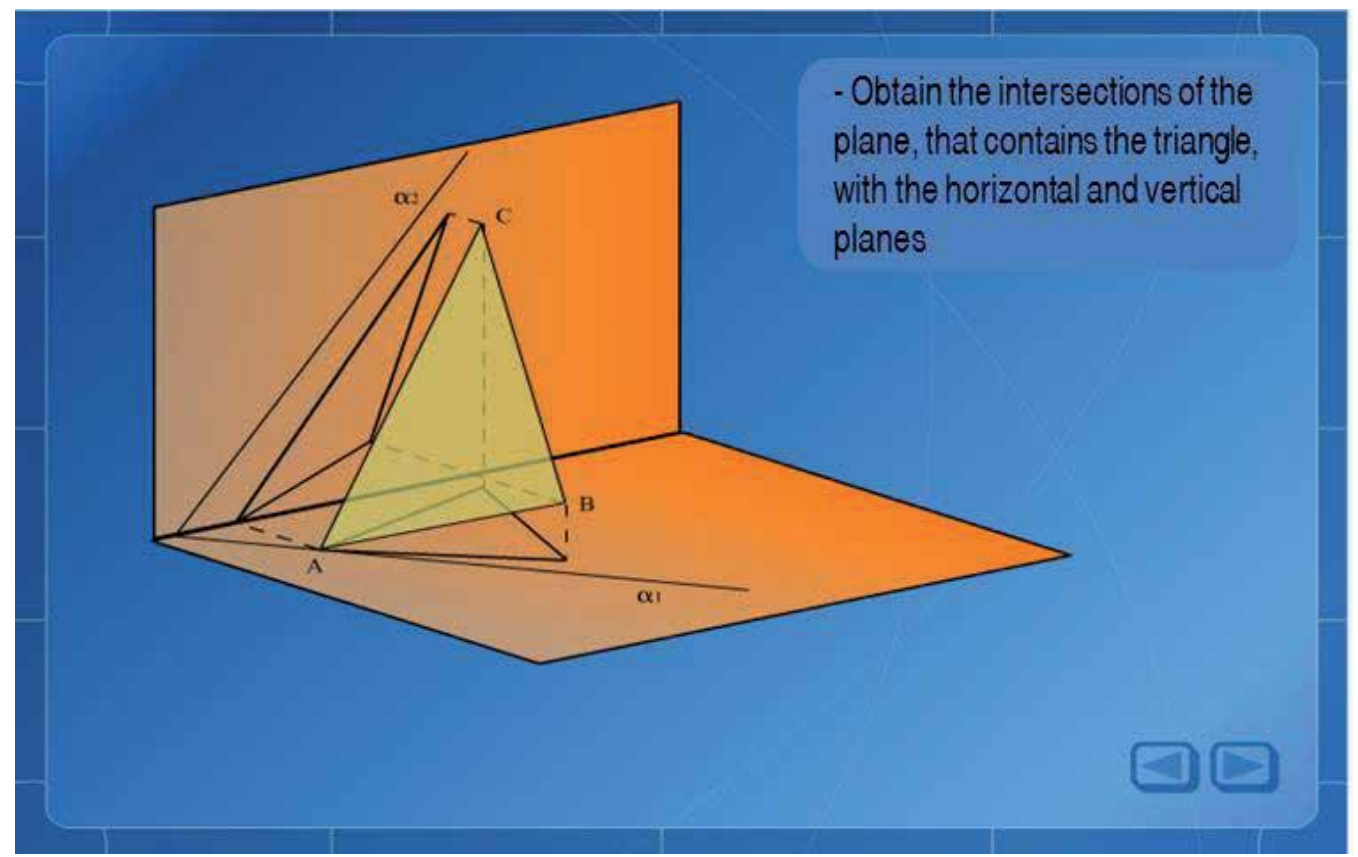

Fig. 14. First snapshot of the 3D solution showing the traces of the plane of the triangle 



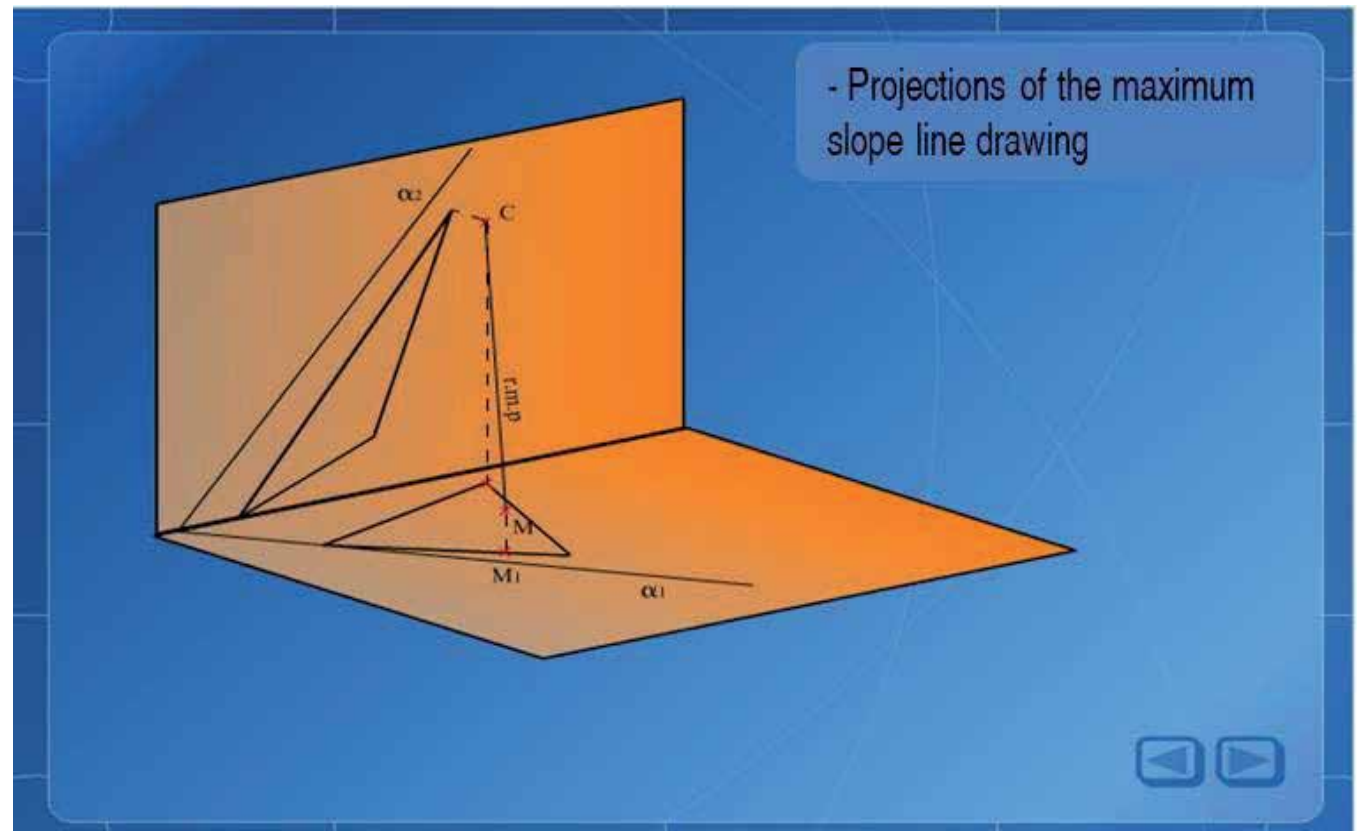

Fig. 17. Third intermediate snapshot where the msl is drawn in the space

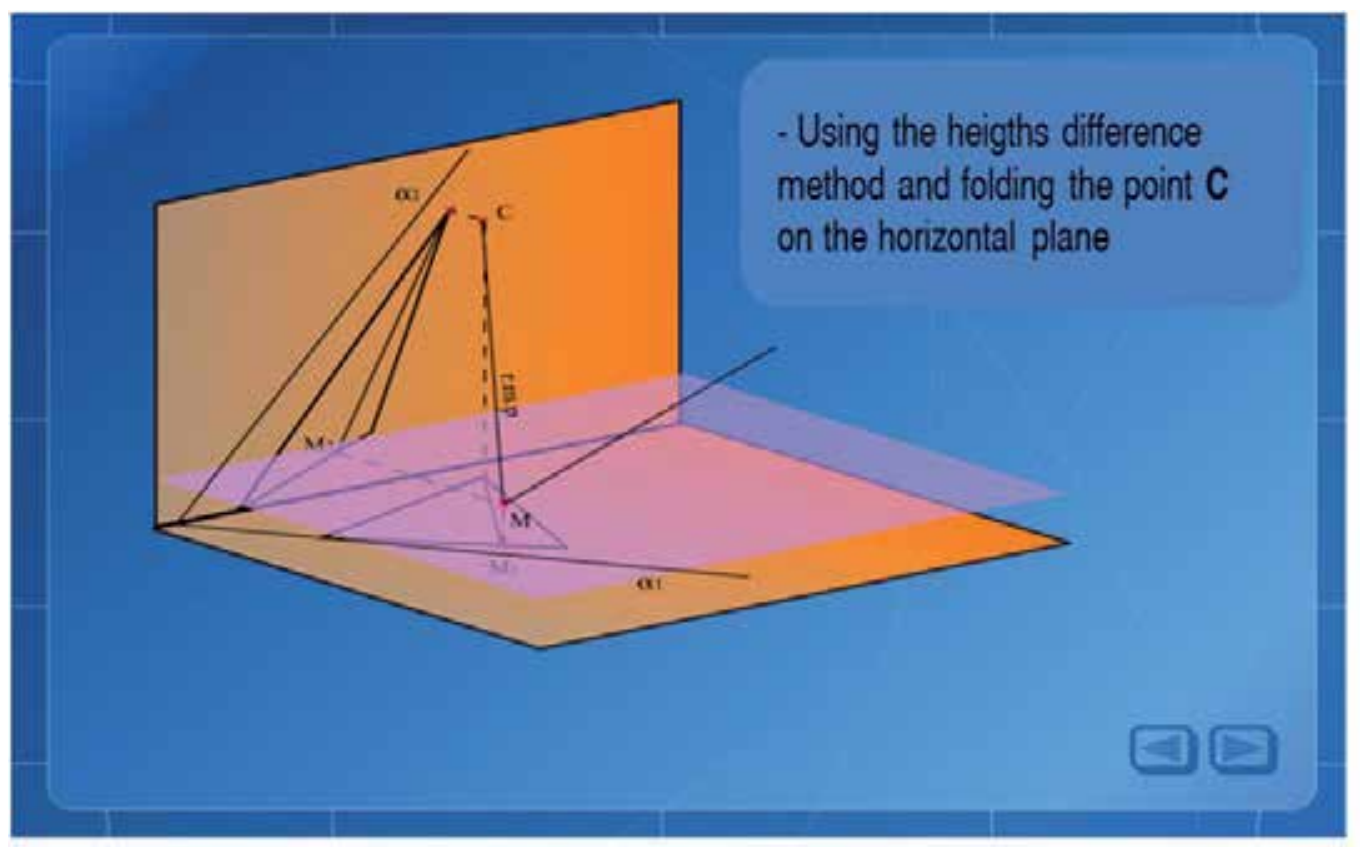

Fig. 18. Fourth intermediate snapshot, application of heights difference method 


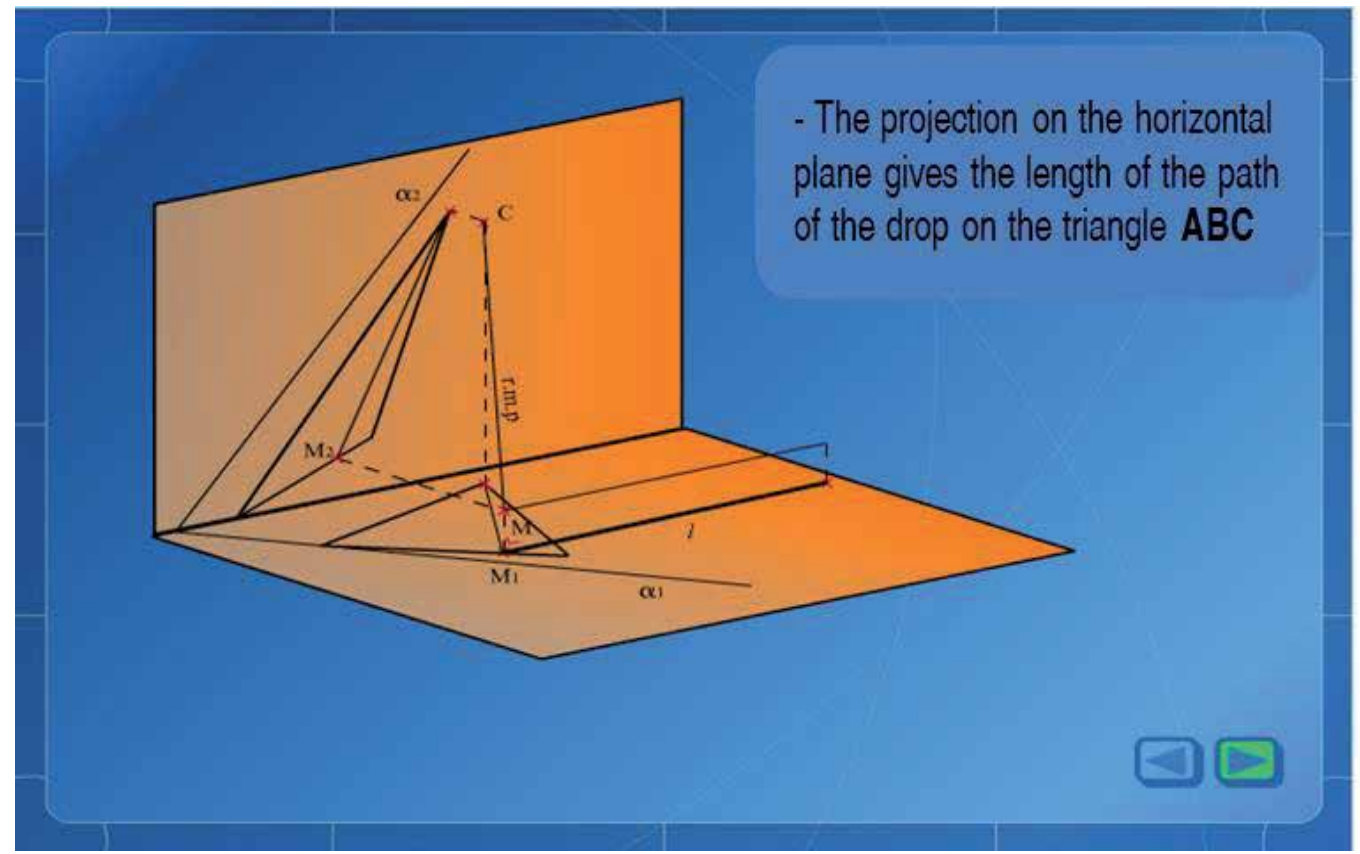

Fig. 19. Last snapshot giving the true size of the path followed by the drop

\section{Analysis of the academic results}

The web application has been used successfully during the two last years with undergraduate students of engineering programs within the Bologna Process in a number greater than 300 students per year. In fact, even though the application was thought, at first, as a tool to help the teachers in the master classes, the very good reception given by the students forced us to transform it into a web application which is the form it has at the moment.

The on-line tool has been of special interest to those students with no previous training in technical drawing. The application gives them the possibility of preparing the subject on their own rhythm, stopping whenever and wherever they need to focus on the different sections of the course.

A measure of the application success could just be the students request to create the web site, but a more accurate measure should be done. The academic results before and after the use of the application has been considered to evaluate the goodness of the application. The percentage of students that passes the subject every year can be a good indicator of the influence of the application. Obviously, the students of different years are not the same, and for that reason the academic results could not be really comparable; and on the other hand the application should not be the only influence factor in the academic results. Apart from the academic results and the requirement of the students to create the application, and also their oral feedback, no other indicator has been considered to analyze the goodness of the application. As an example, between 2004 and 2008 the percentage of students that passed the subject was between $35 \%$ and $40 \%$. Since the year in which we started to use the tool 
(2009), there has been an increase in the results reaching values of $70 \%$. But this is not the only good result, in these last years, the marks of the students that have passed the exams are higher than they used to be in the past. This can be considered also an indicator of the goodness of the tool.

\section{Conclusion}

The teaching of core subjects in undergraduate engineering programs has change in the last years due to the use of the new techniques and technologies. This is the case of Orthographic Projection, Technical Drawing, or Engineering Graphics in general. Here we have presented a Web application (http://turan.uc3m.es/uc3m/dpto/IN/dpin11/fabdis/ index_000.htm) for teaching/studying Orthographic Projection that has been developed firstly as a tool to enrich the master classes, and after, as required by the students, as an online application focused on the personal work they have to carry out in the framework of Bologna Process.

Two softwares have been used in the development of the tool: Flash ${ }^{\circledR}$ to prepare the animated solutions of the proposed exercises, and Dreamweaver ${ }^{\circledR}$ to design and create the web site.

The site is organized in two main parts, apart from the home page: the theoretical tutorials of the main concepts, and the animated proposed exercises that include in every one not only the $2 \mathrm{D}$ step by step animation but also the 3D animation. These 3D animations constitute a very interesting contribution to this kind of applications because they help the students to develop the ability of connecting the 2D pencil-and-paper problems with the $3 \mathrm{D}$ real problems.

It has been proved by the authors that the use of the application in class and on-line by the students themselves, has produced better academic results. The web application is still alive and different sections should be implemented in the future: an interactive exercise solution part and also an evaluation part. That will definitely improve the quality and the scope of the tool for the distance learning purposes.

\section{Acknowledgment}

The authors would like to thank Ministerio de Ciencia e Innovación of Spain for the financial support that made possible this work through Proyectos DPI2006-09906 and DPI2009-13264, and also to Miguel Ángel de Lucas Hernández for his work preparing the teaching material as a part of his Final Study Project.

\section{References}

Bélanger, F. \& Jordan, D.H. (2000), Evaluation and implementation of distance learning: technologies, tools, and techniques. Idea Group Inc (IGI), ISBN : 1878289632.

Honeyman, M. \& Miller, G., Agriculture distance education: A valid alternative for higher education?, Proceedings of the 20th Annual National Agricultural Education Research Meeting, (1993), pp. 67-73. 
Loweryt, J.W. (2001), Dreamweaver Ultradev 4 Bible. Hungry Minds, ISBN : 0764534874, USA.

Marques, P. (September 2011). Educative Software, Available from http://www.lni.ub.es/te/any96/marques_software

Morales, M.P. ; Penin P. ; Sevillano A.P. \& Cerra P.P., Design and Use of a Multimedia Trainer for the Subject Descriptive Geometry, Computer Applications in Engineering Education, Vol.17, (2009), pp. 13-24.

Pardo, M. (2011). Creación y Diseño Web, Anaya Multimedia, ISBN 9788441529427, Spain.

Rubio, L.; Muñoz-Abella B. ; Castejón C. \& Muñoz-Sánchez A., Web-Based application for Descriptive Geometry Learning, Computer Applications in Engineering Education, Vol.18, (2010), pp. 574-581.

Rubio, L. ; Muñoz-Abella, B., (2011), Teaching documentation. Universidad Carlos III de Madrid.

Rubio, R. ; Suárez J. ; Gallego R. ; Martín S. \& Morán, S., Interactive multimedia animation with Macromedia Flash in Descriptive Geometry teaching, Computers $\mathcal{E}$ Education, Vol.49, (2007), pp. 615-639.

Toledo, E. \& Rojas, J.I. (2001). A proposal for an on-line library of Descriptive Geometry problems, Journal of Geometry Graphics, Vol.5, (2001), pp. 93-100.

Rodríguez de Abajo, F.J. (2007), Geometría Descriptiva. Tomo I. Sistema Diédrico (in spanish). Editorial Donostiarra, ISBN : 9788470633539, Spain.

Reinhardt, R. (2004), Macromedia Flash MX 2004 Bible. Wiley, ISBN : 0764543032, USA.

USDLA, available from http://www.usdla.org/ 


\title{
Internet-Supported Multi-User Virtual and Physical Prototypes for Architectural Academic Education and Research
}

\author{
Henriette H. Bier \\ Delft University of Technology, \\ Faculty of Architecture, \\ The Netherlands
}

\section{Introduction}

Even though development of concepts and tools for Internet-based academic research and education may be traced back to the 1960s, only in the last decade concepts such as Internet of Things, Ambient Intelligence (AmI), and ubiquitous computing (ubicomp) have introduced not only a technological but also a conceptual and methodological paradigm shift that implies a general infiltration of Internet-based concepts and tools not only into academic education and research but also into everyday life activities. In this context, Hyperbody at Delft University of Technology (DUT) has been developing in the last decade hardware- and software- prototypes for Internet-supported academic education and research, which were tested in practical experiments implemented mainly in international workshops and lectures. This chapter presents and discusses Hyperbody's past, present and future development and use of software and hardware applications for virtual academic education and research in architectural and urban design within the larger framework of contemporary conceptual, methodological and technological advancements.

\section{Concepts and tools}

The development of concepts and tools for Internet-based academic research and education such as Engelbart's proposal for using computers in the augmentation of human skills (1962) and Sutherland's Sketchpad as first graphical user interface for computers (1963), the establishment of the Internet (1969) and the development of interactive learning environments enabled universities to offer accredited graduate programs through online courses. While at the time, virtual and physical interaction was separated in corresponding educational programs, in the last decade, concepts such as Internet of Things, Ambient Intelligence (AmI), and ubiquitous computing (ubicomp) have introduced a conceptual and methodological paradigm shift manifested in the blur of boundaries between physical and virtual and the continuous integration of Internet-based concepts and tools into the academic everyday life. In this context, ubiquitous computing refers to the integration of information processing into everyday objects and activities (Weiser, 1988) while the Internet 
of Things consists of uniquely identifiable (tagged) objects (Things) and their virtual representations inventoried and connected in an Internet-like structure (Ashton, 1999; Magrassi, et al. 2001).

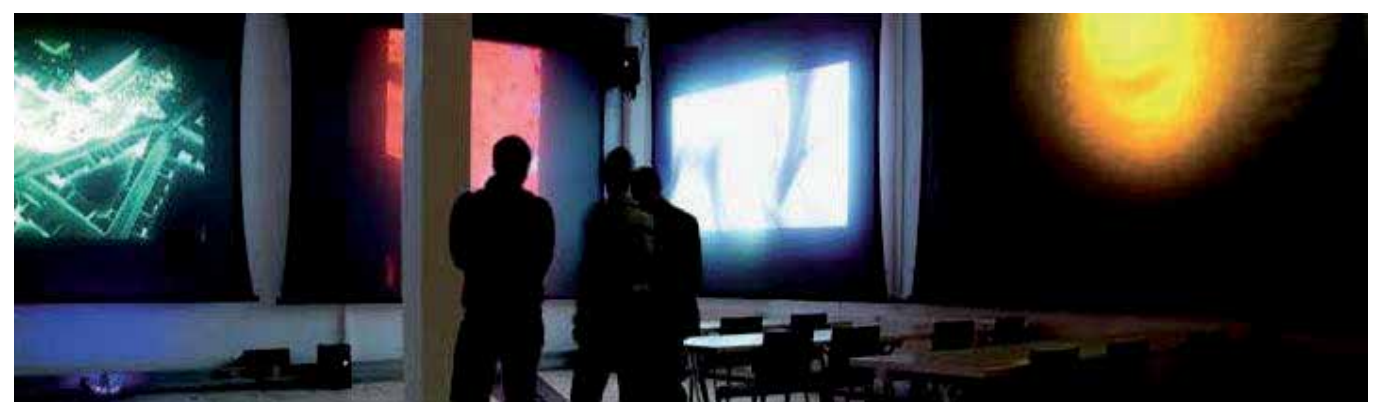

Fig. 1. Protospace: An Internet-based multi-user physical and virtual environment for academic research and education developed by Hyperbody.

Envisioning Ambient Intelligence (AmI) as a physical environment that incorporates digital devices in order to support people in carrying out daily activities by using information and intelligence that is contained within the network connecting these devices (Zelkha et al., 1998), Protospace (http://www.hyperbody.nl/protospace) developed at Hyperbody (Fig. 1) can be seen as an embedded, networked hardware- and software system that is exhibiting characteristics of Ambient Intelligence. This implies that interactive, context aware (sensor-actuator) sub-systems are embedded into the spatial environment in such a way that they are context and user aware by collecting and mapping data with respect to users' movement and behaviour in relation to physical space, they are, when needed, tailored to individual needs, and furthermore, they are adaptive, responding to user and environmental changes, even anticipatory, as for instance, during interactive lectures and workshops described in following sections. Considering that information processing has been, meanwhile, increasingly integrated into physical spaces, everyday objects, human activities (Weiser, 1988) and ubiquitous computing (ubicomp) has become prevalent in everyday life, the following sections aim to critically asses what they offer architectural academic education and research, and thus reveal what challenges remain in their development and application.

\section{Methodologies and processes}

Late 1990s, Internet-based academic education and research were focusing on education methodologies and applied technologies for educators, students and researchers, who are separated by time and distance, or both (Daniel, 1998; Loutchko et al. 2002). In this context, the requirement for synchronous interaction for participants, who are virtually present at the same time while they are physically remotely located would be implemented via timely synchronous videoconferencing and live streaming, telephone, and web-based VoIP. In addition, participants would access educational and research materials on their own schedule, as well as communicate by means of asynchronous information exchange such as E-mail correspondence, message exchange (forums), audio-video recording and replay. 
Other more sophisticated methods would include online three-dimensional (3D) virtual worlds providing synchronous and asynchronous interaction as well as collaboration.

Such systems would, obviously, require high-tech hardware and software equipment and would offer the possibility to flexibly accommodate time and space constraints of users, while reducing the demand on institutional infrastructure such as buildings. Educators, students and researchers attending virtual sessions would exchange and acquire knowledge asynchronously by reading documents from the database or studying videos, for instance, and synchronously by discussing problems, reviewing case studies, or actively participating in workshops. Communication in the synchronous virtual study room is, therefore, conceived as a collaborative study and research experience, where participants are interacting real-time with peers through web-conferencing and 3D gaming.

3D gaming environments inspired, in the last decade, researchers from different disciplines to develop computer-supported collaborative environments such as Protospace in which problem-based studying and researching is implemented. This enables physically and virtually present students and researchers to investigate and solve problems by working in groups, wherein participants identify what they know, what they need to know, and learn how to bridge the gap between the two by searching and accessing information from worldwide available databases that may lead to finding solutions.

In such a context, the role of the instructor, educator, or team leader is that of facilitating the process by suggesting appropriate references, and instigating critical discussions, while open-ended, ill-defined problems, addressed in collaborative group work are driving such a process (Armstrong, 1991). By exploring various strategies in order to understand the nature of the to-be-solved problem, by investigating the constraints and options to its resolution, as well as by acknowledging eventual different viewpoints, participants learn to negotiate between competing, even contradicting resolutions. These approaches implemented in Internet-supported multi-user, collaborative, game-like environments such as Protospace are well suited for addressing architectural and urban planning problems in education and research.

Such approaches are, however, not anymore confined to the classical concepts of the Internet-based education such as distance learning; instead they started to permeate the academic everyday life (Bier, 2011). Internet-based interaction is not anymore employed for distance learning only but it is integrated in the daily interaction, information and knowledge exchange between students, educators and researchers. While learning environments are increasingly accessed in various contexts and situations, ubiquitous increasingly replaces distance learning (Bomsdorf, 2005).

If ubiquitous learning ( $\mathrm{u}$-Learning) represents a relevant advancement in the development of distance learning, its obvious potential results from the enhanced possibilities of accessing content and computer-supported collaborative environments at any time and place. Furthermore, $\mathrm{u}$-Learning enables seamless combination of virtual environments and physical spaces and allows embedding individual learning activities in everyday life so that learning activities are freed from schedule and spatial constraints, becoming pervasive and ongoing, prevalent within a large, diverse community consisting of students, educators, social communities, researchers, etc. 


\section{Applications in education and research}

Within the larger context described in the sections before, Hyperbody has been developing in the last decade Internet-supported applications for academic education and research by employing interactive 3D game technology: As an Internet-based, multi-user game environment, Protospace enables real-time collaborative architectural and urban design and has been tested in graduate education and research including the Internet-based postgraduate program, E-Archidoct, that was offered in collaboration with 14 European universities 2008-10.
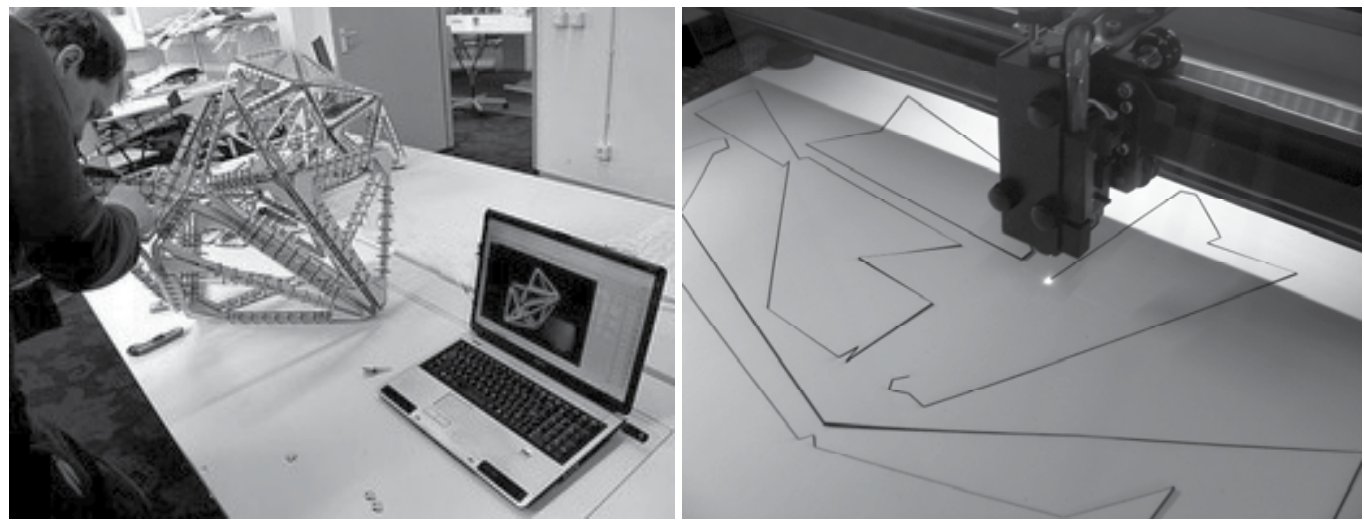

Fig. 2. Rapid seamless CAD-CAM prototyping and CNC fabrication implemented with students in Protospace.

Protospace is, basically, a compound of software and hardware applications for virtual academic education and research equipped with multi-channel immersive audio, multiscreen projection, ubiquitous sensing, wireless input-output devices and (Computer Numerically Controlled) CNC facilities (incorporating a laser cutter and a large mill). It facilitates Internet-supported collaborative design and development of interactive architectural components, supports seamless (Computer-Aided Design and Manufacturing) CAD-CAM workflows, as well as enables implementation of non-standard, complex geometries (Fig. 2) into architecture.

Protospace incorporates, therefore, virtual drafting and modeling as well as physical prototyping tools with shared database capabilities so that changes made by design team members are visible to all other team members, thus allowing for design, evaluation, and dialogue between team members to take place concurrently in real-time. Team members are physically and/or virtually participating in a seamless process of design, prototyping, and review establishing a feedback loop between conceptualization and production.

\subsection{Software and hardware prototypes}

In addition to CNC machines allowing for CAD-CAM production of 1:1 or scaled architectural prototypes, Protospace incorporates Virtual Reality (VR) hardware and software (Fig. 3) devices enabling implementation of specific tasks such as geometrical and behavioral manipulation. 

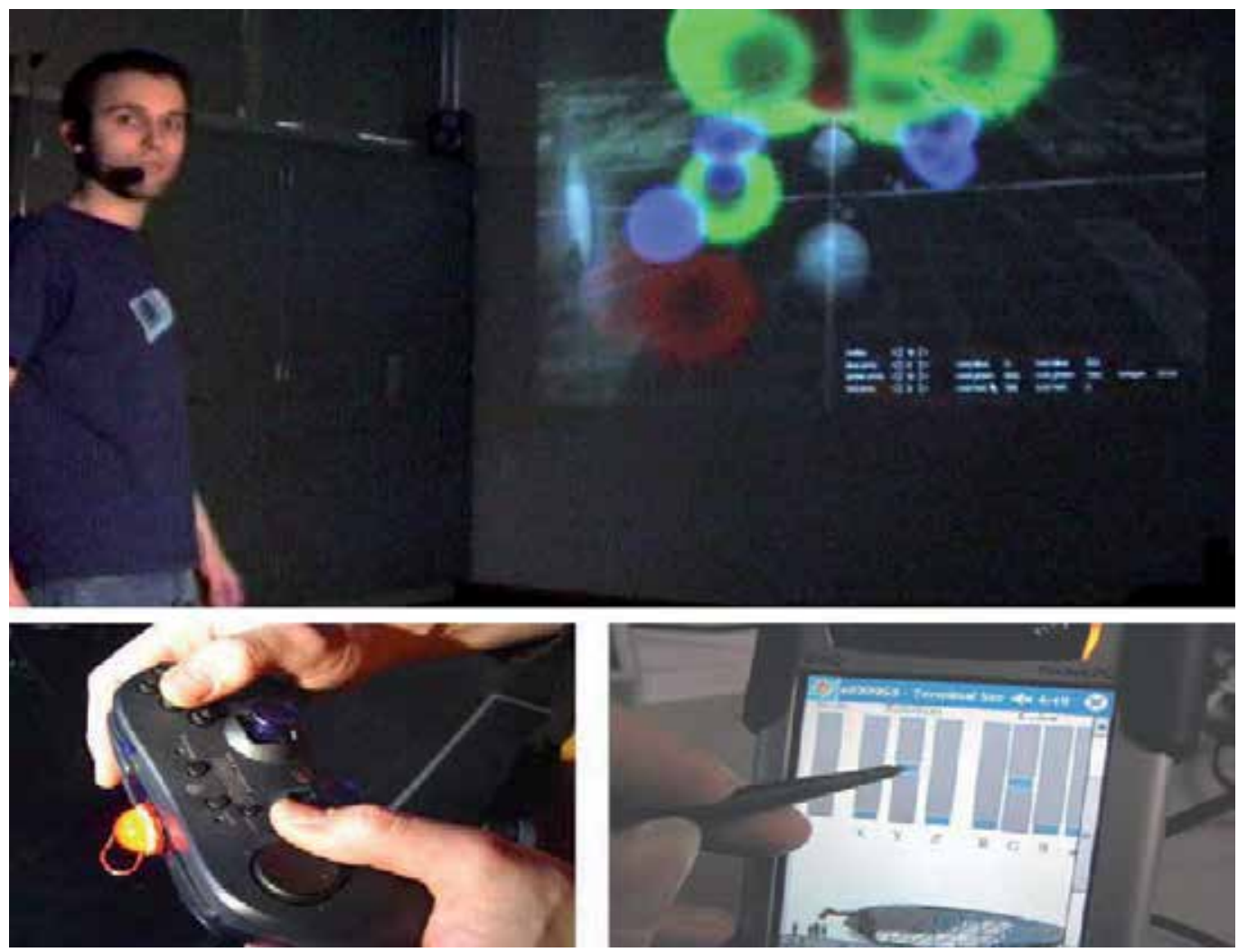

Fig. 3. Protospace: Wireless devices with varying characteristics are available as input devices for implementing specific tasks such as geometrical and behavioral manipulation.

\subsubsection{CAD-CAM processes}

Internet-supported collaborative processes such as CAD-CAM design and fabrication workflows are implemented in Protospace by means of commercial and non-commercial software applications that in part are developed from scratch at Hyperbody. For architectural and urban design Hyperbody employs parametric software such as Virtools, Max MSP, Rhino-Grasshopper and Generative Components. These CAD applications are coupled with CAM facilities in order to allow seamless production of physical prototypes from virtual models.

With respect to their use in education, in case of E-Archidoct, for instance, in addition to the Internet-based individual and collaborative exchange between students and teachers facilitated by the open-source Modular Object-Oriented Dynamic Learning Environment (Moodle) which was incorporated into the E-Archidoct website, Protospace software applications were as well integrated.

Students were, basically, introduced to parametric software such as Virtools, Grasshopper and Generative Components employed in architectural and urban design projects. Liu's 
project (Fig. 4), for instance, applies parametric definition for the development of multiple designs. Parametric manipulation implied, among others, the use of the marching cubes algorithm, which constructs surfaces from numerical values; furthermore, programmatic considerations were parametrically defined with respect to function in relation to volume and orientation in 3D space, etc. CAD structural analysis employing MIDAS/Gen implied that data with respect to forces, moments and stresses was used in order to determine the placement and dimension of main and secondary structure, whereas final design was physically prototyped by means of CAM.

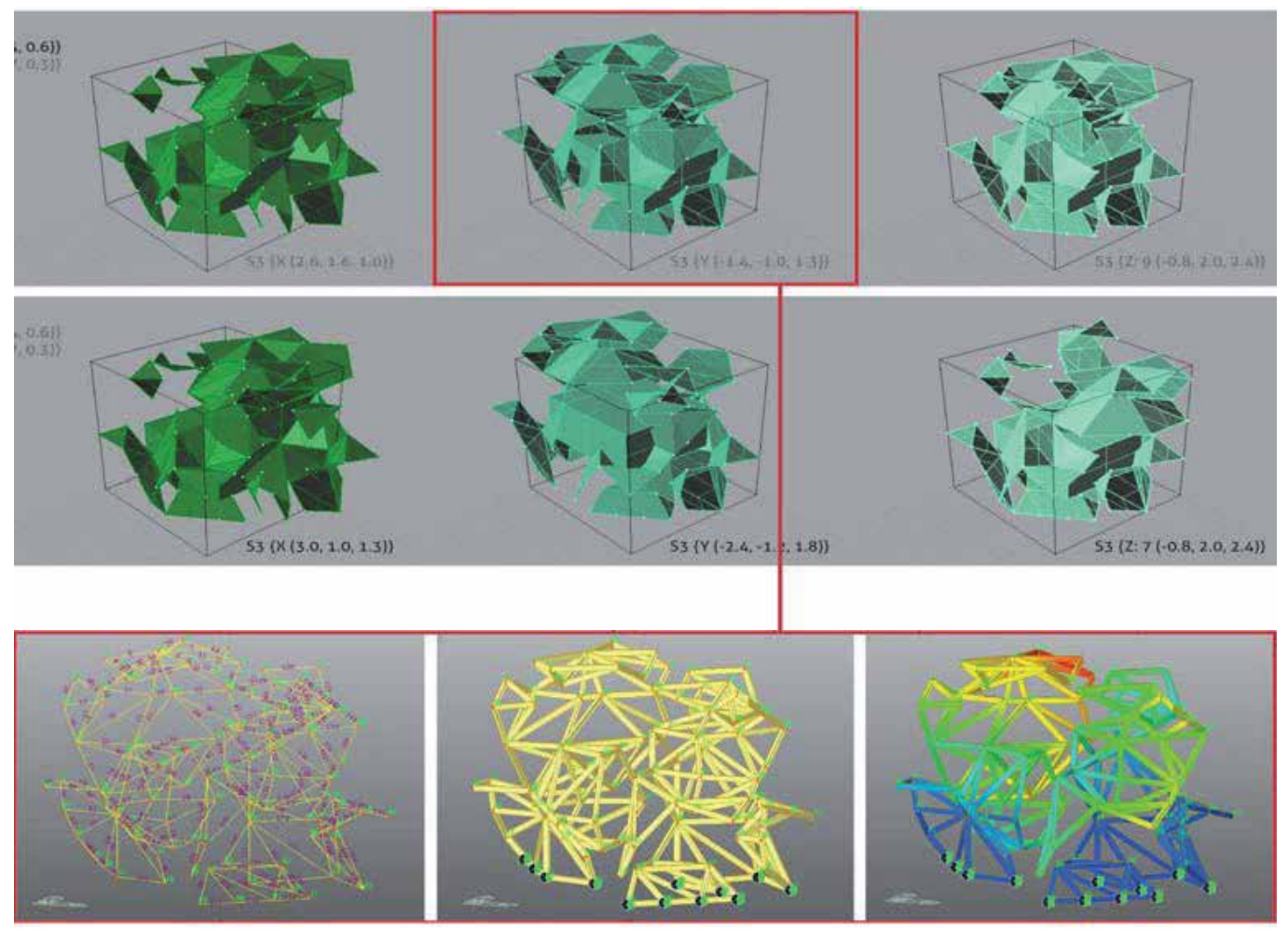

Fig. 4. Liu's project showing multiple design and evaluation phases employing design and structural engineering software.

In addition to CAD-CAM processes in which designers (tutors, students and researchers) may partake physically or virtually, Protospace facilitates interactive presentations that allow physically and virtually present audience to attend and interact with the presenters and their presentations in real-time.

\subsubsection{Interactive lectures}

Non-linear screen presentations are set-up on multiple screens and non-linear talks follow a paradigm in which the audience is enabled to select from predefined content clusters specific topics, images, and/or movies, which the speaker then presents and discusses. 
Following principles of Ambient Intelligence some of the multiple screen projections may be influenced by the audience: The physically present audience can alter the course of the presentation by using laser pointers, or triggering light- and/or pressure-sensors integrated in floor and walls, while audience from all over the world follows and interacts with the presentation via Internet-based interfaces (Fig. 5). In this context, distinct clusters of content are marked with keywords, indicating when audience input is expected or required, while physically and virtually present lecturers introduce and discuss content by means of multimedia and videoconference presentations.
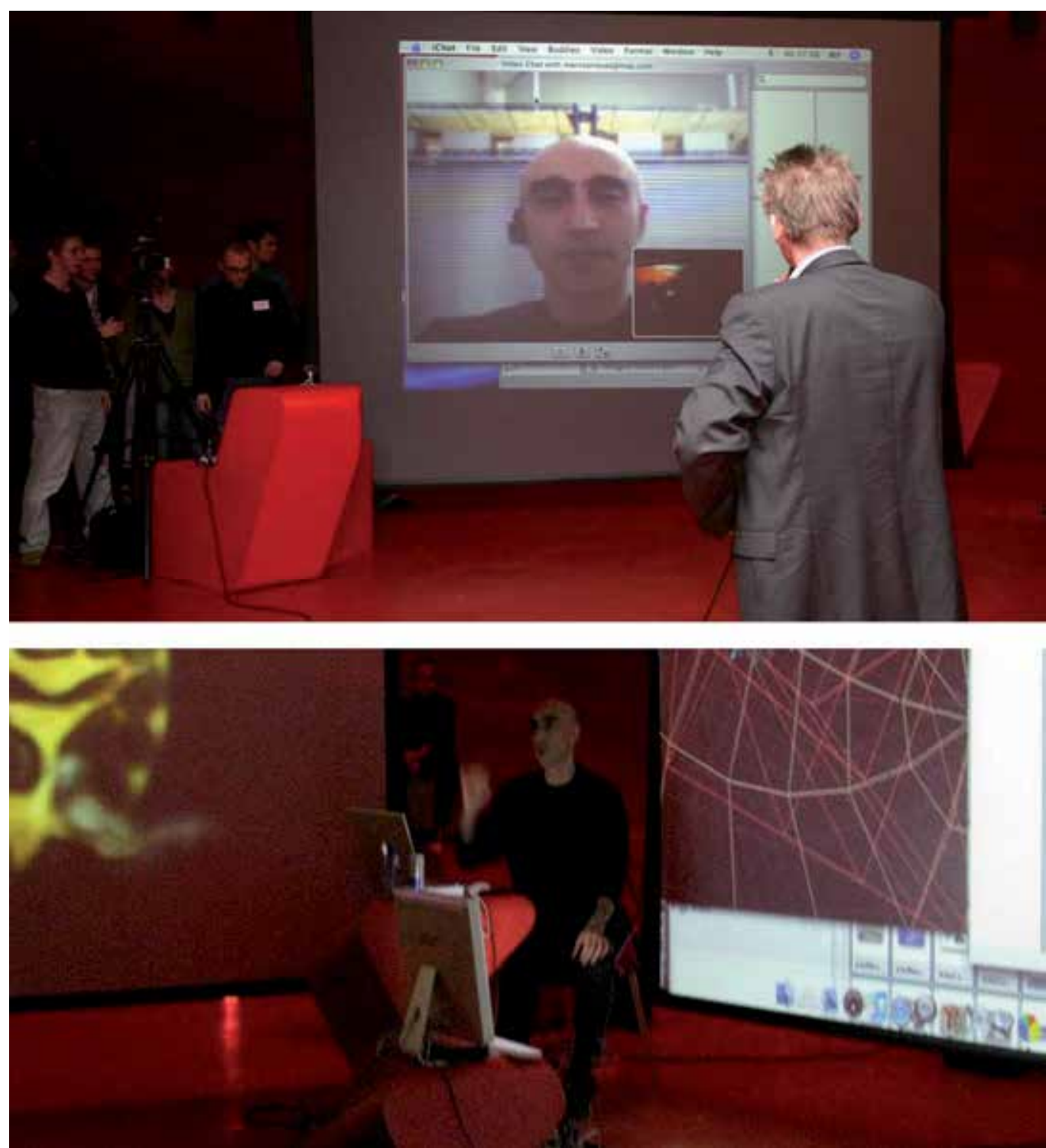

Fig. 5. Interactive presentations with Marcos Novak from University of California in Protospace at TU Delft (iWEB, 2006-07). 


\subsubsection{Multi-user (3D) games}

As one of the most relevant Protospace applications, Virtools allows development of Internet-supported, multi-user (3D) games. Known as serious games (Zyda, 2005) such games have a primary purpose other than entertainment as they are designed for the purpose of solving an architectural or urban design problem. They are accessible via a game interface on the Internet by multiple users that can interact with the virtual environment in real-time. Their development in Virtools is based on the separation of objects, data and behaviors, employing an intuitive user interface with real-time visualization window and graphical programming. This allows programming with spatial arrangements of text and graphic symbols, whereas screen objects are treated as entities that can be connected with lines, which represent relations (Fig. 6).

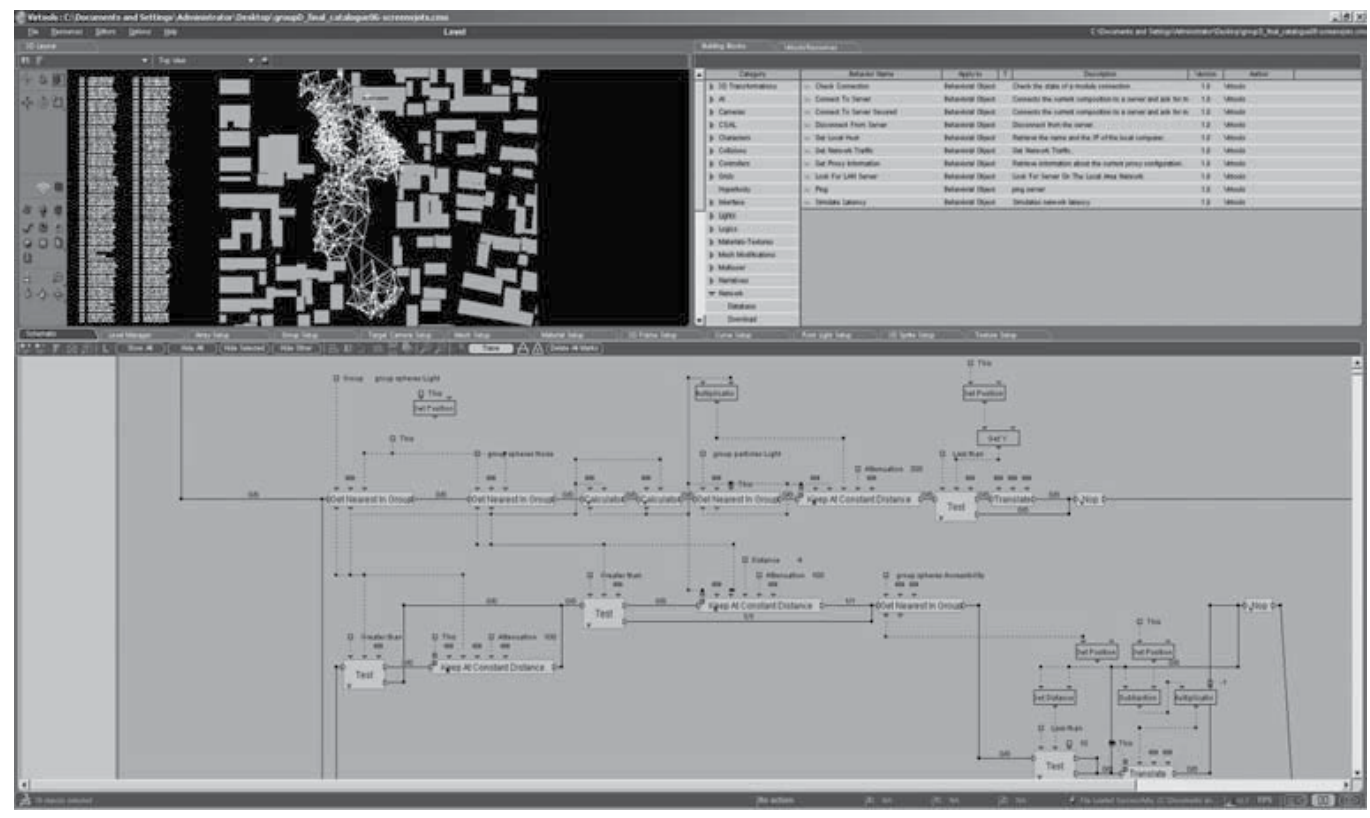

Fig. 6. Hsiao's Virtools script showing graphical programming interface and behaviour setup for urban design simulations.

Virtools' behavior engine runs both custom and out-of-the-box behaviors, whereas behaviors relevant for architectural and urban design at Hyperbody are swarm behaviors relying on principles of self-organization (Reynolds 1987; Oosterhuis et. al. 2004). Swarm behaviors are collective behaviors exhibited by natural or artificial agents, which aggregate together, exhibiting motion patterns at group level (Mach \& Schweitzer, 2003). These behaviors are emergent, arising from simple rules that are followed by individuals (agents).

Protospace applications such as Virtual Operation Room (VOR), Building Relations (BR) employ swarm behaviors in order to address issues such as interactivity in architecture (Bier et al. 2006) and automated placement of programmatic units in 3D space either at city or at building scale (Bier, 2007). 
VOR is, basically, an interactive environment allowing participants to playfully start to understand interactivity principles, which are then applied in design using Protospace's design interface. In order to incorporate behaviors and interactively change geometry in real-time, VOR employs self-organization principles of swarms enabling elements of the structure to respond to external changes. According to Oosterhuis (2006) swarm architecture implies that all building components operate like intelligent agents, whereas the swarm is, in this context, of special interest: Self-organizing swarms go back to Reynolds' computer program developed in 1986, which simulates flocking behavior of birds. The rules according to which the birds are moving are simple: Maintain a minimum distance to vicinity (1), match velocity with neighbors (2) and move towards the center of the swarm (3). These rules are local establishing the behavior of one member in relationship to its next vicinity.

Similar to Reynolds' flocking rules, VOR's icosahedral geometry employs rules regarding the movement of its vertices. The movements of its vertices are controlled as follows: (1) Keep a certain distance to neighboring vertices; move faster if you are further away. (2) Try to be at a certain distance from your neighbors' neighbors; move faster if you are further away. These rules aim to establish a desired state of equilibrium implying that VOR aims to organize itself into the primary icosahedral structure. Under exterior influences VOR executes geometrical-spatial transformations according to the rule (3): Try to maintain a certain distance to the avatar, whereas the avatar is an embodiment of the user in this multiuser virtual reality (Fig. 7).

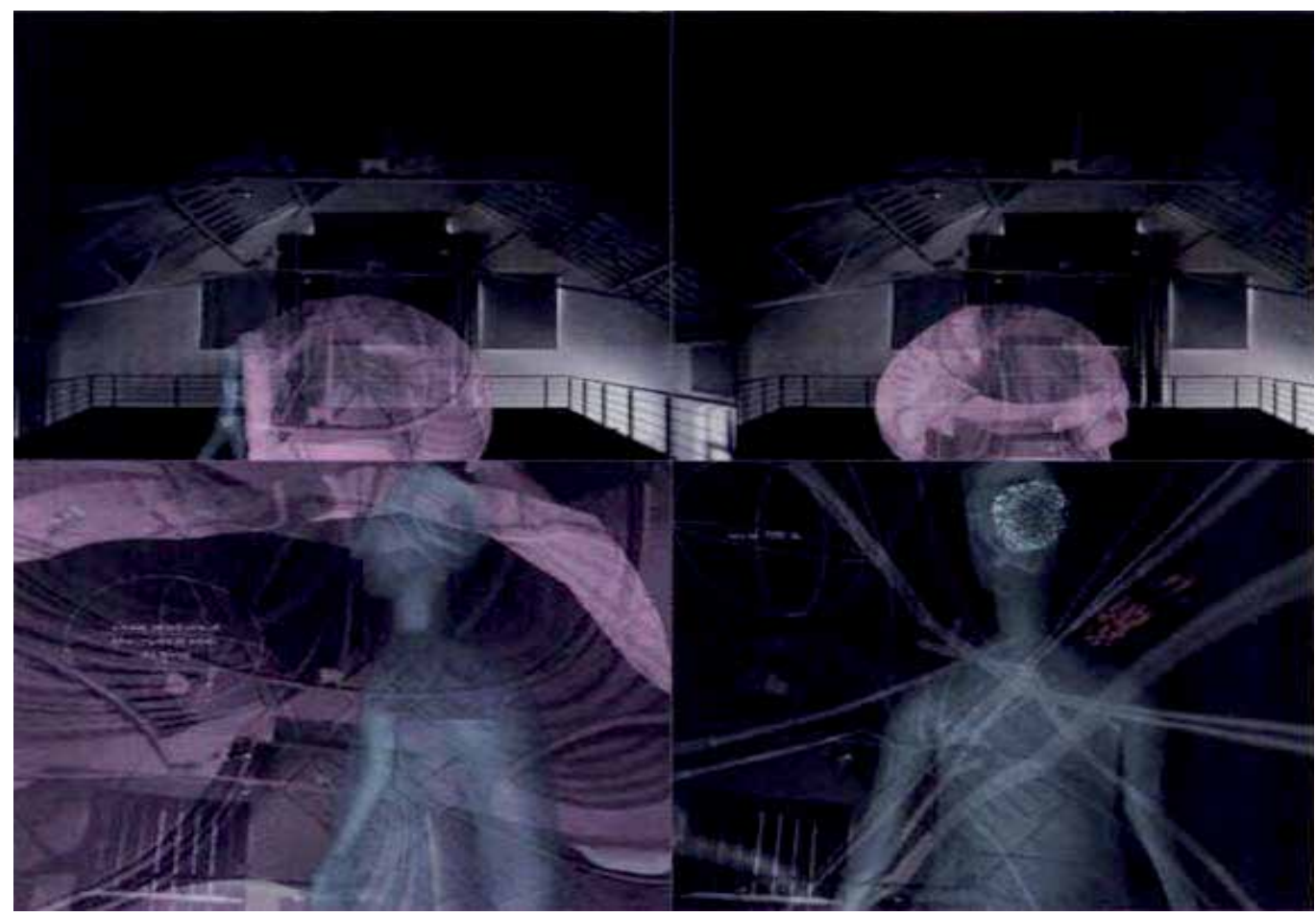

Fig. 7. VOR can be navigated via an avatar that can enter a virtual world represented as an icosahedral structure. 
VOR, as a multi-user interactive environment, is a computer simulation of an imaginary system, a game that enables users to perform operations on the simulated system (Oosterhuis et al. 2004) while showing effects in real-time. Basically, VOR consists of responsive environments with which the user interacts via input devices such as mouse, keyboard, and/or joystick; these allow for intuitive maneuver and navigation.

At building scale, applications developed by Hyperbody have been focusing on the development of interactive design tools, which allow simulation of complex design processes such as space allocation: BuildingRelations (BR), for instance, proposed an alternative design method based on swarm behavior.

BR consists of agents interacting locally with one another and with their environment as follows: In the absence of top-down control dictating how individual agents should behave, local interactions between agents lead to the bottom-up emergence of global behavior. Similarly, all functional units pertaining to a building can be seen as flocking agents striving to achieve an optimal spatial layout (Bier et al. 1998; Bier et al. 2006). In this context, spatial relations between functional units can be described as rules, according to which all units organize themselves into targeted spatial configurations (Fig. 8). This approach is particularly suitable for the functional layout of middle large structures: While the architect might find it difficult to have an overview on all functions and their attributed volume and preferential location, functional units can easily swarm towards local optimal configurations.
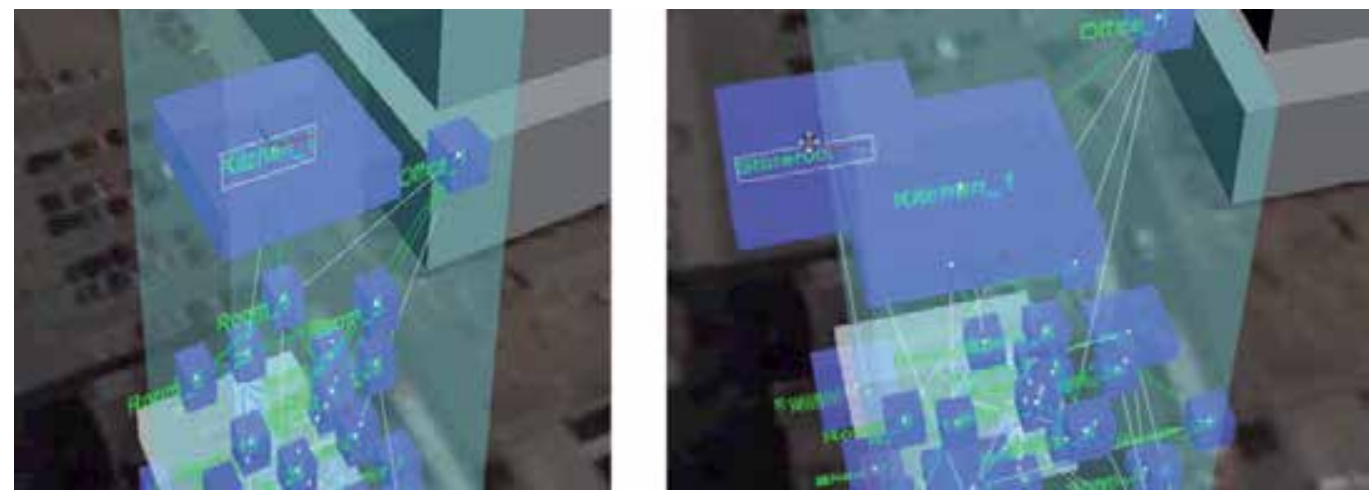

Fig. 8. BR - Architectural design studies implemented in interactive environments developed in Virtools.

Basically, programmatic distribution of functions in architectural design deals with the placement of functions in 3D-space; in this context, building components such as rooms have neither fixed dimensions nor pre-defined positions in space. Attempts to automate the process of layout incorporate approaches to spatial allocation by defining the available space as an orthogonal 2D-grid and use an algorithm to allocate each rectangle of the grid to a particular function. Other strategies break down the problem into parts such as topology and geometry: While topology refers to logical relationships between layout components, geometry refers to position and size of each component of the layout. A topological decision, for instance, that a functional unit is adjacent to another specific functional unit restricts the geometric coordinates of a functional unit relative to another (Michalek et al., 2002; Bier et al. 2007). 
Based on a similar strategy BR generates solutions for complex layout problems in an interactive design process. Furthermore, it operates in the 3D-space and therefore, it represents an innovative approach to semi-automated design processes. The BR database establishes connectivities between different software and functions as a parameter pool containing geometric and functional data. BR is being used interactively and in combination with other software, to achieve non-deterministically designs. It is a design support system, since it supports the user (designer) in the functional layout process rather than prescribes a solution.

At urban scale, applications developed by Hyperbody have been addressing space allocation in a similar way BR does: While at building scale spaces are allocated within a building, at urban scale buildings and building clusters are allocated within an urban area (Fig. 9). The allocation principle is, however, the same: Functions and dedicated volumes swarm within the urban context towards local optimal spatial configurations (Jaskiewicz, 2010).

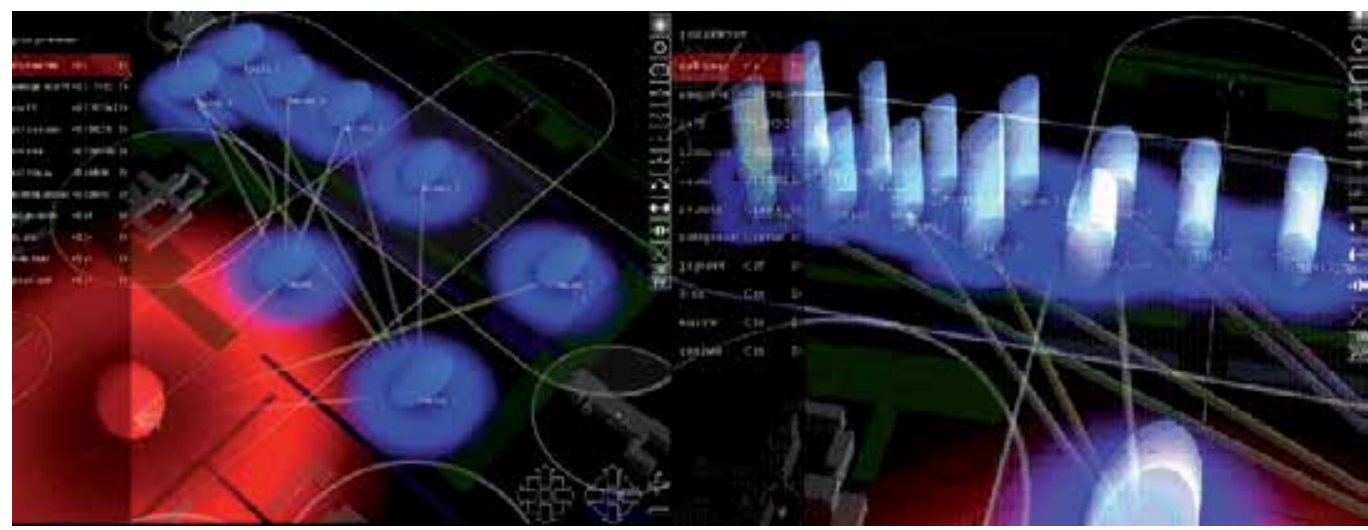

Fig. 9. Urban design studies implemented in interactive environments developed in Virtools.

Obviously, these applications are of interest for Internet-supported education and research as they enable interactive, collaborative, (virtually and physically present) multi-user design and fabrication sessions.

\subsection{Users' interaction in education and research}

The classical concept of distance learning implemented when time and distance separate educators and students is increasingly replaced by Internet-supported systems that are employed to assist daily academic interaction even when researchers, educators and students are not separated by time or distance. This is the result of a conceptual and methodological paradigm shift that implies an ongoing change towards pervasive computing and ubiquitous education and research as already discussed in the previous sections.

Considering the Internet as the start, Castells extrapolates 1996 the expected development of such a networked system towards becoming pervasive, permeating the everyday life. The 
purpose of Internet-supported systems is, therefore, not anymore to only bridge time and distance but to support everyday academic education and research by incorporating ubiquitous, interactive devices into the physical space. In this context, Protospace can be seen as a prototype for pervasive computing that is integrated into physical space and is employed in academic daily life, whereas interaction between users and data takes place in a networked, Internet-supported, embedded system.

In such a networked system, users are connected with other users, multimedia databases and applications enabling reading and editing of data, sensing-actuating, and computing in such a way that users interact physically and virtually as needed in a physical, digitallyaugmented environment.

By integrating concepts such as Autonomous Control (Uckelmann et al., 2010) the Internet of Things is envisioned as a network in which self-organized virtual and physical agents are able to act and interact autonomously with respect to context and environmental factors. Such context awareness (Gellersen et al., 2000) implies data collection and information exchange thus communication between users and physical environment; it may imply acquisition of data with respect to users' habits, emotions, bodily states, their social interaction, and their regular and spontaneous activities as well as context data with respect to spatial location, infrastructure, available resources, and physical conditions such as noise, light, and temperature. Information exchange thus communication between physical (sentient) environment and users may, however, not only imply accommodating but also challenging interactions.

As a context aware system, Protospace is concerned with the acquisition of context data by means of sensors, as mentioned before, the interpretation of the data collected by sensors, and the triggering of accommodating and challenging actions as response to the interpretation of collected data, whereas responses may imply operation of electrical light, sun shading, and projection screens, depending on local and global needs, etc. Furthermore, Protospace's context awareness addresses also activity recognition as implemented in interactive lectures and CAD-CAM sessions described in the previous sections.

\section{Discussion and outlook}

The on-going fusion of the physical and the virtual reflected in the convergence of the Internet, mobile communication systems, and advanced human-computer interaction technologies generates a reality-virtuality continuum (Milgram, 1994) containing all possible degrees of real and virtual conditions so that the distinction between reality and virtuality becomes blurred.

In this context, Protospace as a reality-virtuality continuum facilitates not only interactive design and fabrication sessions but also interactive presentations for Internet-based graduate programs (E-Archidoct) becoming a relevant platform for studying and researching by connecting virtually students, educators and researchers from all over the world. This implies that Protospace connects users and data physically and virtually in such a way that activities in academic education and research are enhanced by the inherent use of knowledge, software and hardware applications incorporated into it and the available multiple interaction modes. 
As technologies evolve and pervasive forms increasingly emerge, permeating all aspects of academic everyday life, concepts such as distance learning are gradually replaced by ubiquitous education and research implemented in sentient, interactive environments. The traditional divide between formal (physical) and informal (virtual) contexts of education and research is blurred. Technological as well as social, cultural, and institutional changes mean that learning, studying, and researching are possible across spatial and temporal barriers. Internet-supported academic education and research implies thus that the physical environment with integrated, networked, interactive devices such as Protospace incorporates increasingly aspects of context-awareness, adaptation, and anticipation, (Zelkha et al., 1998; Aarts et al., 2001) supporting virtual and physical everyday academic activities.

Such systems may show, however, as in the case of the E-Archidoct program, that only a limited amount of students may participate successfully in such a program. Reasons for this may be found not only in technological requirements but also in methodological constraints; Students and educators from all over Europe participating in E-Archidoct were confronted with one of the main barriers to such virtual collaborative interaction, which is the difficulty in achieving agreement when diverse viewpoints, cultural boundaries, and different working and cognitive learning styles exist (Dirckinck-Holmfeld, 2002).

Furthermore, students' limited access to necessary software and hardware as well as insufficient know-how in dealing with software and hardware was an additional problem: Some design assignments within E-Archidoct, for instance, required software and hardware to which not all students had access. Furthermore, local technical support (for tutors and students) was needed in order to ensure successful participation in the program, this, however, could not always be afforded.

Future developments of virtual and physical systems for Internet-based and -supported education require, therefore, access of all participants to software and hardware as well as development of computer literacy and technology know-how among them. This may be implemented via educating students and researchers with respect to the use of Internetbased facilities before starting specific education and research program but also implies development of user-friendly software.

However, interaction models whether menu-driven or GUI-based (Graphical User Interface) are improving and are increasingly supported by applications such as mobile phones, radio-frequency identification tags, and GPS (Global Positioning System). As these devices grow smaller, more connected and more integrated into spatial environments so that only multimodal user interfaces remain perceivable for users (Aarts et al., 2001), Hyperbody investigates and further develops their use for academic education and research. Protospace, for instance, may operate in the future as physical and virtual laboratory enabling users to even remotely conduct physical experiments from other geographical locations. The benefits of such remote laboratories are known in engineering education (Ferreira et al., 2010) and imply advantages such as: (1) Relaxation of time constraints and 24/7 accessibility; (2) Relaxation of geographical constraints and independence from physical locality of researchers; (3) Material costs reduction due to sharing of lab costs and avoiding start-up costs for new laboratories; (4) Enhanced sharing of knowledge, expertise and experience. 
In this context, research and education on architectural and urban design and production may be then implemented with students, educators, and experts from all over the world, interacting virtually and physically by means of multimodal interfaces, collaboratively working in a multi-user, gaming environment, that is enabling them to access and manipulate the same data on a common server synchronously or asynchronously, and even implement remotely CAD-CAM experiments.

The relevant question for the future seems to be, therefore, not whether intelligent, sentient environments may be built, but how these environments may be employed as instruments for enhanced, distributed problem solving (Bowen-James, 1997; Novak, 1997), how ubiquitous education and training may be implement in programs that promote digital democracy and literacy by bridging the digital divide (Norris, 2001), how intelligence may be embed into the physical environment in order to be made available to users.

\section{Acknowledgment}

Content presented in this paper has benefited, inter alia, from the contribution of the Protospace, Hyperbody and E-Archidoct teams including on projects participating students. Additional information with respect to presented projects may be found on the Hyperbody website (http:/ / www.hyperbody.nl/).

\section{References}

Armstrong E. (1991). A hybrid model of problem-based learning, The challenge of problem-based learning, Kogan Page, London, UK

Aarts, E. et al. (2001). Ambient Intelligence, The Invisible Future: The Seamless Integration Of Technology Into Every-day Life, McGraw-Hill, New York, US

Ashton, K. (2009). That 'Internet of Things' Thing, RFID Journal, Melville, US

Bier, H. (2011). Web-based Applications for Virtual Laboratories, eCASE \& eTECH, Tokyo, Japan

Bier, H. (2007). Prototypes for Automated Architectural 3D-Layout, Lecture Notes in Computer Science, Springer, Heidelberg, Germany

Bier, H. et al. (2006). SC: Prototypes for Interactive Architecture, Lecture Notes in Computer Science, Springer, Heidelberg, Germany

Bier, H. et al. (1998). BR: An Interactive Software Prototype for 3D Layout, Architectural Annual, Delft, Netherlands

Bomsdorf, B. (2005). Adaptation of Learning Spaces: Supporting Ubiquitous Learning in Higher Distance Education, Dagstuhl Seminar Proceedings 05181, Mobile Computing and Ambient Intelligence: The Challenge of Multimedia, Dagstuhl, Germany

Bowen-James, A. (1997). Paradoxes and Parables of Intelligent Environments, Intelligent Environments - Spatial Aspect of the Information Revolution, Elsevier, Oxford, UK

Castells, M. (1996). The Rise of the Network Society, The Information Age: Economy, Society and Culture Vol. I. Cambridge, MA, US

Daniel, Sir J. S. (1998). Mega-Universities and Knowledge Media: Technology Strategies for Higher Education, Routledge, London, UK

Dirckinck-Holmfeld, L. (2002). Designing Virtual Learning Environments based on Problem Oriented Project Pedagogy, Learning in Virtual Environments, Copenhagen, Denmark 
Engelbart, D. C. (1962). Augmenting human intellect: A conceptual framework, Report AFOSR3233, Stanford Research Institute, Stanford, US

Ferreira, J. M. M. et al. (2009). Collaborative learning based on a micro-web server remote test controller, International Journal of Online Engineering, Vienna, Austria

Gellersen H.-W. et al. (2000). Sensor-based Context-Awareness for Situated Computing, Workshop on Software Engineering for Wearable and Pervasive Computing at the 22nd International Conference on Software Engineering. Limerick, Ireland

Jaskiewicz, T. (2010). Complex Multiplayer Urban Design System - Concept and Case Studies, Lecture Notes in Computer Science, Springer, Heidelberg, Germany

Loutchko, I. et al. (2002). Production and Delivery of Multimedia Courses for Internet Based Virtual Education, Networked Learning in a Global Environment: Challenges and Solutions for Virtual Education, Berlin, Germany

Mach, R. \& Schweitzer, F. (2003). Multi-agent model of biological swarming, Lecture Notes in Computer Science, Springer, Heidelberg, Germany

Magrassi, P. et al. (2001). Computers to Acquire Control of the Physical World, Gartner research report, Stamford, US

Michahelles, F. et al. (2004). Towards Distributed Awareness - An Artifact based Approach, Sixt IEEE Workshop on Mobile Computing Systems and Applications (WMCSA), Lake District National Park, UK

Michalek, J. J. et al. (2002). Architectural Layout Design Optimization, Engineering Optimization, Taylor and Francis, UK

Milgram, P. et al. (1994). Augmented Reality: A class of displays on the reality-virtuality continuum, Proceedings of Telemanipulator and Telepresence Technologies, Boston, US

Norris, P. (2001). Digital Divide: Civic Engagement, Information Poverty, and the Internet Worldwide, Cambridge University Press, Cambridge, UK

Novak, M. (1997). Cognitive Cities: Intelligence, Environment and Space, Intelligent Environments - Spatial Aspect of the Information Revolution, Elsevier, Oxford, UK

Oosterhuis, K. \& Lenard, I. (2006). Swarm Architecture, GS\&M II, Episode Publishers, Rotterdam, Netherlands

Oosterhuis, K., et al. (2004). File to Factory and Real-time Behavior in Architecture, Fabrication, ACADIA, Cambridge, UK

Oosterhuis, K., et al. (2004). Virtual Operation Room - A Time-based Architecture for the Augmented Body, E-activities in Design and Design Education, Europia Productions, Paris, France

Reynolds, C. (1987). Flocks, Herds, and Schools - A Distributed Behavioral Model, Computer Graphics, 21/4 SIGGRAPH, New York, US

Sloman, A. (1989). The Evolution of Poplog and Pop-11 at Sussex University, POP-11 Comes of Age: The Advancement of an AI Programming Language, pp. 30-54

Sutherland, I. E. (1980). Sketchpad: A Man-Machine Graphical Communication System, Garland Publishers, New York, US

Sweller, J. (1988). Cognitive load during problem solving: Effects on learning, Cognitive Science 12 (2): 257-285

Uckelmann, D. et al. (2010). An integrative approach on Autonomous Control and the Internet of Things, Unique Radio Innovation for the 21st Century: Building Scalable and Global RFID Networks, Springer, Berlin, Germany 
Uckelmann, D. et al. (2011). An Architectural Approach towards the Future Internet of Things, Architecting the Internet of Things, Springer, Berlin, Germany

Weiser, M. (1993). Some Computer Science Problems in Ubiquitous Computing, Communications of the ACM, New York, US

Zelkha, E. et al. (1998). From Devices to "Ambient Intelligence", Digital Living Room Conference, Laguna Niguel, US

Zyda, M. (2005). From visual simulation to virtual reality to games, IEEE Computer Society, West Lafayette, US 



\section{Edited by Joi L. Moore and Angela D. Benson}

This book, written by authors representing 12 countries and five continents, is a collection of international perspectives on distance learning and distance learning implementations in higher education. The perspectives are presented in the form of practical case studies of distance learning implementations, research studies on teaching and learning in distance learning environments, and conceptual and theoretical frameworks for designing and developing distance learning tools, courses and programs. The book will appeal to distance learning practitioners, researchers, and higher education administrators. To address the different needs and interests of audience members, the book is organized into five sections: Distance Education Management, Distance Education and Teacher Development, Distance Learning Pedagogy, Distance Learning Students, and Distance Learning Educational Tools. 